\title{
Prototypic Thermal-Hydraulic Experiment in NRU to Simulate Loss-of-Coolant Accidents
}

Prepared by C. L. Mohr, G. M. Hesson, G. E. Russcher, R. K. Marshall

L. L. King, N. J. Wildung, W. N. Rausch, W. D. Bennett

Pacific Northwest Laboratory

Operated by

Battelle Memorial Institute

Prepared for

U.S. Nuclear Regulatory

Commission 


\section{NOTICE}

This report was prepared as an account of work sponsored by an agency of the United States Government. Neither the United States Government nor any agency thereof, or any of their employees, makes any warranty, expressed or implied, or assumes any legal liability or responsibility for any third party's use, or the results of such use, of any information, apparatus product or process disclosed in this report, or represents that its use by such third party would not infringe privately owned rights.

\section{Available from}

GPO Sales Program

Division of Technical Information and Document Control

U. S. Nuclear Regulatory Commission Washington, D. C. 20555

Printed copy price: $\$ 8.00$

and 


\section{Prototypic Thermal-Hydraulic Experiment in NRU to Simulate Loss-of-Coolant Accidents}

Manuscript Completed: December 1980

Date Published: April 1981

Prepared by

C. L. Mohr, G. M. Hesson, G. E. Russcher, R. K. Marshall,

L. L. King, N. J. Wildung, W. N. Rausch, W. D. Bennett

Pacific Northwest Laboratory

Richland, WA 99352

Prepared for

Division of Reactor Safety Research Office of Nuclear Regulatory Research

U.S. Nuclear Regulatory Commission

Washington, D.C. 20555

NAC FIN B2277 



\section{ACKNOWLEDGMENTS}

The authors would like to thank the Chalk River, Nuclear Laboratories (CRNL) for their assistance in performing this test series. A speciat acknowledgment is due to CRNL staff members S. Z. Hart, D. T. Nishimura, P. E. Kelly, S. H. Kendrick, J. W. Logie, C. A. Herriot, and B. Debrau, who made a major contribution in keeping this work on schedule.

The assistance of R. Van Houten, NRC/RSR/FBR, Project Manager is a)so acknowledged for providing helpful directives to the program.

The authors would also like to thank S. L. Lilly for preparation of this manuscript. 



\section{SUMMARY}

Quick-look test results are reported for the initial test series of the Loss-of-Coolant Accident (LOCA) Simulation in the National Research Universal (NRU) test program, conducted by Pacific Northwest Laboratory (PNL) for the U.S. Nuclear Regulatory Commission (NRC). This test was devoted to evaluating the thermal-hydraulic characteristics of a fulllength light water reactor ( $L W R$ ) fuel bundle during the heatup, reflood, and quench phases of a L.OCA. Experimental results from 28 tests cover

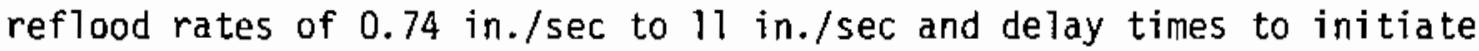
reflood of $3 \mathrm{sec}$ to $66 \mathrm{sec}$. The results indicate that current analysis methods can predict peak temperatures within 10\% and measured quench times for the bundle were significantly less than predicted. For

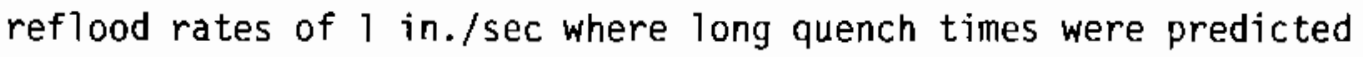
(>2000 sec), measured quench times of $200 \mathrm{sec}$ were found. 



\section{CONTENTS}

ACKNOWLEDGMENTS

SUMMARY

$\checkmark$

1.0 INTRODUCTION

1.1 PROGRAM SCOPE AND OBJECTIVES

1.2 APPLICATION OF RESULTS

2.0 TEST SERIES DESCRIPTION AND ORGANIZATION

2.1 TEST TRAIN AND INSTRUMENTATION DESCRIPTION

2.2 TEST SERIES ORGANIZATION

9

11

12

12

4.2 TEST OUTLET TEMPERATURES

17

4. 3 NEUTRON FLUX

4.4 COOLANT DENSITY VARIATIONS

4.5 POWER COUPLING

20

4.6 INSTRUMENTATION FAILURE

22

4.7 SHROUD LEAK RATE CHARACTERISTICS

22

4.8 REFLOOD CHARACTERISTICS FOR FLECHT COMPARISON TESTS

26

5.0 REFERENCES

28

APPENDIX - QUICK-LOOK REPORT DATA

PART 1 - TEMPERATURE PROBES

A. 1

PART 2 - NEUTRON FLUX DISTRIBUTIONS

A. 121

PART 3 - STEAM TEMPERATURE PROBE DISTRIBUTIONS

A. 175

PART 4 - SHROUD LEAK RATE CHARACTERISTICS

A. 235

PART 5 - FLOWMETER RATES FOR THE FLECHT COMPARISON TEST SERIES 



\subsection{INTRODUCTION}

The Loss-of-Coolant Accident (LOCA) Simulation in NRU test program is being conducted in the National Research Universal (NRU) reactor at Chalk River Nuclear Laboratories (CRNL) ${ }^{\text {(a) }}$ by Pacific Northwest Laboratory (PNL). (b) The project is sponsored by the Fuel Behavior Research Branch of the U.S. Nuclear Regulatory Commission (NRC) to evaluate the themalhydraulic and mechanical defomation behavior of a full-length fuel rod bundle during heatup, reflood, and quench phases of a LOCA. The tests are driven by low-level fission heat and simulate the temperature gradients in the fuel and cladding typical of a LOCA.

\subsection{PROGRAM SCOPE ANO OBJECTIVES}

The program's current scope calls for the irradiation of six fulllength test assemblies. The geometric configuration of each assembiy represents a $6 \times 6$ segment of a $17 \times 17$ pressurized water reactor (PWR) fue 1 bundle. The tests, which are being performed in the U-2 loop of the NRU reactor, provide the following data:

- temperature distributions in a full-length bundle as a function of time

- interaction between thermal-hydraulics and cladding deformation

- quench front propagation

- quenching characteristics of nuclear-heated Zircaloy-clad rods for comparison with electrically heated Inconel or stainless-clad rods

- temperature-stress-time of cladding deformation

- distribution of cladding strain within bundle and information on failure propagation

- axial distribution of diametral strain in test fuel rods

- flow area reduction from cladding expansion.

(a) Operated by Atomic Energy of Canada, Limited (AECL).

(b) Operated for the U.S. Department of Energy (DOE) by Battelle Memorial Institute. 
The test matrix for the program is broken into a therma 1-hydraulic test series (using a single test assembly) and five materials deformation tests (using a separate assembly for each test). The thermal-hydraulic test series results ${ }^{(a)}$ are reported and consist of 28 tests using unpressurized fuel rods that did not deform or rupture during the test series. The results of this experiment provide a reference for evaluating the quenching characteristics of Zircaloy nuclear fuel rods (Hann 1979).

The subsequent five materials deformation tests will concentrate on evaluating not only ballooning and rupture but also the added effects on the thermal-hydrautic behavior of flow blockage.

\subsection{APPLICATION OF RESULTS}

The data will be used to assess various calculational models for reactor safety analyses and conclusions derived from the large series of electrically heated tests and smaller scale in-pile tests being conducted elsewhere. The test data provide information for evaluating coolingdegraded cores as a result of either an accident or an off-normal operating transient. The experimental results of the program address 17 specific items outlined in the Code of Federal Regulations 10 CFR 50.46 and 10 CFR 50, Appendix K. These 17 areas are generally characterized by the following seven more general groups:

- Peak Cladding Temperature

- Evaluation Model Assessment

- Swelling and Rupture

- Flow Blockage

- Droplet Entrainment

- Reflood Rate

- Refill and Reflood Heat Transfer $50.46(b)(1)$

$50.46(b)(5)(2)$

Appendix $(K)(I)(B)$

Appendix $(K)(I)(C)(2)$

Appendix $(K)(I)(C)(I)(C)(2)$

Appendix $(K)(\mathrm{I})(\mathrm{D})(3)$

Appendix $(K)(I)(D)(5)$

(a) Designated prototypic thermal-hydrautic (PTH). 
The results of the program will be used to provide data for model calibration or to help define the primary heat transfer mechanisms for new analytical models. The geometry, mass flux, heat capacity, and materials are all prototypic, which eliminates much of the uncertainty of prior test results from other programs. Major concerns of other programs, such as length of fuel bundle or type of heating (nuclear versus electrical), should be answered by these test results. 


\subsection{TEST SERIES DESCRIPTION AND ORGANIZATION}

\subsection{TEST TRAIN ANO INSTRUMENTATION OESCRIPTION}

A schematic of the overall test train is depicted in Figure 1. The total length of the test train, including both the closure head and the test region, is $9.18 \mathrm{~m}$ (30 ft, $1-1 / 2 \mathrm{in}$.). The closure region provides the primary pressure boundary and includes penetrations for 183 instrumentation leads. The hanger tube is used to suspend the test bundle and shroud from the closure plug, and instrument leads are attached to the hanger to protect them during testing and transport. The shroud supports the fuel bundle; it serves as a protective liner during the experiment and transfer operations and provides proper flow distribution during various stages of the experiment. The stainless steel (SS) shroud consists of two halves clamped together at $17.78-\mathrm{cm}$ (7-in.) intervals and attached at the end fittings. The split shroud design will make it possible to disassemble, reassemble, and examine the test train underwater. The shroud assembly is approximately $4.27 \mathrm{~m}$ (14 ft) long and is instrumented with 22 self-powered neutron detectors (SPNOs) and 38 thermocouples (TCs).

The fuel bundle consists of a $6 \times 6$ segment of a $17 \times 17$ PWR design with the four corner rods removed for easier insertion in the shroud. This provides a basic test array of $6 \times 6-4$ or 32 rods. The outer row of rods, including the corner rods of the next inner ring, will not be pressurized and will serve as guard rod heaters during the test. The test section consists of 11 fuel rods and 1 instrument thimble tube arranged in a cruciform pattern. The test rods in the test section were unpressurized for the thermal-hydraulic test series; subsequent tests will use pressurized rods. The fuel rod design variables are:

$\begin{array}{lll}\text { Cladding Material Specification } & =\text { Zircaloy }-4 \\ \text { Cladding Outside Diameter (OD) } & =0.963 \mathrm{~cm}(0.379 \mathrm{in} .) \\ \text { Cladding Inside Diameter (ID) } & =0.841 \mathrm{~cm}(0.331 \mathrm{in} .) \\ \text { Pitch } & =1.275 \mathrm{~cm}(0.502 \mathrm{in} .) \\ \text { Fuel Pellet Diameter } & =0.826 \mathrm{~cm}(0.325 \mathrm{in} .) \\ \text { Fuel Pellet Length } & =0.953 \mathrm{~cm}(0.375 \mathrm{in} .) \\ \text { Active Fueled Length } & =365.76 \mathrm{~cm}(144 \mathrm{in.}) \\ \text { Total Shroud Length } & =423.1 \mathrm{~cm}(170.125 \mathrm{in} .) .\end{array}$




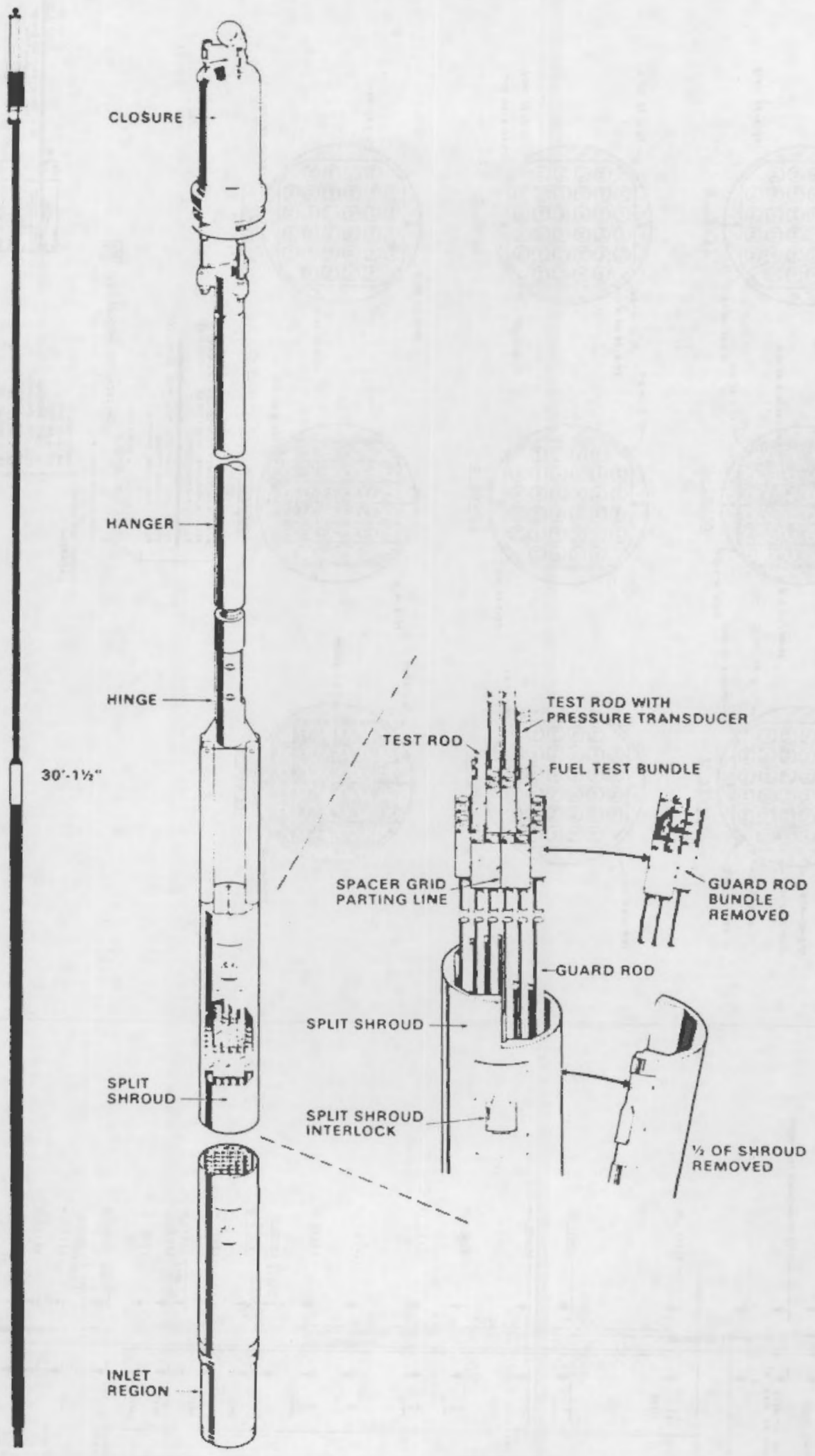

FIGURE 1. Schematic of the NRU LOCA Test Train 


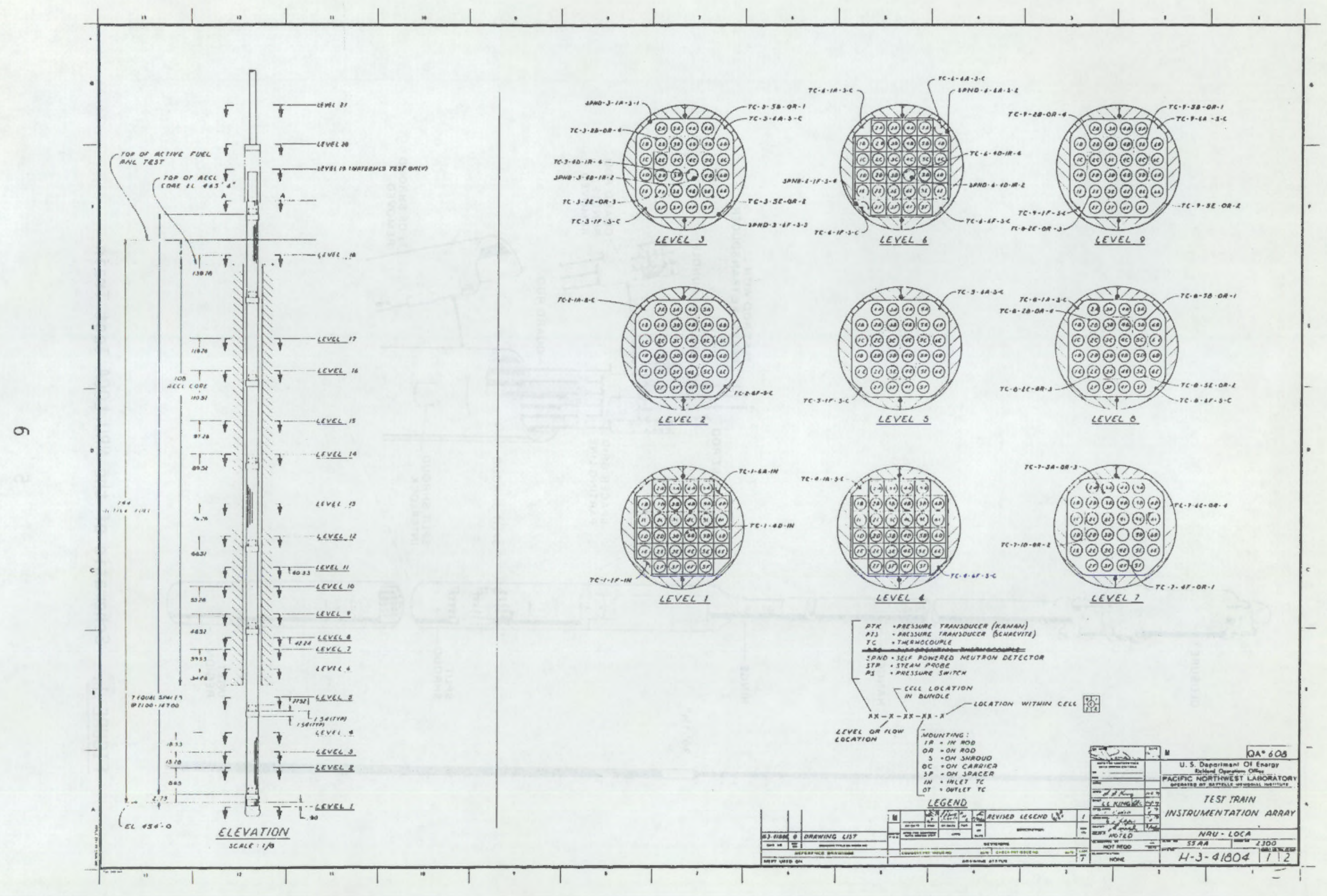

FIGURE 2. Axial Instrumentation Elevations and Instrumentation Cross Sections for Levels 1 through 9 


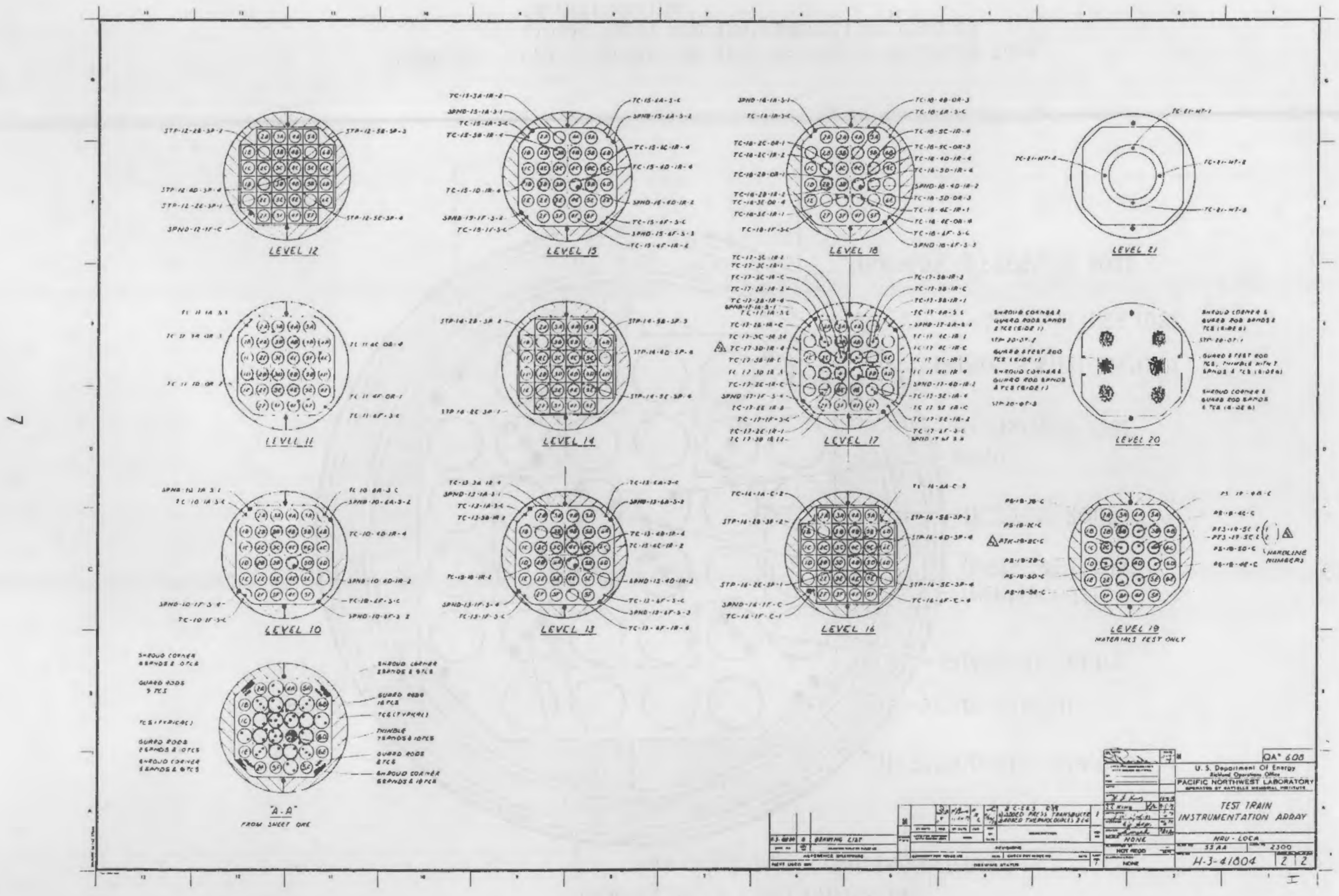

FIGURE 3. Instrumentation Cross Sections for Levels 10 through 21 


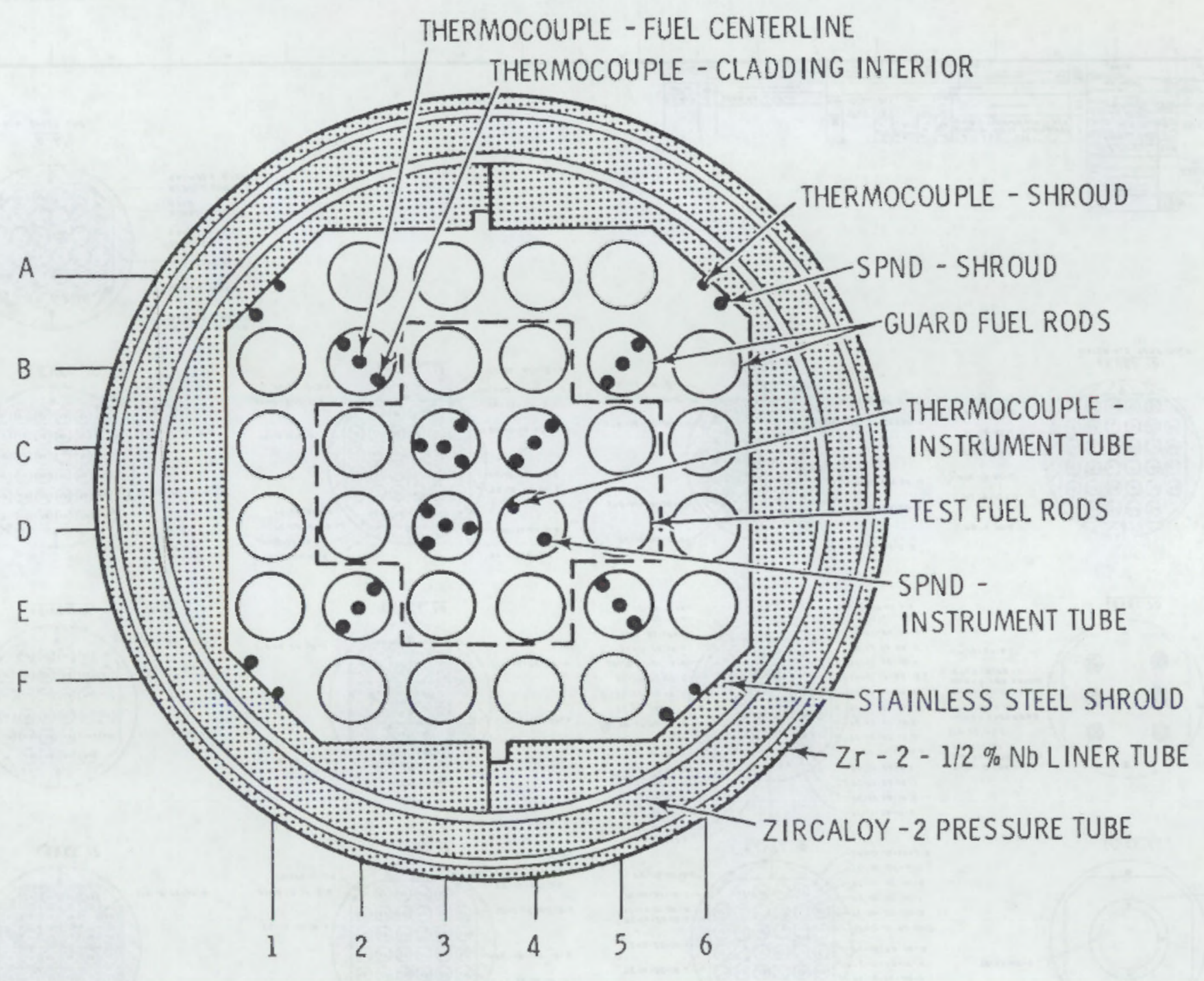

FIGURE 4. Cross Section of Test Assembly, Pressure Tube, Linear Tube, and Instrumentation Channel

Identification 
The test train instrumentation includes SPNDS (31), thermocouples (120), steam temperature probes (STPS) (18), and pressure transducers (11) ${ }^{(a)}$ and/or pressure switches. These instruments were monitored on a real-time basis by the Data Acquisition and Control System (DACS). The data received allowed the temperature, power, and time history of the test train to be determined and provided an indication of when cladding rupture occurs.

TC measurements provide the main source of the thermal-hydraulic information. Measurement of quench front velocities and indications of water entrainment are determined from the steam probe (TC) instruments. TCs are also placed inside the cladding surface to measure azimuthal temperature variations.

The SPNDS provide relative power measurements within the fuel bundle during steady-state operation. These cobalt detectors are also able to detect density variations associated with the froth front that is present during the reflood phase of the transient.

A total of 21 levels along the axial length of the assembly have been defined where instrumentation is located. Figures 2 and 3 define the axial elevation of each of these levels and the associated instruments at each ievel. The nomenclature used to identify the instrumentation channels is keyed to a set of coordinate indicators defined in Figure 4.

\subsection{TEST SERIES ORGANIZATION}

The PTH test series was composed of three phases: preconditioning, pretransient, and transient operations (Mohr 1980; Russcher 1980). The preconditioning phase was conducted with the U-2 loop operating with water cooling and at an average fuel rod power of $187 \mathrm{~W} / \mathrm{cm}(5.7 \mathrm{~kW} / \mathrm{ft})$. Two rises to full power were made in an attempt to allow the fuel to crack and relocate within the fuel cladding in a prototypic manner.

(a) Pressure transducers and/or pressure switches were not used on the PTH test but will be used on all deformation and rupture tests. 
The pretransient phase was conducted with steam cooling at a flow rate of about $0.378 \mathrm{~kg} / \mathrm{s}\left(30001 \mathrm{~b}_{\mathrm{m}} / \mathrm{hr}\right)$ and an average rod power of $12.2 \mathrm{~W} / \mathrm{cm}(0.37 \mathrm{~kW} / \mathrm{ft})$. This phase was used to initiate each of the specific 28 transient test runs in this test series. The operation consisted of bringing the assembly to power with a maximum measured cladding temperature of $700 \mathrm{~K}\left(800^{\circ} \mathrm{F}\right)$ in preparation for the transient phase.

Both the pretransient and transient phases of operation were repeated for each test in the thermal-hydraulic test series. In the transient phase, the cladding was allowed to heat up in stagnant steam. At a preselected delay time, reflood water was introduced at a specified rate. At the point where either the loop was reflooded or all of the TCs were quenched, the test was terminated and the reactor power was tripped. 


\subsection{REPORT SCOPE AND ORGANIZATION}

This report presents the most significant experimental results of the thermal-hydraulic test series in a timely manner without the benefit of supporting analysis or evaluation. Subsequent reports will provide more in-depth analysis of the neutronic and thermal-hydraulic behavior represented by the data presented in this report.

The remainder of the text portion of this report discusses the test conditions and major results from the following general areas:

- test assembly temperatures

- test outlet temperatures

- neutron flux

- coolant density variations

- power coupling

- instrumentation failure

- shroud leak rate characteristics

- reflood characteristics for FLECHT comparison tests.

The extensive Appendix of this report contains computer-generated plots of the data from the thermal-hydraulic test series. The data have been divided into five general parts: temperature profiles, neutron flux distributions, steam probe temperature distributions, shroud leak rate characteristics, and flowmeter rates for the FLECHT comparison test series.

No explanation is offered for apparent anomalies or differences between subsequent test data of the series. The data test series number for each test is clearly identified on each figure (e.g., PTH101) along with the real time when the first data of the set were recorded. 


\subsection{SUMMARY OF TEST CONDITIONS AND MAJOR RESULTS}

A summary of the test conditions used in each of the 28 PTH experiments is detailed in Tables 1 and 2 .

Table 1 describes the test conditions, including reflood rate, reflood delay time, and peak cladding temperatures measured during the test. The peak cladding temperatures reported are those at the start of the transient (at the start of the adiabatic heatup), at the start of reflood, and at turnaround. The peak cladding temperatures were measured by TCs on the inside surface of the fuel rods. Calculations have shown that the measured temperatures of these TCs are probably $11-22 \mathrm{~K}\left(2040^{\circ} \mathrm{F}\right.$ ) higher than the clad temperatures. The peak clad temperatures predicted by the Combustion Engineering proprietary THERM code and by use of the Westinghouse FLECHT correlation in the TRUMP heat transfer code are also shown in Table 1; predicted and experimental results show reasonable agreement.

Table 2 gives the quench times for both the peak temperature rod and the bundle as well as the quench times predicted by the THERM code. The measured values are significantly shorter than the predicted values.

The remainder of this section consists of sumrnaries of the data results from the thernal-hydraulic test series. Computergenerated data plots for each general section can be found in the Appendix.

\subsection{TEST ASSEMBLY TEMPERATURES}

Test assembly temperatures were measured in four major components: test assembly shroud, instrument tube, guard fuel rods, and test fuel rods. Data for each of these components can be found in Part 1 of the Appendix where the preconditioning, pretransient, and transient test operations are summarized. 
TABLE 1. Experimental Heat Cladding Temperatures

\begin{tabular}{|c|c|c|c|c|c|c|c|c|}
\hline \multirow[b]{2}{*}{ TEST } & \multirow[b]{2}{*}{ No. } & \multirow[b]{2}{*}{$\begin{array}{l}\text { REFLOOD RATE } \\
\text { IN/SEC }\end{array}$} & \multirow[b]{2}{*}{$\begin{array}{l}\text { DELAY TIME. } \\
\text { SEC }\end{array}$} & \multicolumn{2}{|c|}{$\begin{array}{l}\text { PEAK CLAD TEMP AT } \\
\text { START OF }\end{array}$} & \multirow{2}{*}{$\begin{array}{l}\text { PEAK CLAD } \\
\text { MEASURED. } \\
\text { DEG_F_. }\end{array}$} & \multicolumn{2}{|c|}{$\begin{array}{l}\text { TEMP AT TURNAROUND } \\
\text { PREDICTED }\end{array}$} \\
\hline & & & & $\begin{array}{l}\text { TRANSIENT } \\
\text { DEG F }\end{array}$ & $\begin{array}{l}\text { REFLOOD } \\
\text { DEGF }\end{array}$ & & $\begin{array}{c}\text { FLECHT-TRUMP } \\
\text { DEGEF }\end{array}$ & $\begin{array}{l}\text { THERM } \\
\text { DEG_F }\end{array}$ \\
\hline $\begin{array}{l}101 \\
104 \\
105 \\
106 \\
107 \\
108 \\
109 \\
110 \\
111 \\
112 \\
113 \\
114 \\
115 \\
116 \\
117 \\
118 \\
119 \\
120 \\
121 \\
122 \\
123 \\
124 \\
125 \\
126 \\
127 \\
128 \\
129 \\
130\end{array}$ & & $\begin{array}{l}3.8 \\
3.8 \\
1.9 \\
10.5(2) \\
1.9 \\
1.4 \\
1.3 \\
1.9 \\
1.4(3) \\
3.8 \\
7.6 \\
7.6 \\
9.5 \\
3.8 \\
3.8 \\
2.9 \\
2.9 \\
5.9 \\
3.8 \\
7.6 \\
2.9 \\
5.9 \\
1.4 \\
1.2 \\
1.0 \\
2.0 \\
1.4 \\
0.7(4)\end{array}$ & $\begin{array}{r}28(1) \\
37 \\
7 \\
19 \\
19 \\
11 \\
22 \\
30 \\
11 \\
37 \\
37 \\
32 \\
66 \\
51 \\
66 \\
52 \\
46 \\
51 \\
36 \\
52 \\
51 \\
52 \\
20 \\
3 \\
3 \\
50 \\
32 \\
5\end{array}$ & $\begin{array}{l}871 \\
853 \\
858 \\
873 \\
891 \\
891 \\
865 \\
895 \\
817 \\
843 \\
845 \\
858 \\
795 \\
836 \\
817 \\
844 \\
862 \\
847 \\
833 \\
866 \\
848 \\
861 \\
872 \\
797 \\
943 \\
911 \\
940 \\
929\end{array}$ & $\begin{array}{r}881 \\
1336 \\
907 \\
1107 \\
1154 \\
1010 \\
1158 \\
1314 \\
962 \\
1330 \\
1408 \\
1368 \\
1666 \\
1500 \\
1599 \\
1480 \\
1451 \\
1460 \\
1304 \\
1486 \\
1532 \\
1556 \\
1138 \\
800 \\
966 \\
1604 \\
1371 \\
998\end{array}$ & $\begin{array}{l}1403 \\
1487 \\
1364 \\
1223 \\
1578 \\
1676 \\
1881 \\
1665 \\
1696 \\
1589 \\
1526 \\
1477 \\
1758 \\
1707 \\
1788 \\
1756 \\
1673 \\
1611 \\
1579 \\
1611 \\
1788 \\
1688 \\
1802 \\
1644 \\
1991 \\
1991 \\
1898 \\
2040\end{array}$ & $\begin{array}{l}1350 \\
1400 \\
1400 \\
1100 \\
1500 \\
1700 \\
1800 \\
1600 \\
1700 \\
1400 \\
1400 \\
1300 \\
1800 \\
1600 \\
1800 \\
1700 \\
1600 \\
1600 \\
1400 \\
1600 \\
1700 \\
1600 \\
1800 \\
1700 \\
1900 \\
1800 \\
1900\end{array}$ & $\begin{array}{l}1365 \\
1445 \\
1370 \\
1150 \\
1420 \\
1500 \\
1580 \\
1525 \\
1500 \\
1425 \\
1395 \\
1300 \\
1720 \\
1605 \\
1800 \\
1675 \\
1620 \\
1580 \\
1425 \\
1575 \\
1675 \\
1580 \\
1565 \\
1530 \\
1650 \\
1735 \\
1670\end{array}$ \\
\hline $\begin{array}{l}(1) \\
(2) \\
(3) \\
4)\end{array}$ & $\begin{array}{l}\text { Unp } \\
\text { Mal1 } \\
\text { lst } \\
\text { Rea }\end{array}$ & $\begin{array}{l}\text { ned delay cau } \\
\text { ctioning equi } \\
\text { o seconds of } \\
r \text { tripped at }\end{array}$ & $\begin{array}{l}\text { problems } \\
\text { caused gr } \\
\text { missing } \\
50 \text { of }\end{array}$ & $\begin{array}{l}\text { prefill } \\
\text { r refloo }\end{array}$ & te th & ned & & \\
\hline
\end{tabular}


TABLE 2. Comparisons of Predicted and Measured Quench Times

\begin{tabular}{|c|c|c|c|c|c|c|c|}
\hline TEST & NO. & $\begin{array}{c}\text { REFLOOD RATE } \\
\text { IN/SEC. }\end{array}$ & $\begin{array}{c}\text { DELAY TIME } \\
\text { SEC }\end{array}$ & $\begin{array}{l}\text { QUENCH OF } \\
\text { MEASURED } \\
\text { TIME_.s }\end{array}$ & $\begin{array}{l}\text { PEAK POINT } \\
\text { PREDICTED } \\
\text { IIME, S }\end{array}$ & $\begin{array}{l}\text { QUENCH } \\
\text { MEASUREO } \\
\text { TIME }, \underline{5}\end{array}$ & $\begin{array}{l}F \text { BUNDLE } \\
\text { PREDICTED } \\
\text { TIME, } 5\end{array}$ \\
\hline $\begin{array}{l}101 \\
104 \\
105 \\
106 \\
107 \\
108 \\
109 \\
110 \\
111 \\
112 \\
113 \\
114 \\
115 \\
116 \\
117 \\
118 \\
119 \\
120 \\
121 \\
122 \\
123 \\
124 \\
125 \\
126 \\
127 \\
128 \\
129 \\
130\end{array}$ & & $\begin{array}{l}3.8 \\
3.8 \\
1.9 \\
10.5(2) \\
1.9 \\
1.4 \\
1.3 \\
1.9 \\
1.4(3) \\
3.8 \\
7.6 \\
7.6 \\
9.5 \\
3.8 \\
3.8 \\
2.9 \\
2.9 \\
5.9 \\
3.8 \\
7.6 \\
2.9 \\
5.9 \\
1.4 \\
1.2 \\
1.0 \\
2.0 \\
1.4 \\
0.7(4)\end{array}$ & $\begin{array}{r}28(1) \\
37 \\
7 \\
19 \\
19 \\
11 \\
22 \\
30 \\
11 \\
37 \\
37 \\
32 \\
66 \\
51 \\
66 \\
52 \\
46 \\
51 \\
36 \\
52 \\
51 \\
52 \\
20 \\
3 \\
3 \\
50 \\
32 \\
5\end{array}$ & $\begin{array}{r}85 \\
101 \\
125 \\
42 \\
154 \\
189 \\
268 \\
173 \\
205 \\
109 \\
82 \\
73 \\
107 \\
148 \\
150 \\
170 \\
141 \\
113 \\
122 \\
100 \\
157 \\
113 \\
219 \\
207 \\
314 \\
162 \\
216\end{array}$ & $\begin{array}{r}150 \\
255 \\
50 \\
290 \\
410 \\
440 \\
315 \\
410 \\
150 \\
115 \\
185 \\
140 \\
180 \\
210 \\
230 \\
220 \\
150 \\
150 \\
135 \\
230 \\
150 \\
440 \\
450 \\
625 \\
355 \\
470\end{array}$ & $\begin{array}{l}120 \\
138 \\
155 \\
153 \\
173 \\
276 \\
292 \\
193 \\
235 \\
138 \\
93 \\
83 \\
107 \\
159 \\
163 \\
172 \\
165 \\
120 \\
126 \\
108 \\
165 \\
122 \\
269 \\
257 \\
344 \\
220 \\
287\end{array}$ & $\begin{array}{r}180 \\
200 \\
780 \\
\\
800 \\
1800 \\
1700 \\
810 \\
1800 \\
200 \\
120 \\
280 \\
160 \\
240 \\
270 \\
320 \\
310 \\
170 \\
200 \\
140 \\
320 \\
170 \\
1700 \\
>2000 \\
>2000 \\
830 \\
1700\end{array}$ \\
\hline $\begin{array}{l}(1) \\
(2) \\
(3) \\
(4)\end{array}$ & $\begin{array}{l}\text { Unp } \\
\text { Mat } \\
\text { lst } \\
\text { Rea }\end{array}$ & $\begin{array}{l}\text { ned delay cau } \\
\text { ctioning equi } \\
\text { o seconds of } \\
r \text { tripped at }\end{array}$ & $\begin{array}{l}\text { by problem } \\
t \text { caused } 9 \\
\text { missing } \\
50{ }^{\circ} \mathrm{F}\end{array}$ & $\begin{array}{l}\text { refill } \\
\text { refloc }\end{array}$ & te that & & \\
\hline
\end{tabular}




\subsubsection{Preconditioning Test Assembly Temperatures}

Data were recorded as test PRECTH during the full-power steadystate Preconditioning Phase of NRU reactor operation. The average axial temperature profile for the shroud is shown (see Part 1.1 of the Appendix) as are the individual corner channel axial temperature profiles. Inlet piping $27.4 \mathrm{~m}$ (1080 in.) upstream from the test assembly, the outlet region (Level 20), the hanger tube (Level 21), and the outlet piping $8.2 \mathrm{~m}$ (324 in.) downstream from the test assembly are also provided in the profile. Coolant temperature gradients across the test assembly are also shown.

The instrument tube (see location 40 of Figure 4 ) has two types of temperature sensors. TCS are located on the inside radius (IR) of the tube, and steam probes with protective hoods removed are mounted on the outer radius (OR) of the tube. These sensors supplied the data (see Appendix, Part 1.1.2) for axial temperature profiles during the watercooled preconditioning phases for comparison with grid-mounted STP data.

Guard fuel rod temperatures during preconditioning are summarized in Part 1.1 of the Appendix. TC sensors were located on both the interior and exterior of the guard fuel rods, and axial temperature distributions are provided by both types of sensor. Data for the same type and instrument level are either averaged or plotted independently to show power stress. Temperature gradients across the test assembly are also shown at several levels.

Test fuel rod temperatures during preconditioning are also provided by several IR, three center Level 17 , and one Level 18 exterior TCs. The average IR axial temperature profiles are also shown in the Appendix for comparison with average fuel center and exterior cladding temperatures; individual test fuel rod temperatures are also compared with their center temperature. A diagonal temperature profile across the test assembly at Level 17 clearly shows the temperature gradient. The instrument tube (location shown in Figure 4 ) is adjacent to the test fuel rod locations plotted ( $3 D$ and $4 C$ ); the effect of the tube is evident. 


\subsubsection{Pretransient and Transient Test Assembly Temperatures}

Temperature data summaries are presented in the Appendix, Part 1.2, for four major test assembly components: shroud, instrument tube, guarc fuel rods, and test fuel rods. Pretransient (steady-state) operation in the NRU uses steam cooling at higher temperatures than preconditioning. During transient operation, several additional sensors failed, and when erratic behavior was obvious, they were deleted from the data graphs.

Some suspicious data remain, however. The test assembly coolant temperature profile across the diagonal at Level $i 6$ is shown for the pretransient operation, which is typical of the many transient tests; it is a combination of STP and lead carrier TC data. An axial temperature profile of the shroud during pretransient operation is also provided, showing typical channel wall temperatures for each corner of the shroud. A set of eiapsed time temperature profiles is also provided that shows the (measured) axial temperature gradients and peak temperatures of the shroud at 10 time intervals between the time when reflooding was started and when the shroud was quenched. TC data at the TA inlet (Leve 1 1), the TA outlet (Level 20), and the hanger tube (Level 21) provide temperature data continuity over the entire test train, although none of these are contained in the instrument tube.

Guard fuel rod temperatures recorded during each transient test are presented in the Appendix, Part 1.2.3, as time histories averaged at each of the sensor levels $(13,15$, and 17). These data are from interior TCs located between the fuel pellets and cladding. Typical temperature differences between these guard fuel rods can be seen in the preconditioning data summary (Appendix, Part 1.1.3).

Appendix, Part 1.2.4, contains time histories of the test fuel rod temperatures at the same sensor levels $(13,15$, and 17) used for guard fuel rods. These data are from interior TCs with the addition of a central TC from instrumentation Level 17 for comparison. It is noted that the last Leve1 13 TC failed during test PTH-117 when the temperature exceeded $1255 \mathrm{~K}\left(1800^{\circ} \mathrm{F}\right)$. Leve 15 TCs remained operational even though the temperature reached $1350 \mathrm{~K}\left(1970^{\circ} \mathrm{F}\right)$ in test $\mathrm{PTH}-130$. 


\subsection{TEST OUTLET TEMPERATURES}

A special section of outiet temperature data is not provided in the Appendix. Rather, this information is inciuded in sections that present data sumnaries for the test assembly shroud, instrument tube, and test train.

\subsubsection{Preconditioning Outlet Temperatures}

During water-cooled preconditioning operation, the test assembly outlet region, hanger tube, and outlet piping operate at about $544 \mathrm{~K}$ $\left(520^{\circ} \mathrm{F}\right)$ as shown in Figures 1.1.1.3, 1.1.2.1, and 1.1.2.2 in the Appendix.

\subsubsection{Pretransient and Transient 0utlet Temperatures}

The axial temperature profile of the test assembly during pretransient operation is shown in Appendix Figure 1.2.1.2; the outlet region temperatures do not exceed $589 \mathrm{~K}\left(600^{\circ} \mathrm{F}\right)$. During the transients, the test train axial temperature profiles (see Figures 1.2.1.3.01 through 1.2.2.30) show that the maximum temperatures of the test assembly outlet region (Level 20) and hanger tube (Level 21) were about $716 \mathrm{~K}\left(830^{\circ} \mathrm{F}\right)$ and $658 \mathrm{~K}\left(725^{\circ} \mathrm{F}\right)$, respectively.

\subsection{NEUTRON FLUX}

The neutron flux is measured by SPNDs mounted in the instrument tube and on the test assembly shroud at several locations. Typical locations are shown in Figure 4. Similar data are provided for preconditioning (water-cooled), pretransient, and transient (steamcooled) operations for comparison.

\subsubsection{Preconditioning Neutron Flux}

Fu11-powered NRU reactor operation provided the steady-state environment that is summarized on neutron flux distributions in the Appendix, Part 2.0. Neutron flux axial profiles are provided for the instrument tube and each corner channel of the shroud. The areas under 
each curve of Appendix Figures 2.1.1 and 2.1.2 were integrated to provide an average neutron flux for each location. They are:

Test Assembly Location

IT 4D

Corner IA

Corner IF

Corner $6 \mathrm{~A}$

Corner $6 \mathrm{~F}$
Neutron Flux

2.71

4.97

5.28

4.50

4.97

When normalized to these averages, the five flux distributions collapse into one curve, which conforms to the neutronic design distribution (Heaberlin et a1. 1979). That neutron flux axial profile has a peak-toaverage ratio of 1.53 with the peak at an elevation of $2.13 \mathrm{~m}$ (84 in.). The ratio of the average flux at the shroud corners to the neutron flux at the instrument tube is a measure of flux depression and is measured to be 1.82 ; the ratio of maximum to minimum flux is 1.68 for the design neutron distribution extrapolated to the radius of the shroud SPNDs. The ratio of the shroud corner flux provides a measure of the flux tilt across the test assembly. It is 1.17 from corner If to corner $6 \mathrm{~A}$ with a tilt axis along the $1 \mathrm{~A}$ to $6 \mathrm{~F}$ diagonal.

\subsubsection{Pretransient and Transient Neutron Flux}

Reactor operation at nominally $6 \%$ of full power provides the steady-state heat source for pretransient operation and the transient LOCA test series. These data are summarized in the Appendix, Part 2.2. For a comparison between water- and steam-cooled neutron flux distributions, the diagonal neutron flux profile across the test assembly is shown in Appendix Figure 2.2.1.1 for pretransient operation.

The axial neutron flux profile is provided in Figure 2.2.1.2 for each corner of the shroud for comparison with preconditioning data. The average pretransient neutron flux for each location is: 
Test Assembly Location

IT 40

Corner IA

Corner JF

Corner 6A

Corner 65
Neutron Flux

0.213

0.300

0.311

0.271

0.304

The normalized axial flux distribution for each channel collapses to the same curve that conforms to the neutronic design distribution. The maximum to minimum flux depression ratio is 1.4 , which is somewhat less than in the preconditioning operation; however, it is only $11 \%$ less than predicted in the neutronic design distribution. The flux tilt is 1.15 or $2 \%$ less than in the preconditioning operation, and the flux tilt orientation is the same.

Subtle changes in the neutron flux are caused by the neutron absorption effects of the reflood water. To evaluate the changing density of the coolant, the changing neutron flux is presented for various instrument tube levels during each transient test. The plotted delta flux is the difference between the current flux and the average flux calculated for at least $10 \mathrm{sec}$ before the reflood began. In addition to the problem of SPND failures, the data presented may include the effects of the NRU reactor control system response to the reflood water neutronic absorption. For comparison with real-time histories of changing neutron flux, instrument tube axial flux profiles are also provided at several intervals after the time reflooding begins. Because some shroud SPNDs survived longer than instrument tube SPNDs, a comparabTe set of real-time histories of changing neutron flux at the shroud corner $6 \mathrm{~F}$ are also provided in the Appendix, Part 2.2.

\subsection{COOLANT DENSITY VARIATIONS}

The evaluation of coolant density variations as a function of time during the transient operation is based on TC and SPND data (see Appendix, Part 2.2). The test assembly coolant changes from superheated steam during the pretransient operation to stagnant steam at the start of the transient. This condition changes to stagnant steam with entrained 
water droplets, water froth, and saturated steam during the reflooding and quench periods. The results obtained from these instruments have been given a preliminary review; however, no conclusions have been drawn as to how much density information can be developed from these readings.

The evaluation of the coolant densicy throughout the test assembly as a function of time has an axial dependence based on reflood the test assembly from the lower end and upper dependence in the upper hanger bar region due to potential fall-back and condensation. TCS on the hanger rod as well as high-pressure instrument connectors located in the same region provide some time/temperature information that can be used to help evaluate density variations.

\subsubsection{Preconditioning Coolant Density Variations}

The STP response to steady-state (full-power) operation is shown in the Appendix, Part 3.1. Data from each instrument level are averaged to provide the axial temperature profile in woter. Thermocouple data for the high-pressure connectors located on the upper region of the hanger bar are also included. Air TCS monitor the environment inside the connector and wa11 TCS are mounted on the connector walls. These data are included to indicate the bulk out\}et temperature.

\subsubsection{Pretransient and Transient Coolant Density Variations}

Average STP data are shown for instrument levels 12, 14, 16, and 20 in the Appendix, Part 3.2. These, together with high-pressure connector TC data, are comparable with the preconditioning data summary. A temperature history of STP data is provided for each transient as is a temperature history of the high-pressure connectors.

\subsection{POWER COUPLING}

\subsubsection{NRU Power}

The NRU reactor power indication is provided by the normal reactor instrumentation and is given both as percentage of full reactor power 
and as MW. The calculations presented here are based on percentage values.

\subsubsection{Test Assembly Preconditioning Power}

The test assembly power during preconditioning was determined by calorimetric methods at several power levels during the two rises to power. The data used were the flow rate provided by the loop instrumentation and an inlet temperature obtained by averaging the three test assembly TCs below the fueled region and the three test assembly TCS above the fueled region. Using TCS rather than loop instrumentation eliminated concern over heat losses in the loop piping. The powers calculated in this manner are:

\begin{tabular}{lll} 
Reactor Power, \% & $\begin{array}{l}\text { Test Assembly } \\
\text { Power, kW }\end{array}$ & Coupling (a) \\
\cline { 2 - 3 } 20 & 425 & 21.3 \\
40 & 898 & 22.4 \\
50 & 936 & 18.7 \\
98 & 2058 & 21.5 \\
97 & 2173 & 21.8 \\
& & Average 21.1
\end{tabular}

(a) Coupling is defined as Test Assembly Power $/ \%$ Reactor Power

\subsubsection{Test Assembly Pretransient Power}

The test assembiy powers were determined in the same manner as the caluclations for preconditioning power for runs PTH-COH and PTH-106. The powers were 138 and $135 \mathrm{~kW}$, respectively. The nominal react " power was $6 \%$, which gives coupling values (test assembly power $/ \%$ reactor power) of 23.0 and 22.5, which may be compared to the average coupling value of 21.1 determined for the preconditioning operation. This implies a $9 \%$ decrease in assembly power upon going from steam-filled to waterfilled operation. 
Some uncertainty exists concerning the accuracy of the nomina? reactor power percentages used in the foregoing calculations, and the probiem is being investigated and will be resolved.

\subsection{INSTRUMENTATION FAILURE}

During the course of the testing, many of the sensors including TCs, STPS, and neutron detectors behaved in odd ways. In many cases, a sensor appeared to have failed but later in the same test or in a later test it was once again performing as expected. This behavior was especially prevalent among the SPNDs.

More analysis will be required to determine the difference between actual instrument failure and instrument behavior that is real but not currently understood. Tabie 3 presents a preliminary list of the sensors whose output showed inexplicable response patterns when plotted versus time. Although Table 3 is listed in chronological order of failure, the tests were not always performed in the direct numerical sequence of the test identification number.

\subsection{SHROUD LEAK RATE CHARACTERISTICS}

The shroud leak rate tests were designed to test both the shroud integrity and to verify the reflood rate calibration. Each test consisted of one reflood cycle with the reactor at essentially zero power. The data consist of STP measurements plotted versus time. Identical leak rate tests were performed at different times during the thermal-hydrautic test series. Optimally, each of these tests would result in identical instrument responses. The data from STPS at different elevations are

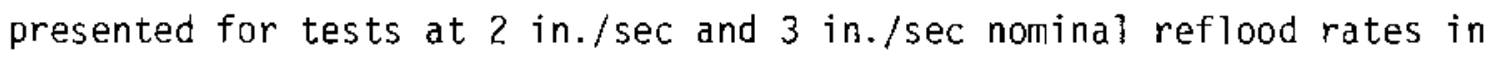
Appendix Figures 5.1.1 through 5.7.4. Table 4 contains the elevations of these instruments to be used in evaluating the actual reflood rates.

\subsubsection{Low Reflood Rate (2 in./sec)}

The first shroud leak tests were performed early in the test series to set a base response curve. The reflood rate as measured by 
TABLE 3. Failed Sensors

Test Number

101

174

107

110

108

109

112
Sensor Designation

TC-13-6C-IR-2

TC-13-1F-S-C

TC- 15-6F-S-C

TC- 17-4C-IR-C

TC-17-3C-IR-7

TC-77-5B-IR-C

TC-18-1A-S-C

SPND-15-IF-S-4

SPND-3-6F-S-3

SPND-15-1A-S-1

SPND-13-1F-S-4

$T C-17-6 F-S-C$

SPND-17-4D-7R-2

SPND-17-1A-S-1

TC-3-6A-S-C

STP-14-5E-SP-4

SPND-15-4D-IR-2

SPND-15-6F-S-3

SPND-15-6A-S-2

SPND-18-4D- ]R-2

TC- $11-1 D-0 R-2$

SPND-17-6A-S-C

STP-12-2B-SP-2

SPND- 17-6F-S-C

STP-14-58-SP-3

SPND-T3-6F-S-3

SPND-13-6A-S-2

SPND-13-4D-IR-2

SPND-16-IF-S-C

TC- $] 1-4 F-0 R-7$ 
TABLE 3. Fajled Sensors (continued)

Test Number

116

117

118

119

122

124

125

127

128

130
Sensor Designation

$\mathrm{TC}-7-3 \mathrm{~A}-0 \mathrm{R}-3$

$T C-20-0 T-3$

STP-14-2E-SP-1

TC $-11-3 \mathrm{~A}-\mathrm{OR}-3$

TC-13-3B-1R-2

$T C-7-6 C-0 R-4$

STP-16-5E-SP-4

STP-14-2B-SP-2

STP-16-2E-SP- 1

STP-12-5B-SP-3

IC $-11-6 C-0 R-4$

TC-6- IA-S-C STP-12-5E-SP-4 STP-12-2E-SP- ]

SPND-18-6F-S-3

SPND-13-1A-S-1

SPND-10-6F-S-3 
TABLE 4. Steam Probe Identification and Axial Locations

\begin{tabular}{llll} 
& \multicolumn{2}{l}{ Elevation } \\
& \multicolumn{2}{l}{ in. } & \multicolumn{1}{l}{$(m)$} \\
STP-12-4D-SP-4 & 68.8 & $(1.748)$ \\
STP-12-5E-SP-4 & 68.8 & $(1.746)$ \\
STP-12-5B-SP-3 & 68.8 & $(1.746)$ \\
STP-12-2B-SP-2 & 68.8 & $(1.746)$ \\
STP-12-2E-SP-1 & 68.8 & $(1.746)$ \\
STP-14-4D-SP-4 & 89.8 & $(2.282)$ \\
STP-14-5E-SP-4 & 89.8 & $(2.281)$ \\
STP-14-5B-SP-3 & 89.8 & $(2.281)$ \\
STP-14-2B-SP-2 & 89.8 & $(2.281)$ \\
STP-14-2E-SP-1 & 89.8 & $(2.281)$ \\
STP-16-4D-SP-4 & 110.8 & $(2.815)$ \\
STP-16-5E-SP-4 & 110.8 & $(2.814)$ \\
STP-16-5B-SP-3 & 110.8 & $(2.814)$ \\
STP-15-2B-SP-2 & 110.8 & $(2.814)$ \\
STP-16-2E-SP-1 & 110.8 & $(2.814)$ \\
STP-20-0T-2 & 160 & $(4.06)$
\end{tabular}


the turbine flowmeter is shown in Appendix Figure 5.1.7. The temperature responses for the three STPS mounted on the instrument tube are shown in Appendix Figure 5.1.2. Appendix Figures 5.1.3 and 5.1.4 show the temperatures measured by the STPS mounted on the grid spacers in the bundle. Two figures were used to show the large number of instruments.

It can be seen that as the coolant reached the level of each instrument, the temperature dropped suddenly. By using the times at which different elevations were reached, it is possible to determine the actual rate at which the shroud filled with water. Appendix Figures 5.2.1 to 5.3.3 show information from the second and third shroud leak

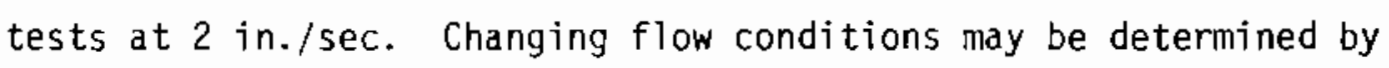
comparing these measurements with the first test.

\subsubsection{Nomina1 Reflood Rate (3 in./sec)}

Shroud leak test data from tests at $3 \mathrm{in./ \textrm {sec }}$ are presented in the same manner as those for the low reflood rate data. Results from the first test at $3 \mathrm{in./ \textrm {sec }}$ are shown in Appendix Figures 5.4.1 through 5.4.4; and tests 2, 3, and 4 are presented in Appendix Figures 5.5.1 through 5.7.4. These plots indicate that very little, if any, shroud leakage was experienced during these tests. Further evaluations are being performed to better define the leakage.

\subsection{REFLOOD CHARACTERISTICS FOR FLECHT COMPARISON IESTS}

Three pairs of tests were designed to provide data for comparison with FLECHT data: PTH-108, PTH-111, PTH-118, PTH-123; and PTH-120, PTH124. Tests PTH-108, PTH-118, and PTH-120 used a normal prefill that introduced reflood water up to the bottom of the fuel rod at a fast rate of $0.229-0.254 \mathrm{~m} / \mathrm{sec}(9-10 \mathrm{in} . / \mathrm{sec})$ followed by the preselected reflood rate for the duration of the test. The companion tests used a fastfilled sequence to insert reflood water at the fast rate up to the $0.305-\mathrm{m}(1-\mathrm{ft})$ level on the fuel column, followed by the preselected reflood rate for the duration of the test. A reflooding rate history is provided in Part 5 of the Appendix for each of these FLECHT comparison tests. 
In addition, the reflood rate history is provided for three replicable tests that were conducted between the FLECHT comparison test pairs. Those tests (PTH-104, PTH-112, and PTH-121) al1 used normal prefil1 reflooding sequences and compared very well. Because the remaining tests of the series used this normal prefill sequence, additional reflood rate history graphs are not provided. 


\subsection{REFERENCES}

1. Hann, C. R. 1979. Program Plan LOCA Simulation in the National Research Universal (NRU) Reactor. PNL-3056, Pacific Northwest Laboratory, Richland, Washington.

2. Mohr, C. L., et a1. 1981. Safety Analysis Report: Loss-of-Coolant Accident Simulations in the National Research Universal Reactor. PNL-3093, NUREG/CR-1208, Pacific Northwest Laboratory, RichTand, Washington. *

3. Heaberlin, S. W., et a1. 1979. Design Basis Neutronics Calculations for NRU-LOCA Experiments. PNL-3113, NUREG/CR-1025, Pac if ic Northwest Laboratory, Richland, Washington.*

*Available for purchase from the NRC/GPO Sales Program, U.S. Nuclear Regulatory Commission, Washington, DC 20555, and/or the National Technical Information Service, Springfield, VA 22161. 
APPENDIX

QUICK-LOOK REPORT CATA 

PART I

TEMPERATURE PROFILES 


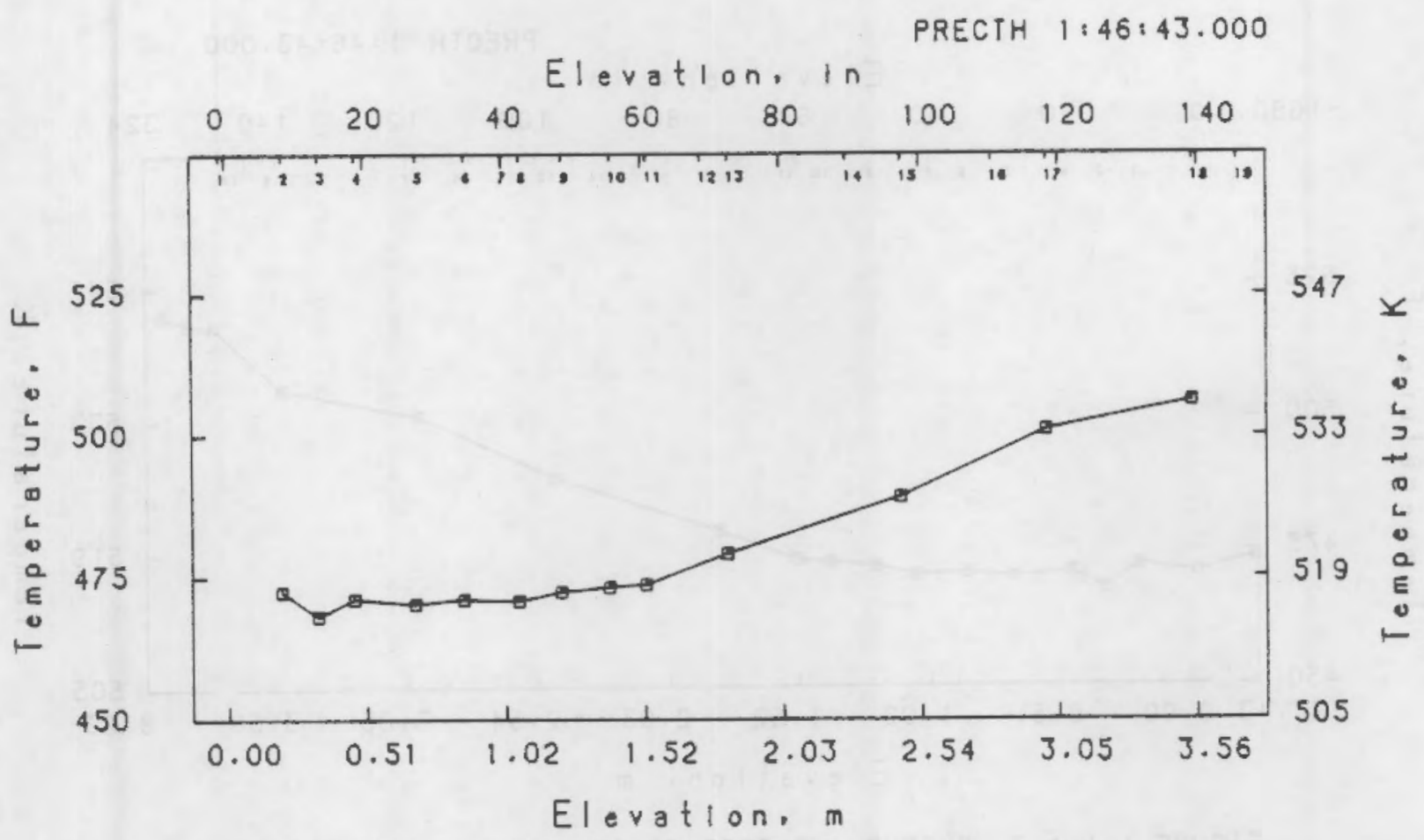

FIGURE 1.1 .1 .1 AVERAGE SHROUD AXIAL TEMPERATURE PROFILE

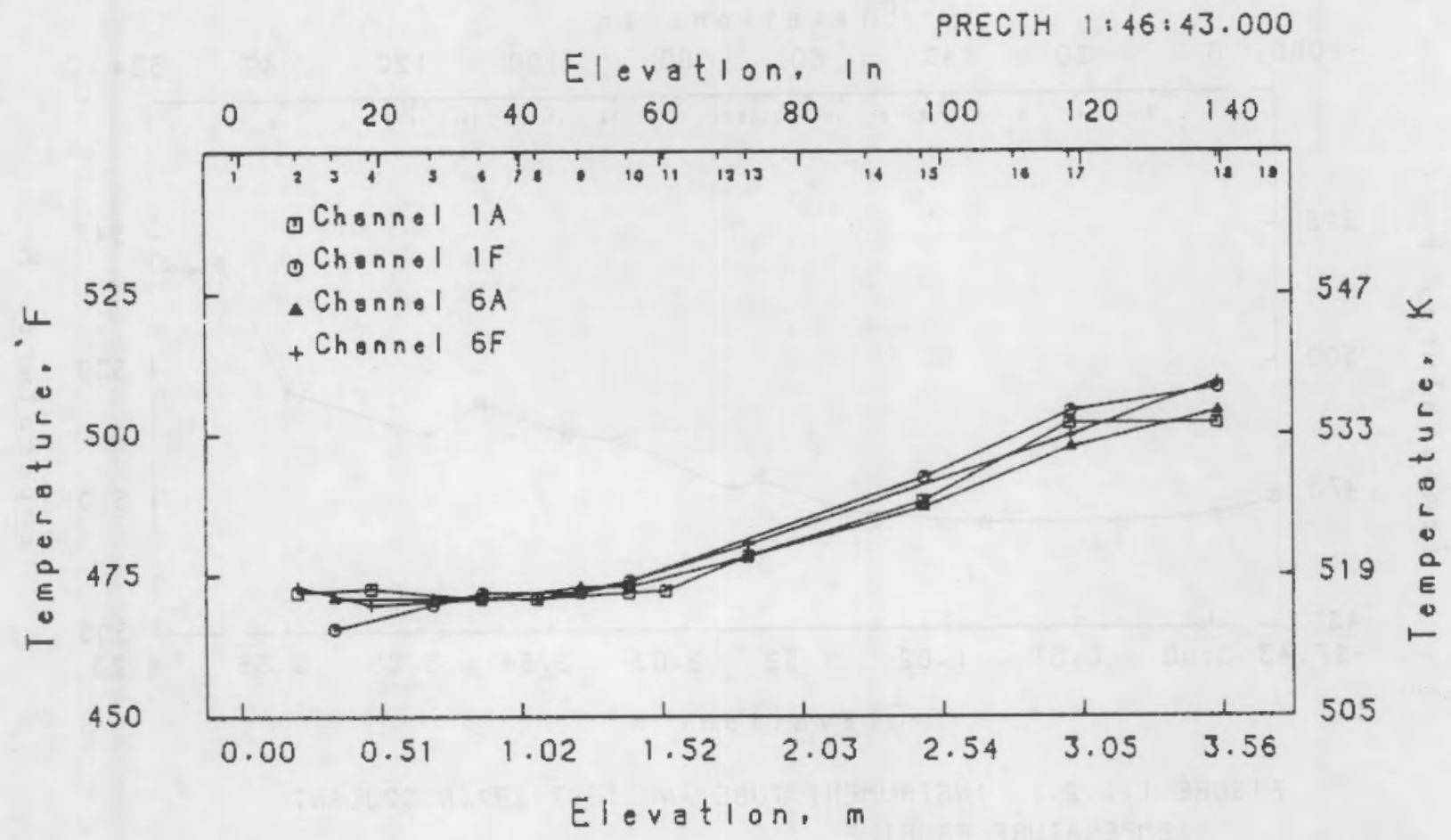

FIGURE 1.1 .1 .2 SHROUD AXIAL TEMPERATURE PROFILE 


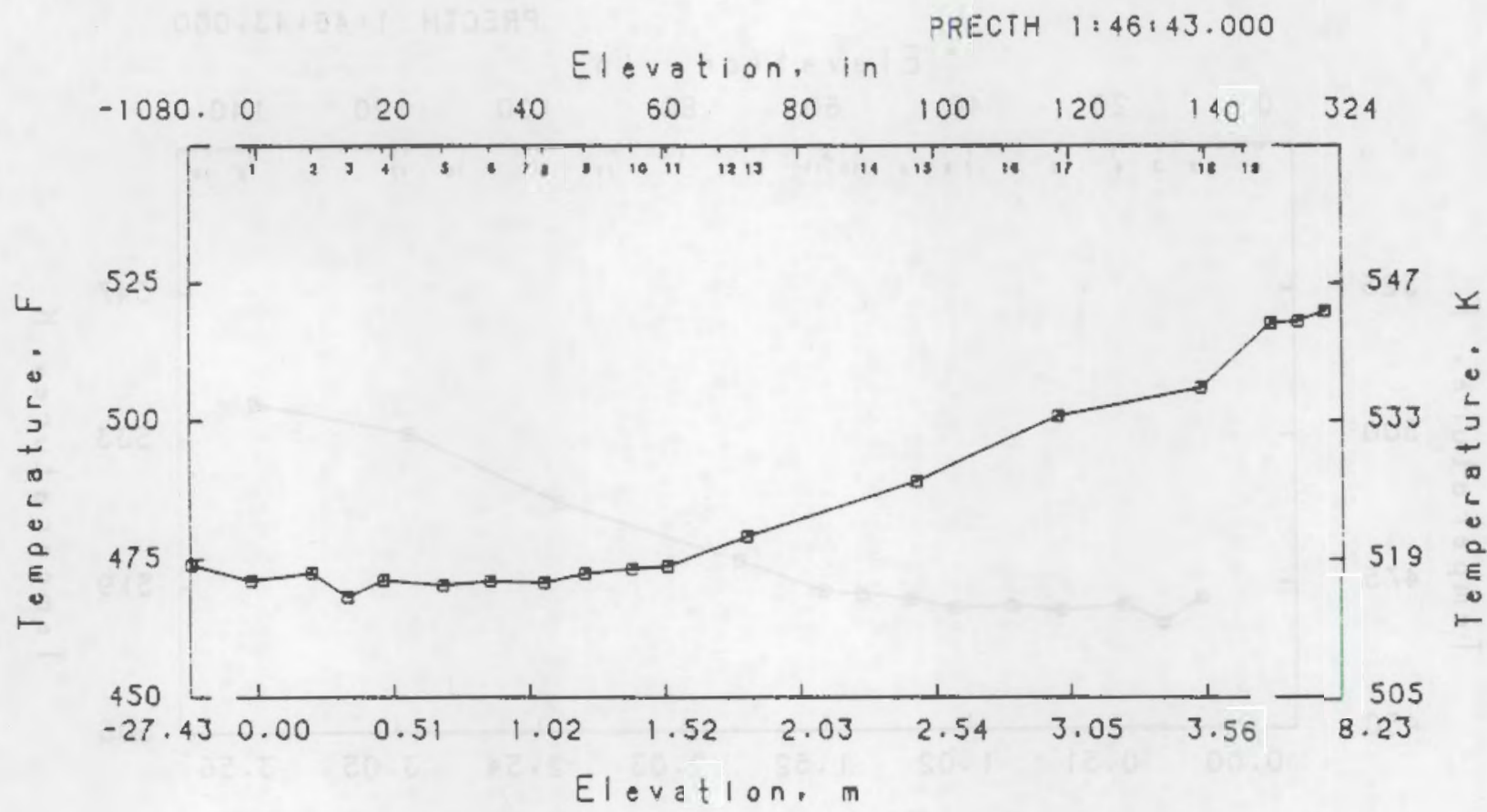

FIGURE 1.1 .1 .3 SHROUD AND TEST TRAIN COOLANT TEMPERATURES

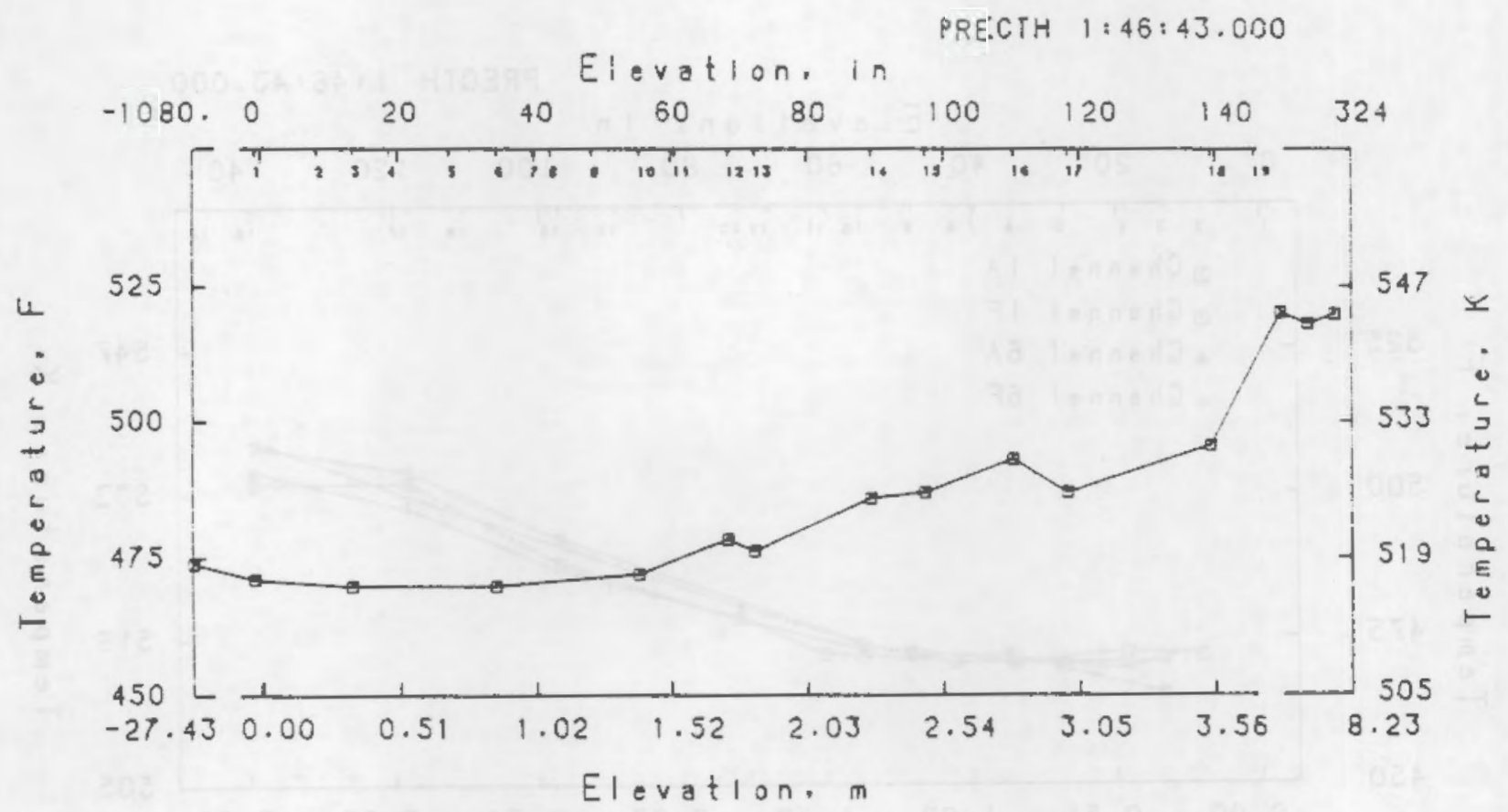

FIGURE 1.1 .2 .1 INSTRUMENT TUBE AND TEST TRAIN COOLANT TEMPERATURE PROFILE 


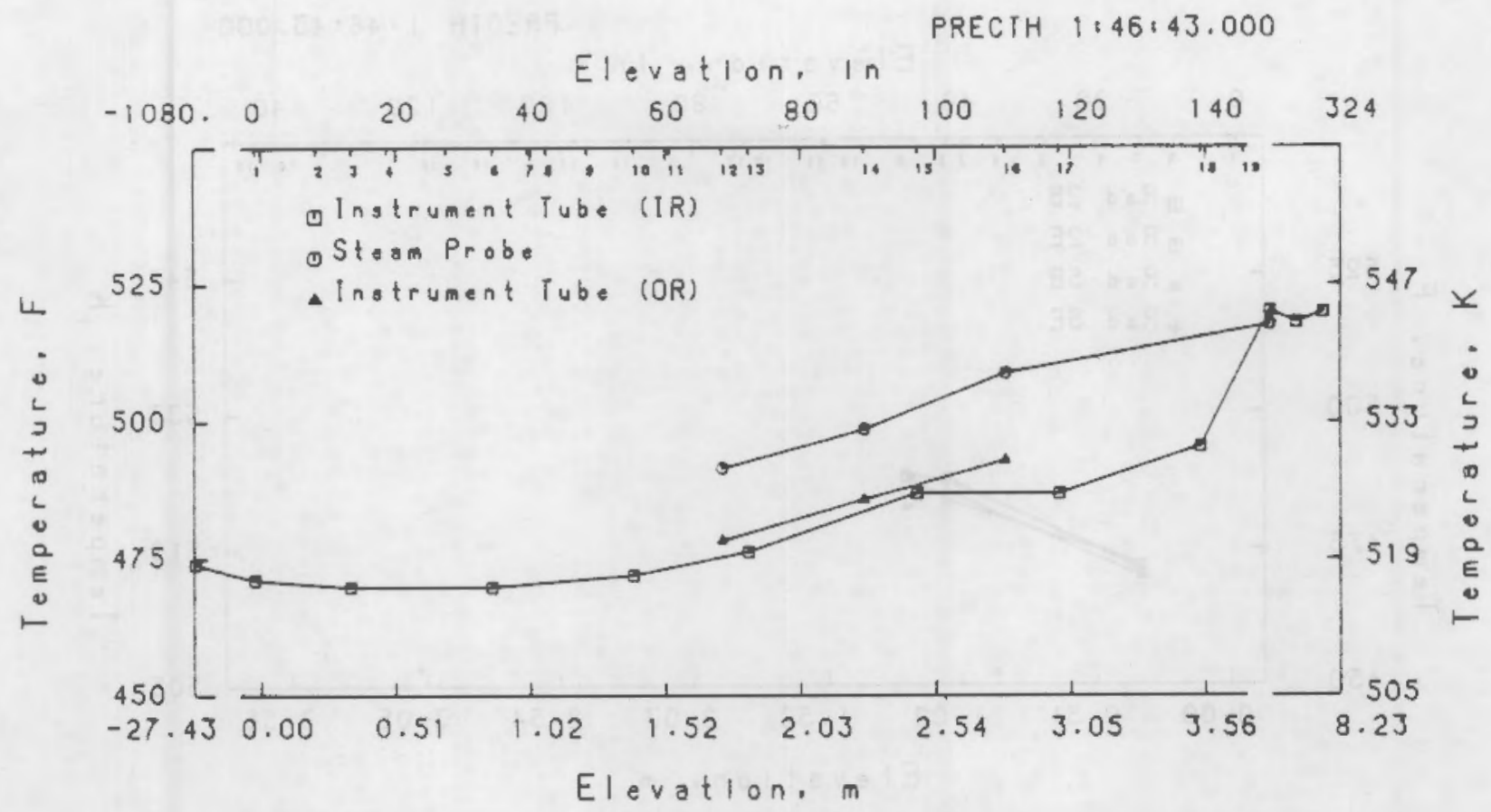

FIGURE 1.1 .2 .2 COMPARISON OF STEAM PROBE HITH INSTRUMENT TUBE AND TEST TRAIN TEMPERATURE PROFILES

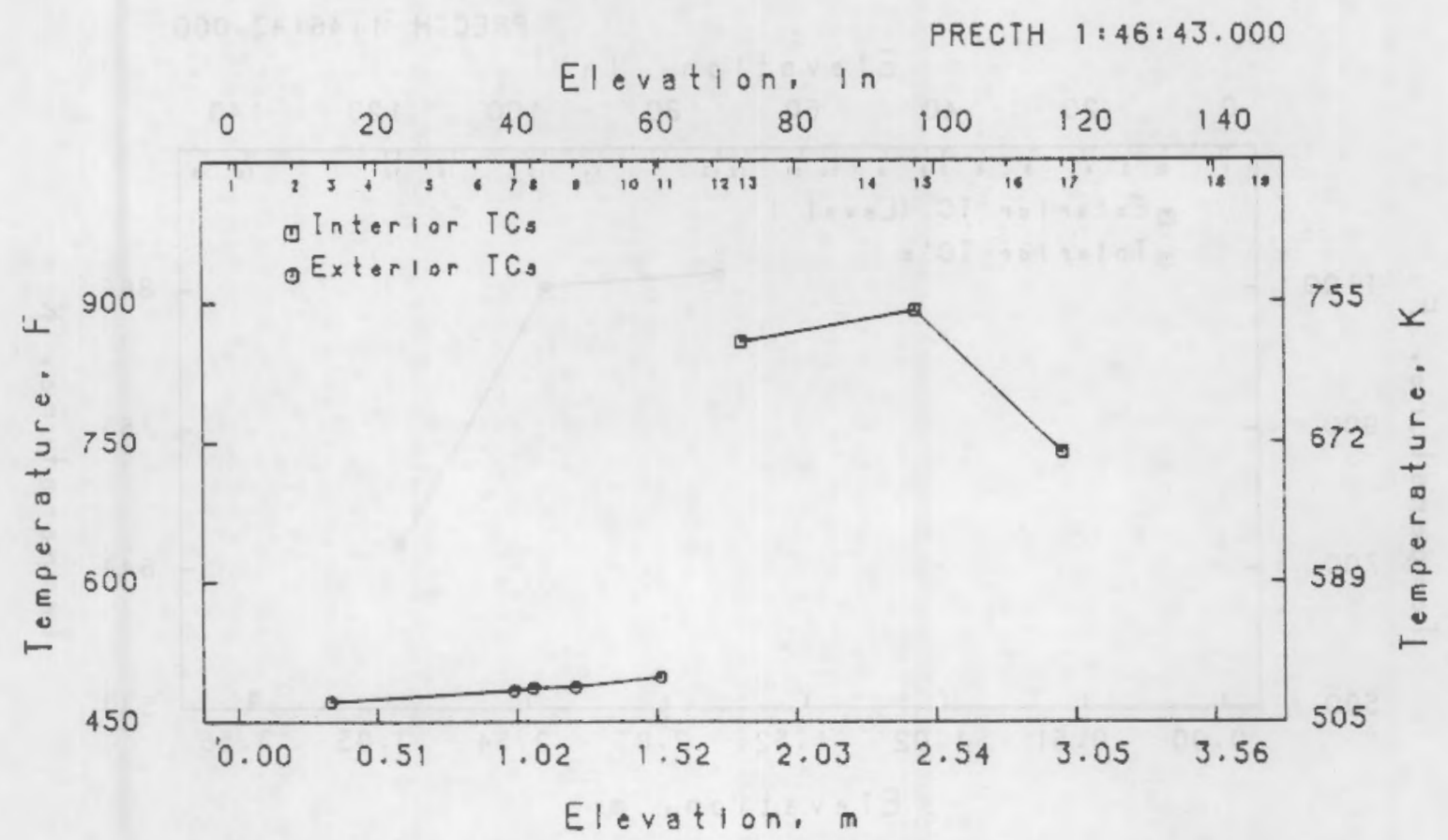

FIGURE 1.1 .3 .1 AVERAGE GUARD FUEL ROD CLADOING TEMPERATURE PROFILES - INTERIOR ANO EXTERIOR TC'S 


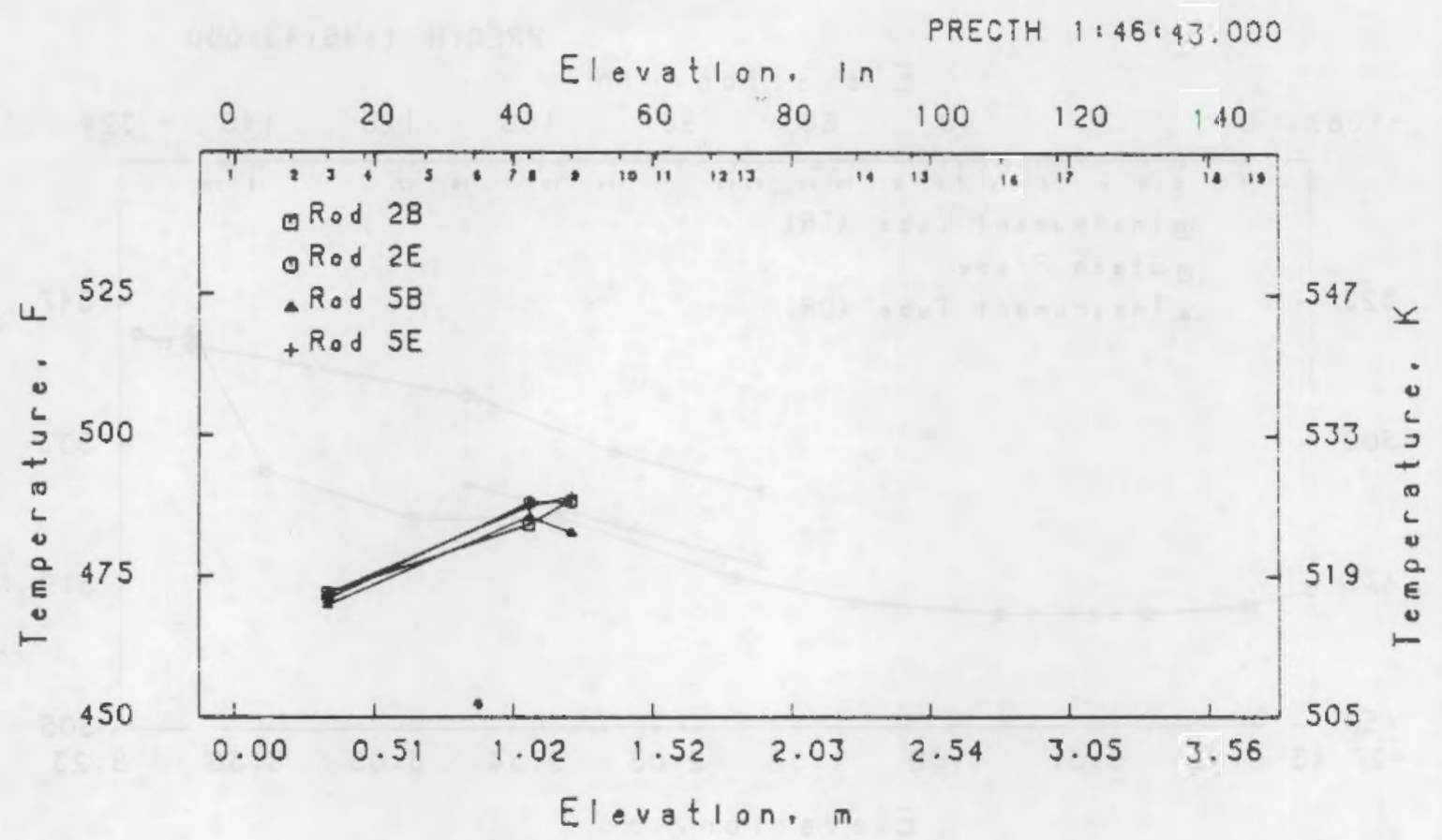

FIGURE 1.1 .3 .2 INDIVIDUAL GUARD FUEL ROD CLADDING EXTERIOR TEMPERATURE PROFILES

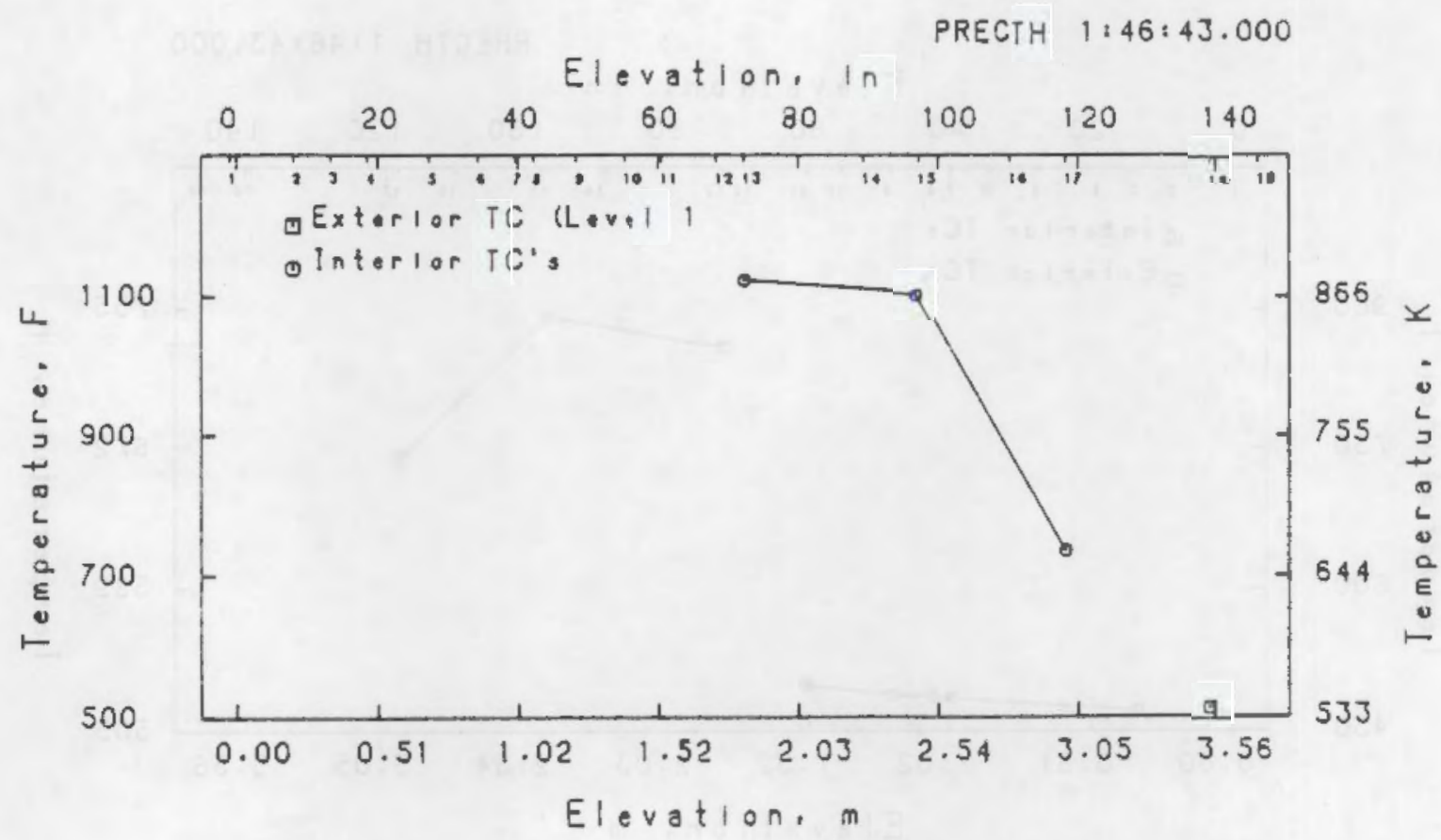

FIGURE 1.1 .4 .1 AVERAGE TEST FUEL ROD CLADDING TEMPERATURE PROFILE - EXTERIOR AND INTERIOR TC'S 


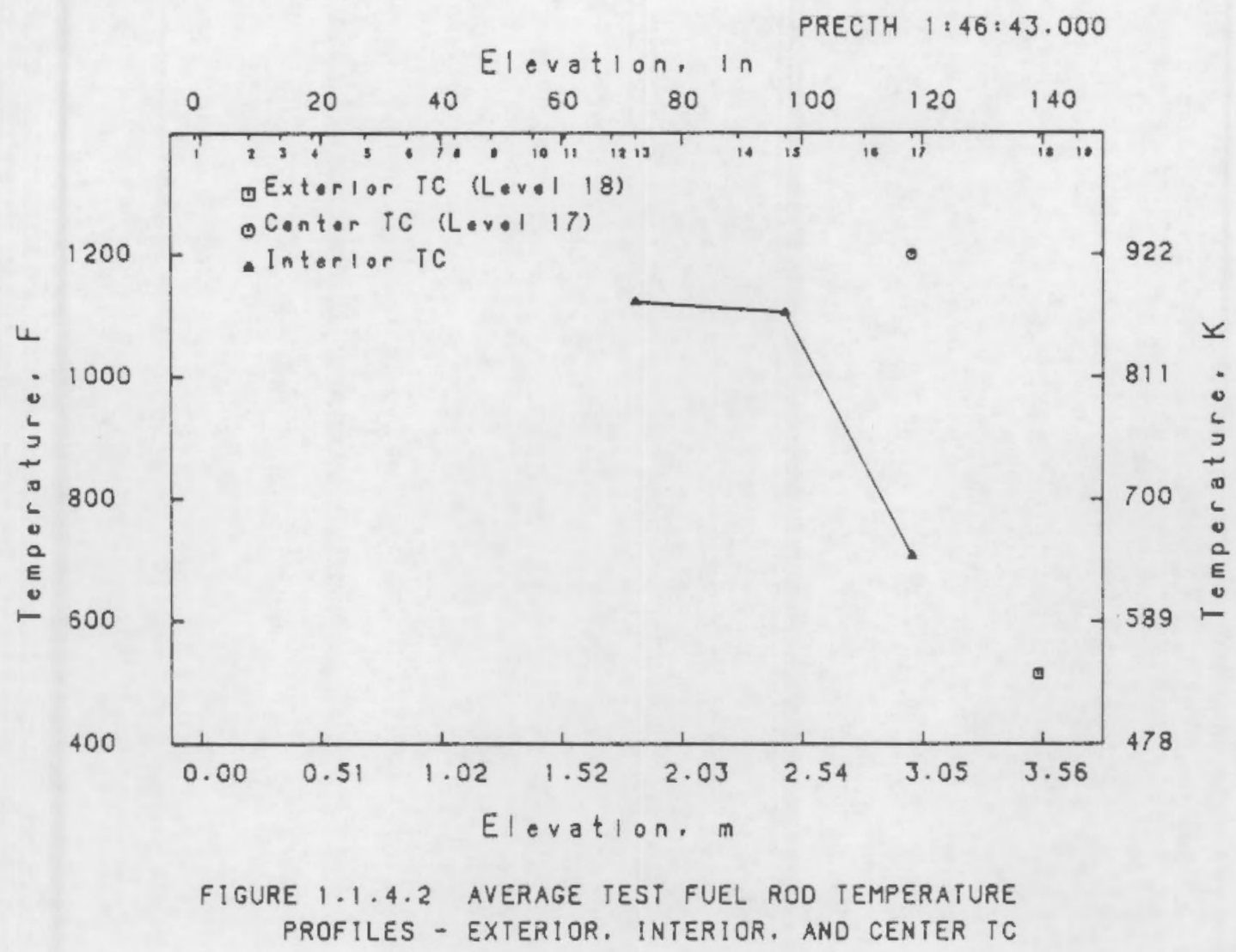

A. 5 

PTH101 17:35:40.664

FIGURE 1.2 .1 .1 DIAGONAL TEMPERATURE PROFILE ACROSS TEST ASSEMBLY COOLANT DURING PRETRANSIENT - LEVEL 16

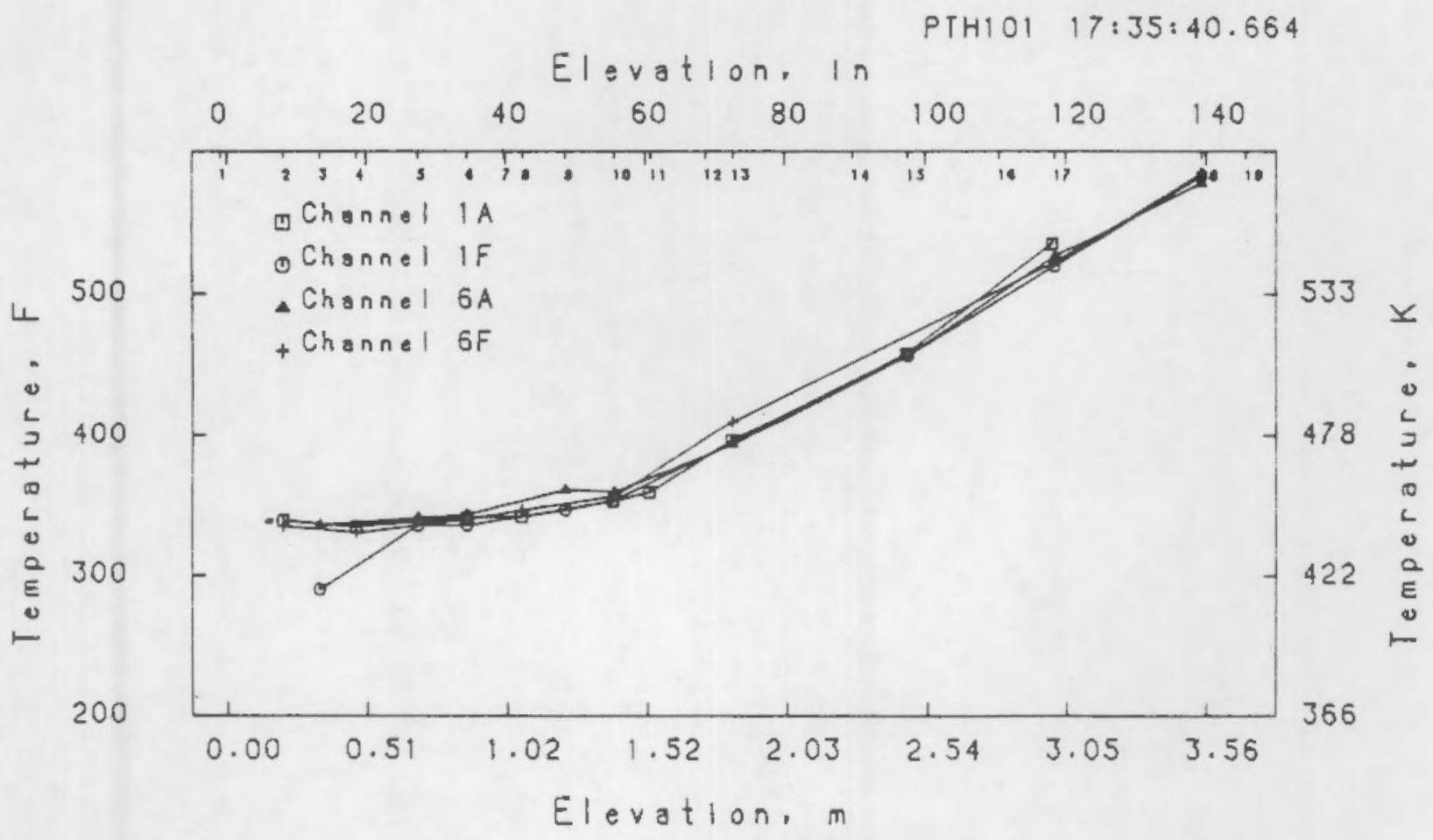

FIGURE 1.2 .1 .2 SHROUD AXIAL TEMPERATURE PROFILE PRETRANSIENT PTHIOI 



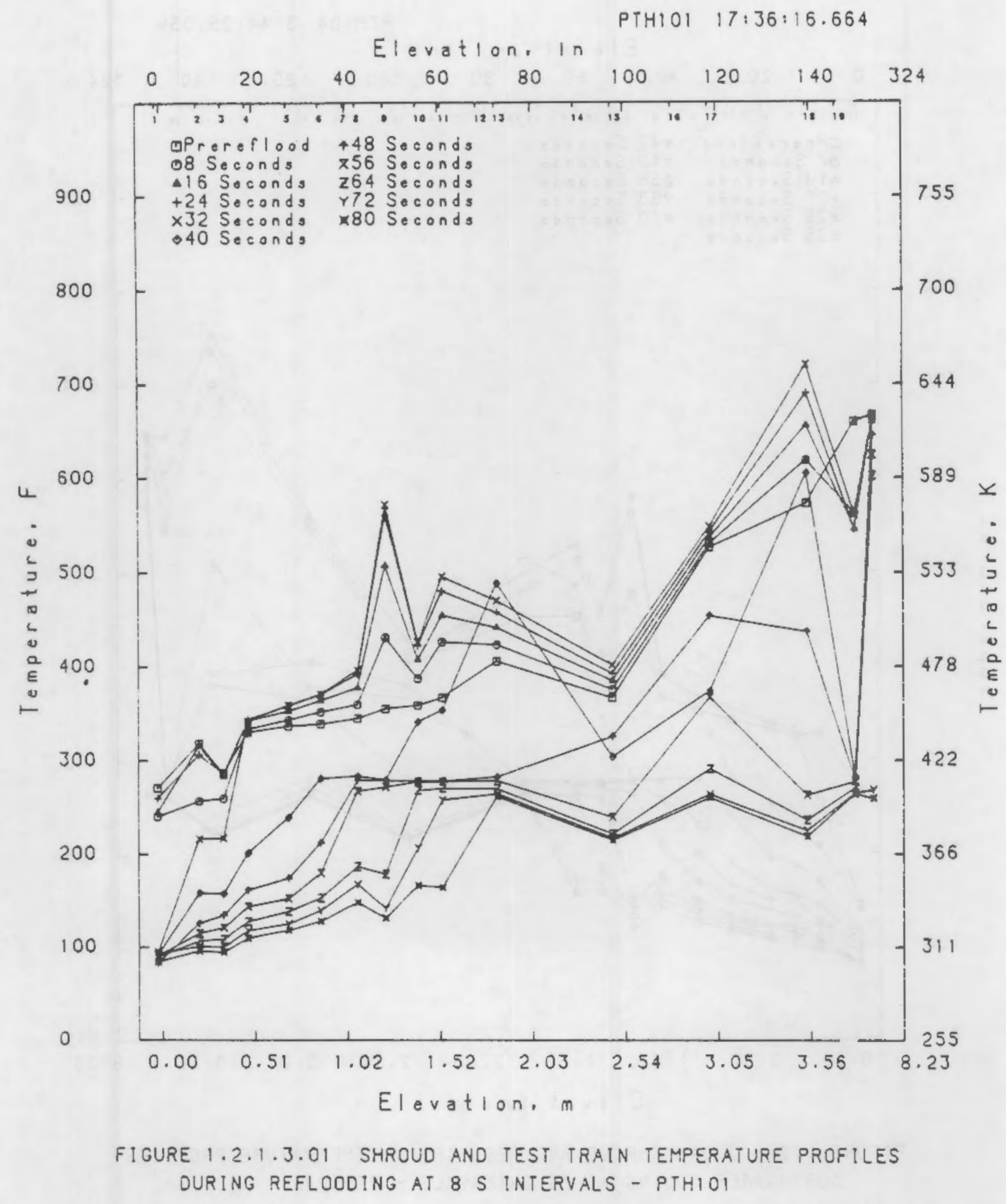




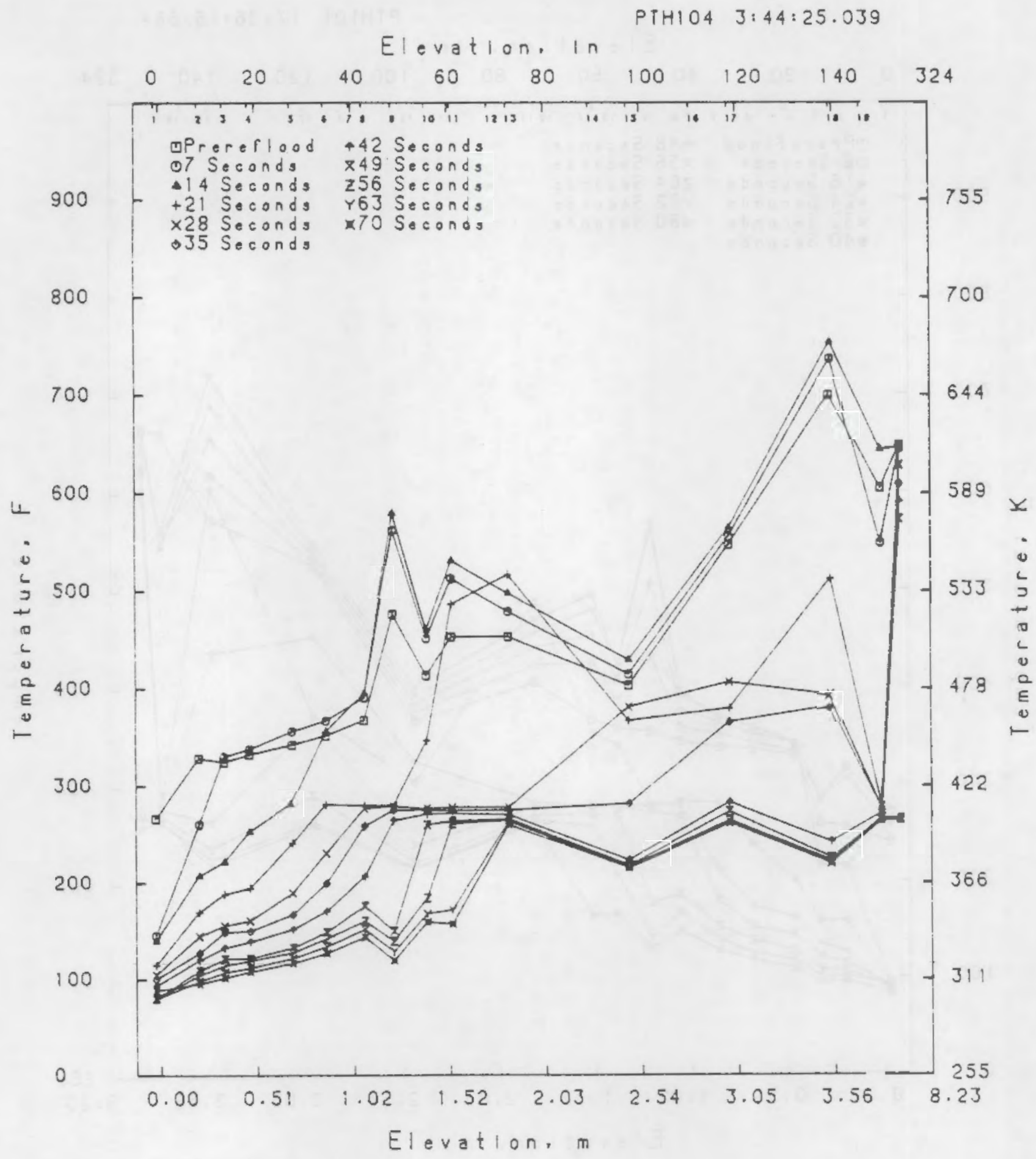

FIGURE 1.2 .1 .3 .04 SHROUD AND TEST TRAIN TEMPERATURE PROFILES DURING REFLOODING AT $7 S$ INTERVALS - PTHIO4 
Elevation, in

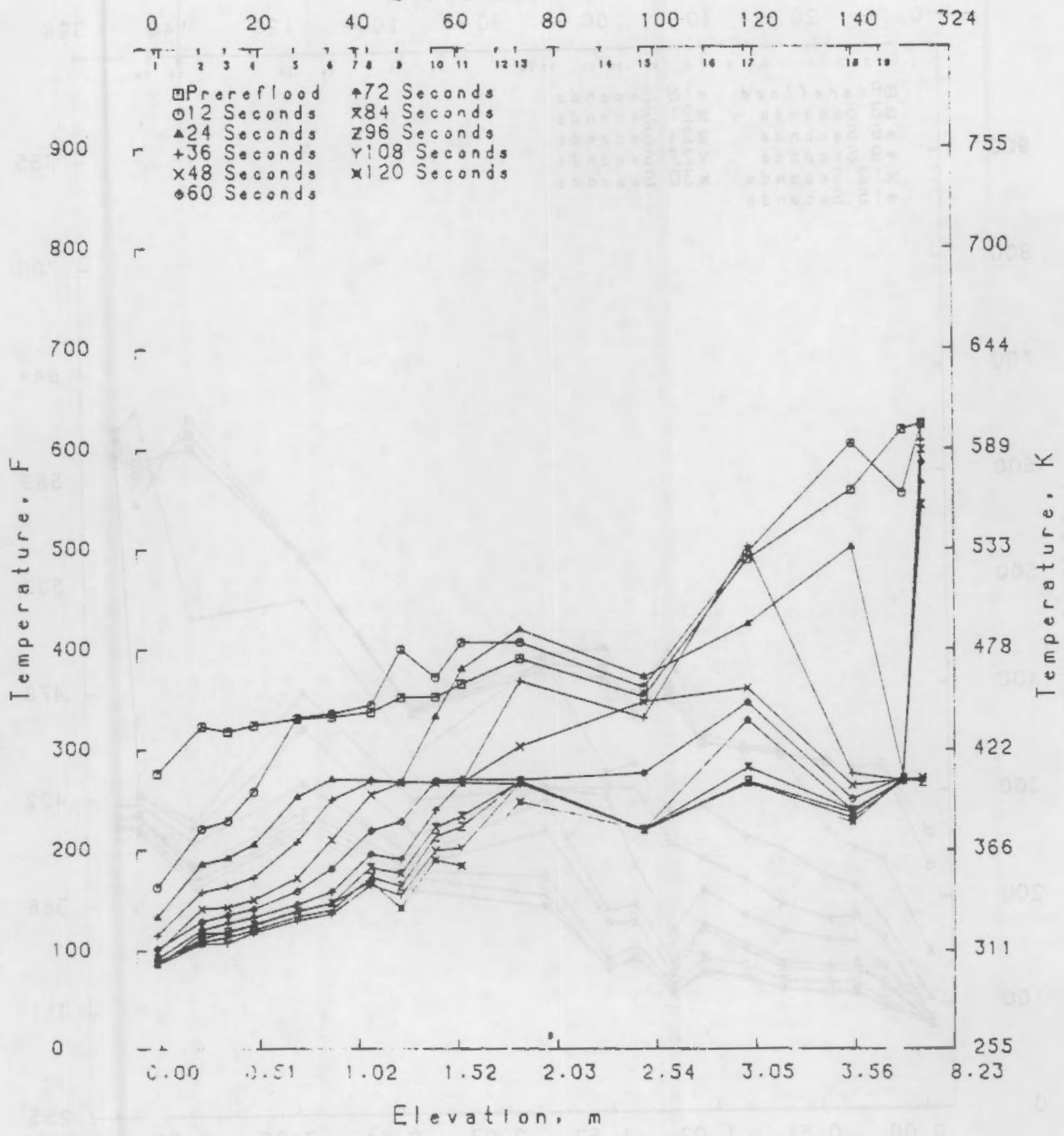

FIGURE $1.2 \cdot 1.3 .05$ SHROUD AND TEST TRAIN TEMPERATURE PRDFILES DURING REFLOODING AT I2S INTERVALS - PTHIOS 


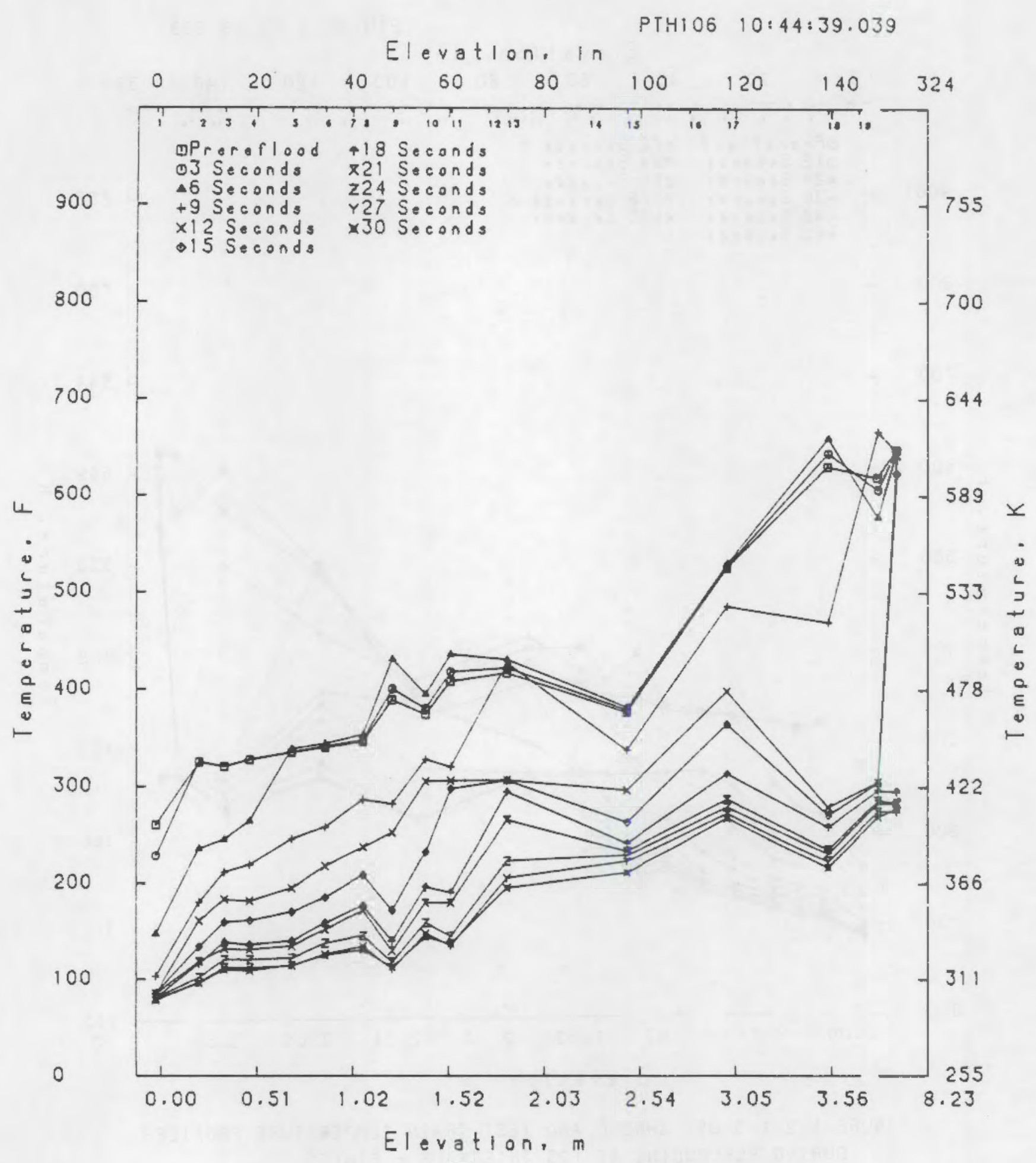

FIGURE 1.2.1.3.06 SHROUD AND TEST TRAIN TEMPERATURE PROFILES DURING REFLOODING AT JS INTERVALS - PTHIO6 


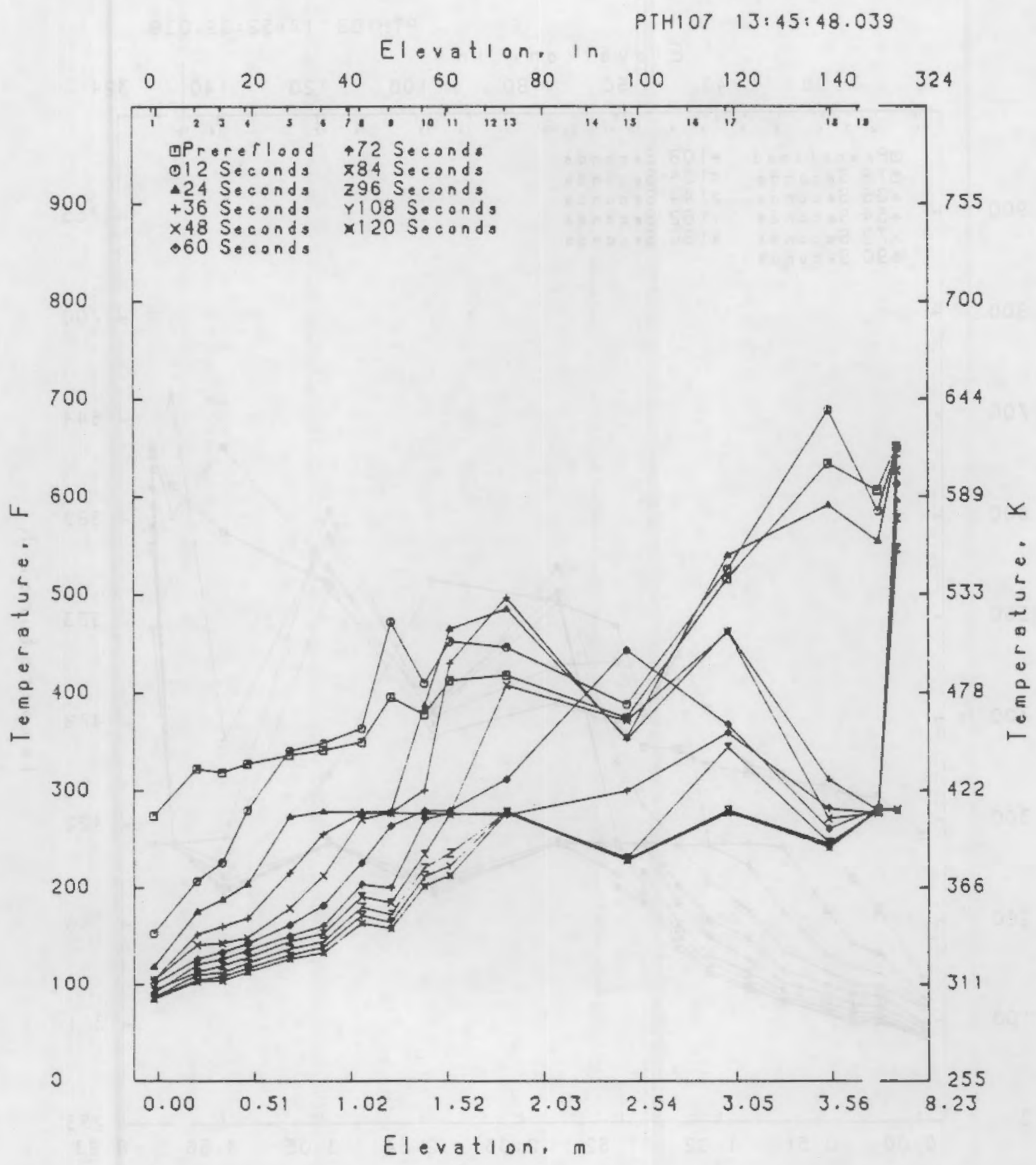

FIGURE 1.2.1.3.07 SHROUD AND TEST TRAIN TEMPERATURE PROFILES DURING REFLOODING AT $12 S$ INTERVALS 


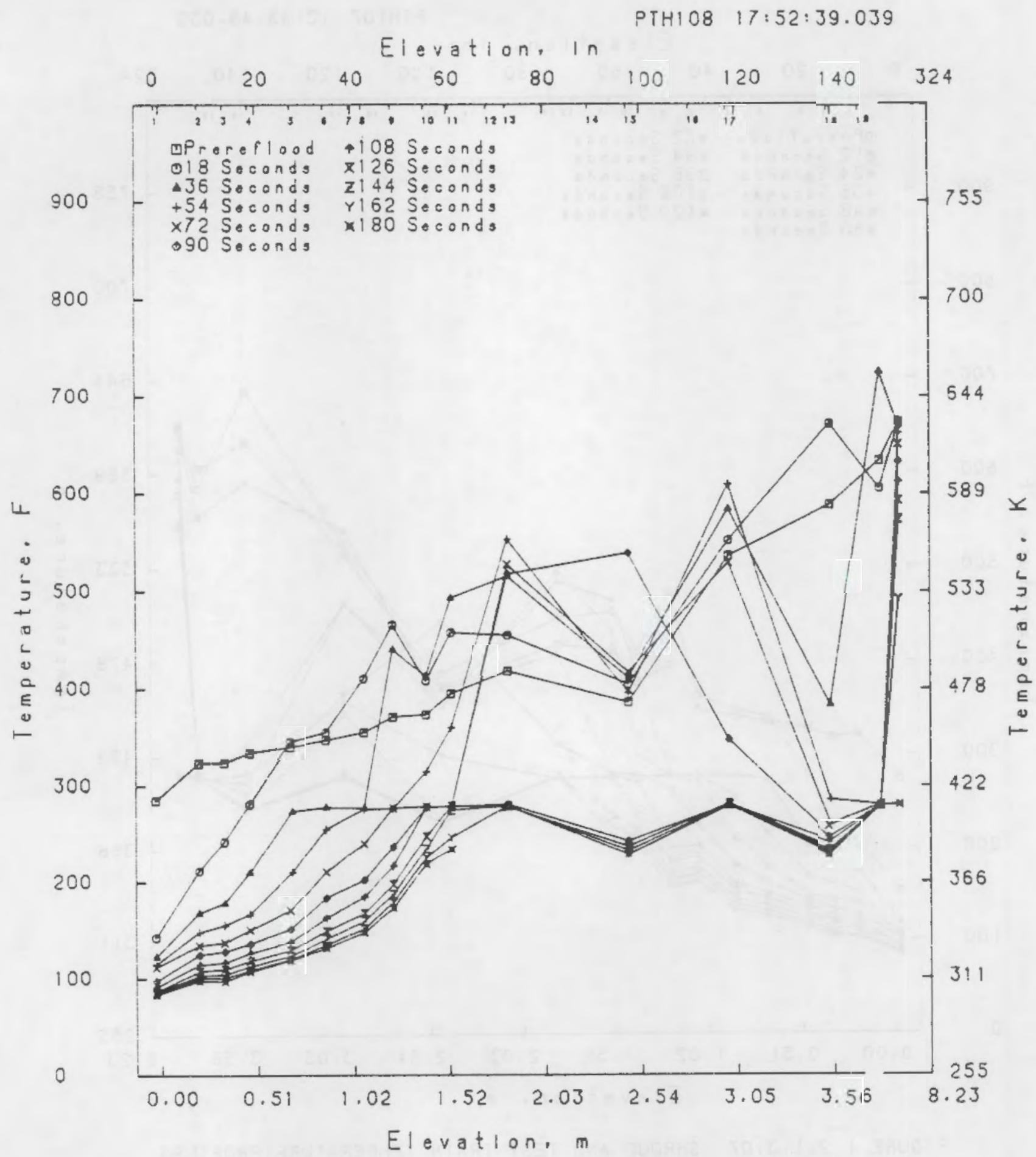

FIGURE 1.2 .1 .3 .08 SHROUD AND TEST IRAIN TEMPERATURE PROFILES DURING REFLOODING AT 18S INTERVALS - PTHI08 


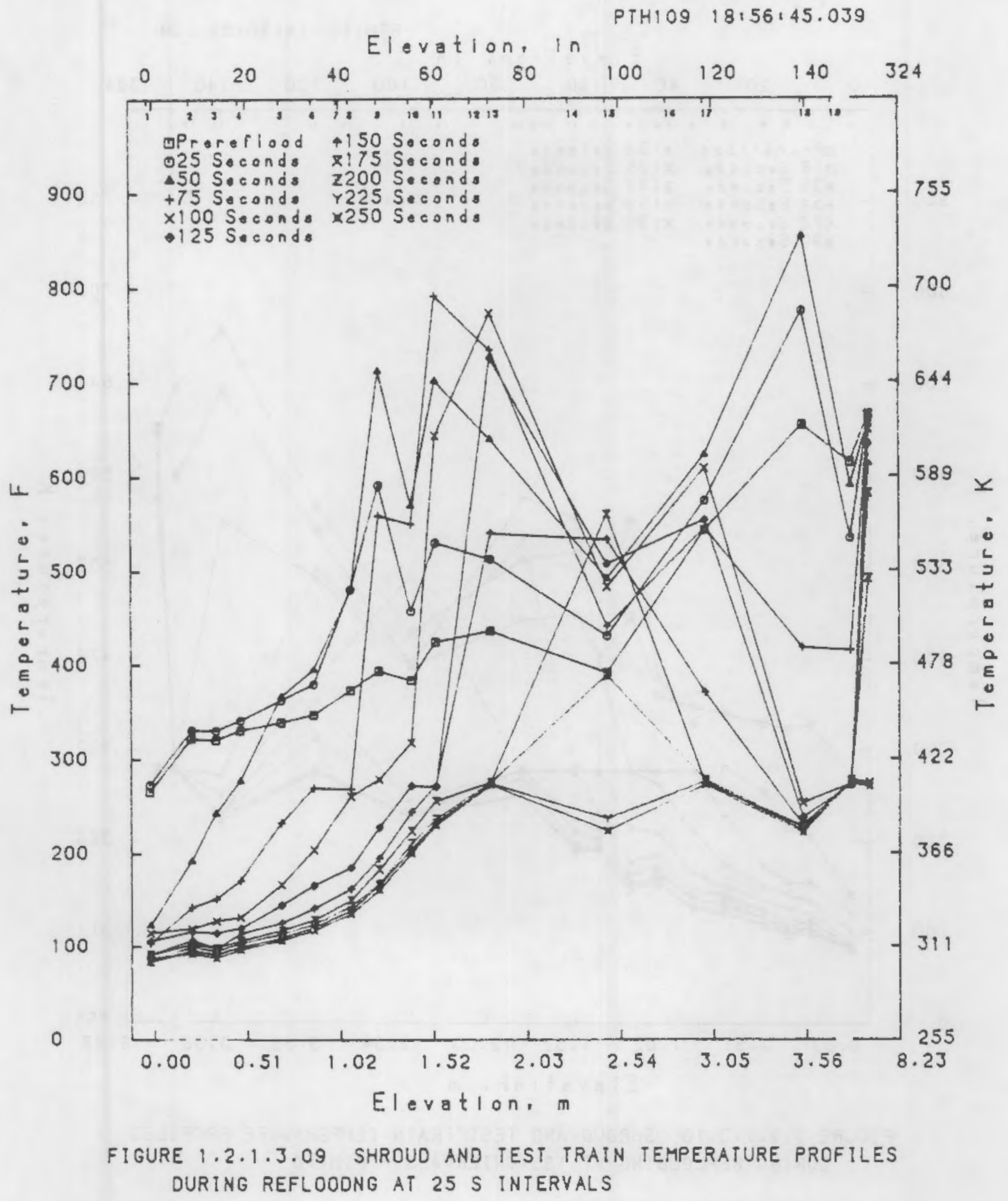




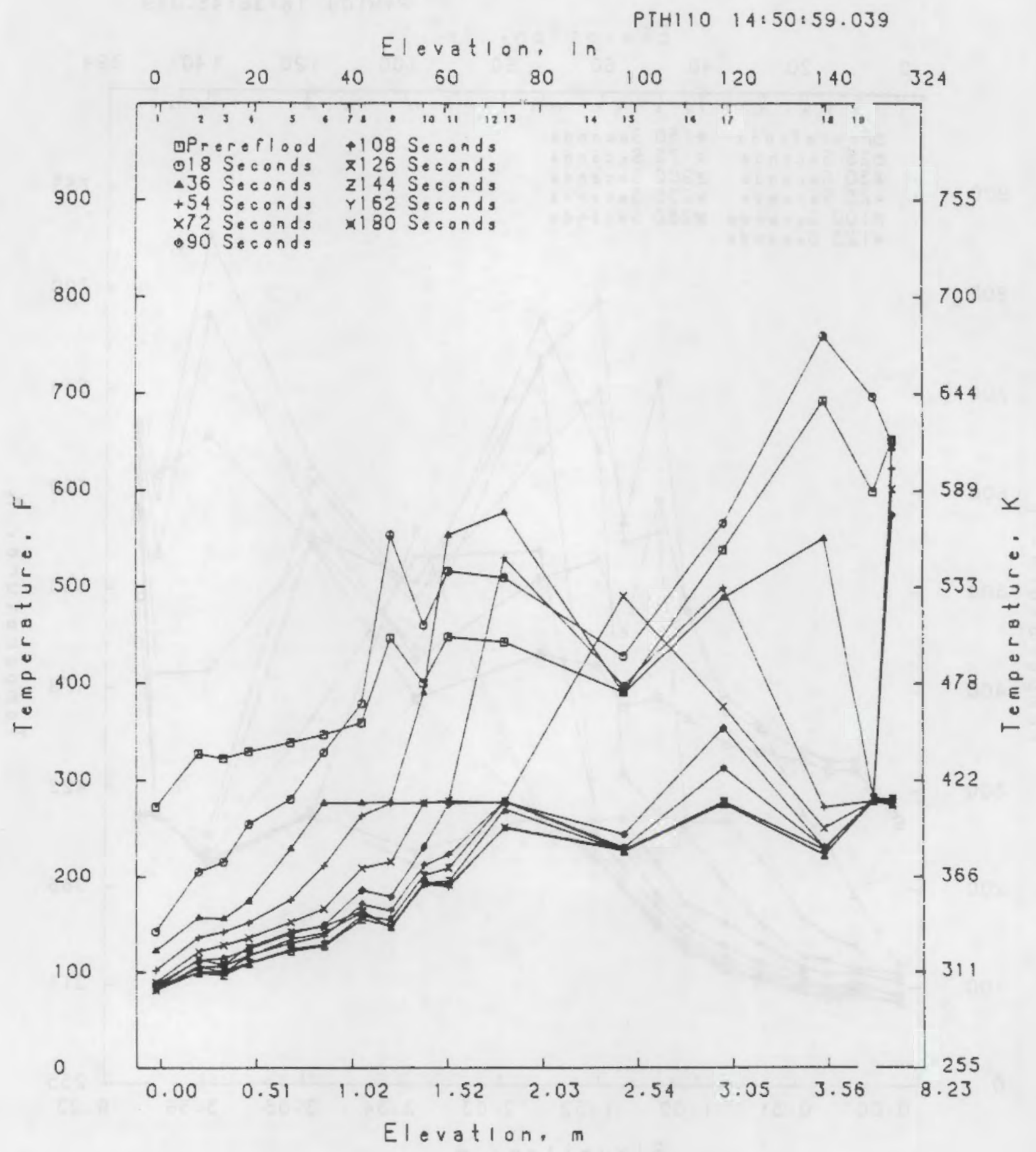

FIGURE $1.2 \cdot 1.3 \cdot 10$ SHROUD AND TEST TRAIN TEMPERATURE PROFILES DURING REFLOODING AT 18 S INTERVALS - PTHIIO 


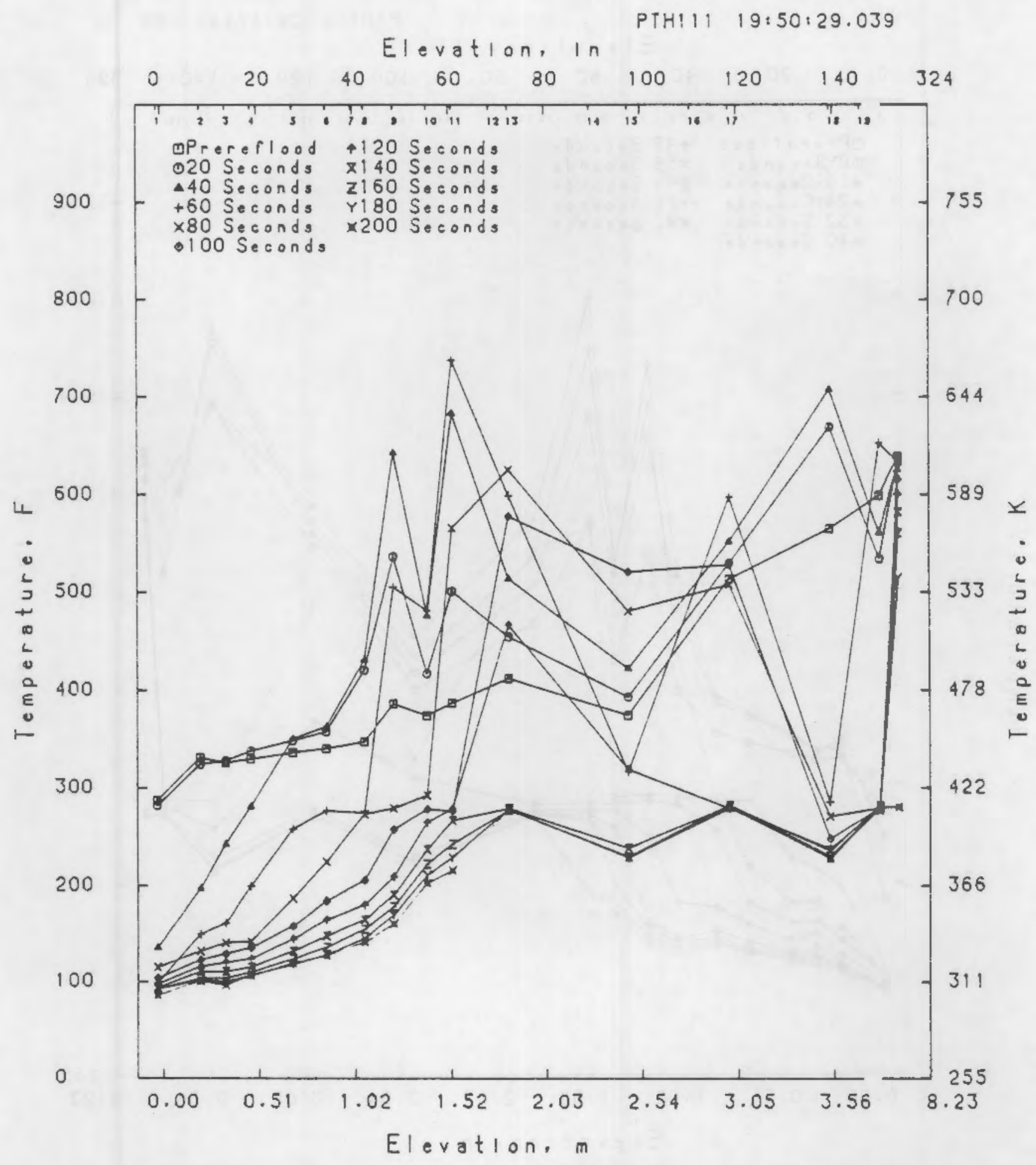

FIGURE $1.2 \cdot 1 \cdot 3 \cdot 11$ SHROUD AND TEST TRAIN TEMPERATURE PROFILES DURING REFLOODNG AT 20 S INTERVALS - PTHIII 


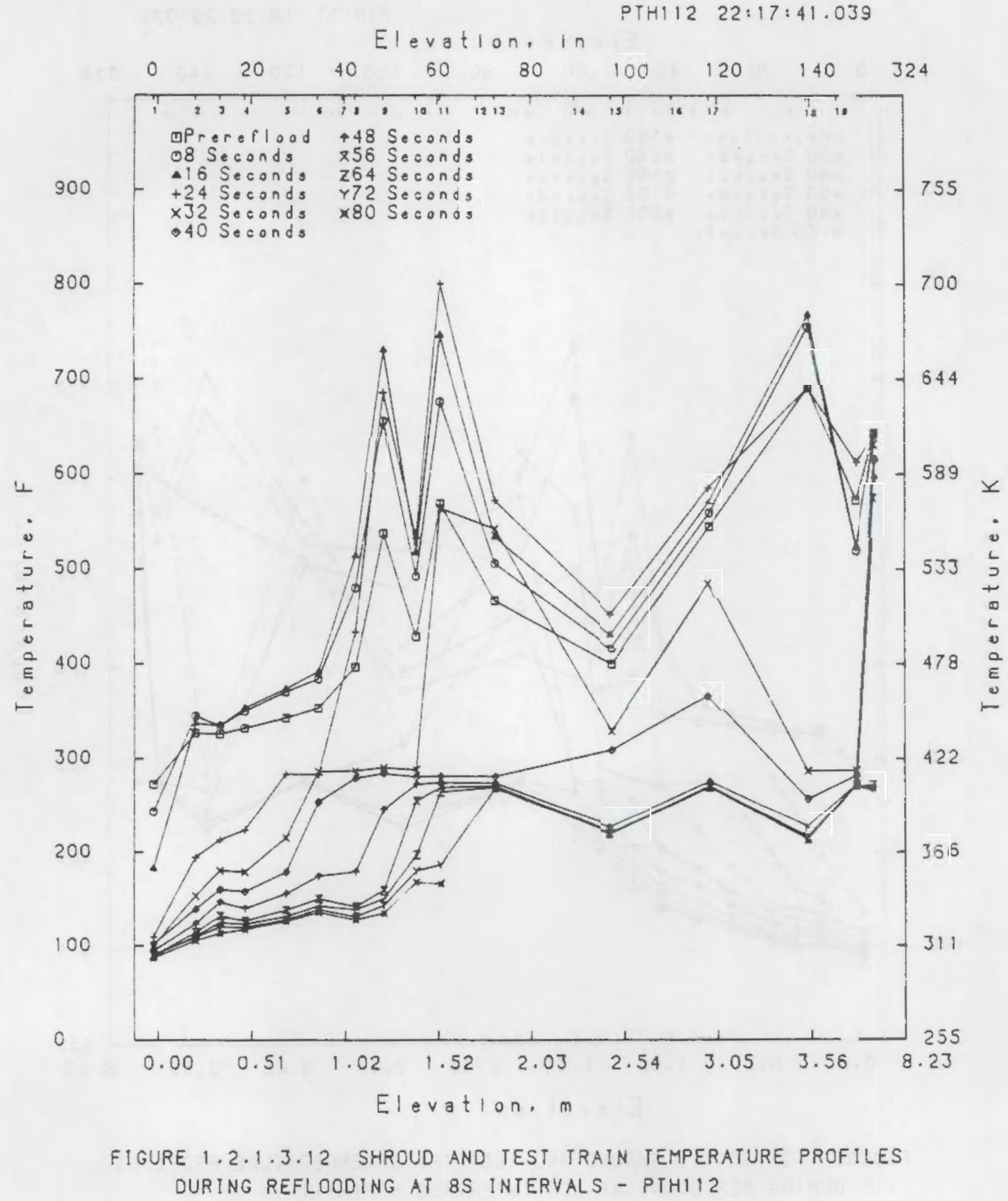




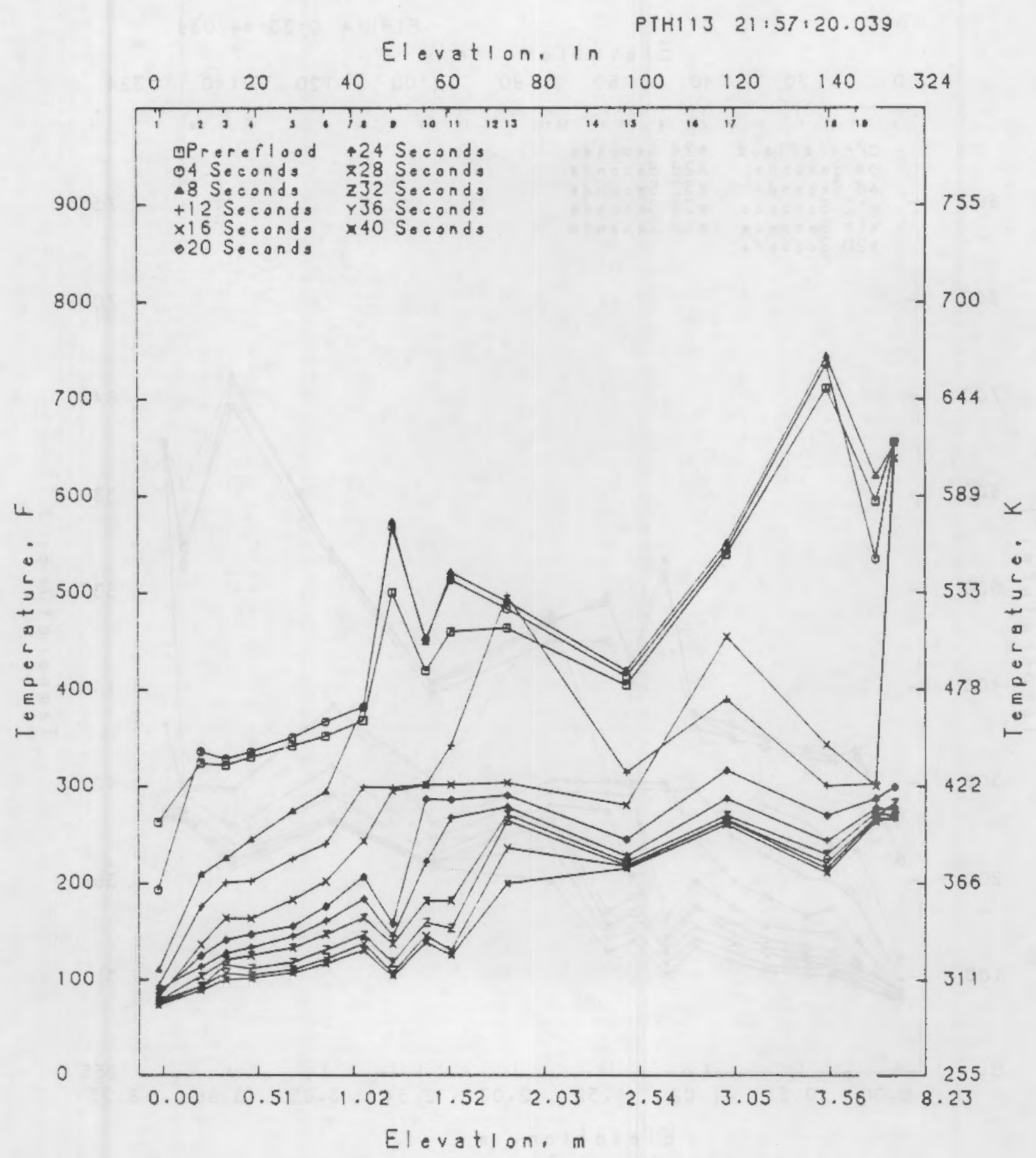

FIGURE $1.2 \cdot 1 \cdot 3 \cdot 13$ SHROUD AND TEST TRAIN TEMPERATURE PROFILES DURING REFLOODING AT 4S INTERVALS - PTHIIJ 


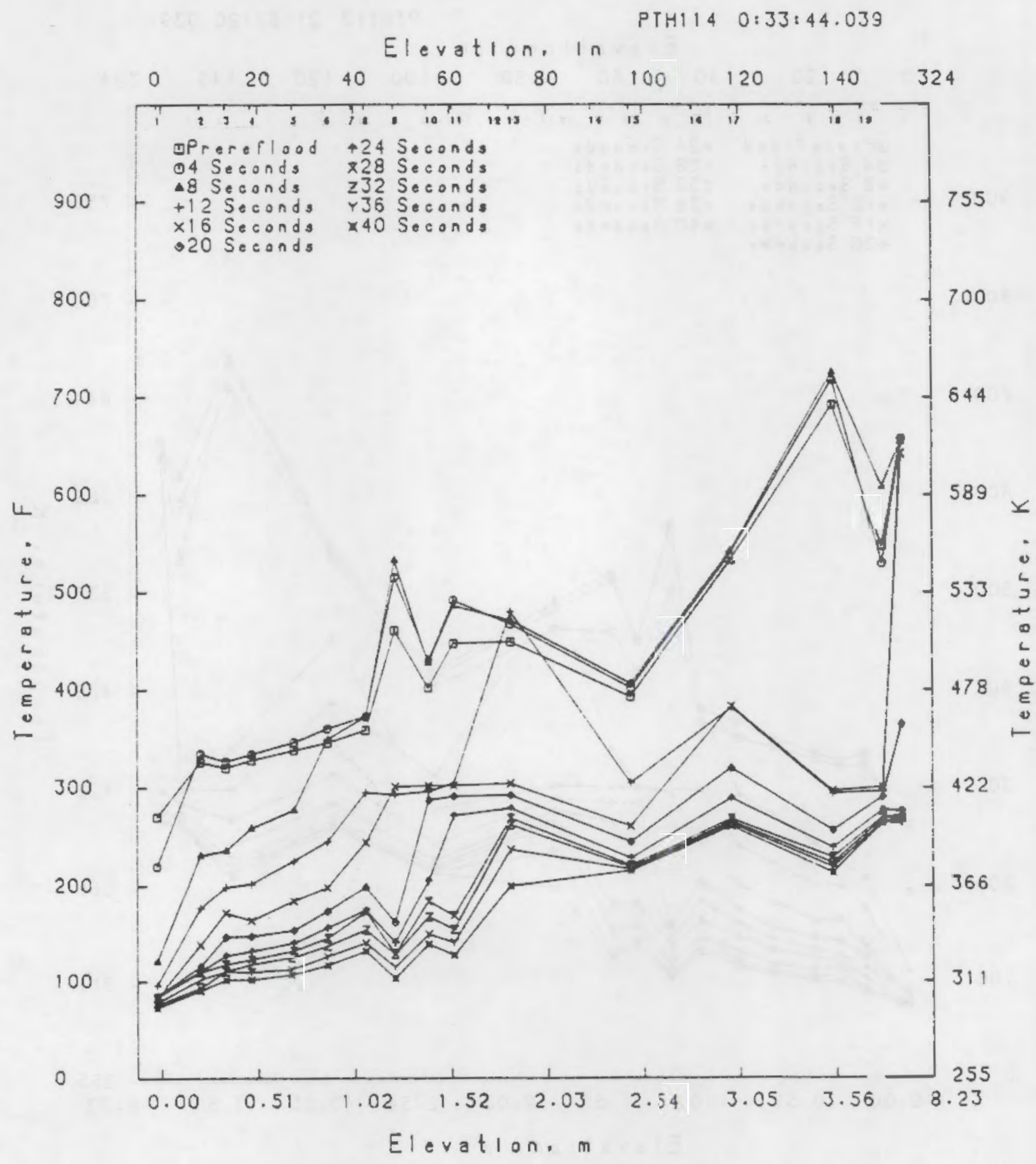

FIGURE $1 \cdot 2 \cdot 1 \cdot 3.14$ SHROUD ANO TEST TRAIN TEMPERATURE PROFILES DURING REFLOODING AT 4 S INTERVALS 
PTH115 23:38:55.039

Elevation, in

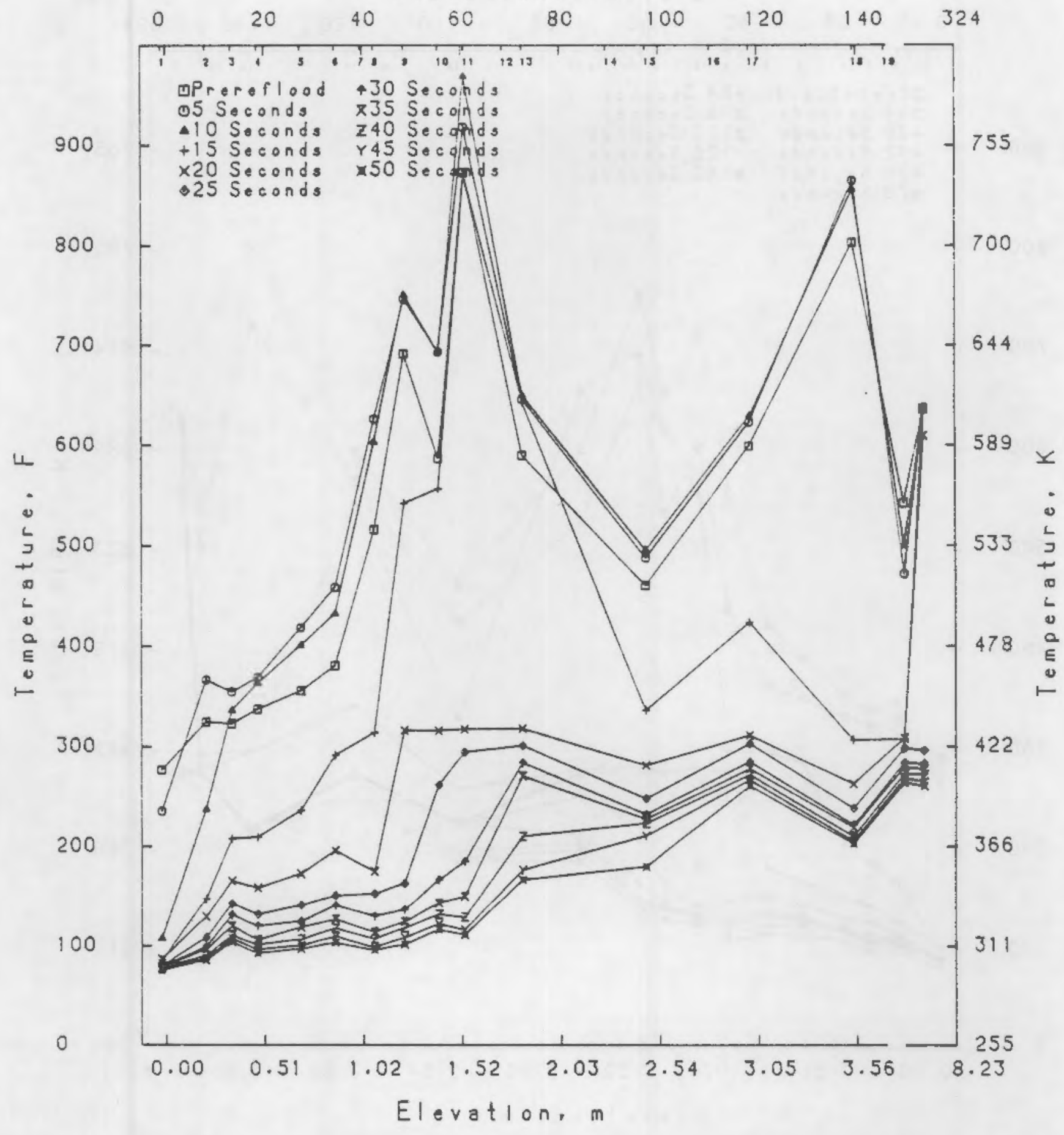

FIGURE $1.2 \cdot 1.3 .15$ SHROUD AND TEST TRAIN TEMPERATURE PROFILES DURING REFLOODING AT $5 S$ INTERVALS - PTHIIS 


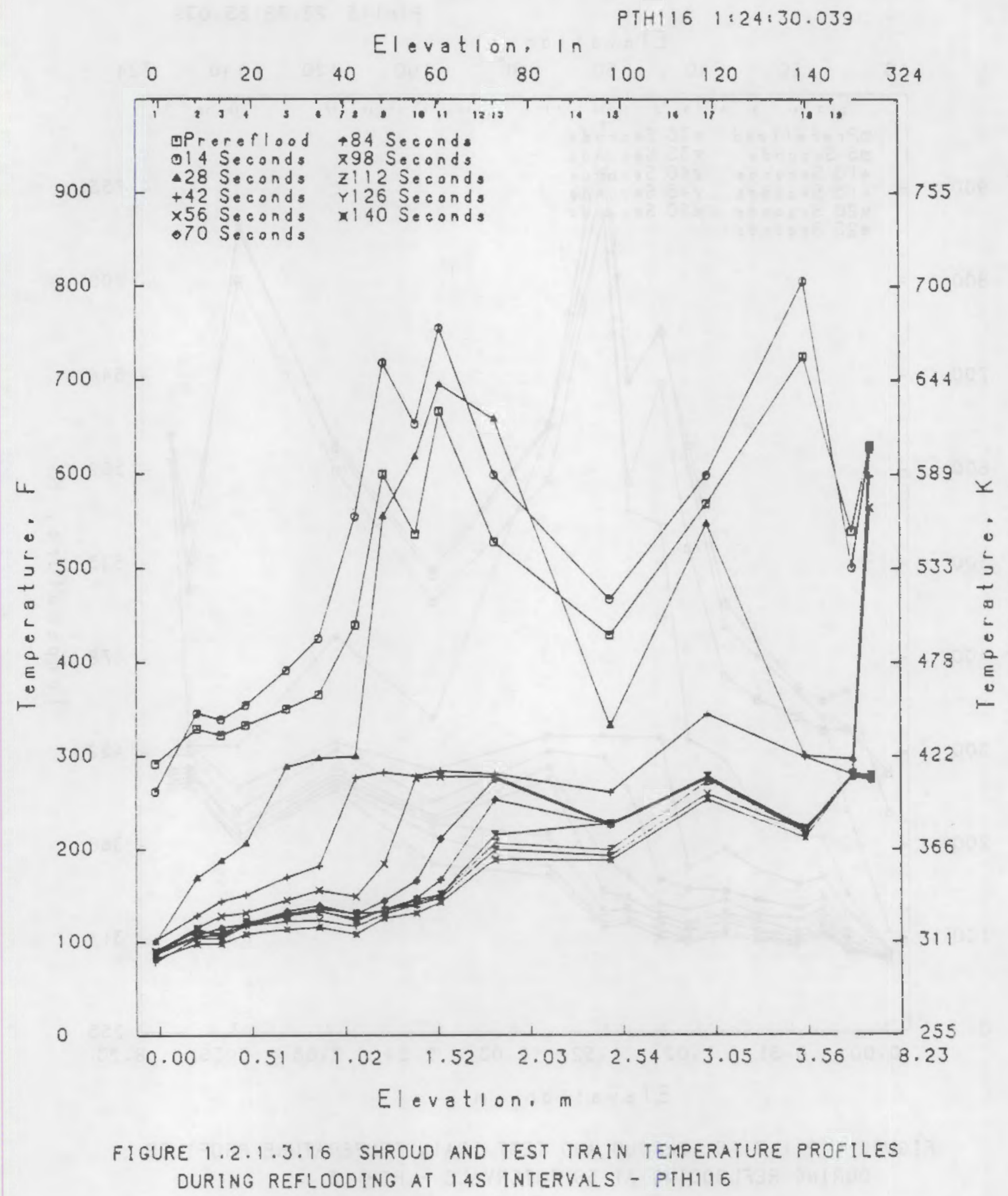




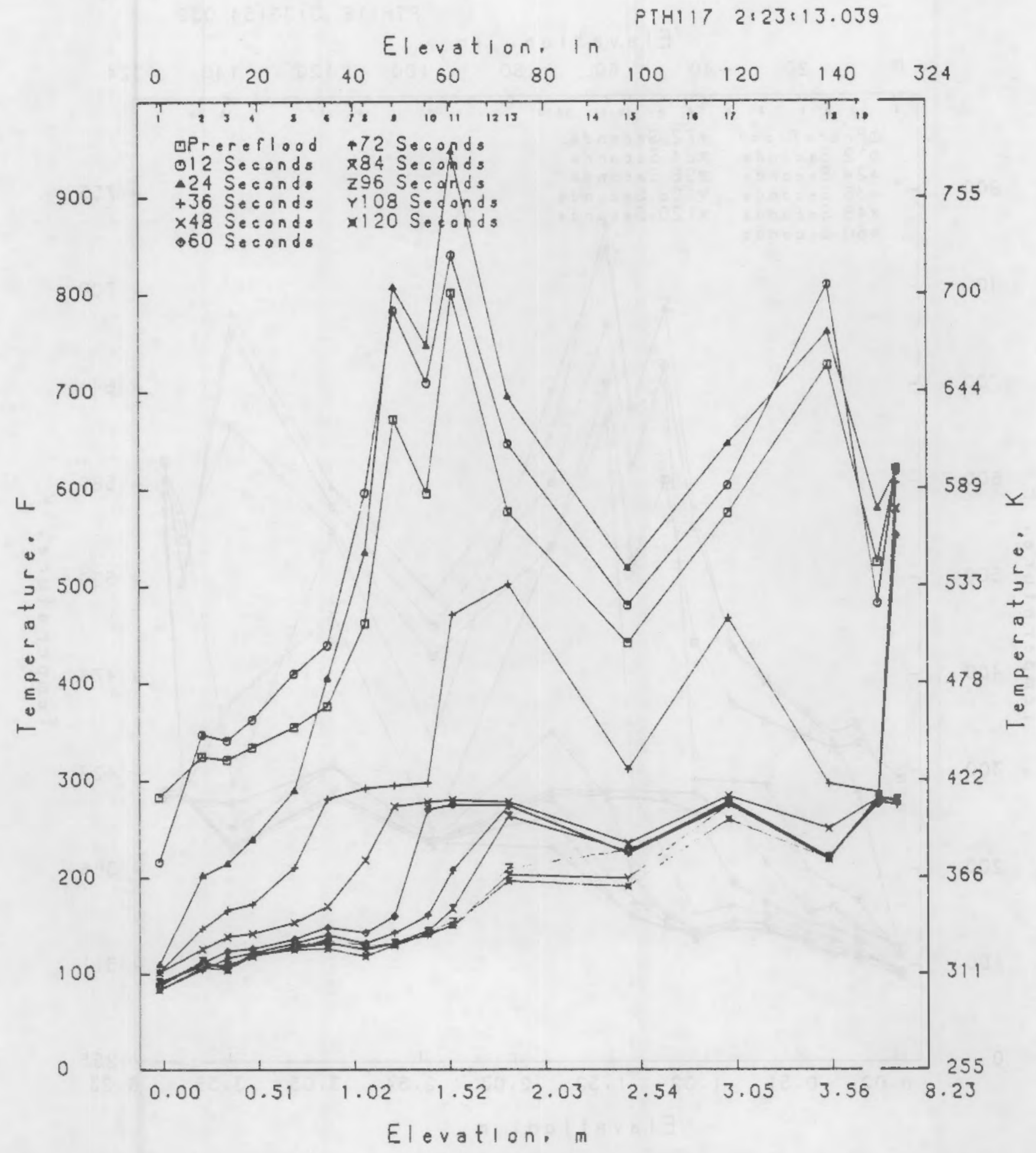

FIGURE $1.2 \cdot 1.3 .17$ SHROUD ANO TEST TRAIN TEMPERATURE PROFILES OURING REFLOODING AT I2S INTERVALS - PTHII7 


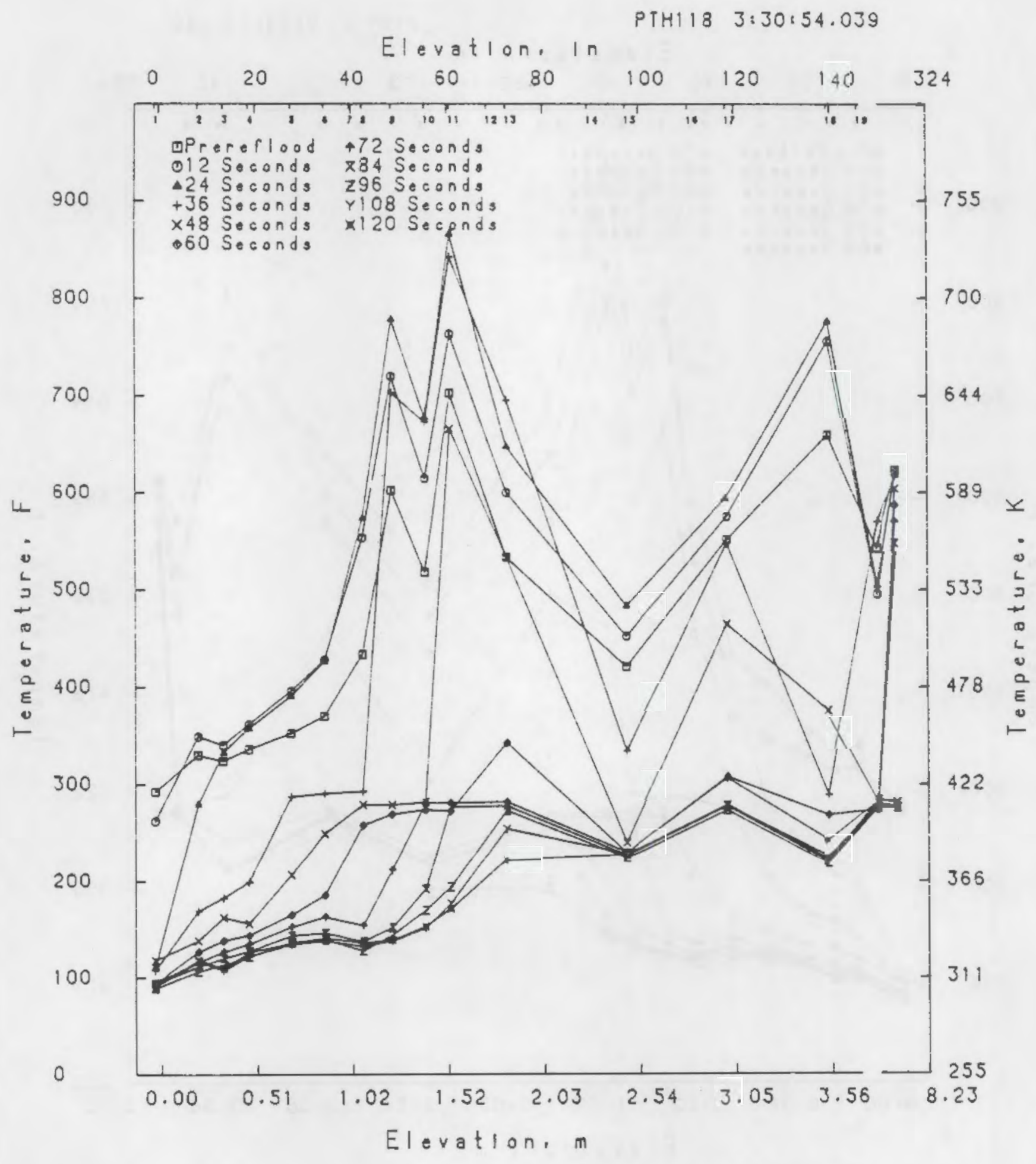

FIGURE 1.2 .1 .3 .18 SHROUD AND TEST TRAIN TEMPERATURE PROFILES DURING REFLOODING AT I2S INTERVALS 


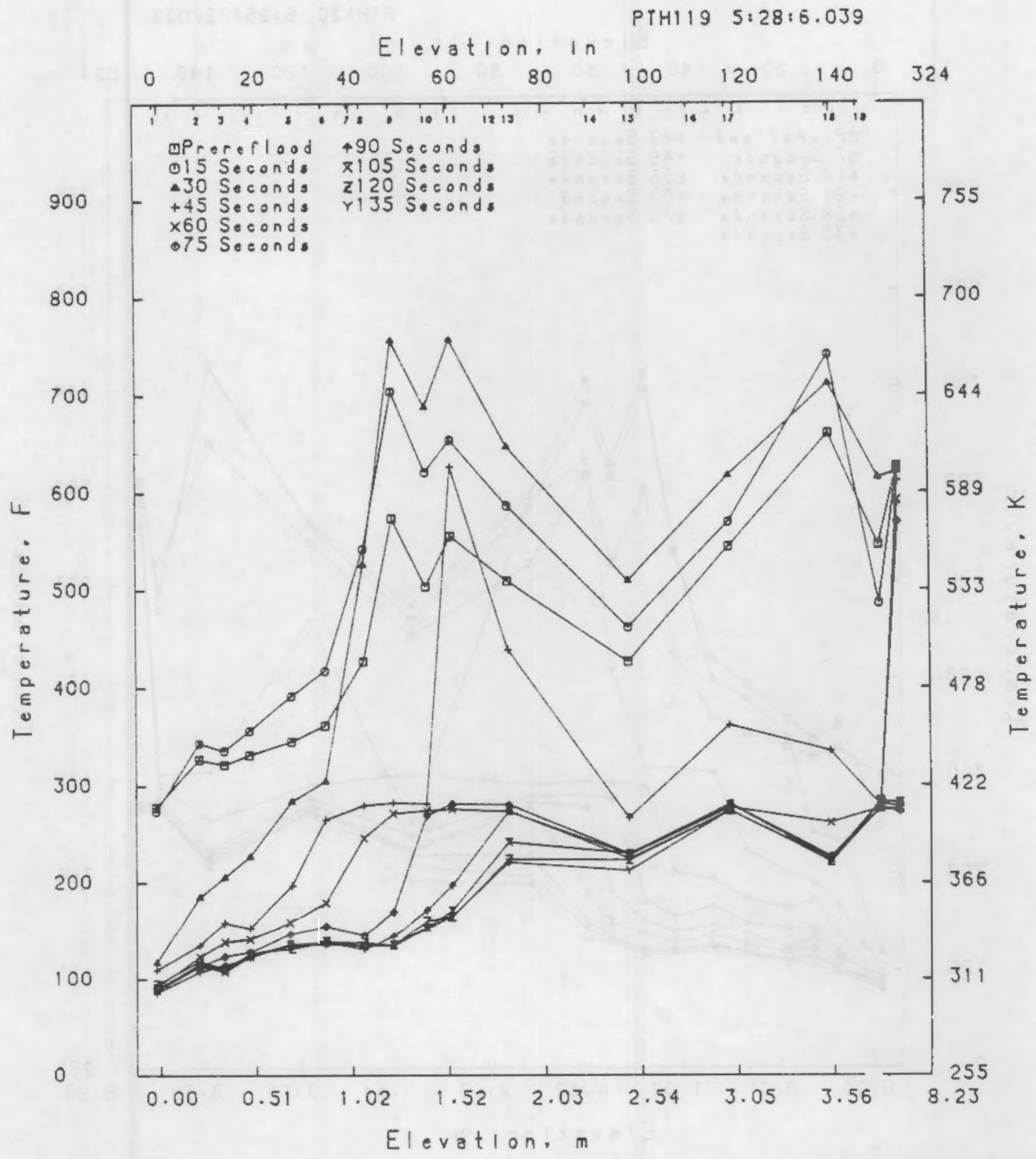

FIGURE $1.2 \cdot 1.3 .19$ SHROUD AND TEST TRAIN TEMPERATURE PROFILES DURING REFLOODING AT ISS INTERVALS - PTHII9 


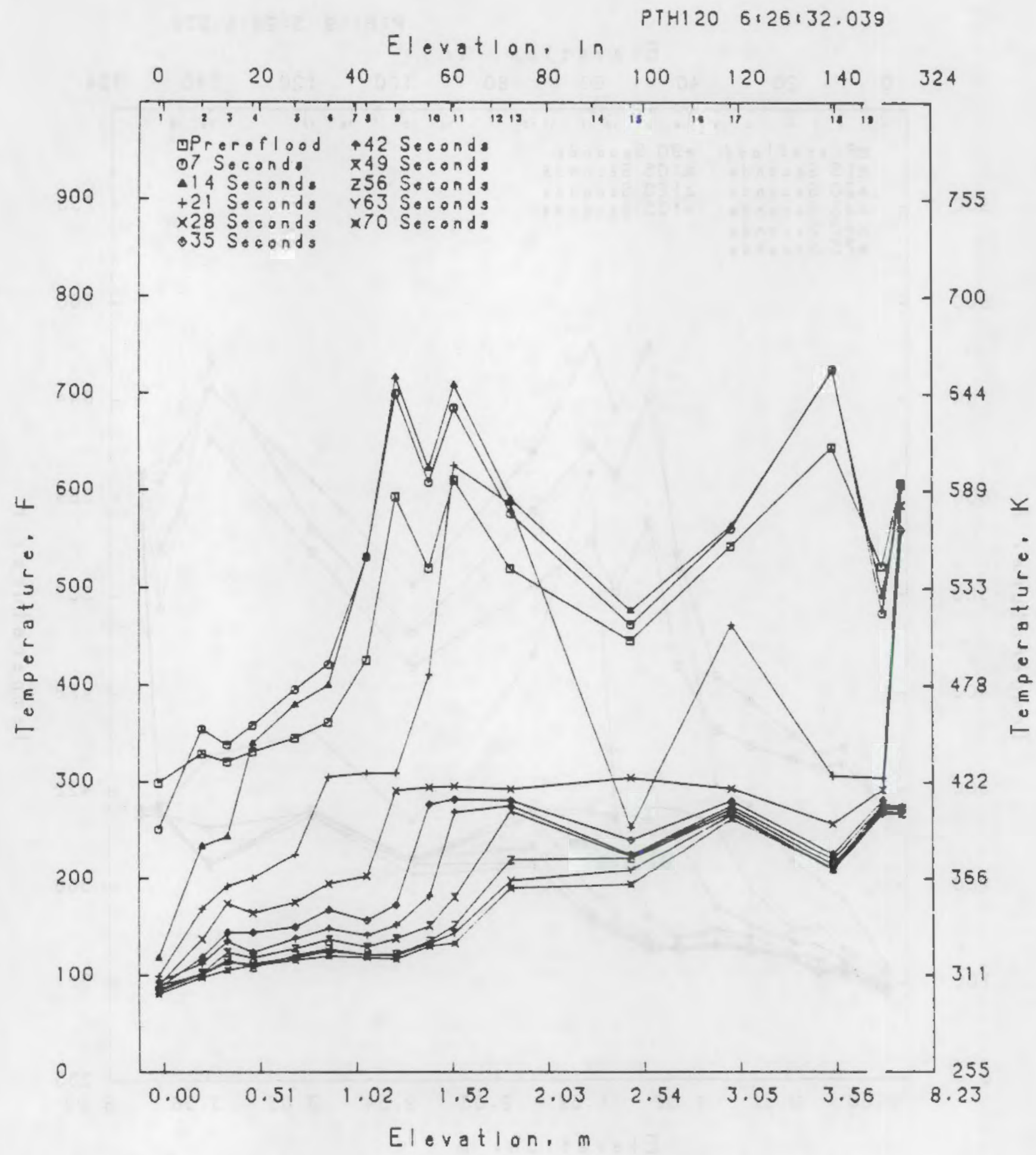

FIGURE $1.2 \cdot 1 \cdot 3 \cdot 20$ SHROUD ANO TEST IRAIN TEMPERATURE PROFILES DURING REFLOODING AT TS INTERVALS 


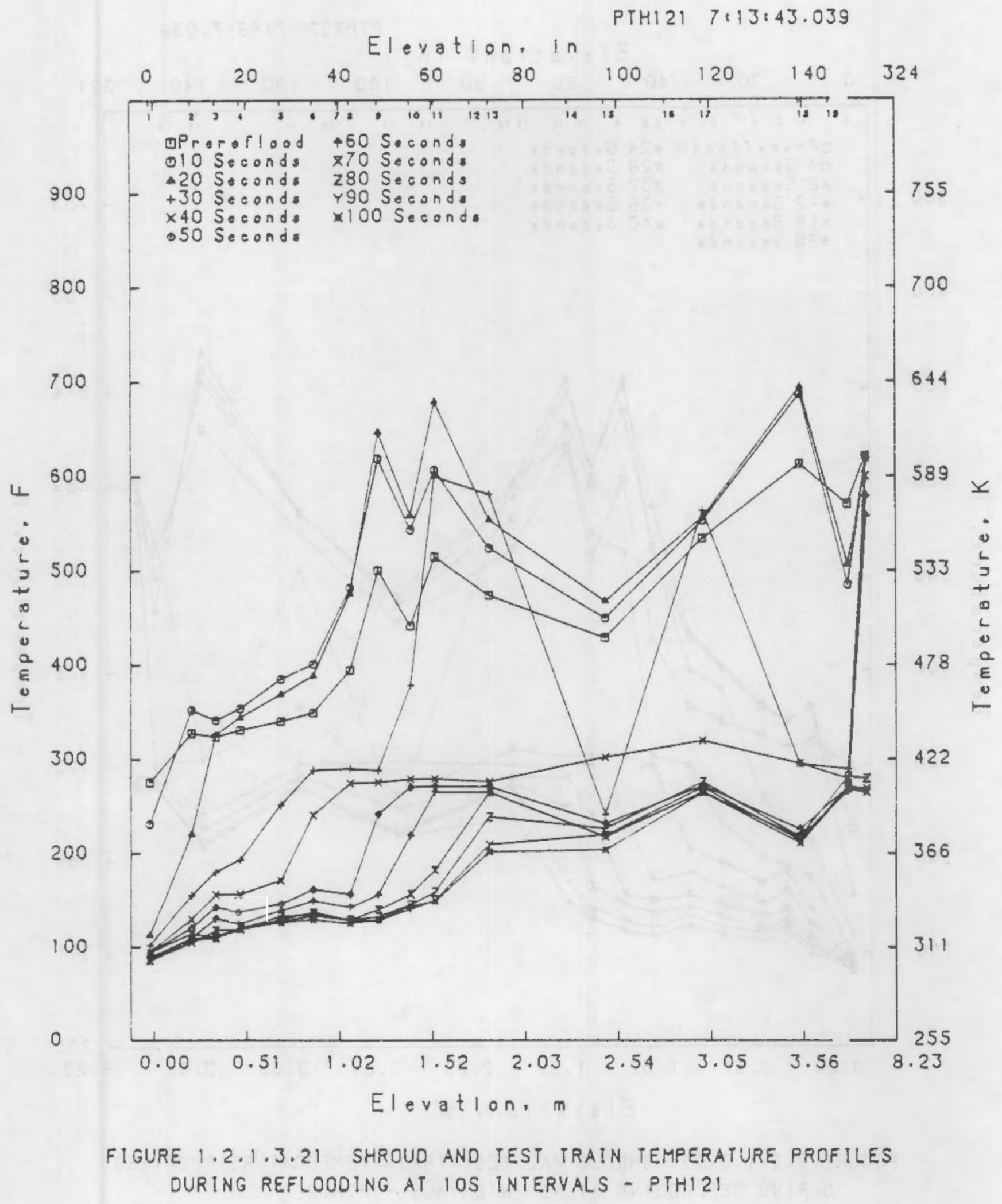




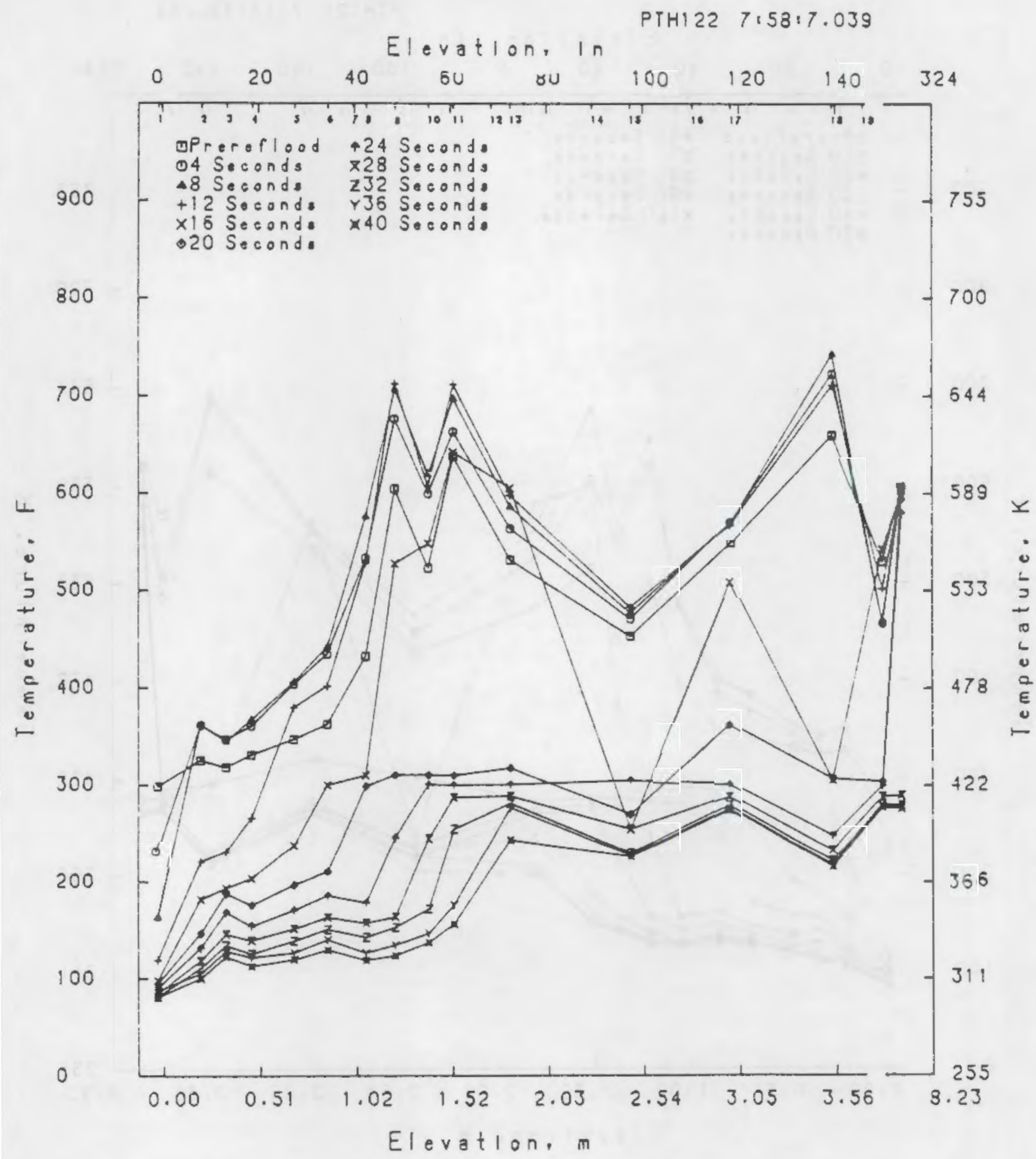

FIGURE 1.2 .1 .3 .22 SHROUD AND TEST TRAIN TEMPERATURE PROFILES DURING REFLOODING AT 4S INTERVALS - PTHI 22 


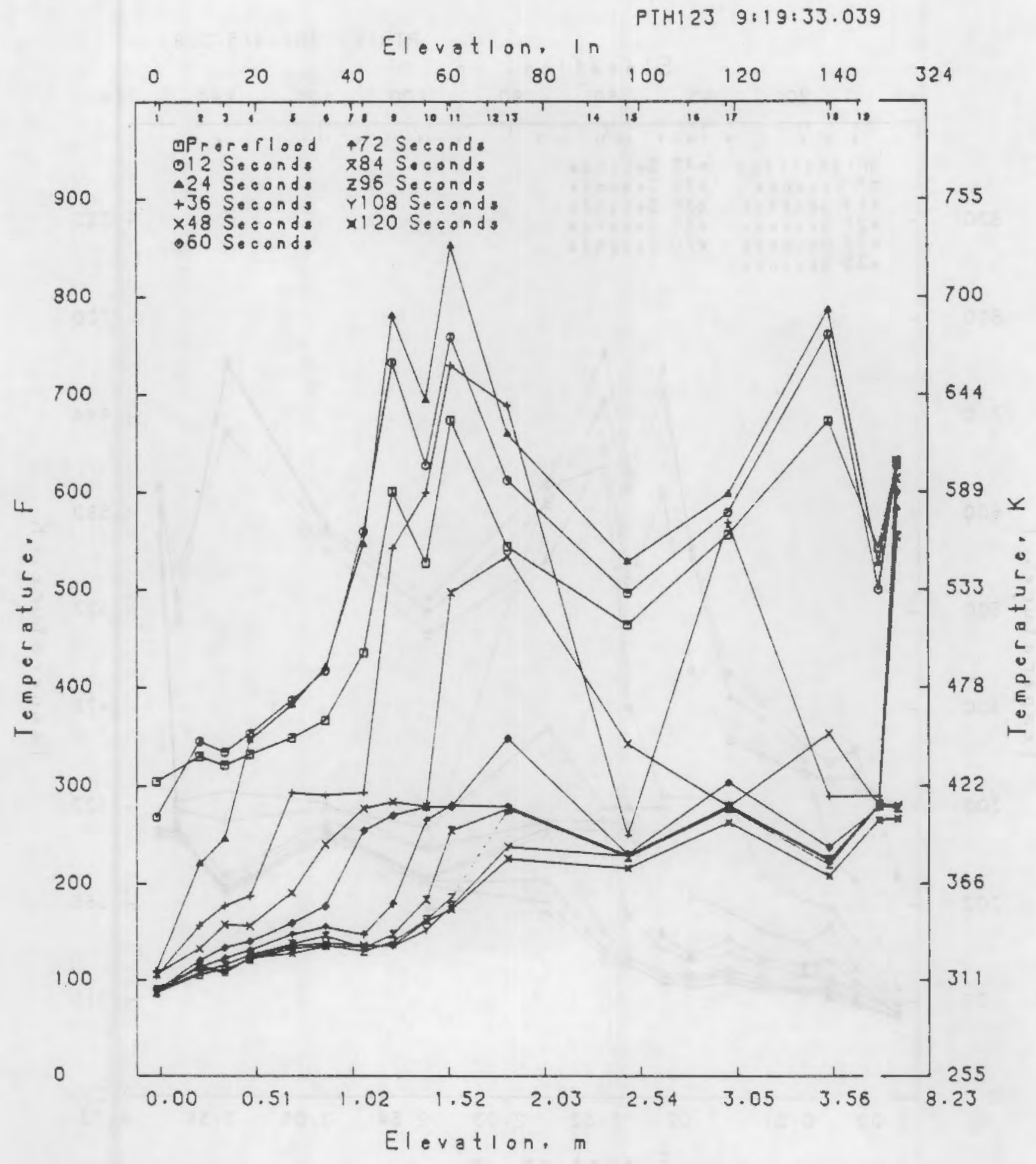

FIGURE $1.2 \cdot 1.3 .23$ SHROUD AND TEST TRAIN TEMPERATURE PROFILES DURING REFLOODING AT I2S INTERVALS - PTHI2J 


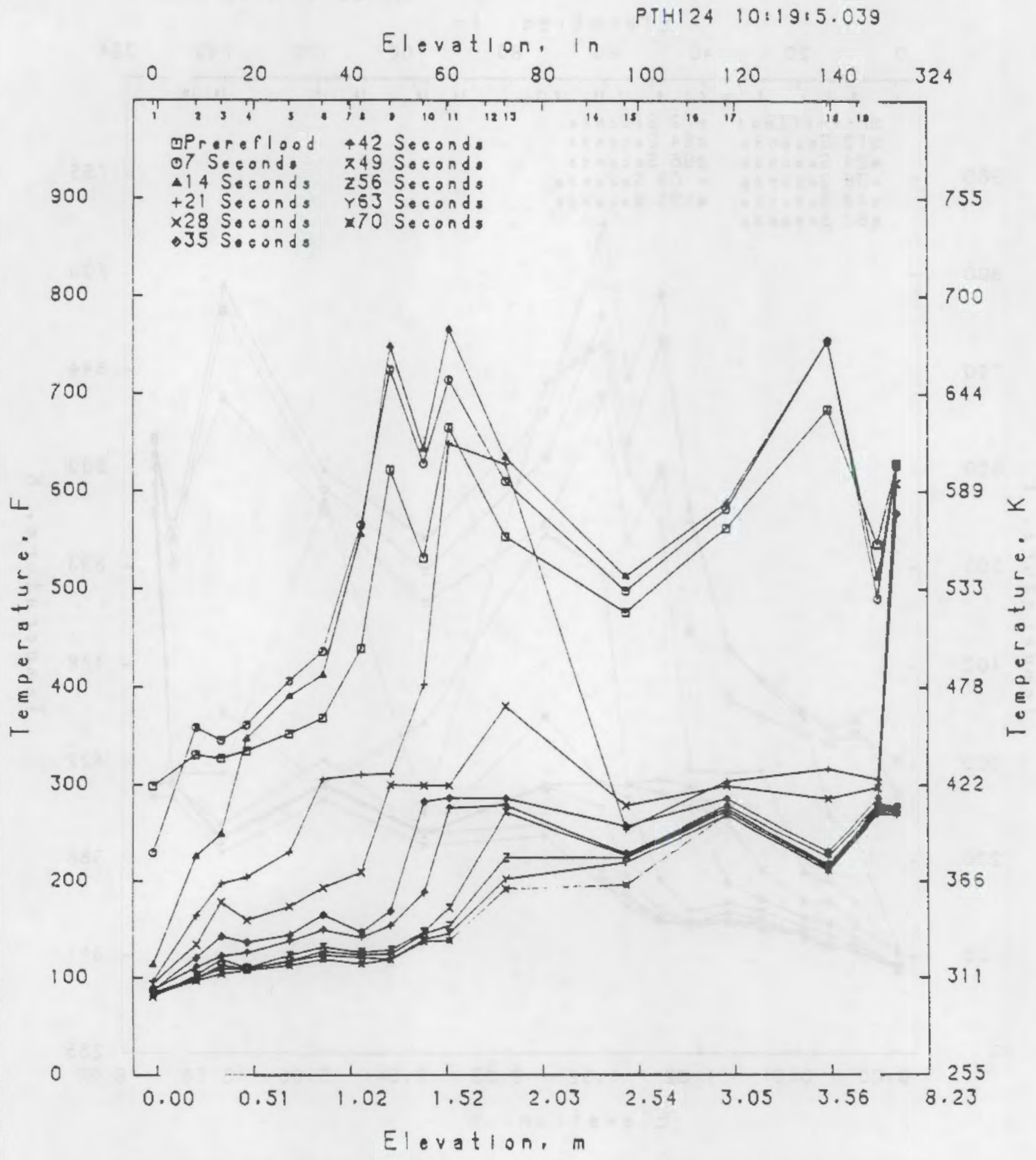

FIGURE 1.2 .1 .3 .24 SHROUD AND TEST TRAIN TEMPERATURE PROFILES DURING REFLOODING AT TS INTERVALS - PTHI24 


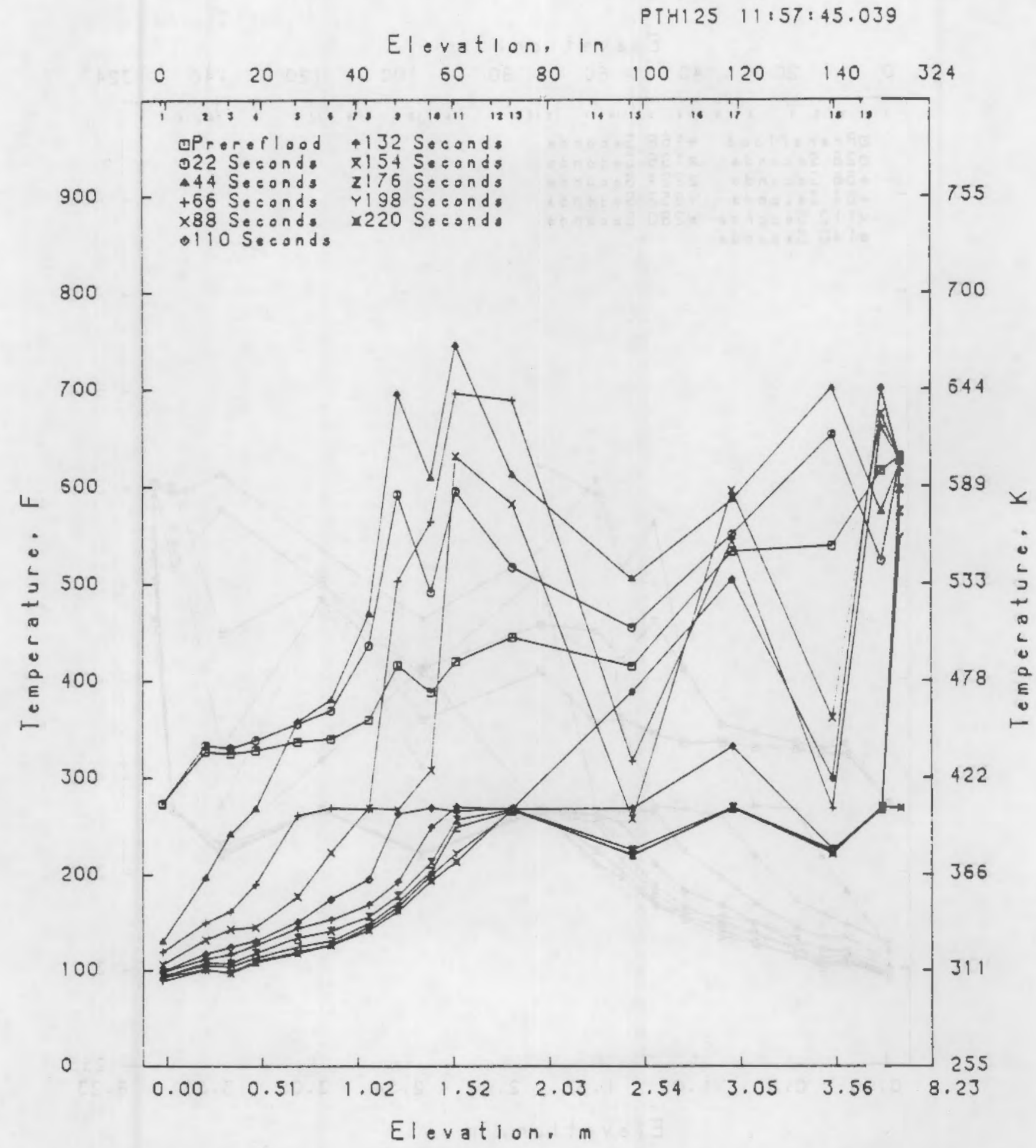

FIGURE $1.2 \cdot 1 \cdot 3.25$ SHROUD AND TEST TRAIN TEMPERATURE PROFILES DURING REFLOODING AT 22S INTERVALS 


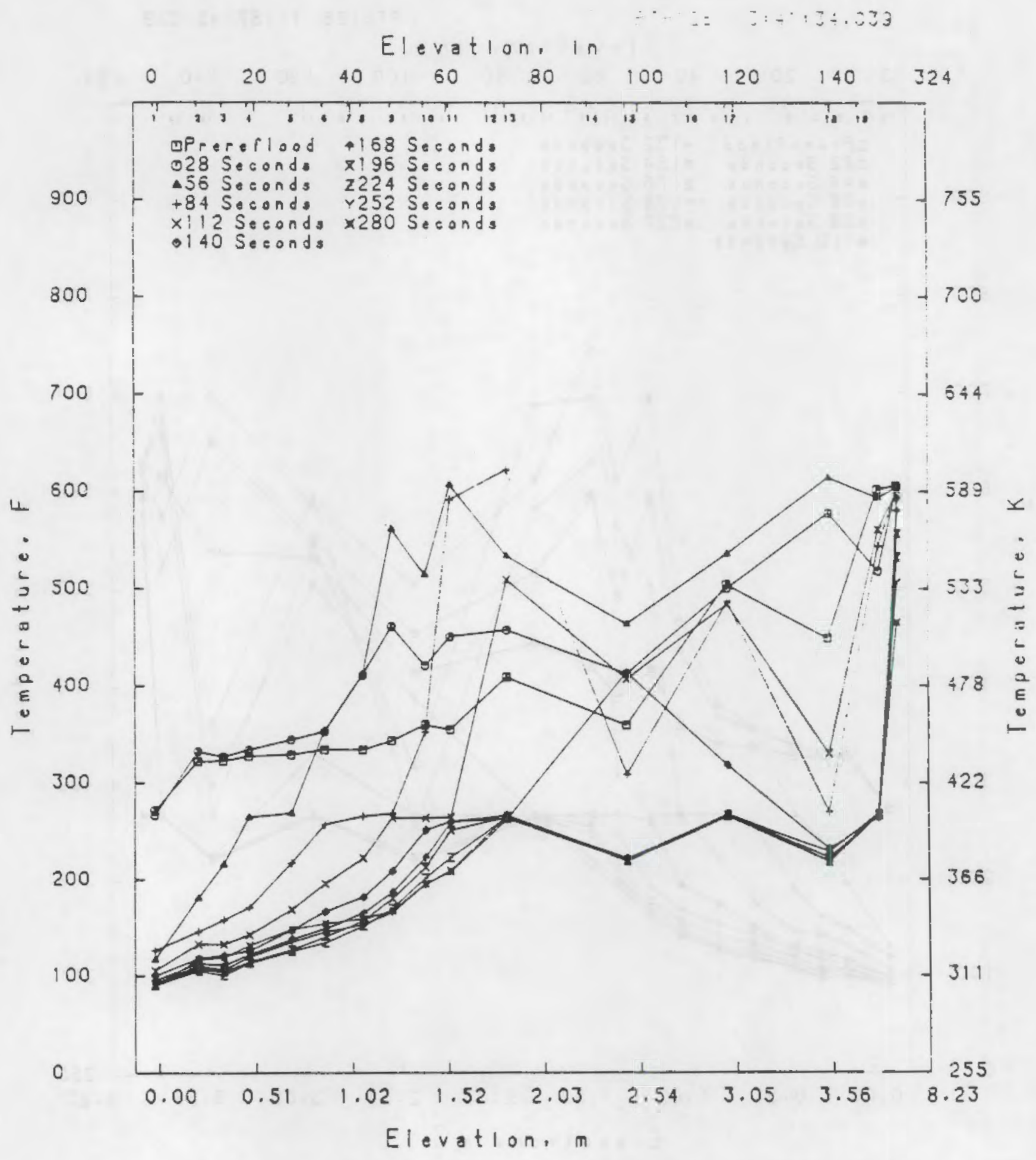

FIGURE $1.2 \cdot 1.3 .26$ SHROUD AND TEST TRAIN TEMPERATURE PROFILES DURING REFLOOOING AT 28 S INTERVALS - PTHI 28 


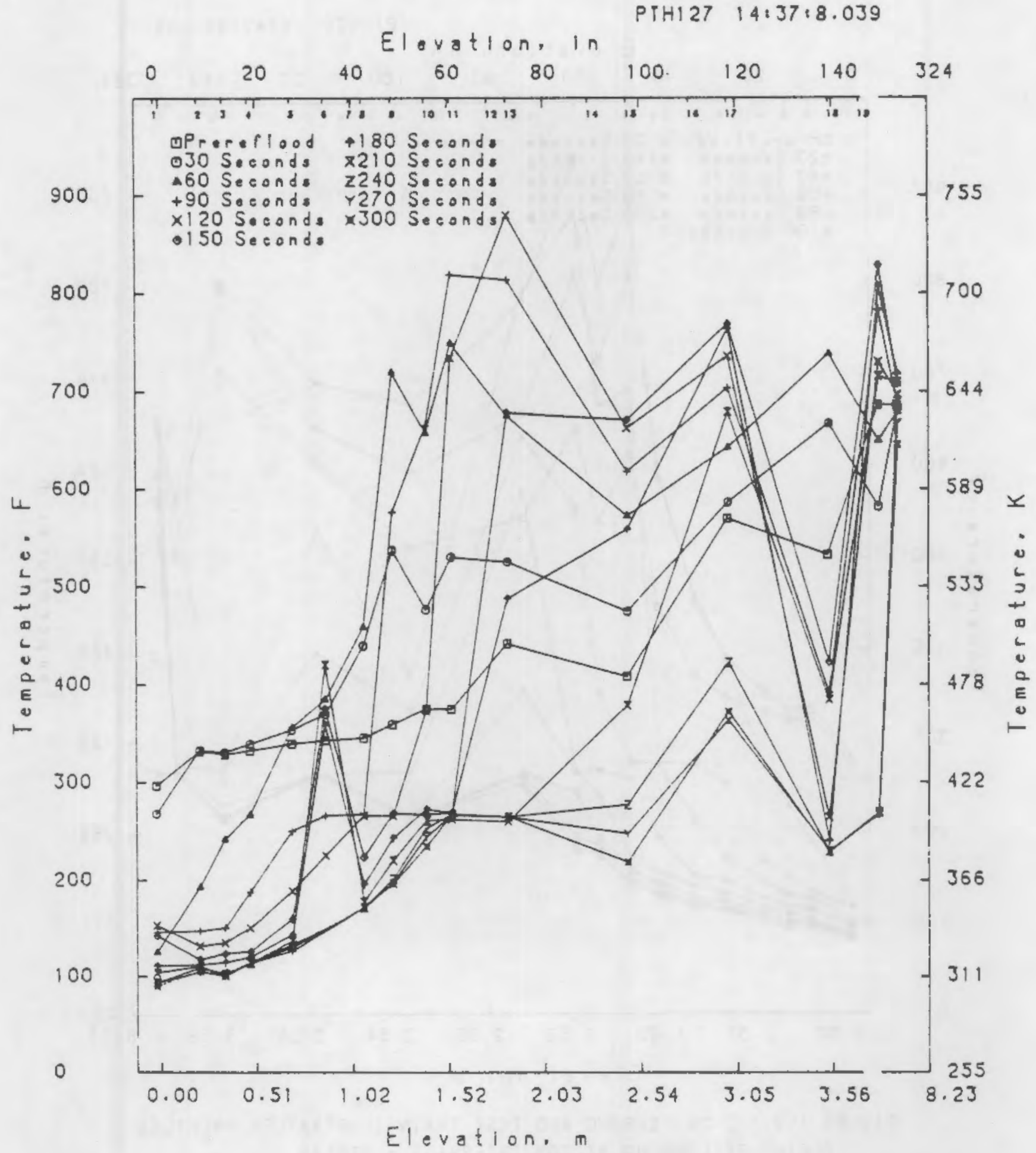

FIGURE $1.2 \cdot 1 \cdot 3.27$ SHROUD AND TEST TRAIN TEMPERATURE PROFILES DURING REFLOODING AT 30 S INIERVALS 


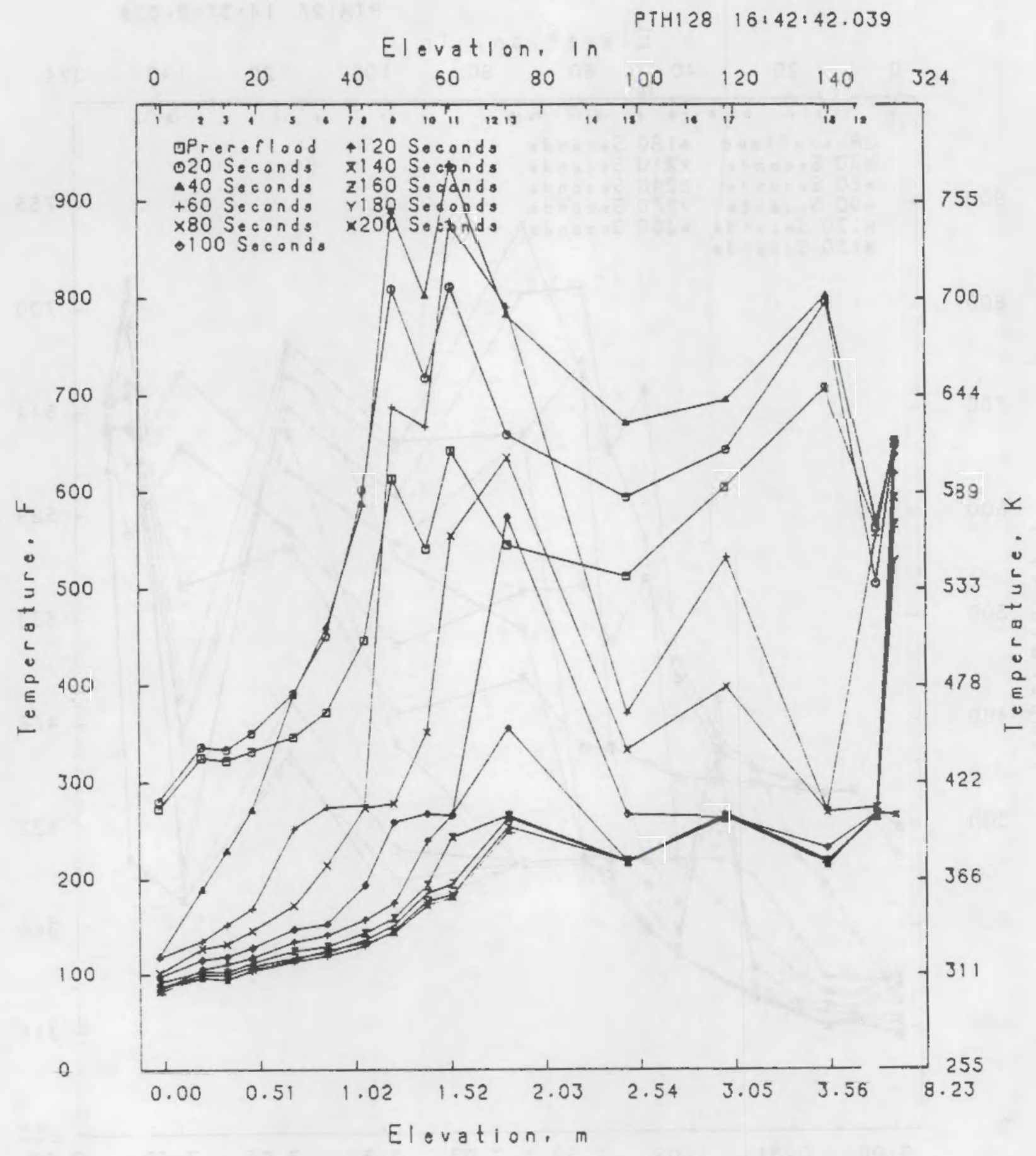

FIGURE 1.2 .1 .3 .28 SHROUD AND TEST TRAIN TEMPERATURE PROFILES DURING REFLOODING AT 2OS INTERVALS - PTHI28 


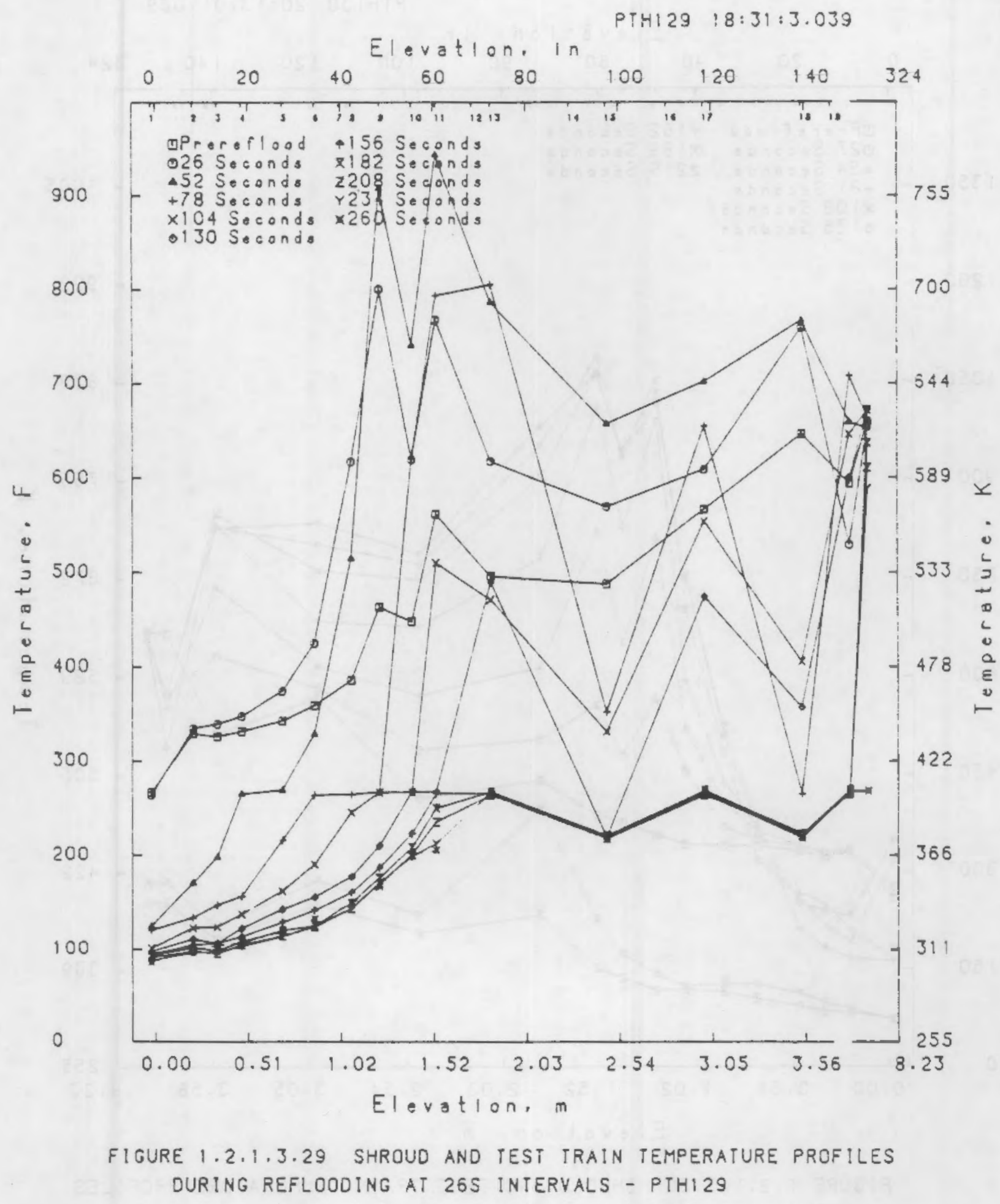




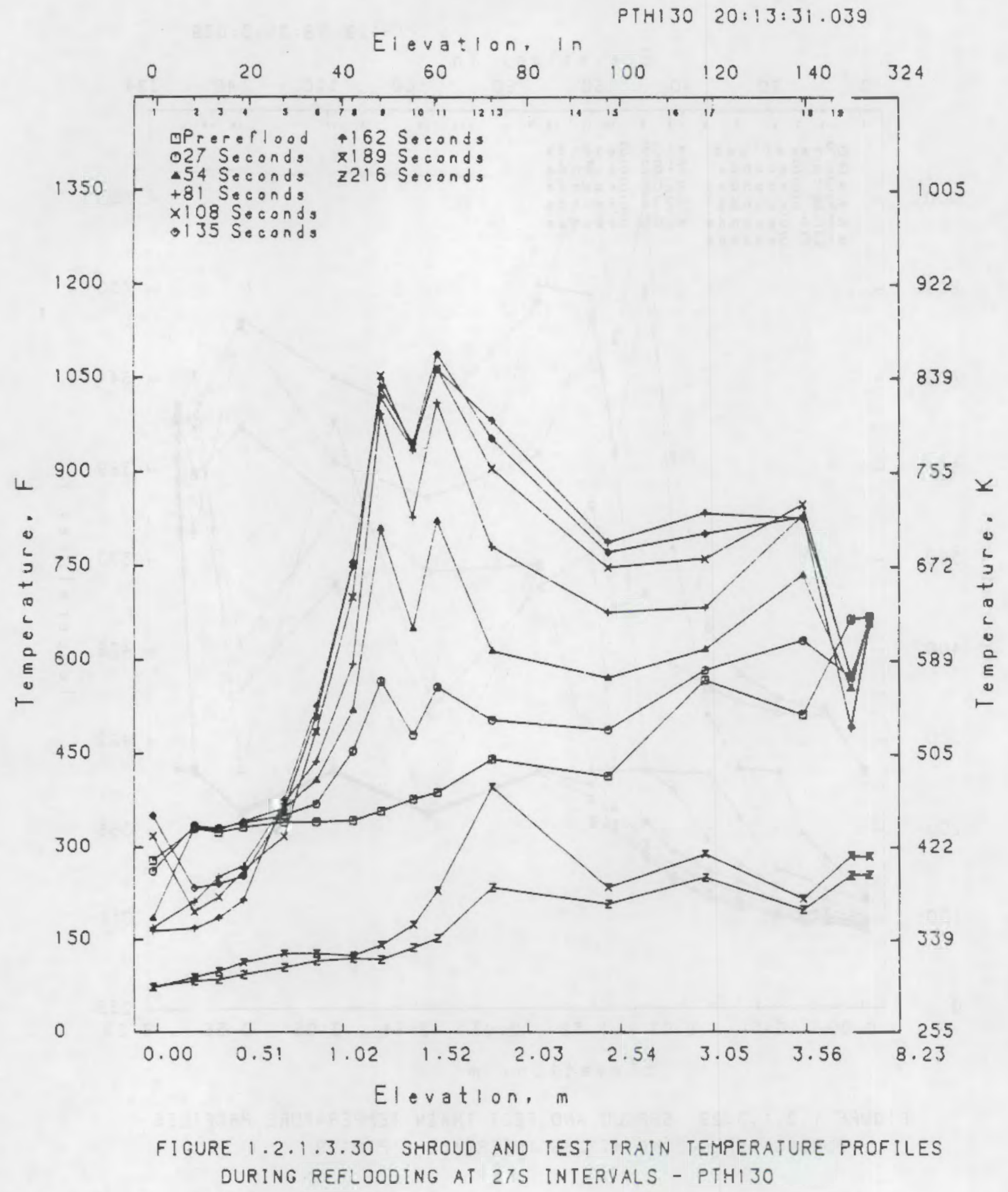




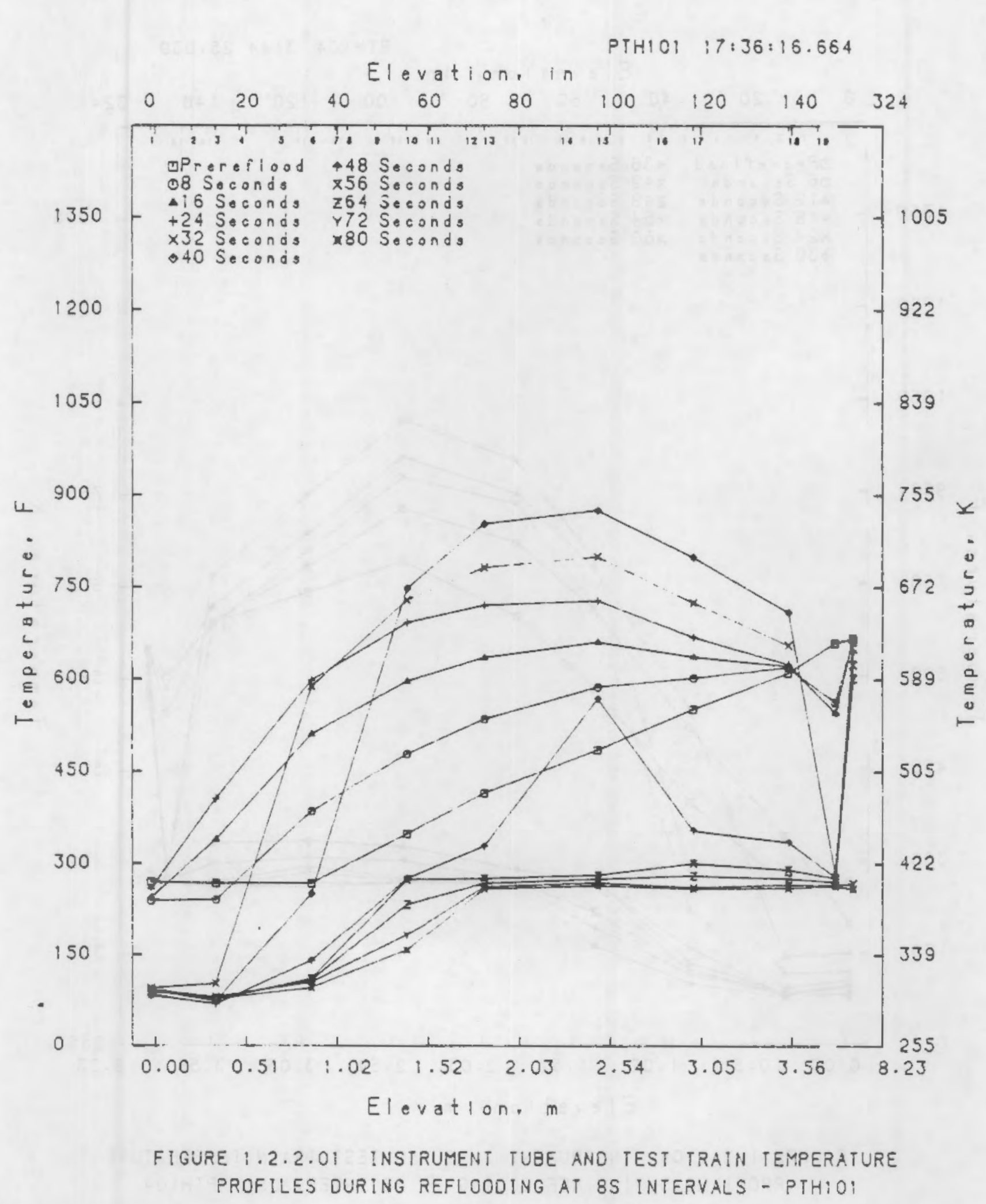




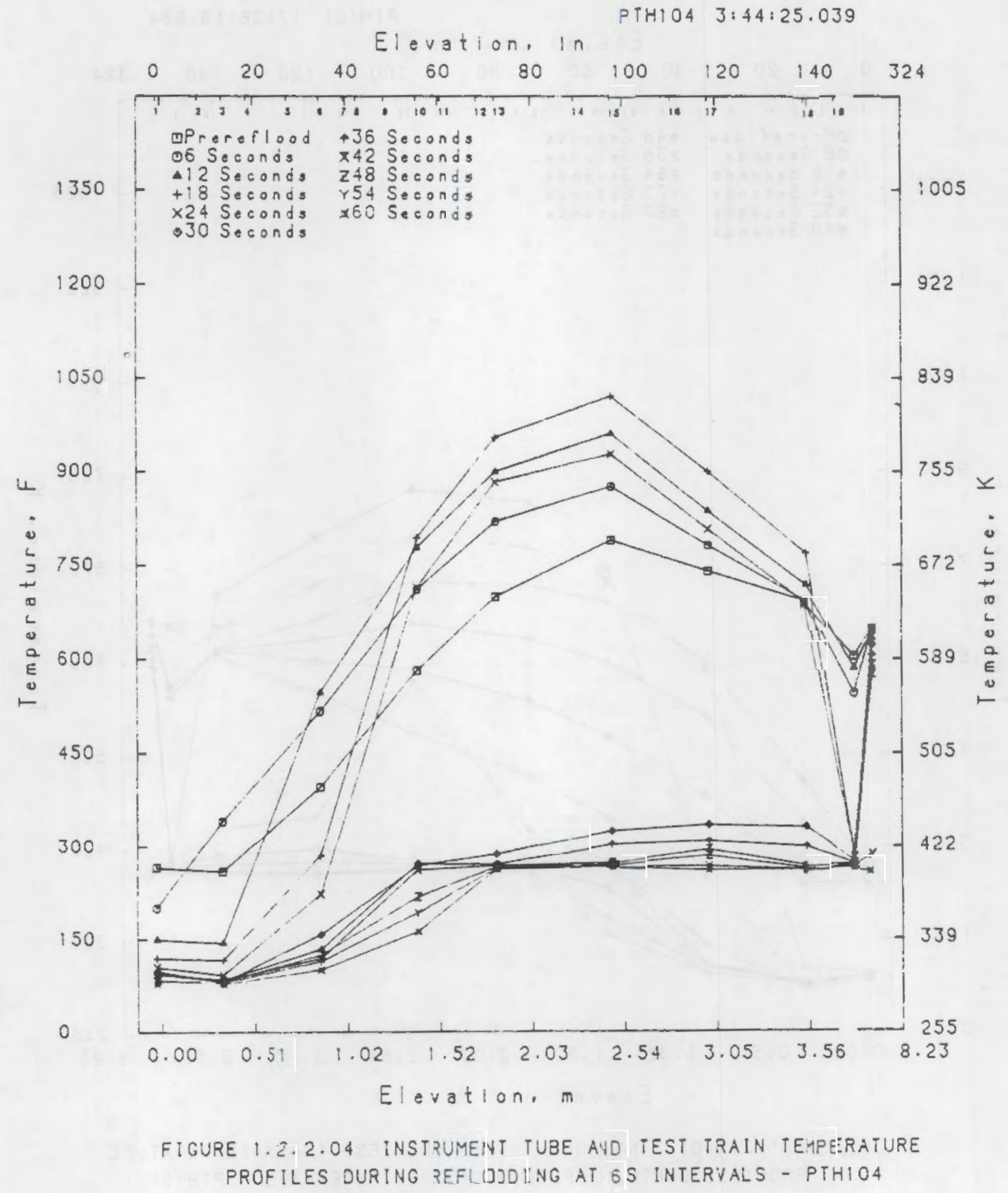


PTHIOS 7:22:49.039

Elevation, in

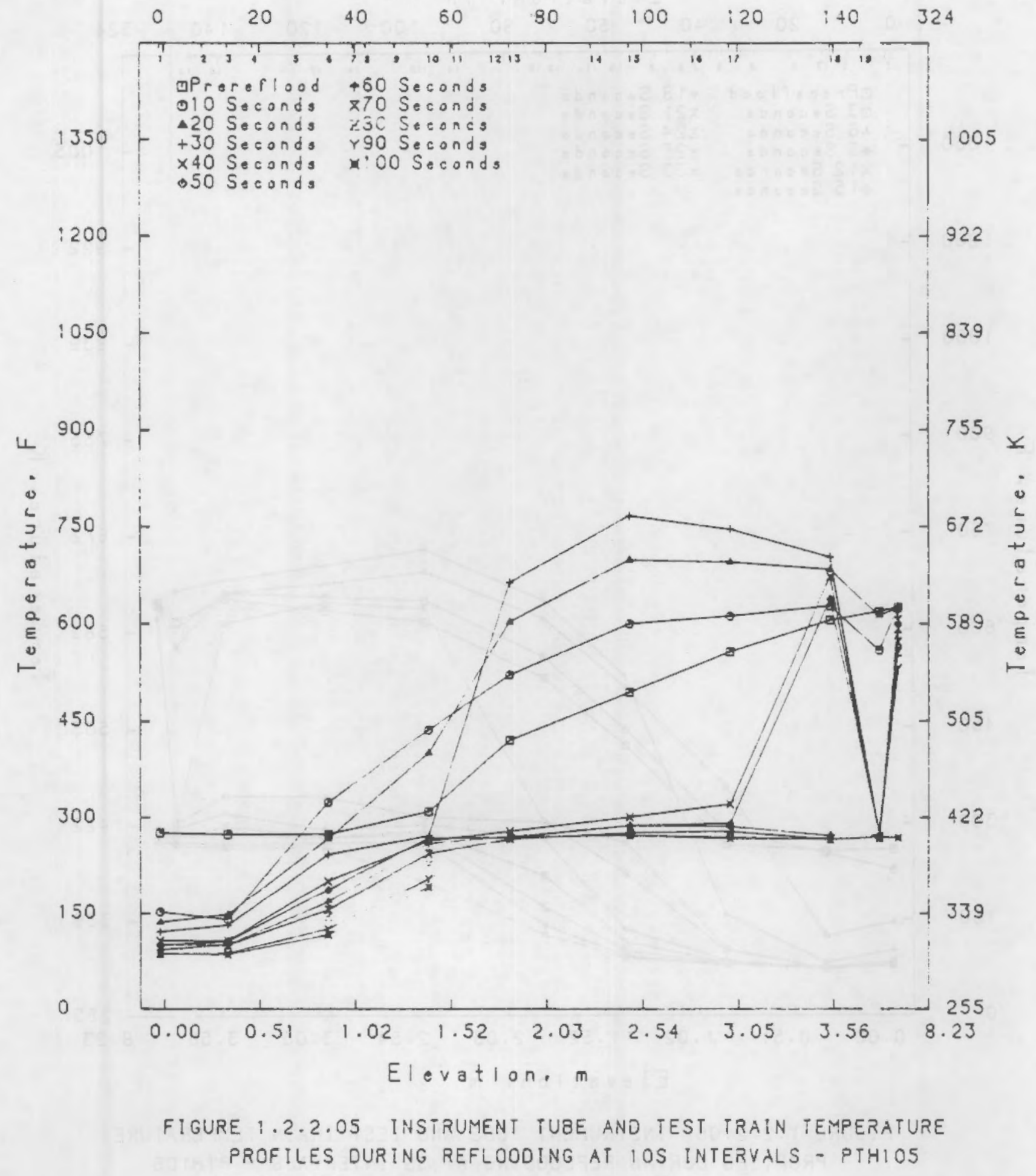




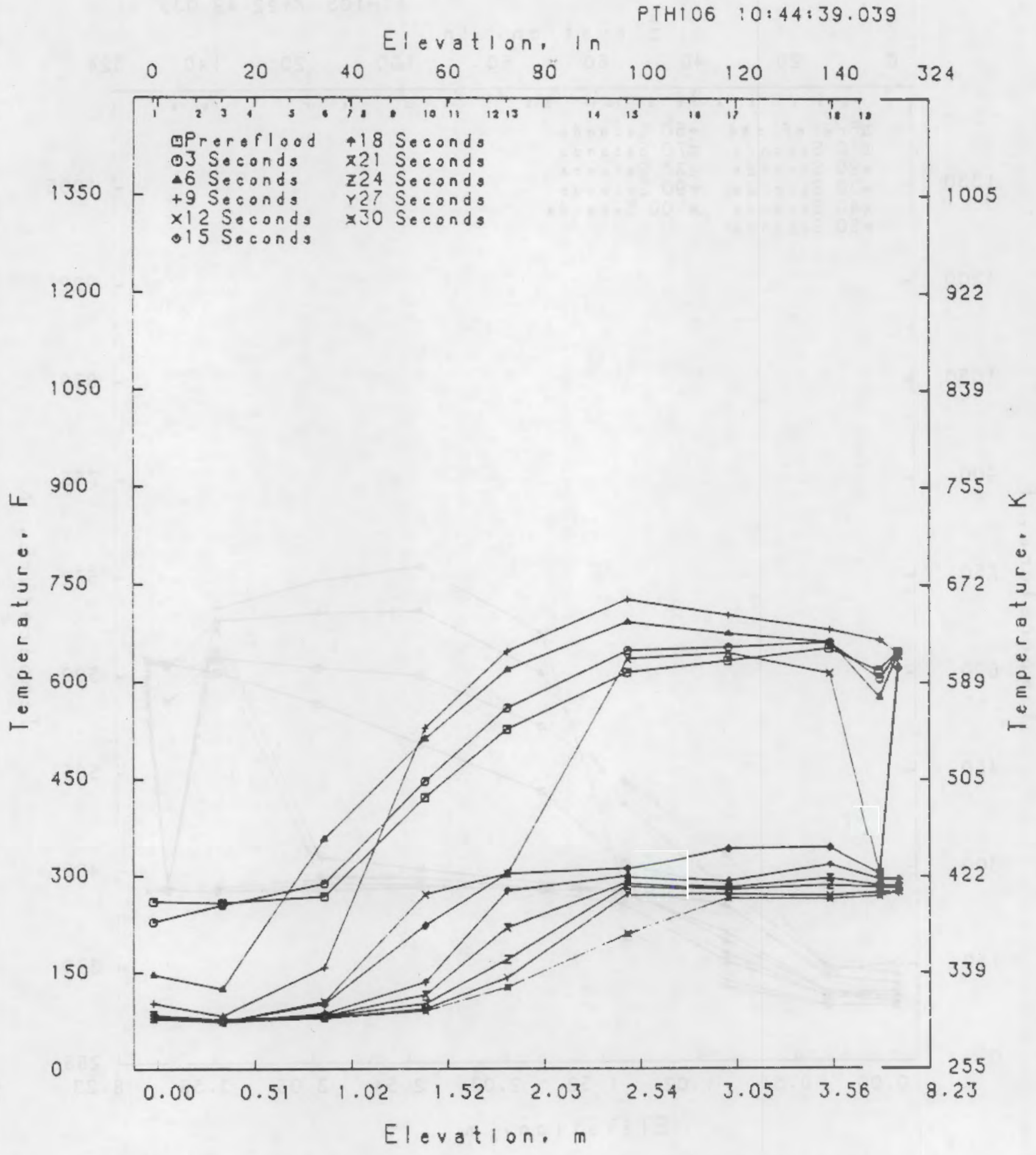

FIGURE 1.2 .2 .06 INSTRUMENT TUBE AND TEST TRAIN TEMPERATURE PROFILES DURING REFLOODING AT JS INTERVALS - PTHIO6 


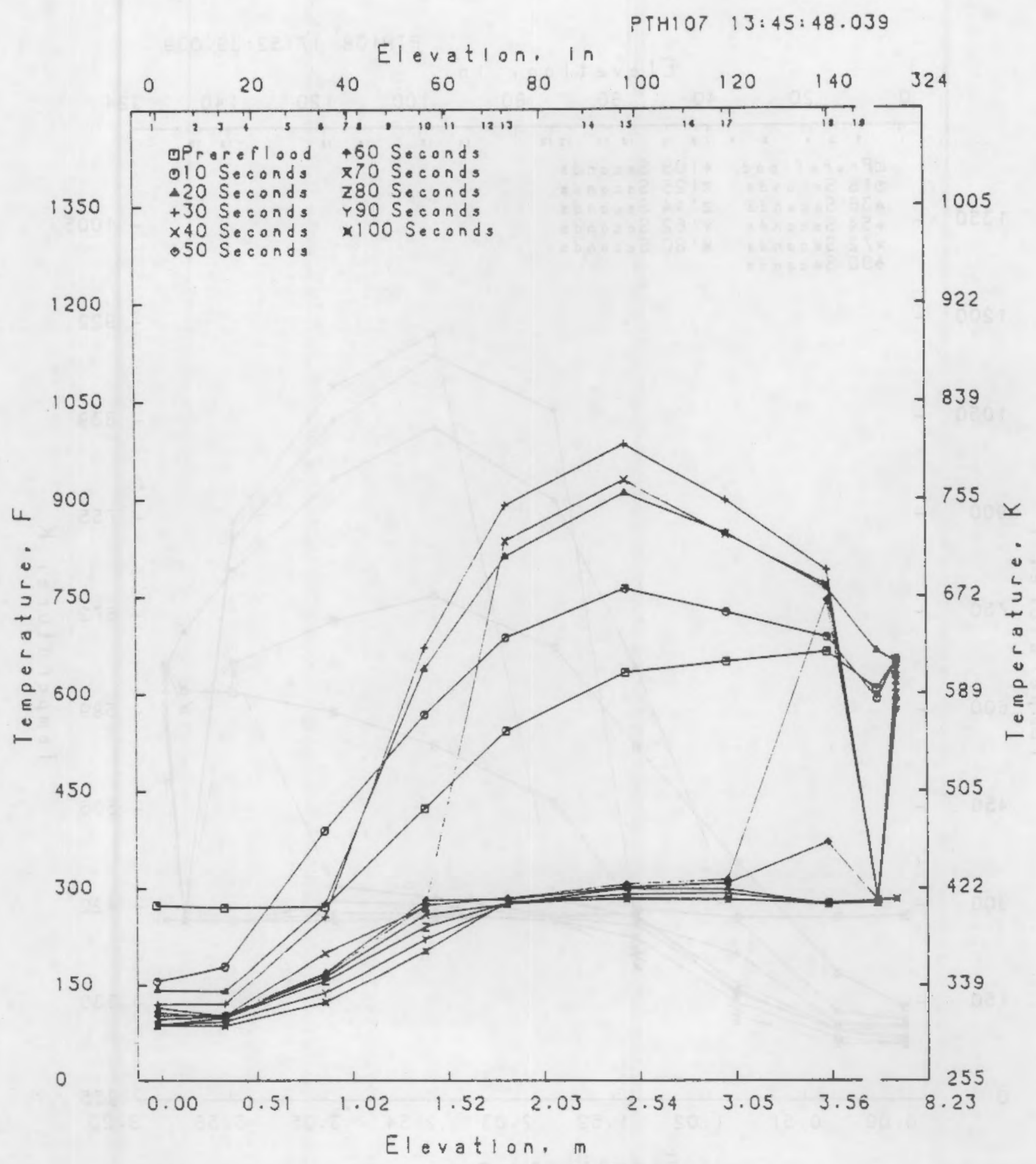

FIGURE 1.2.2.07 INSTRUMENT TUBE AND TEST TRAIN TEMPERATURE PROFILES DURING REFLOOOING AT IOS INTERVALS - PTHIOT 


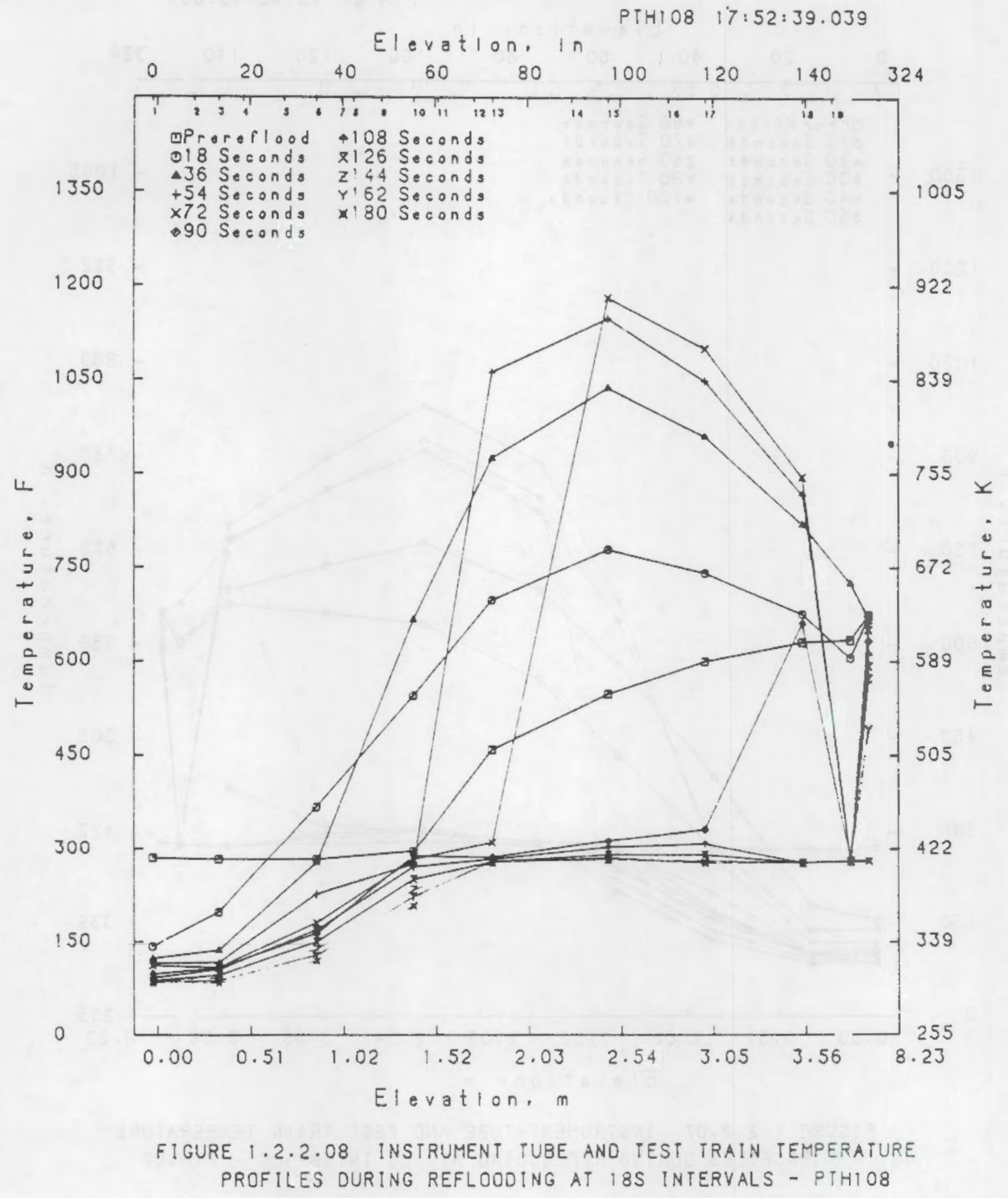




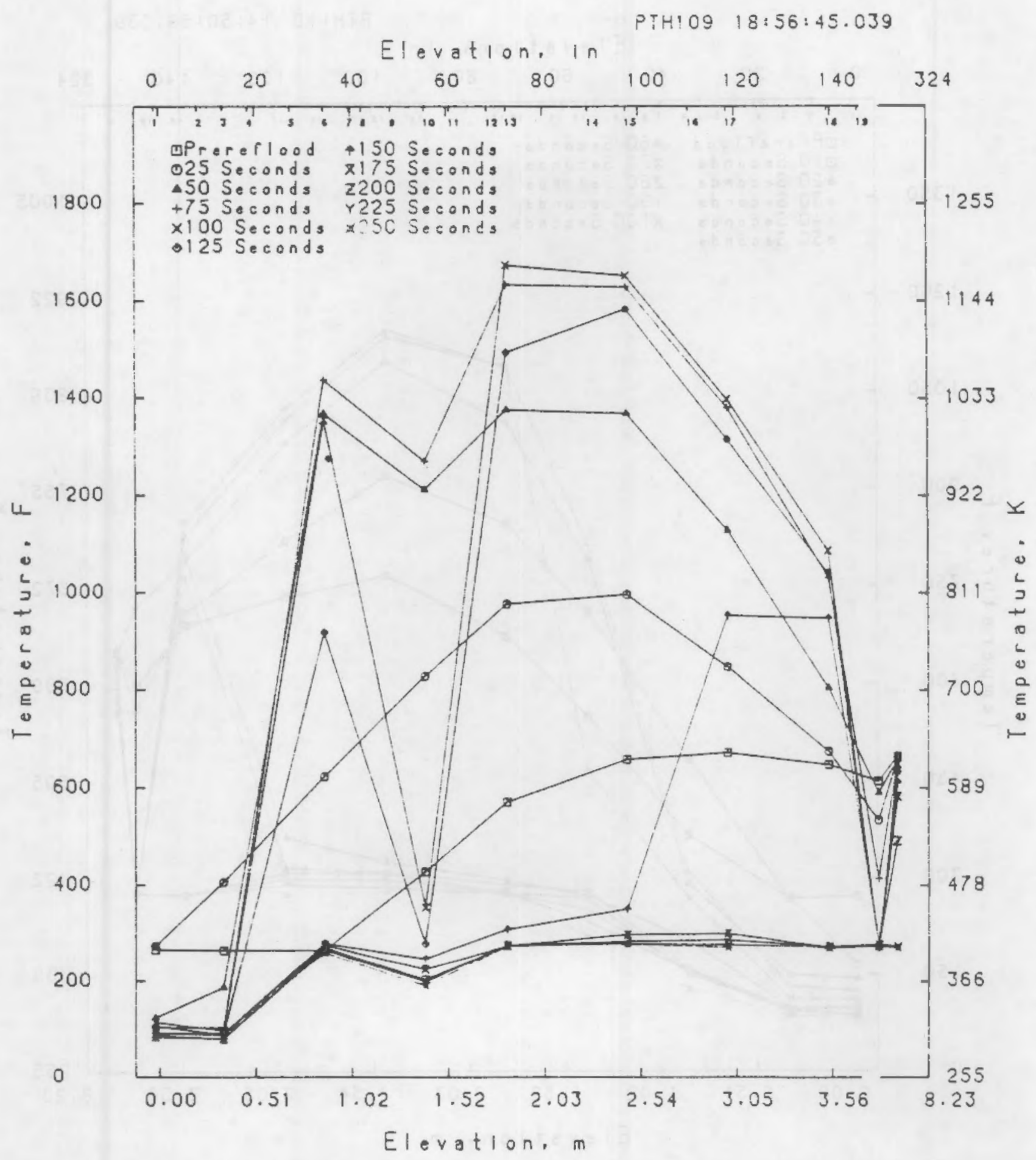

FIGURE 1.2.2.09 INSTRUMENT TUBE AND TEST TRAIN TEMPERATURE PROFILES DURING REFLOOOING AT 2SS INTERVALS - PTHIO9 


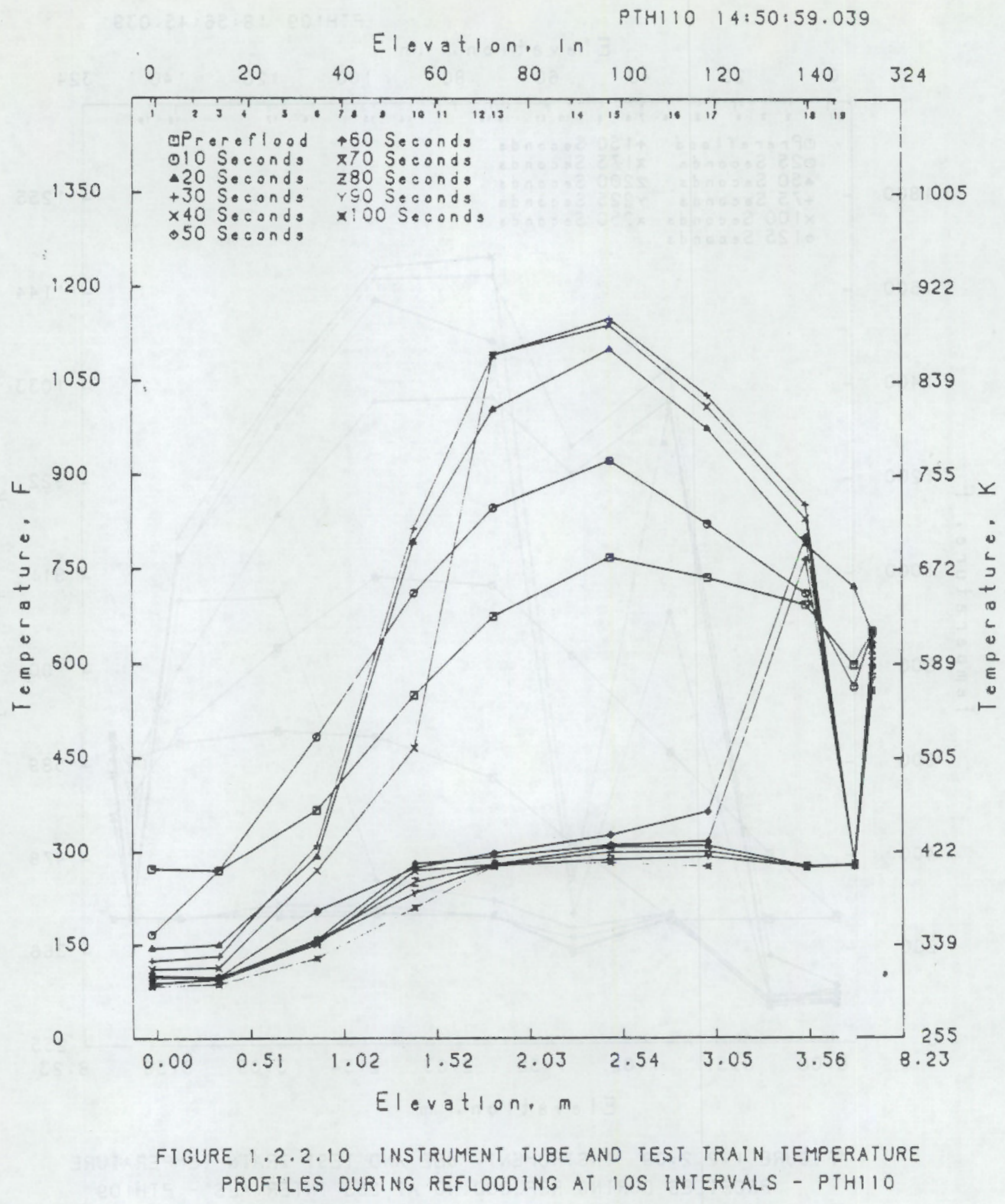




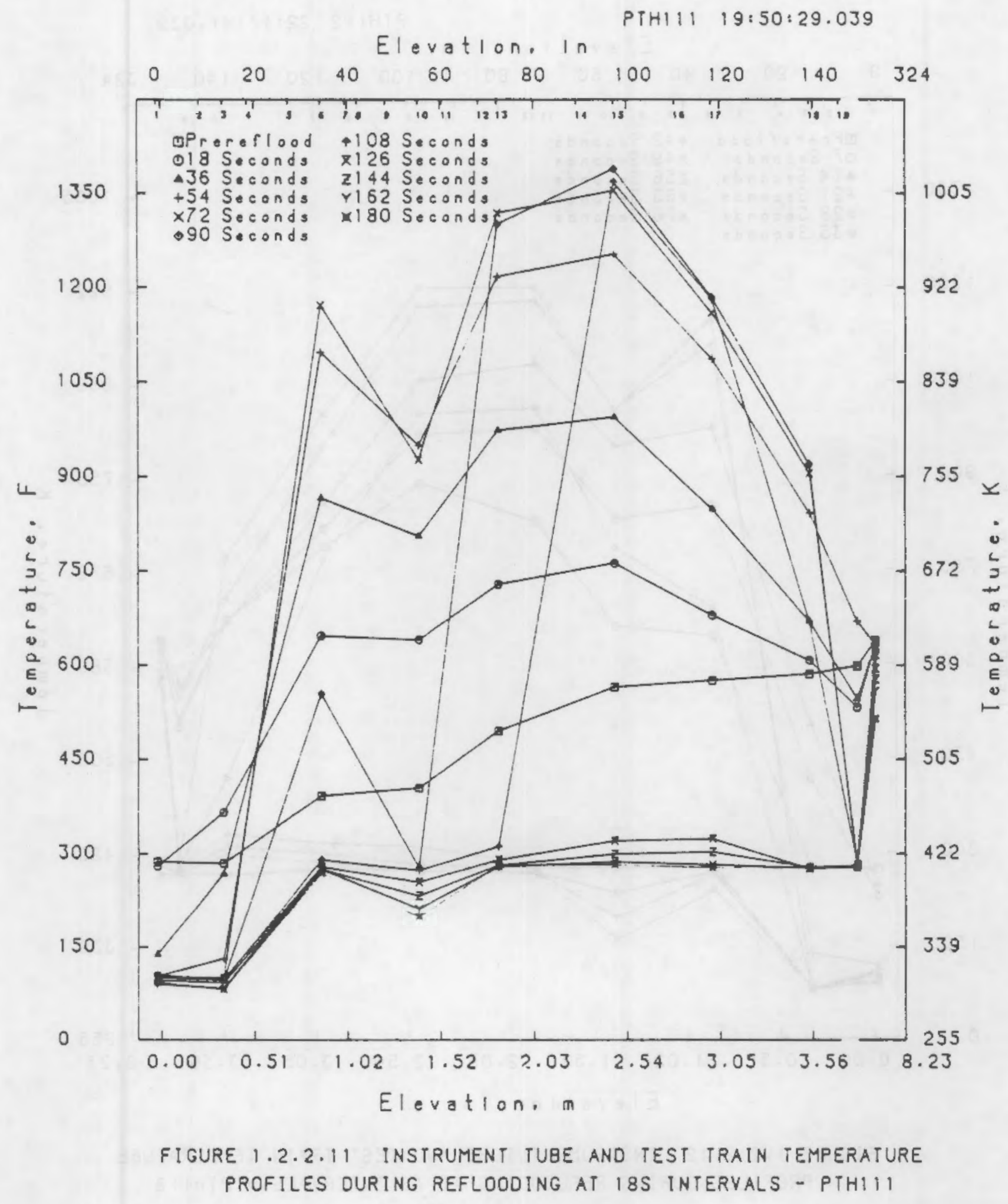




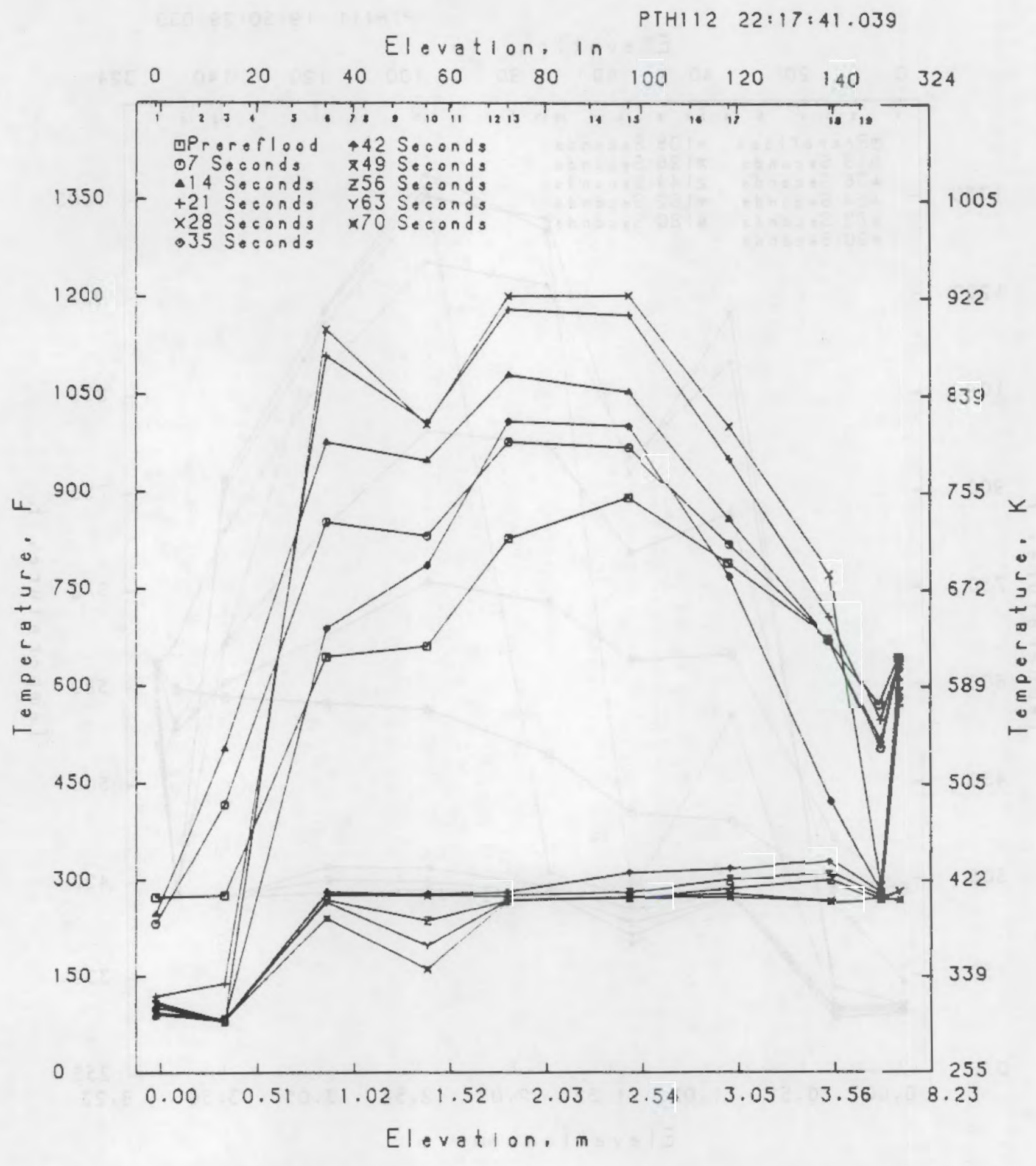

FIGURE $1.2 \cdot 2 \cdot 12$ INSTRUMENT TUBE AND TEST TRAIN TEMPERATURE PROFILES DURING REFLOODING AT TS INTERVALS - PTHI12 


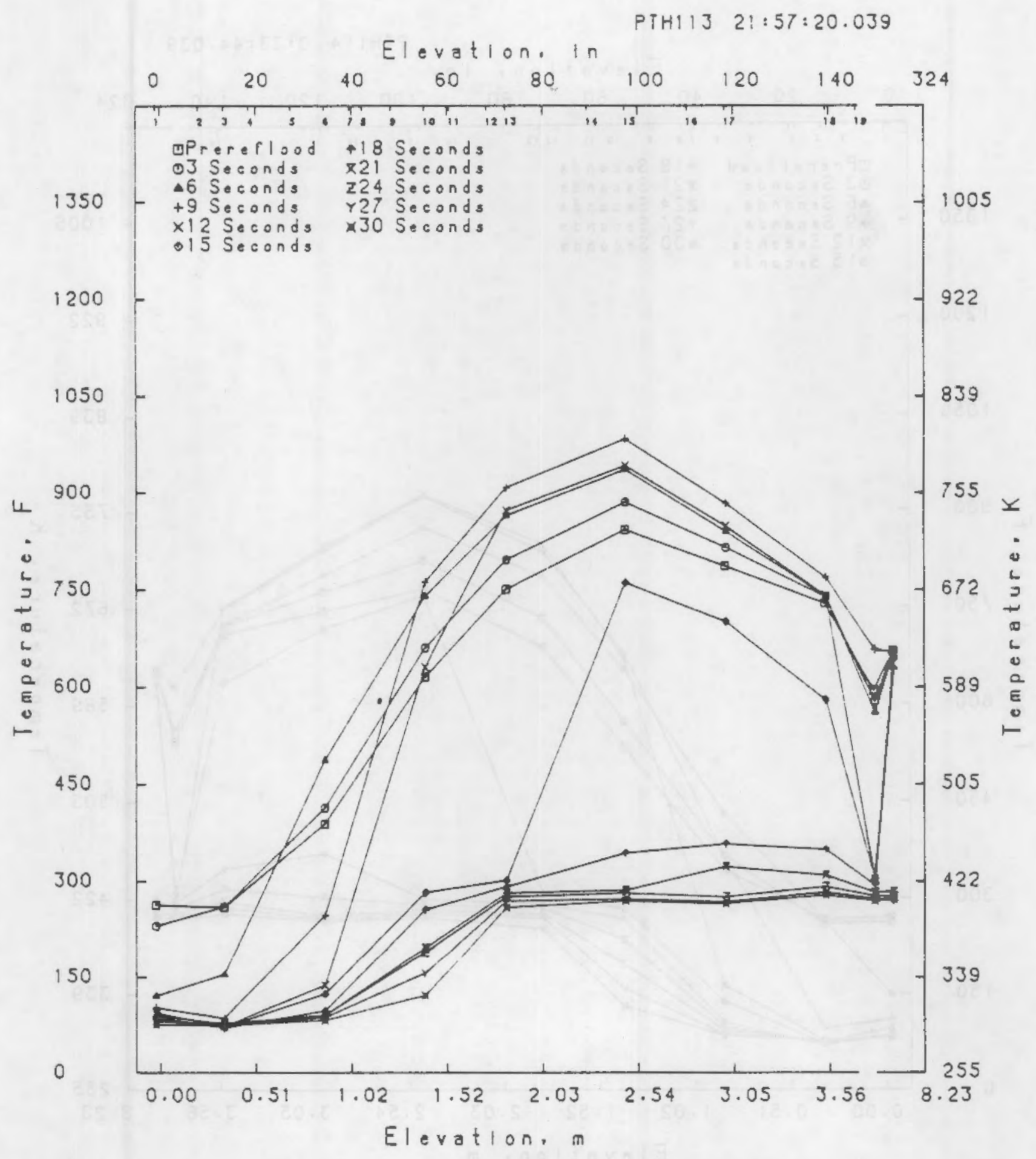

FIGURE 1.2 .2 .13 INSTRUMENT TUBE AND TEST TRAIN TEMPERATURE PROFILES DURING REFLOOOING AT JS INTERVALS - PTHIIJ 


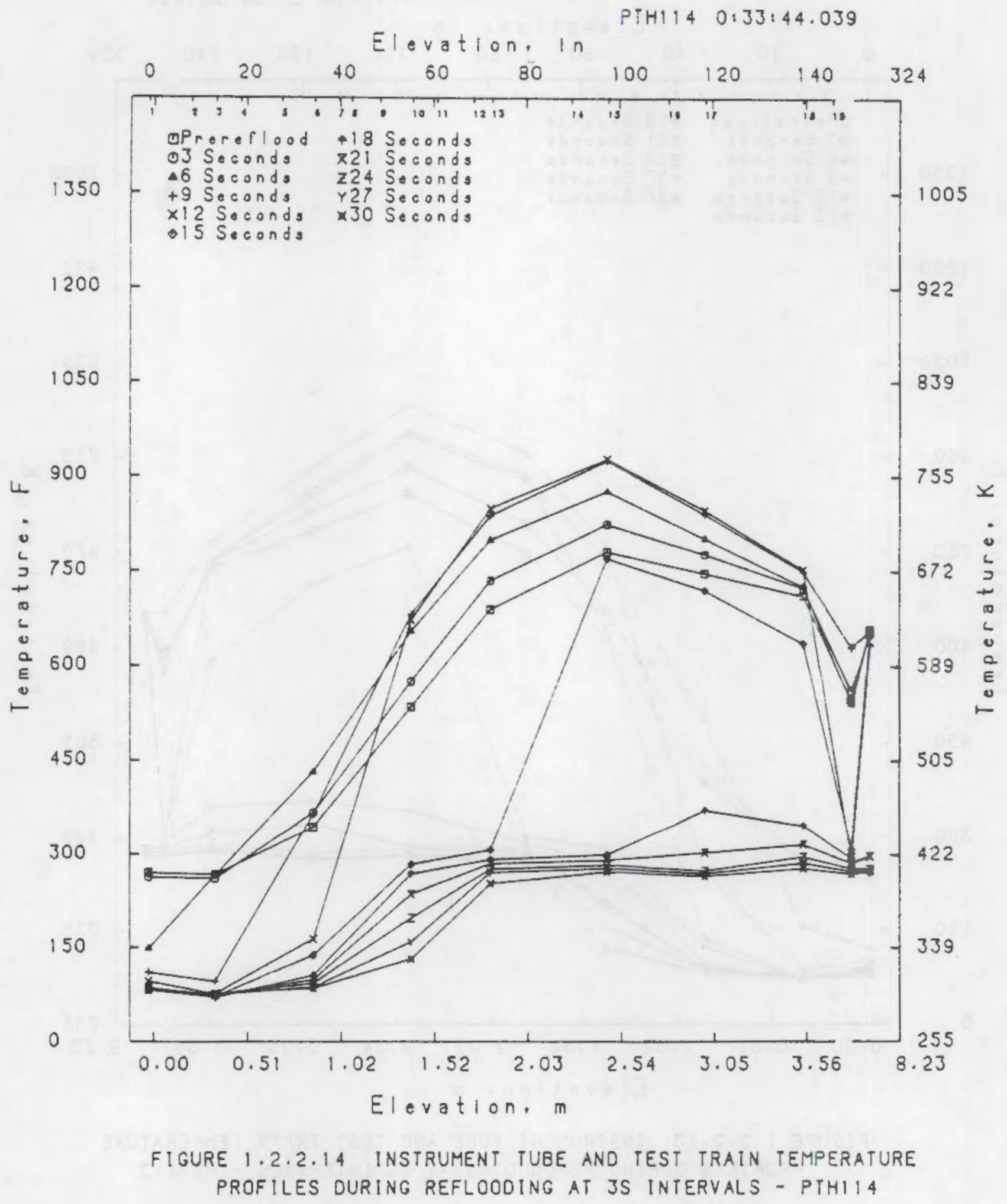




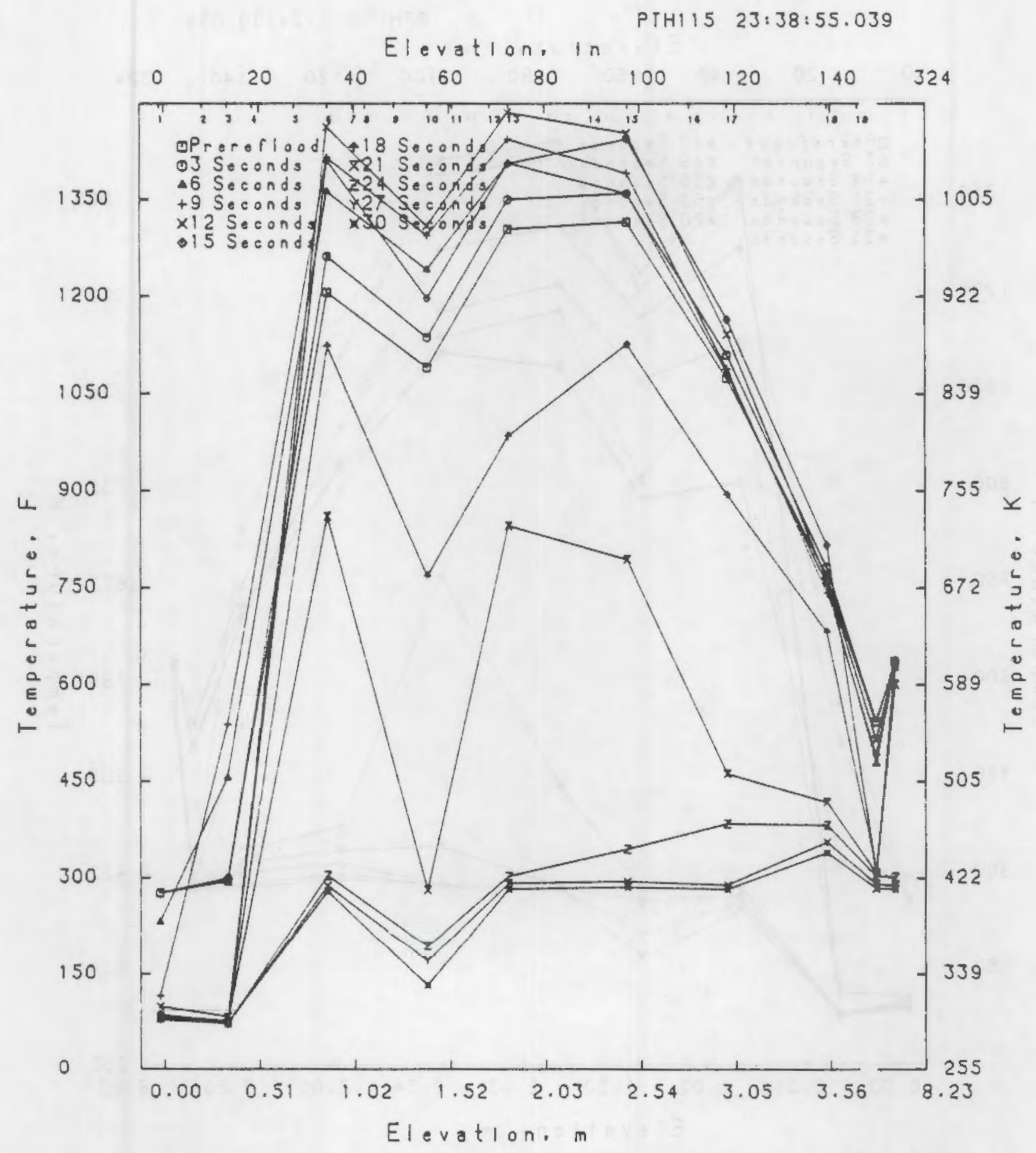

FIGURE 1.2 .2 .15 INSTRUMENT TUBE AND TEST TRAIN TEMPERATURE PROFILES DURING REFLOODING AT JS INTERVALS - PTHIIS 


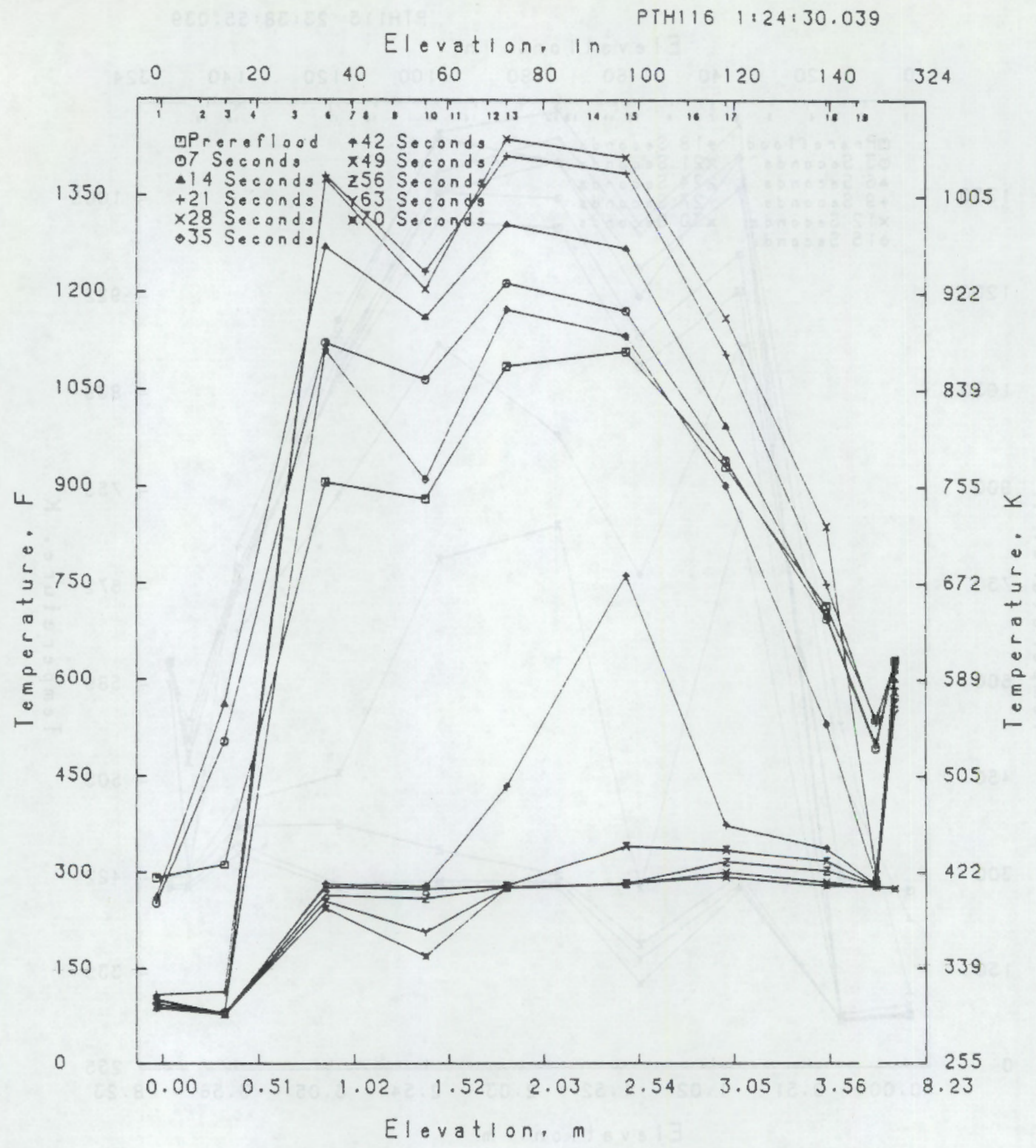

FIGURE 1.2 .2 .16 INSTRUMENT TUBE AND TEST TRAIN TEMPERATURE PROFILES OURING REFLOODING AT 7S INTERVALS - PTHII6 


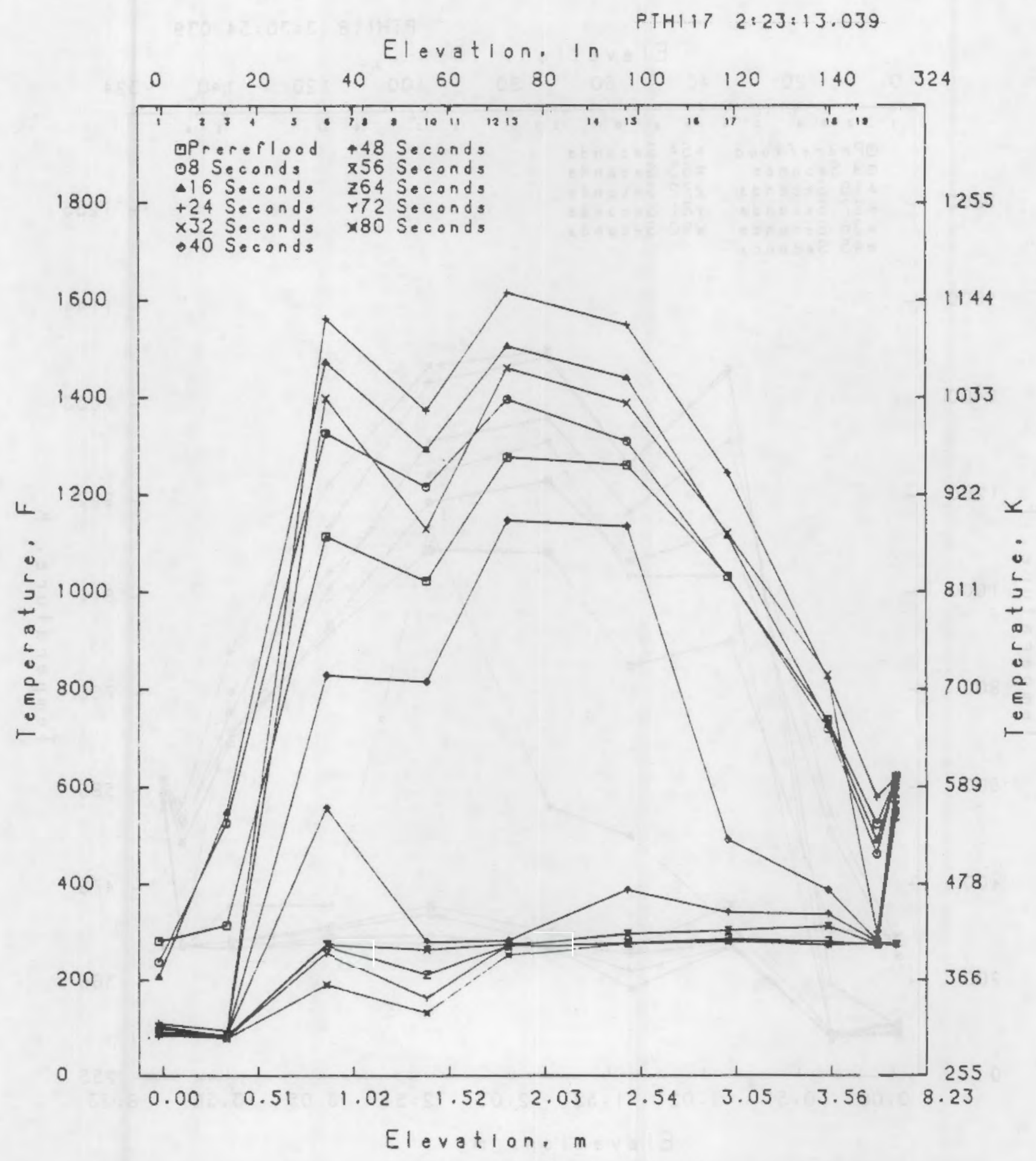

FIGURE 1.2 .2 .17 INSTRUMENT TUBE AND TEST TRAIN TEMPERATURE PROFILES DURING REFLOOOING AT BS INTERVALS - PTHIIT 


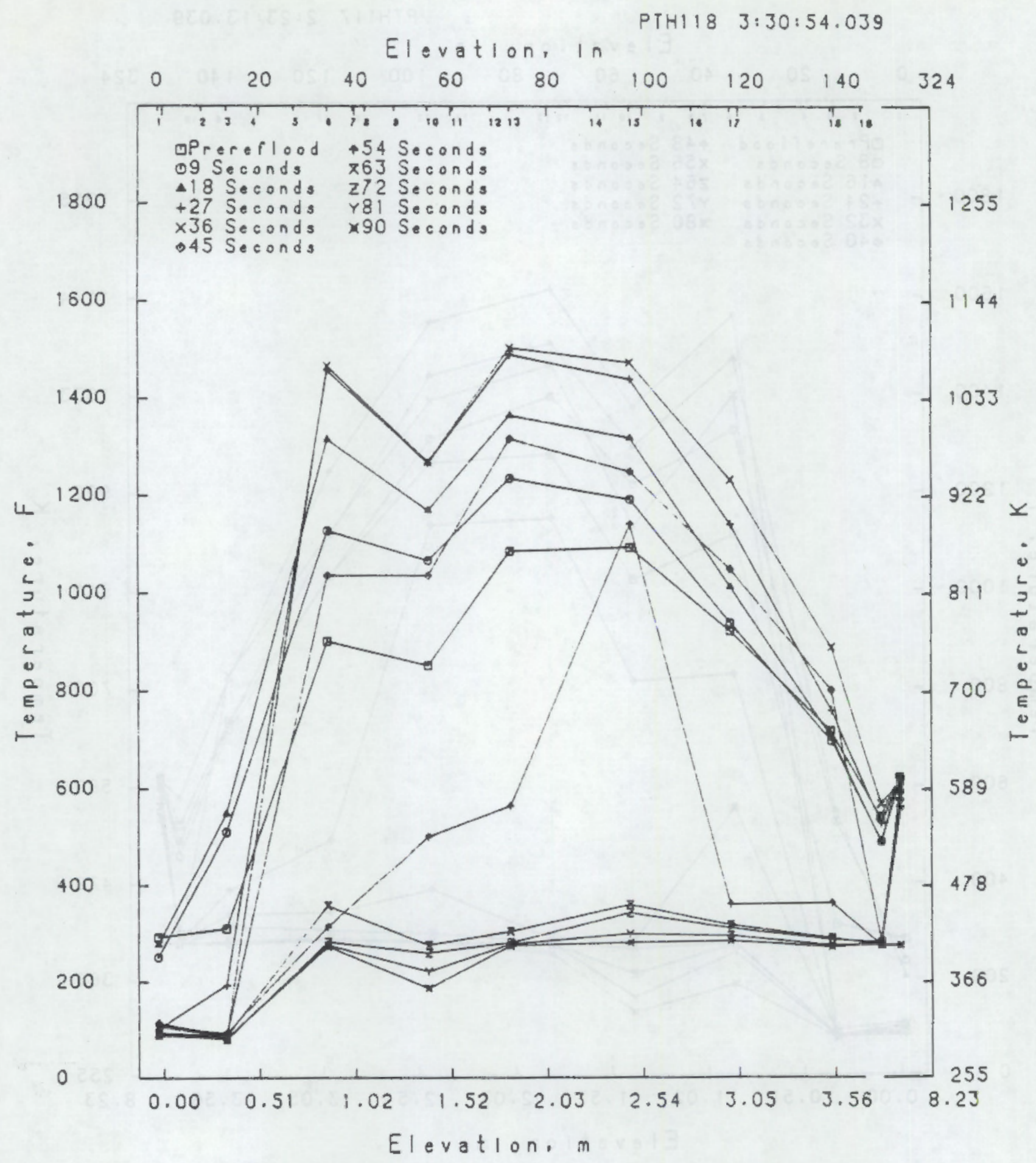

FIGURE 1.2 .2 .18 INSTRUMENT TUBE AND TEST TRAIN TEMPERATURE PROFILES DURING REFLOCOING AT GS INTERYALS - PTHII8 


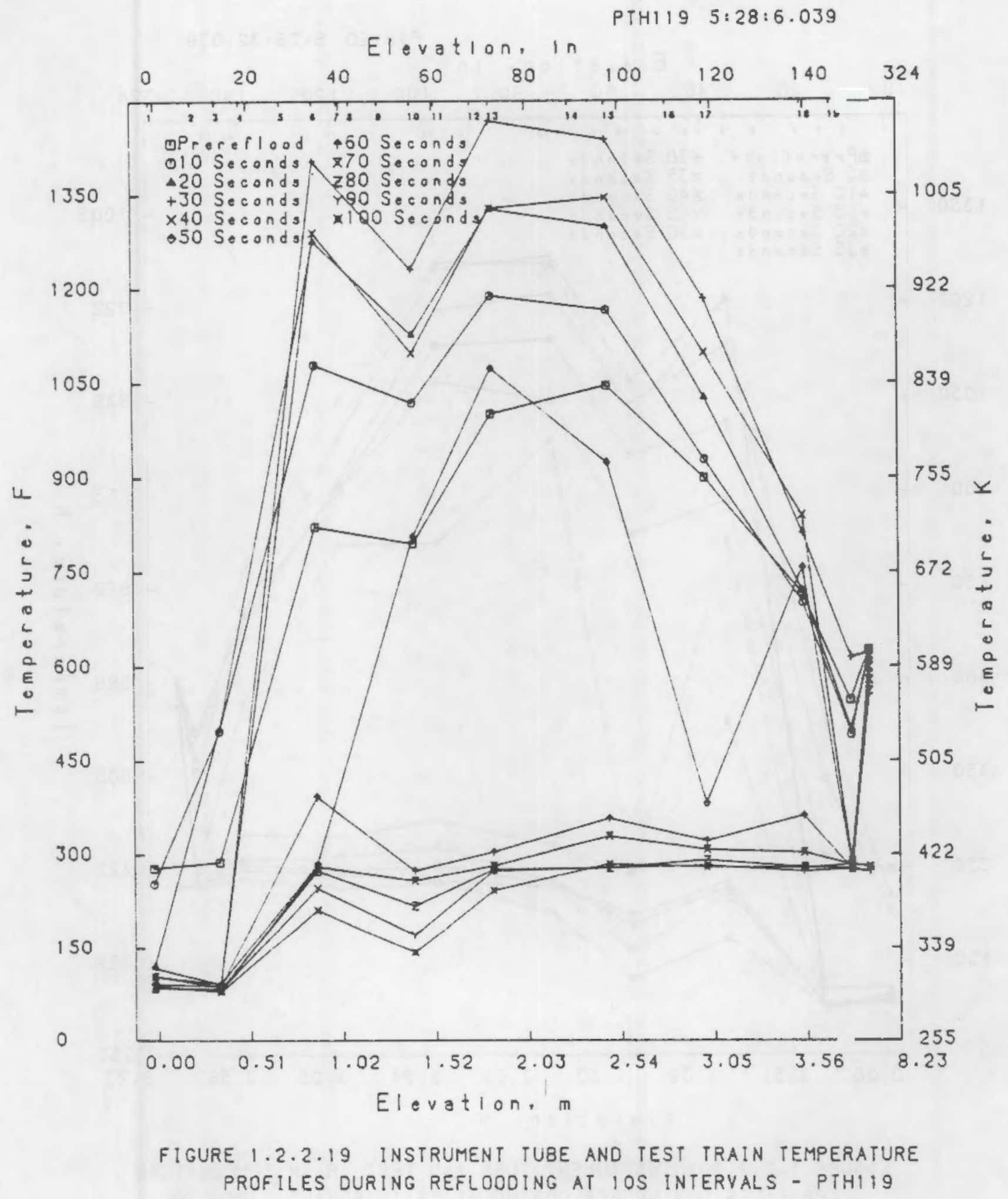




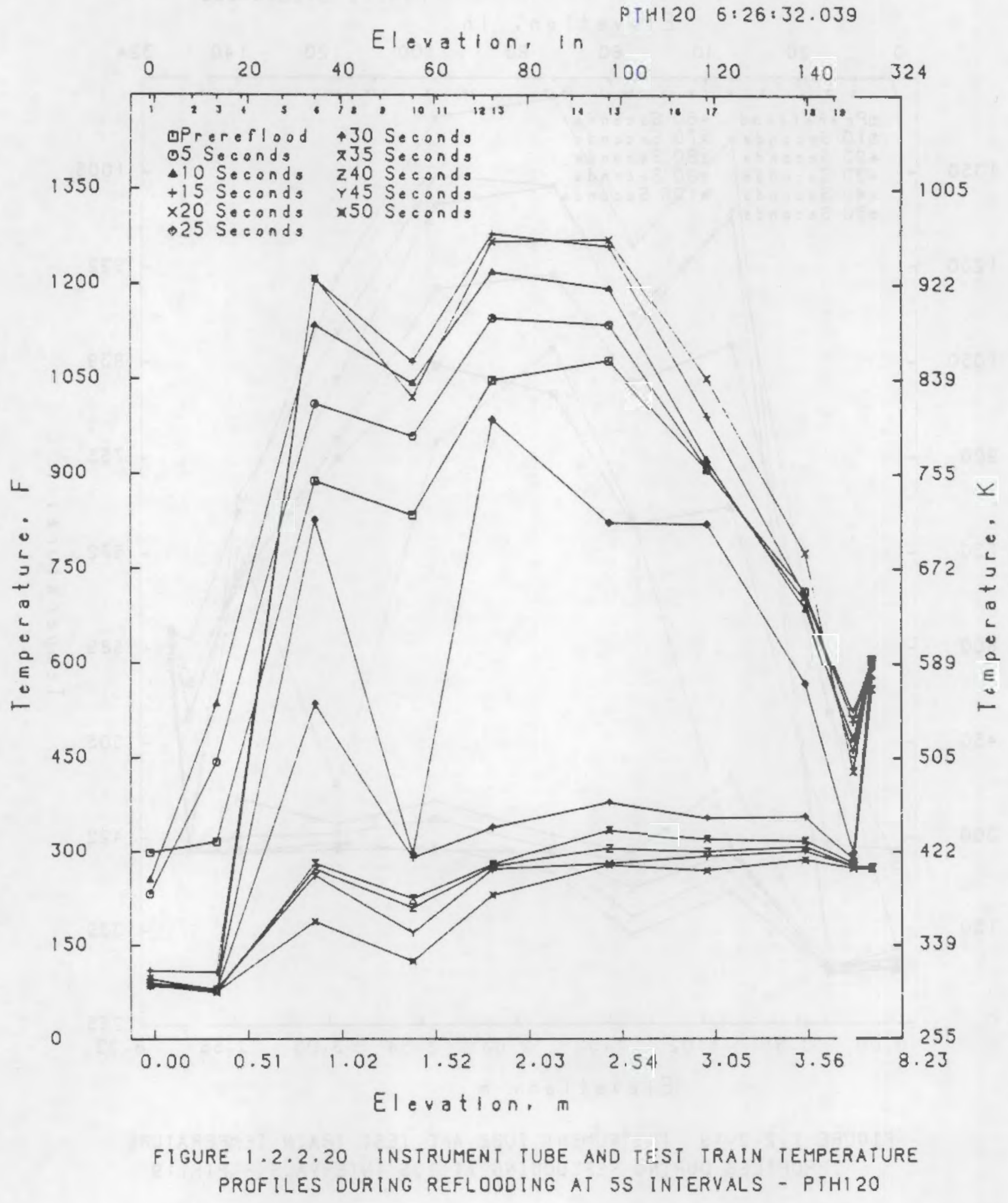




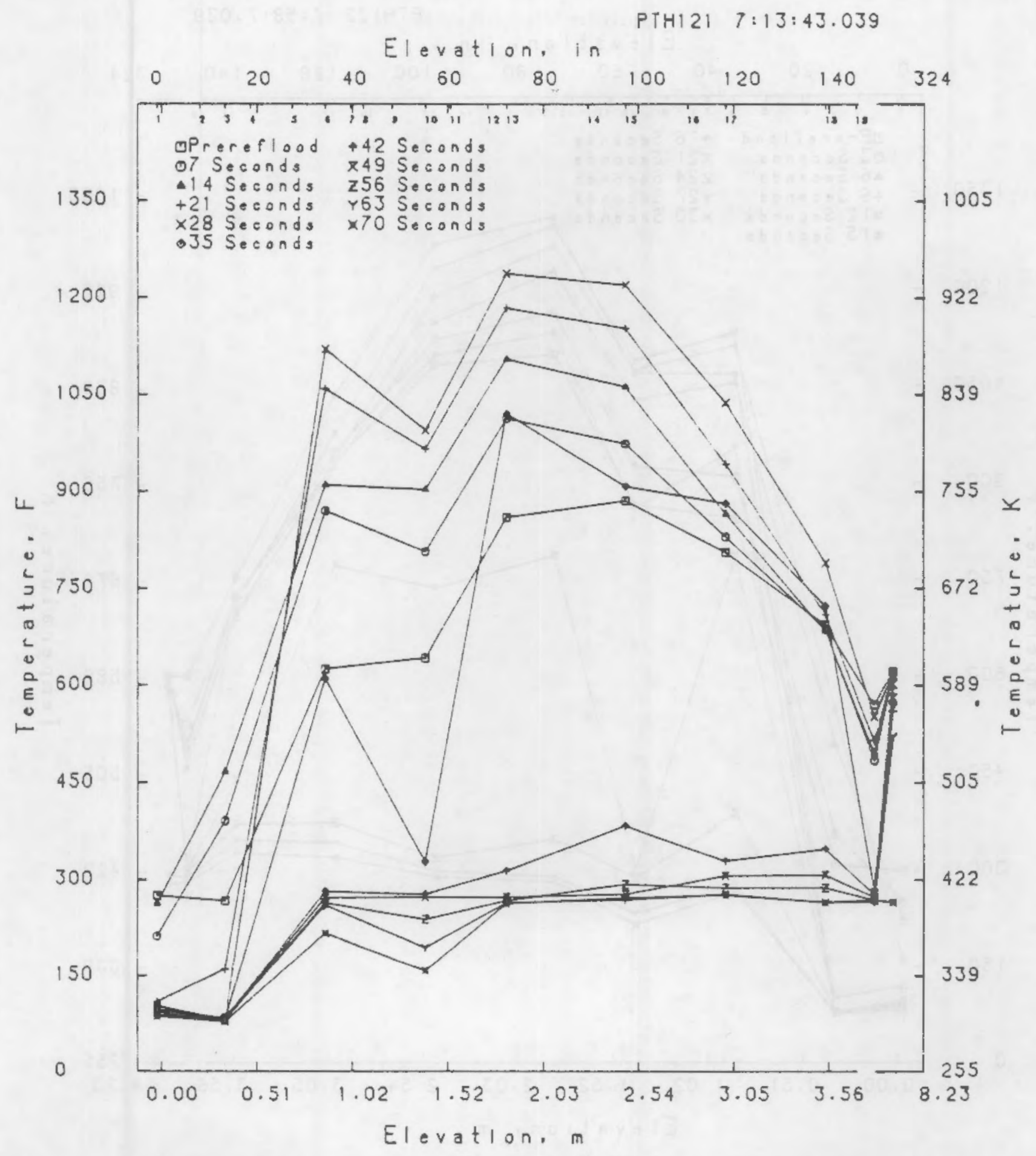

FIGURE 1.2 .2 .21 INSTRUMENT TU8E AND TEST TRAIN TEMPERATURE PROFILES DURING REFLODOING AT 7S INTERVALS - PTHII21 


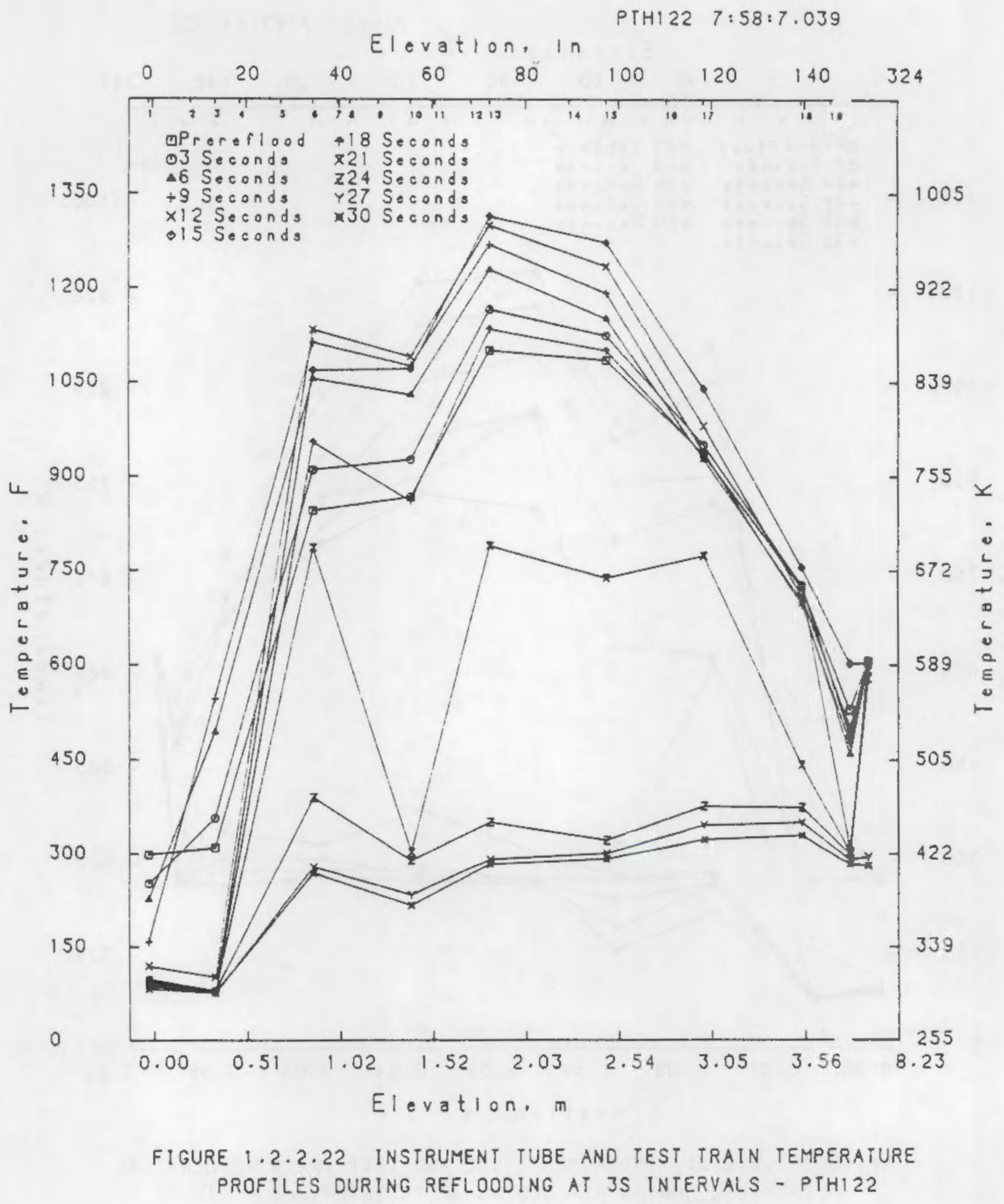




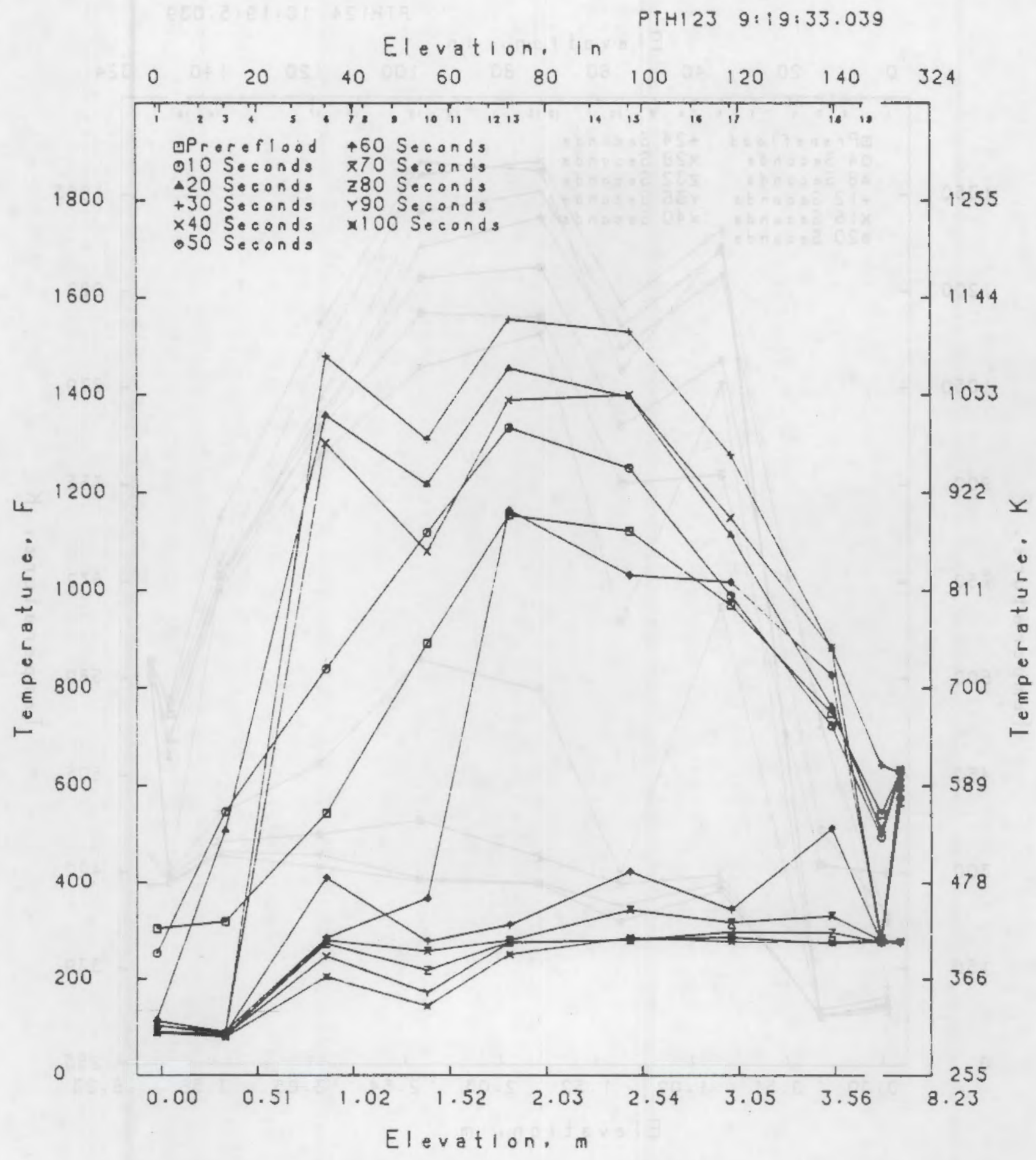

FIGURE 1.2.2.23 INSTRUMENT TUBE AND TEST TRAIN TEMPERATURE PROFILES DURING REFLOODING AT IOS INTERVALS - PTHI23 


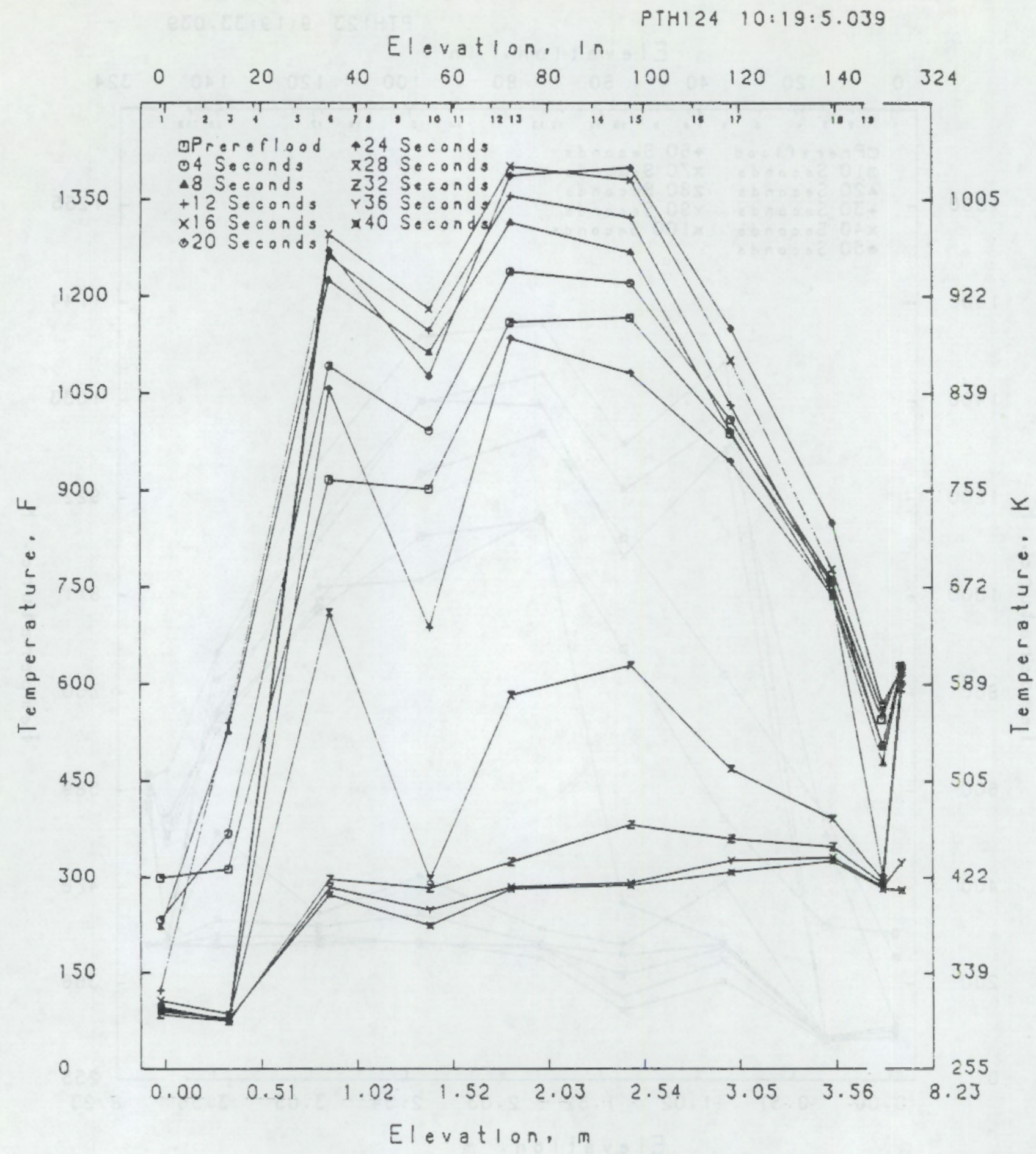

FIGURE 1.2 .2 .24 INSTRUMENT TUBE AND TEST TRAIN TEMPERATURE PROFILES DURING REFLOODING AT 4S INTERYALS - PTHI24 


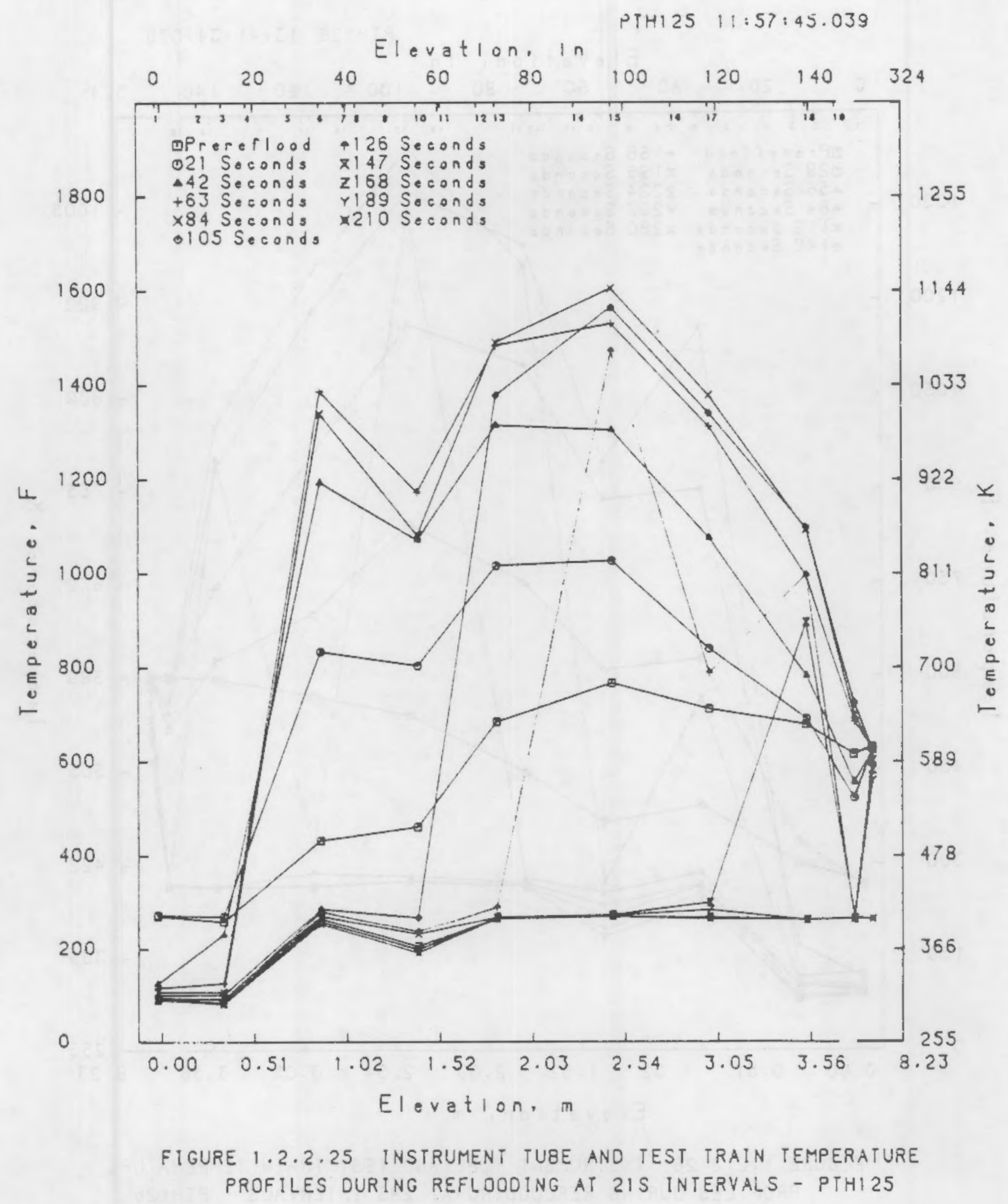




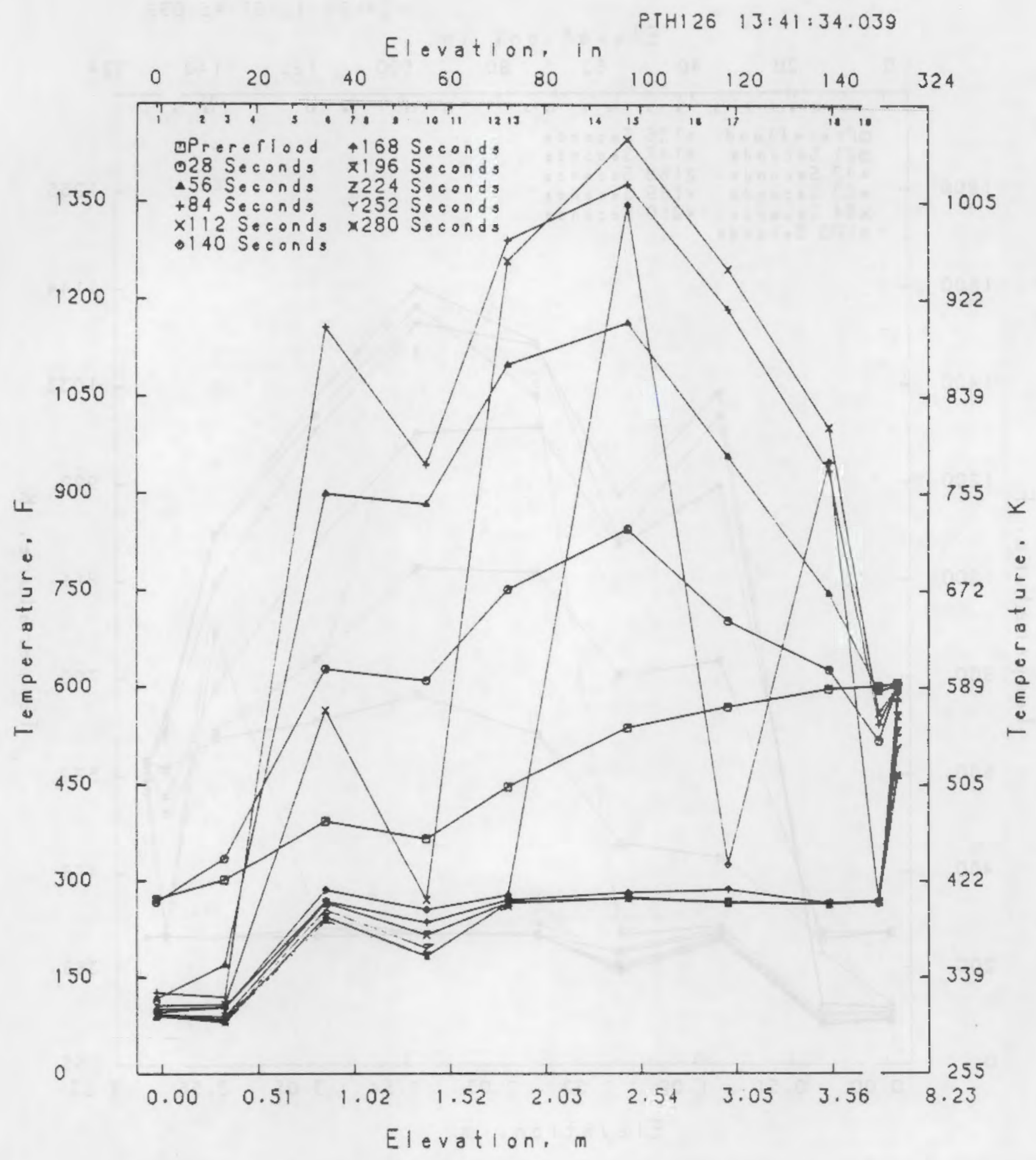

FIGURE $1.2 \cdot 2.26$ INSTRUMENT TUBE AND TEST TRAIN TEMPERATURE PROFILES DURING REFLOODING AT 28S INTERVALS - PTHI26 


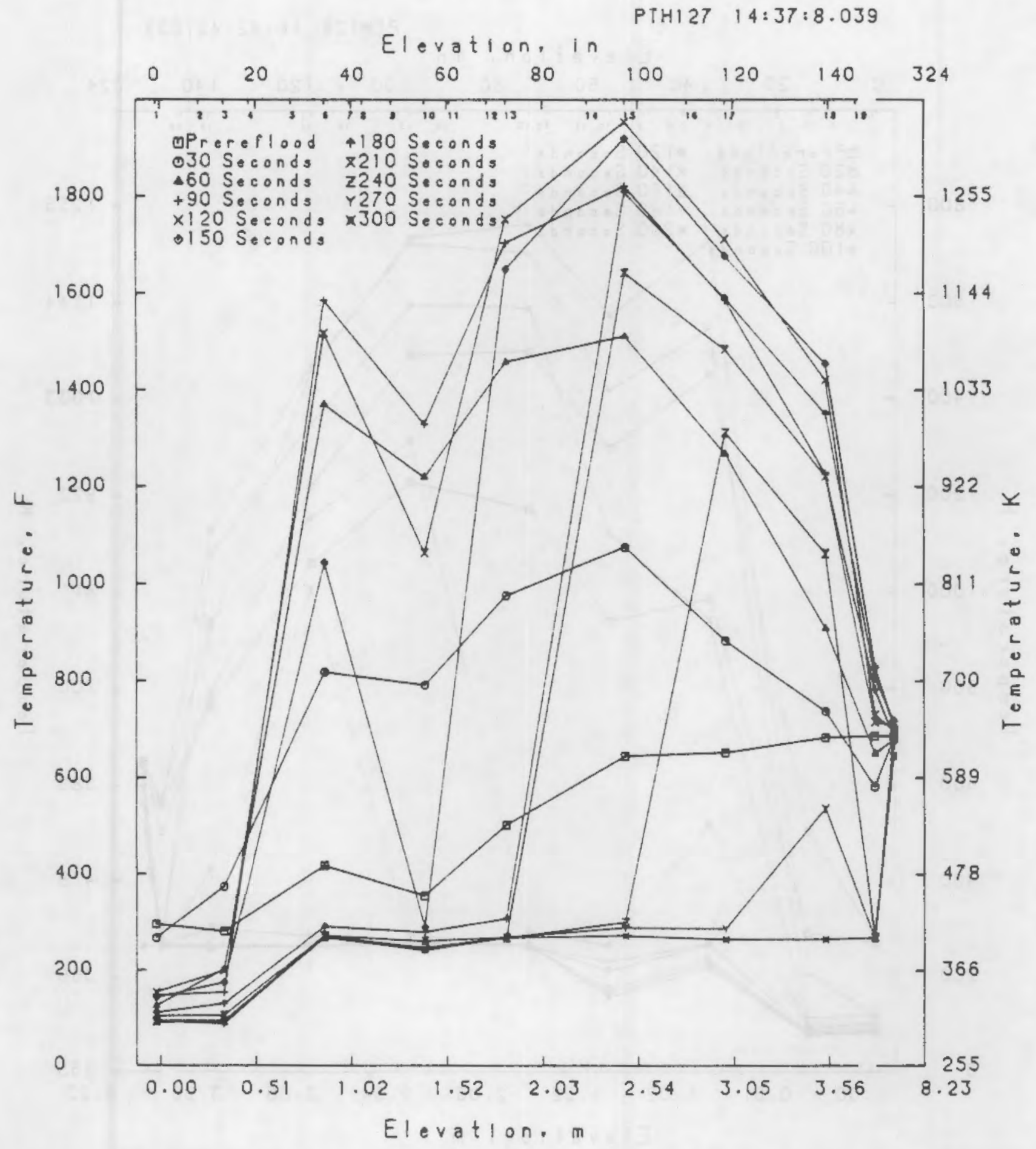

FIGURE 1.2 .2 .27 INSTRUMENT TUBE AND TEST TRAIN TEMPERATURE PROFILES DURING REFLOODING AT 30 S INTERVALS - PTHI 27 


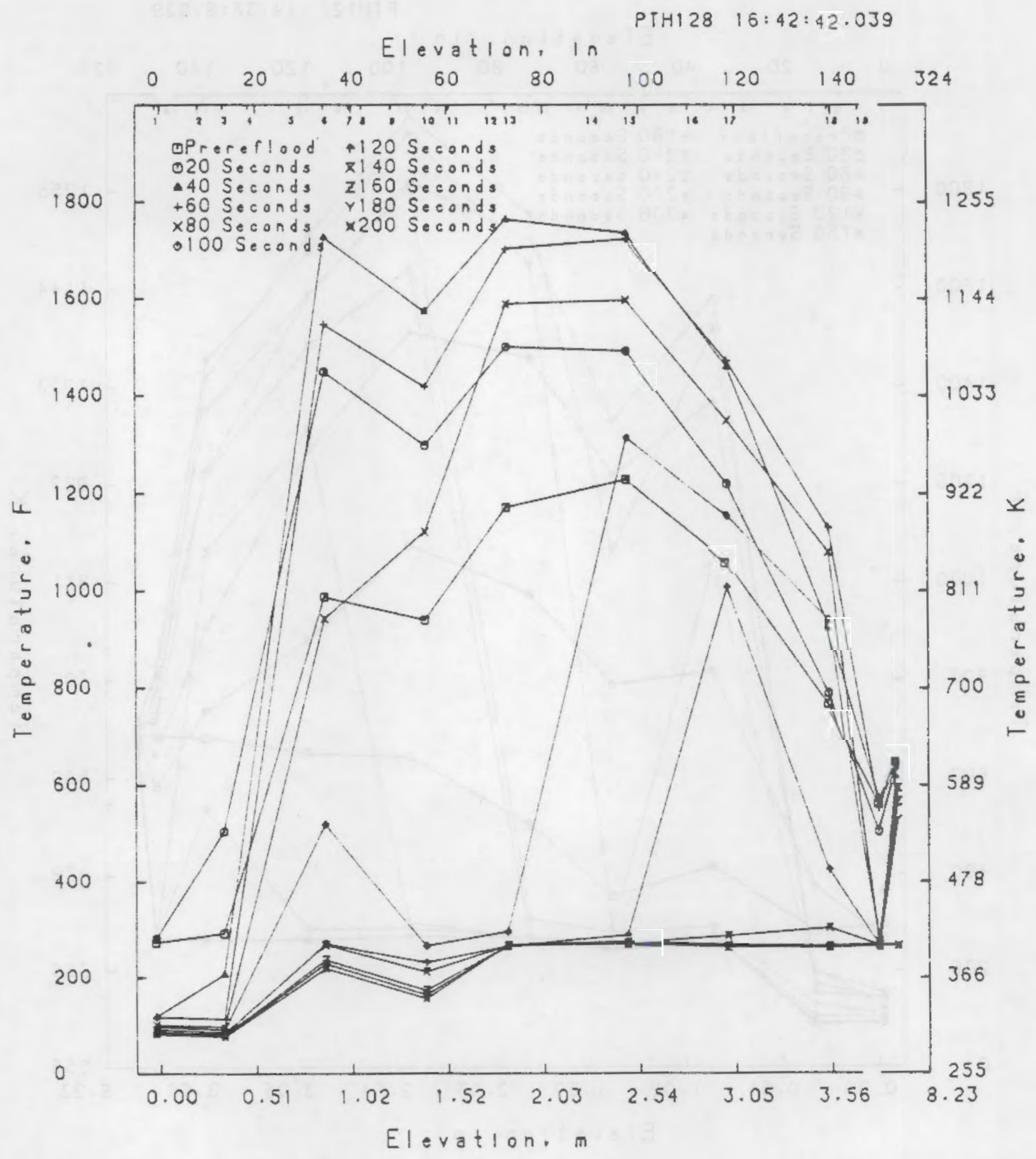

FIGURE 1.2 .2 .28 INSTRUMENT TUBE AND TEST TRAIN TEMPERATURE PROFILES DURING REFLOODING AT 2OS INTERVALS - PTHI 28 


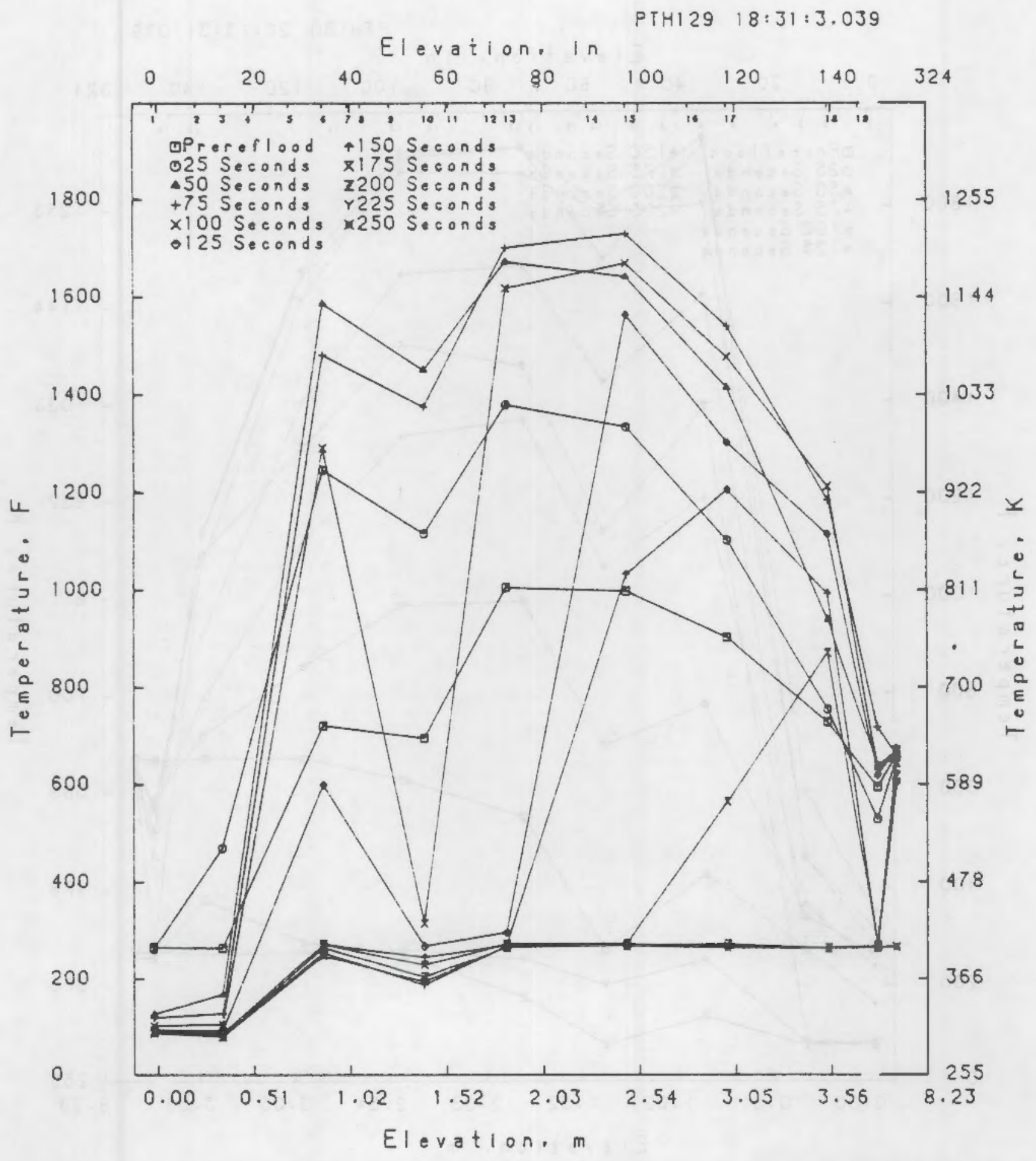

FIGURE 1.2 .2 .29 INSTRUMENT TUEE AND TEST TRAIN TEMPERATURE PROFILES DURING REFLOODING AT 25S INTERVALS - PTHI29 


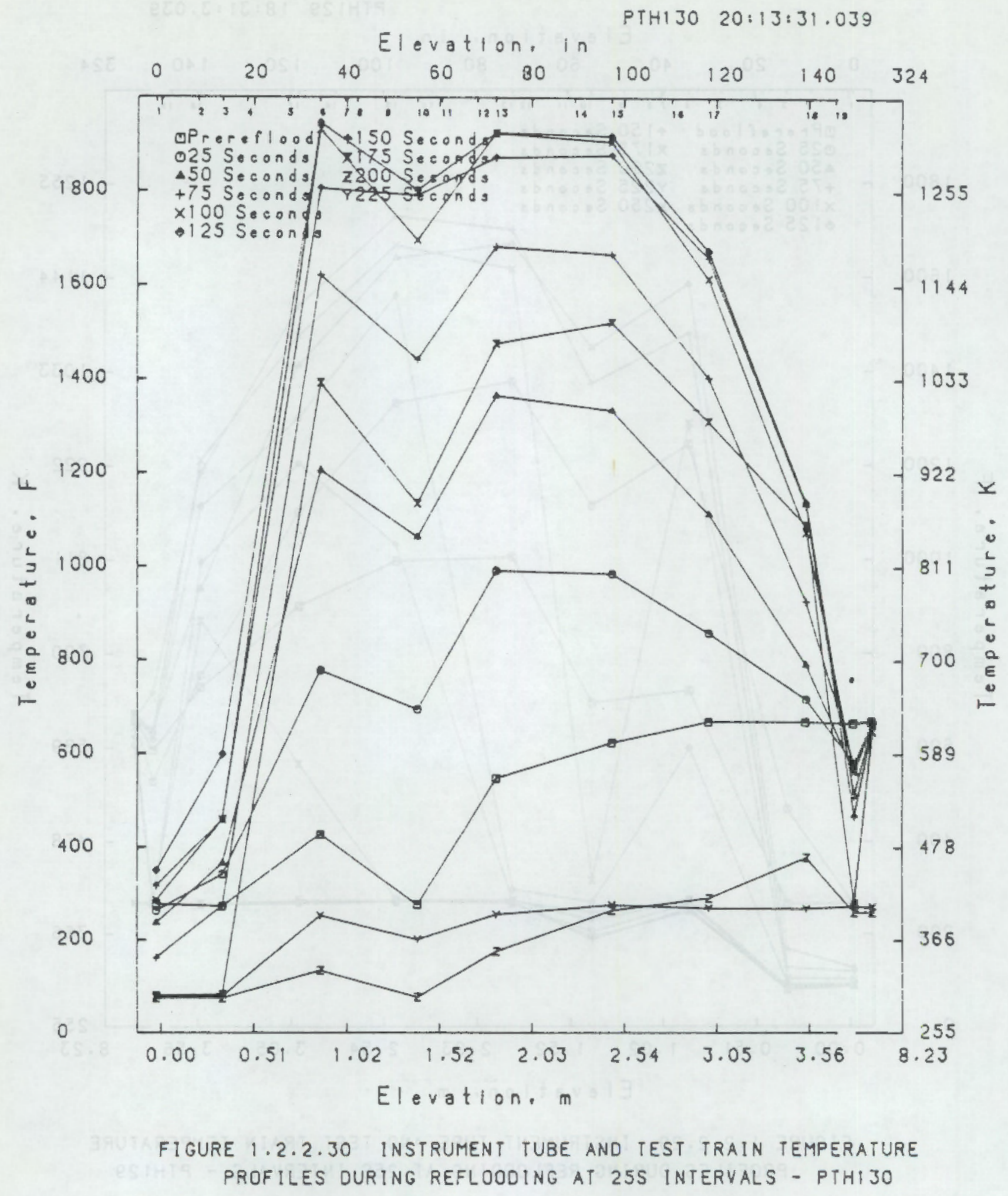




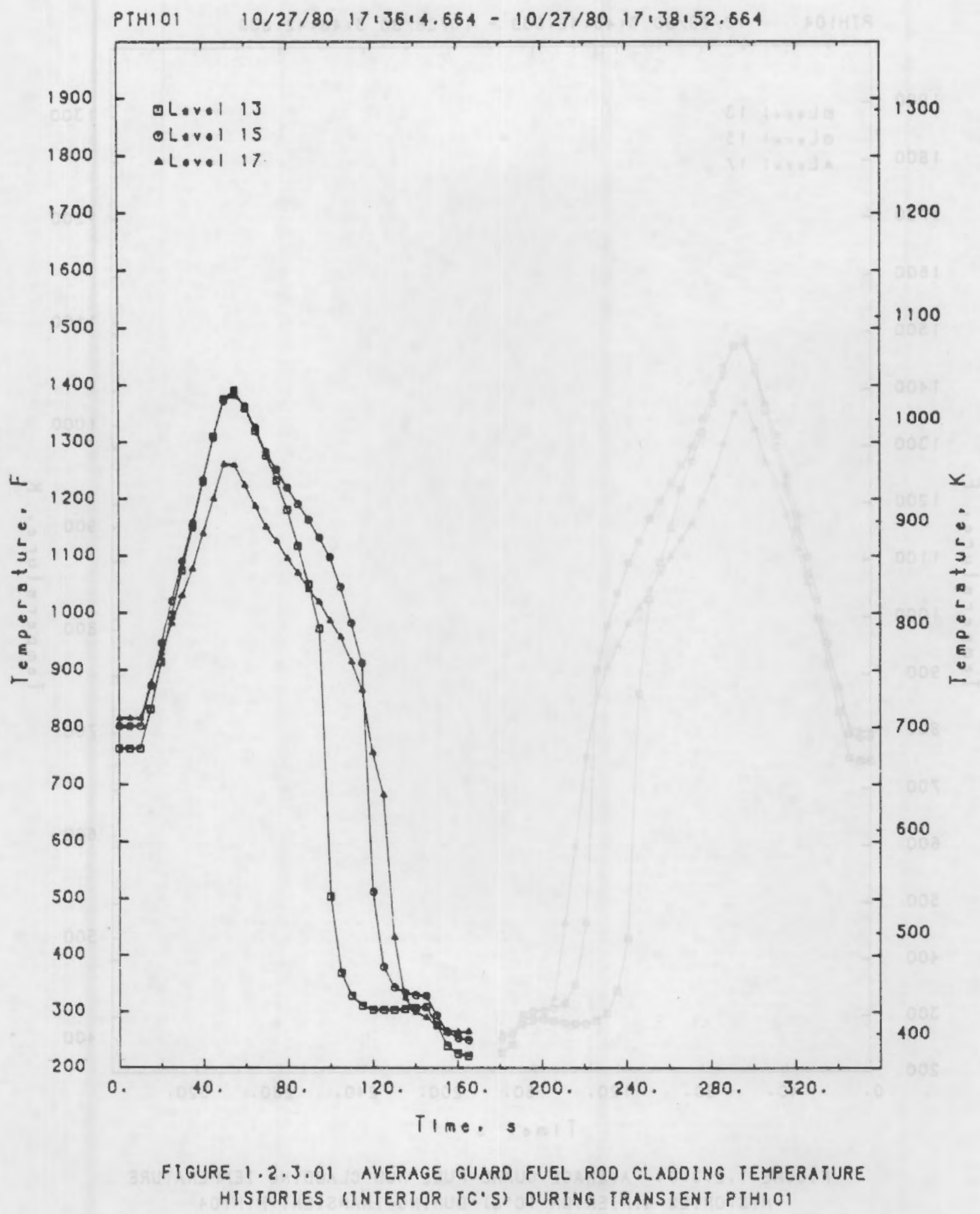

A. 65 


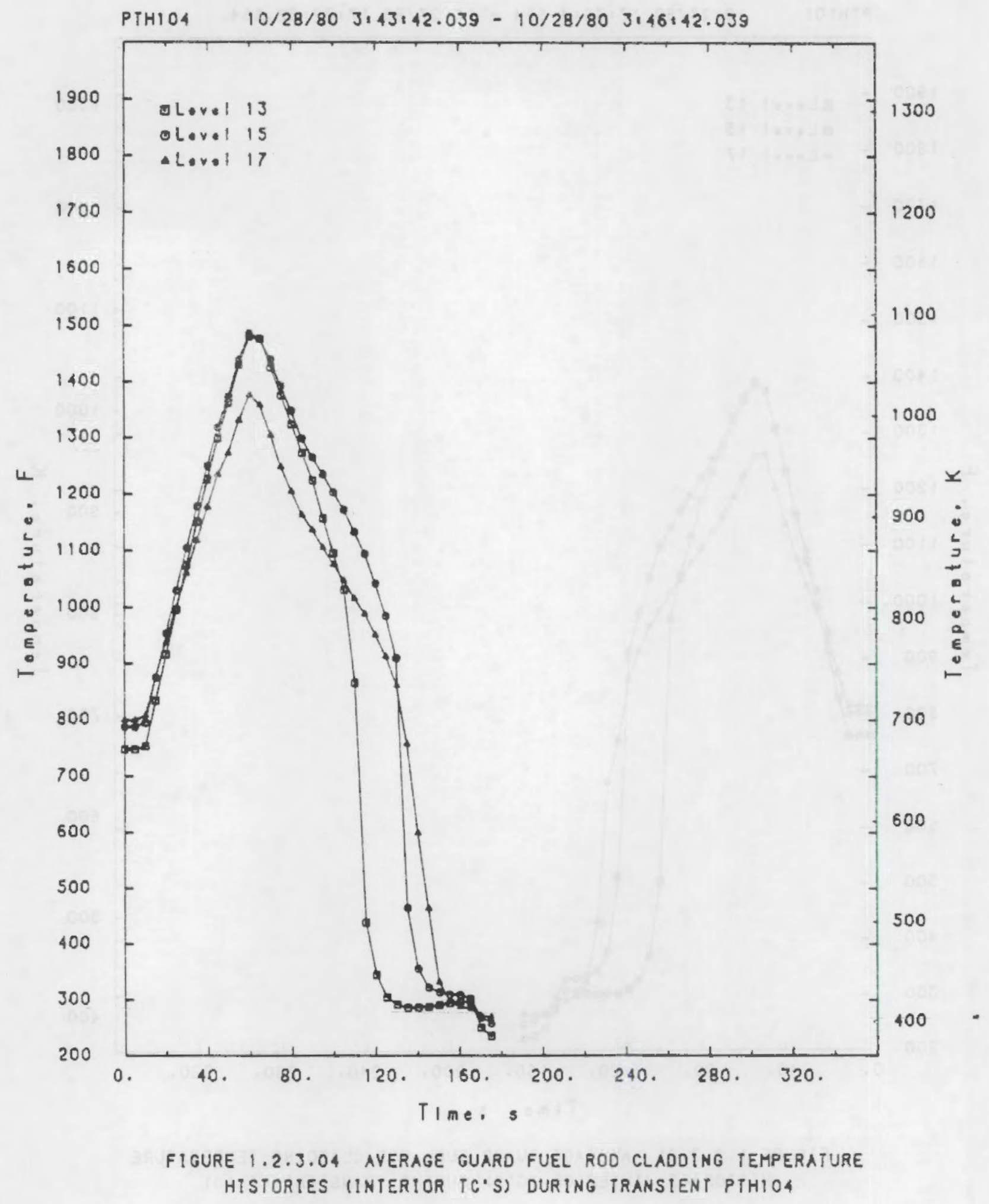




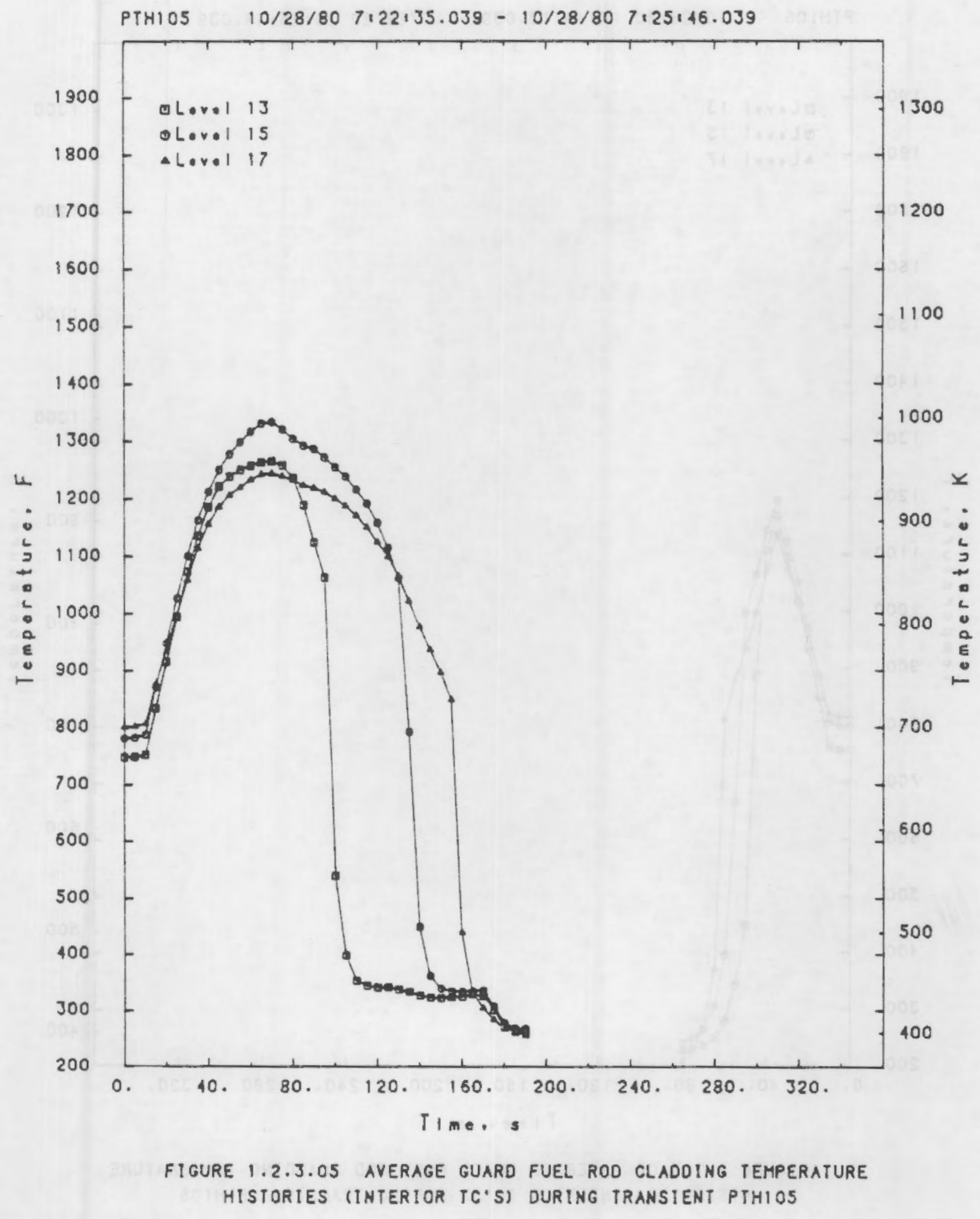




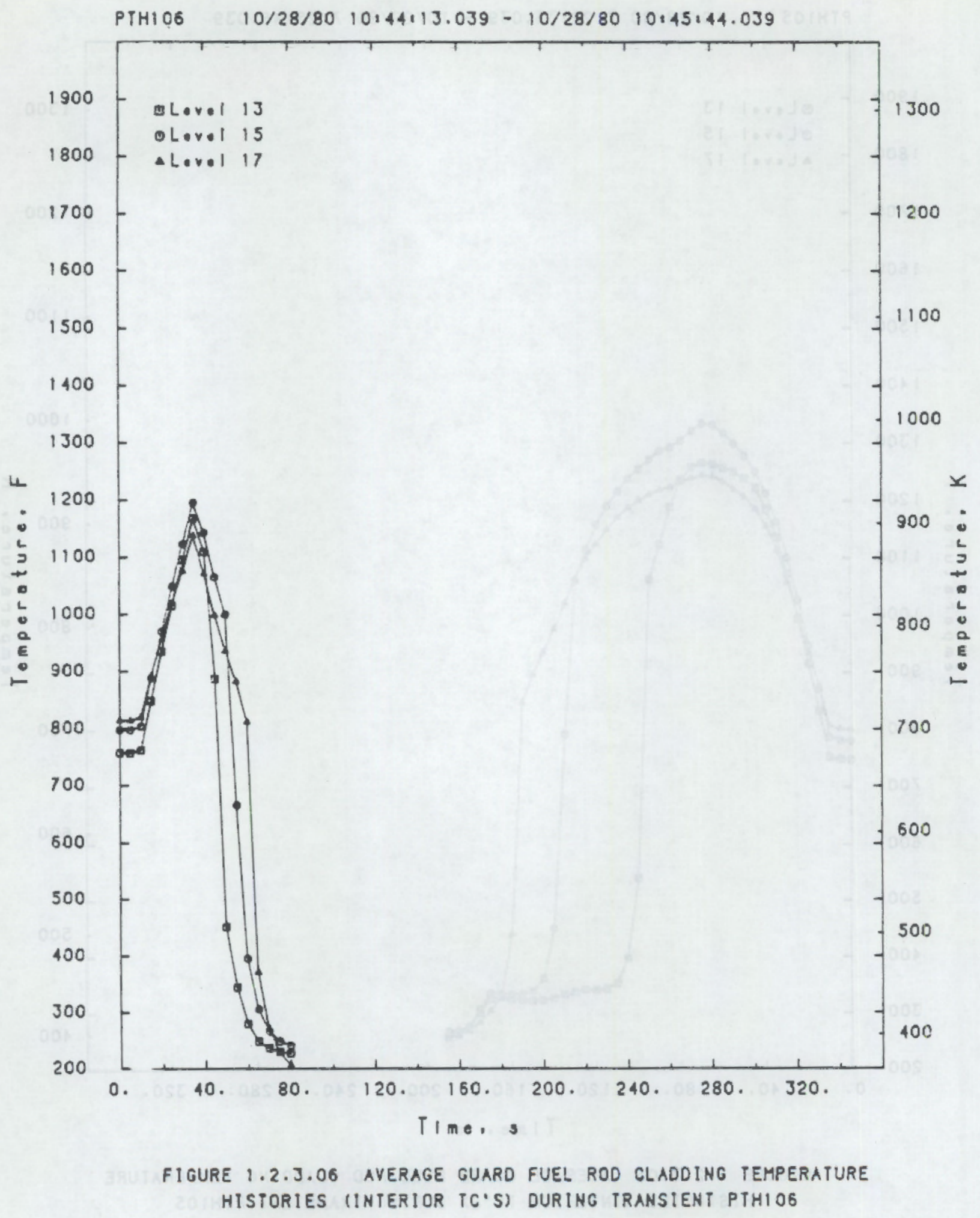

A. 68 


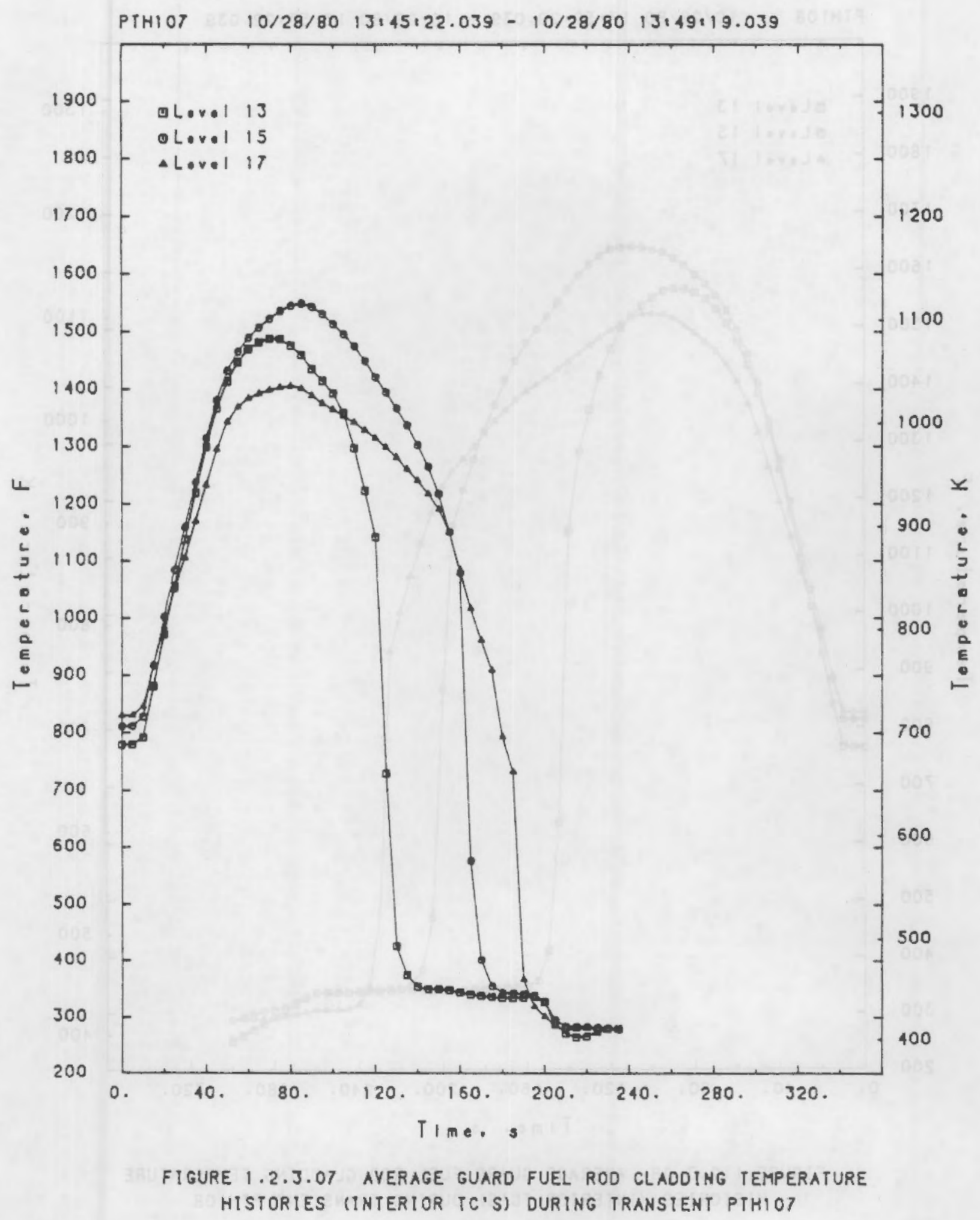




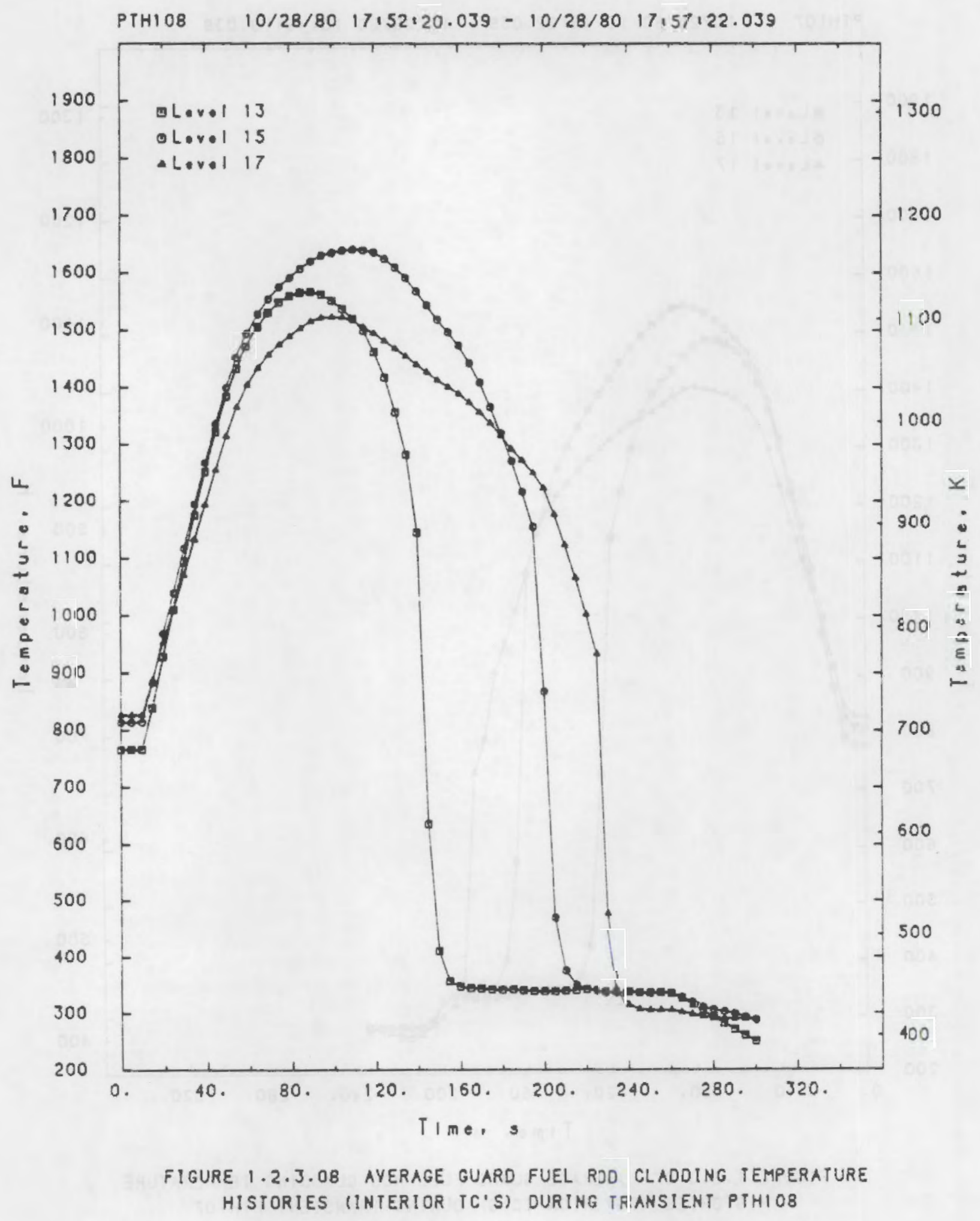

A. 70 


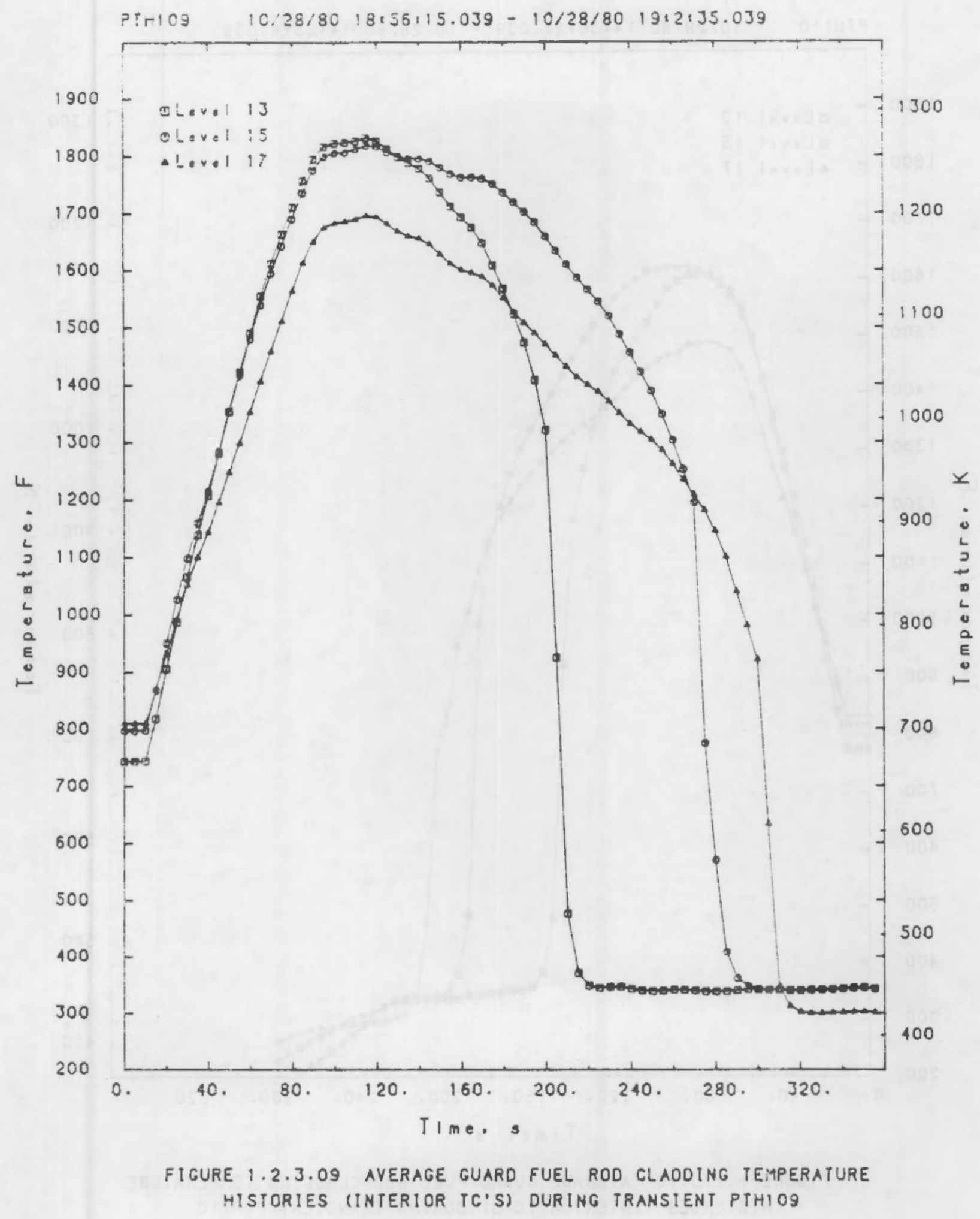

A. 71 


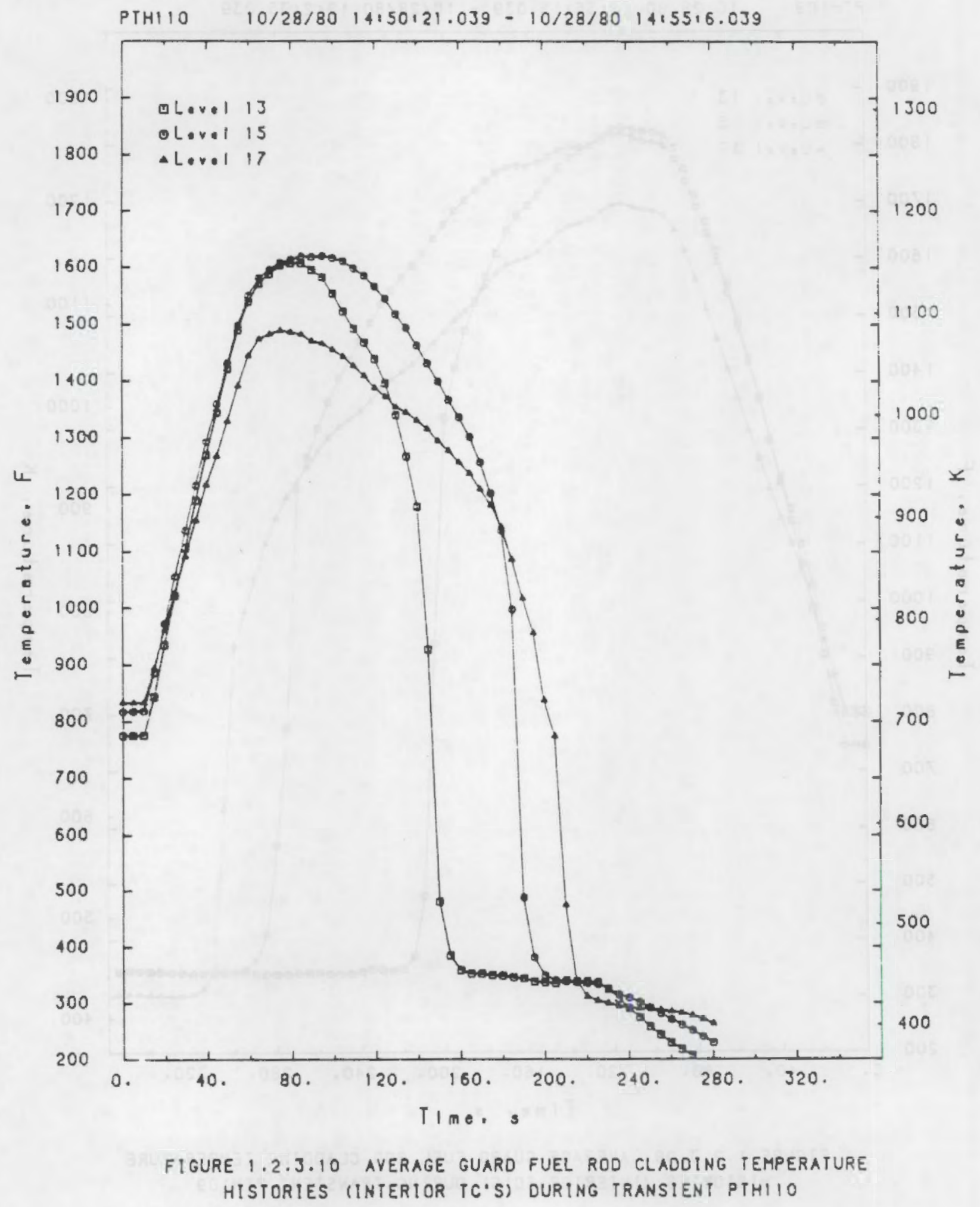

A. 72 


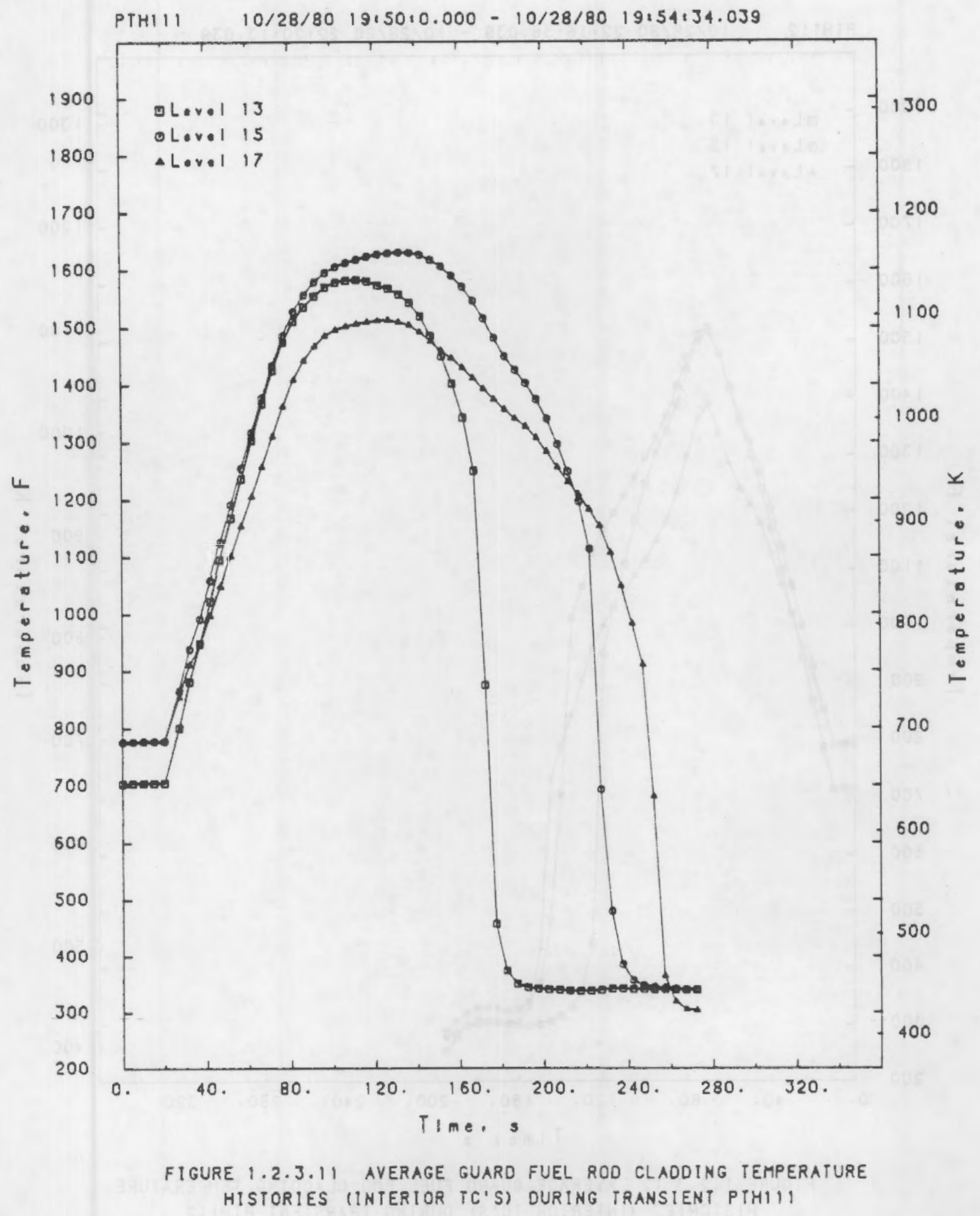

A. 73 


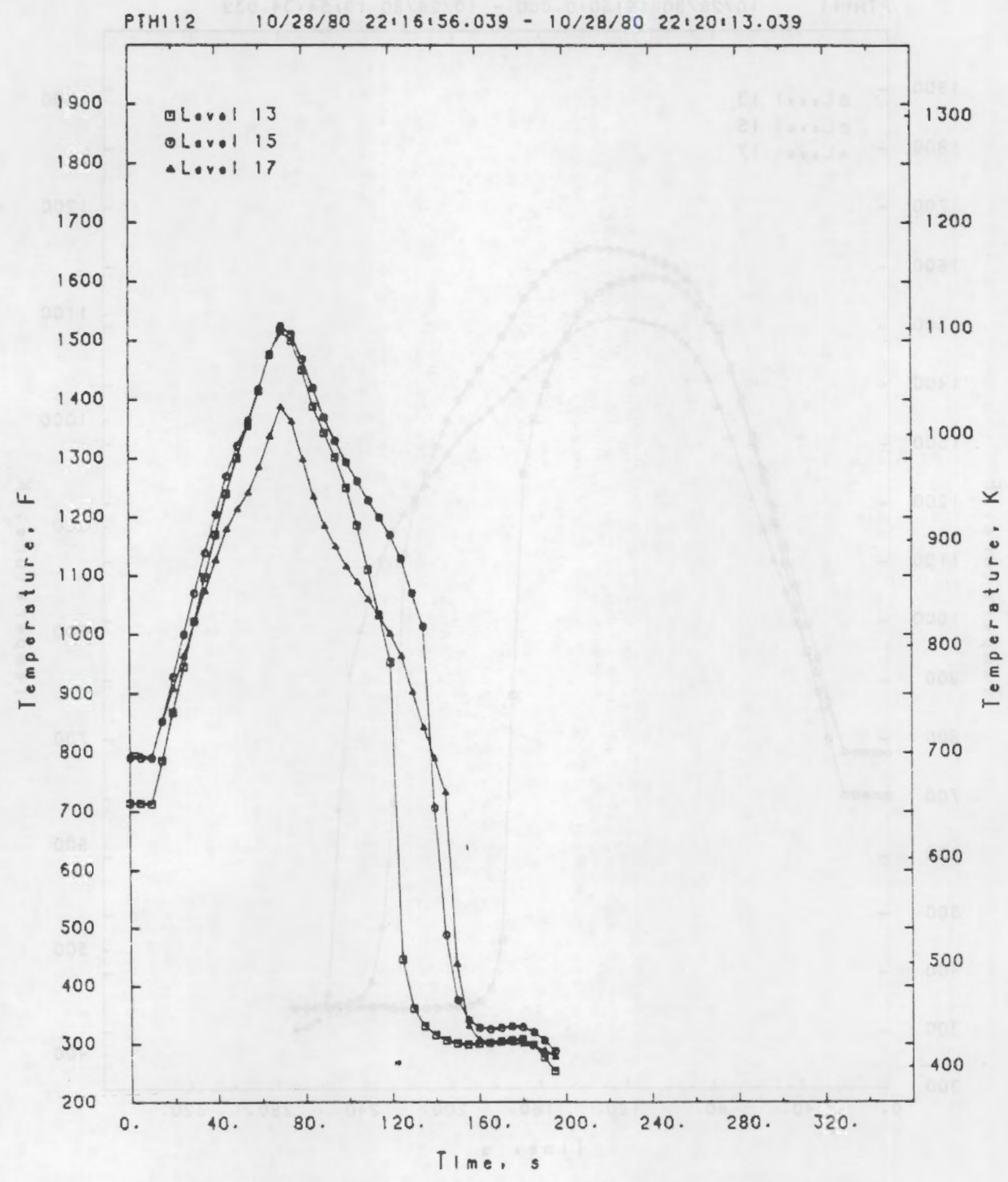

FIGURE 1.2.3.12 AVERAGE GUARO FUEL RDO CLADDING TEMPERATURE HISTORIES (INTERIOR IC'S) OURING TRANSIENT PTHI12 


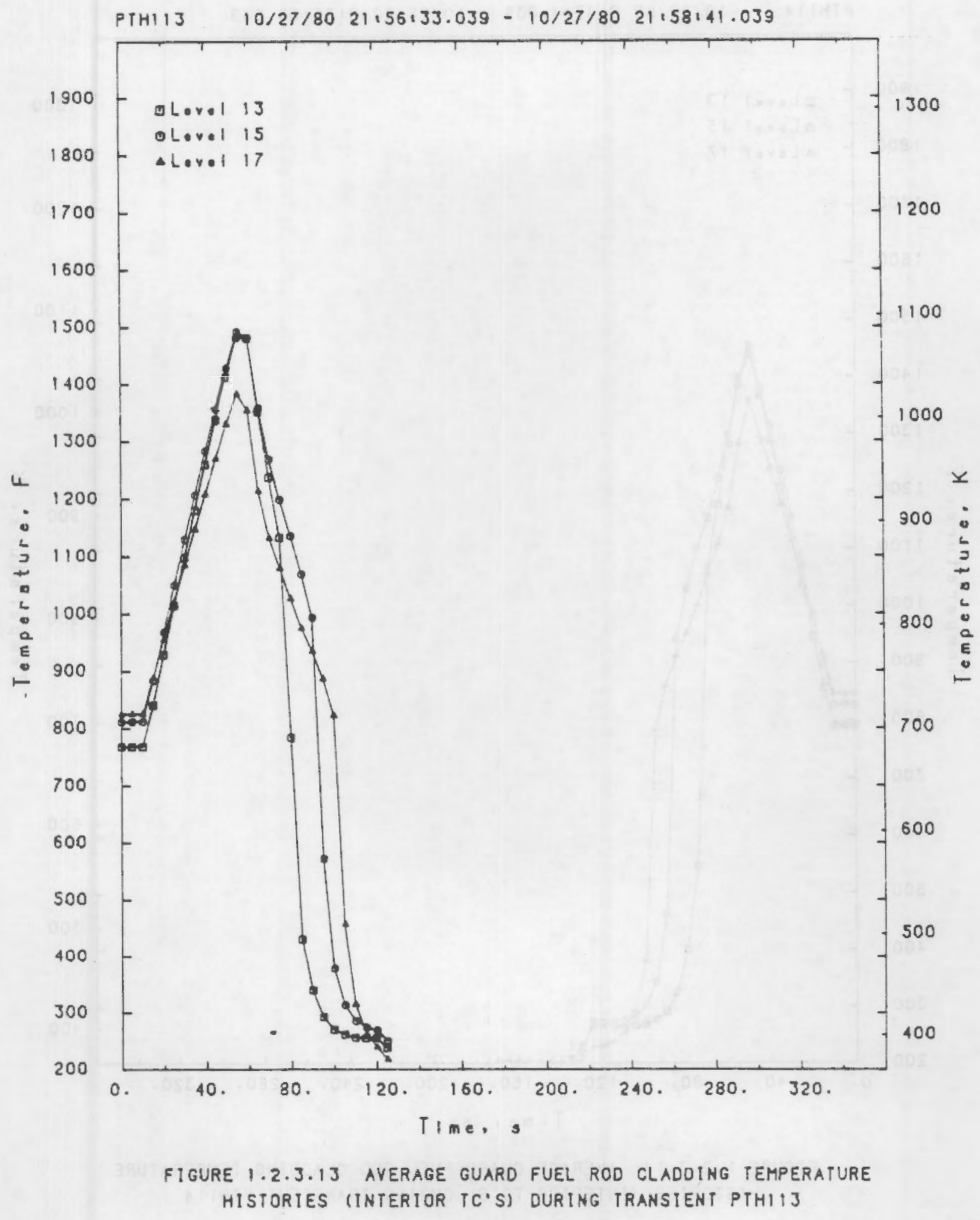

A. 75 


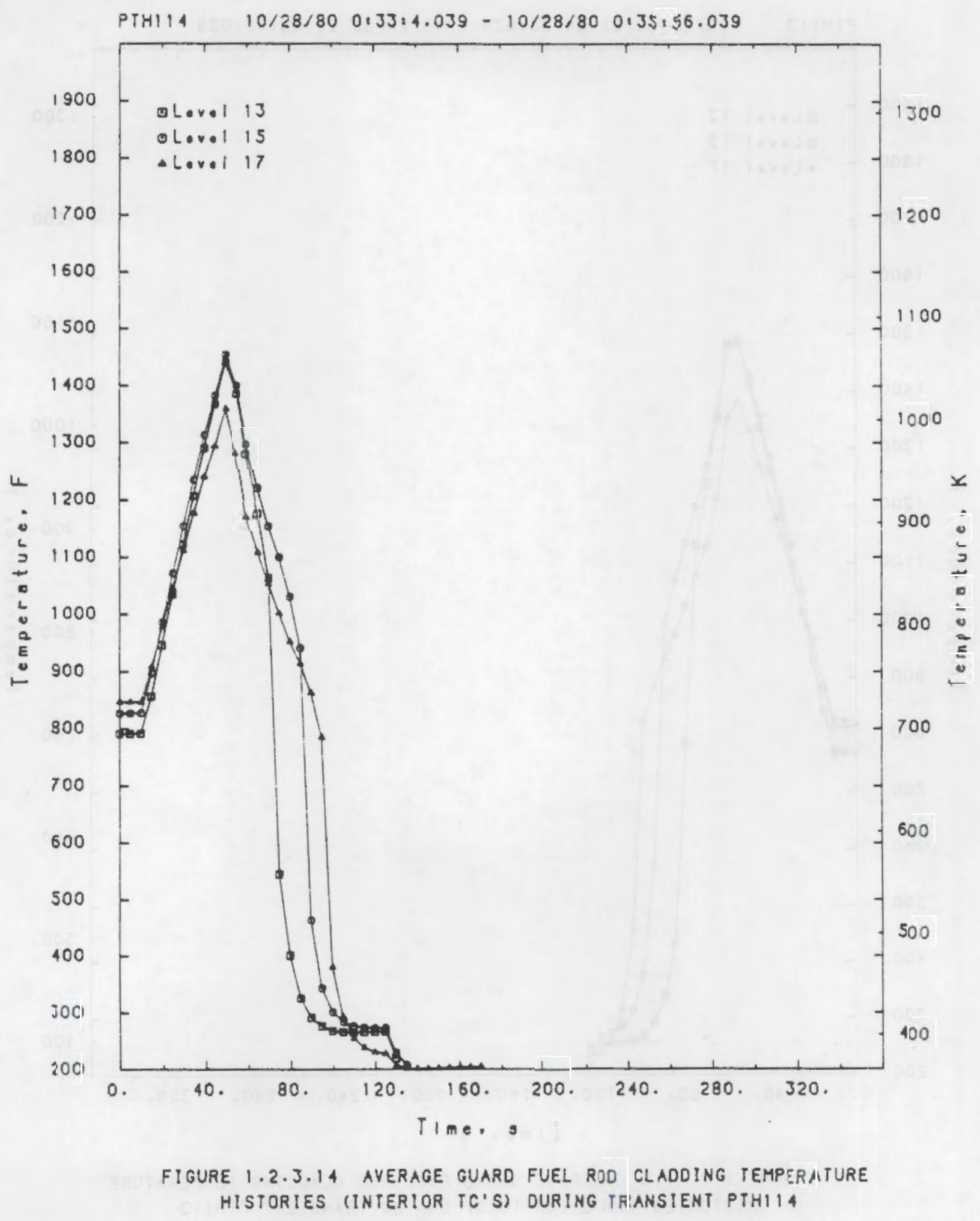

A. 76 


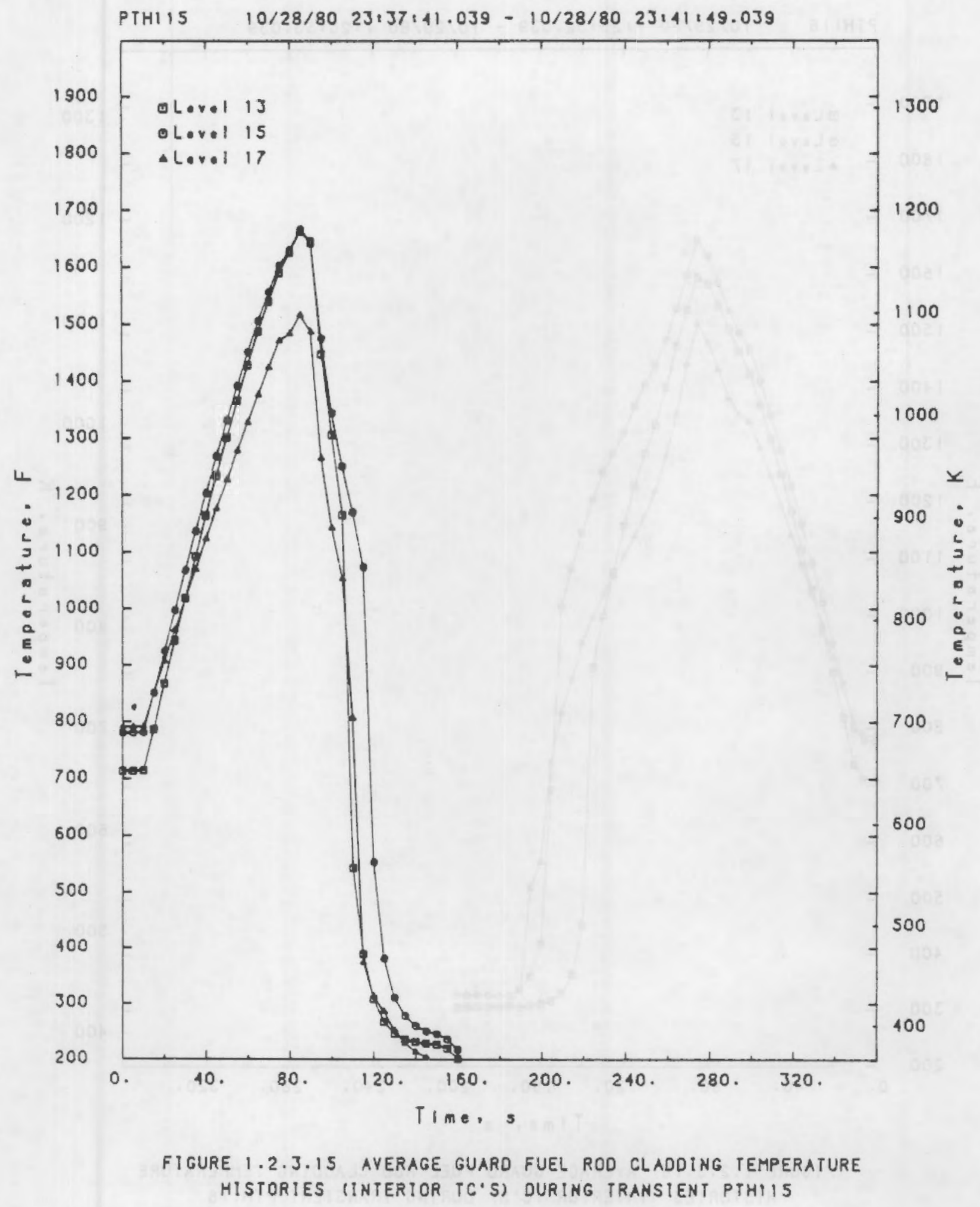

A. 77 


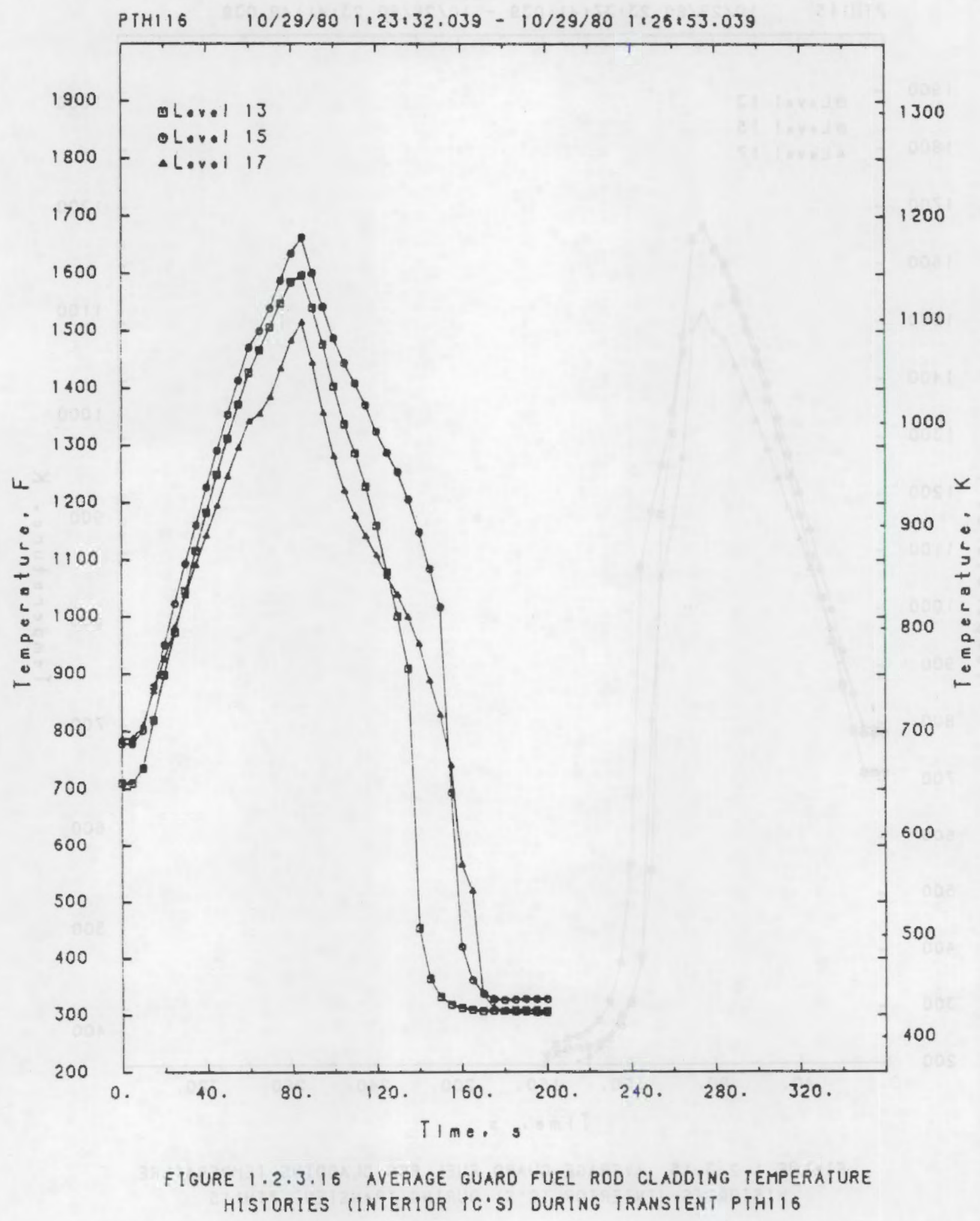

A. 78 


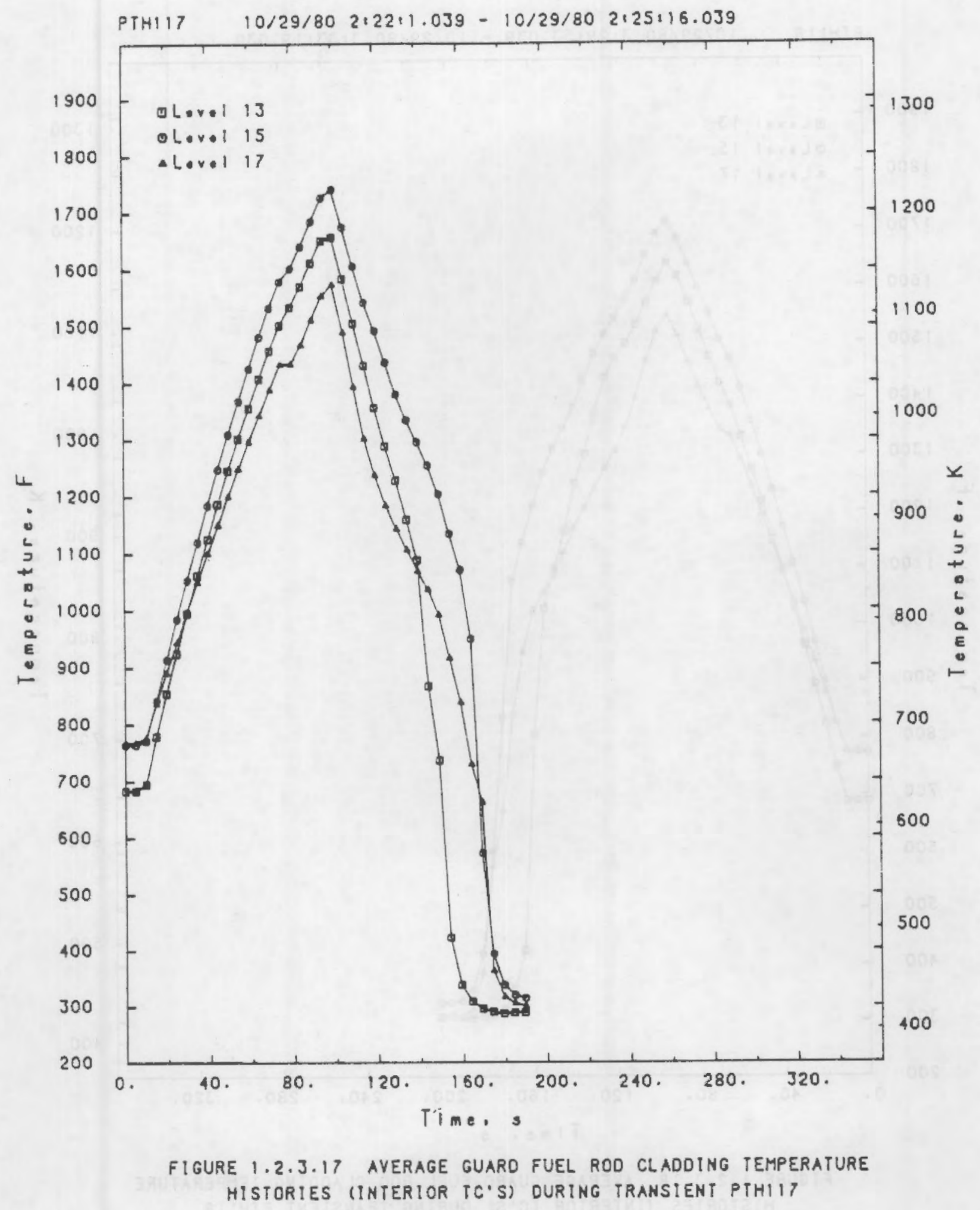

A. 79 


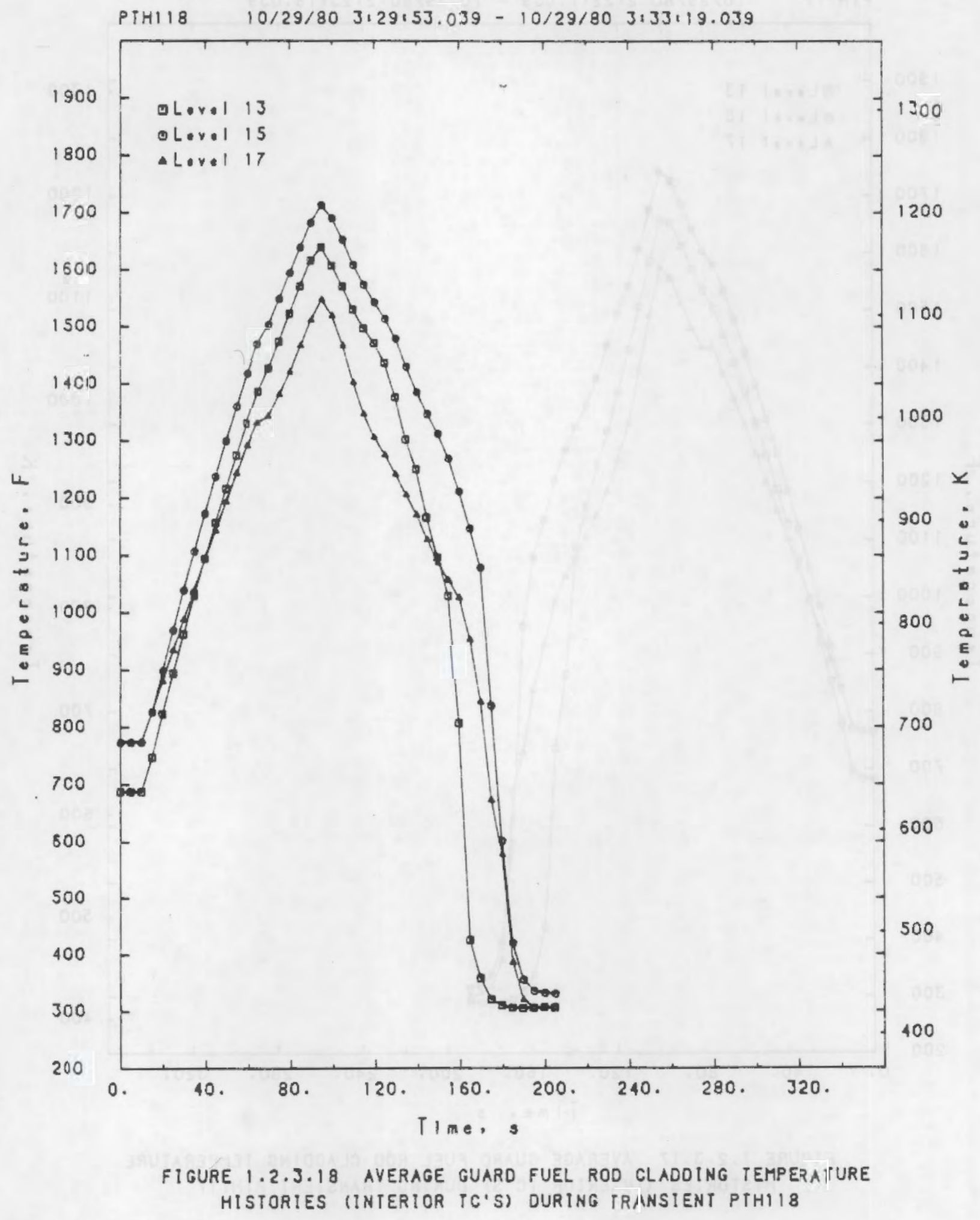

A. 80 


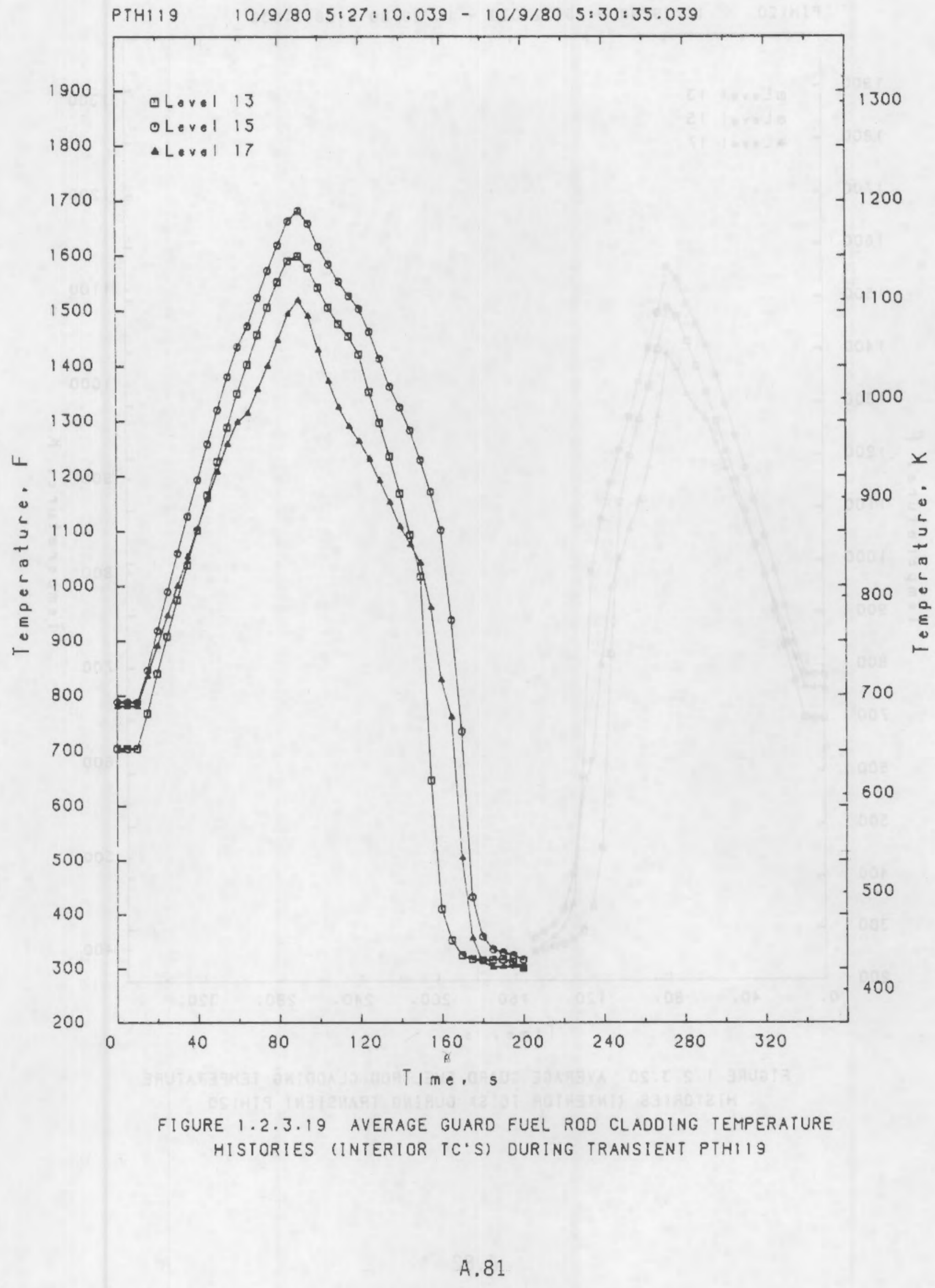




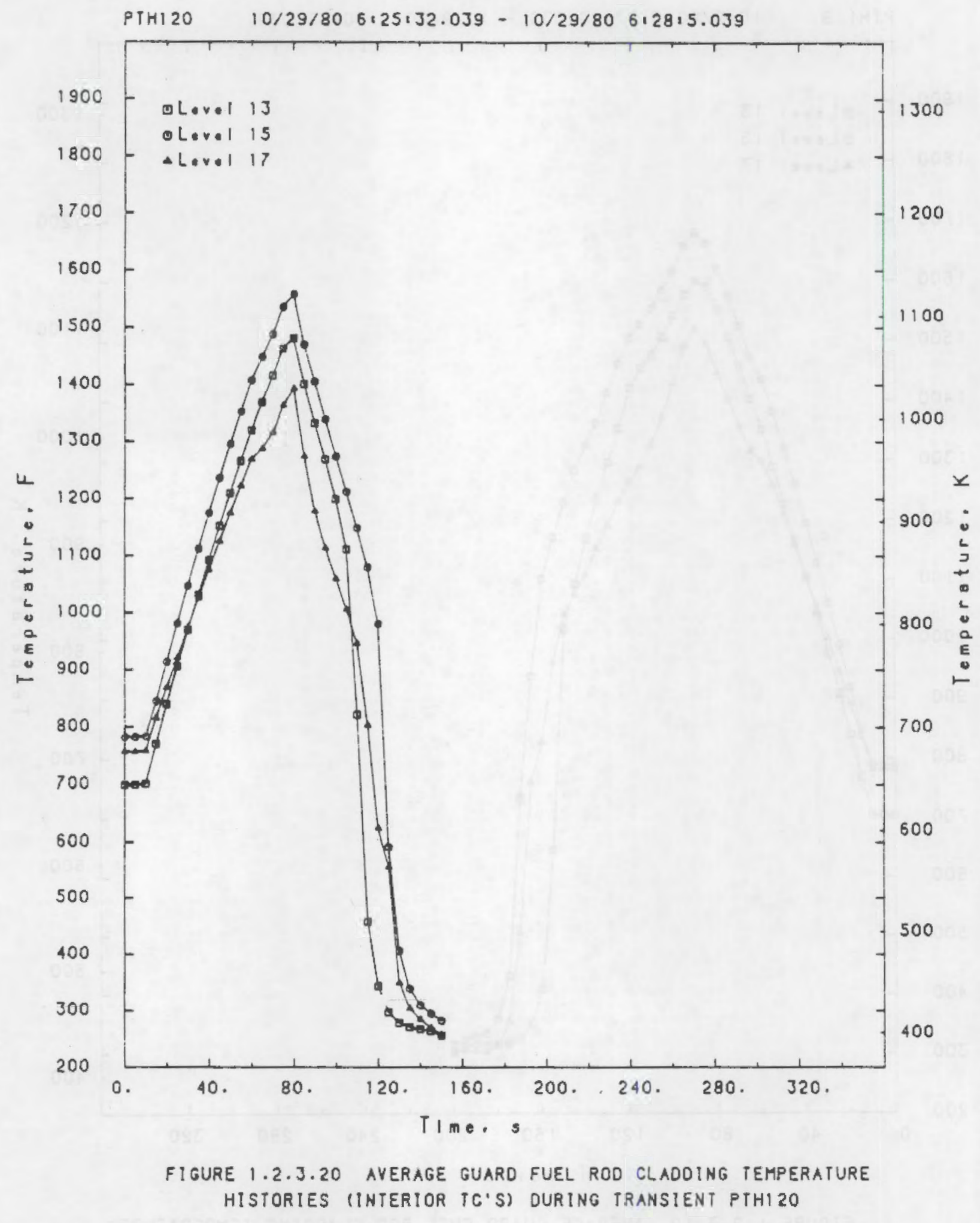




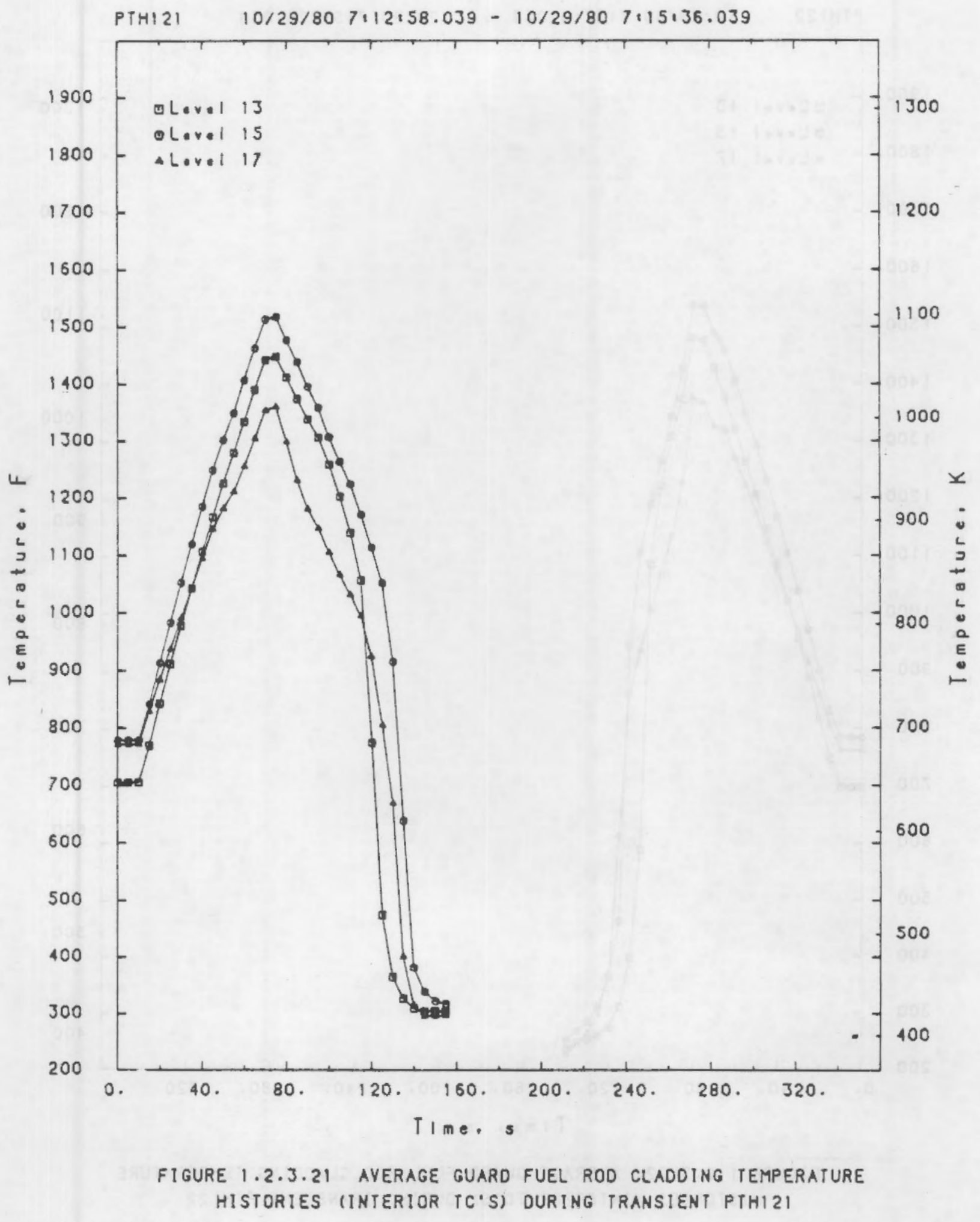




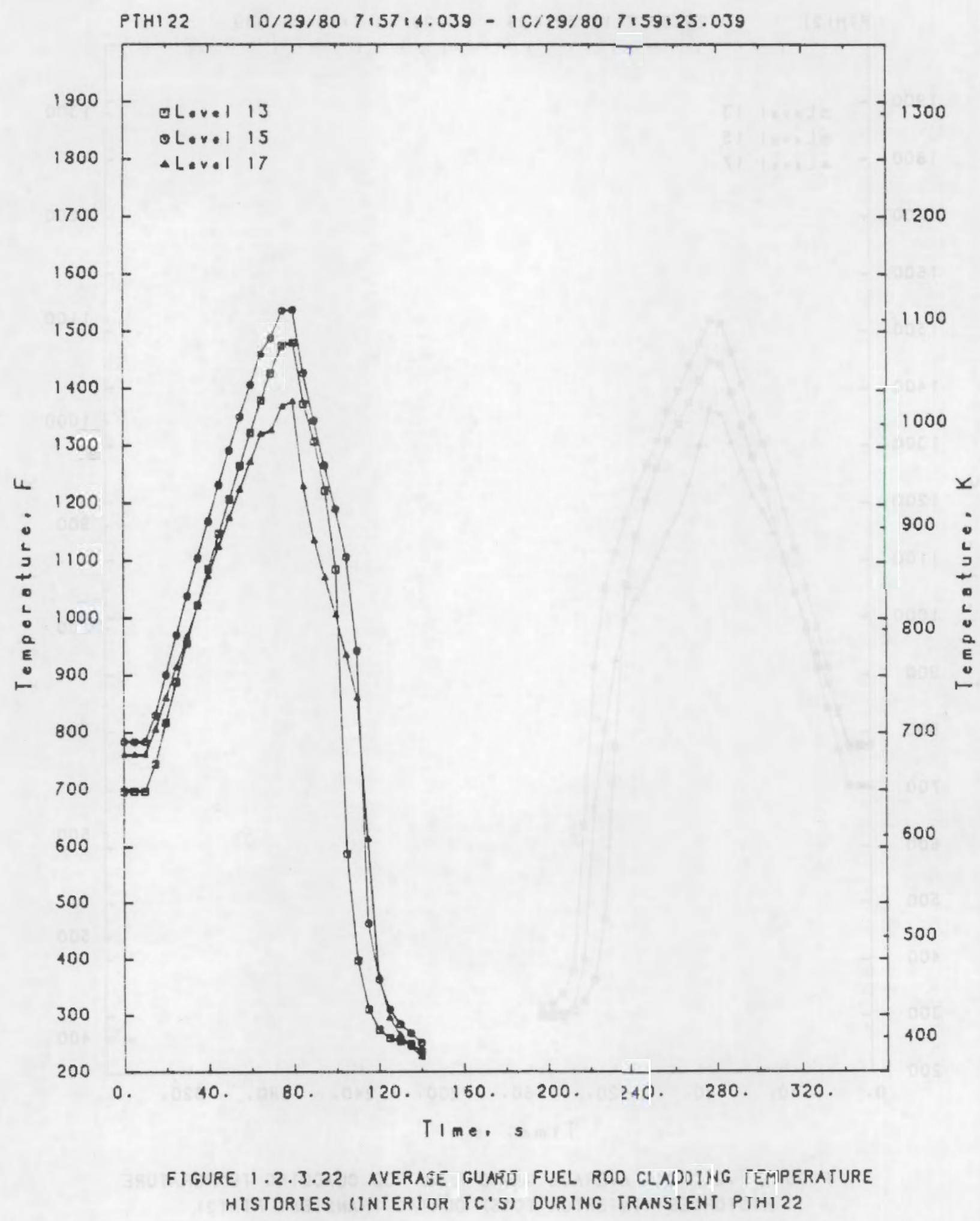




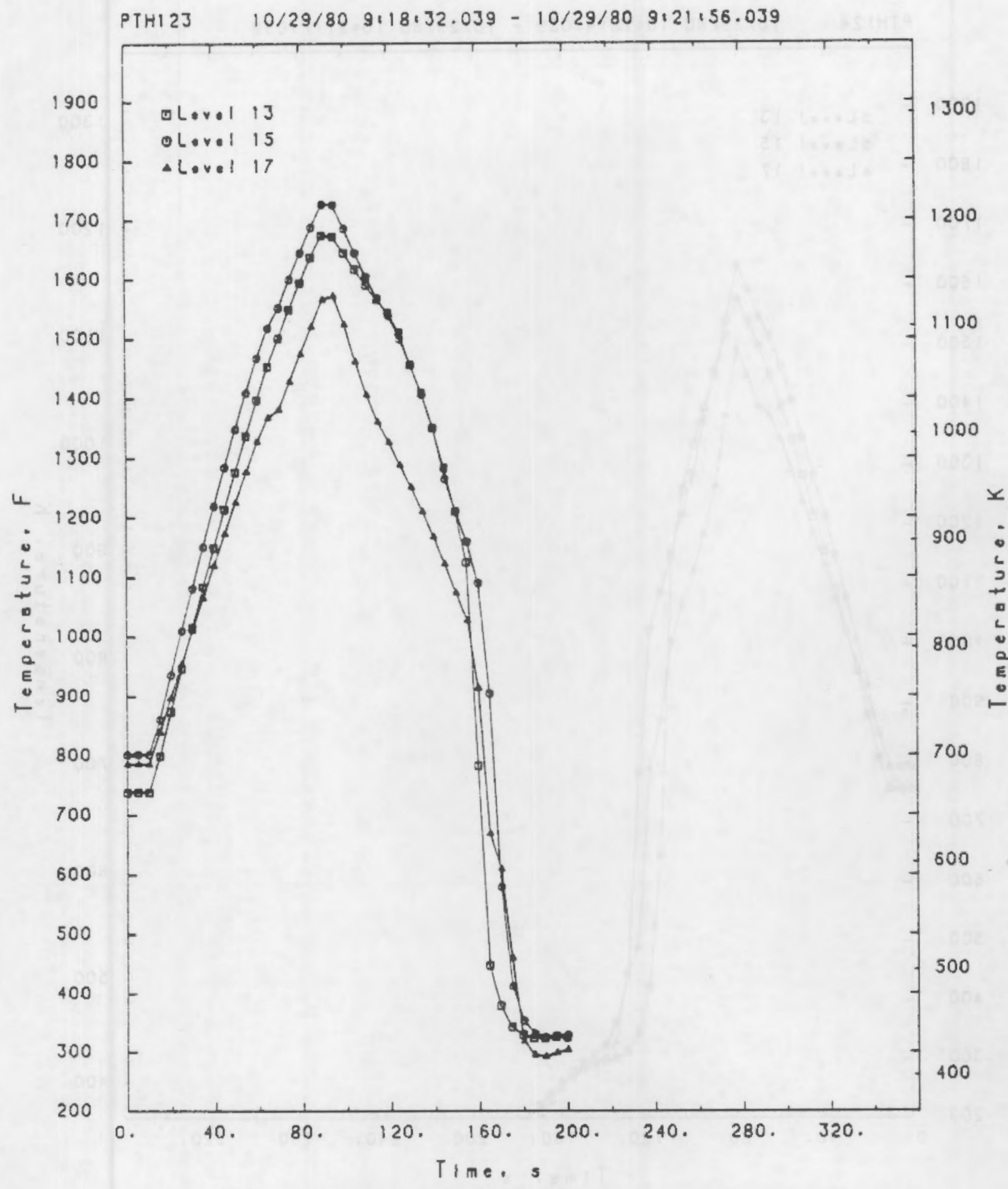

FIGURE 1.2.3.23 AVERAGE GUARD FUEL ROD CLADDING TEMPERATURE HISTORIES (INTERIOR TC'S) DURING TRANSIENT PIHI2J 


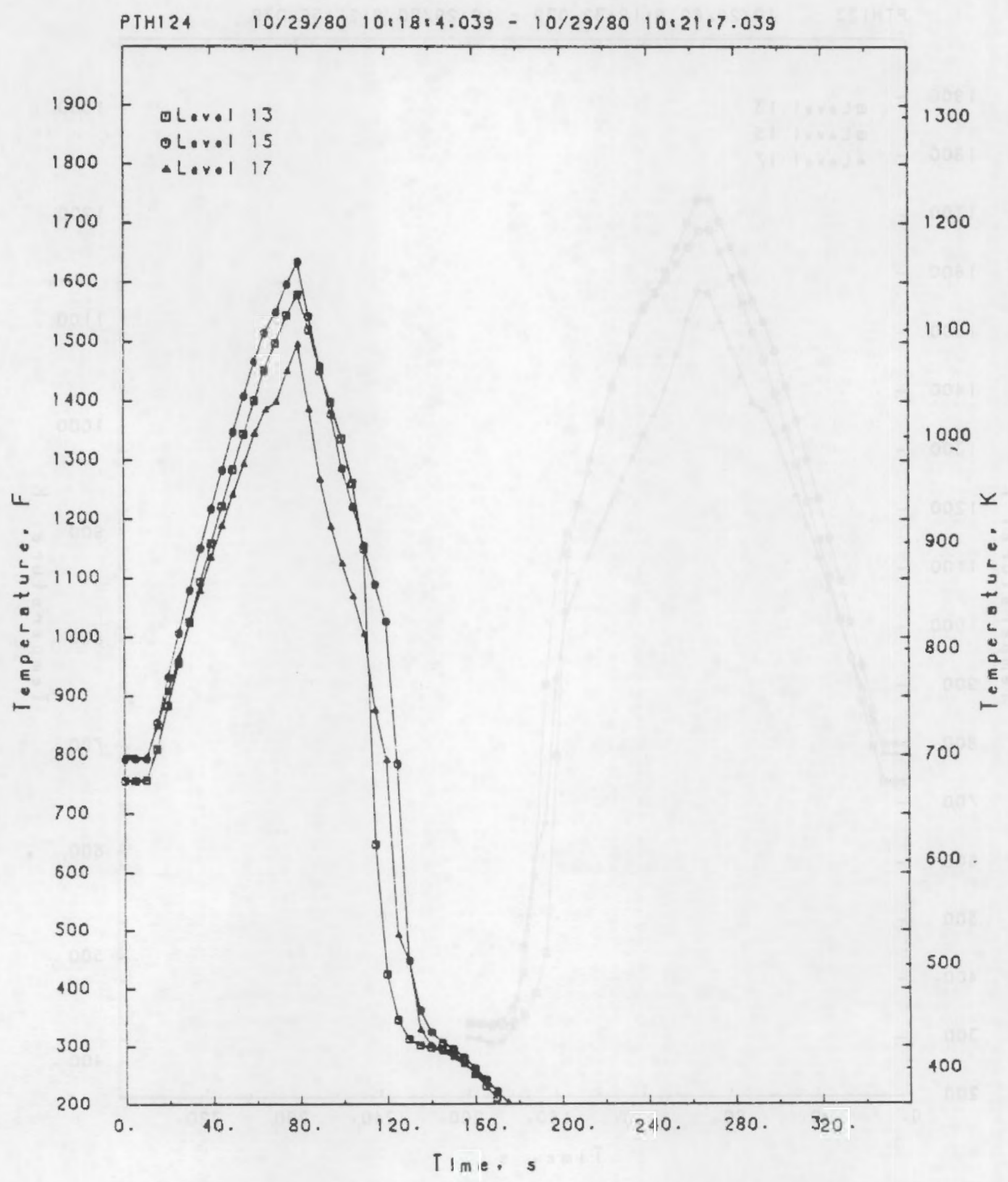

FIGURE 1.2.3.24 AVERAGE GUARO FUEL ROD GLADDING TEMPERATURE HISTORIES (INTERIOR TC'S) OURING TRANSIENT PTHI24 


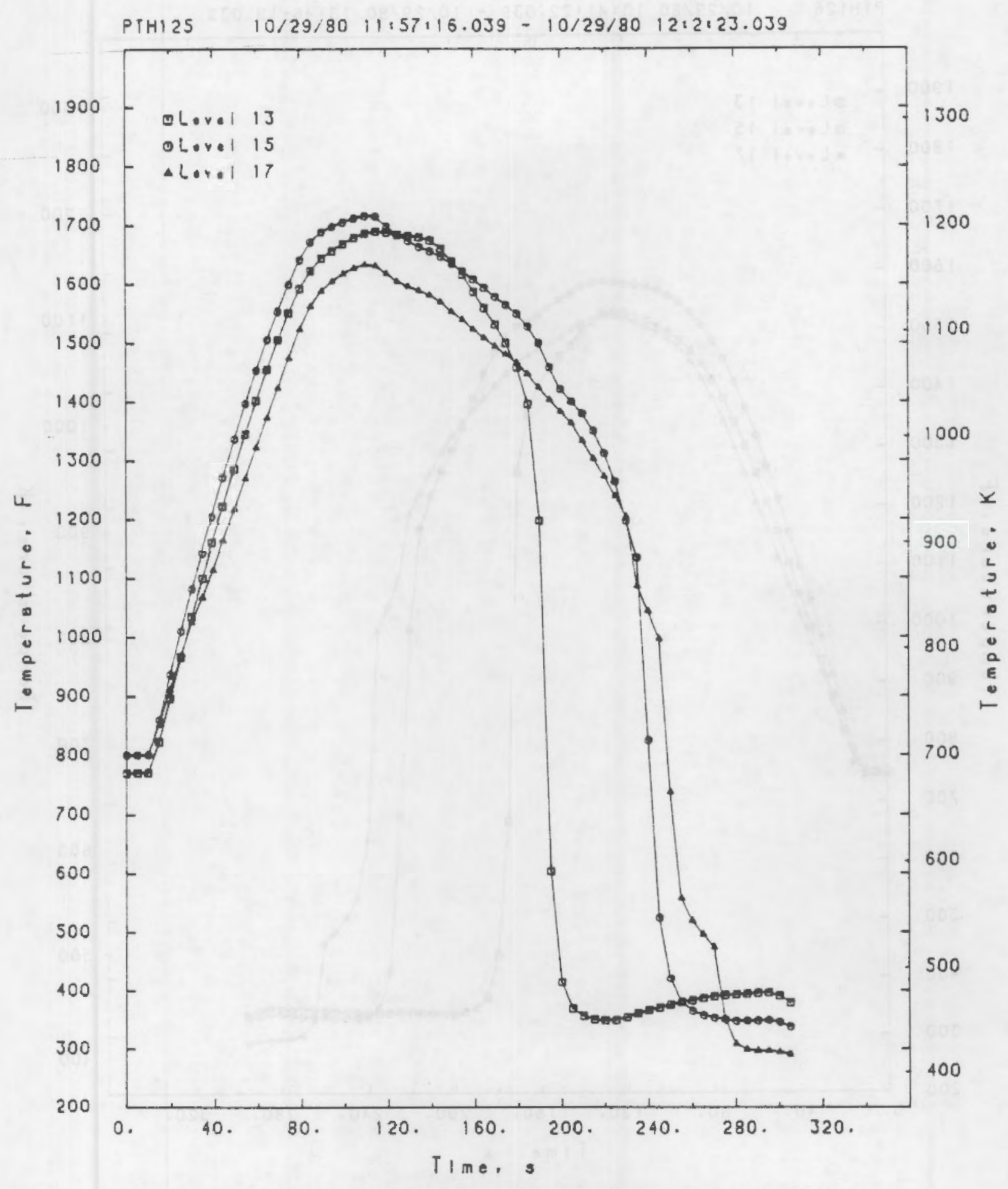

FIGURE 1.2.3.25 AVERAGE GUARD FUEL ROD CLADOING TEMPERATURE HISTORIES (INTERIOR TC'S) DURING TRANSIENT PTHI 25 


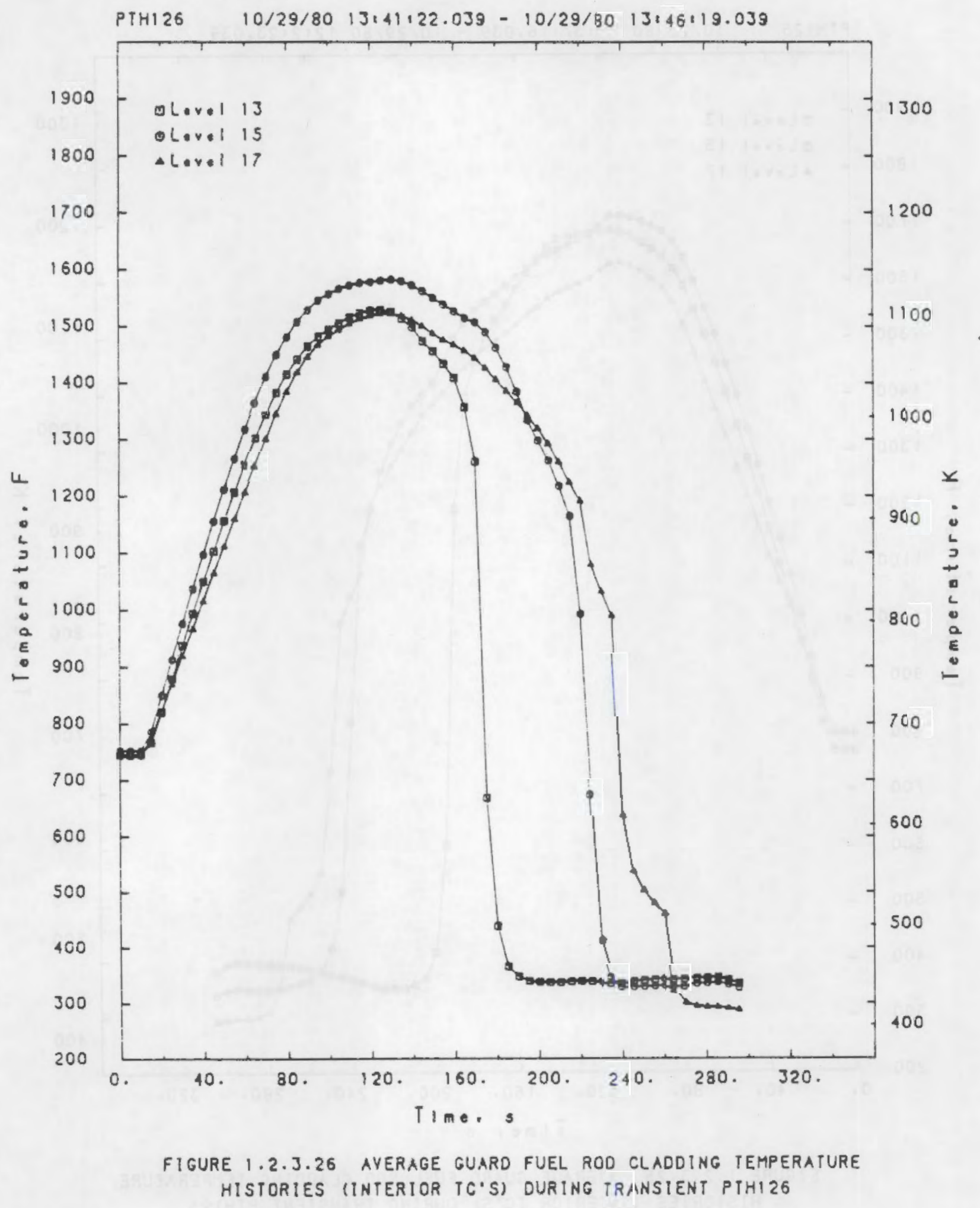




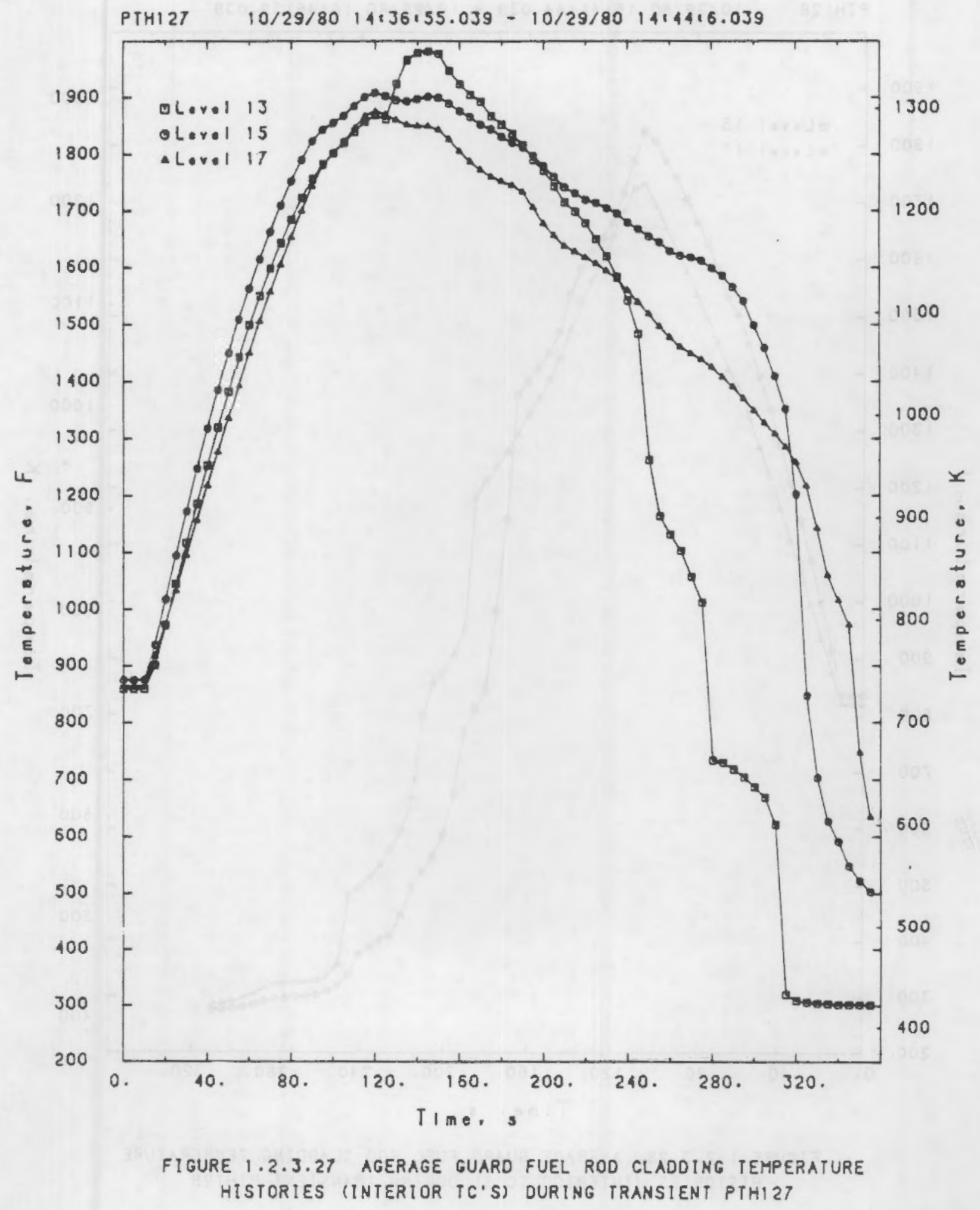




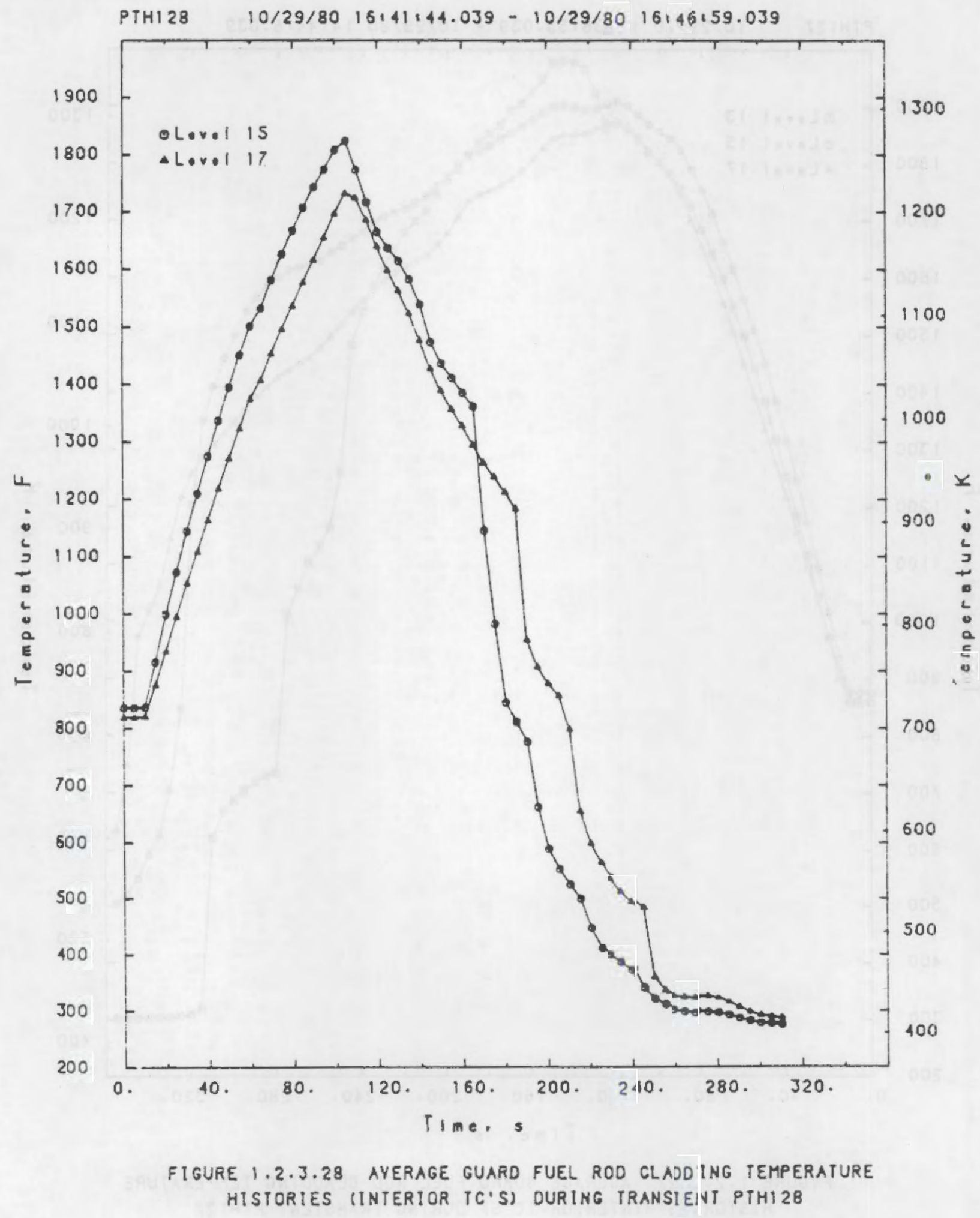




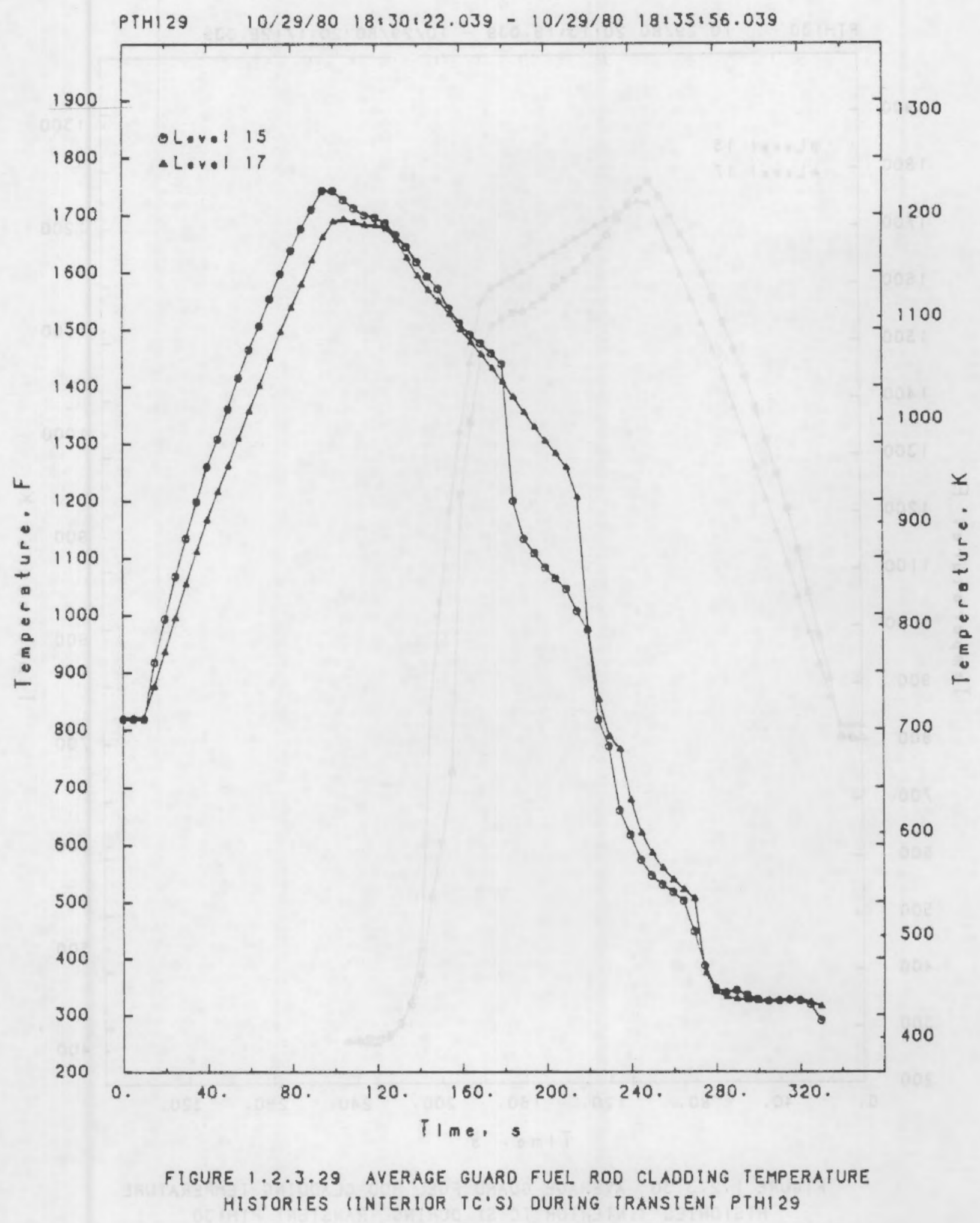




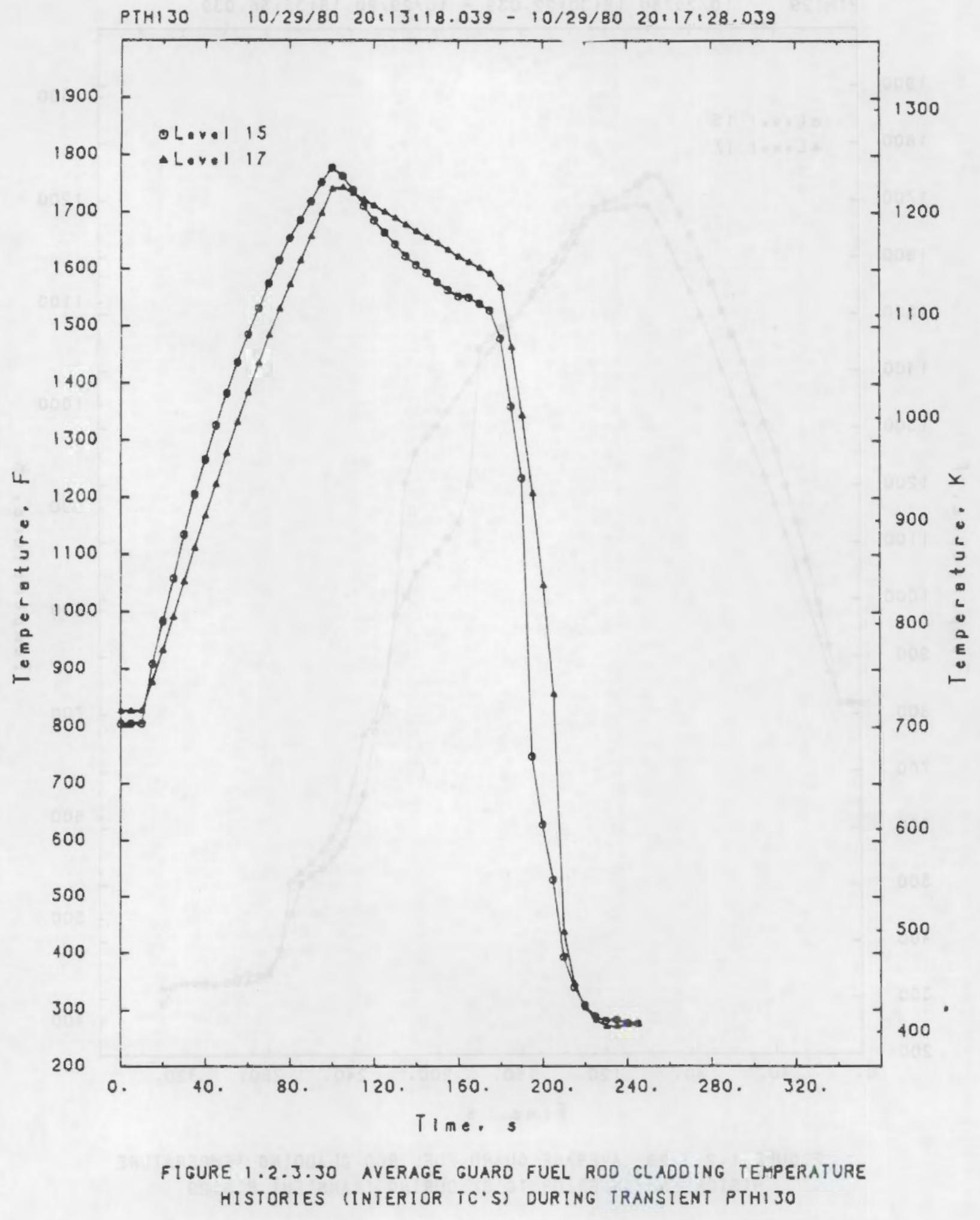

A. 92 


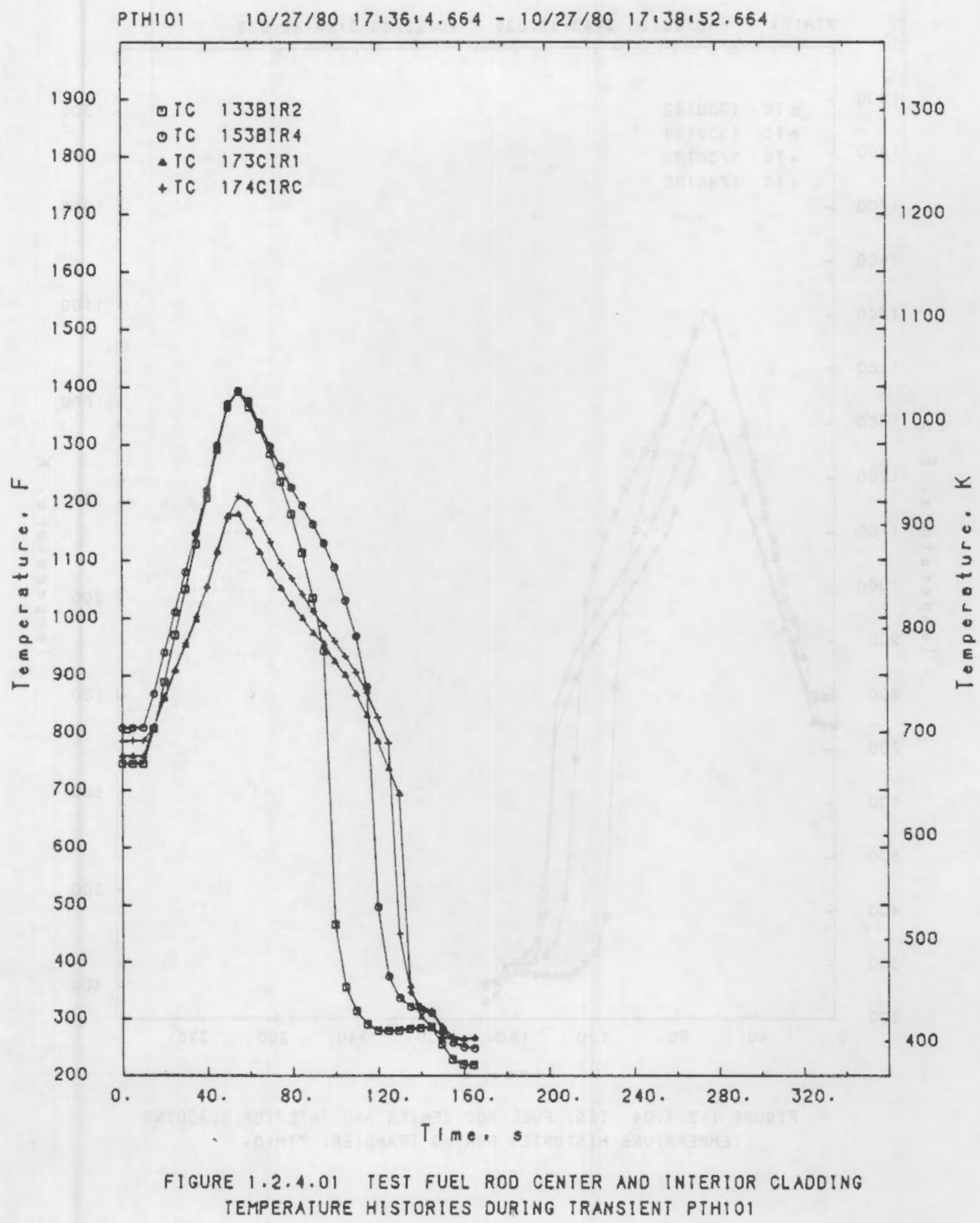

A. 93 


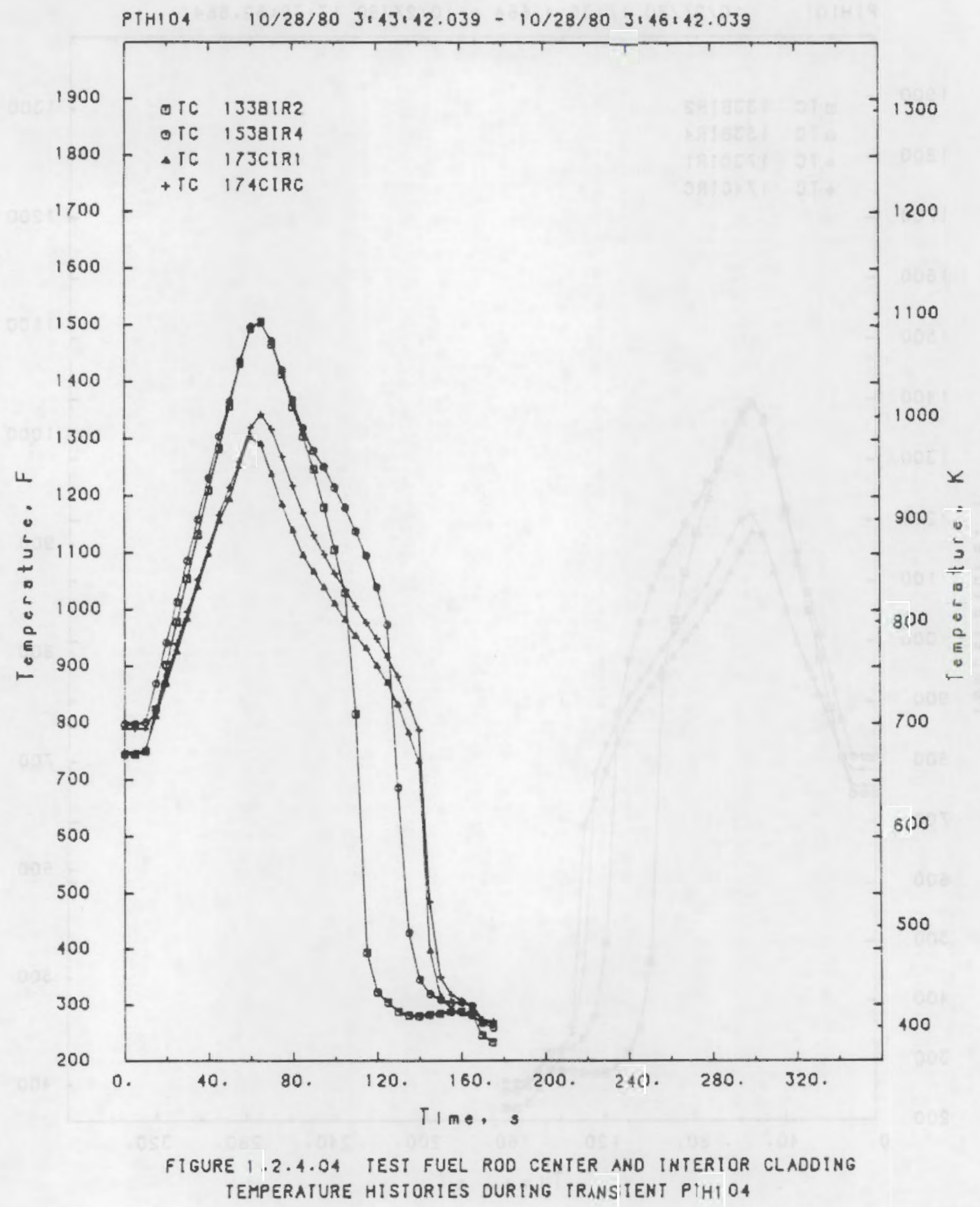




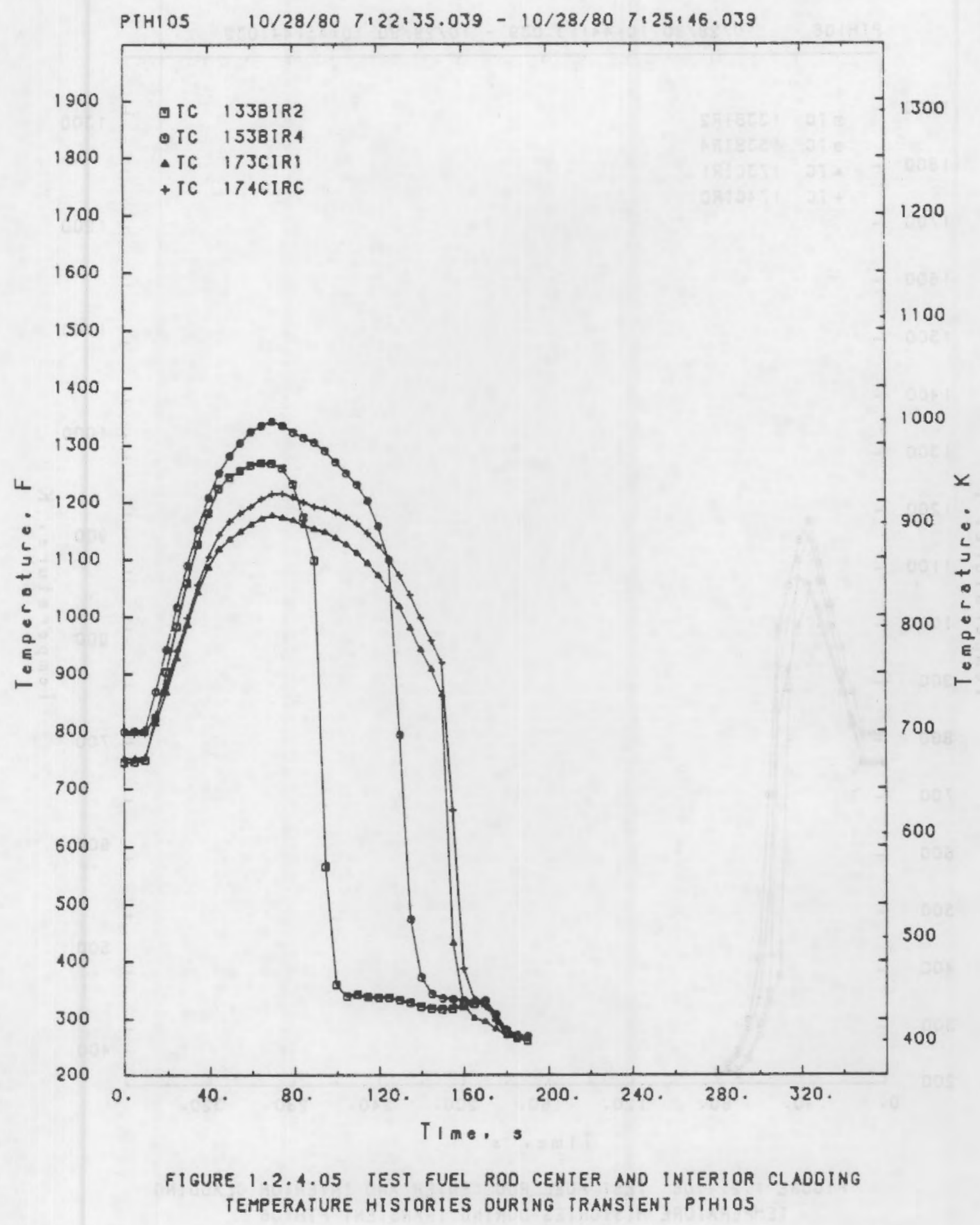

A. 95 


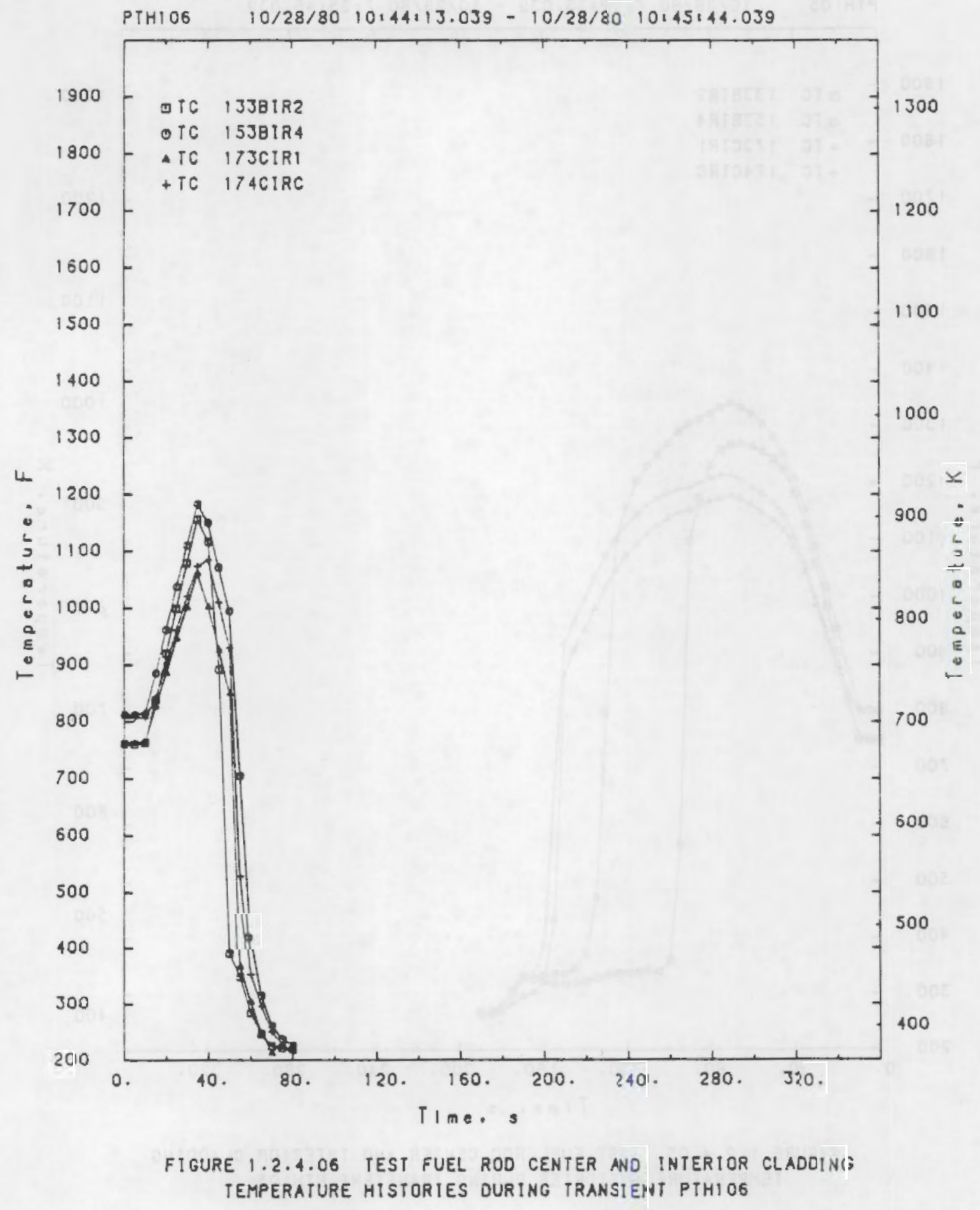

A. 96 


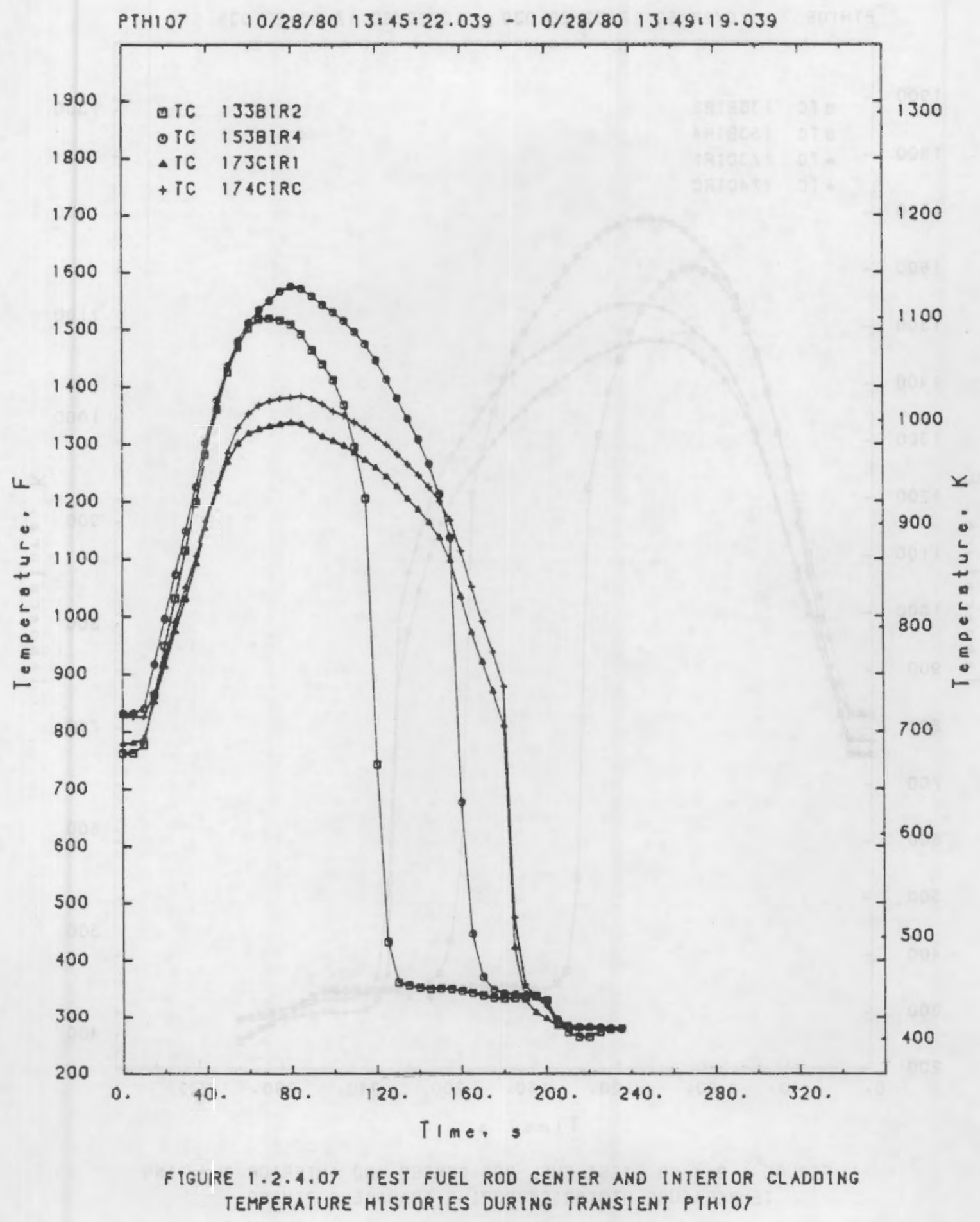




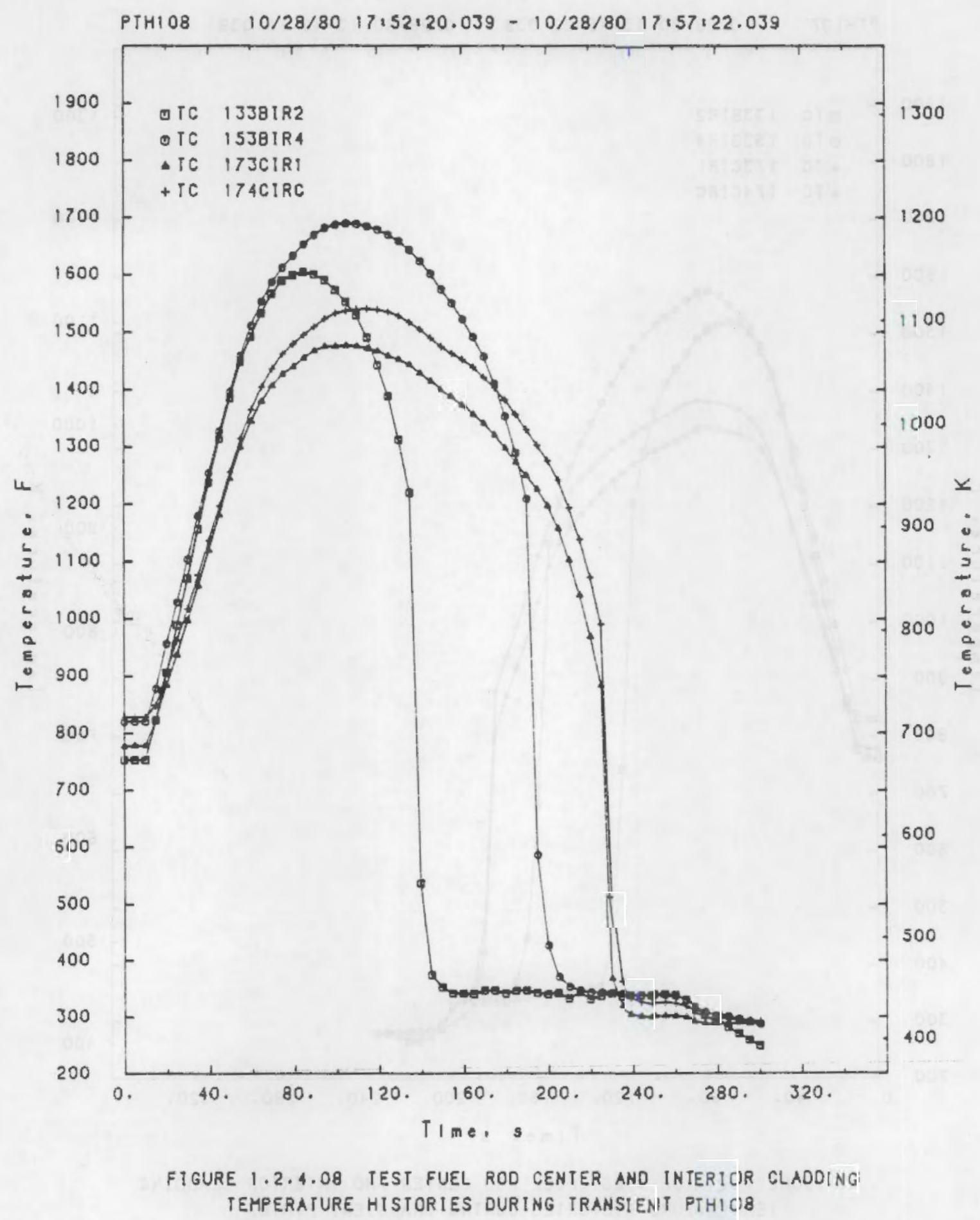




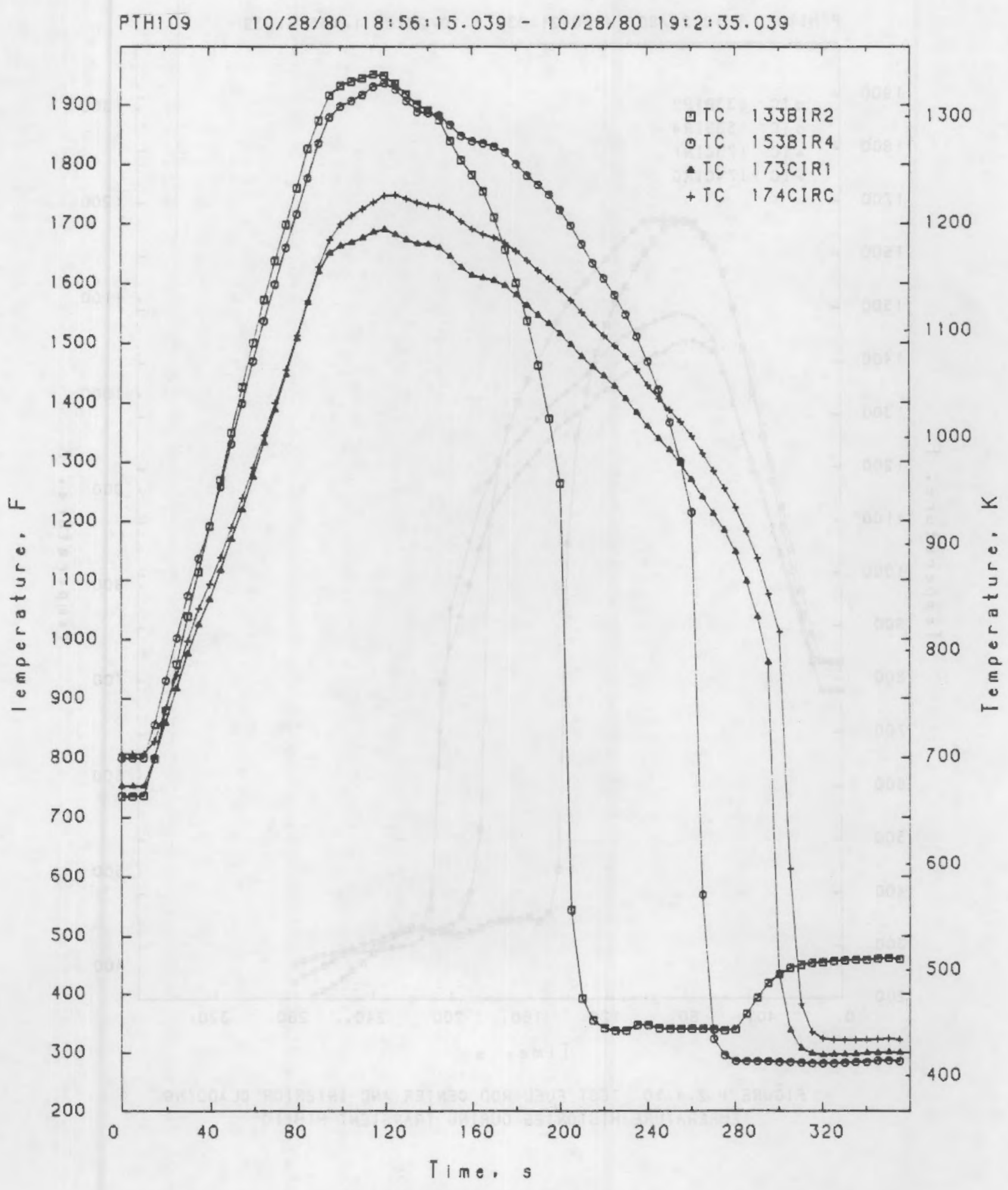

FIGURE 1.2 .4 .09 TEST FUEL ROD CENTER AND INTERIOR CLADDING TEMPERATURE HISTORIES DURING TRANSIENT PTHIOQ 


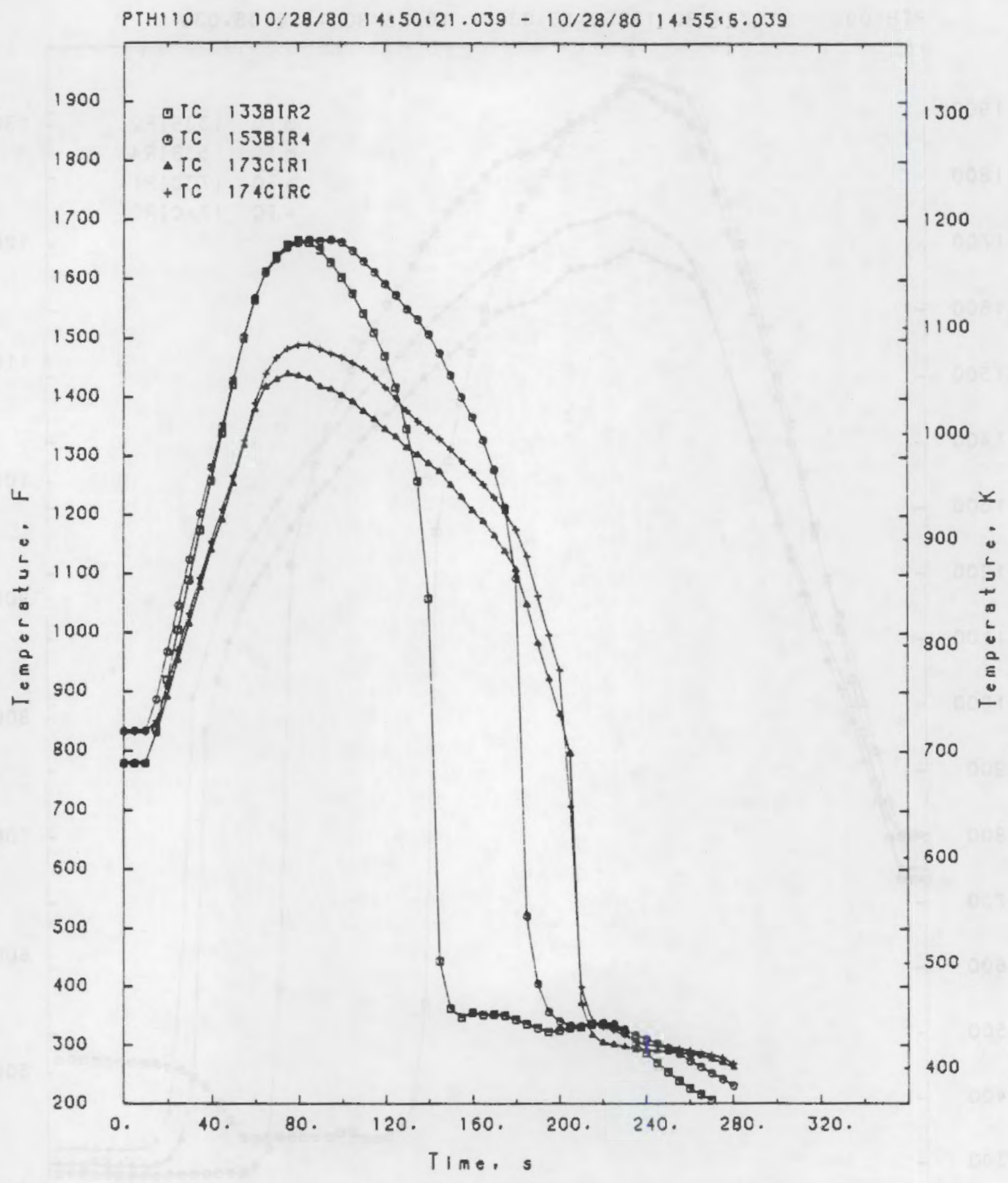

FIGURE 1.2 .4 .10 TEST FUE! ROD CENTER AND INTERIOR CLADOING TEMPERATURE HISTORIES DURING TRANSIENT PTHIIO 


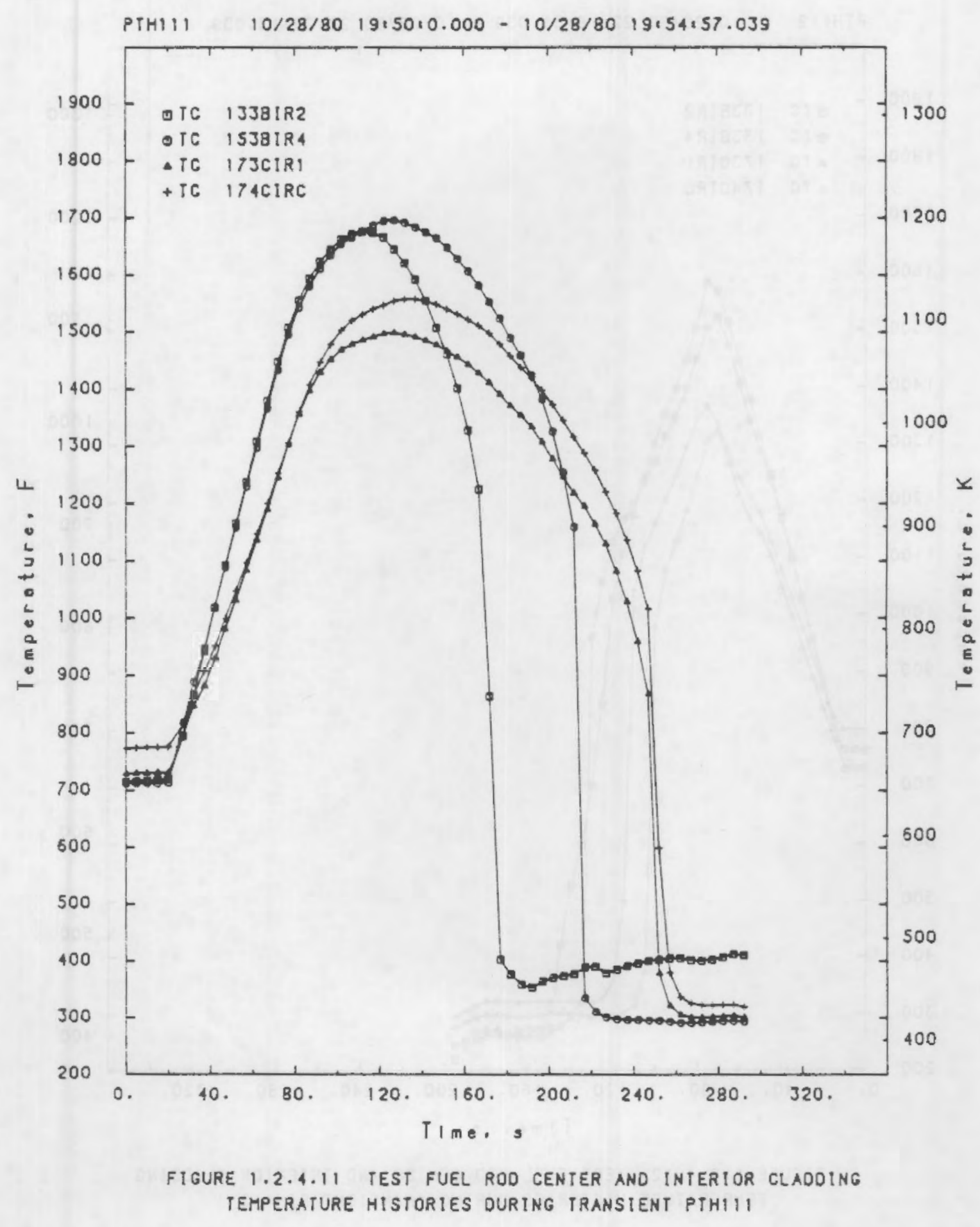

A. 101 


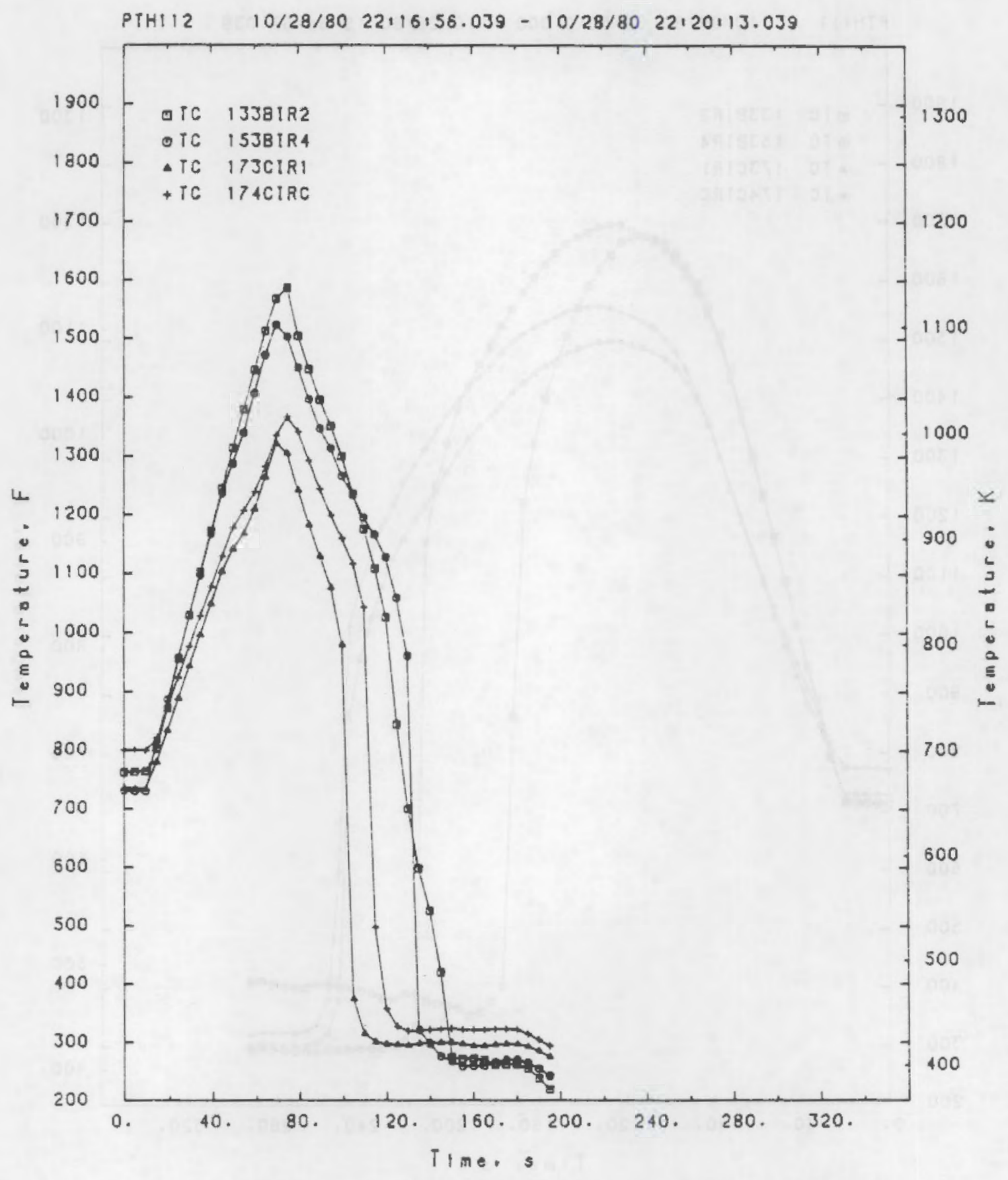

FIGURE 1.2 .4 .12 TEST FUEL ROD CENTER AND INTERIOR CLADDING TEMPERATURE HISTORIES DURING TRANSIENT PIHI12 


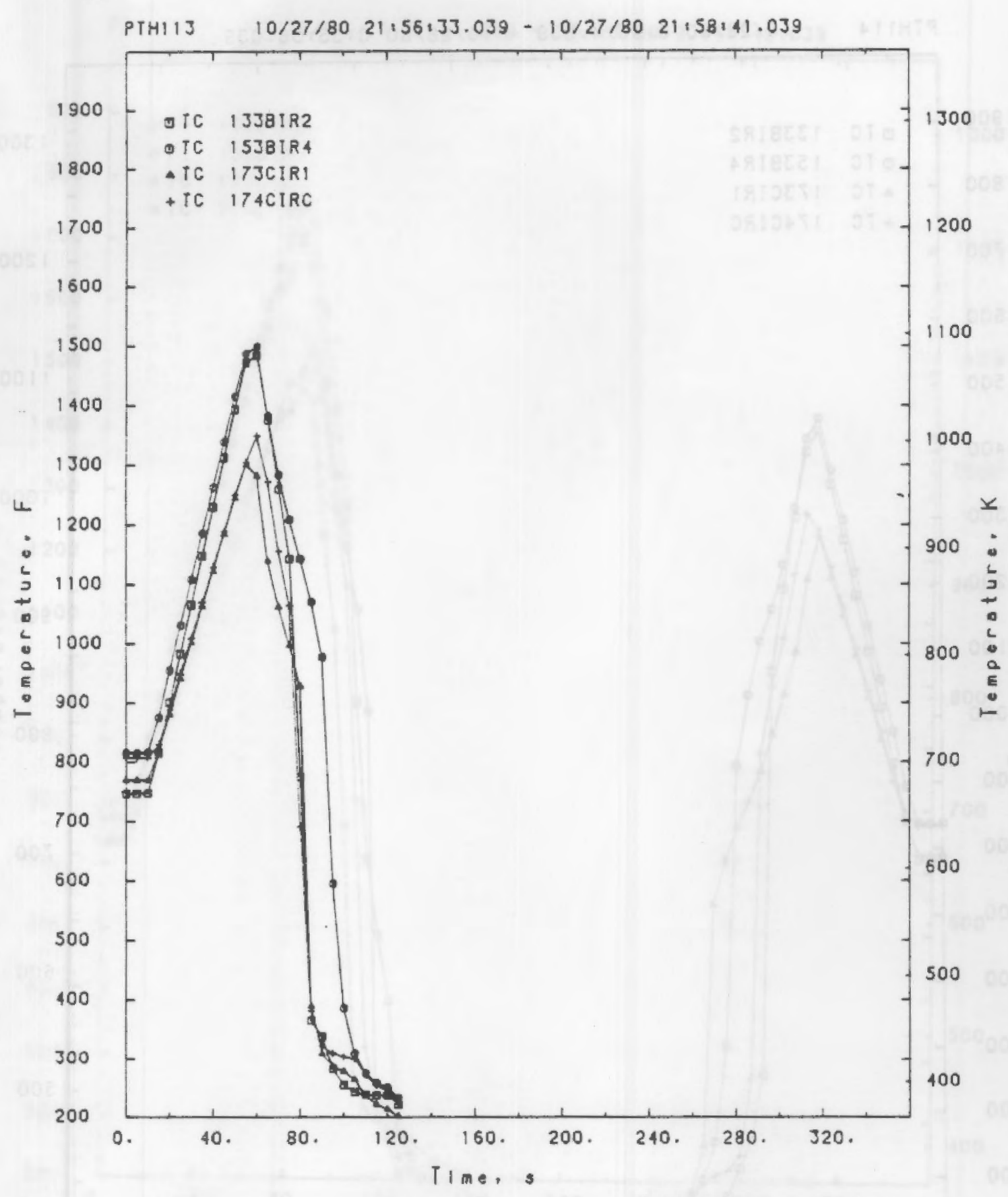

FIGURE 1.2.4.1J TEST FUEL ROD CENTER ANO INTERIOR CLADDING TEMPERATURE HISTORIES DURING TRANSIENT PTHIIJ 


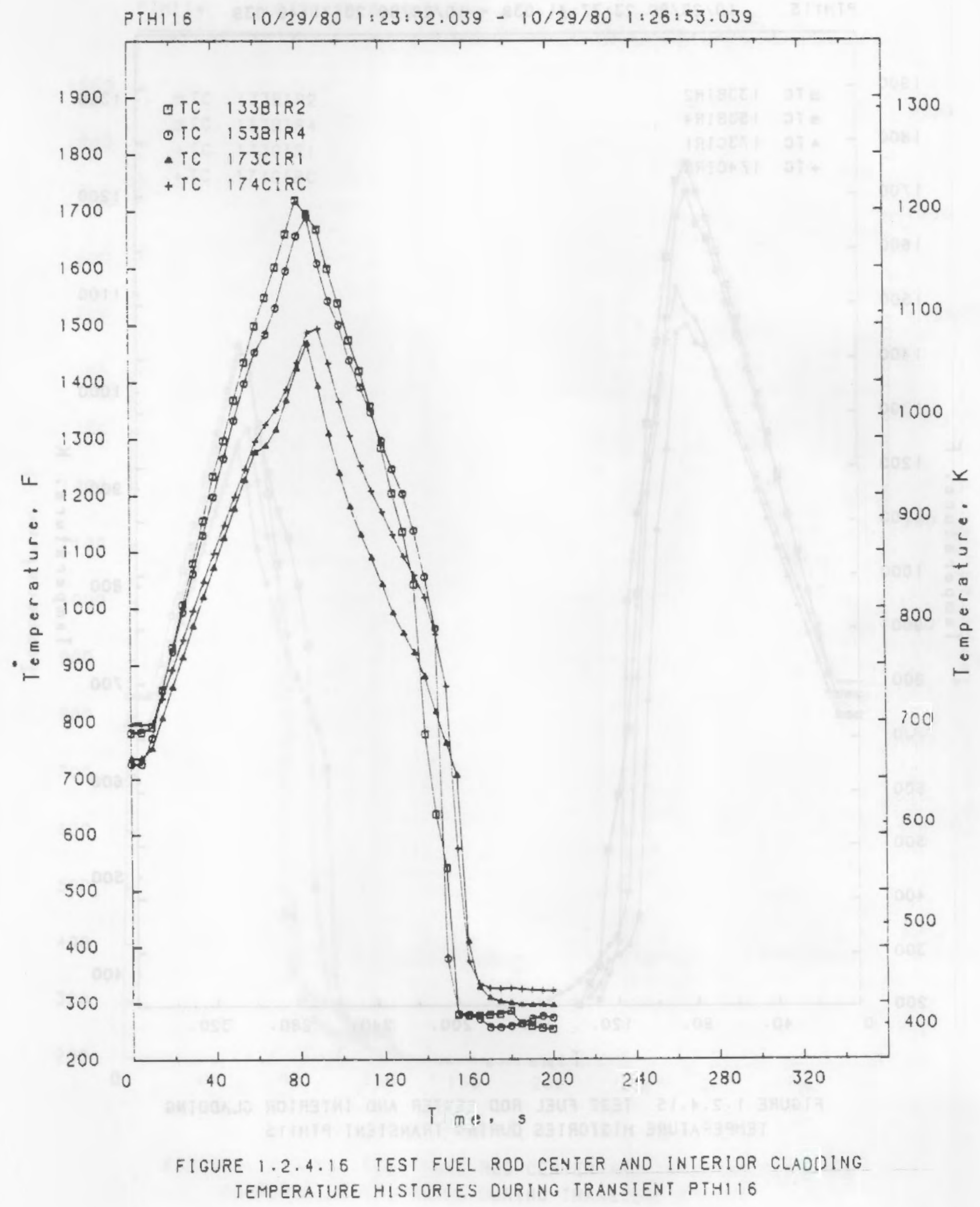

A. 106 


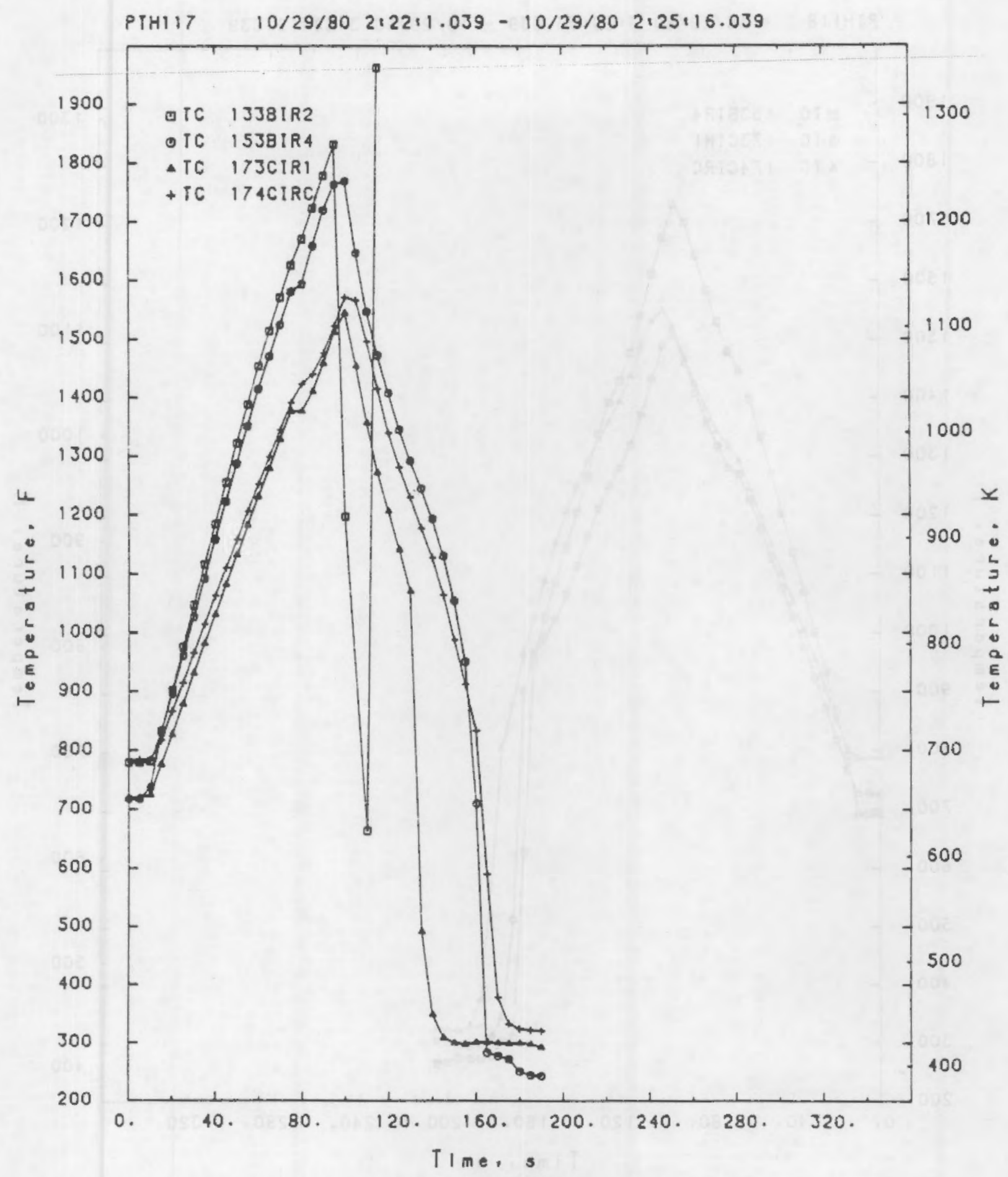

FIGURE 1.2.4.17 TEST FUEL ROD CENTER AND INIERIOR CLADDING TEMPERATURE HISTORIES DURING IRANSIENT PIHII7 


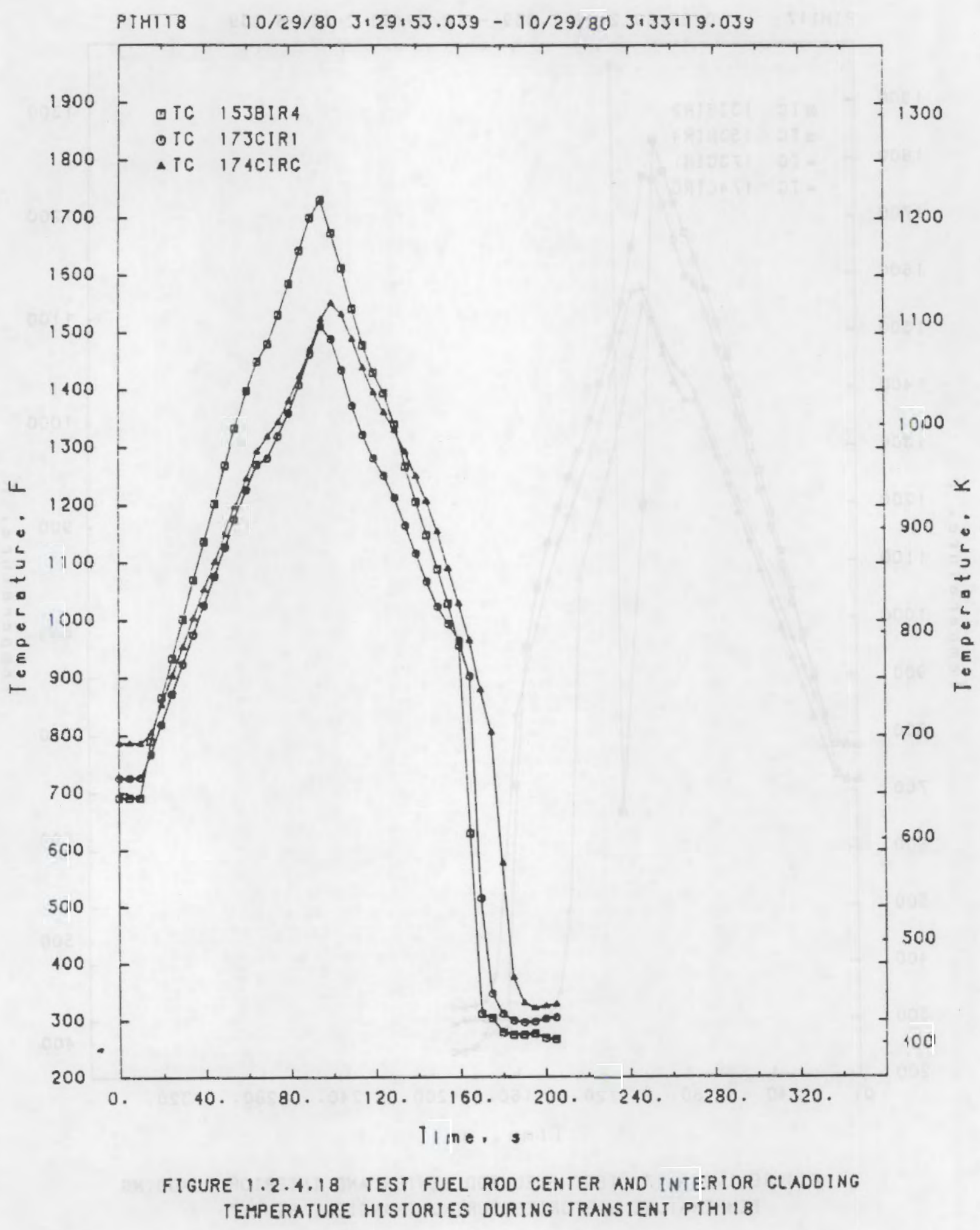

A. 108 


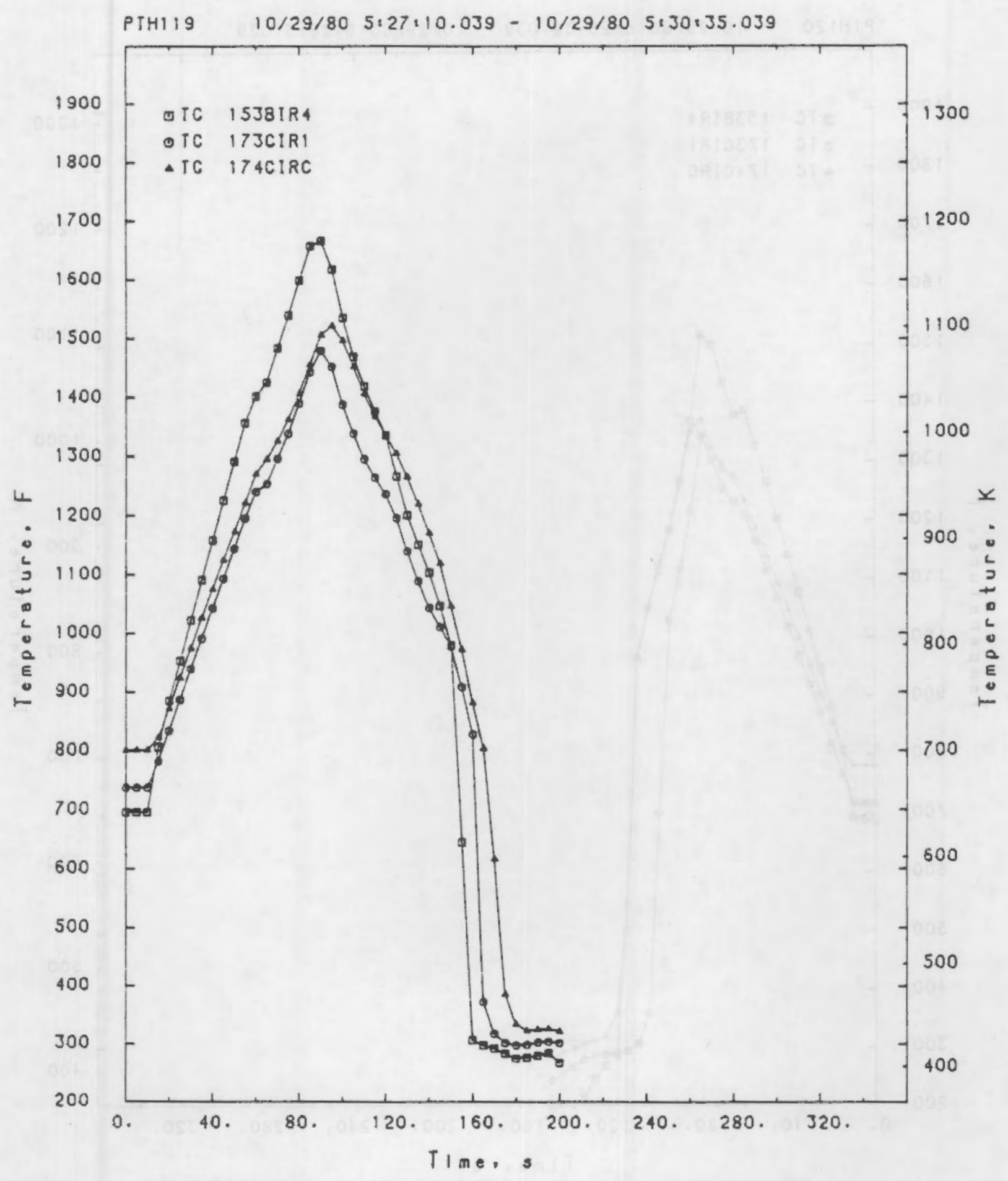

FIGURE 1.2.4.19 TEST FUEL ROD CENTER AND INTERIOR CLADDING TEMPERATURE HISTORIES DURING TRANSIENT PTHIIG 


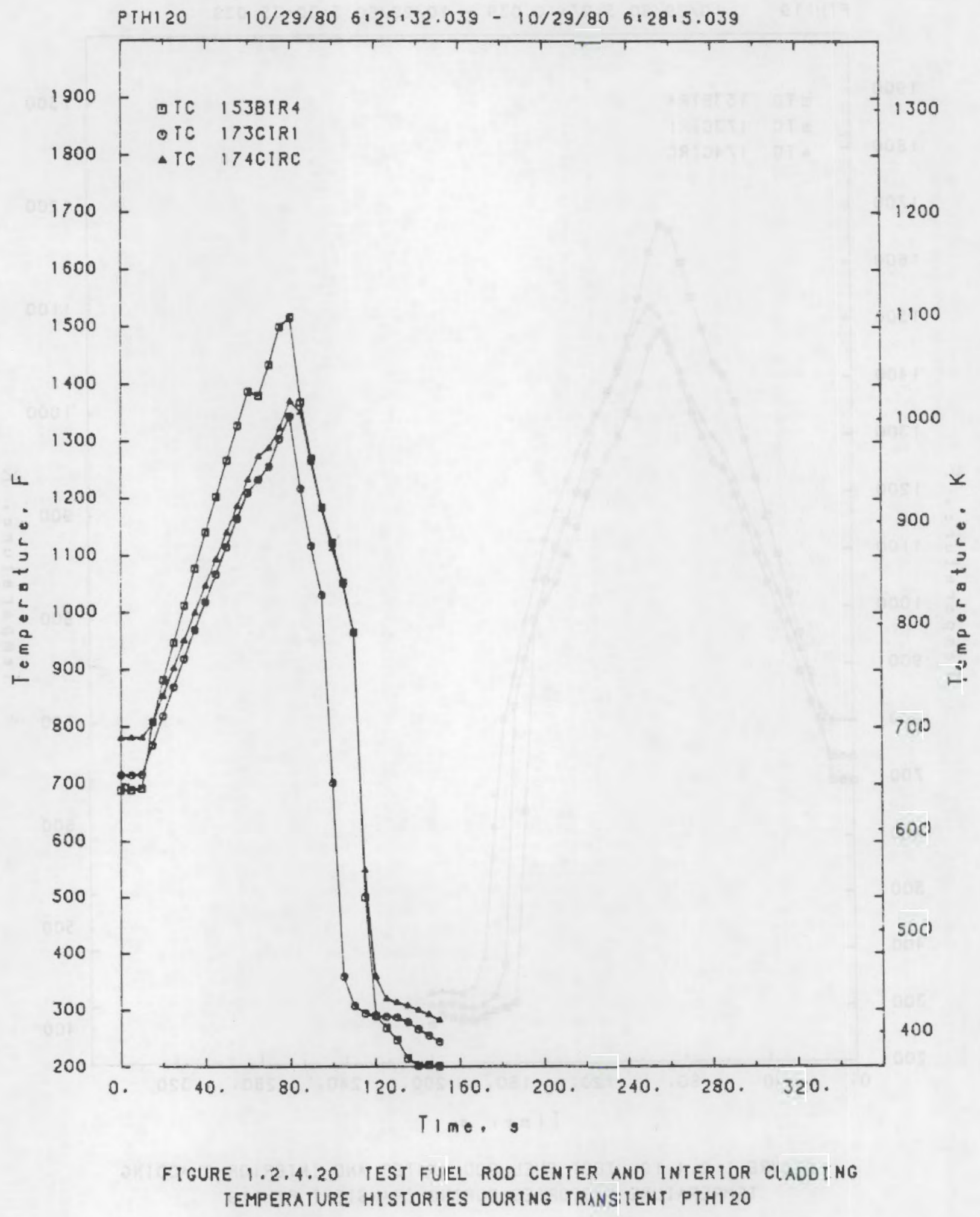




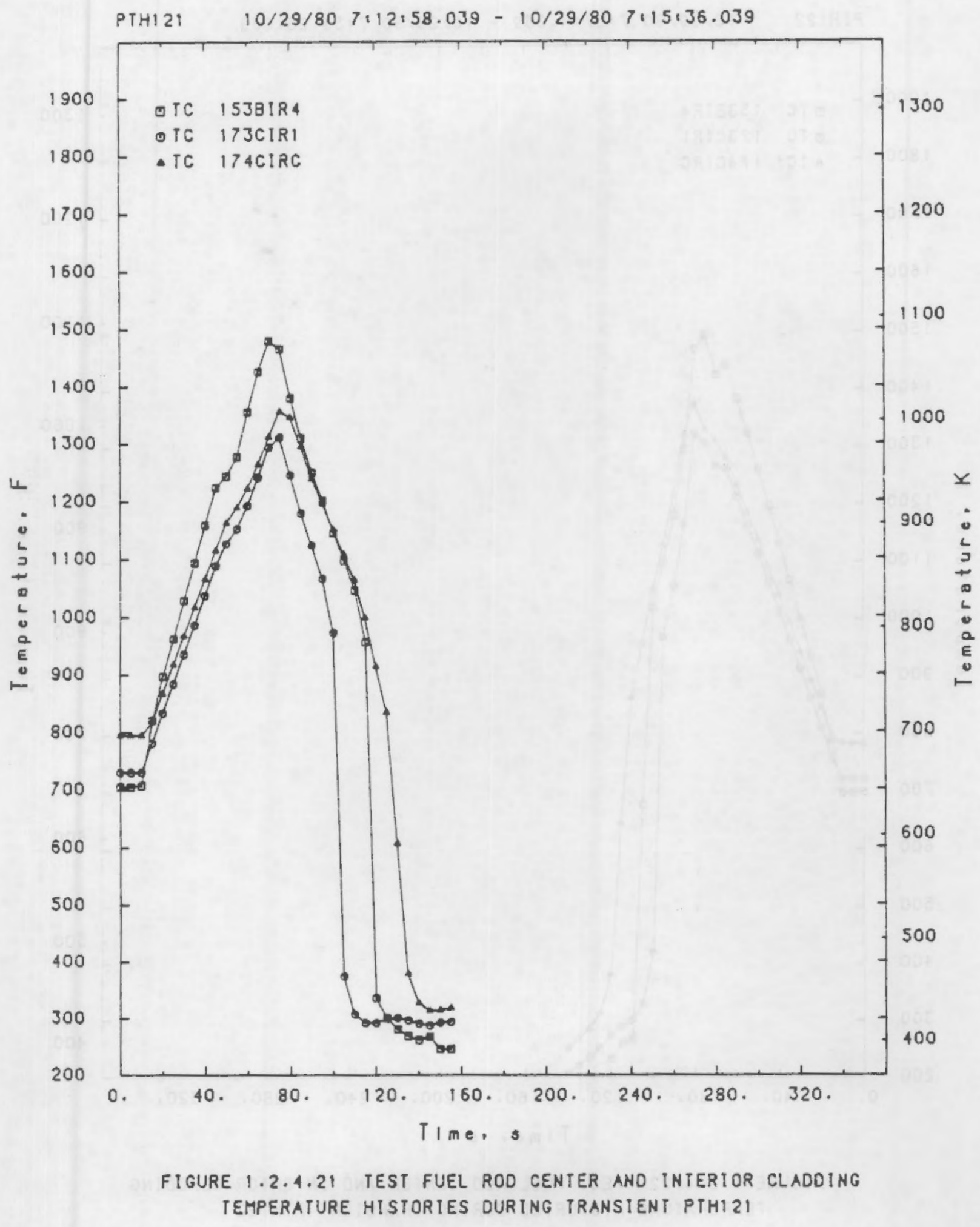

A. 111 


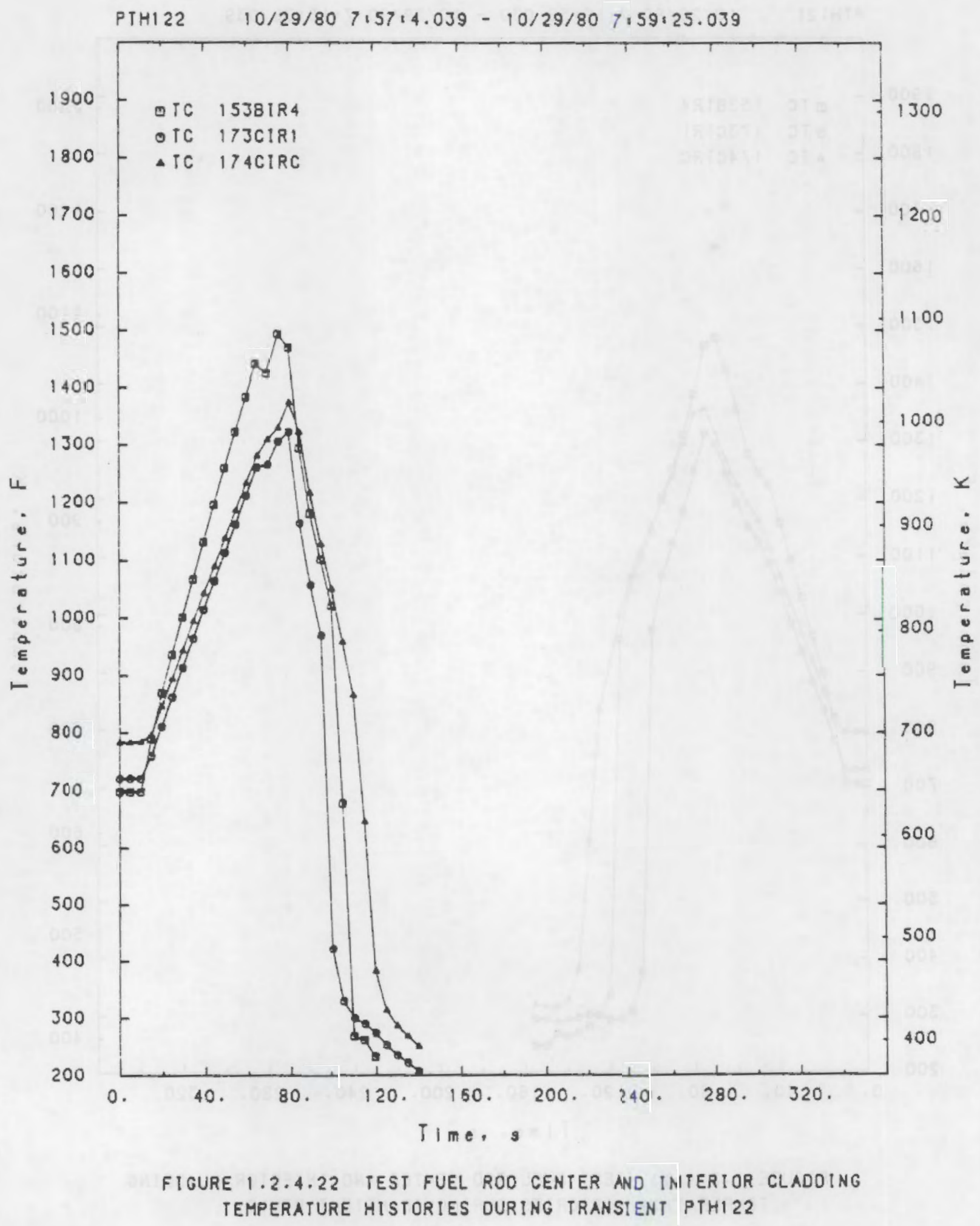

A. 112 


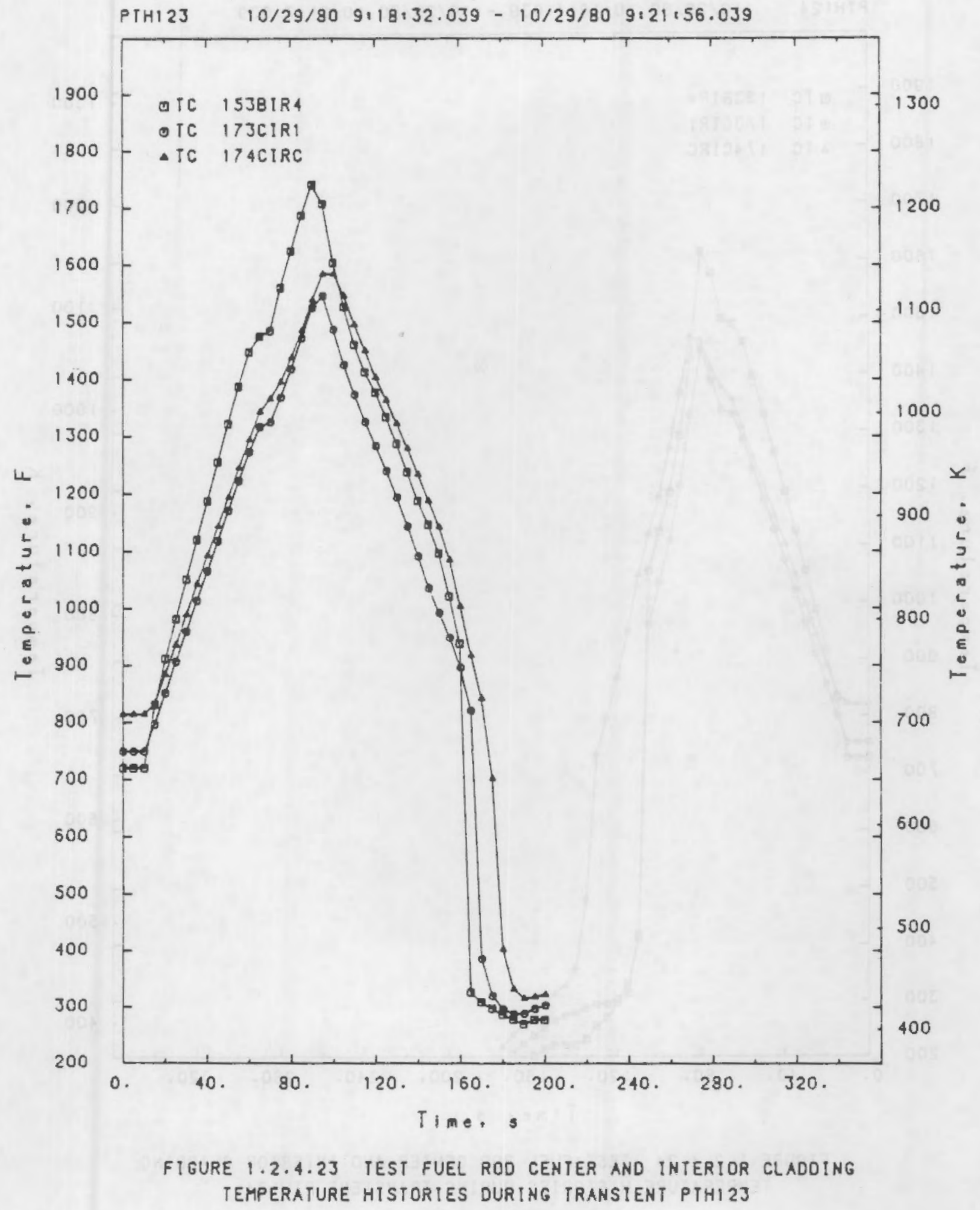

A. 113 


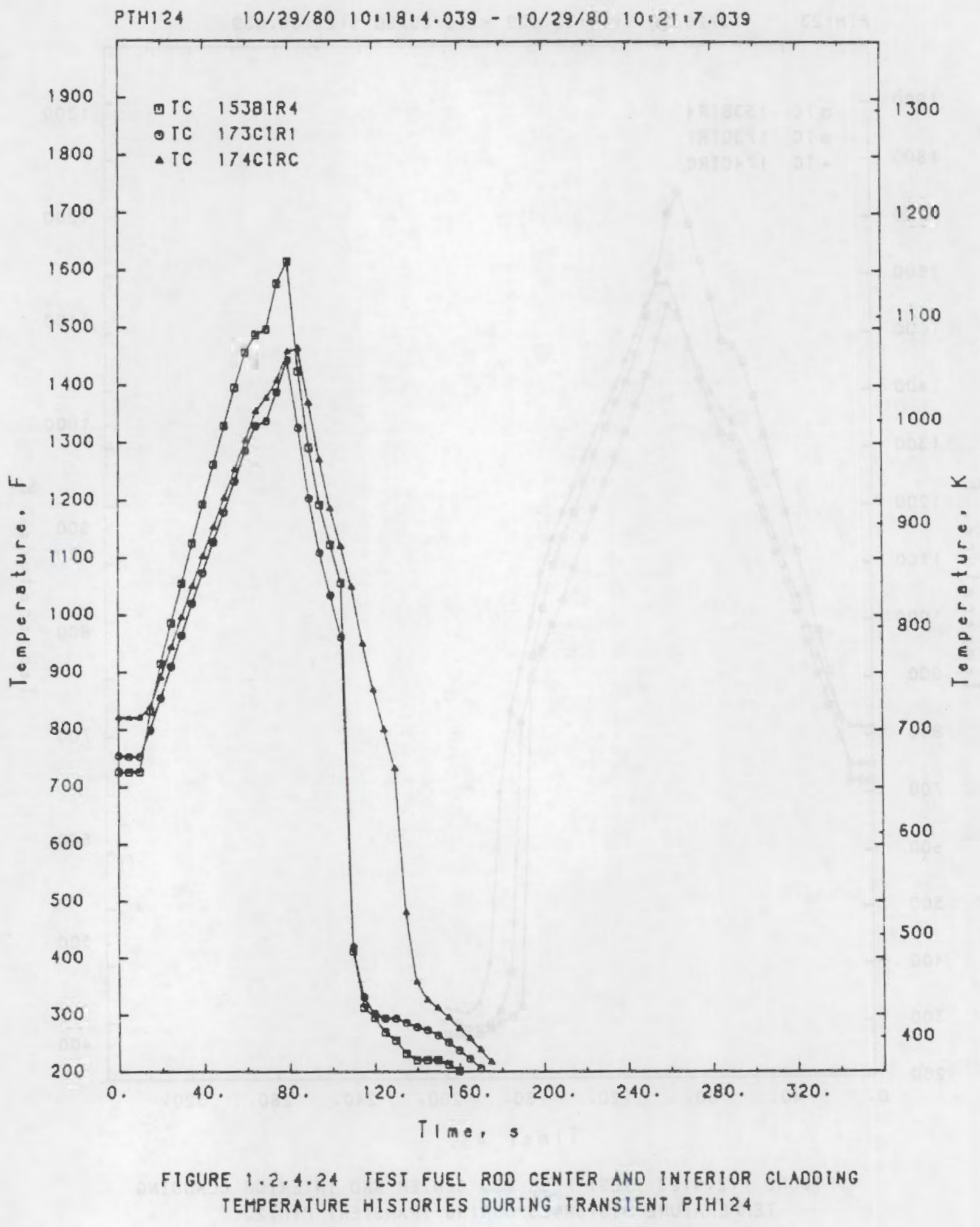




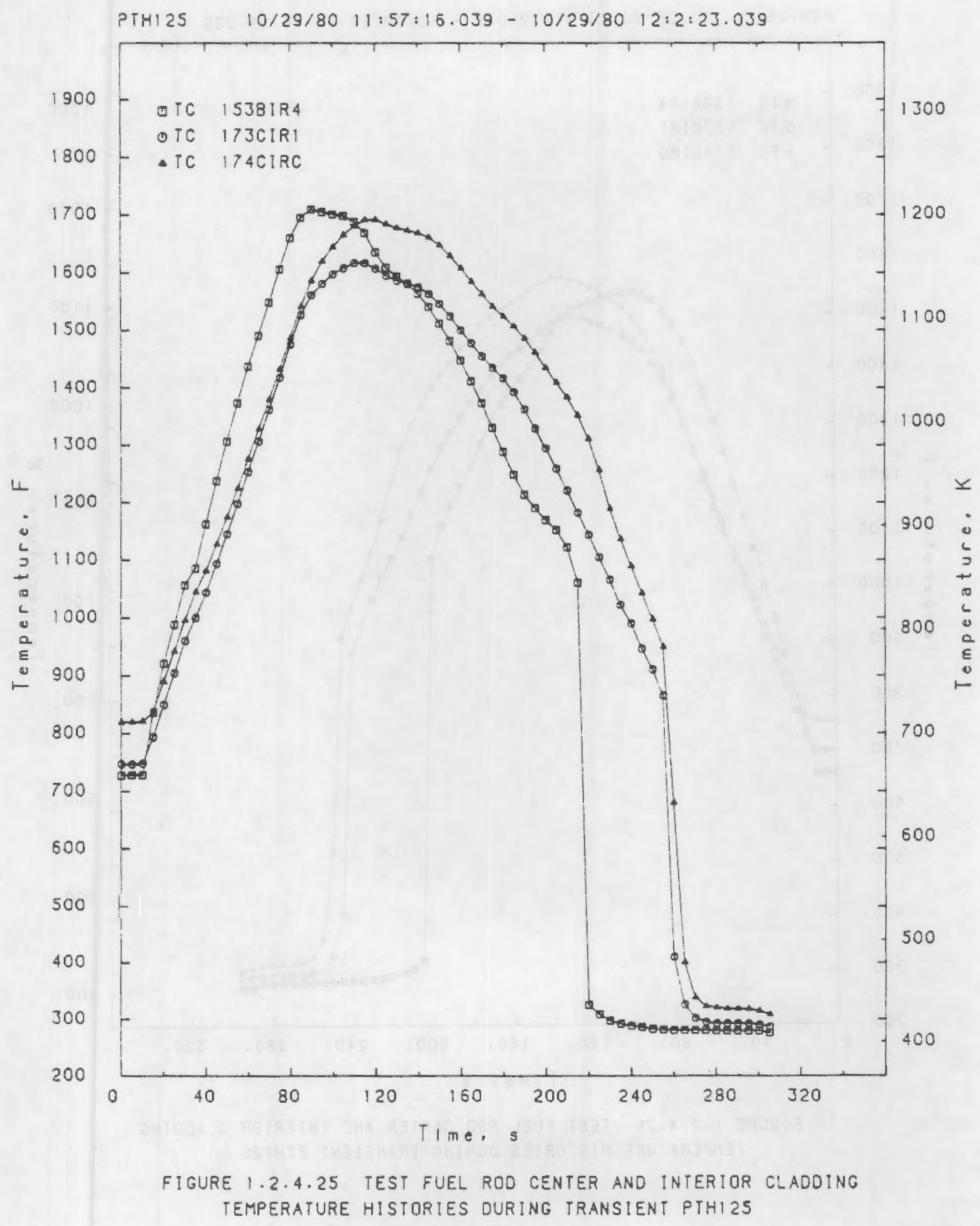




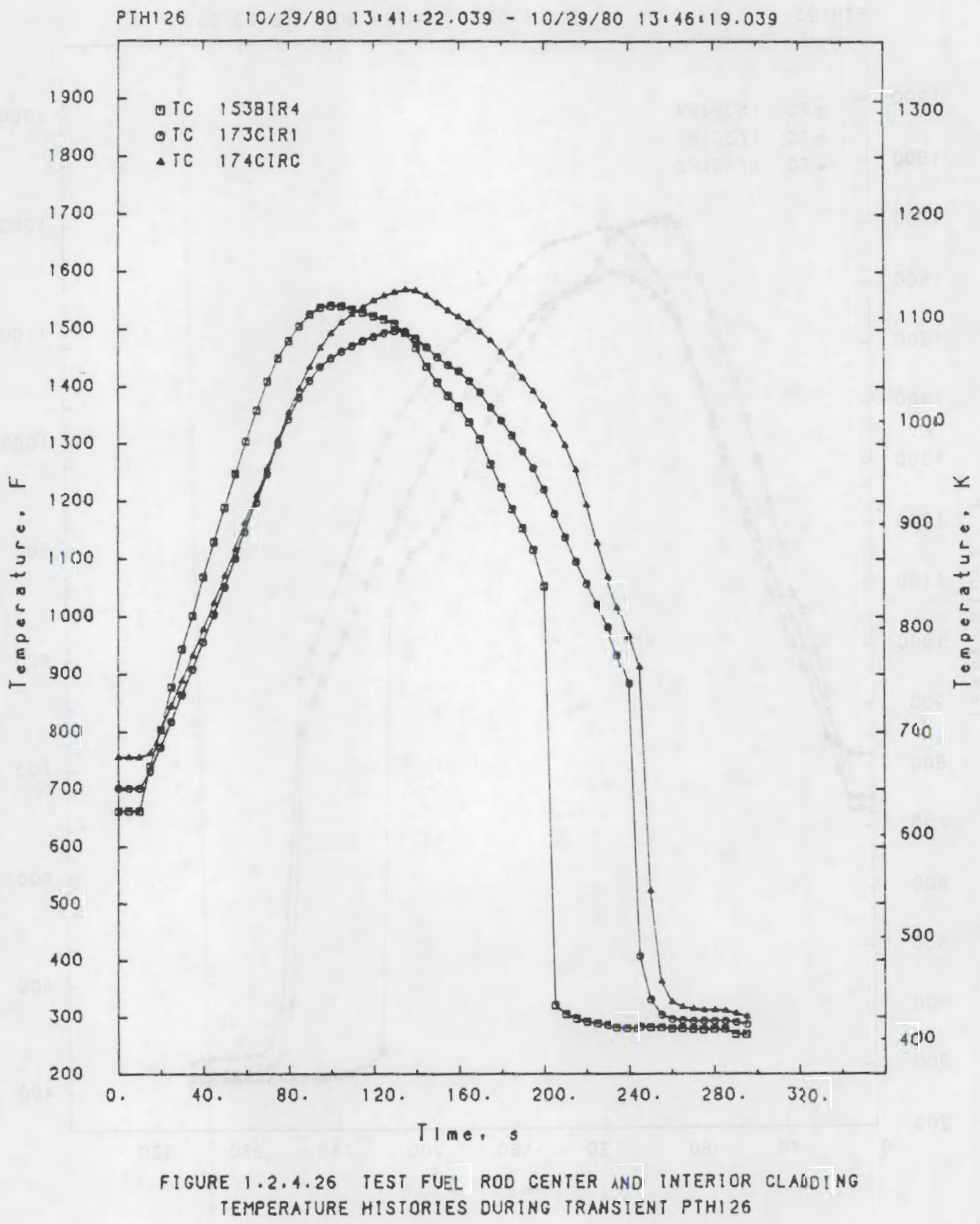

A. 115 


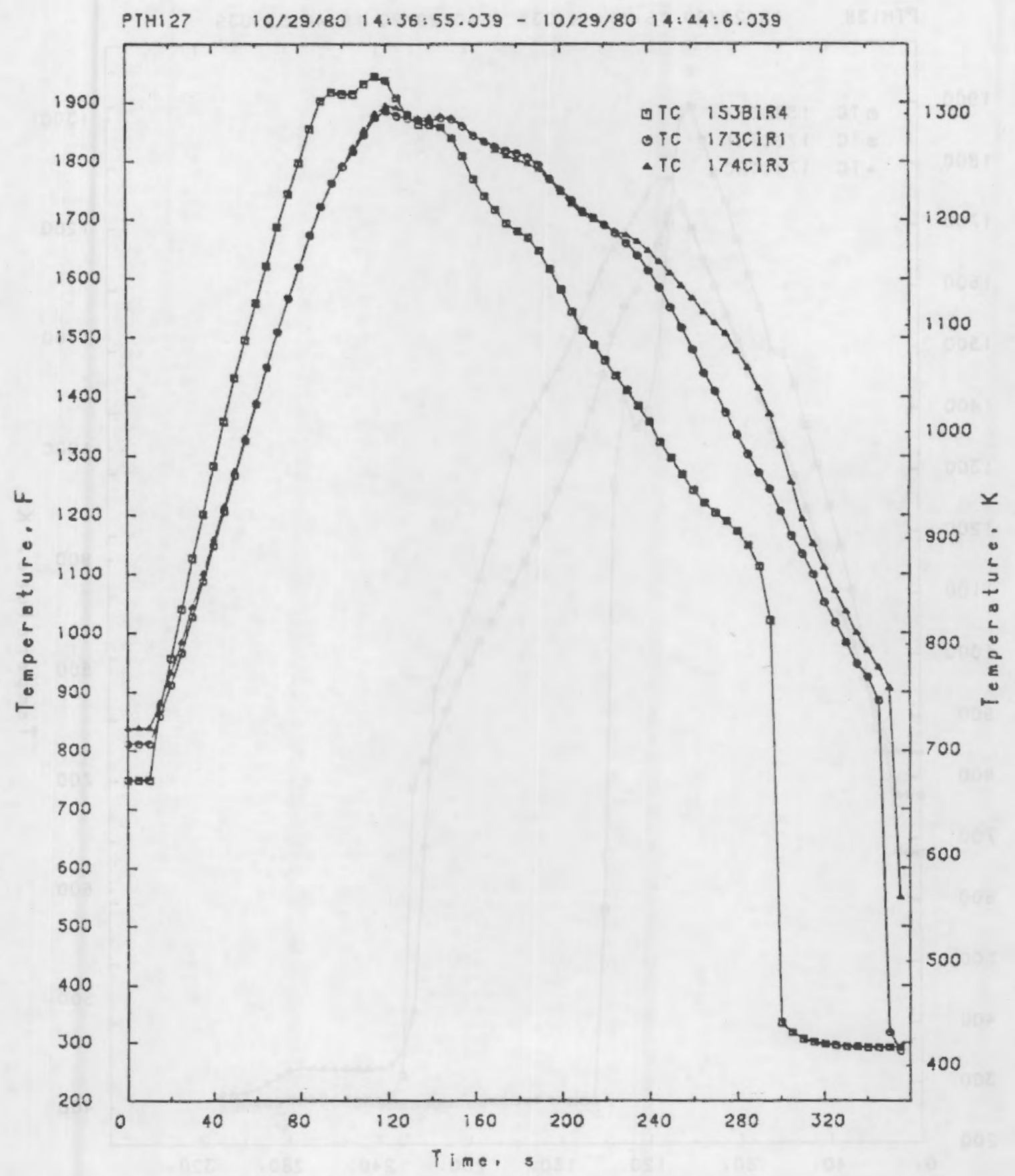

FIGURE 1.2 .4 .27 TEST FUEL ROD CENTER AND INTERIOR CLADDING TEMPERATURE HISTORIES DURING TRANSIENT PTHI 27 


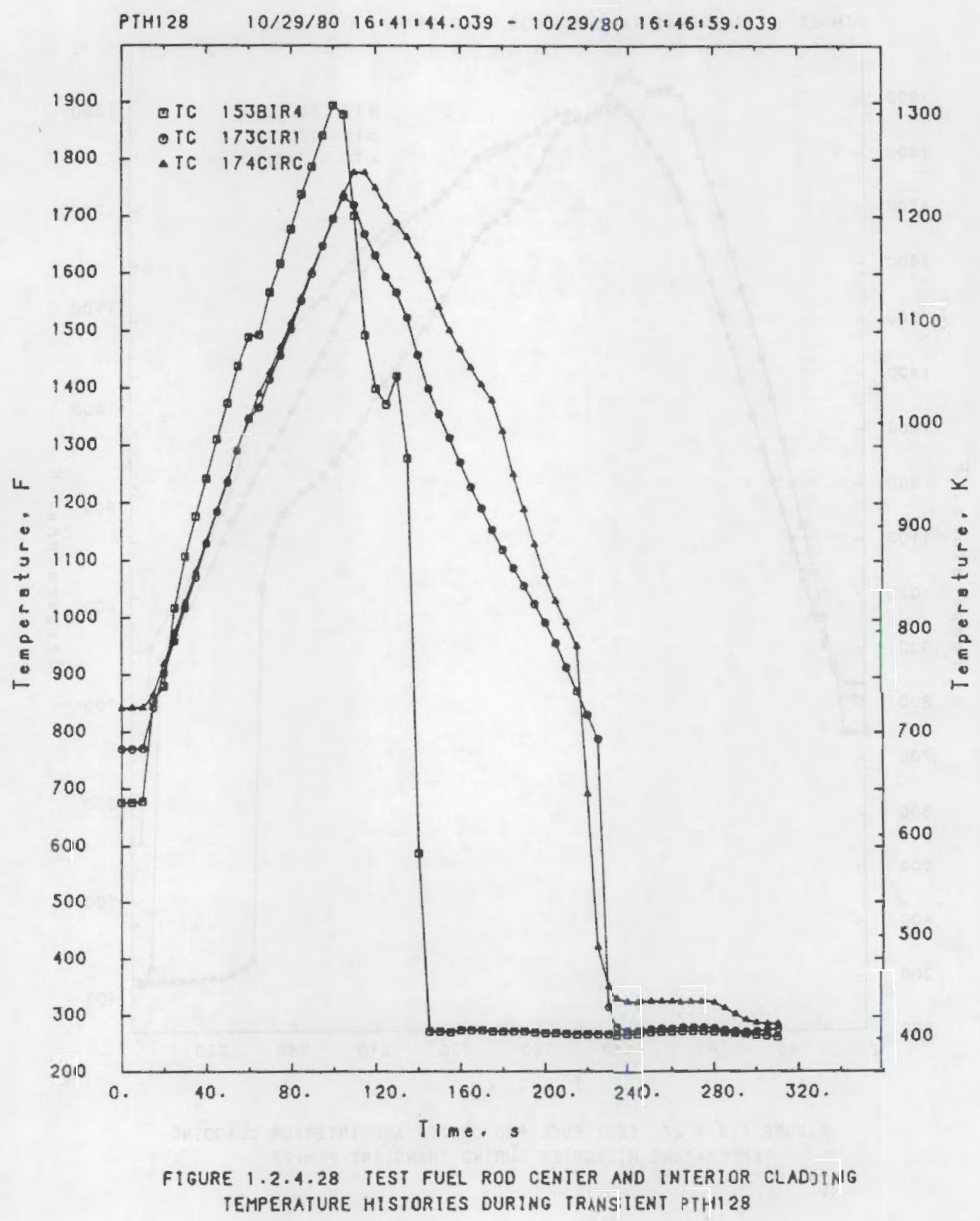




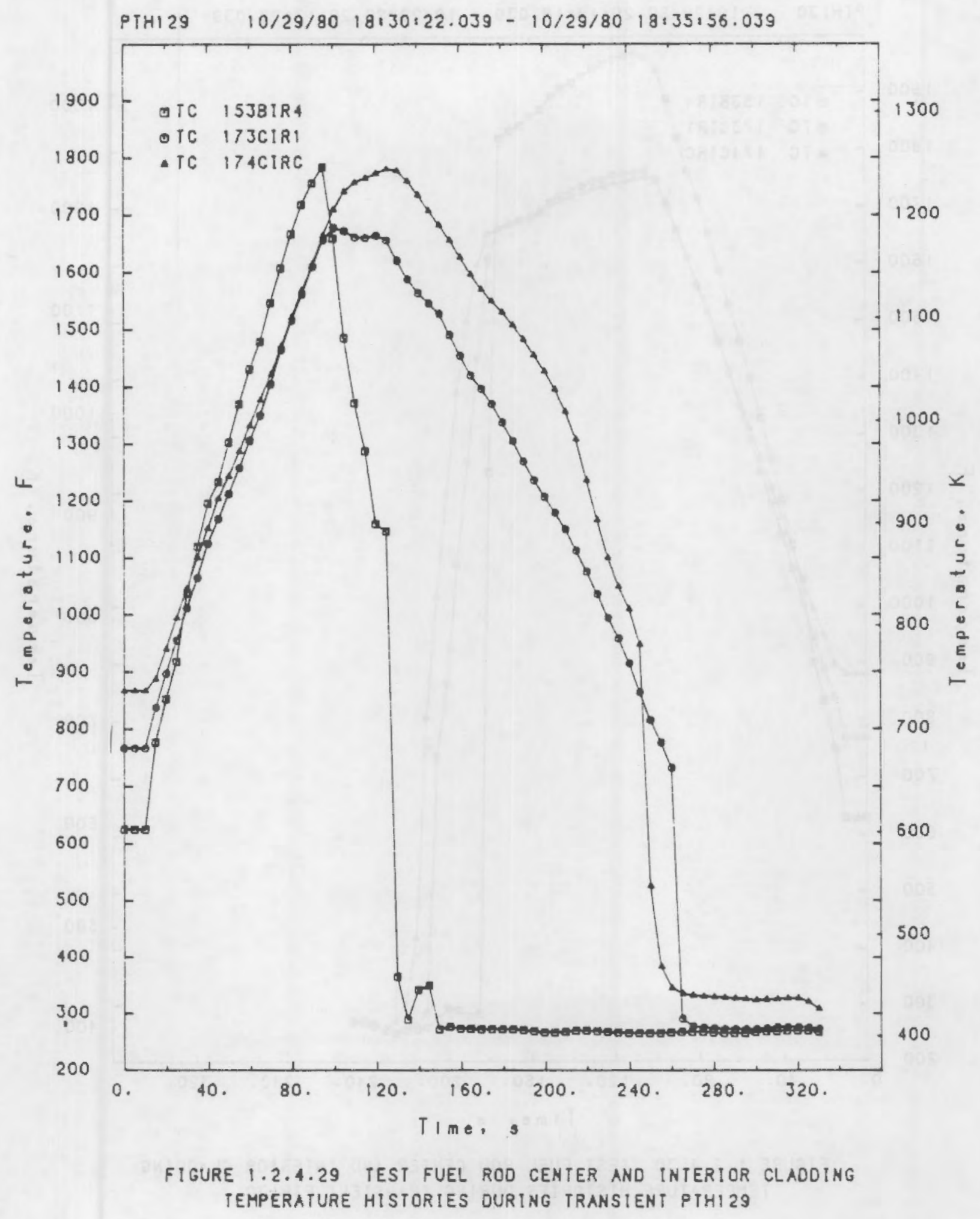

A. 119 


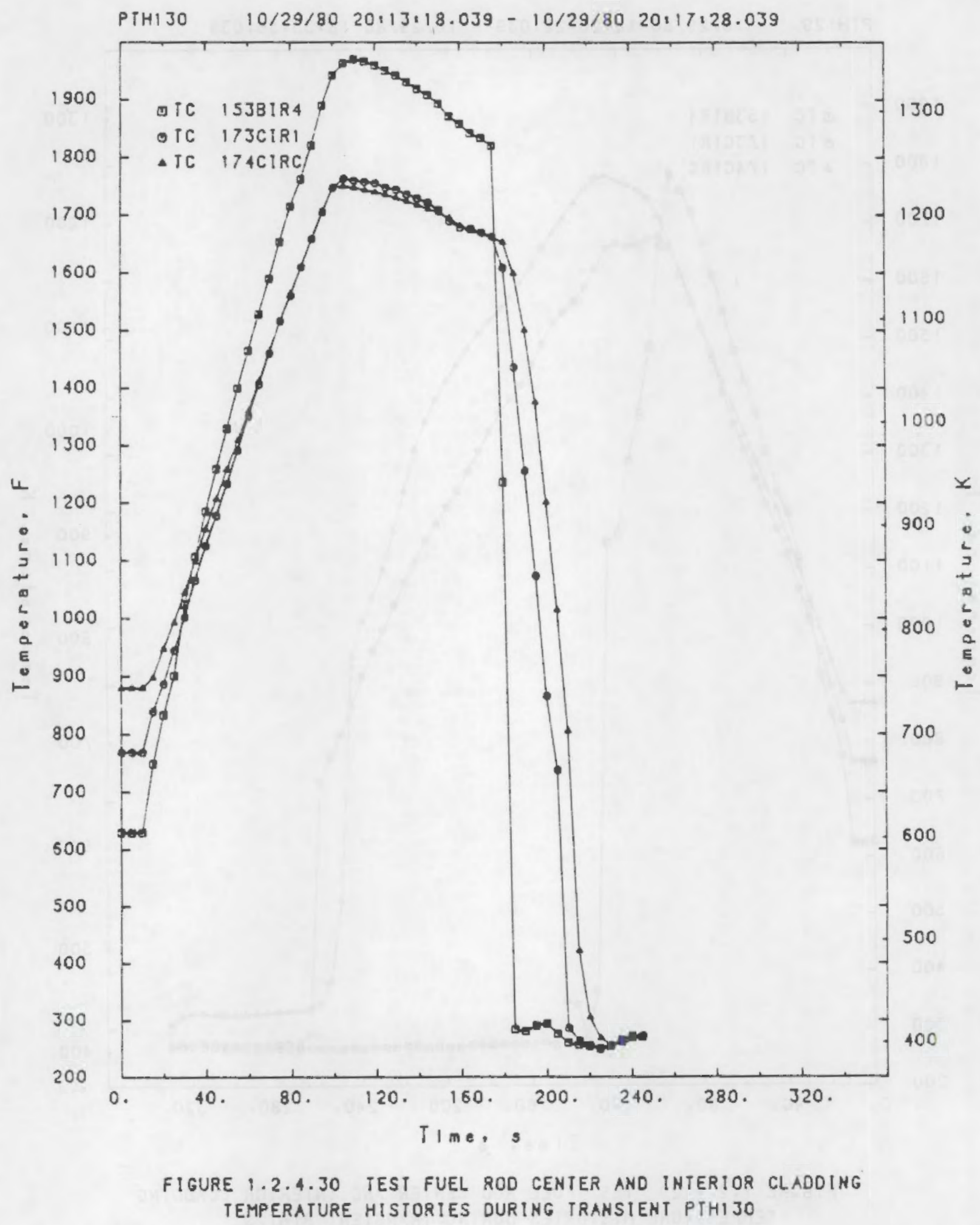

A. 120 
PART 2

NEUTRON FLUX DISTRIBUTIONS 


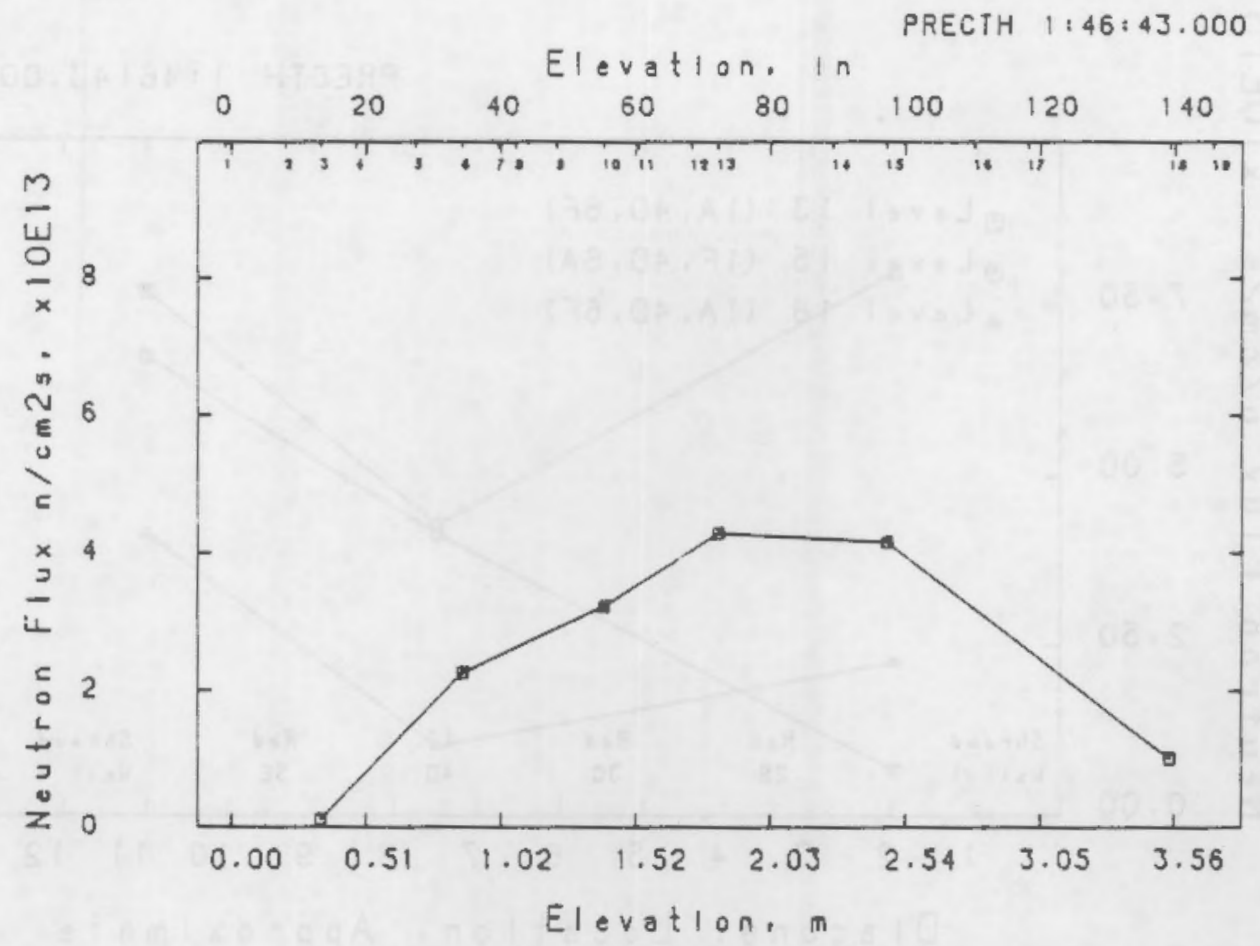

FIGURE 2.1.1 PRECONDITIONTNG (INSTRUMENT TUBE) NEUTRON FLUX AXIAL PROFILE

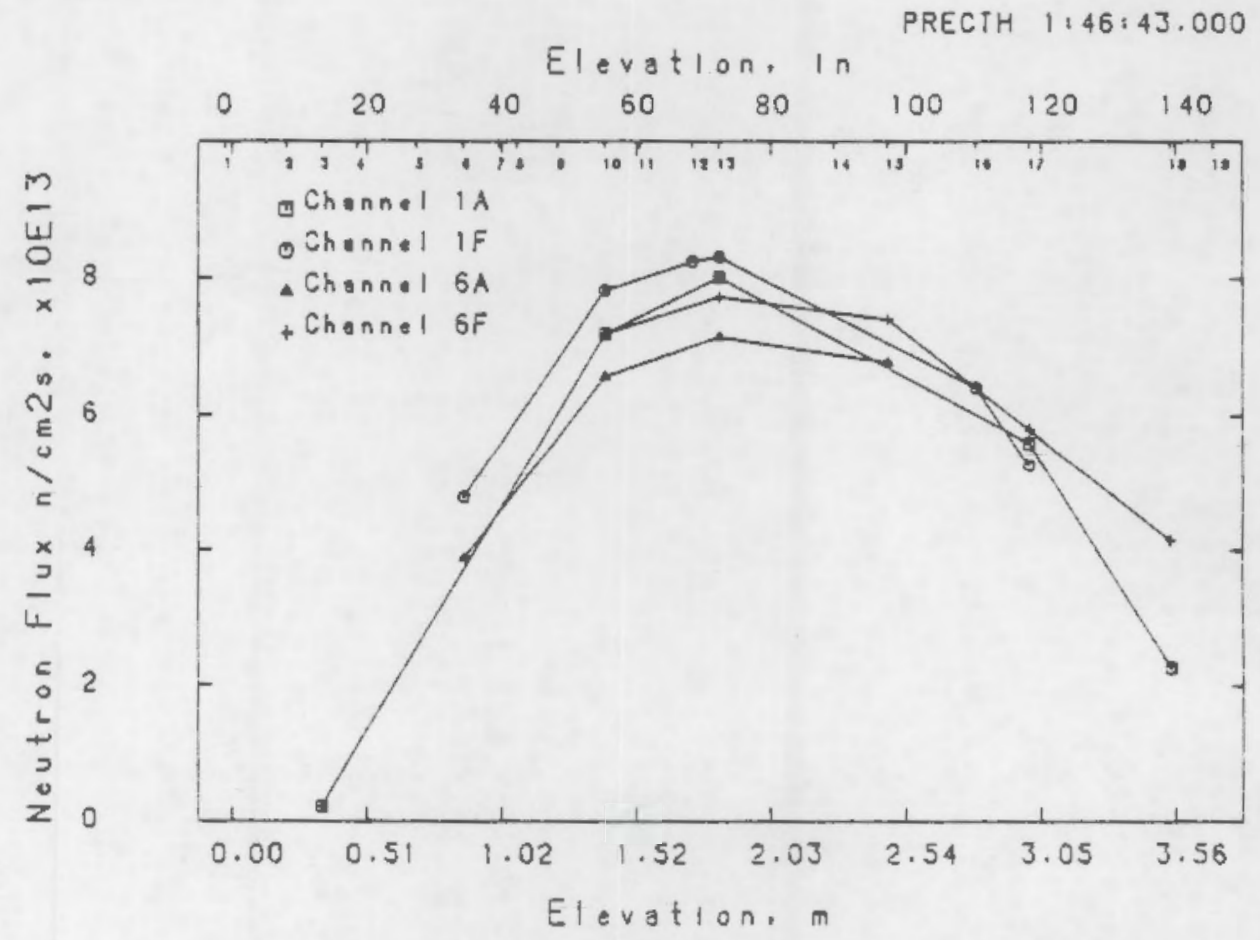

FIGURE 2.1.2 PRECONDITIONING (SHROUD) NEUTRON FLUX AXIAL PROFILES 


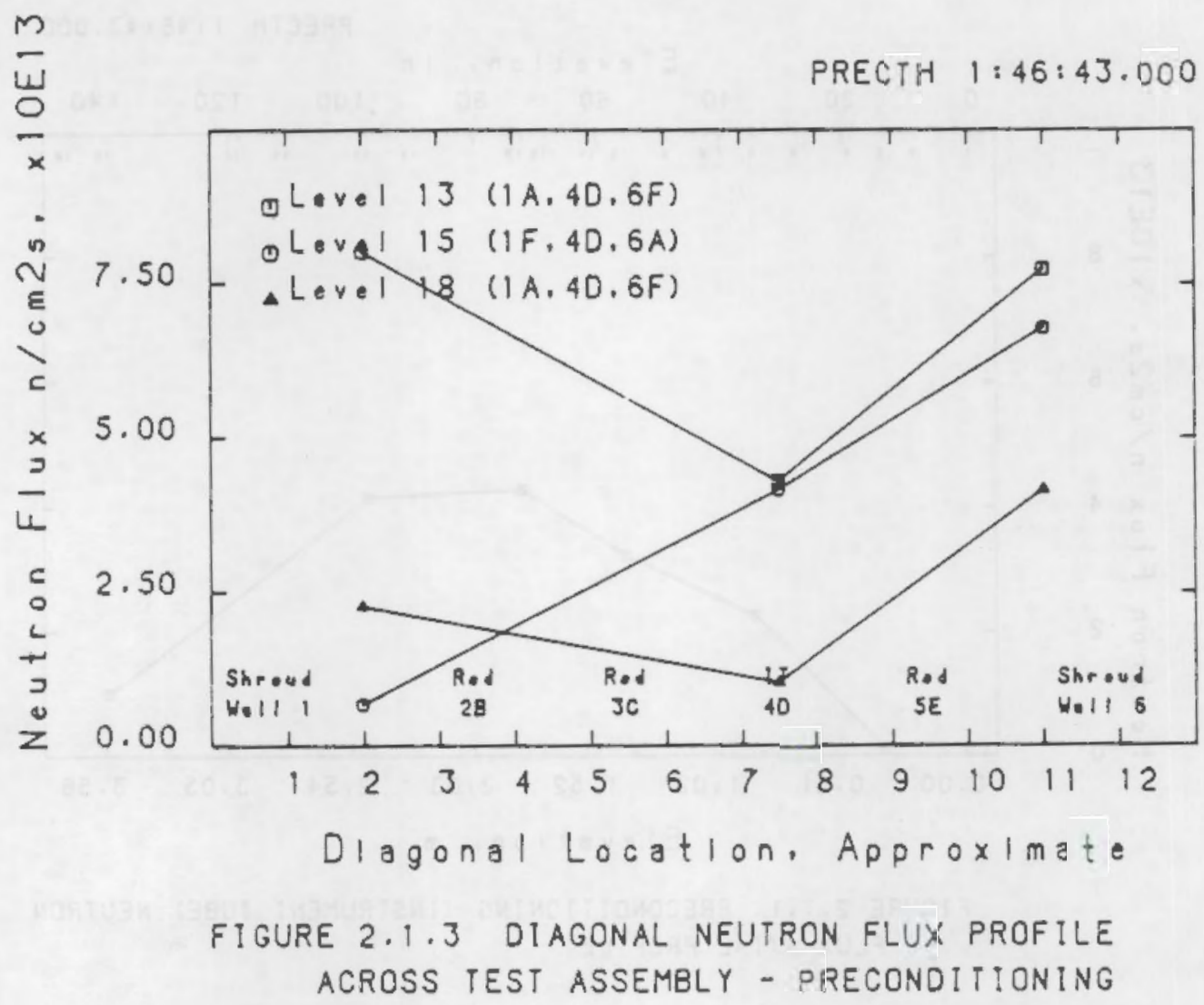

A. 122 


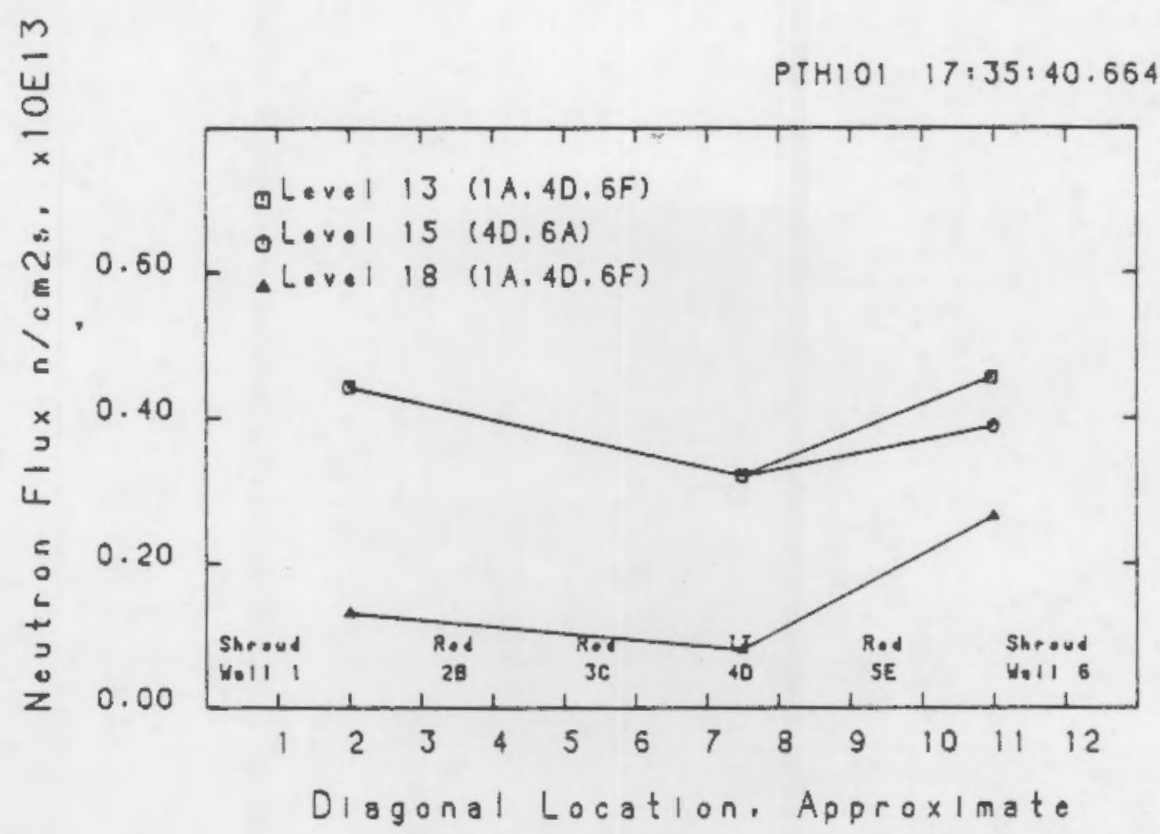

FIGURE 2.2.1.1 DIAGONAL NEUTRON FLUX PROFILE ACROSS THE TEST ASSEMBLY - PRETRANSIENT - PTHIO1

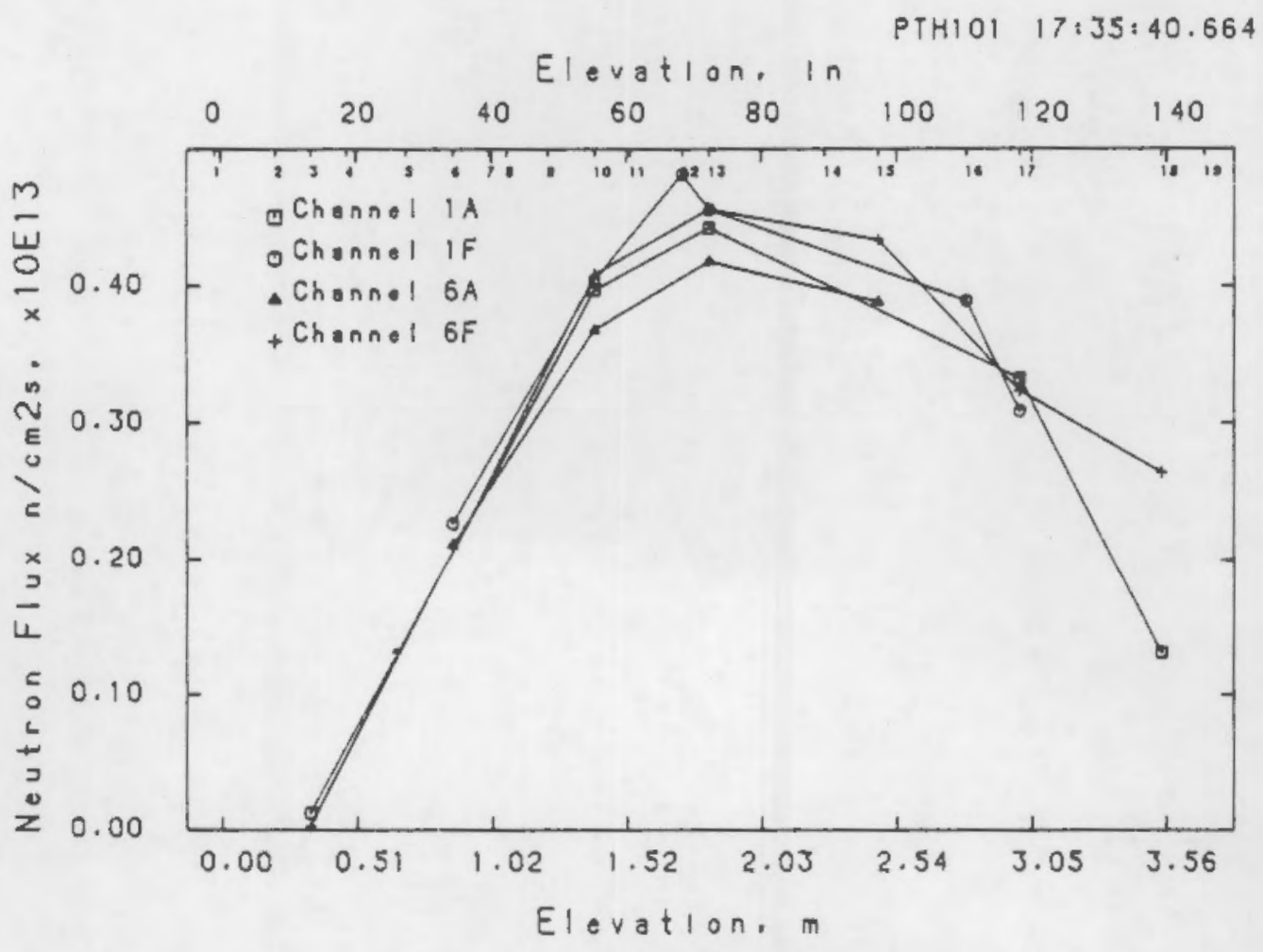

FIGURE 2.2.1.2 PRETRANSIENT SHROUD NEUTRON FLUX AXIAL PROFILE 



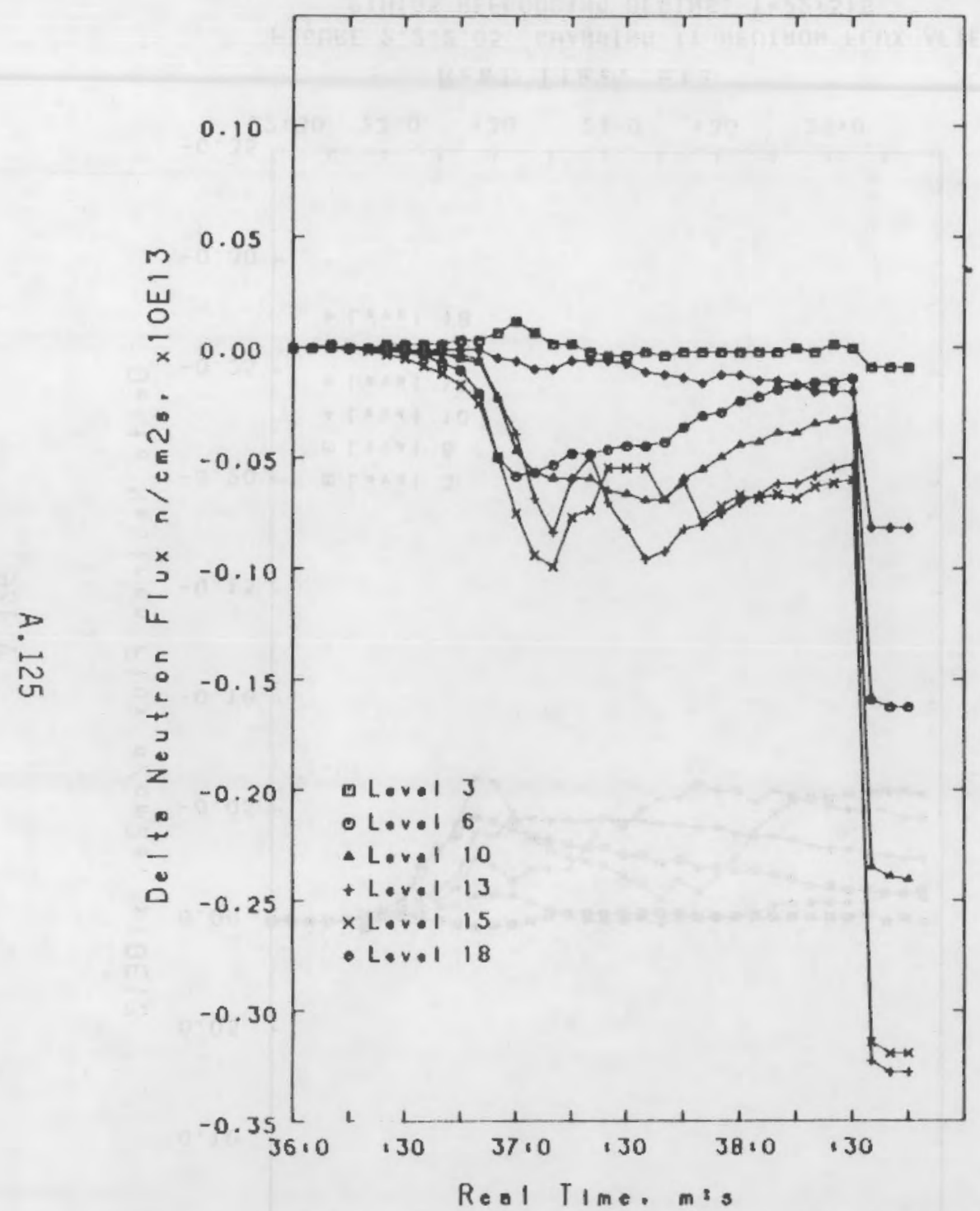

FIGURE 2.2.2.01 CMANGING II NEUIRON FLUX AFIER PIHIOI REFLOODING BEGINS. $I=36: 18 S$

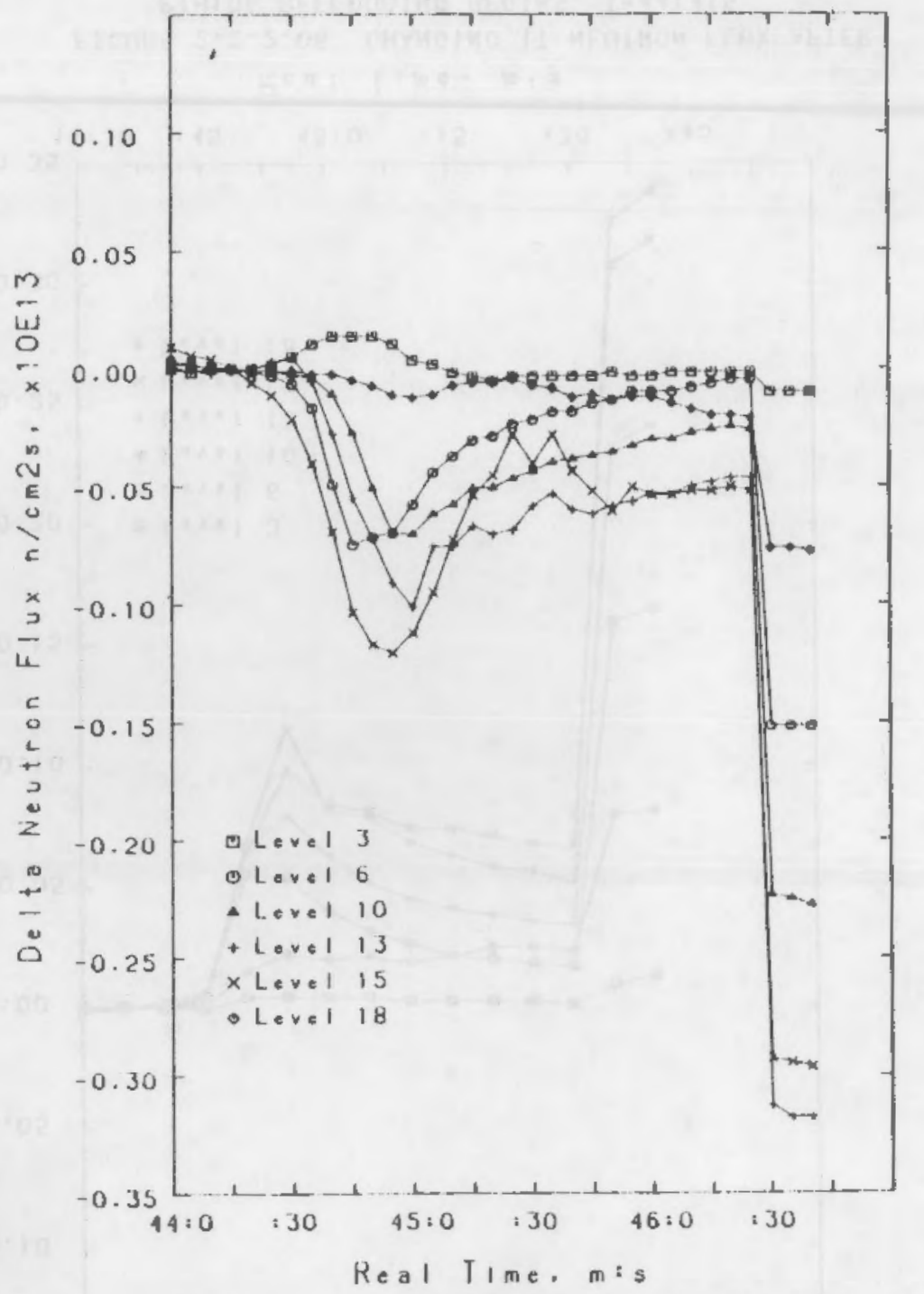

FIGURE 2.2.2.04 CHANGING II NEUIRON FLUX AF IER PIHIO4 REFLOODING BEGINS. $I=44 \mathrm{M}: 275$ 
PIHIOS 7.22:30.000

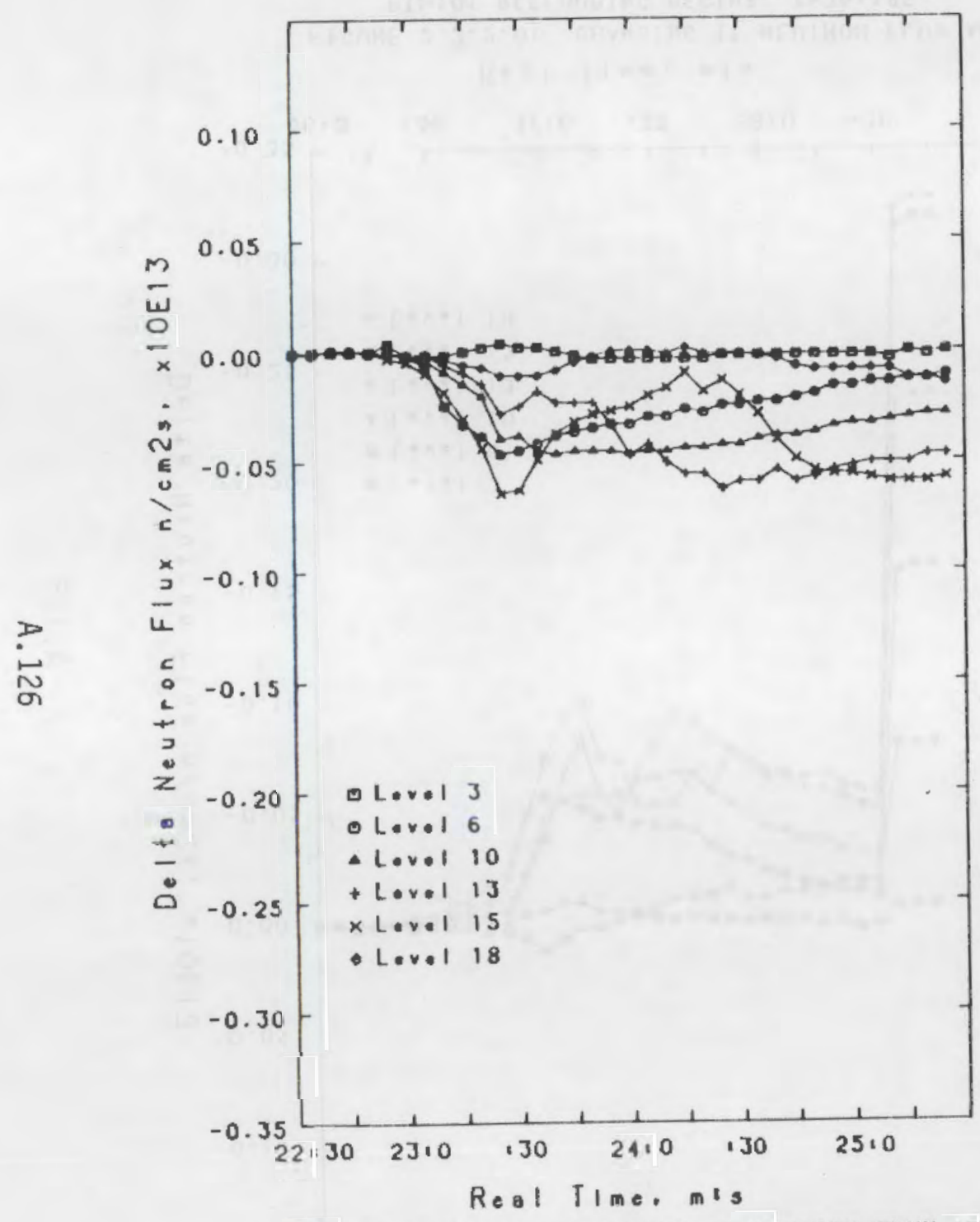

FIGURE 2.2.2.05 CHANGING IT NEUTRON FLUX AFTER PIHIOS REFLOODING BEGINS. $T=22,51 \mathrm{~S}$

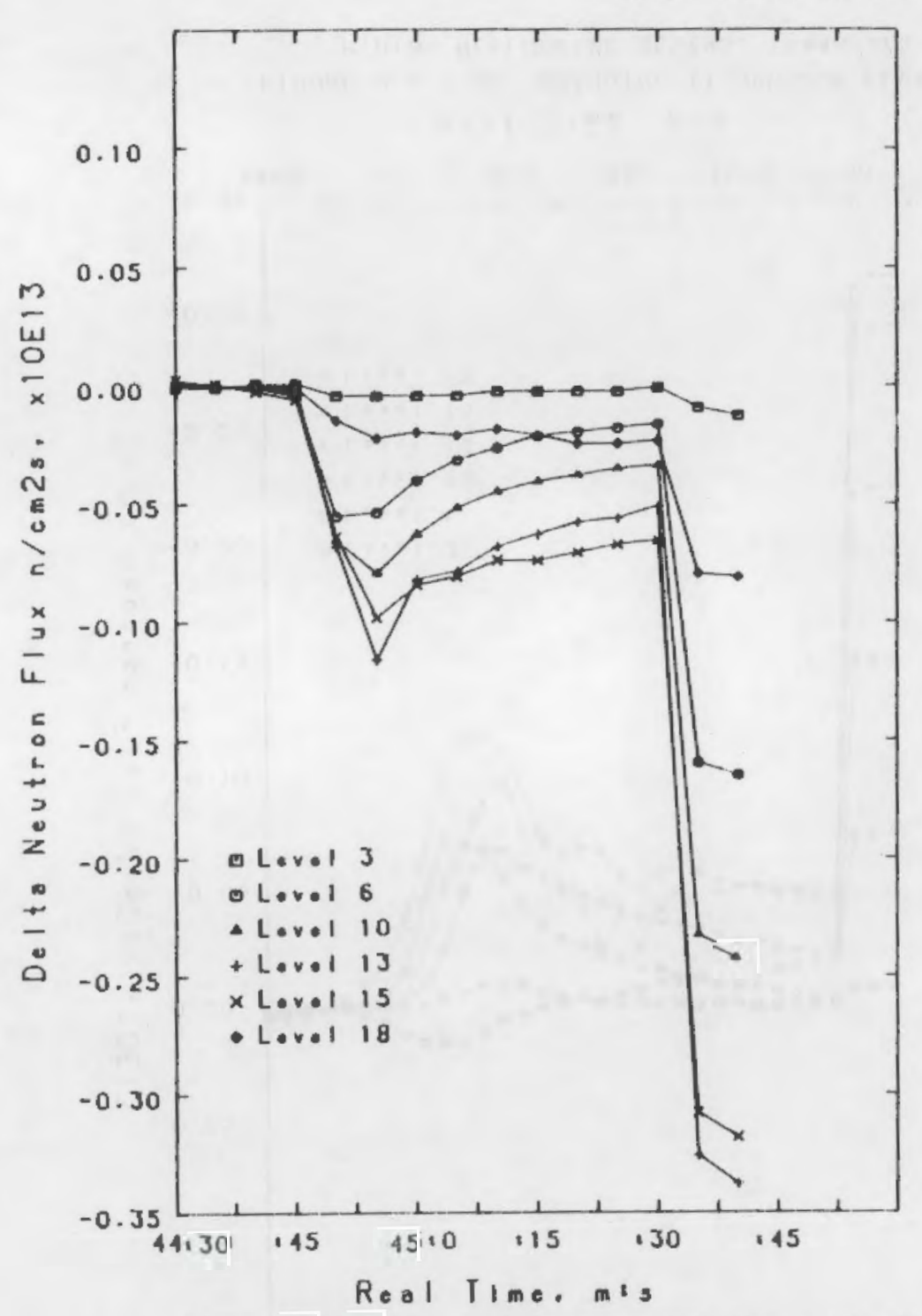

FIGURE 2.2.2.06 CHANGING IT NEUTRON FLUX AFIER PIHIO6 REFLOODING BEGINS. I=44:41S 
PIHI07 13:45:30.000

PIH108 $17: 52: 0.000$
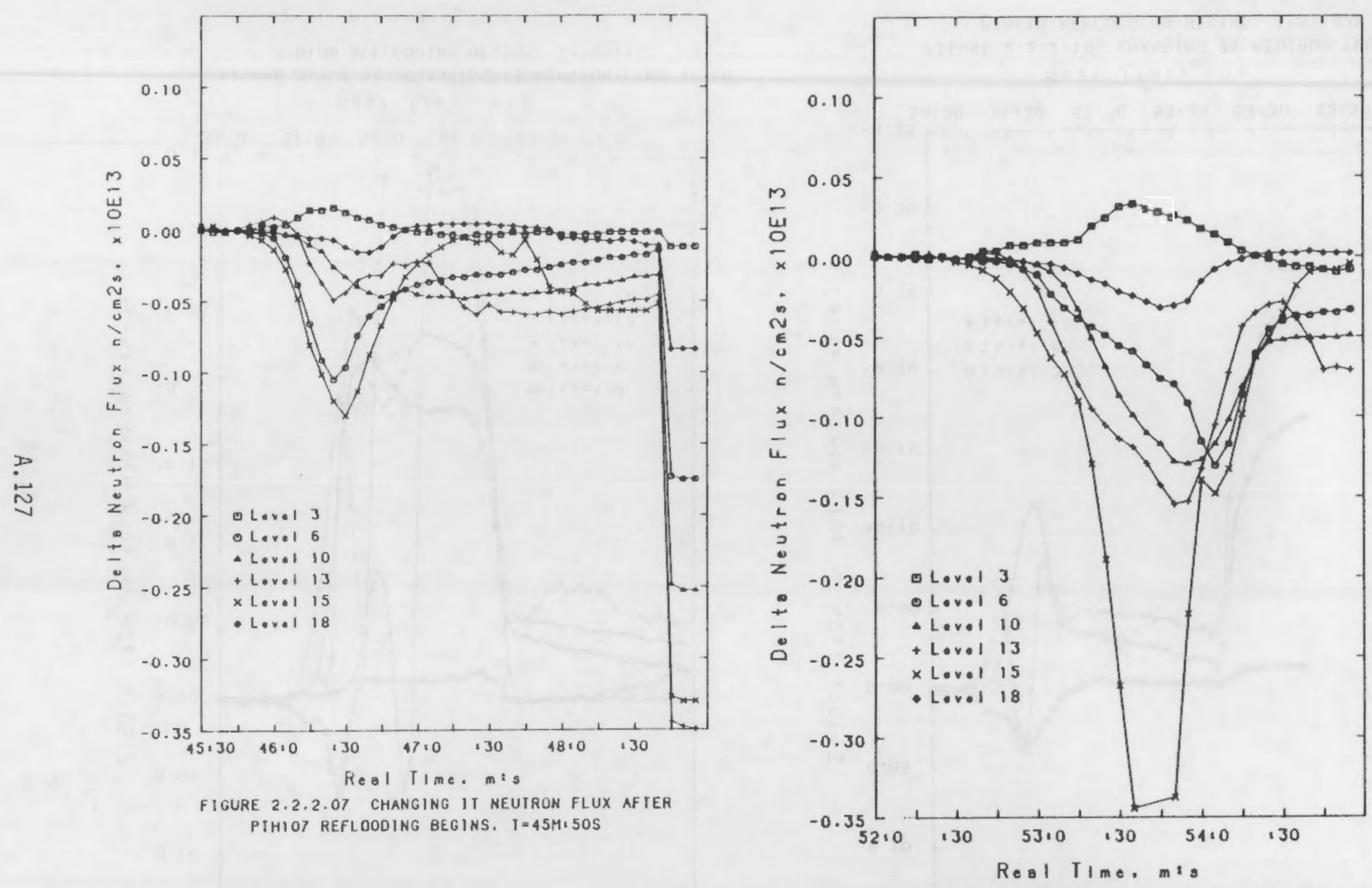

FIGURE 2.2.2.08 CHANGING IT NEUTRON FLUX AFIER PTHIOB REFLOODING BEGINS, $T=52.41 \mathrm{~S}$ 


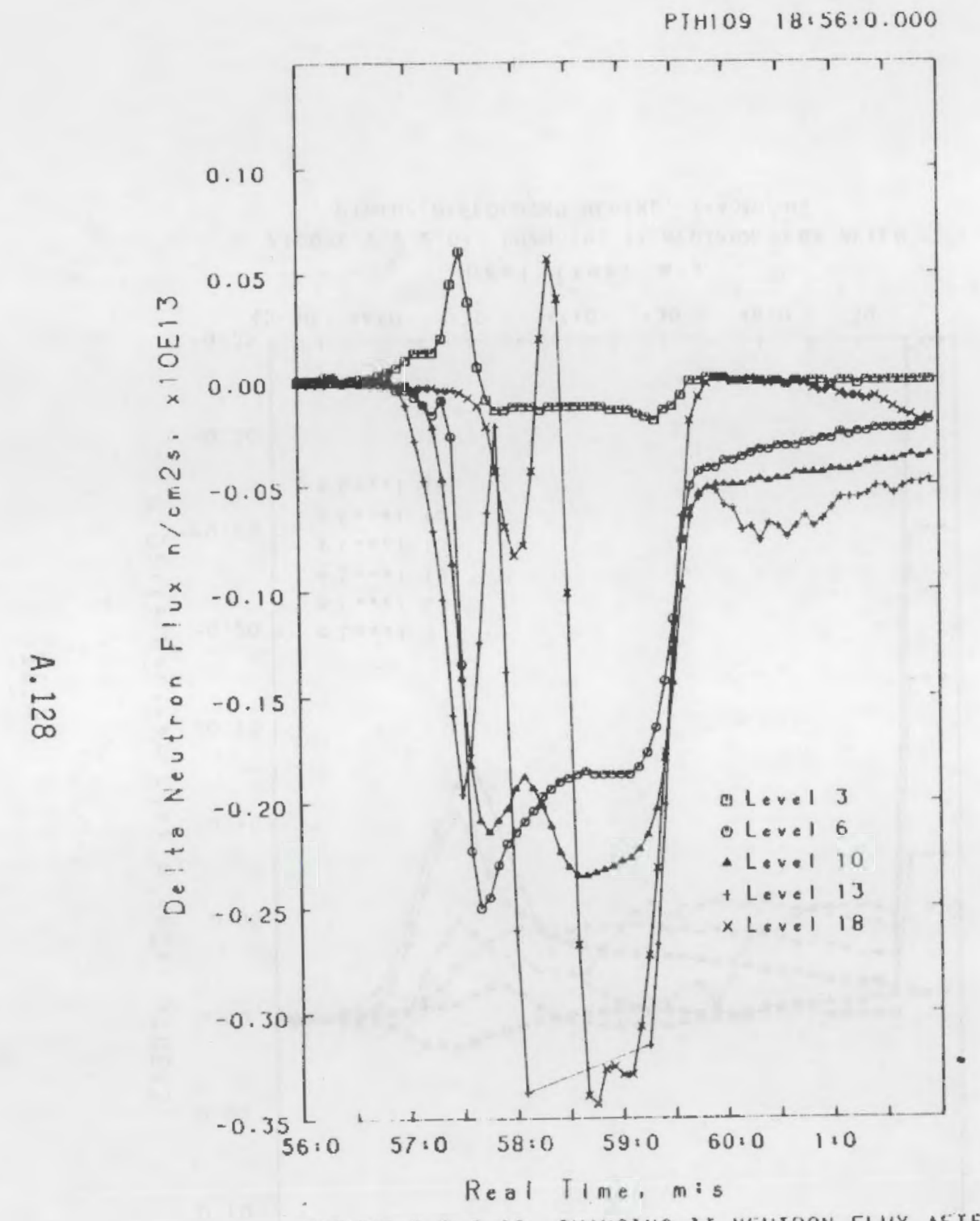

FIGURE 2.2.2.09 CHANGING II NEUIRON FLUX AFTER PIHIO9 REFLOODING BEGINS, $r=56 M: 47 S$

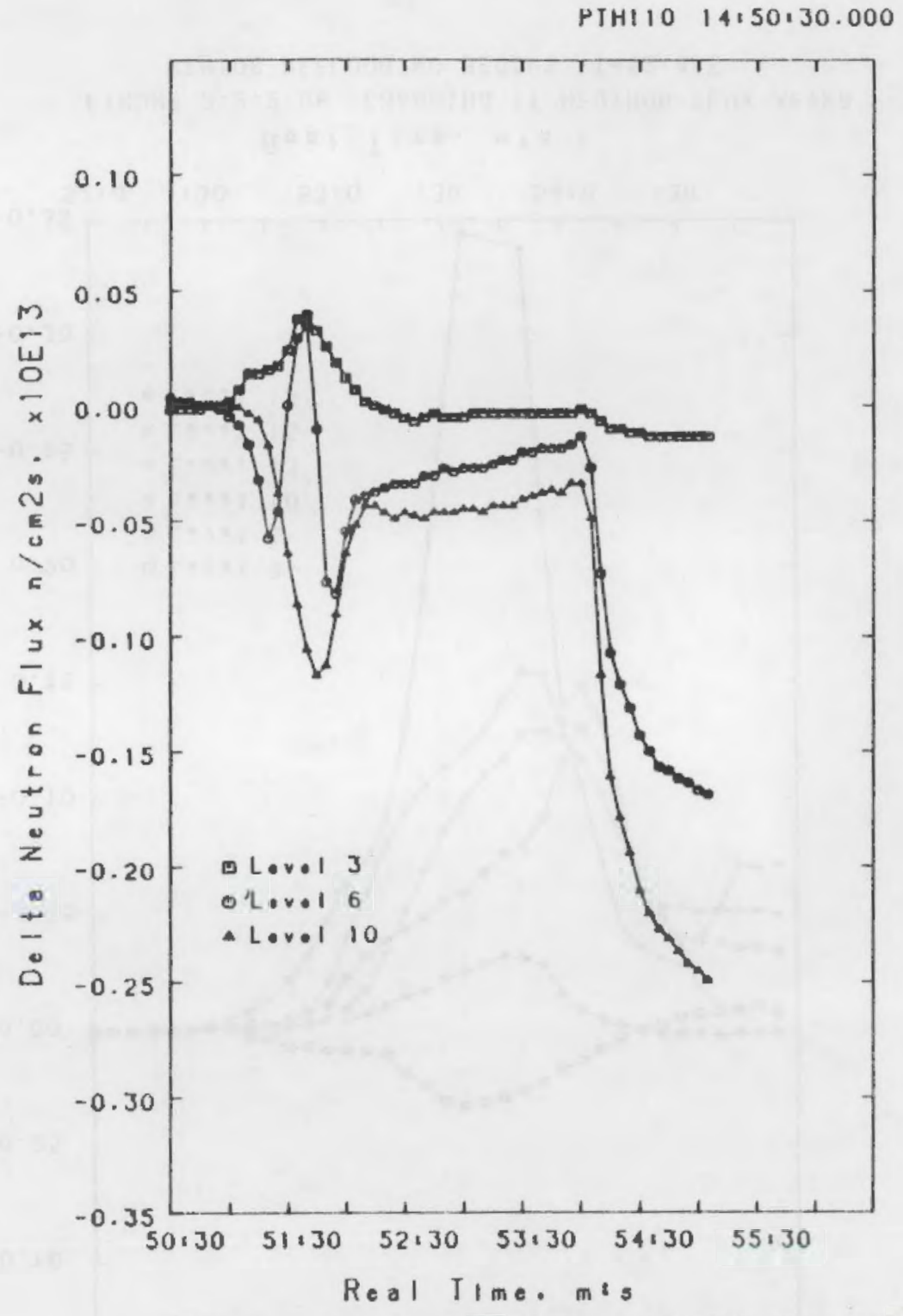

FIGURE 2.2.2.10 CHANGING IT NEUIRON FLUX AFTER PIHIIO REFLOODING BEGINS. I=51,02S 
PIHIII 19:50,0.000

PTHII2 22:17.30.000
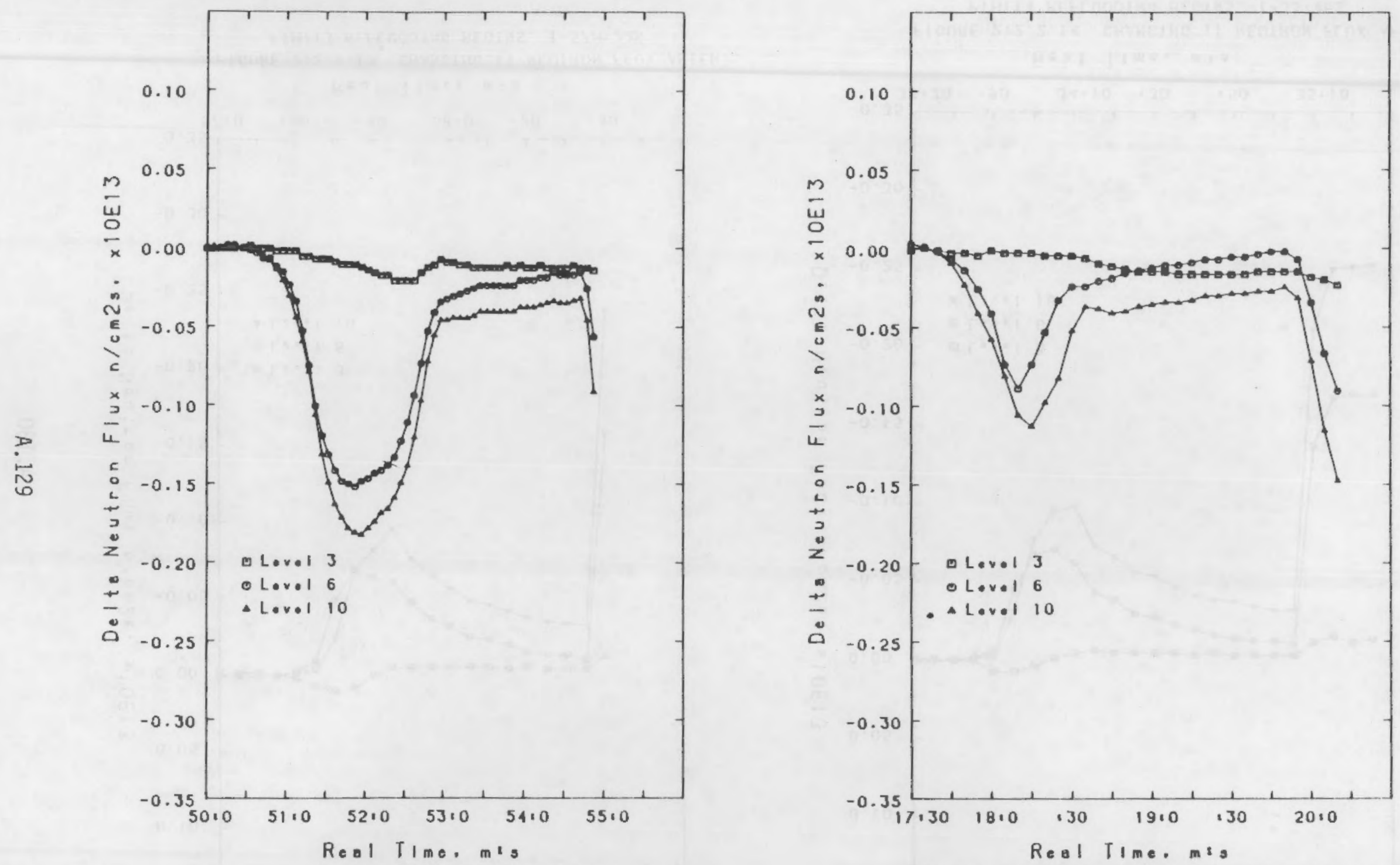

FIGURE 2.2.2.1I CHANGING IT NEUTRON FLUX AFTER PIHIII REFLOODING BEGINS. $I=50131 \mathrm{~S}$

FIGURE 2.2.2.12 CHANGING II NEUTRON FLUX AFIER PIHII2 REFLOODING BEGINS. T-17:43S 
PIH:13 21:57:0.000

PIHI14 $0.33,30.000$

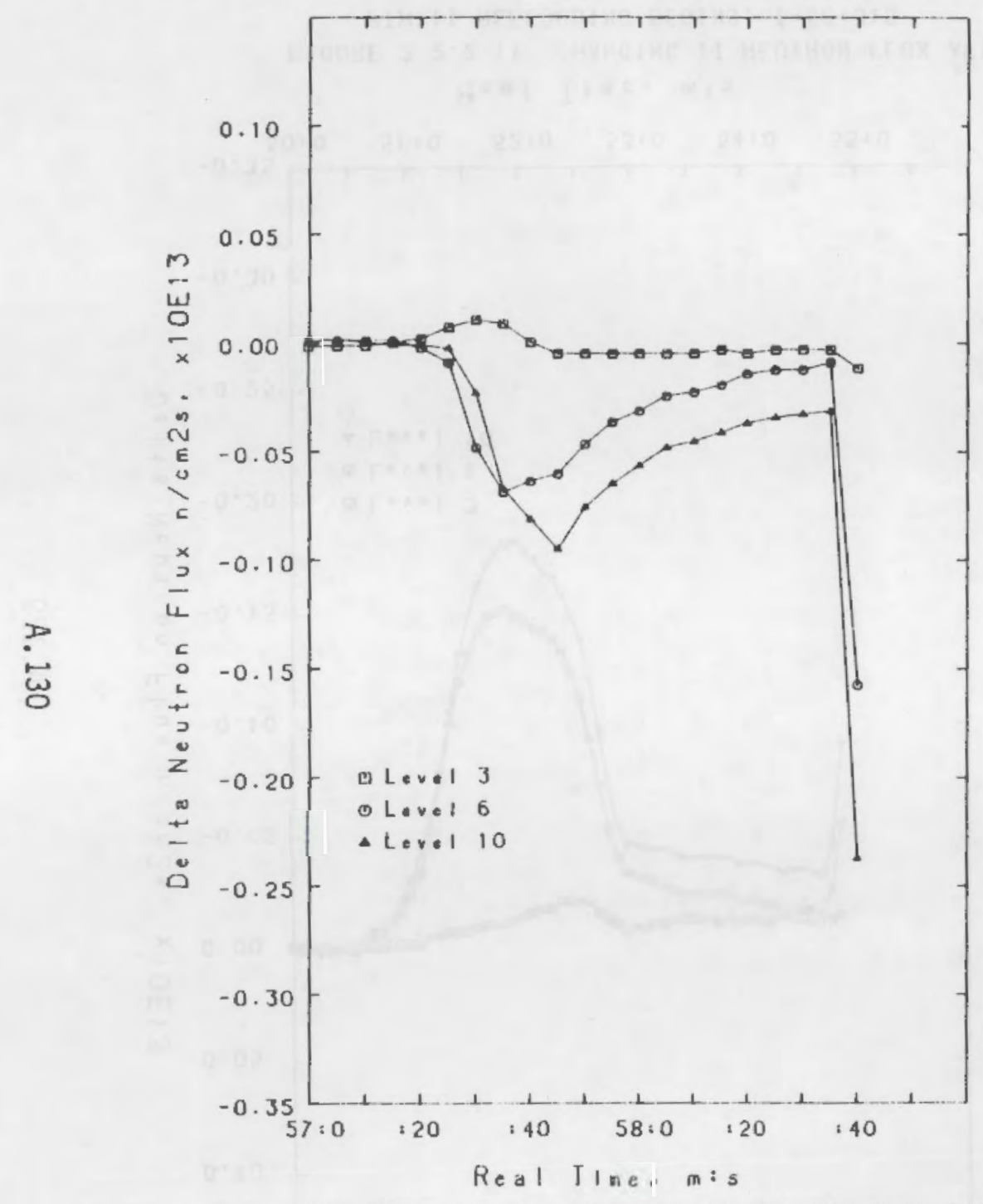

FIGURE 2.2.2.13 CHANGING IT NEUTRON FLUX AFTER PIHIIJ REFLODDING BEGINS. $I=57 M: 22 S$

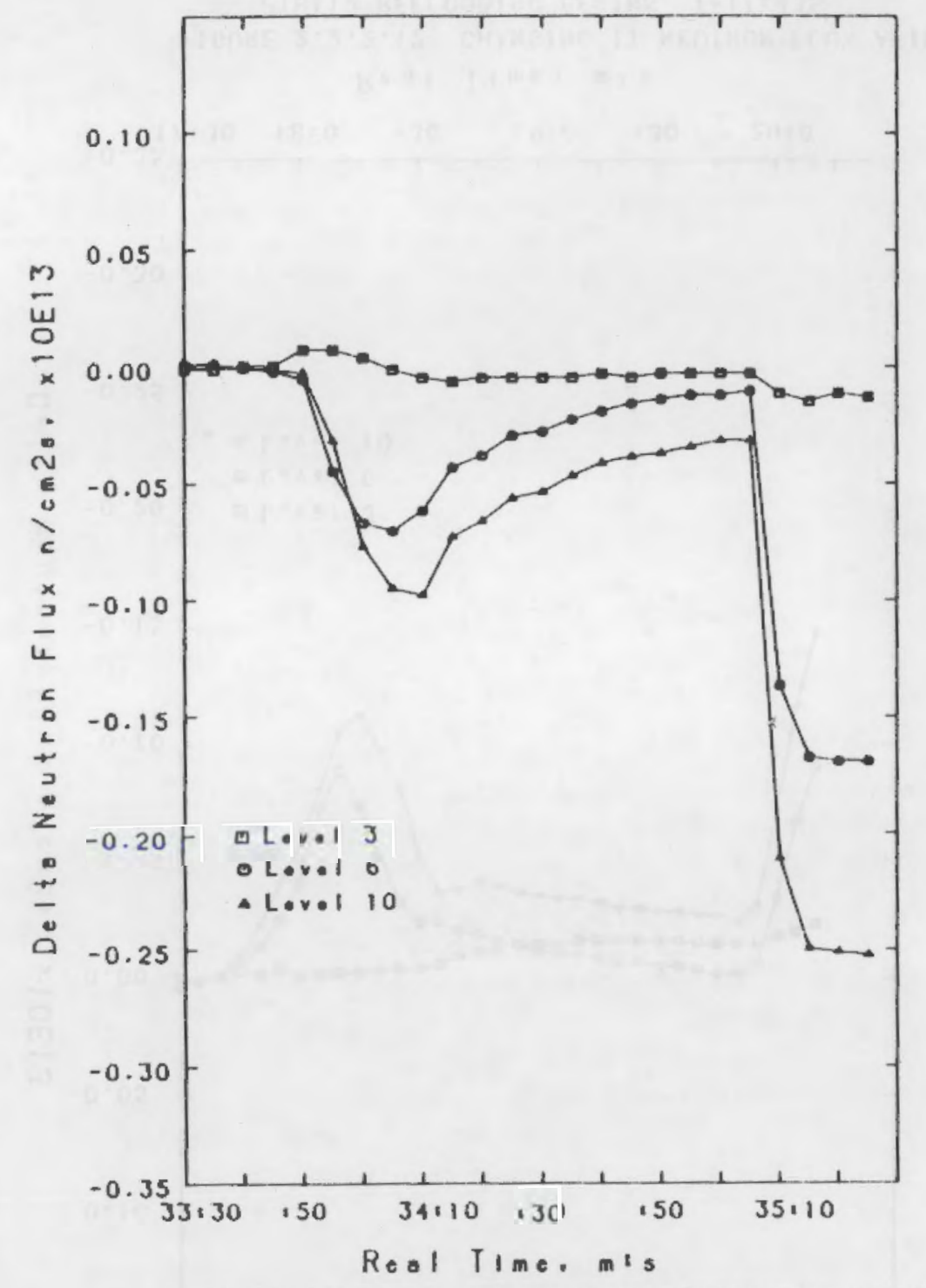

FIGURE 2.2.2.14 CHANGING II NEUTRON FLUX AFIER PIHII 1 REFLOODING BEGINS, I $=33: 46 S$ 

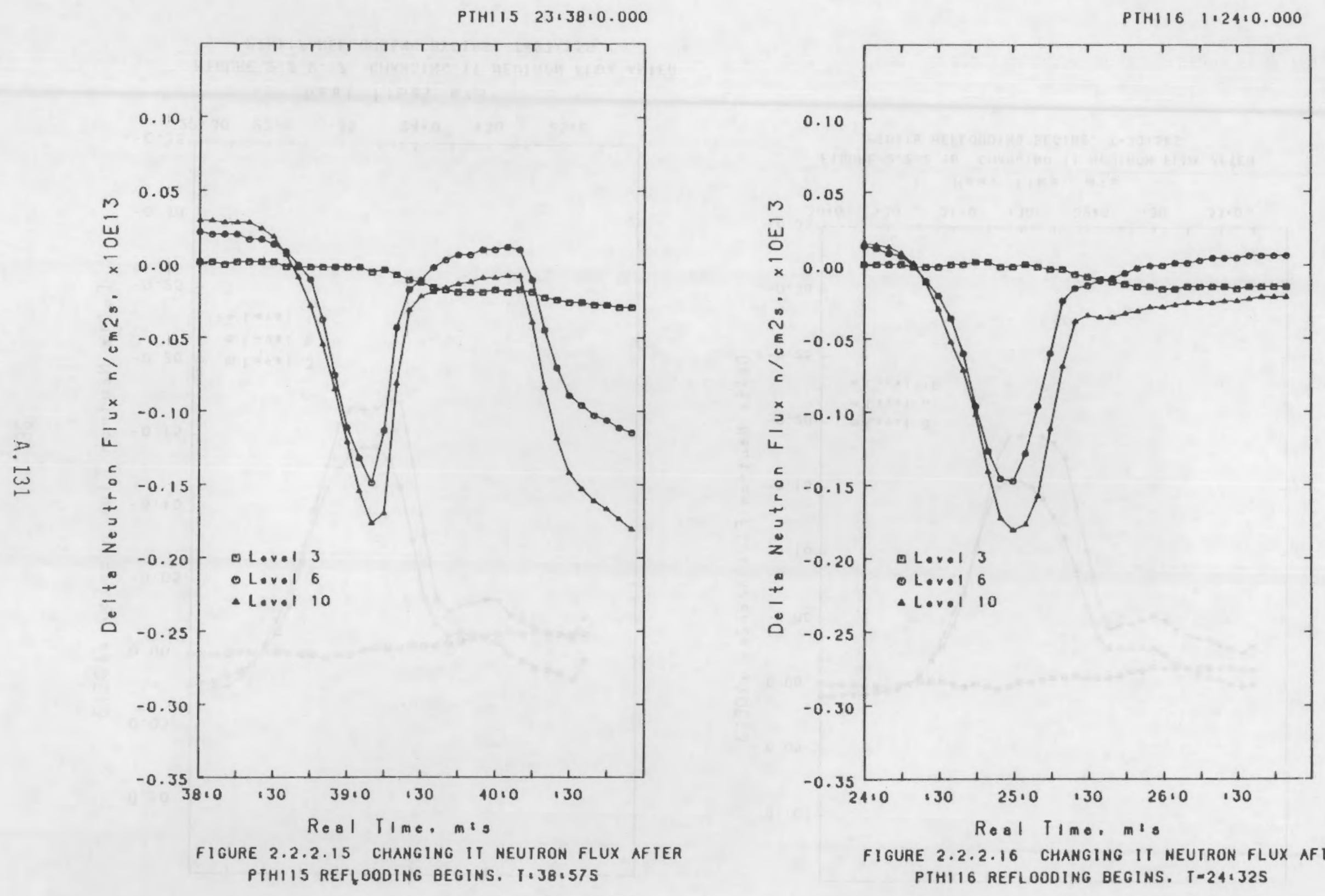

PIHIIS REF L OODING BEGINS. T:38:575

FIGURE 2.2.2.16 CHANGING II NEUTRON FLUX AFIER PIHI16 REFL OODING BEGINS. T-24:32S 
PIH117 2.22,30.000

PIH!I8 3:30:0.000
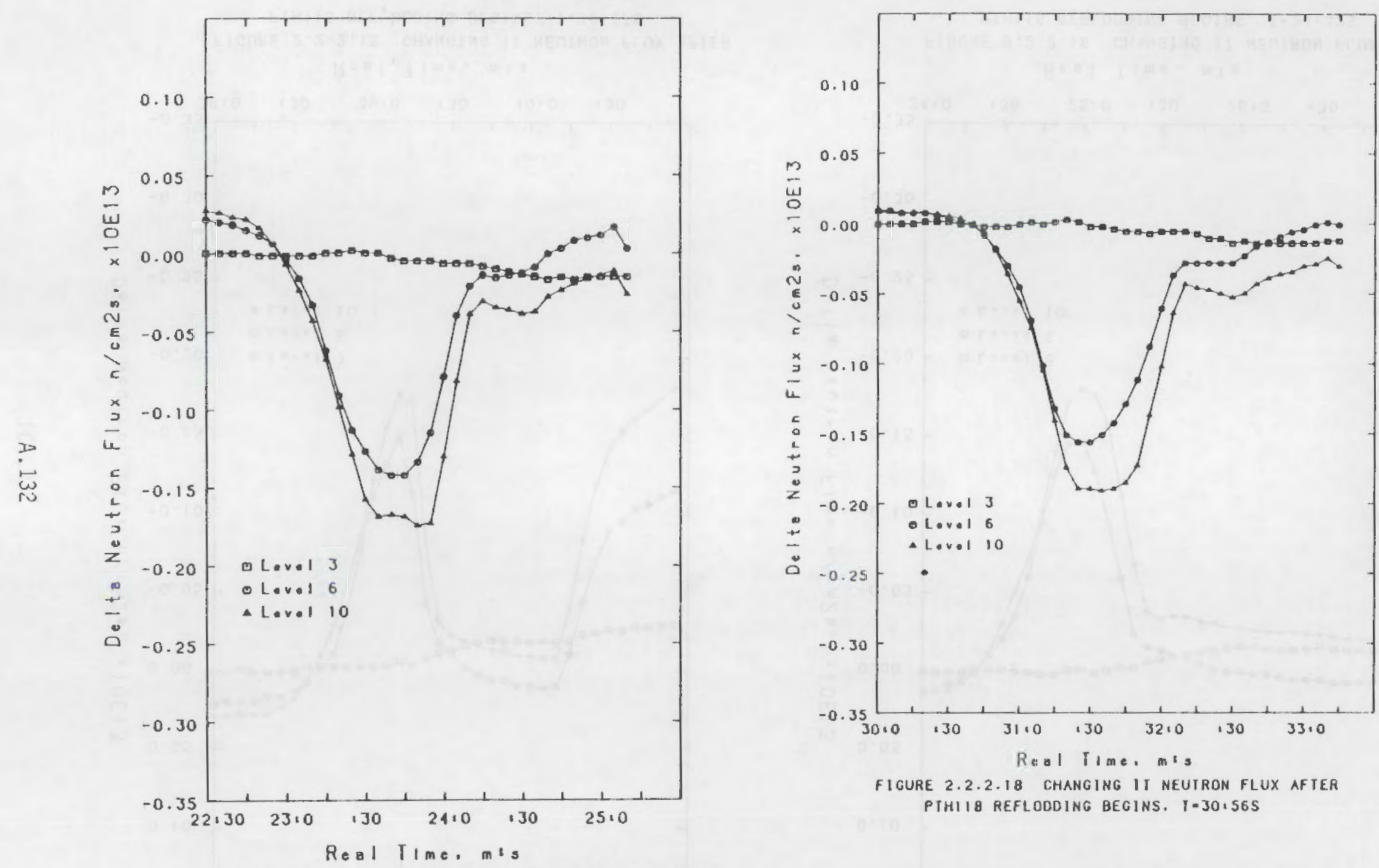

FIGURE 2.2.2.18 CHANGING II NEUTRON FLUX AFTER PIHIIQ REFLODDING BEGINS. $I=30.56 \mathrm{~S}$

FIGURE 2.2.2.17 CHANGING II NEUTRON FLUX AFIER PIHII7 REFLOODING BEGINS, $I=23,15 S$ 
PIHI19 $5.27: 30.000$

PIHI20 612610.000
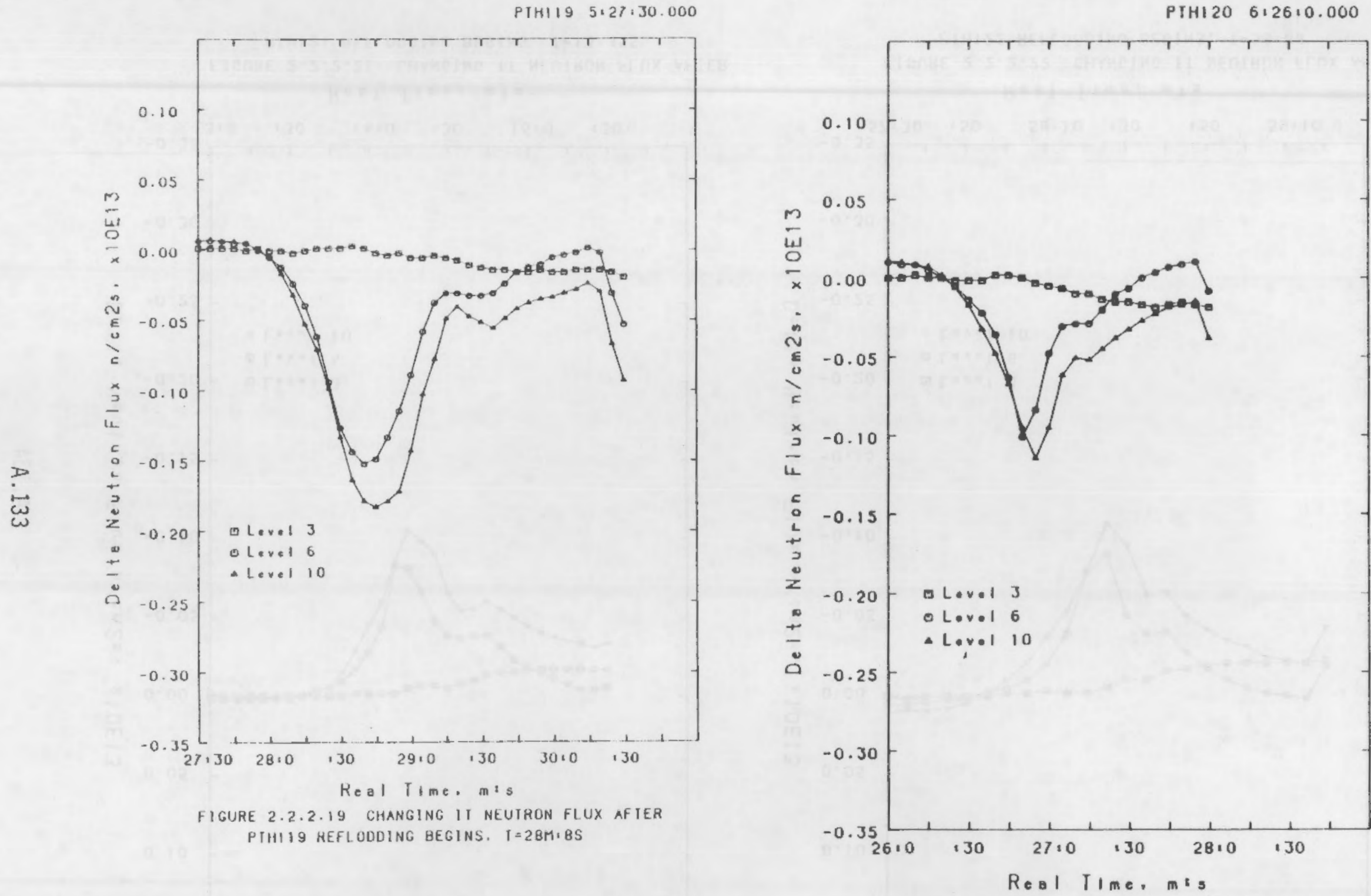

PIHIII REFL ODDING BEGINS. $T=28 M, B S$

FIGURE 2.2.2.20 CHANGING II NEUIRON FLUX AFIER PIHI20 REFLOODING BEGINS. $I=26.34 S$ 
PIH121 $7: 13: 0.000$

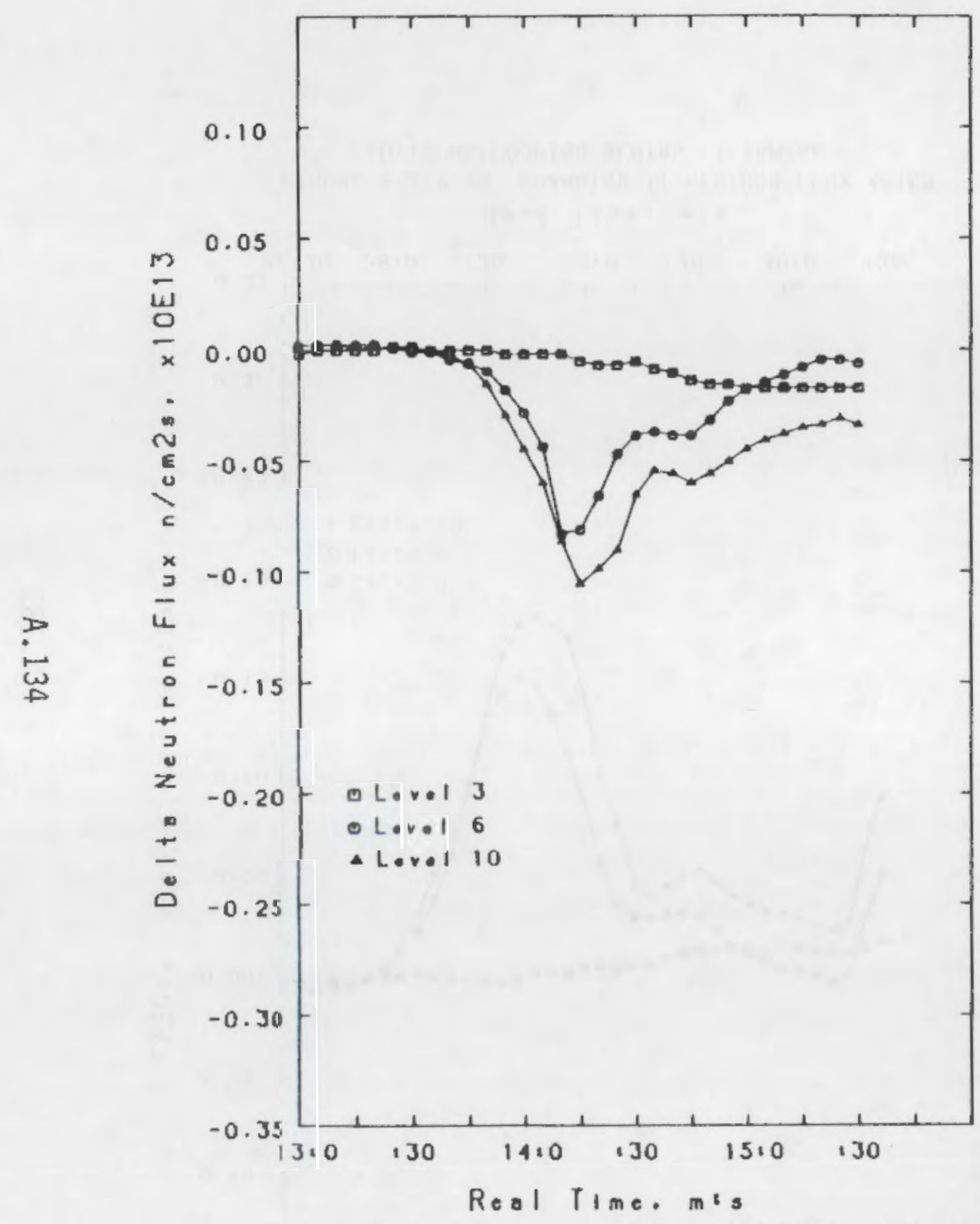

FIGURE 2.2.2.21 CHANGING IT NEUTRON FLUX AFIER PIHI2I REFLOODING BEGINS, T=13,45S
PIH122 7:57:30.000

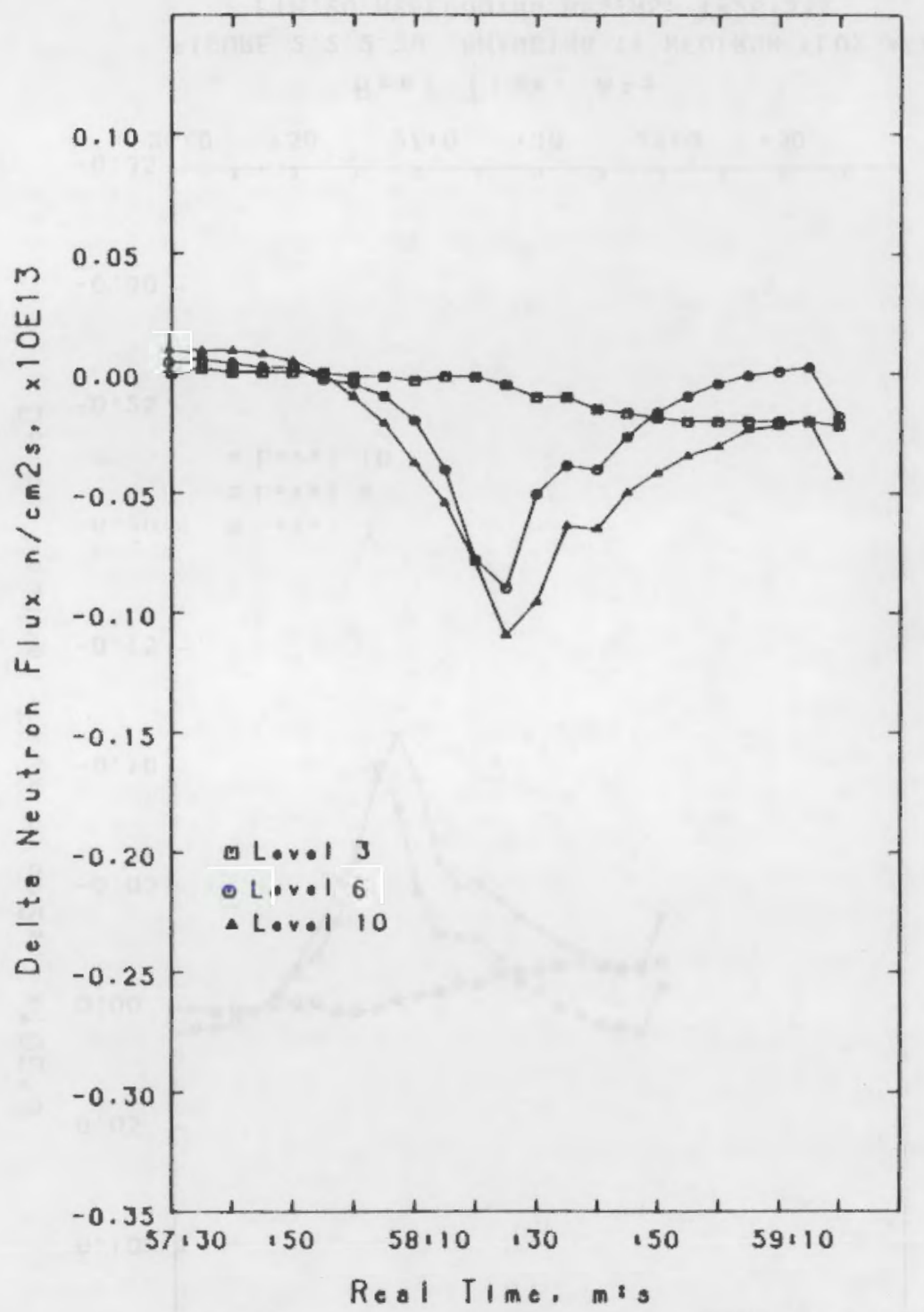

FIGURE 2.2.2.22 CHANGING IT NEUTRON FLUX AFIER PIMI 22 REFLOODING BEGINS. $T=58: B S$ 
PIHI2J $9: 19 \cdot 0.000$

PIH124 $10,18,30.000$
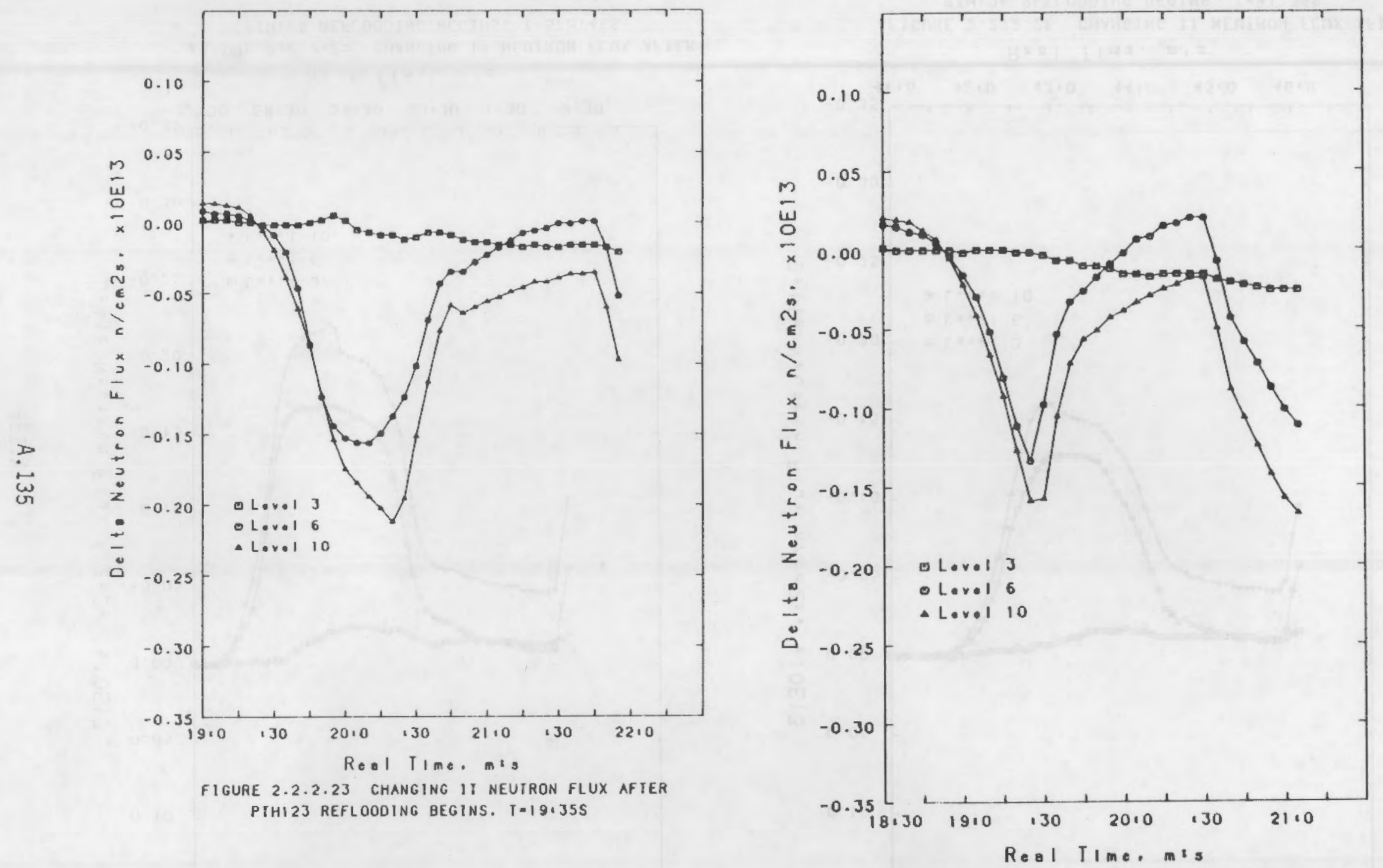

FIGURE 2.2.2.24 CHANGING IT NEUTRON FLUX AFIER PIHI24 REFLOODING BEGINS. $T=19107 \mathrm{~S}$ 
PIHI25 11:57:30.000

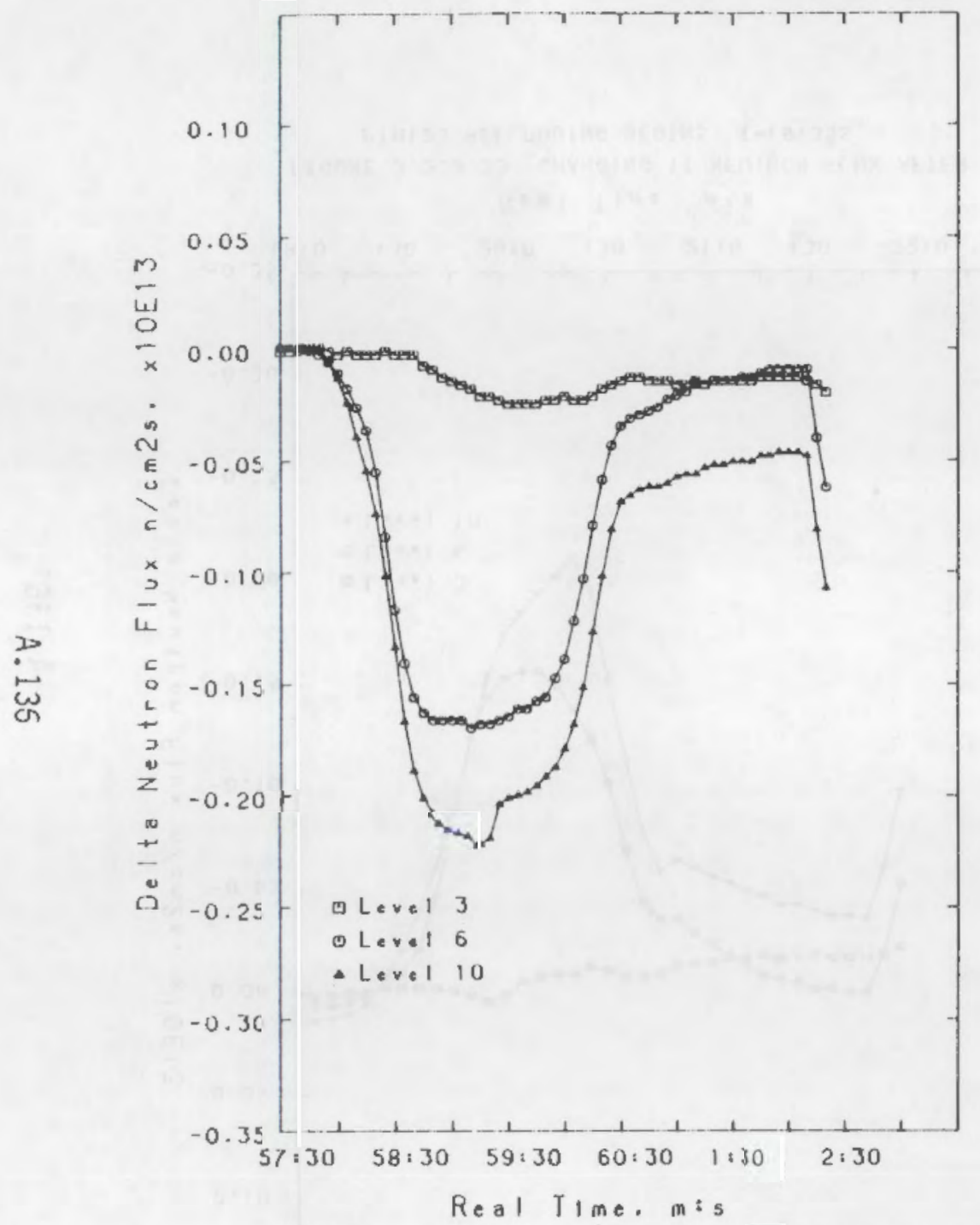

FIGURE 2.2.2.25 CHANGING IT NEUIRON FLUX AFIER PIHI2S REFLOODING BEGINS. $Y=57 M: 46 S$
PTHI26 13:4110.000

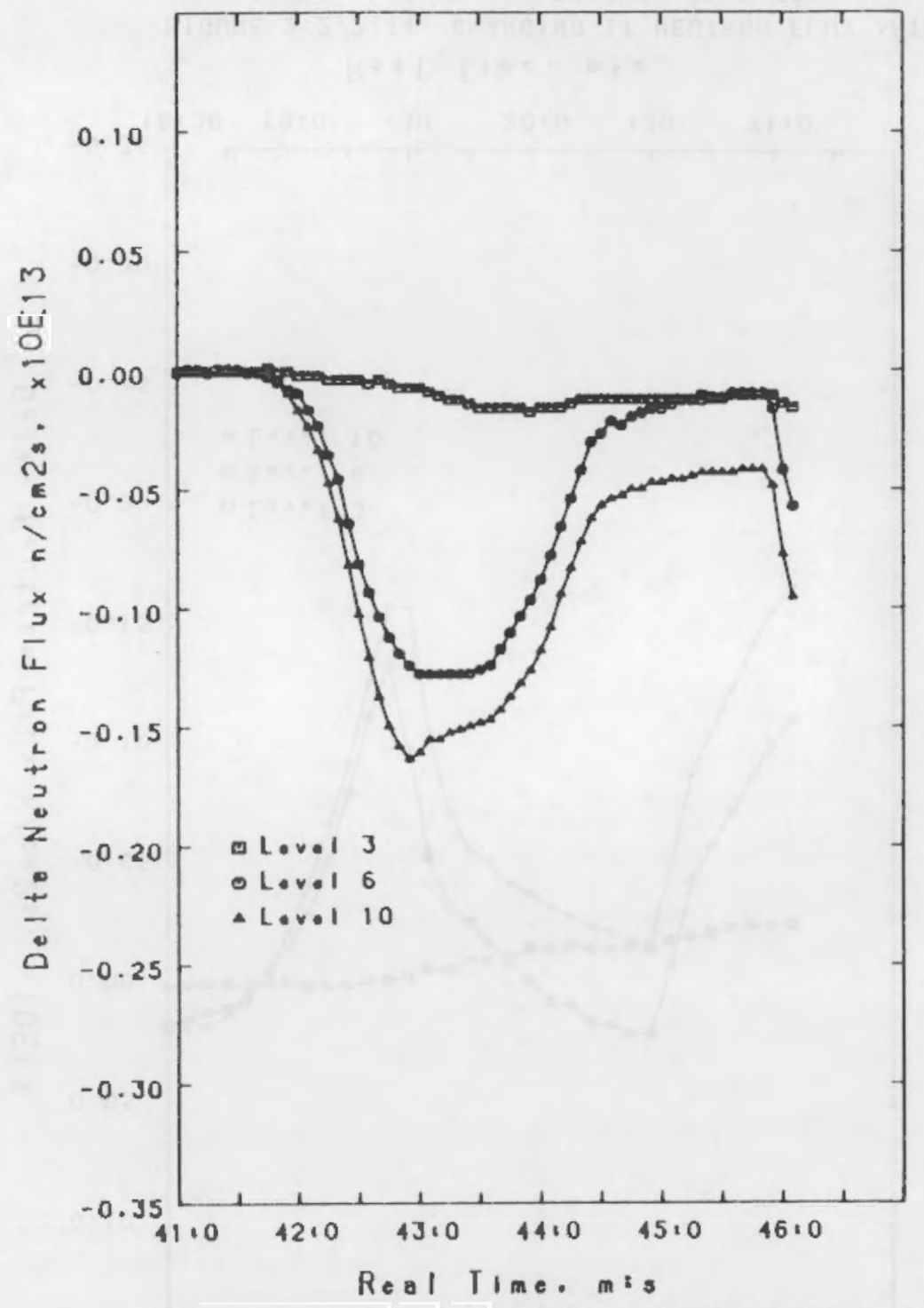

FIGURE 2.2.2.26 CHANGING IT NEUTRON FLUX AFTER PYHI26 REFLOODING BEGINS. $T=41,36 \mathrm{~S}$ 
PIH127 14:36:30.000

PIHI28 16:42:0.000
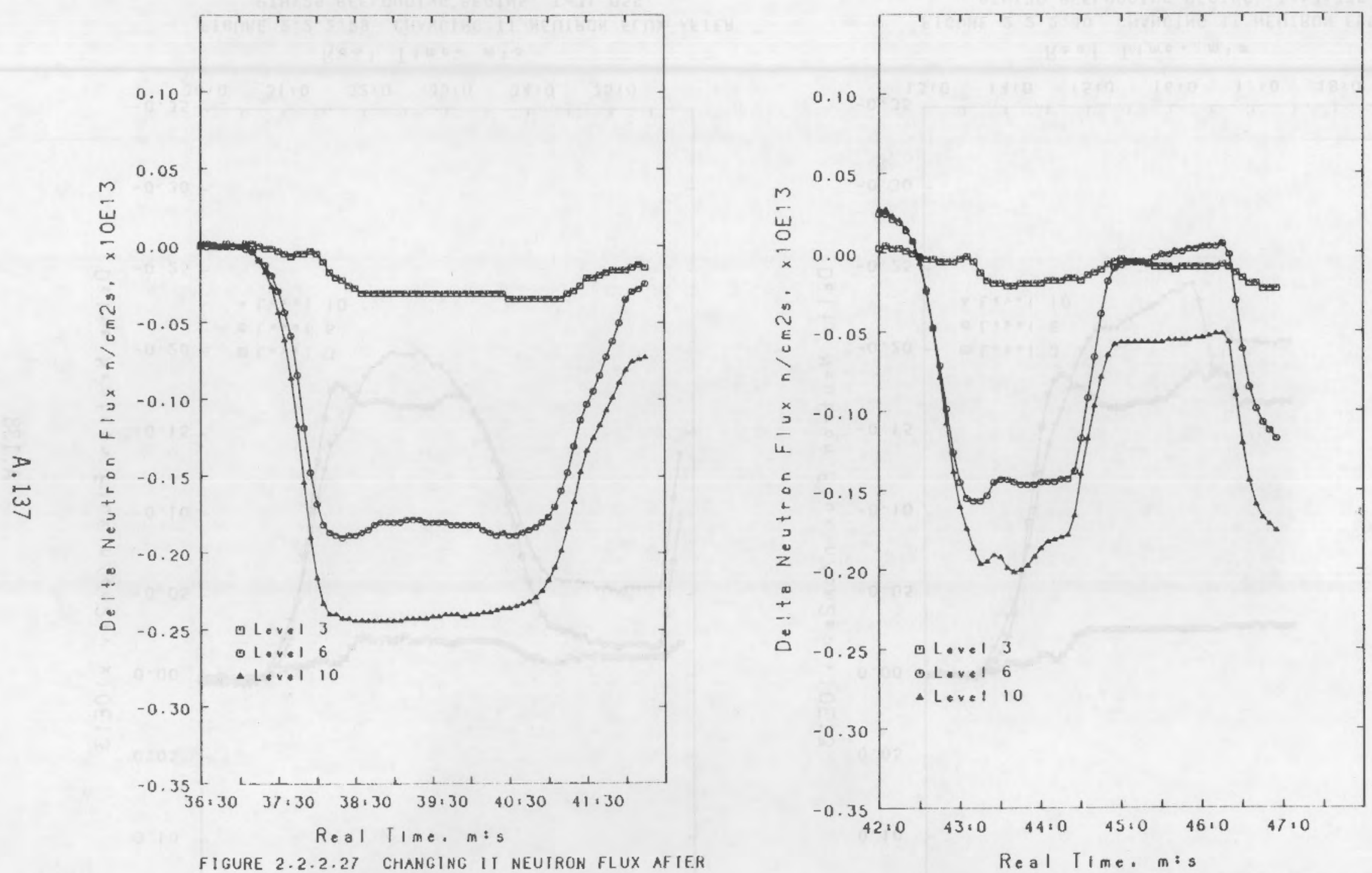

!GURE 2.2.2.27 CHANGING II NEUIRON FLUX AFIER PIHI27 REFLUODING BEGINS, $I=37: 09 S$

FIGURE 2.2.2.28 CHANGING II NEUIRON FLUX AFIER PIHI 28 REFLOODING BEGINS. $I=42 M+44 S$ 
PIH129 18:3010.000

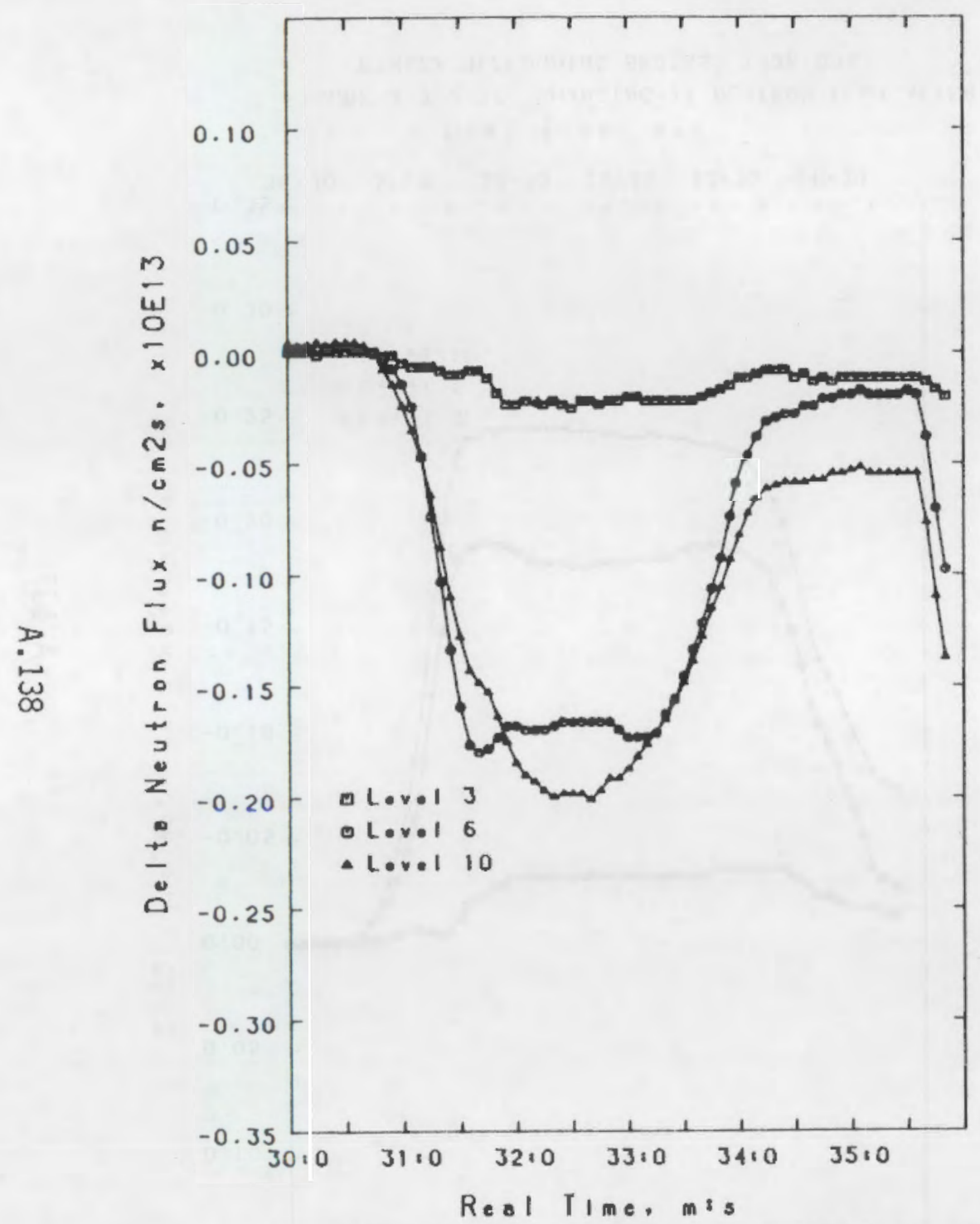

FIGURE 2.2.2.29 CHANGING IT NEUTRON FLUX AFTER PIHI29 REFLODDING BEGINS, $T=31.05 S$
PIHI30 20:13:0.000

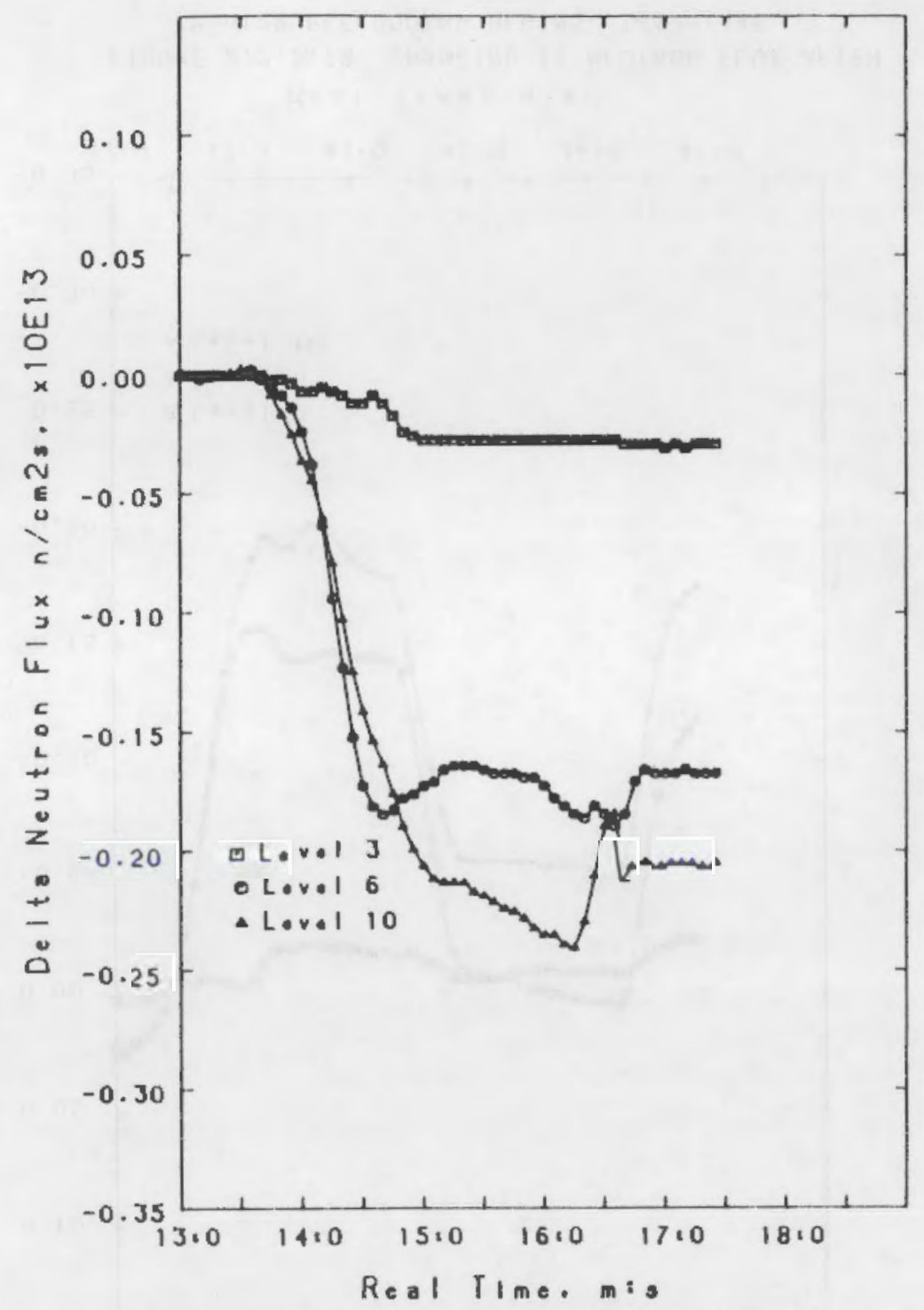

FIGURE 2.2.2.JO CHAHGING IT NEUTRON FLUX AFTER PTHIJO REFLOODING BEGINS. T=13.J3S 


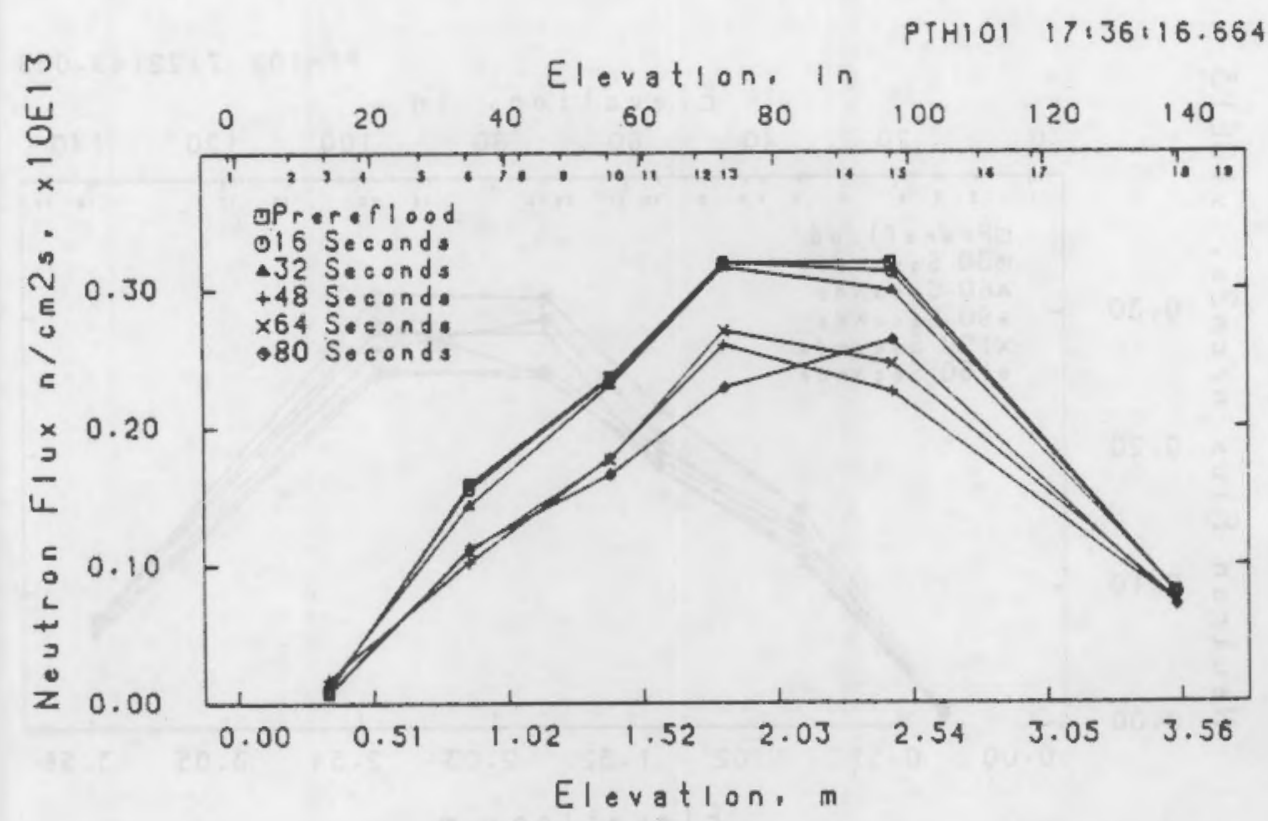

FIGURE 2.2.3.01 IT NEUTRON FLUX AXIAL PROFILES AFTER REFLOODING, AT IGS INTERVALS - PTHIOI

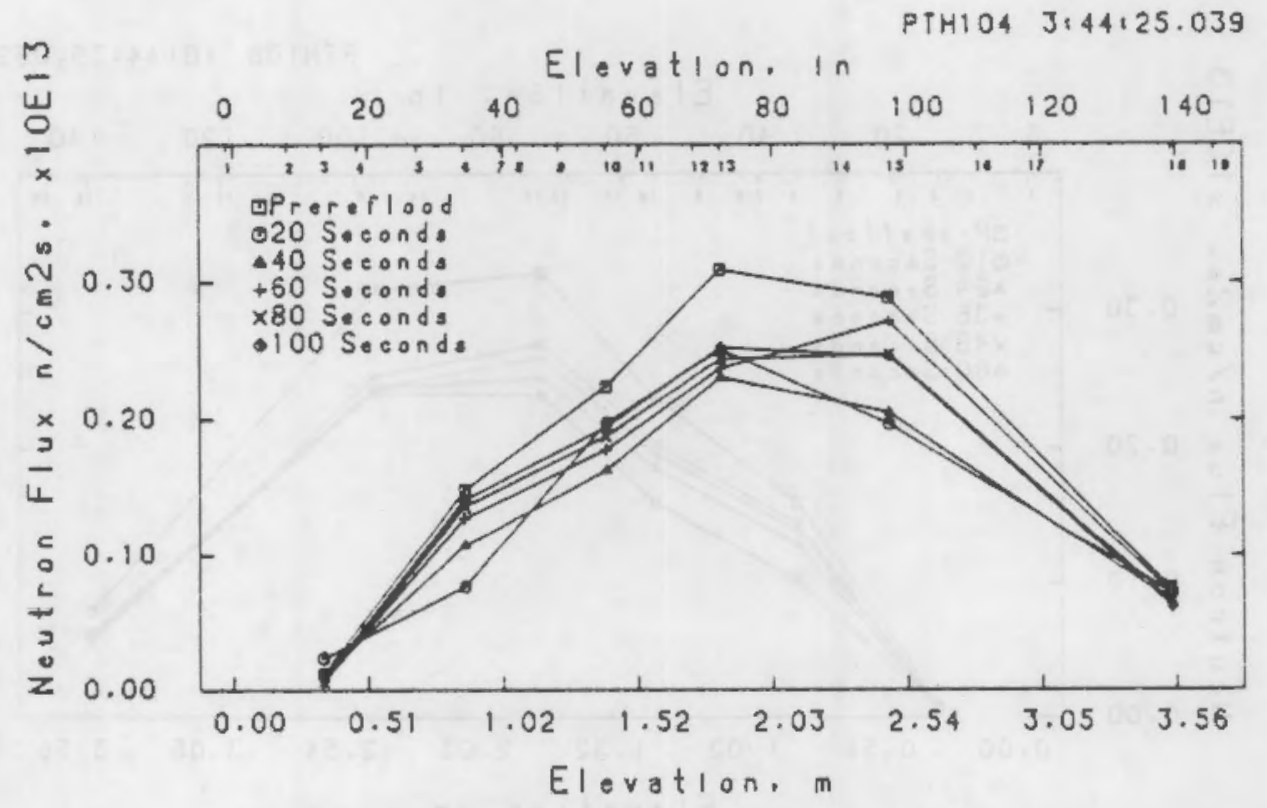

FIGURE 2.2.3.04 IT NEUTRON FLUX AXIAL PROFILES AFTER REFLOODING. AT 2OS INTERVALS - PTHIOA 


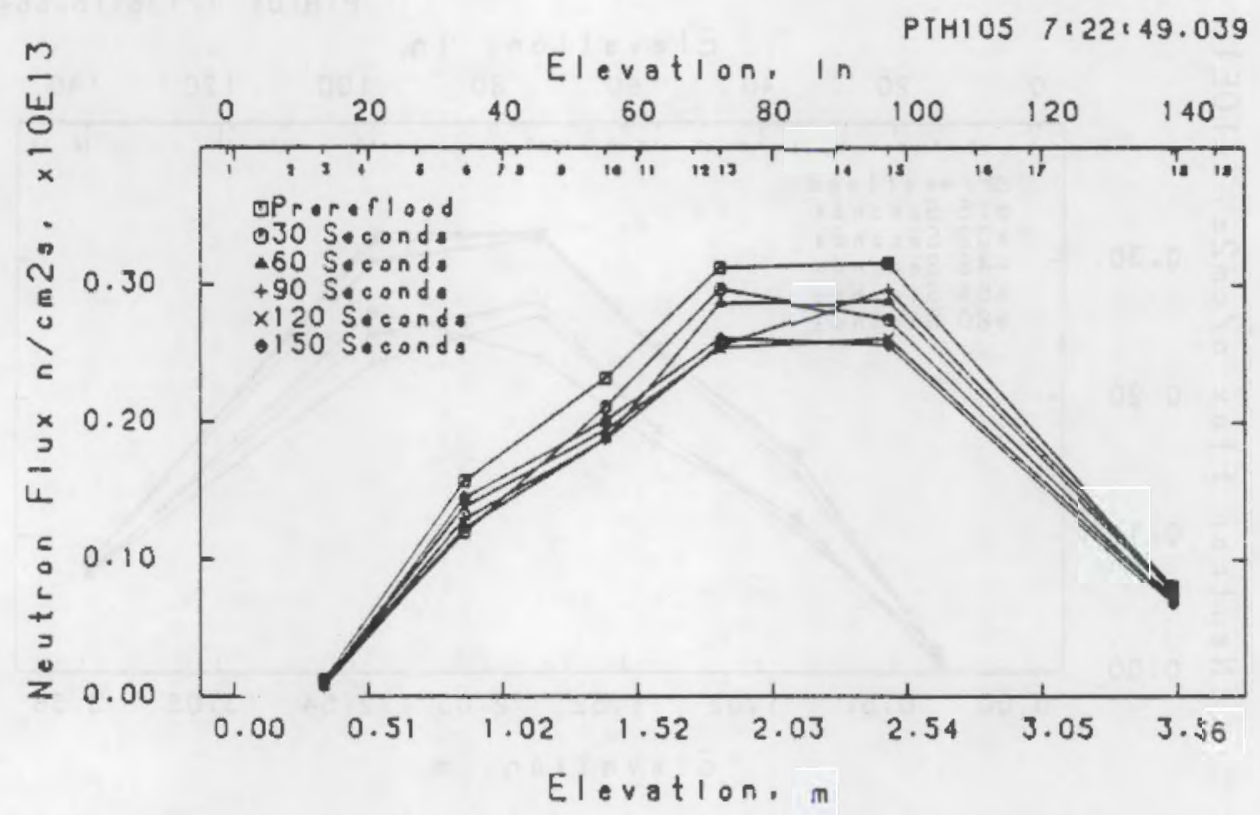

FIGURE 2.2.3.05 IT NEUTRON FLUX AXIAL PROFILES AFTER REFLOODING, AT JOS INTERVALS - PTHIOS

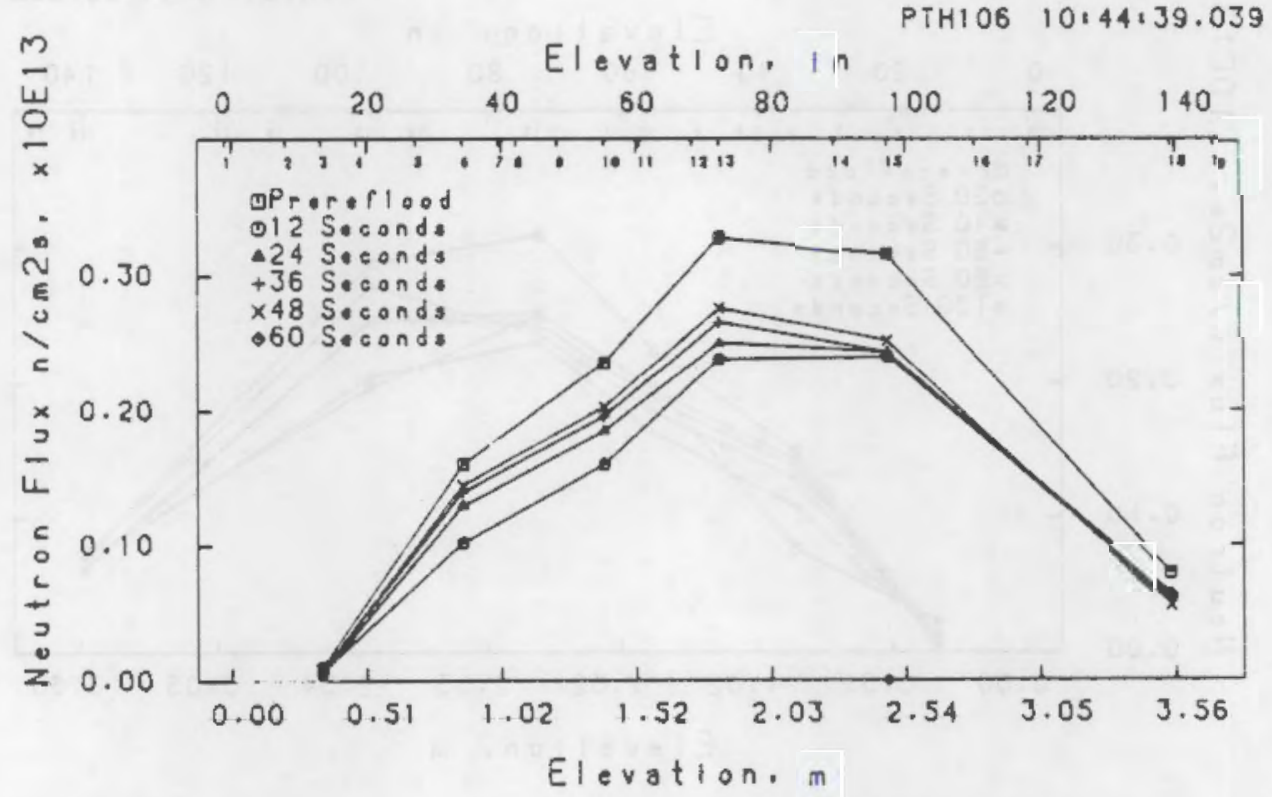

FIGURE 2.2 .3 .06 IT NEUTRON FLUX AXIAL PROFILES AFTER REFLOODING. AT 12S INTERVALS - PTHIO6 


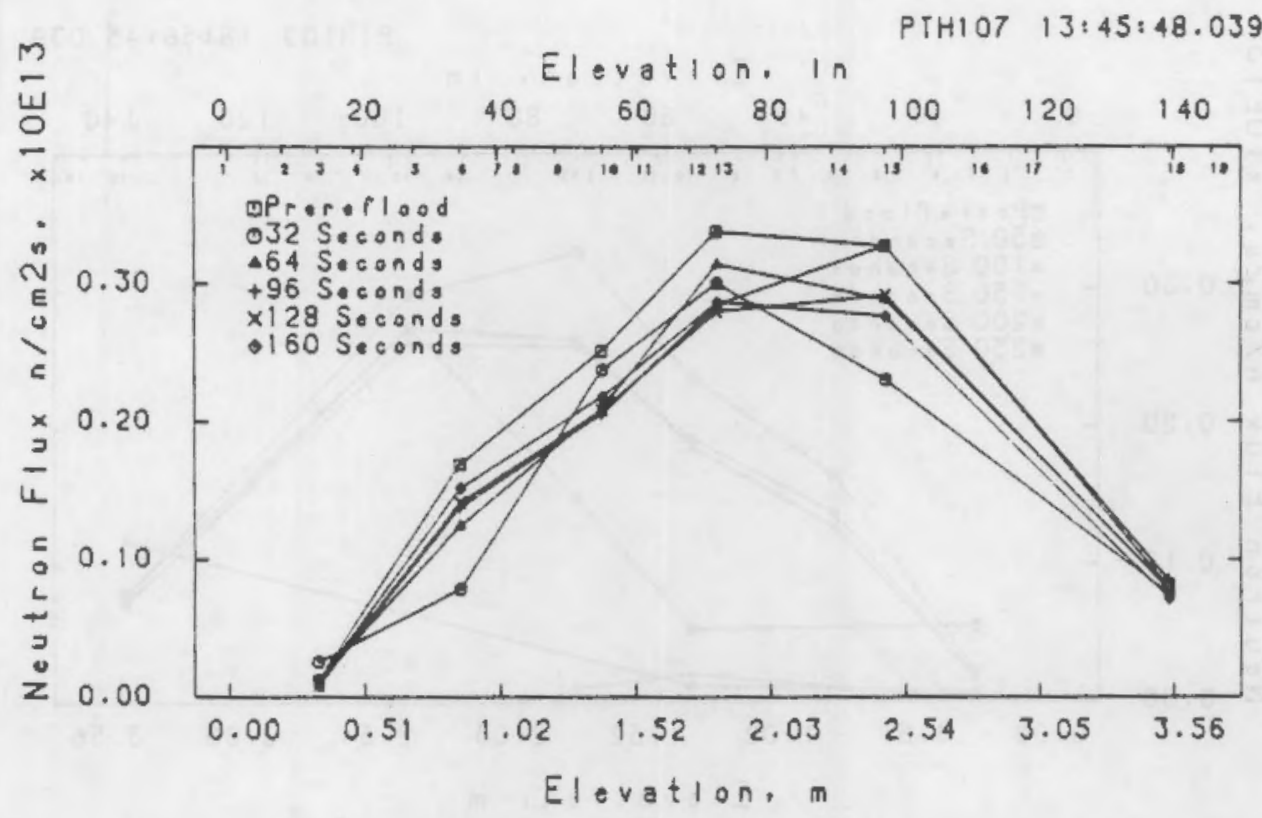

FIGURE 2.2.3.07 IT NEUTRON FLUX AXIAL PROFILES AFTER REFLOODING. AT 32S INTERYALS - PTHIOT

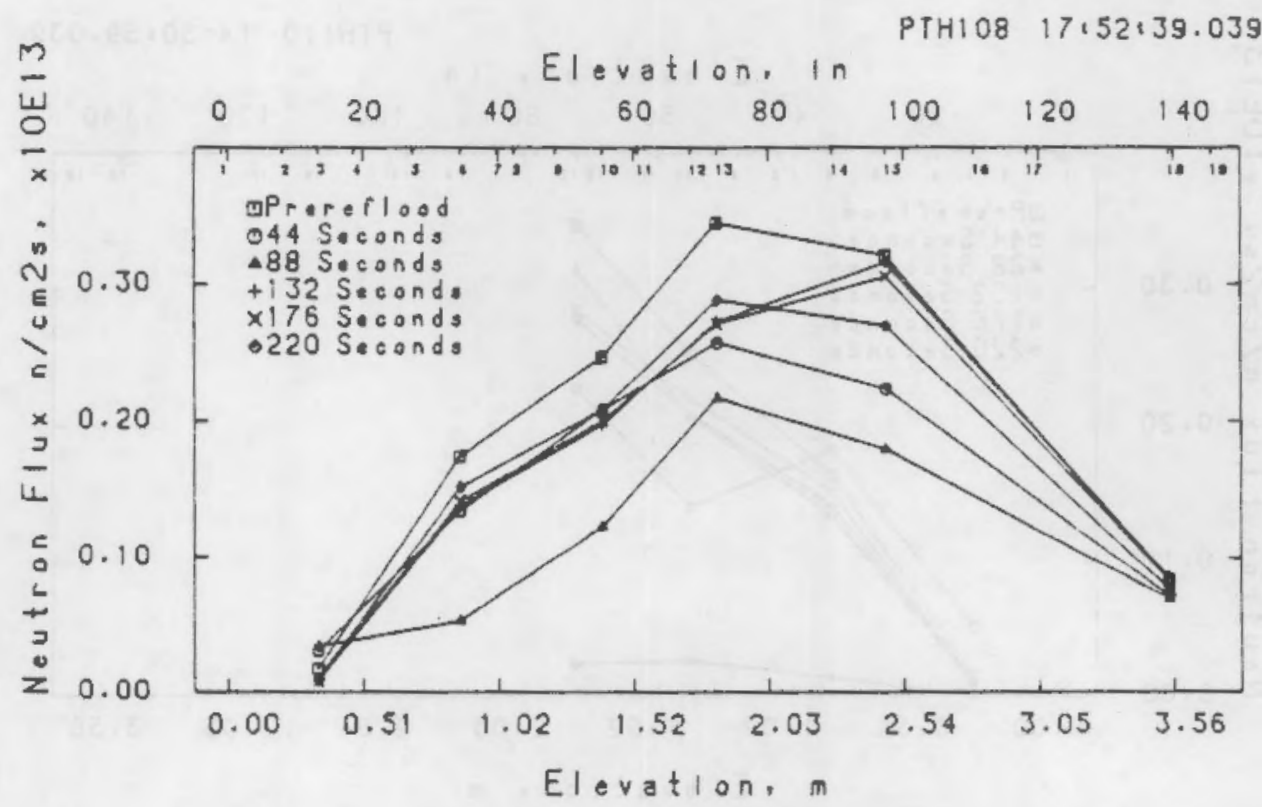

FIGURE 2.2.3.08 IT NEUTRON FLUX AXIAL PROFILES AFTER REFLOOOING, AT 44S INTERYALS - PTHIO8 


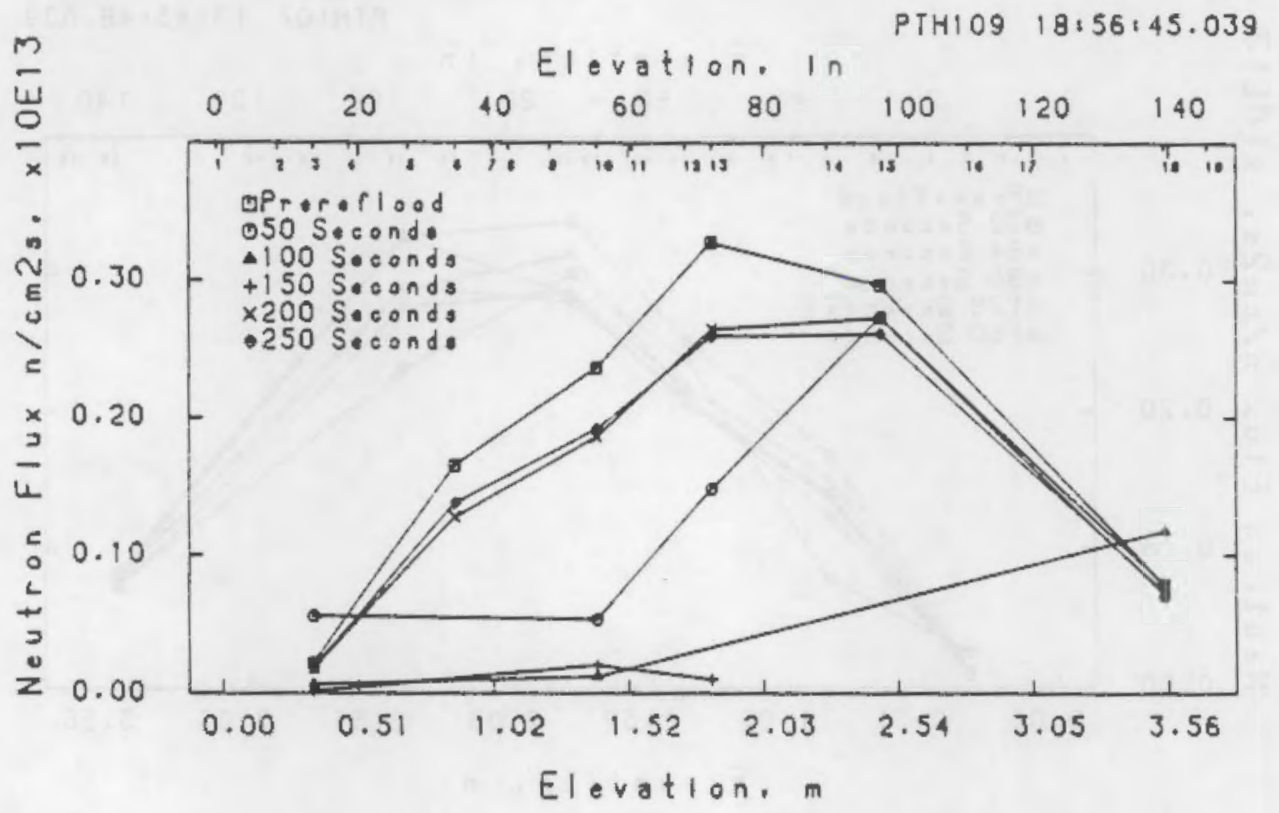

FIGURE 2.2.3.09 IT NEUTRON FLUX AXIAL PROFILES AFTER REFLOODING AT SOS INTERVALS - PTHIOS

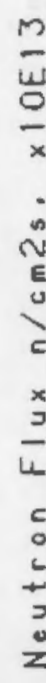

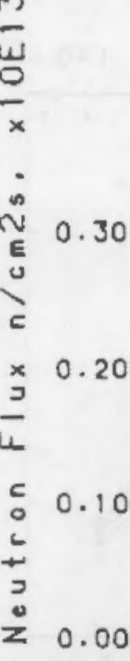

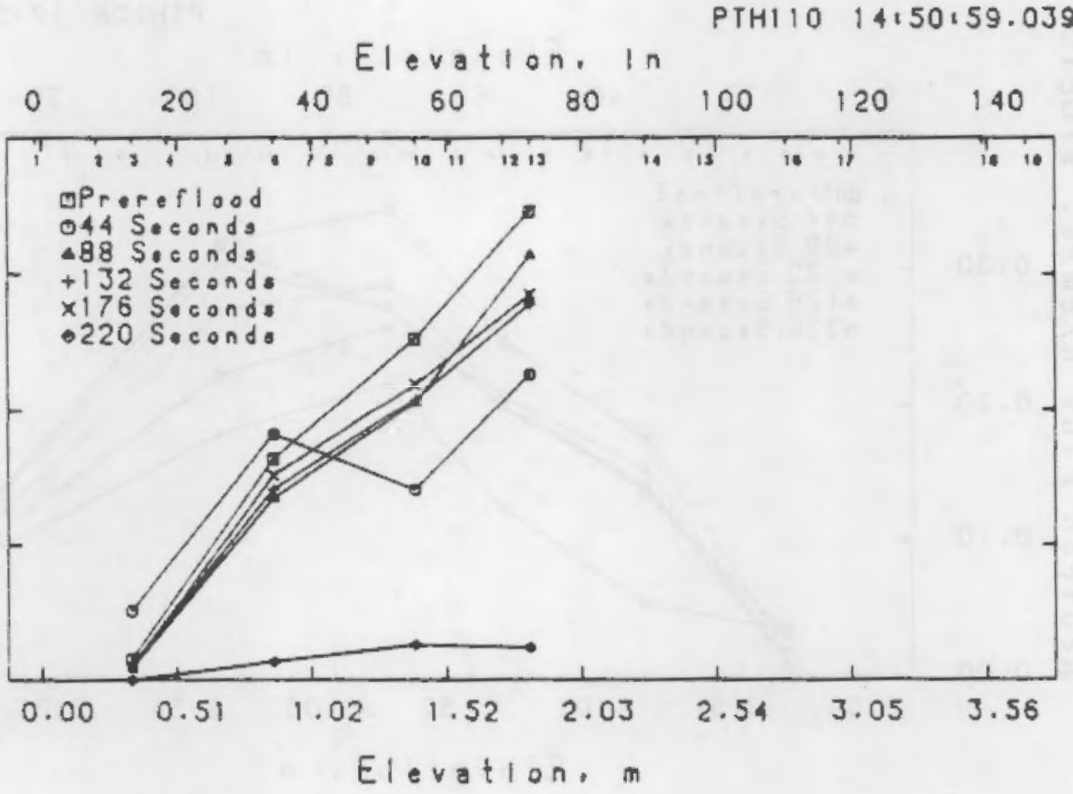

FIGURE 2.2.3.10 IT NEUTRON FLUX AXIAL PROFILES AFTER REFLOODING AT 44S INTERVALS - PTHIIO 


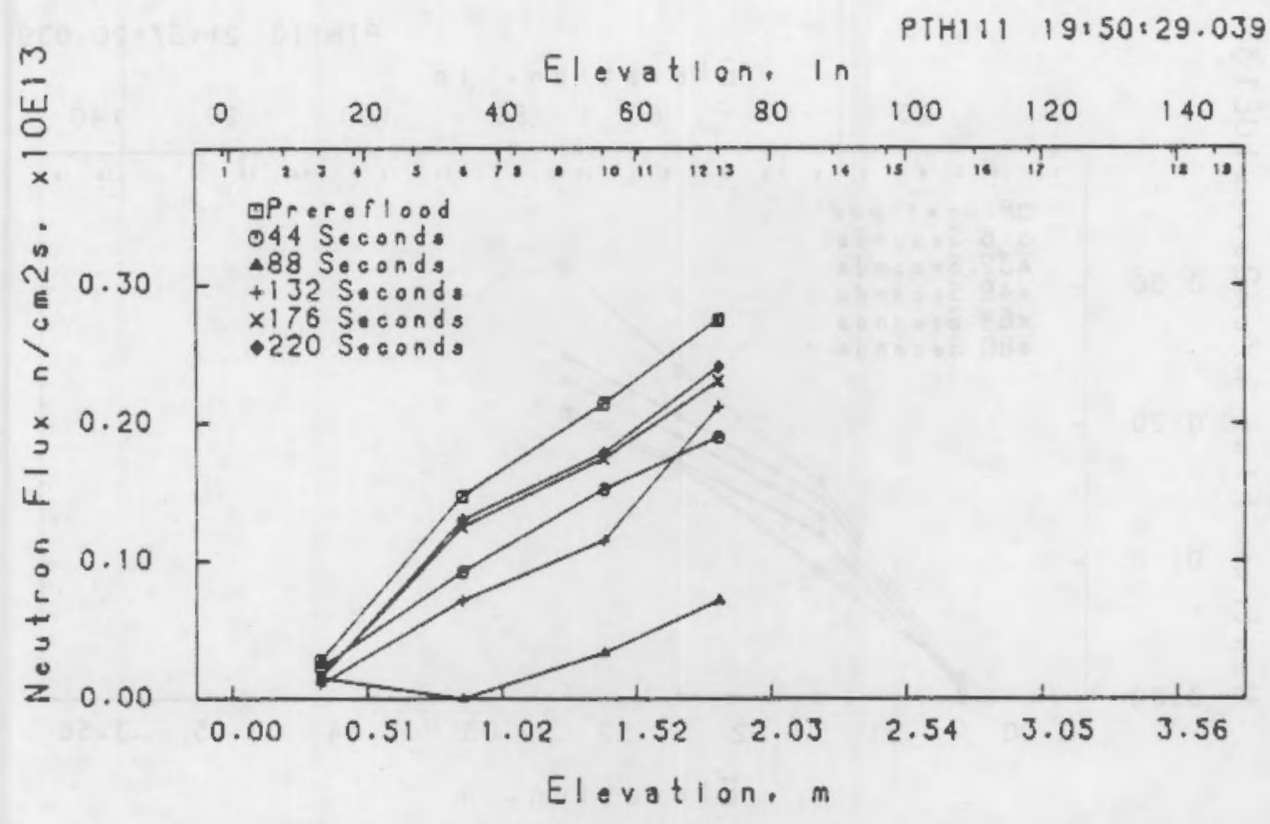

FIGURE 2.2.3.11 IT NEUTRON FLUX AXIAL PROFILES AFTER REFLOODING AT 44S INTERVALS - PTHIII

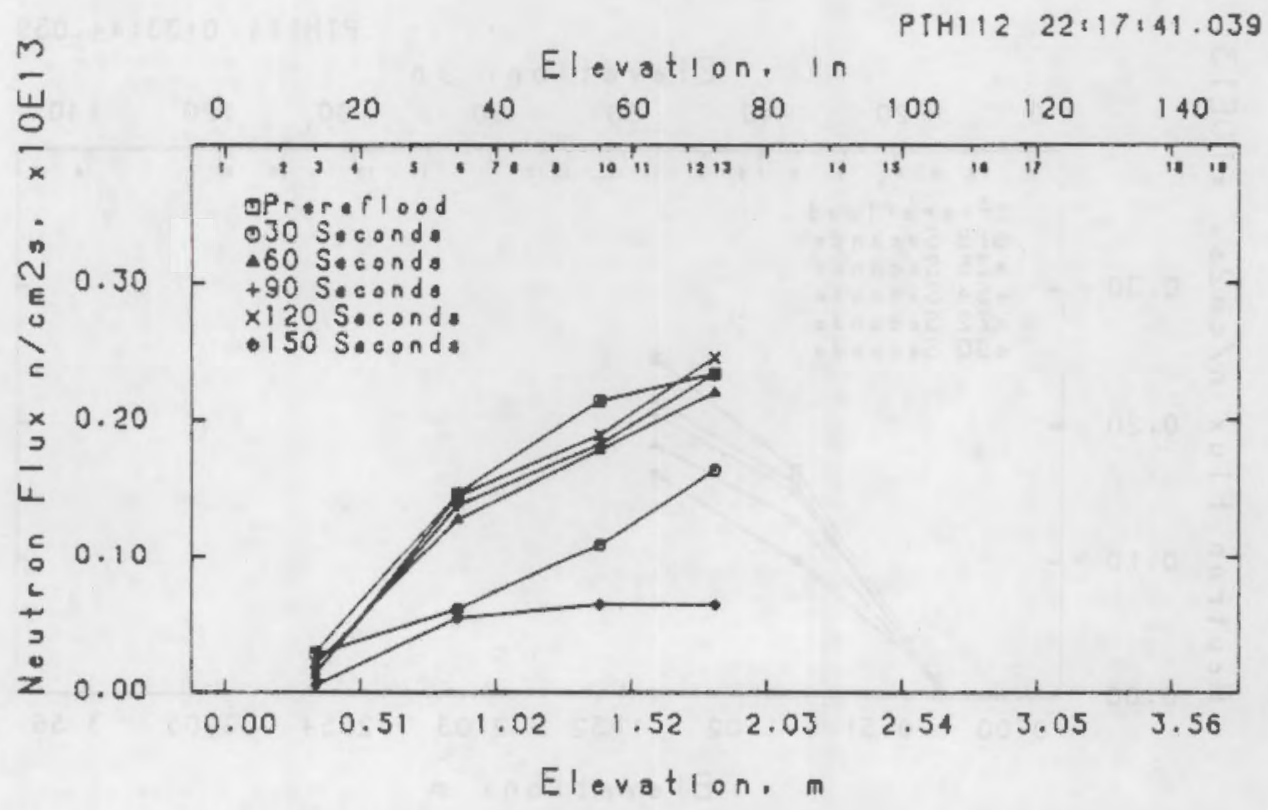

FIGURE 2.2.3.12 IT NEUTRON FLUX AXIAL PROFILES AFTER REFLOODING AT JOS INTERVALS - PTHI12 


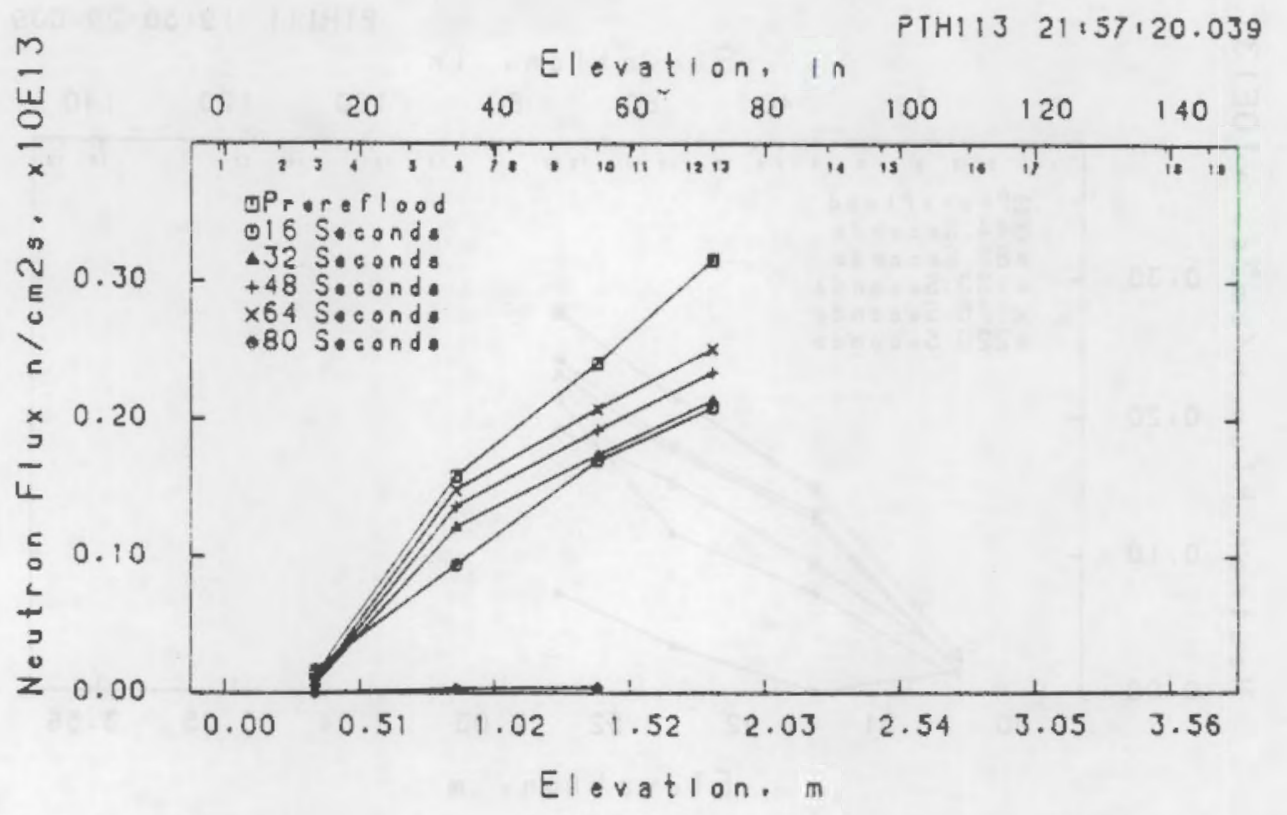

FIGURE 2.2 .3 .13 IT NEUTRON FLUX AXIAL PROFILES AFTER REFLOODING AT ISS INTERYALS - PTHIIJ

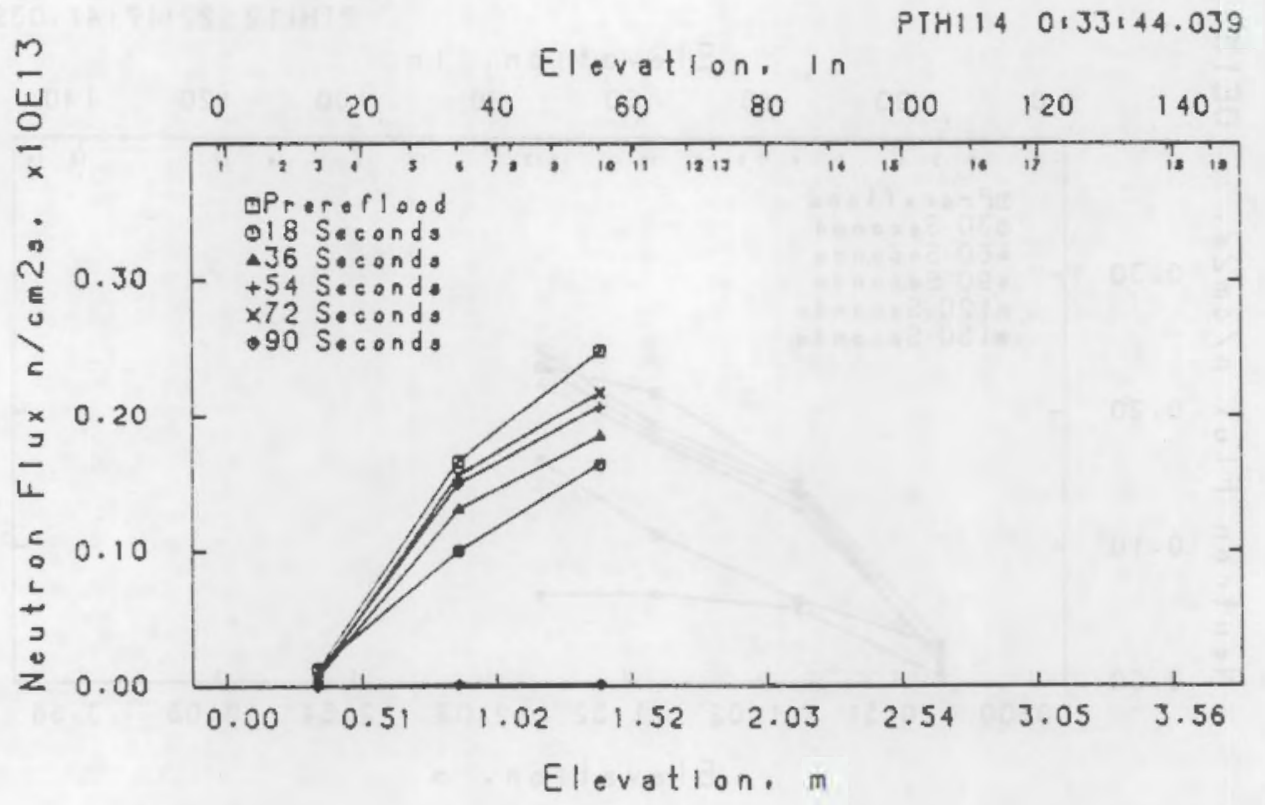

FIGURE 2.2.3.14 IT NEUTRON FLUX AXIAL PROFILES AFTER REFLOODING AT I8S INTEVALS - PIHI14 
PTH115 23:38:55.039

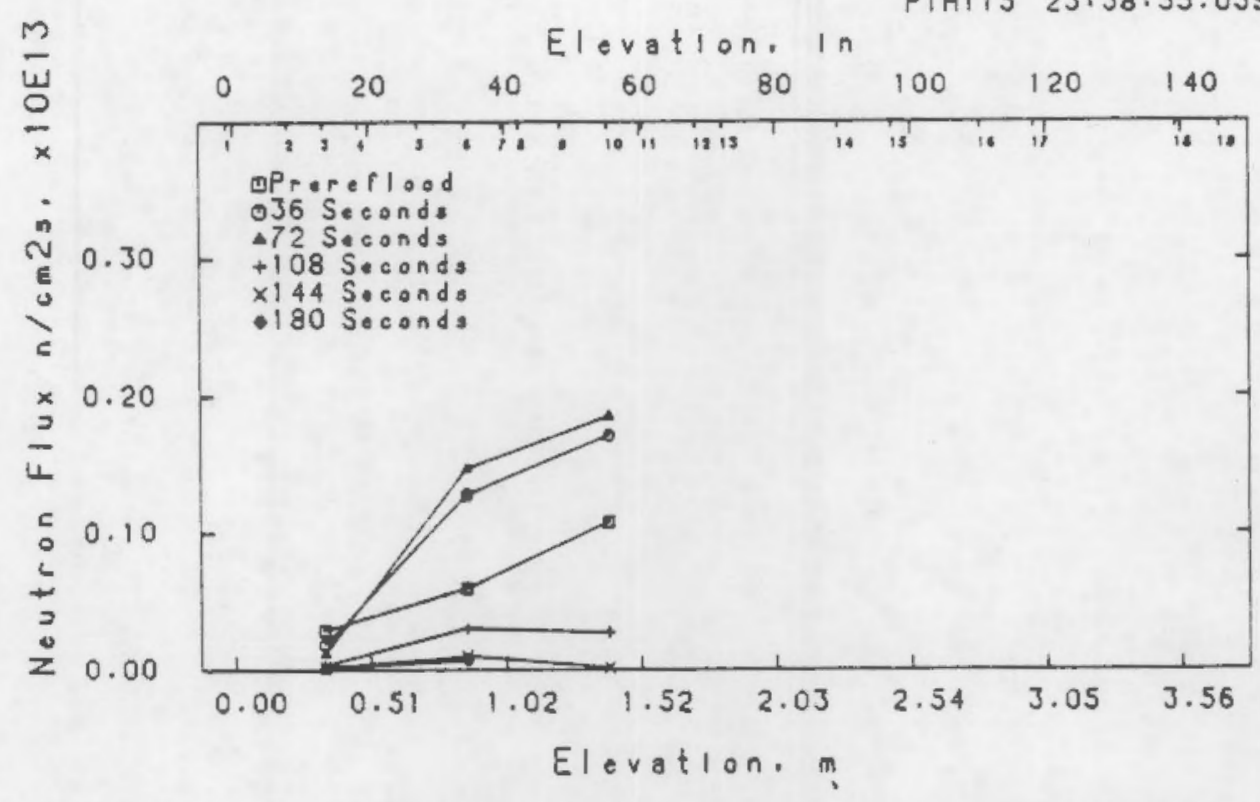

FIGURE $2 \cdot 2 \cdot 3 \cdot 15$ IT NEUTRON FLUX AXIAL PROFILES AFTER REFLOODING AT J6S INTERVALS - PTHI15

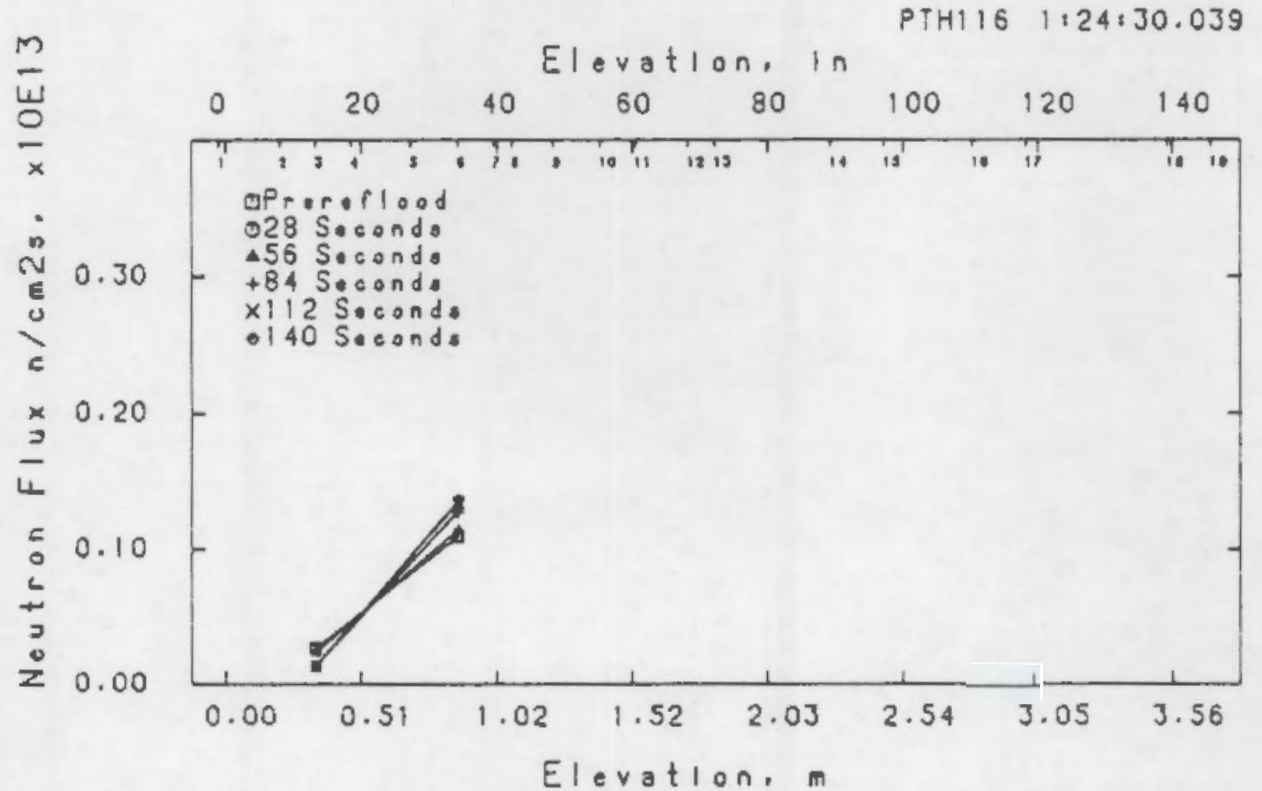

FIGURE 2.2.3.16 IT NEUTRON FLUX AXIAL PROFILES AFTER REFLOOOING AT $28 S$ INTERYALS - PIHI16 



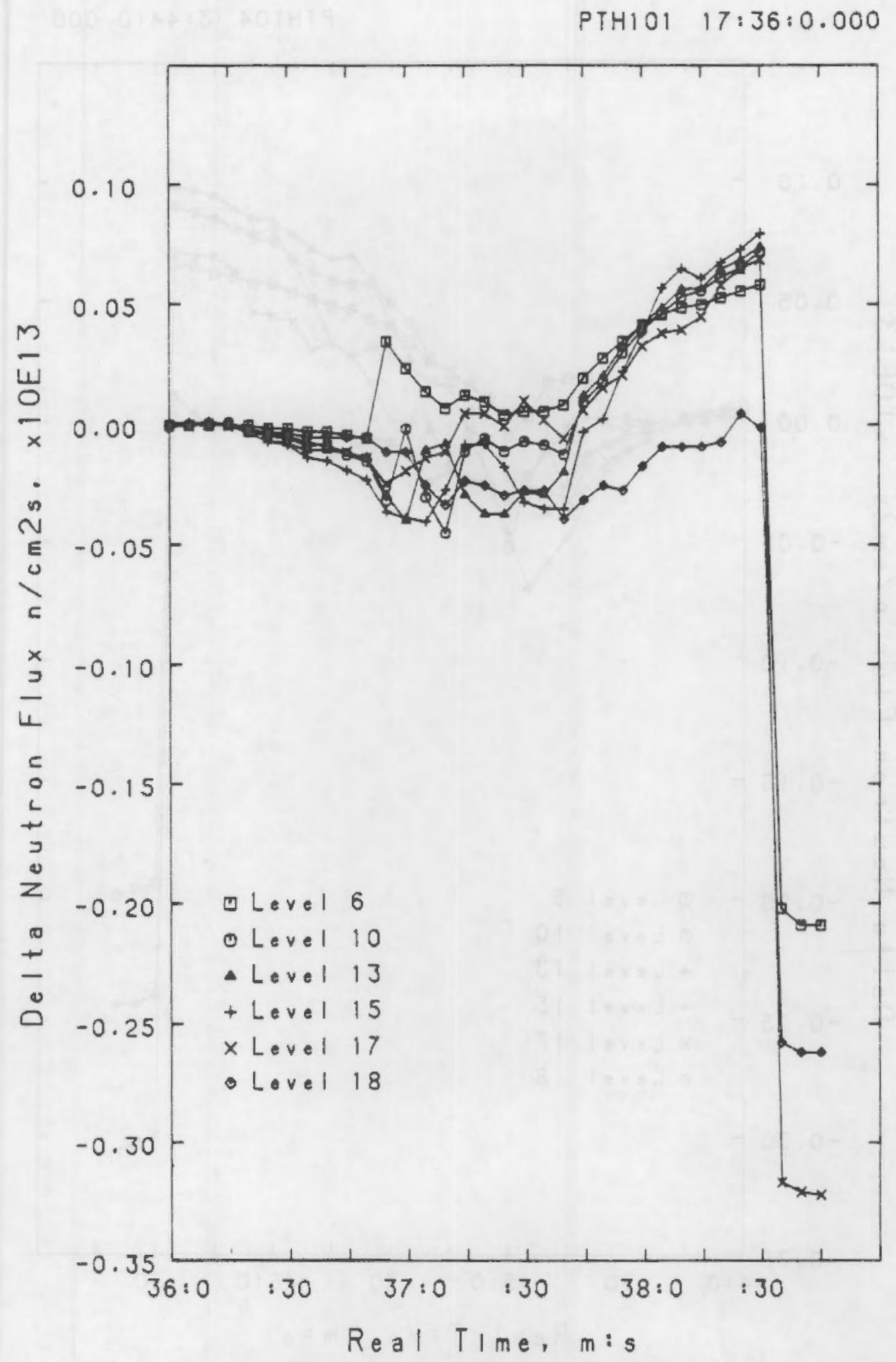

FIGURE 2.2.4.01 CHANGING NEUTRON FLUX (SHROUD) AFTER REFLOODING BEGINS, $T=36: 18 \mathrm{~S}$ 


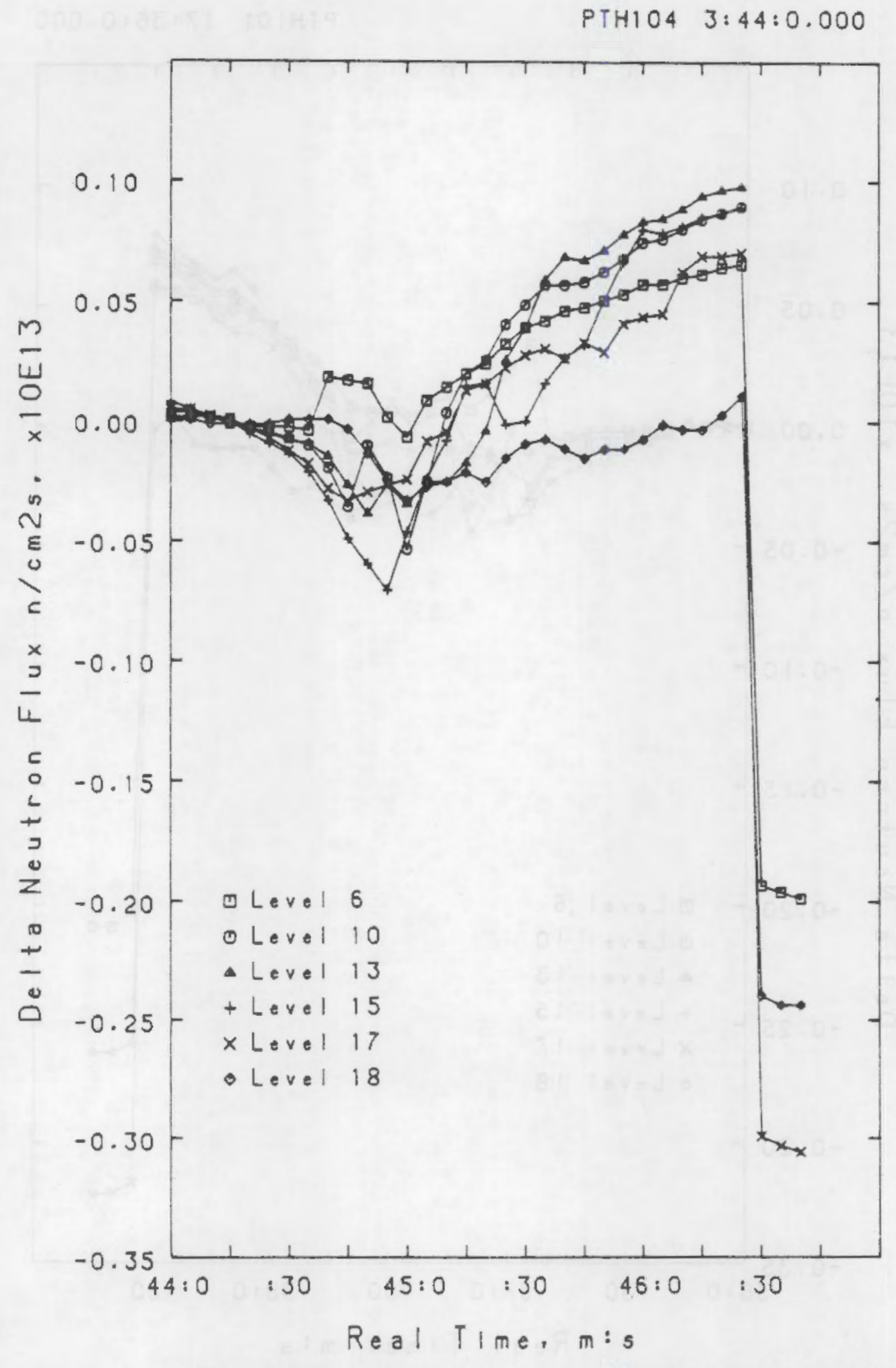

FIGURE 2.2.4.04 CHANGING NEUTRON FLUX (SHROUD) AFTER REFLOODING BEGINS. $T=44: 27 \mathrm{~S}$ 


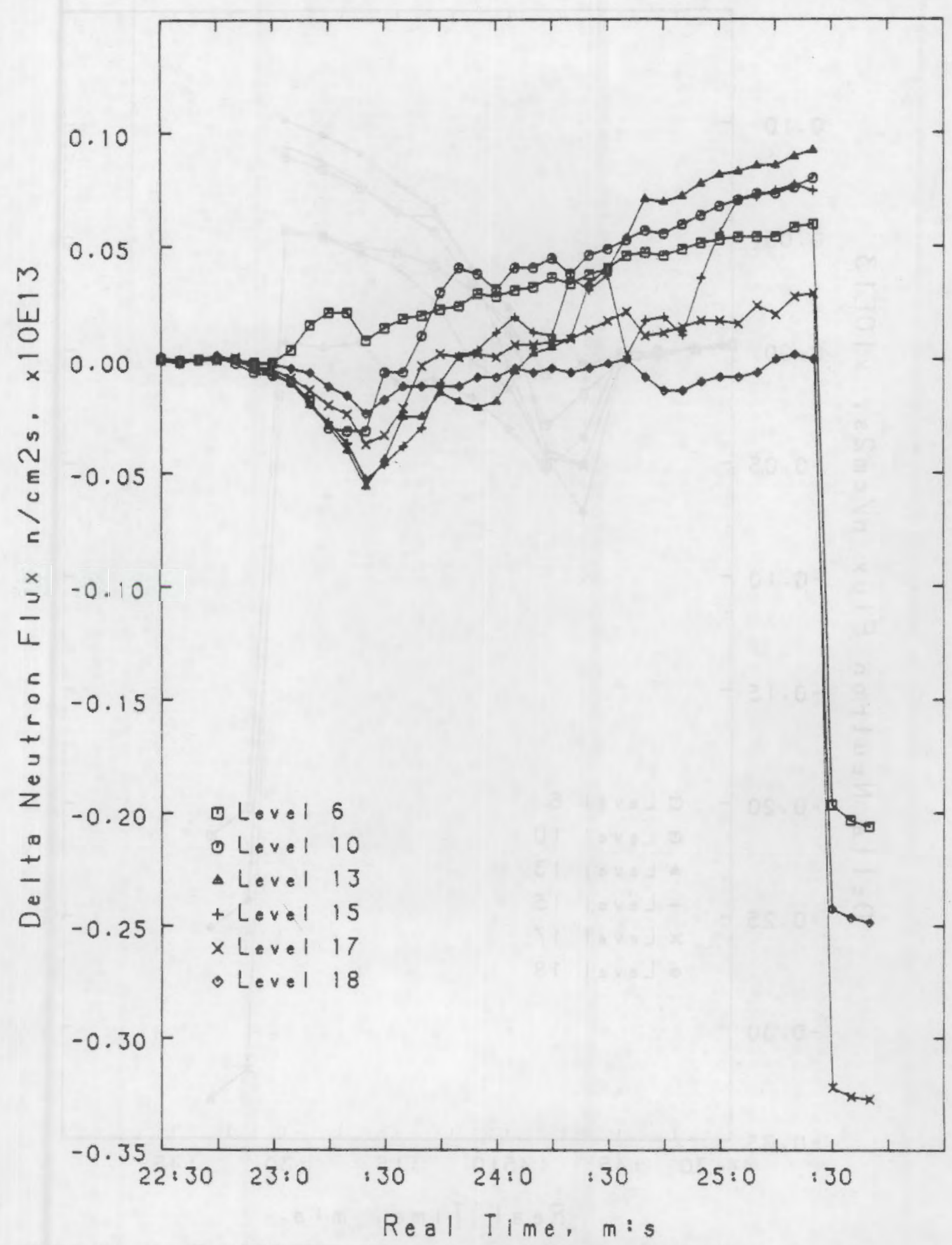

FIGURE 2.2.4.05 CHANGING NEUTRON FLUX (SHROUD) AFTER REFLOODING BEGINS, $T=22: 51 \mathrm{~S}$ 
PTH1O6 10:44:30.000

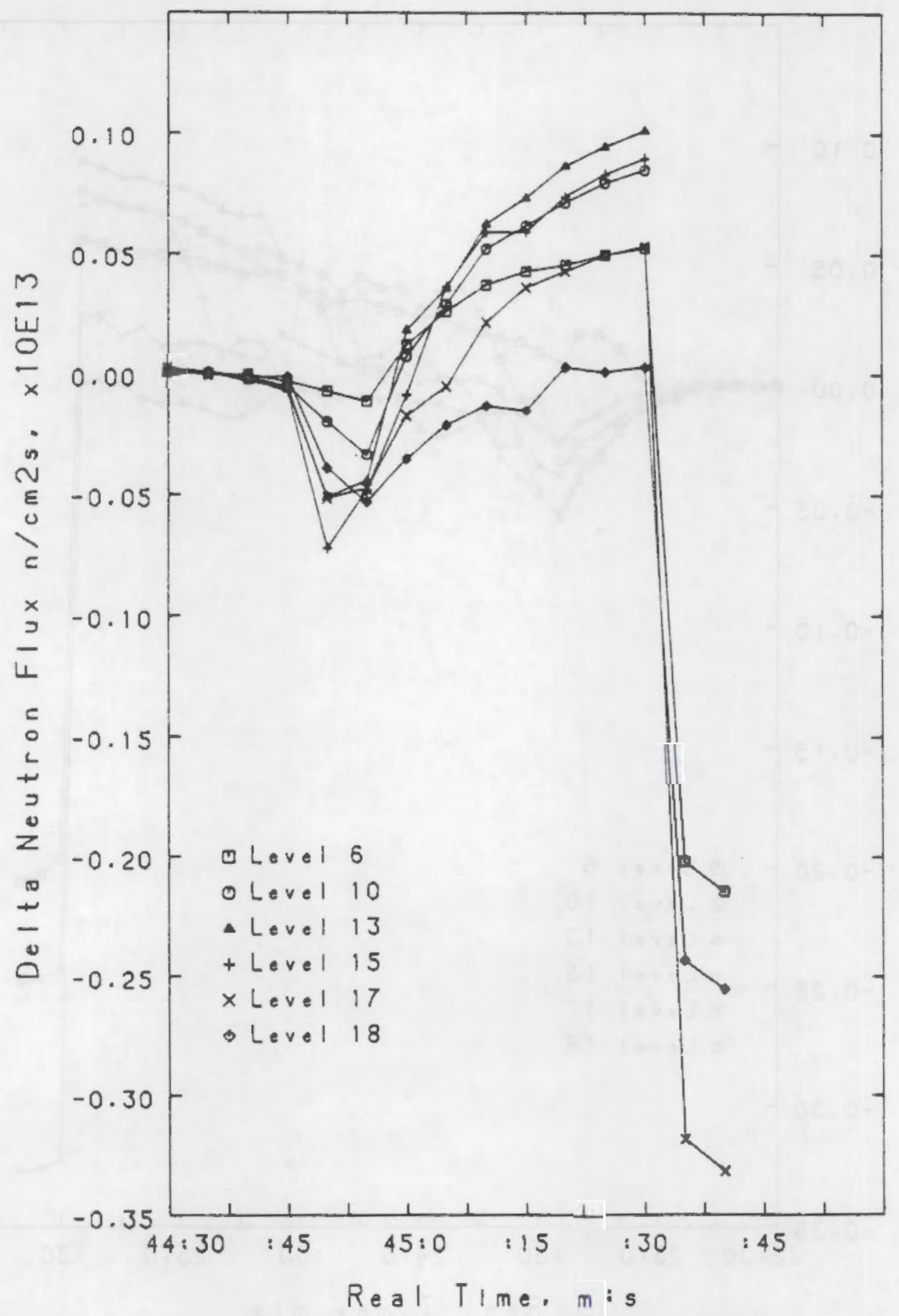

FIGURE 2.2.4.06 CHANGING NEUTRON FLUX (SHROUD) AFTER REFLOODING BEGINS, $T=44: 41 \mathrm{~S}$ 


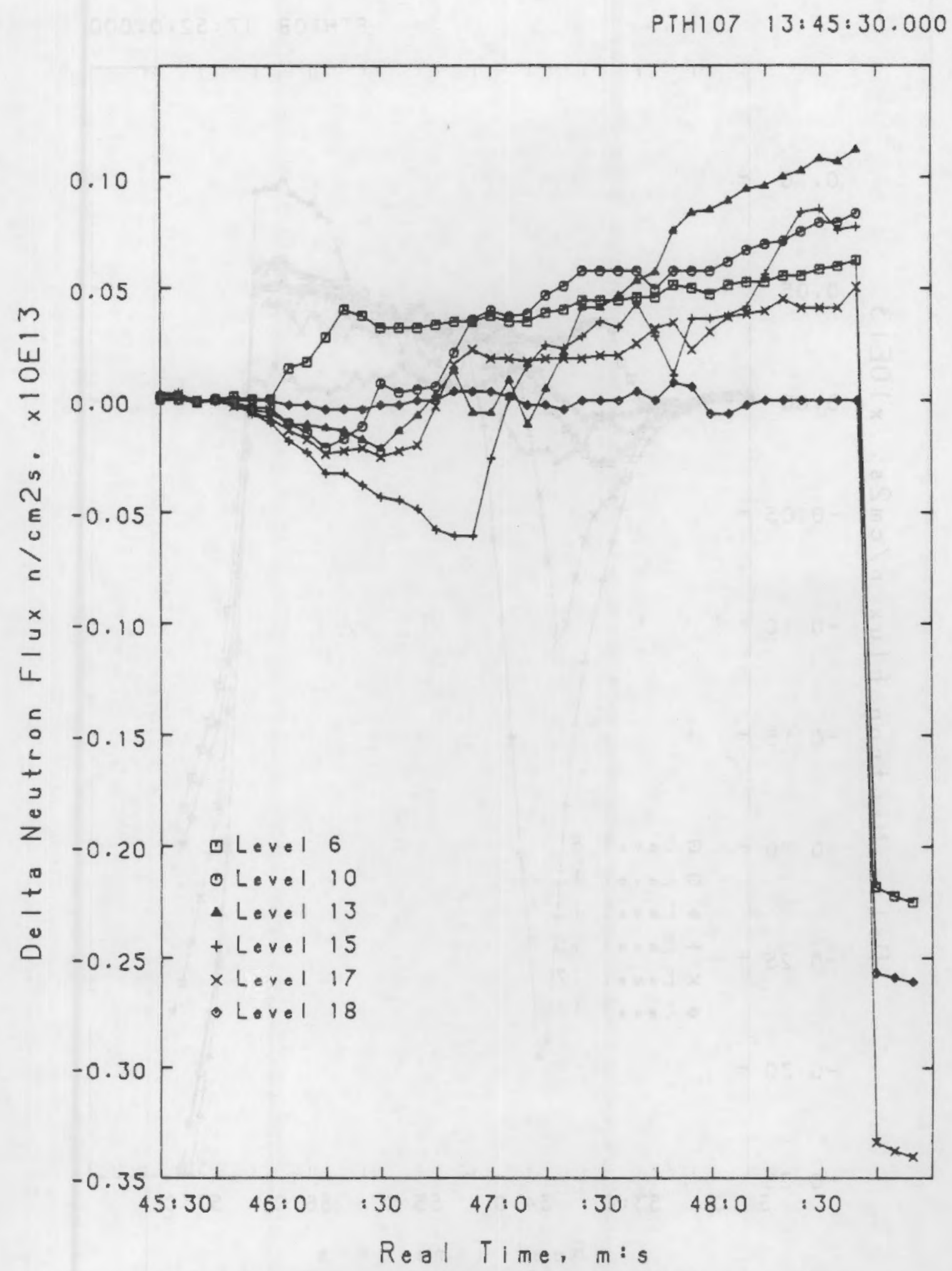

FIGURE 2.2.4.07 CHANGING NEUTRON FLUX (SHROUD) AFTER REFLOODING BEGINS, $T=45: 50$ S 
PTH:O8 17:52:0.000

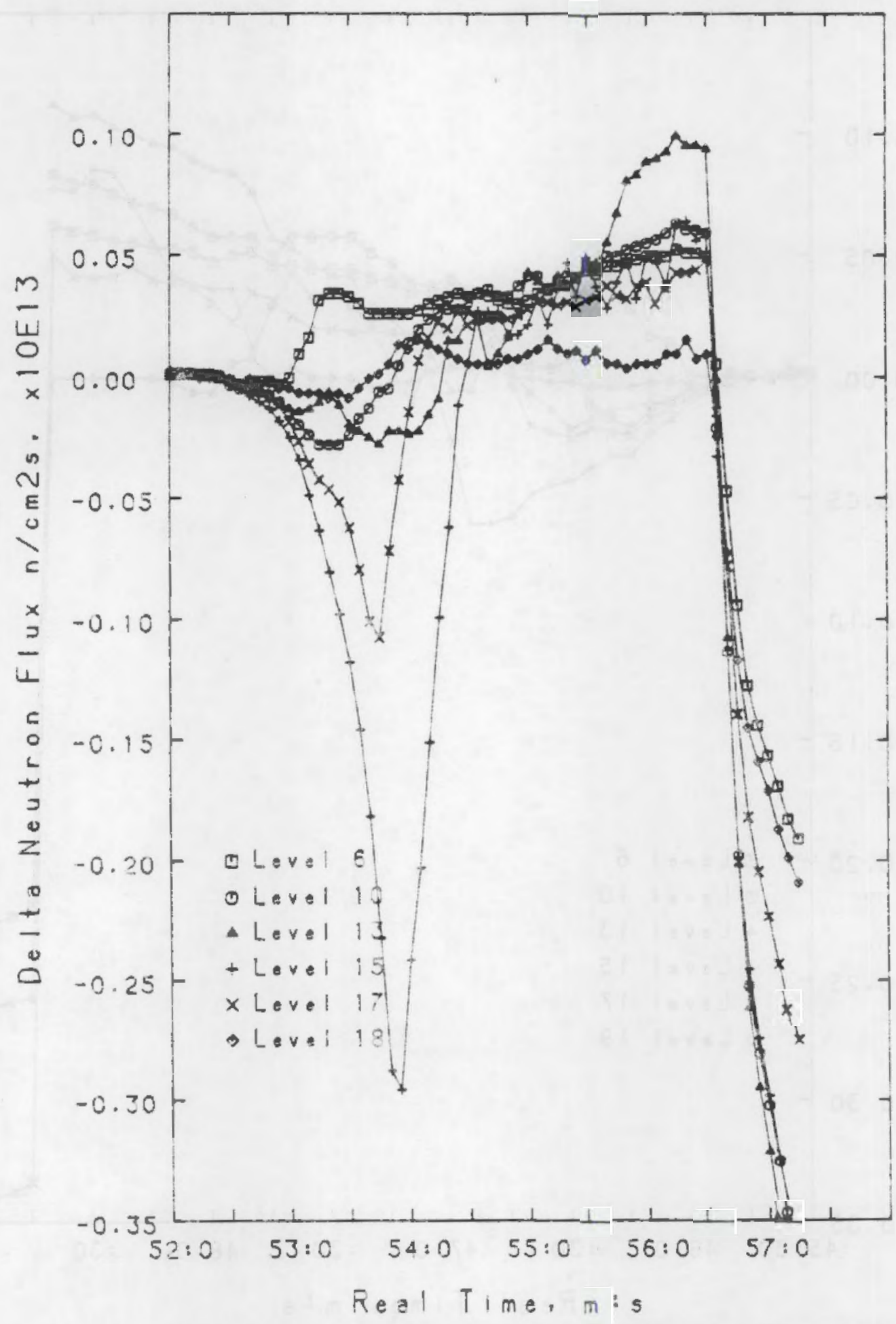

FIGURE 2.2.4.08 CHANGING NEUTRON FLUX (SHROUD) AFTER REFLOODING BEGINS. $T=52: 41 \mathrm{~S}$ 


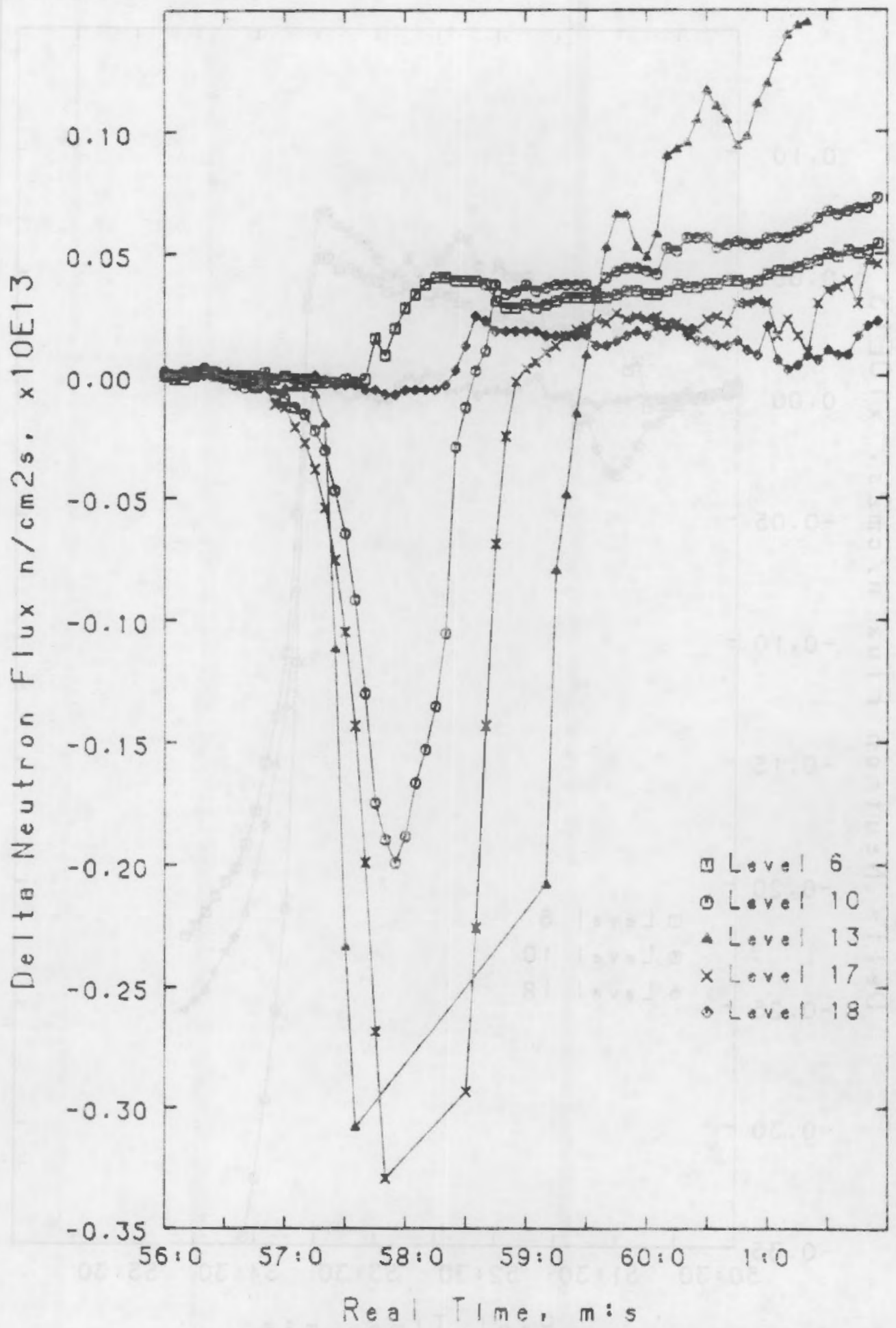

FIGURE 2.2.4.09 CHANGING NEUTRON FLUX (SHROUD) AFTER REFLOODING BEGINS, $T=56 \mathrm{M}: 47 \mathrm{~S}$ 
PTH110 14:50:30.000

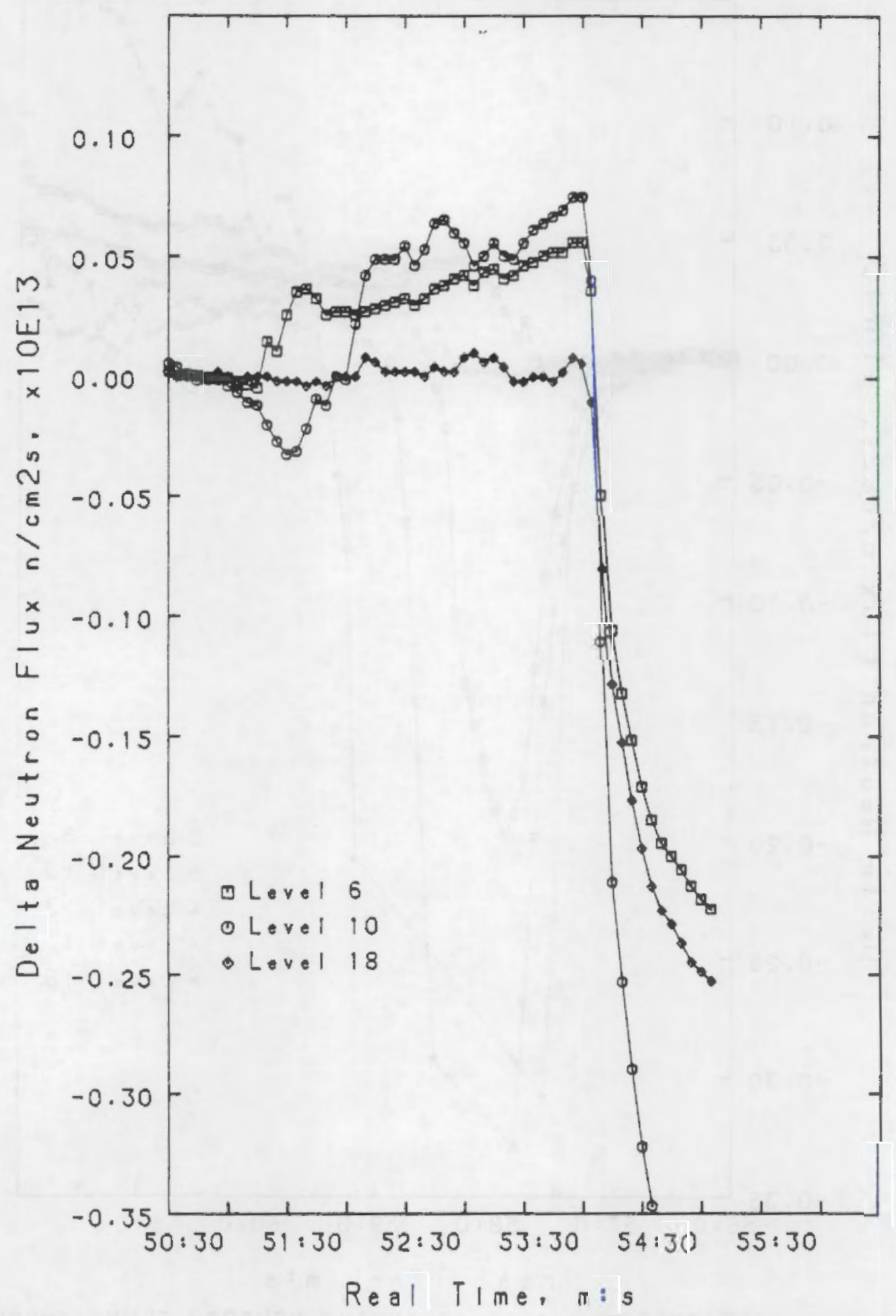

FIGURE 2.2.4.10 CHANGING NEUTRON FLUX (SHROUD) AFTER REFLOODING BEGINS. T $=51 \mathrm{M}: 02 \mathrm{~S}$ 
PTHIII 19:50:0.000

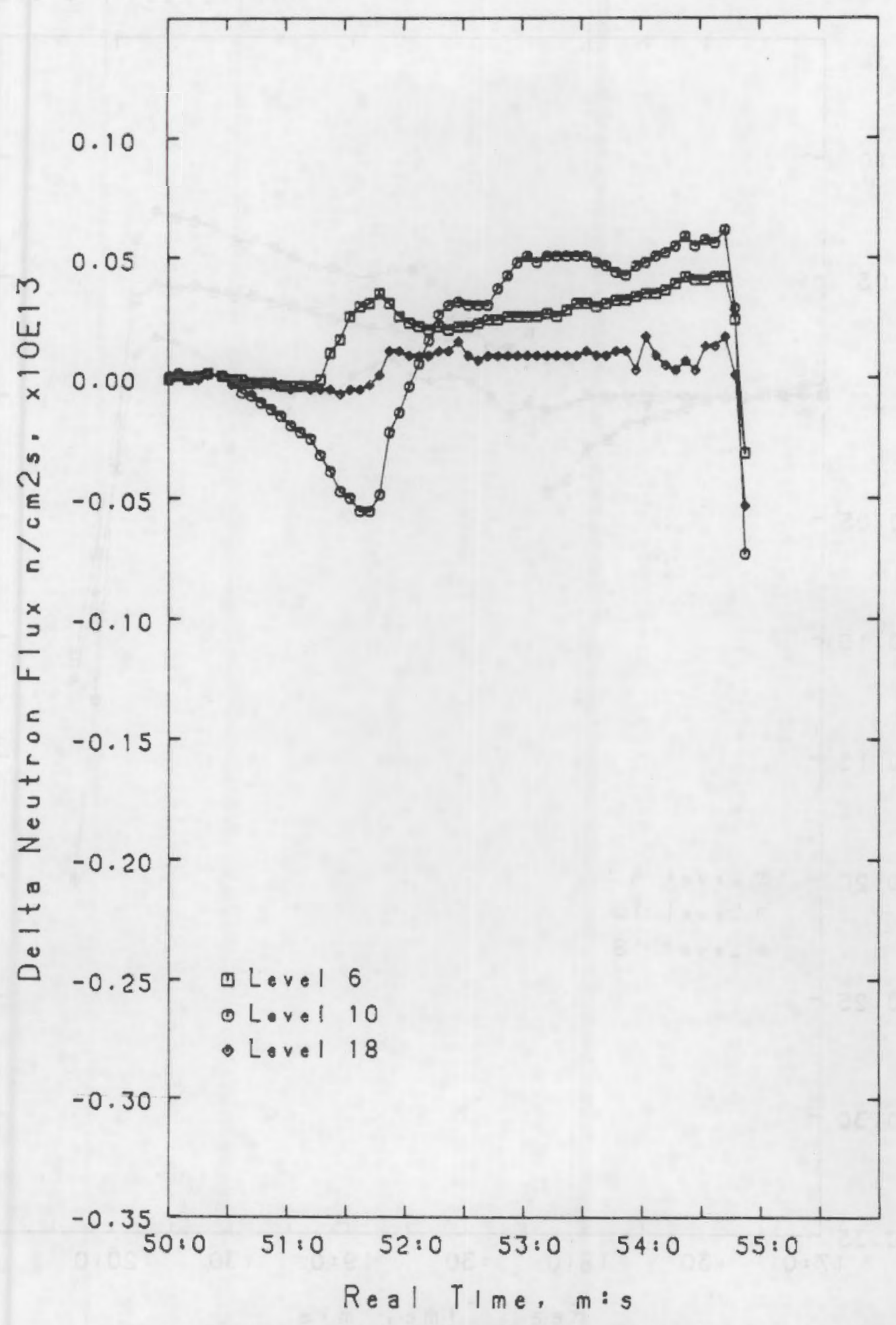

FIGURE 2.2.4.11 CHANGING NEUTRON FLUX (SHROUD) AFTER REFLDODING BEGINS, $T=50 \mathrm{~m}: 31 \mathrm{~S}$ 
PTH:12 $22: 17: 0.000$

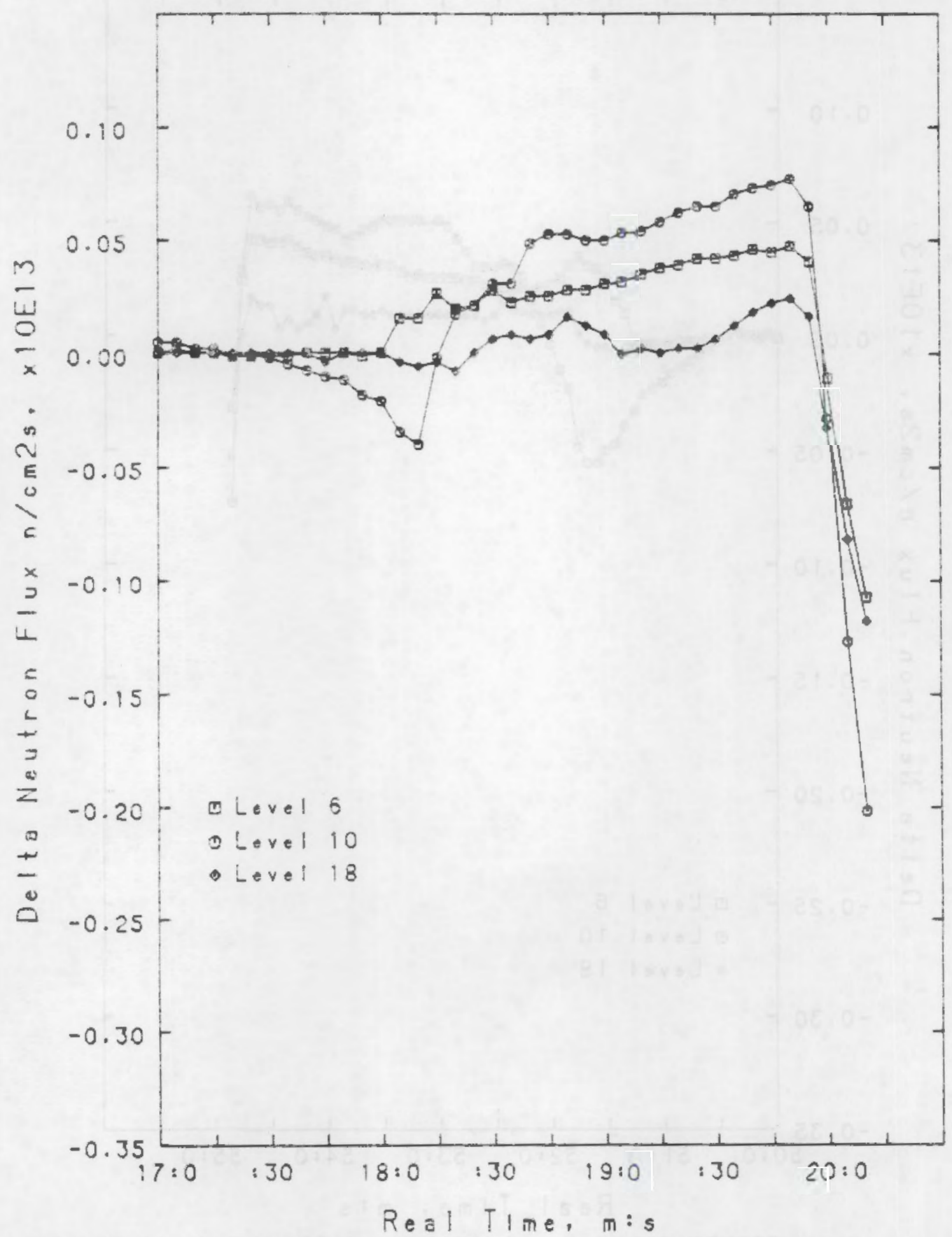

FIGURE 2.2.4.12 CHANGING NEUTRON FLUX (SHROUD) AFTER REFLOODING BEGINS, $T=17 \mathrm{M}: 43 \mathrm{~S}$ 
PTHII3 21:57:0.000

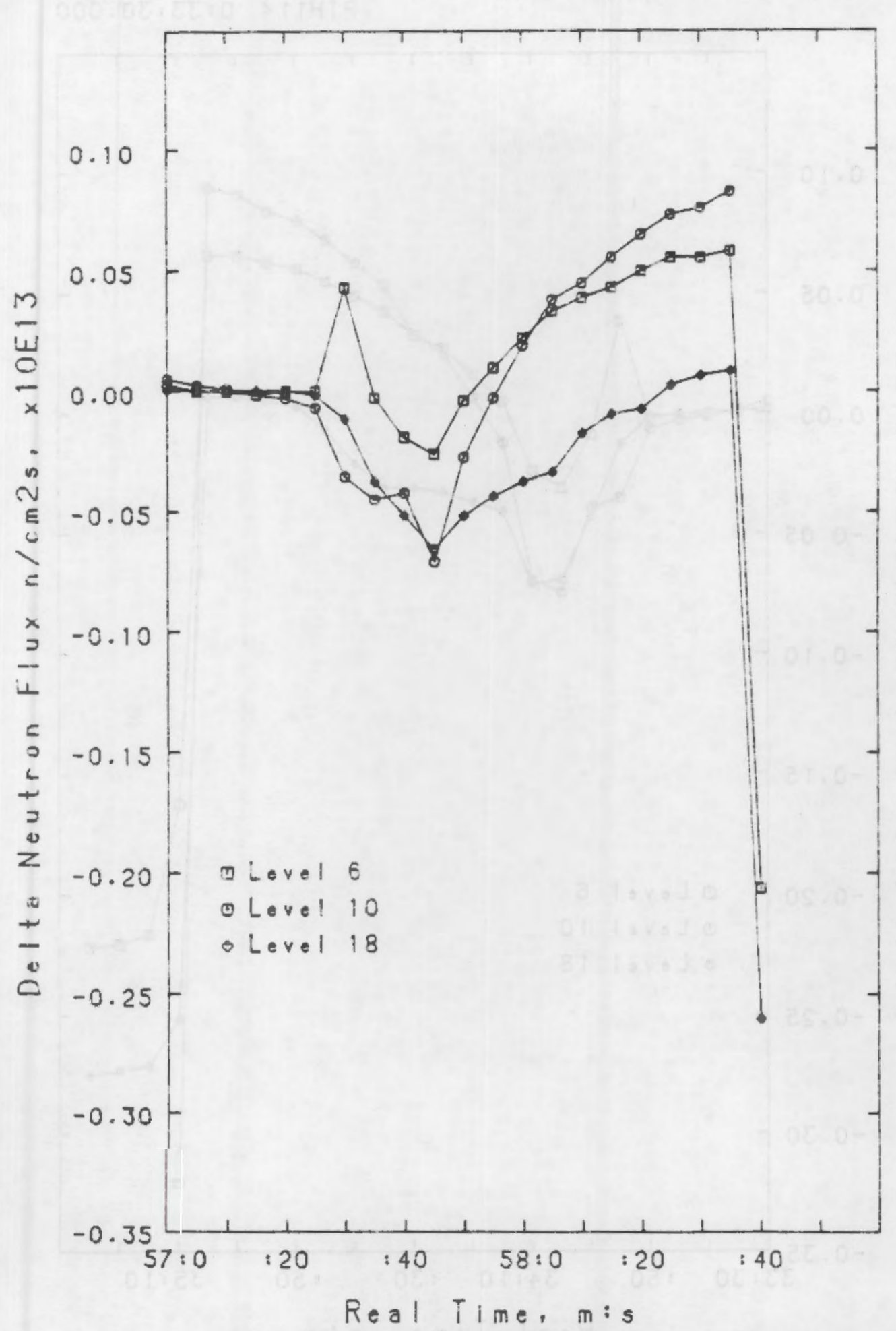

FIGURE 2.2.4.13 CHANGING NEUTRON FLUX (SHROUD) AFTER REFLOODING BEGINS. $T=57 \mathrm{M}: 22 \mathrm{~S}$ 
PTH114 0:33:30.000

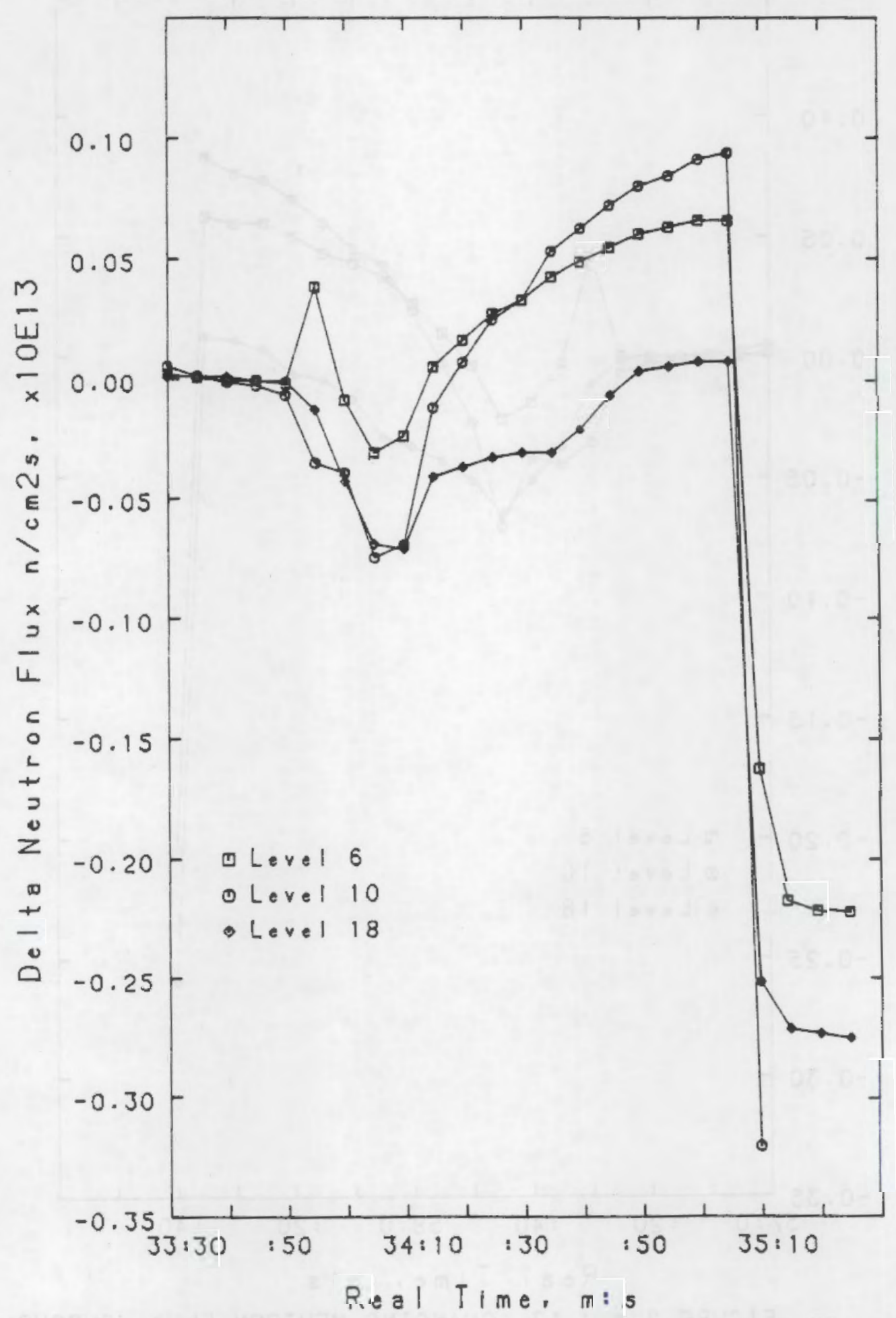

FIGURE 2.2.4.14 CHANGING NEUTRON FLUX (SHROUD) AFTER REFLOODING BEGINS, $T=33 M: 46 S$ 
PTH115 23:38:0.000

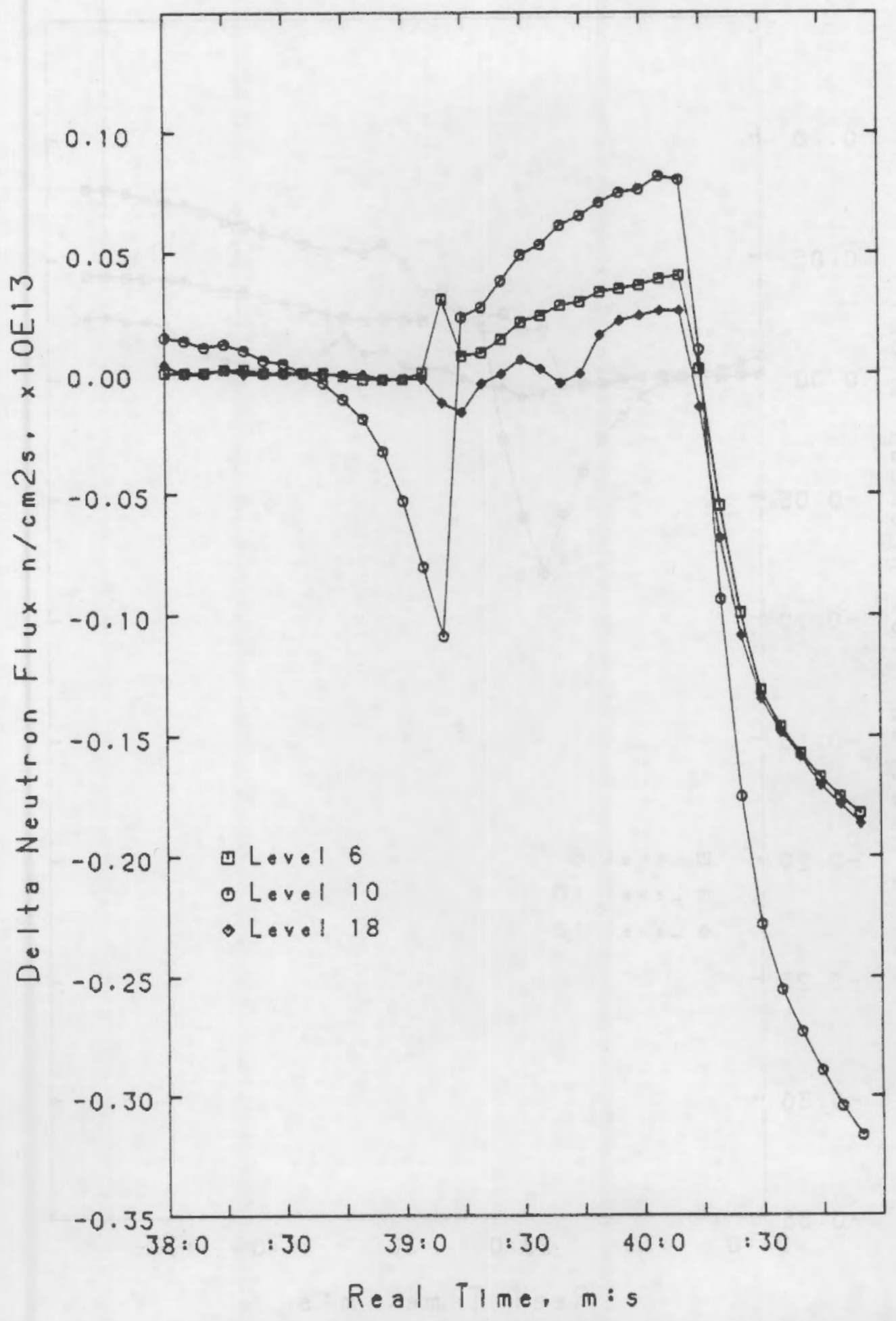

FIGURE 2.2.4.15 CHANGING NEUTRON FLUX (SHROUD) AFTER REFLOODING BEGINS. $T=38 \mathrm{M}: 57 \mathrm{~S}$ 
PTH1:6 I:24:0.000

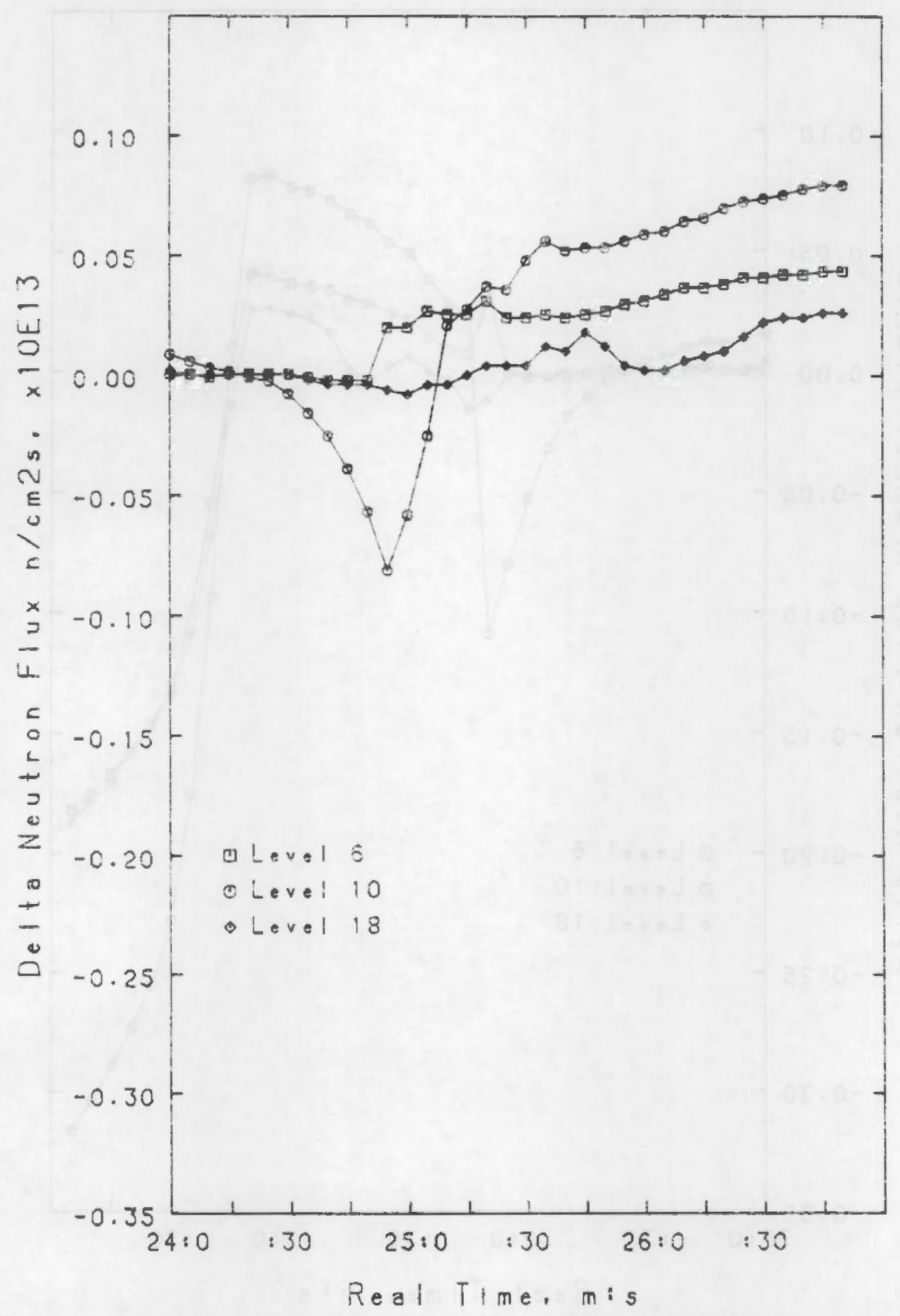

FIGURE 2.2.4.16 CHANGING NEUTRON FLUX (SHROUD) AFTER REFLOODING BEGINS. $T=24 M: 32 S$ 
PTH:17 2:22:30.000

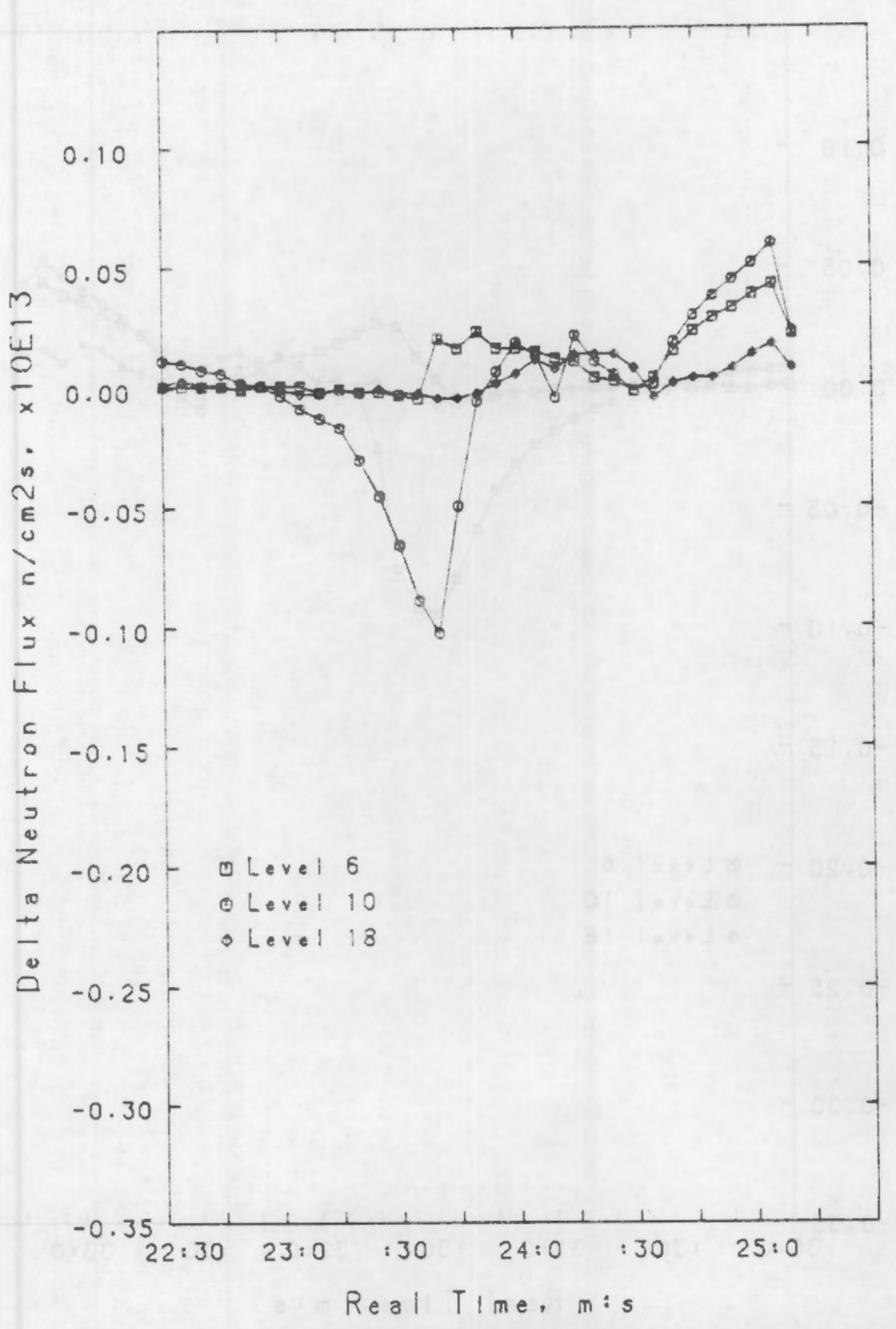

FIGURE $2.2 \cdot 4 \cdot 17$ CHANGING NEUTRON FLUX (SHROUD) AFTER REFLOODING BEGINS. $T=23 M: 15 S$ 
PTH118 3:30:0.000

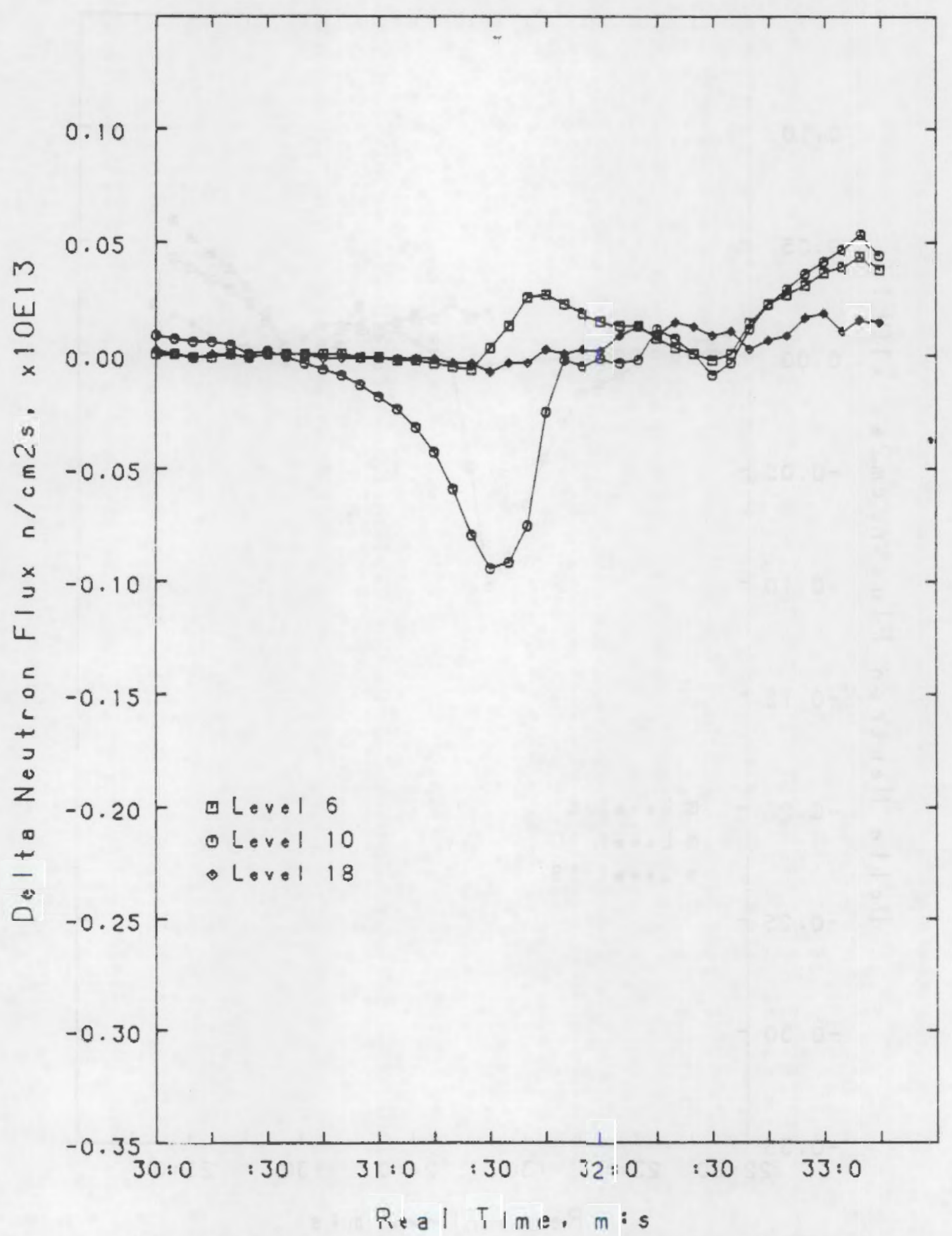

FIGURE 2.2.4.18 CHANGING NEUTRON FLUX (SHROUD) AFTER REFLOODING BEGINS, $T=30 M: 56 S$ 
PTHI19 5:27:30.000

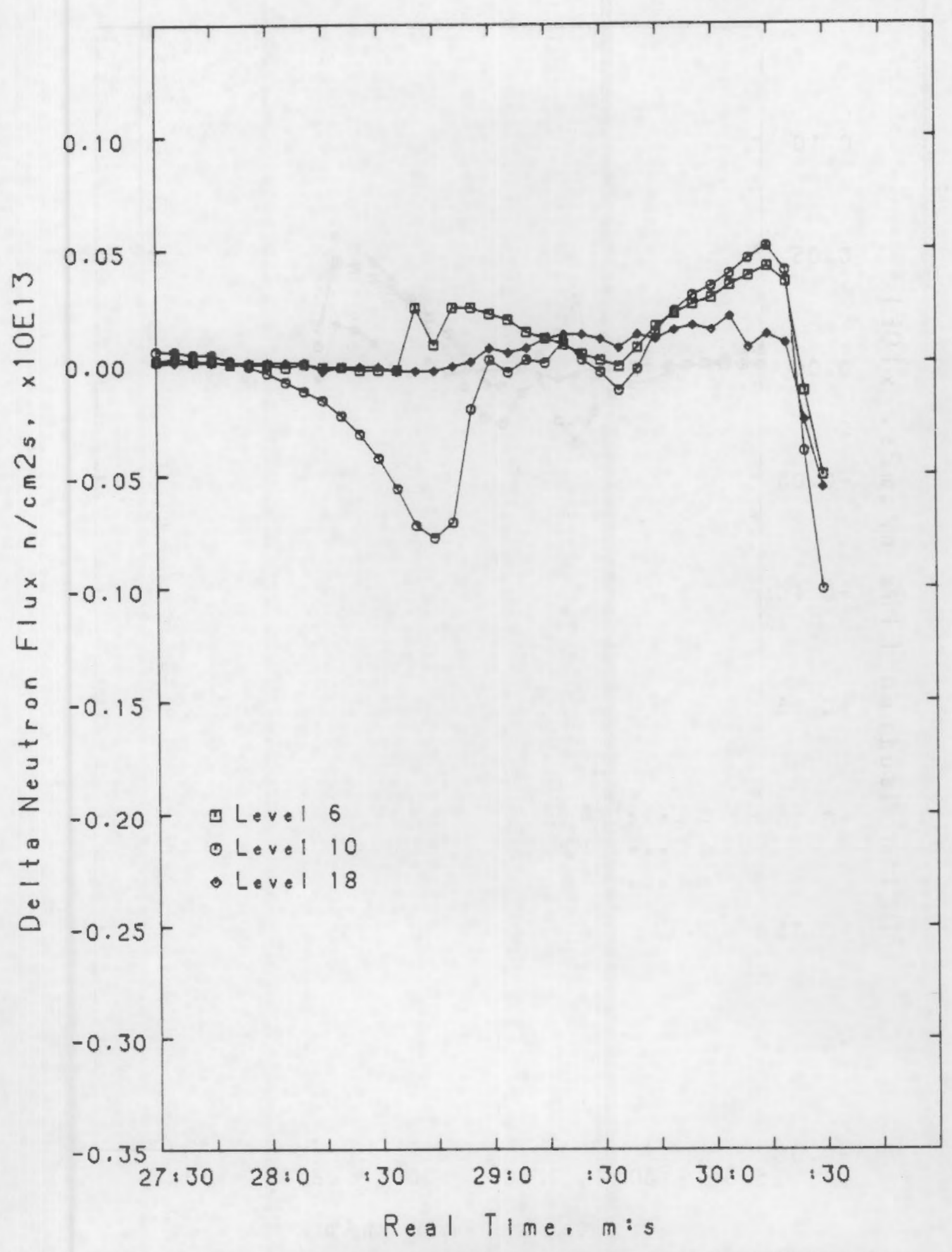

FIGURE 2.2.4.19 CHANGING NEUTRON FLUX (SHROUD) AFTER REFLOODING BEGINS, $T=28 \mathrm{M}: 8 \mathrm{~S}$ 
PTH120 6:25:0.000

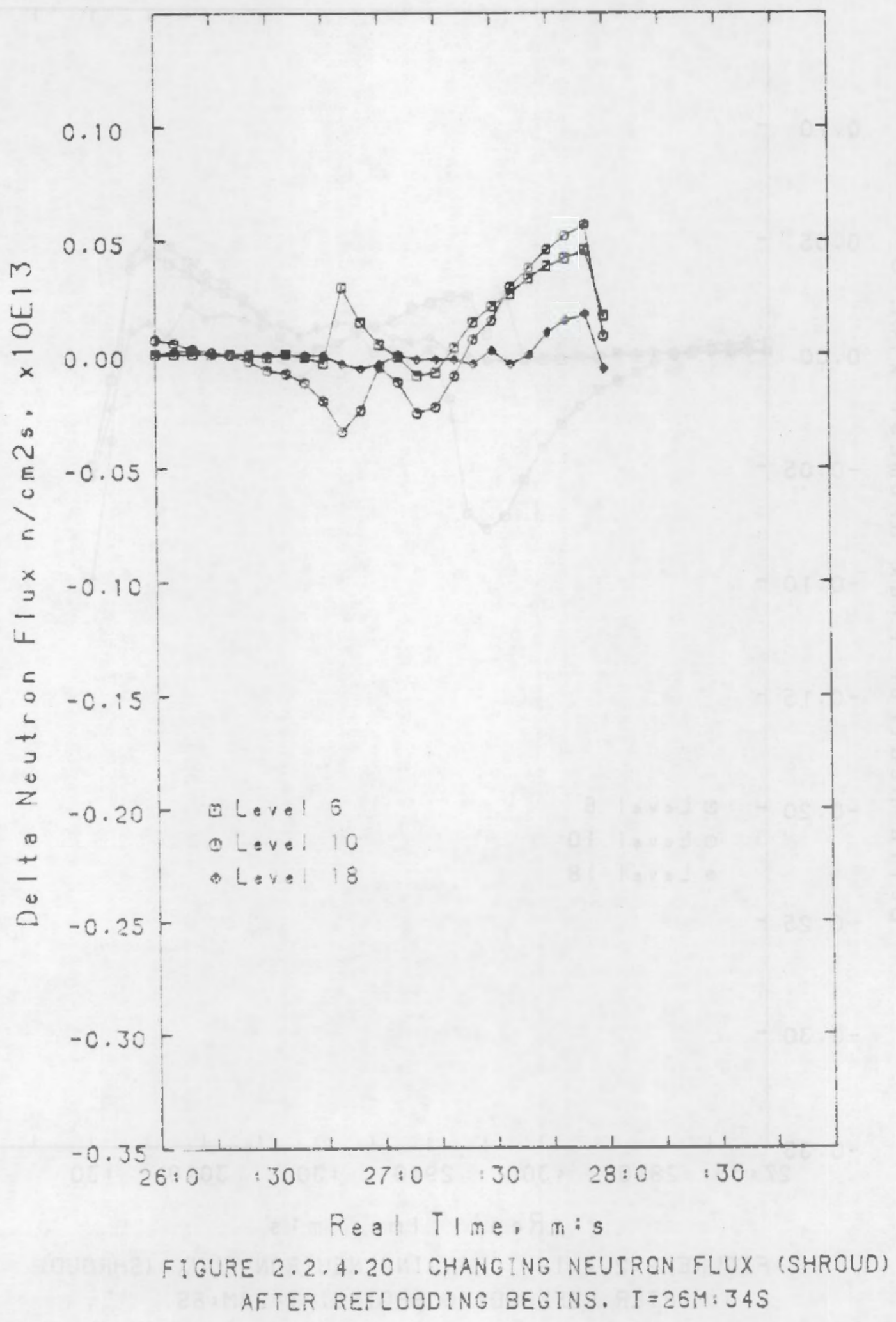

A. 164 
PTH:21 $7: 13: 0.000$

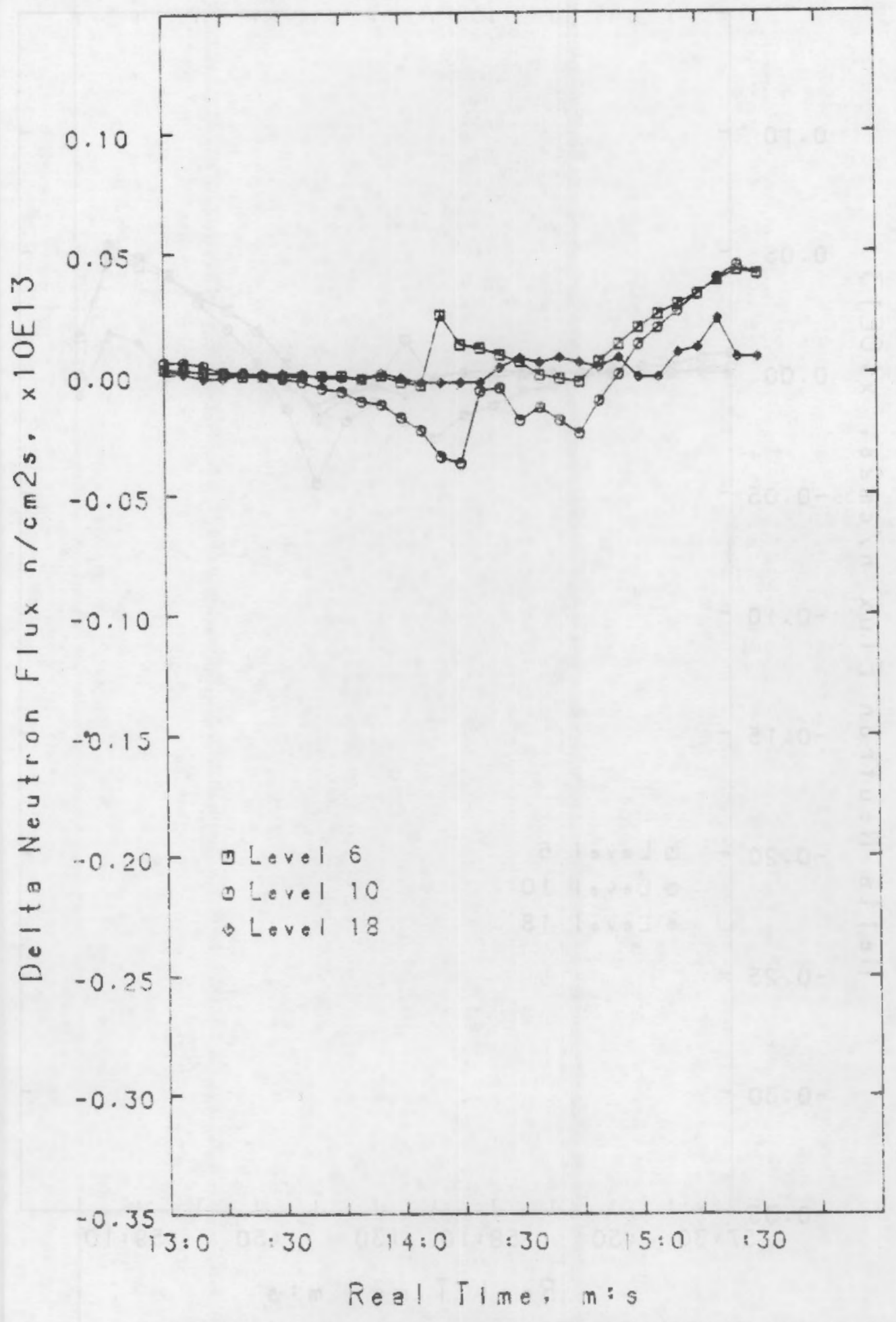

F!GURE 2.2.4.21 CHANGING NEUTRON FLUX (SHROUD) AFTER REFLCODING BEGINS. $T=13 M: 45 S$ 
PTH122 7:57:30.000

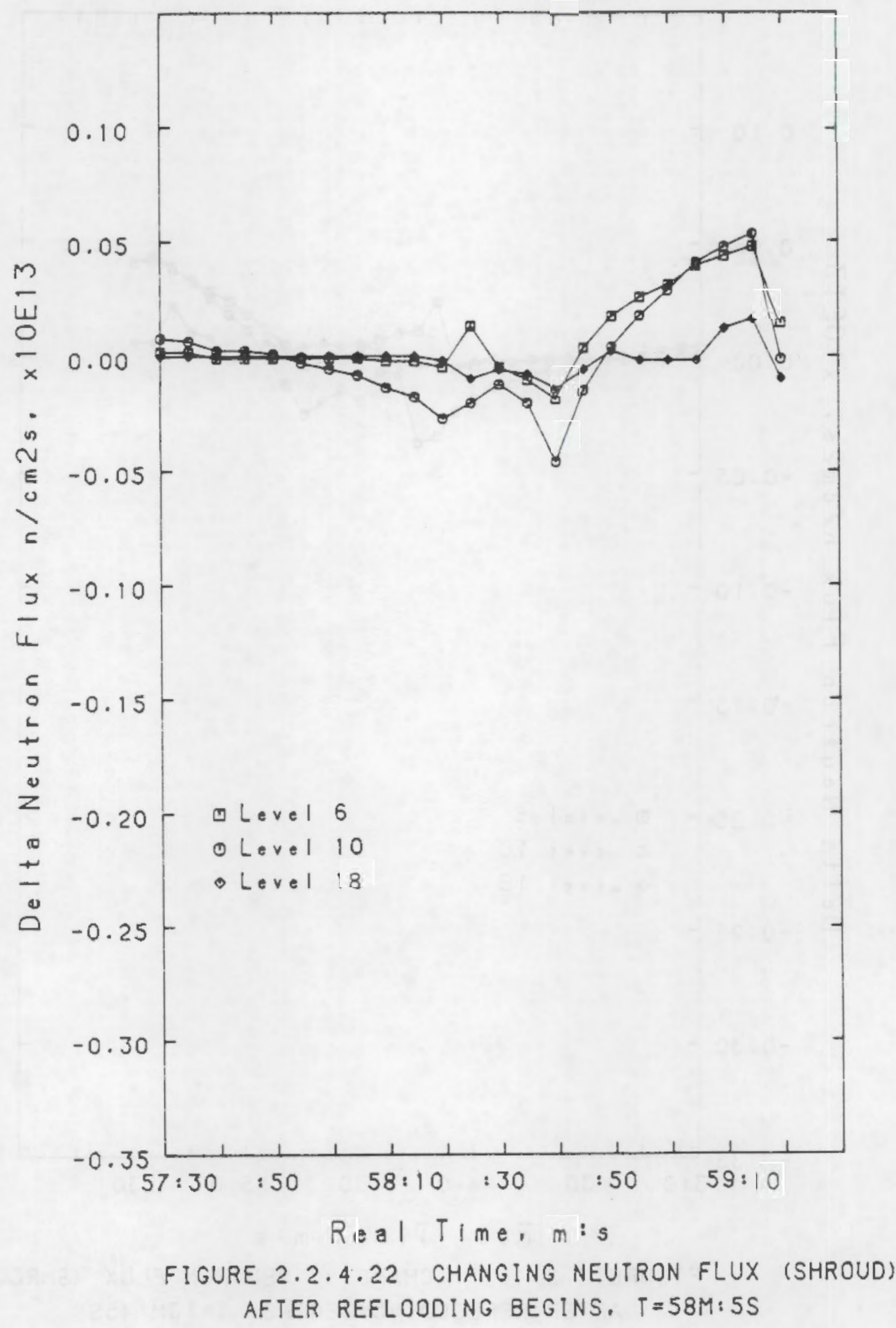

A. 166 
PTH123 9:19:0.000

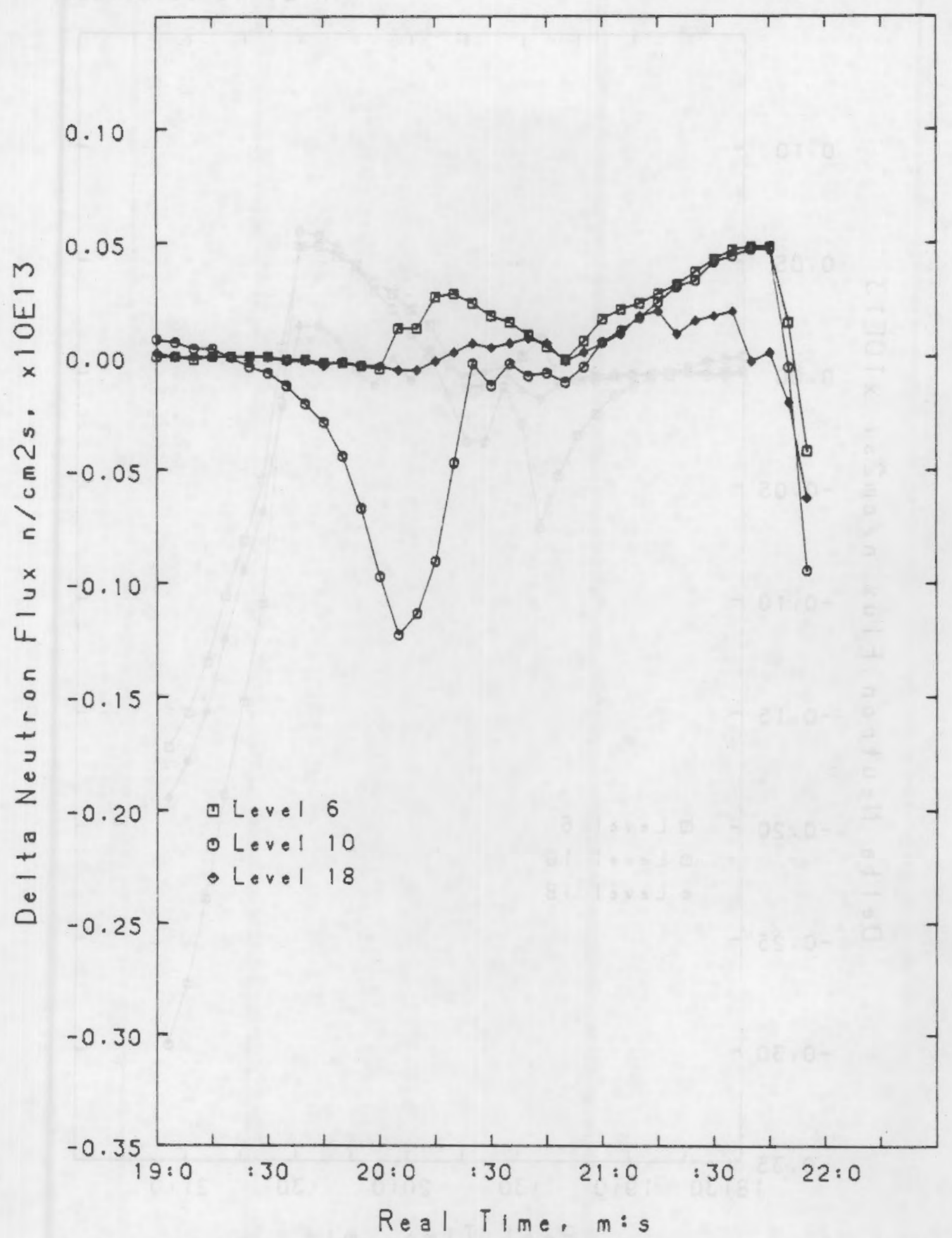

FIGURE 2.2.4.23 CHANGING NEUTRON FLUX (SHROUD) AFTER REFLOODING BEGINS. $T=19 M: 35 S$ 
PTHI24 10:18:30.000

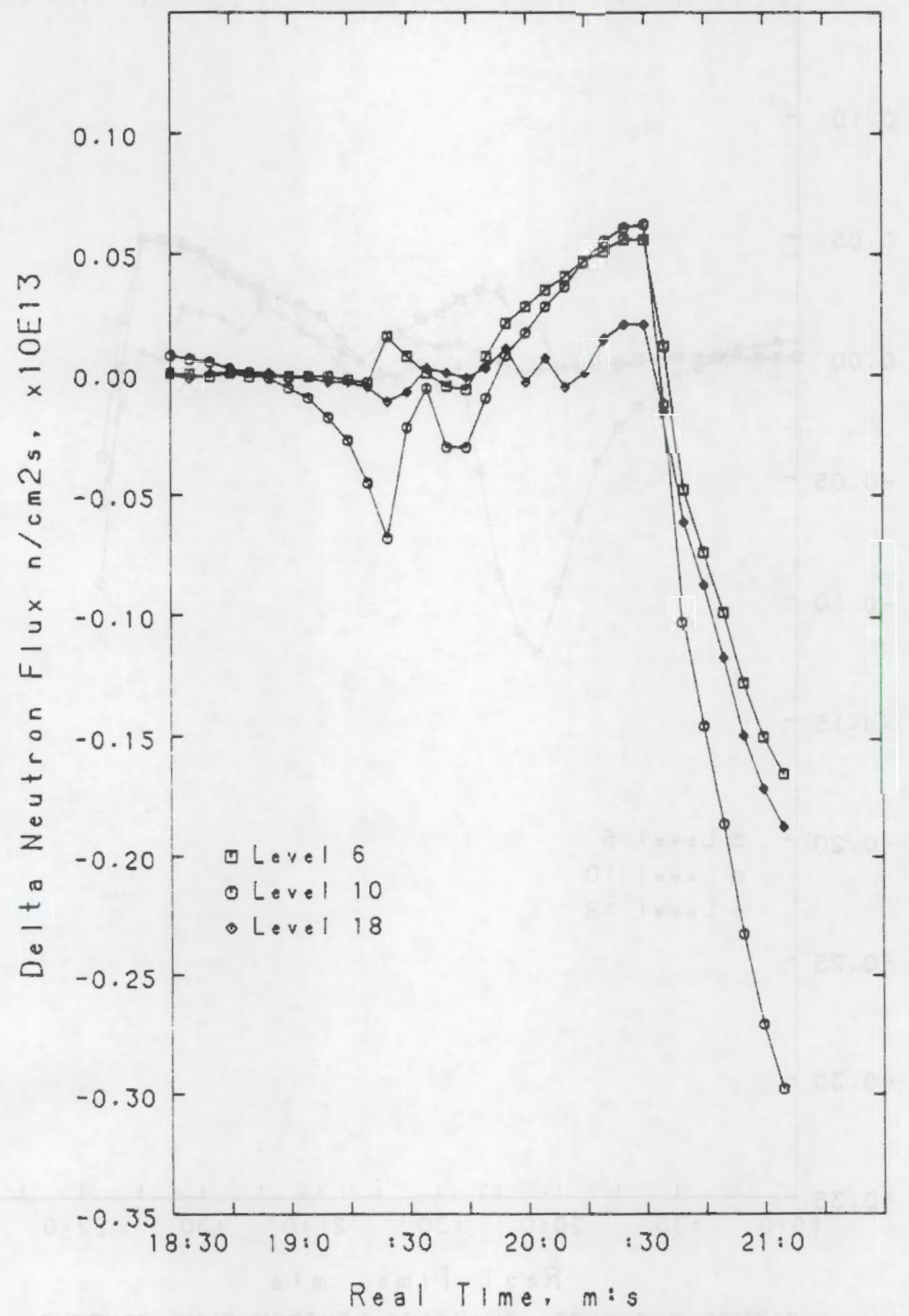

FIGURE 2.2.4.24 CHANGING NEUTRON FLUX (SHROUD) AFTER REFLOODING BEGINS, $T=19 M: 075$ 
PTH125 $11: 57: 30.000$

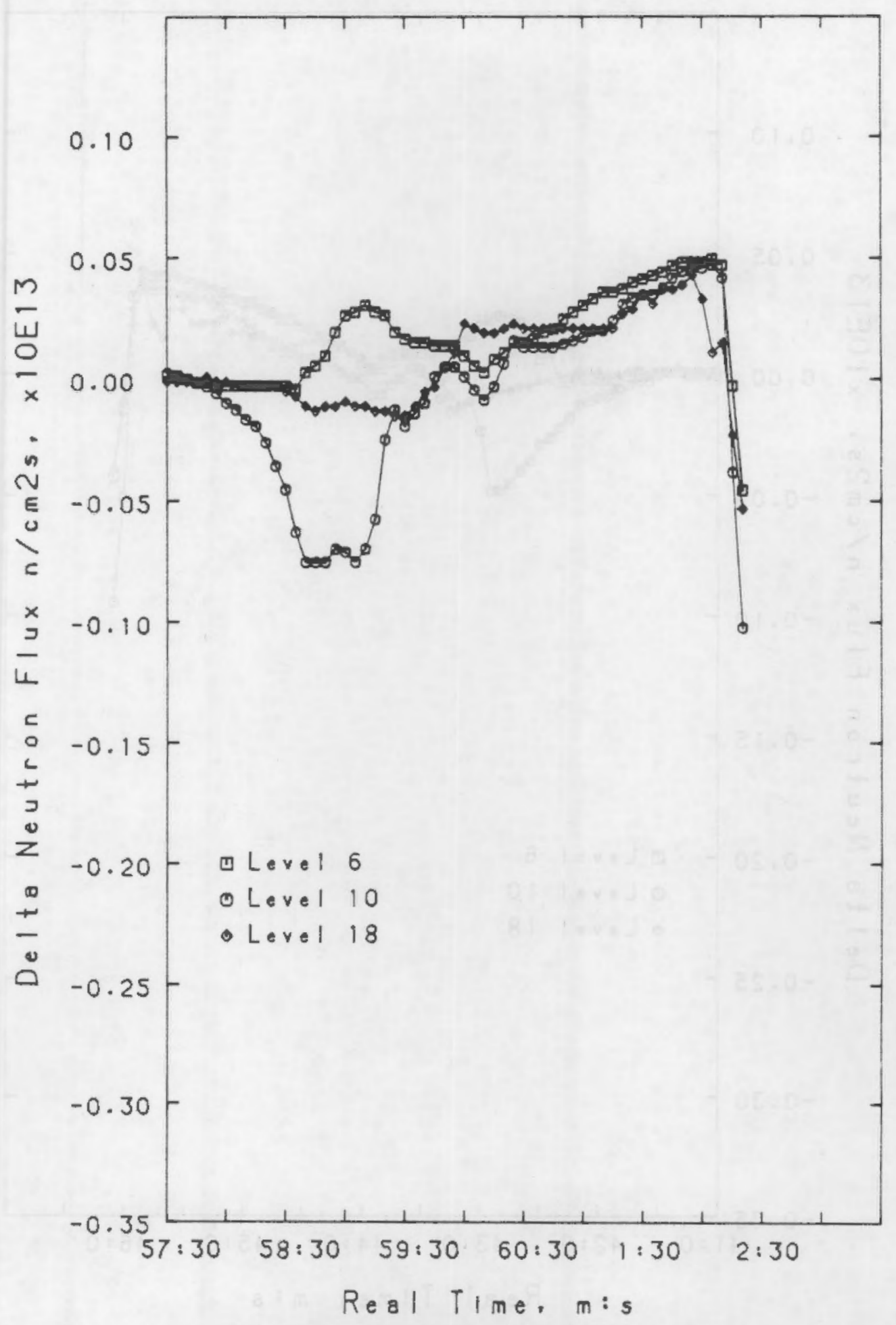

FIGURE 2.2.4.25 CHANGING NEUTRON FLUX (SHROUD) AFTER REFLODDING BEGINS, $T=57 M: 46 \mathrm{~S}$ 
PTH126 13:41:0.000

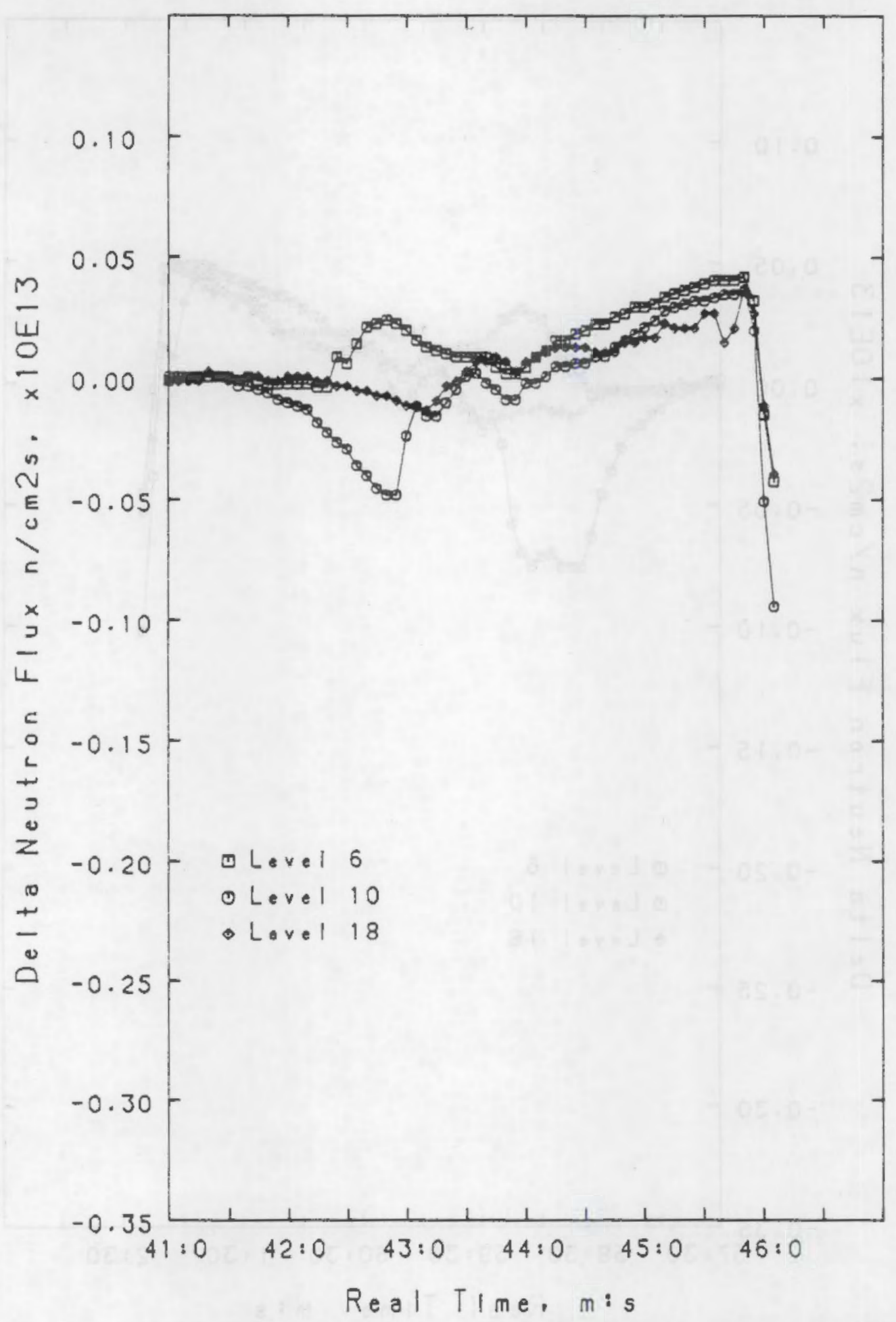

FIGURE 2.2.4.26 CHANING NEUTRON FLUX (SHROUD) AFTER REFLOODING BEGINS, $T=41 \mathrm{M}: 36 \mathrm{~S}$ 
PTH127 14:36:30.000

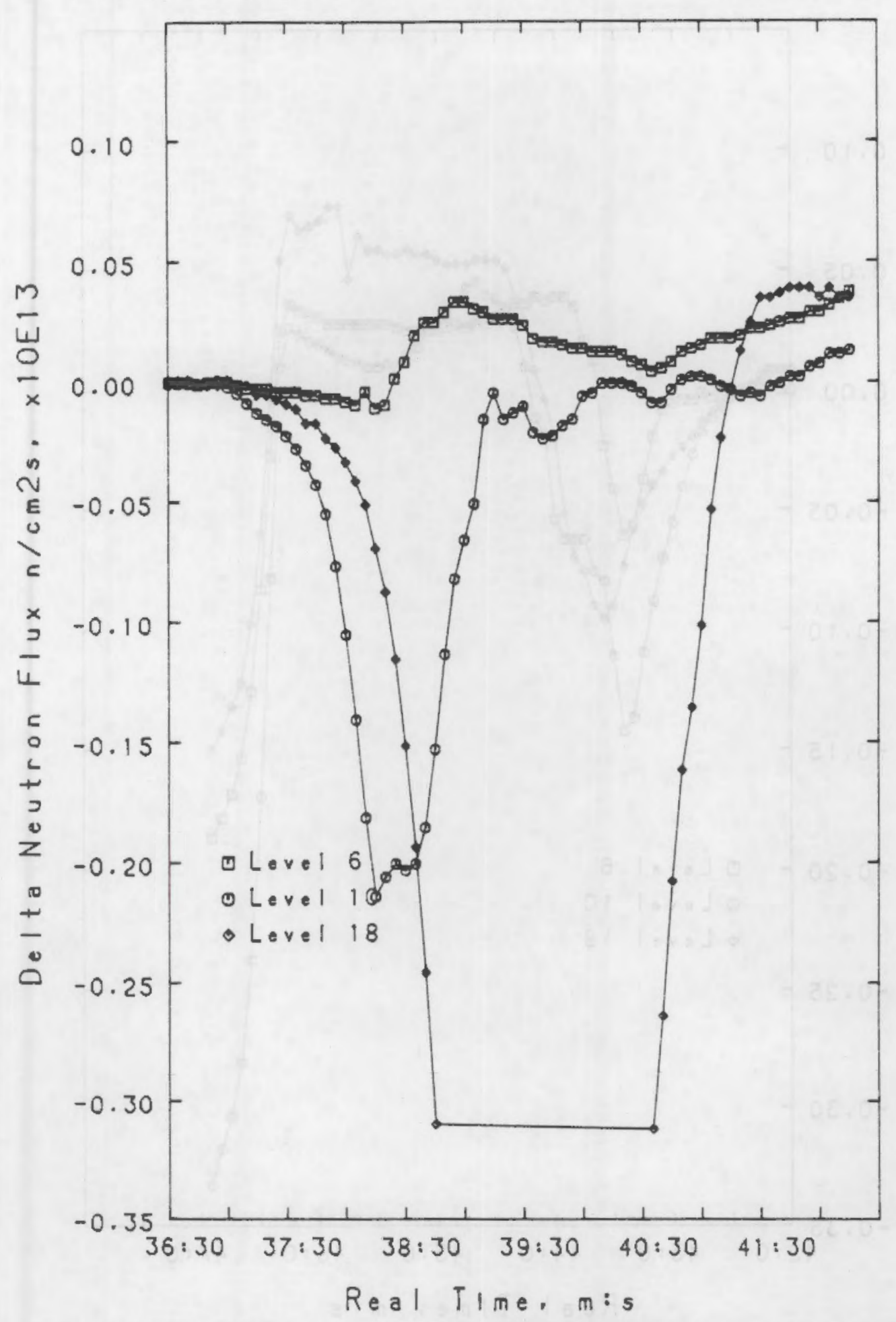

FIGURE 2.2.4.27 CHANGING NEUTRON FLUX (SHROUD) AFTER REFLOODING BEGINS, $T=37 M: 09 S$ 
PTH128 16:42:0.000

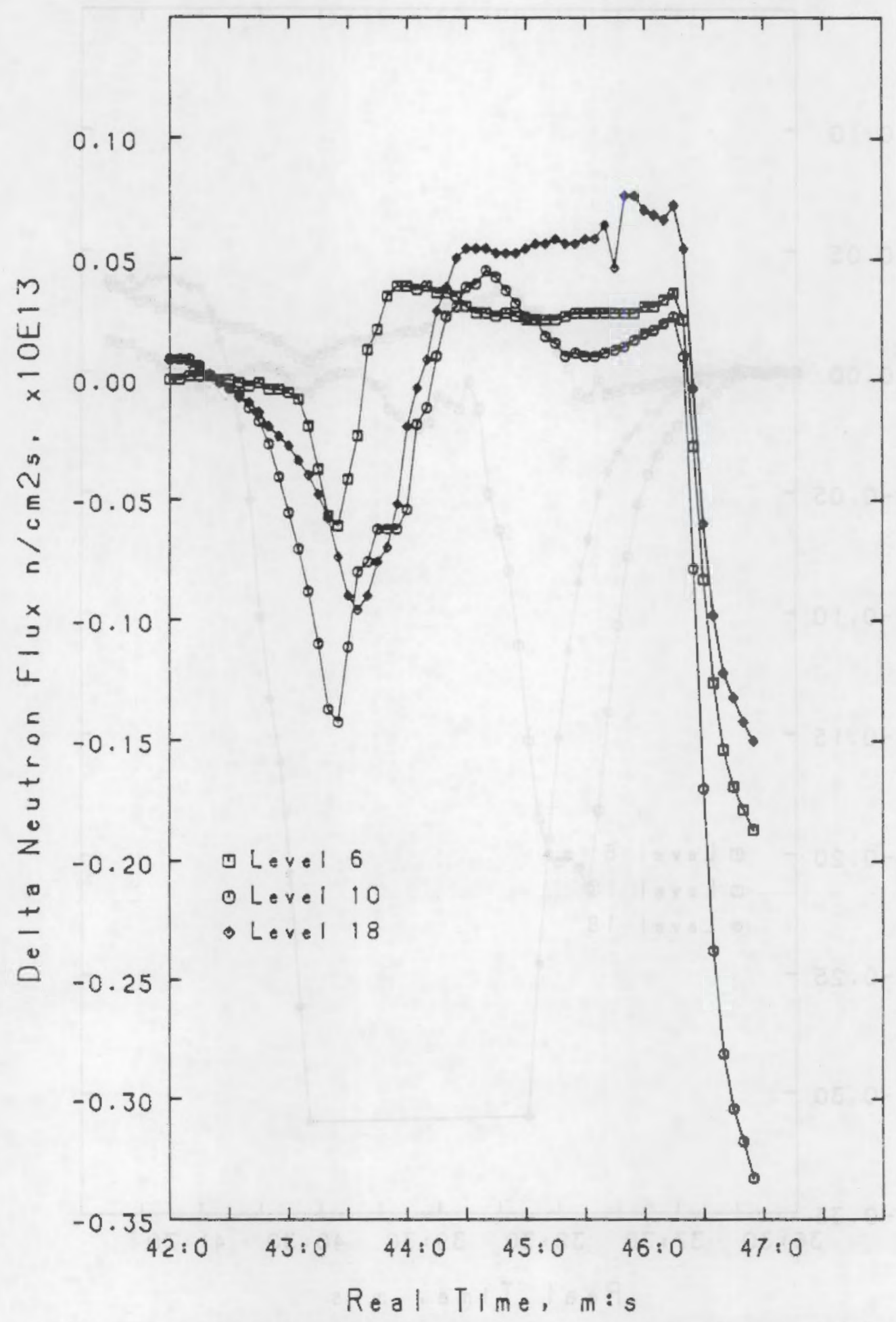

FIGURE 2.2 .4 .28 CHANGING NEUTRON FLUX (SHROUD) AFTER REFLDODING BEGINS, $T=42 M: 44 S$ 
PIHI29 18:30:0.000

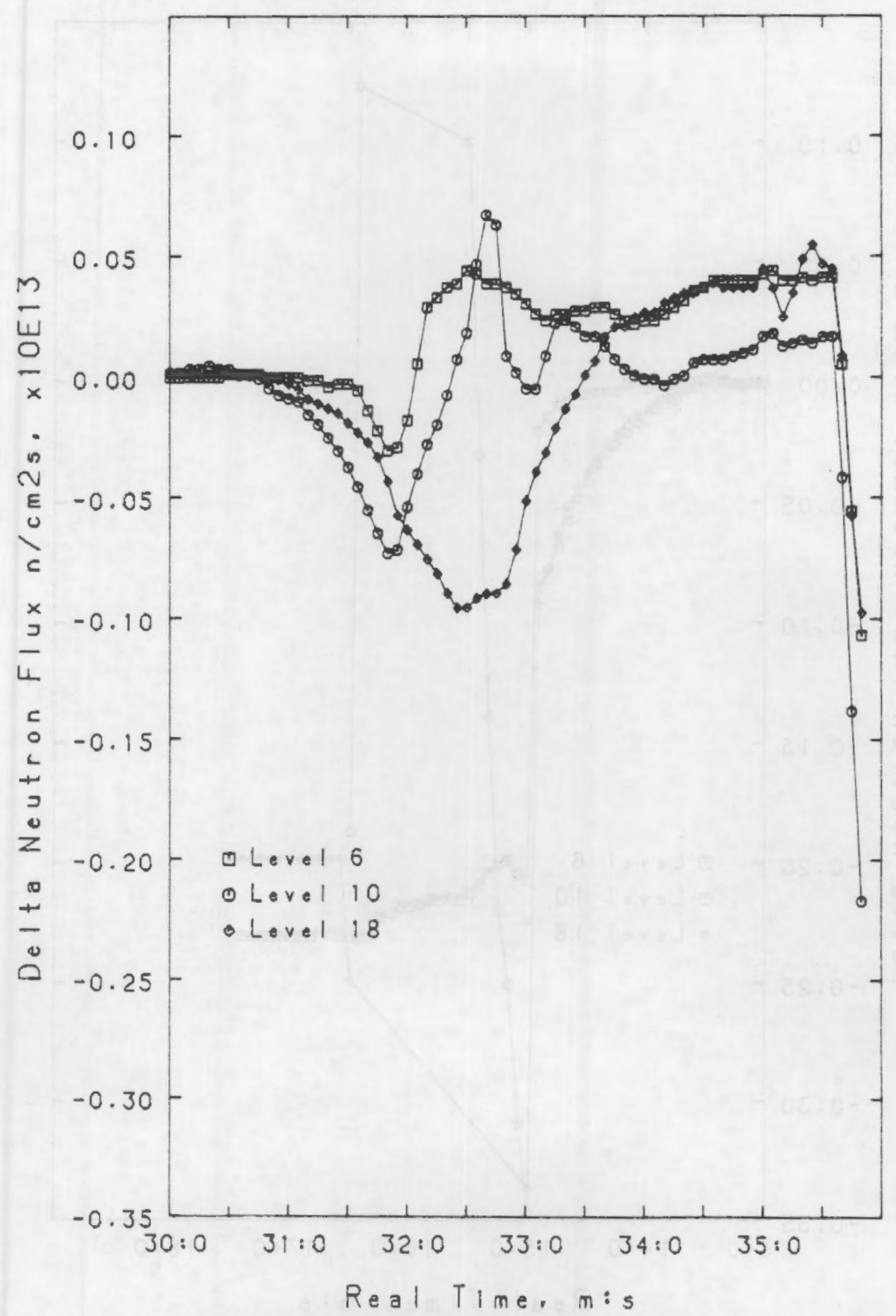

FIGURE 2.2.4.29 CHANGING NEUTRON FLUX (SHROUD) AFTER REFLOODING BEGINS. $T=31 \mathrm{M}: 05 \mathrm{~S}$ 


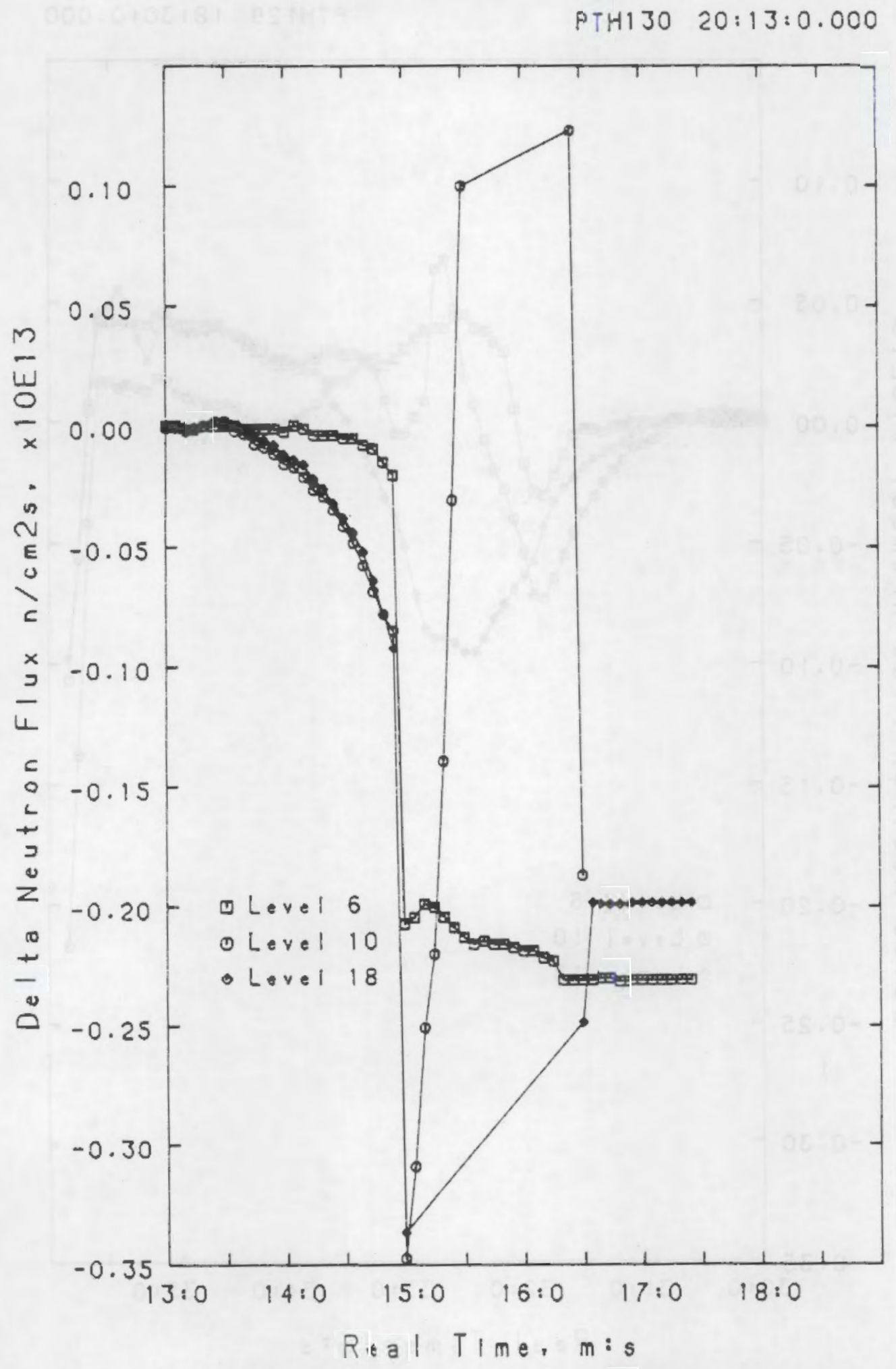

FIGURE 2.2.4.30 CHANGING NEUTRON FLUX (SHROUD) AFTER REFLOODING BEGINS, $T=13 M: 335$ 
PART 3

STEAM TEMPERATURE PROBE DISTRIBUTIONS 



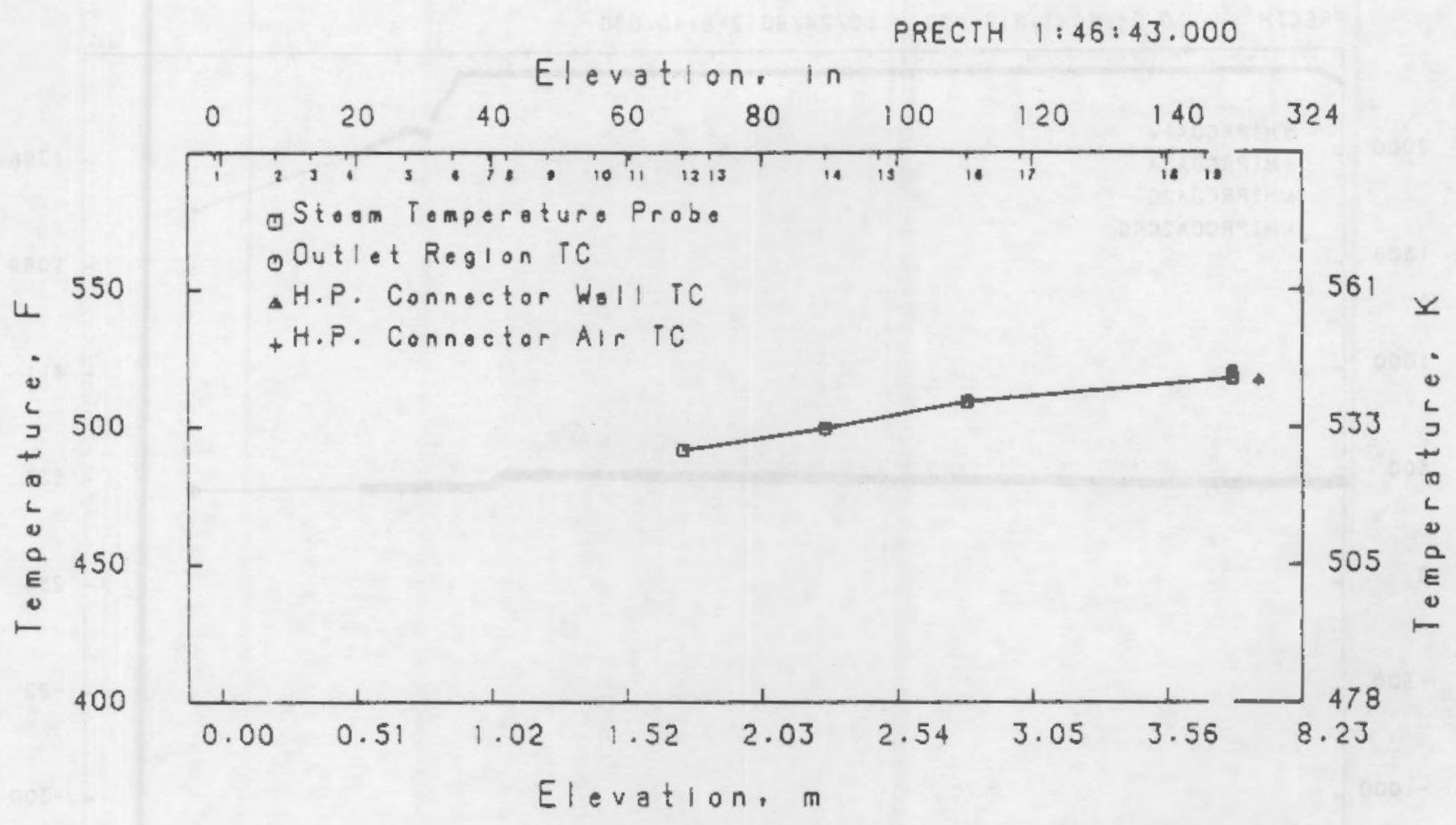

FIGURE 3.1.1 AVERAGE STEAM PROBE AND HP CONNECTOR TEMPERATURE PROFILE (IN WATER-PRECONDITIONING) 


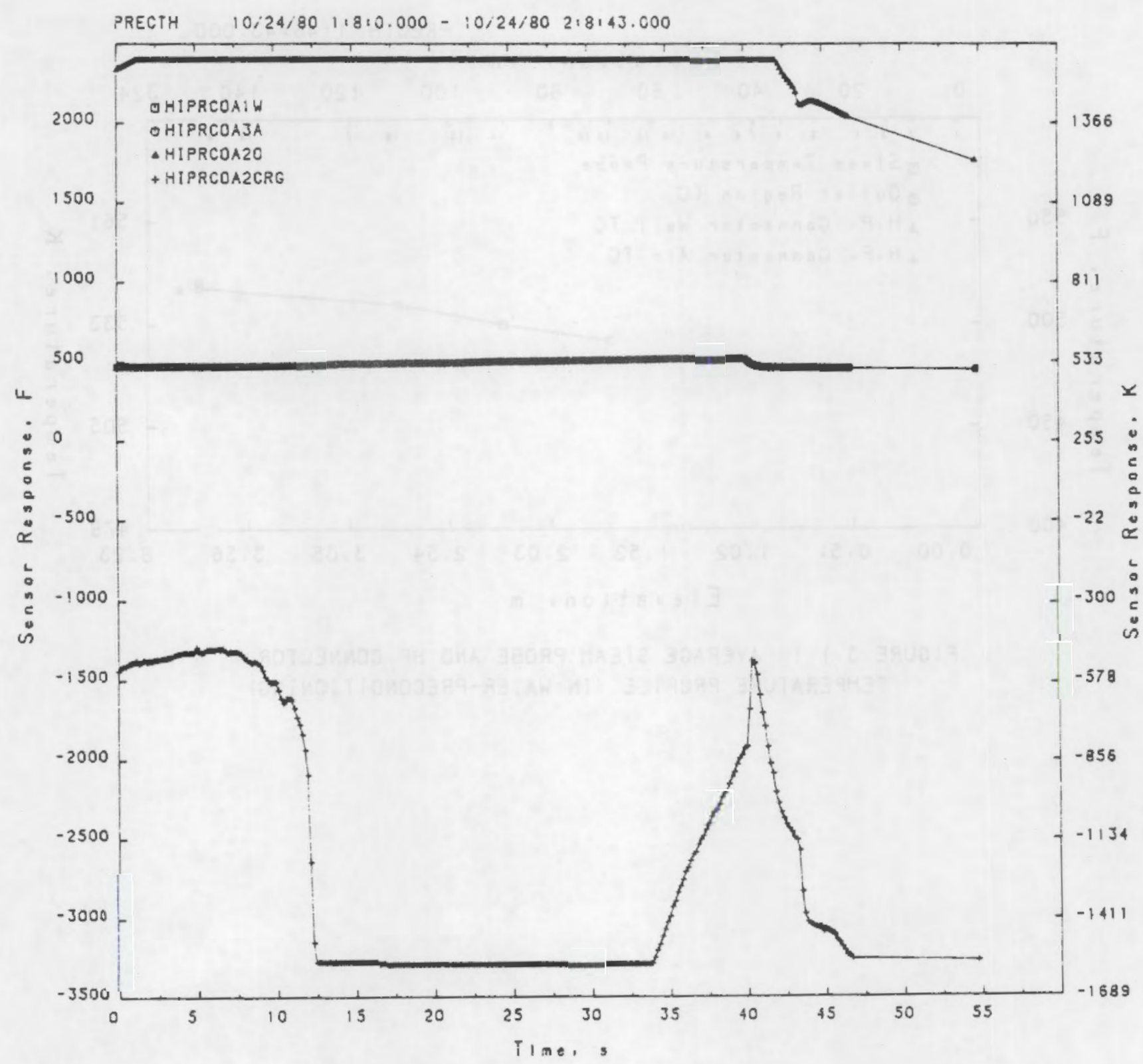

FIGURE 3.1.2 HIGH PRESSURE CONNECTOR TC RESPONSE HISTORY DURING PRECONOITIONING OPERATION 


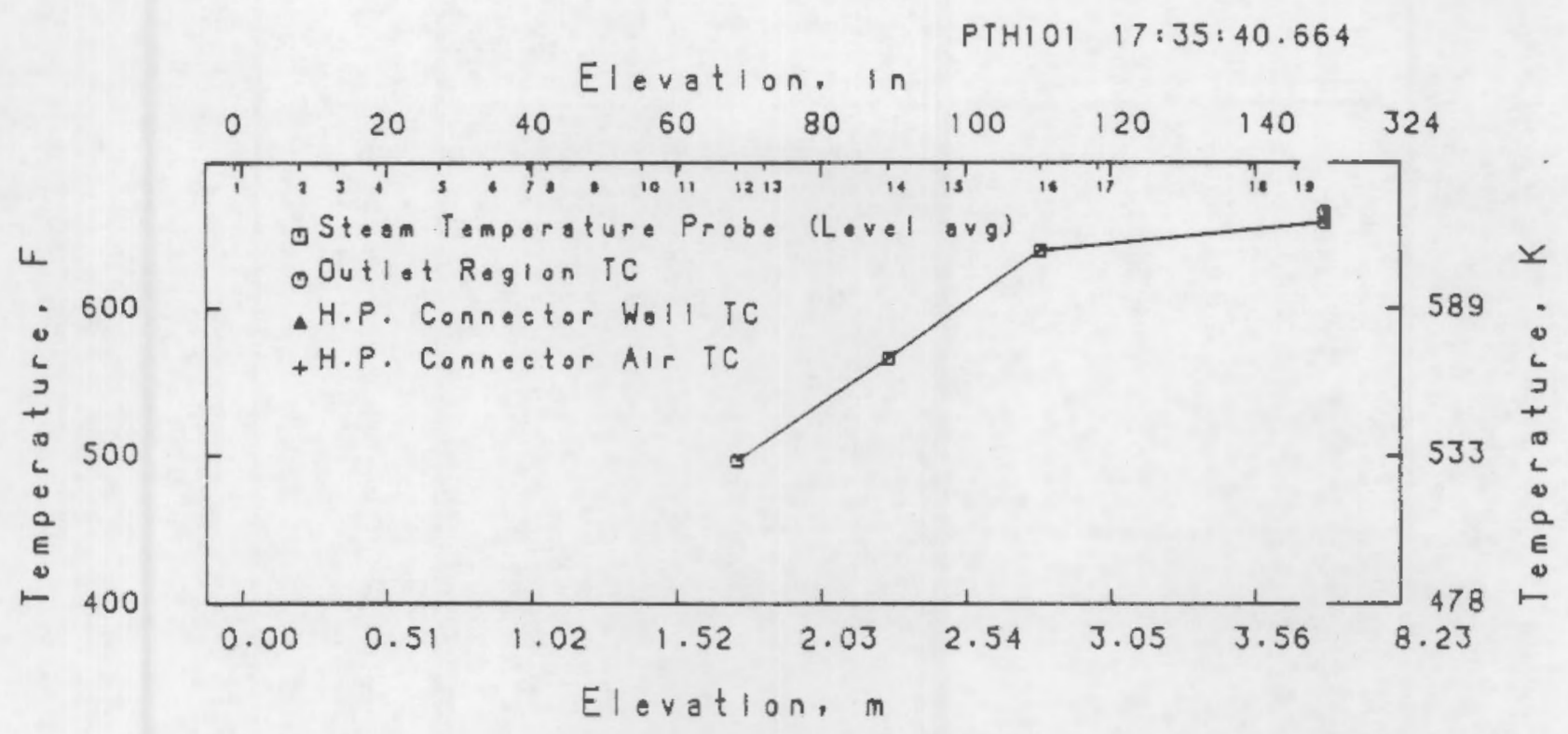

FIGURE 3.2.1 STEAM PROBE AND CONNECTOR TEMPERATURE PROFILE (IN STEAM-PRETRANSIENT) 



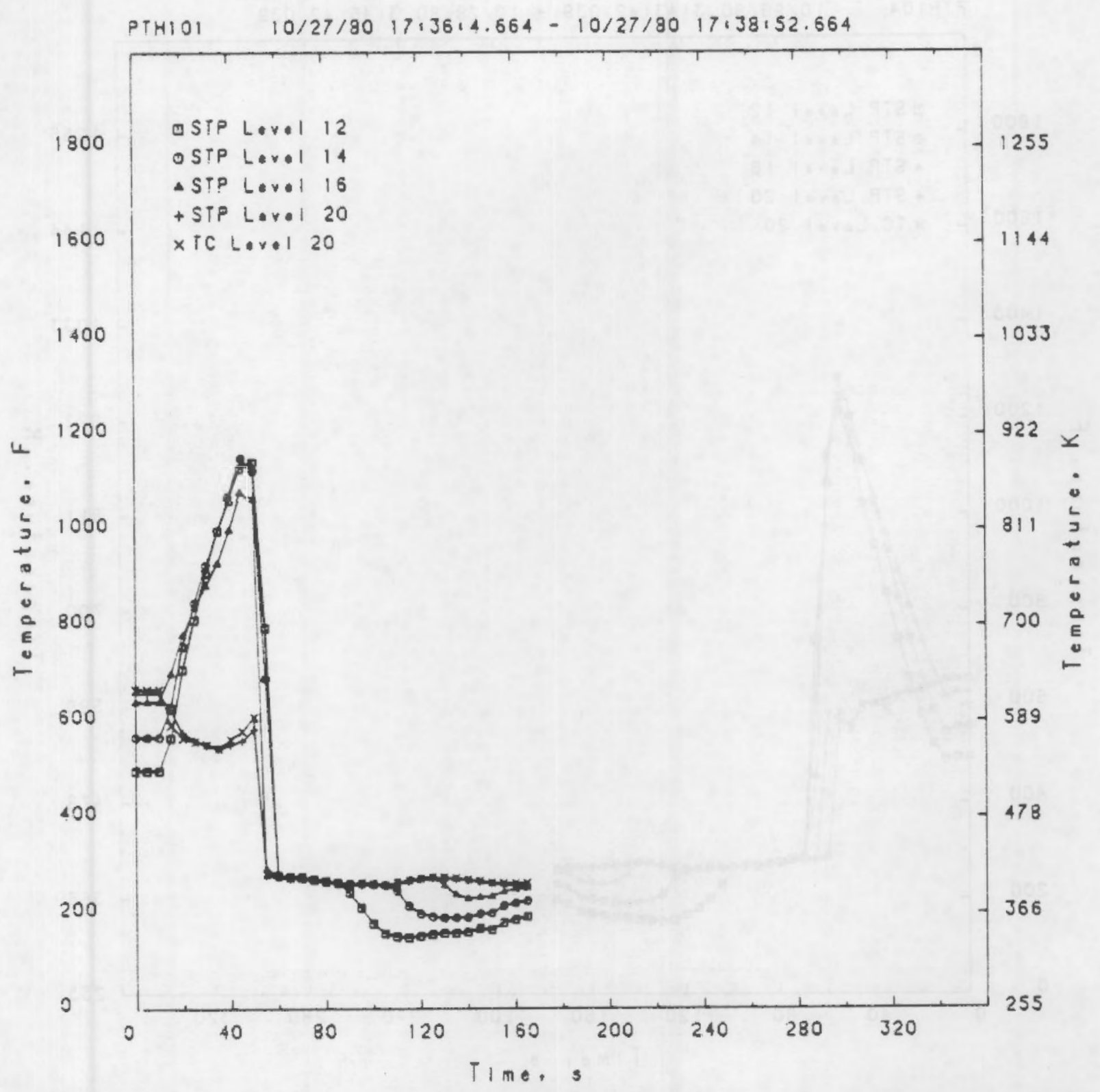

FIGURE 3.2.2.01 STEAM TEMPER.ATURE PROBE HISTORY OURING TRANSIENT PTHIOI 


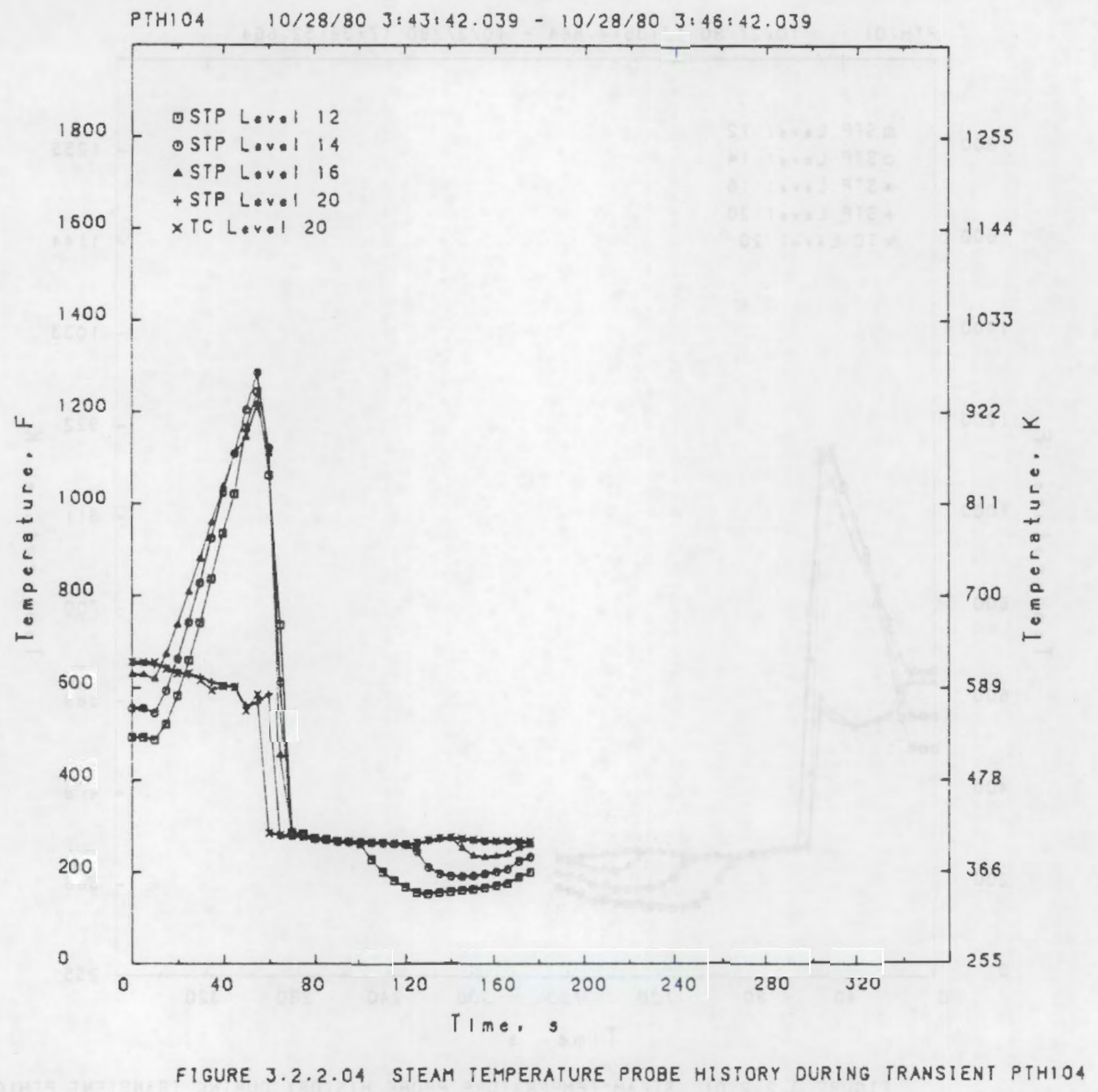

A. 180 


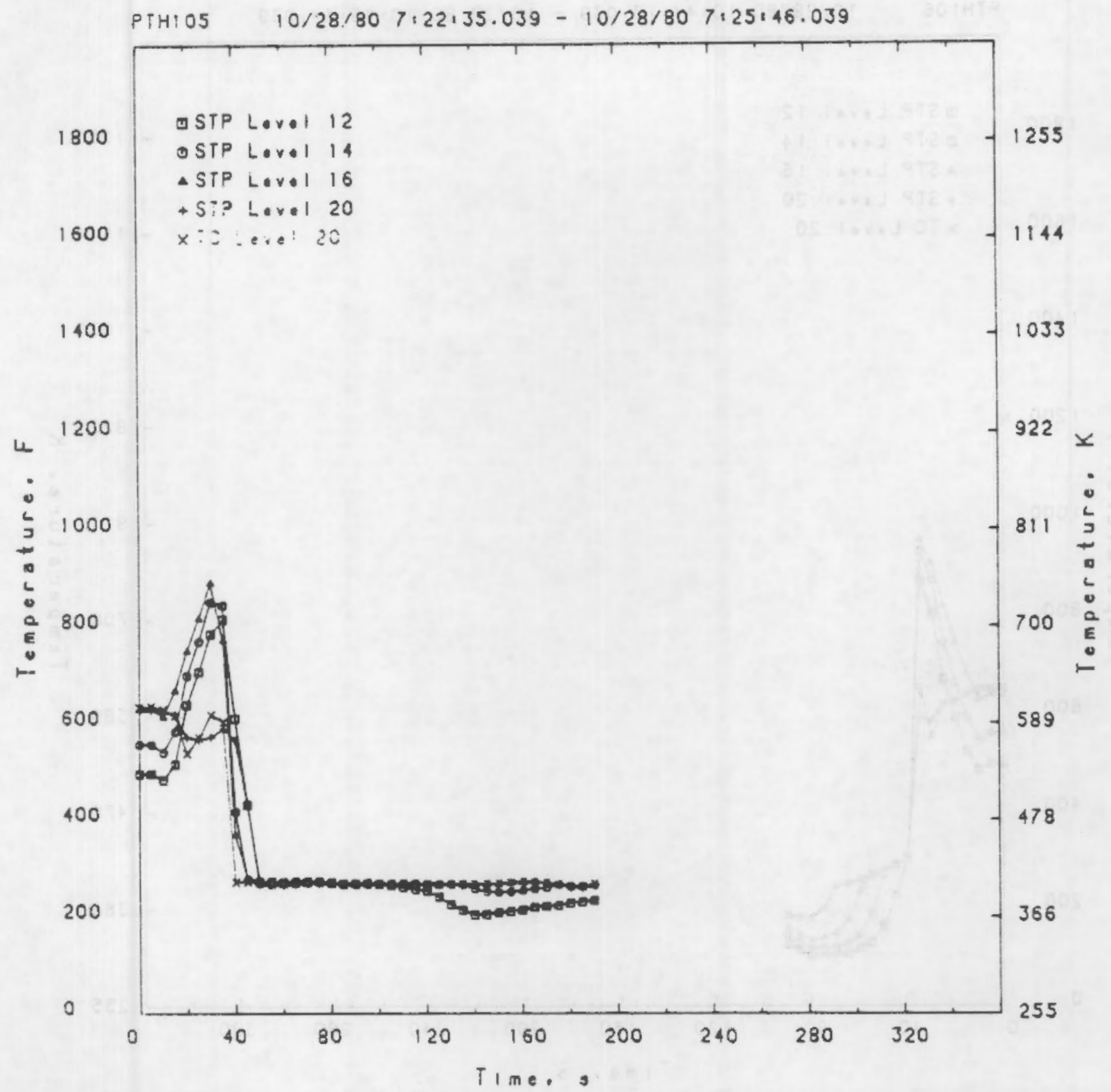

FIGURE 3.2.2.05 STEAM IEMPERATURE PROBE HISTORY DURING TRANSIENT PTHIOS 


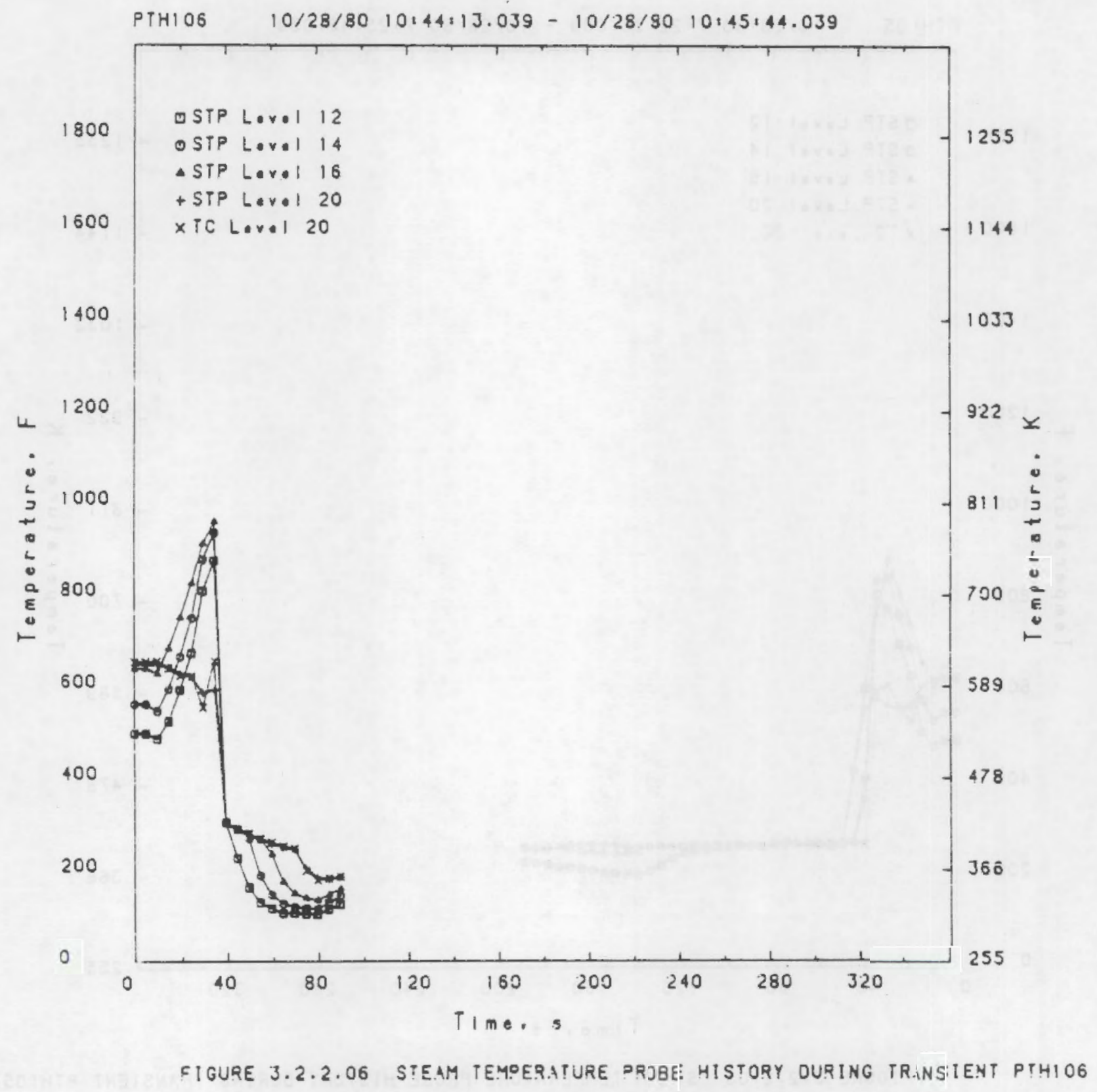

A. 182 


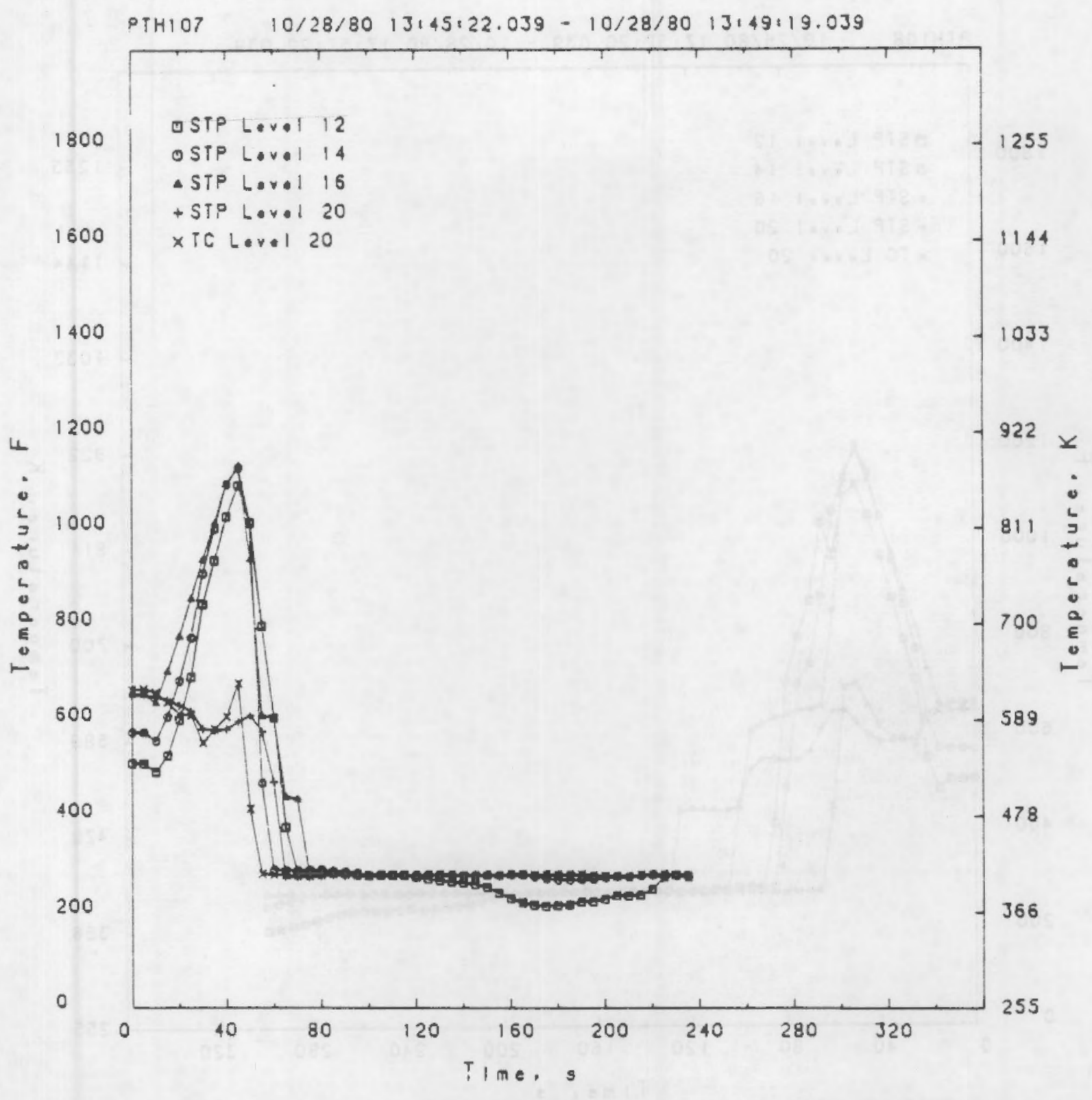

FIGURE 3.2.2.07 STEAM TEMPERATURE PROBE HISTORY DURING TRANSIENT PTHIOT 


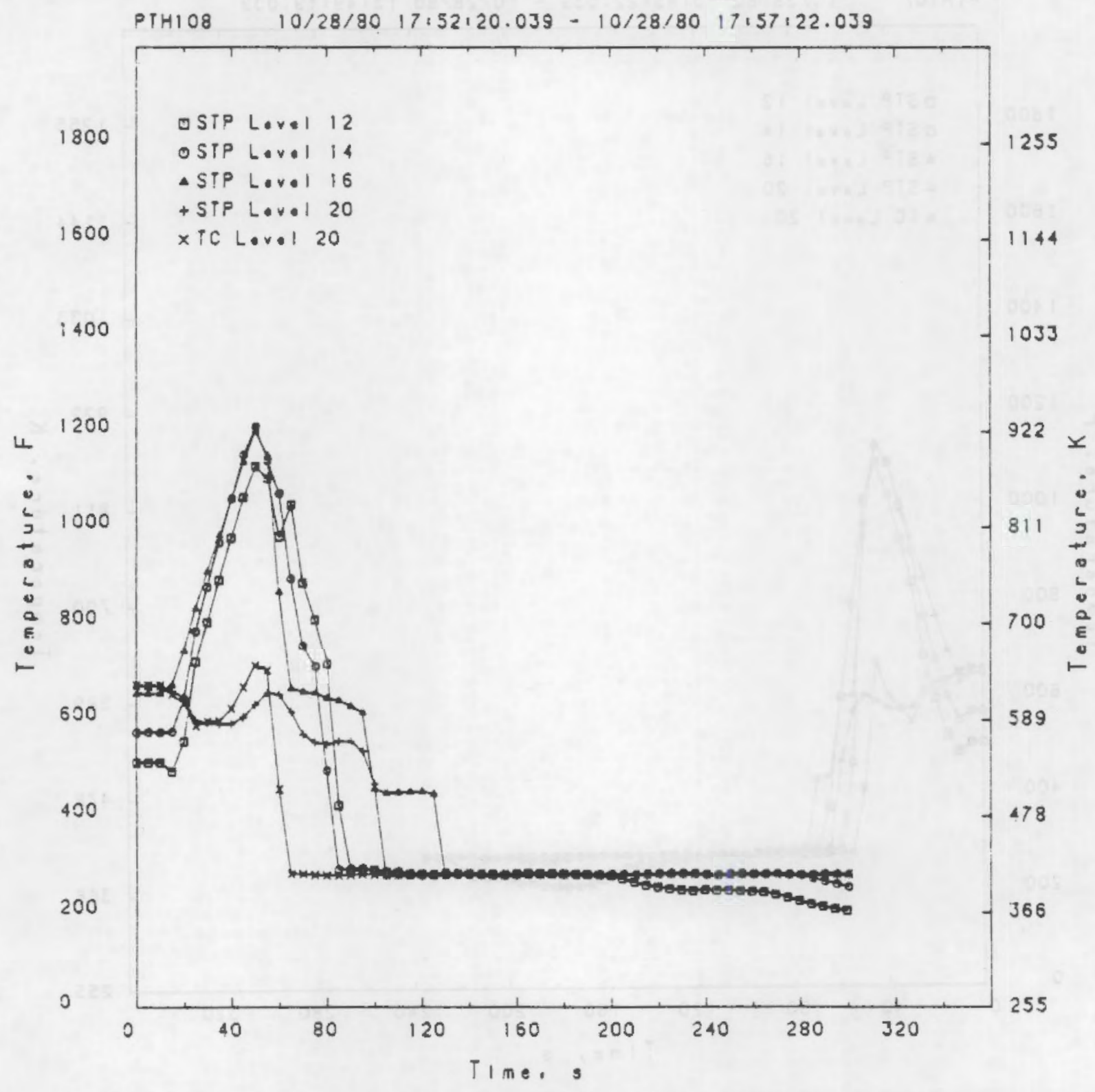

FIGURE 3.2.2.08 STEAM TEMPERATURE PROBE HISTORY DURING TRANSIENT PTHIO8 


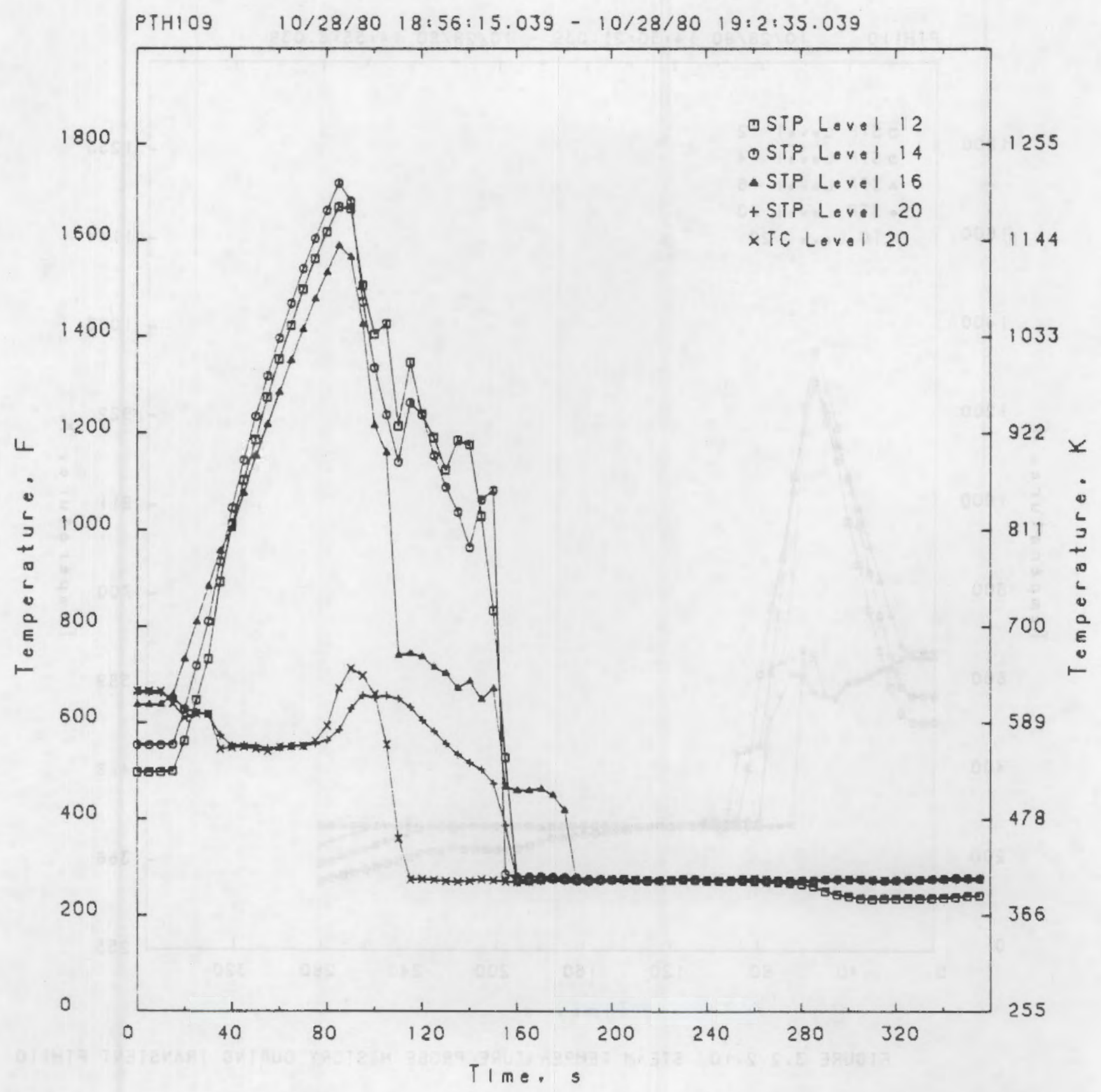

FIGURE 3.2.2.09 STEAM TEMPERATURE PROBE HISTORY FOR TRANSIENT PIHIOG 


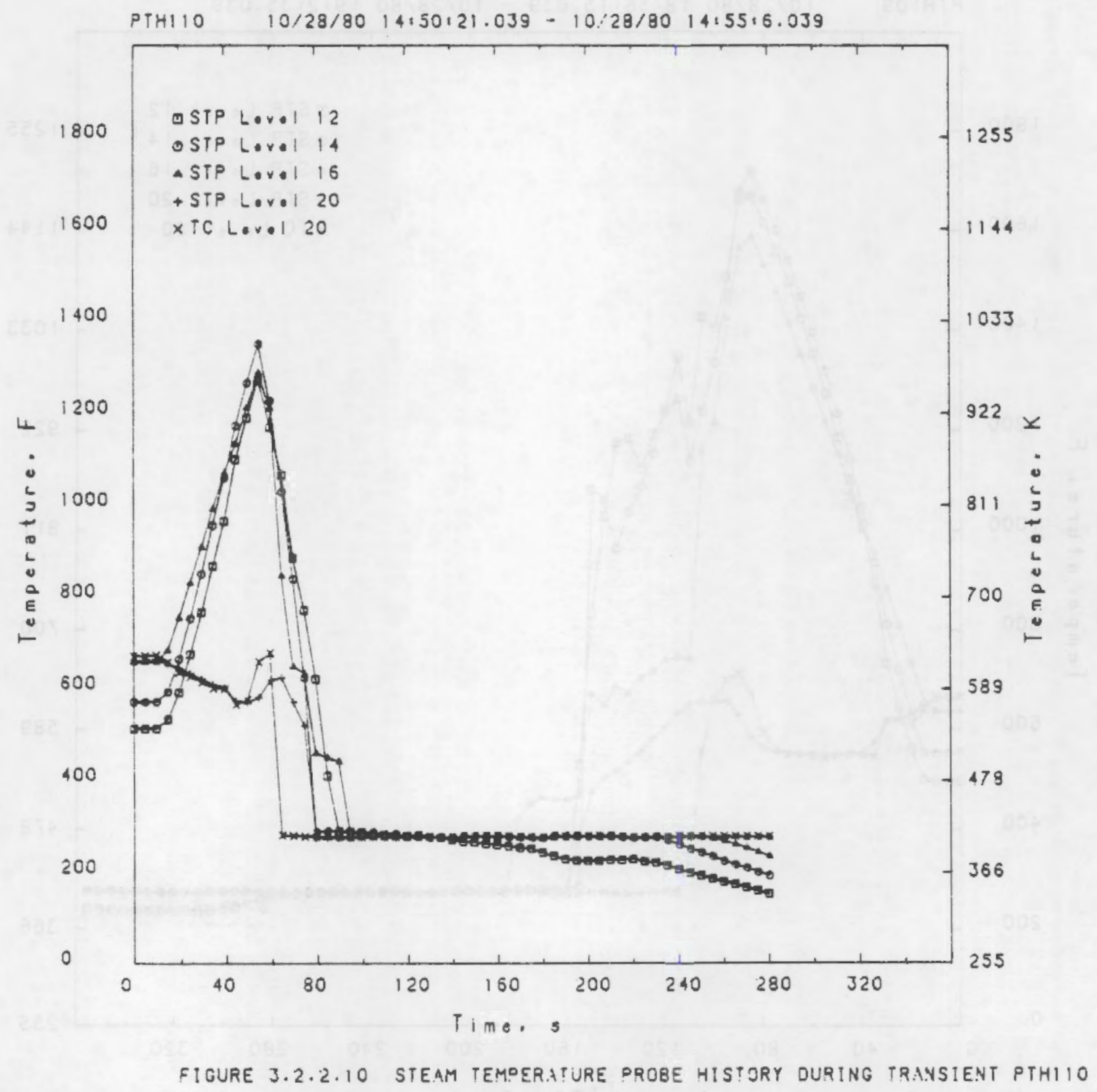

A. 185 


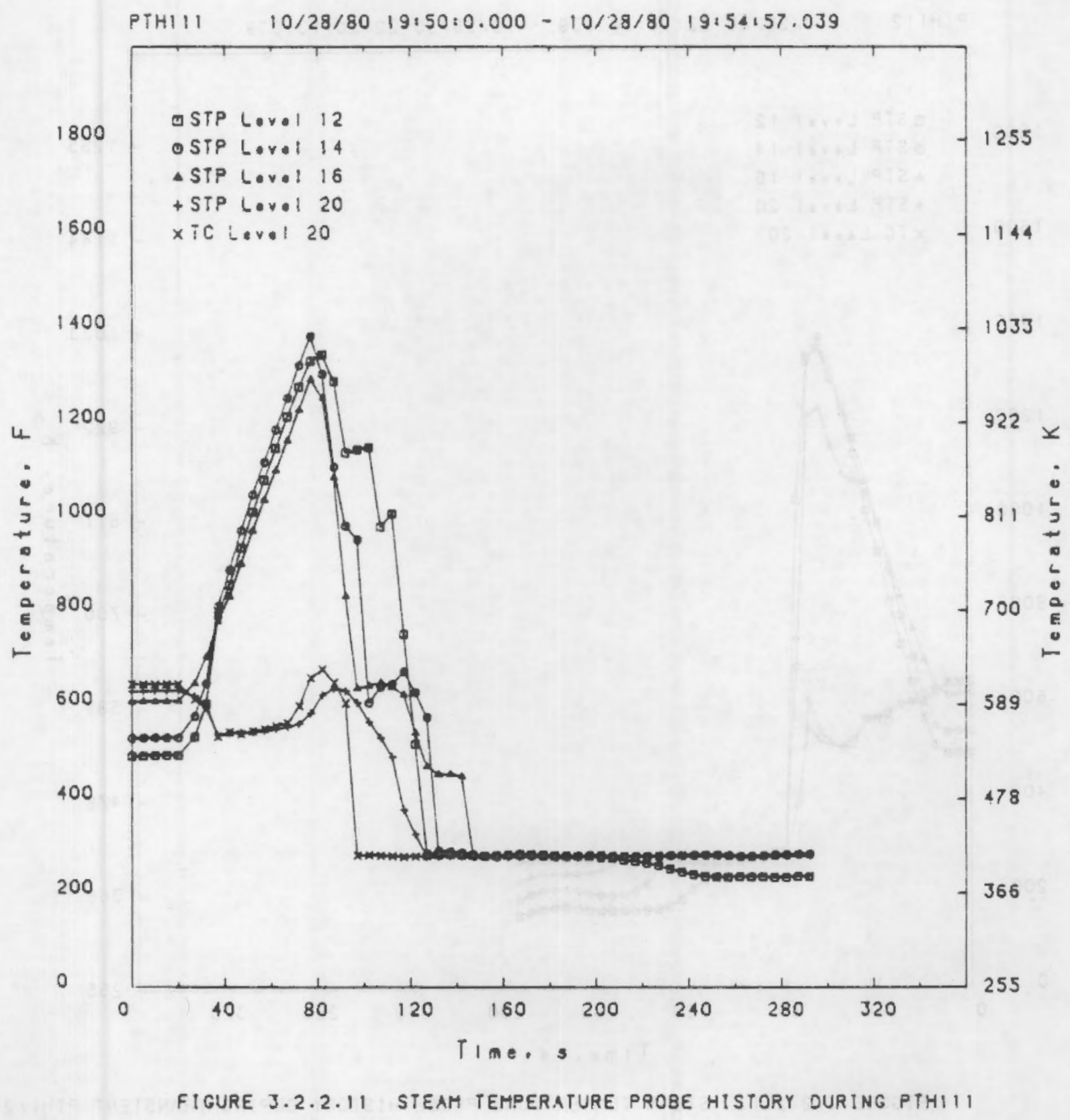




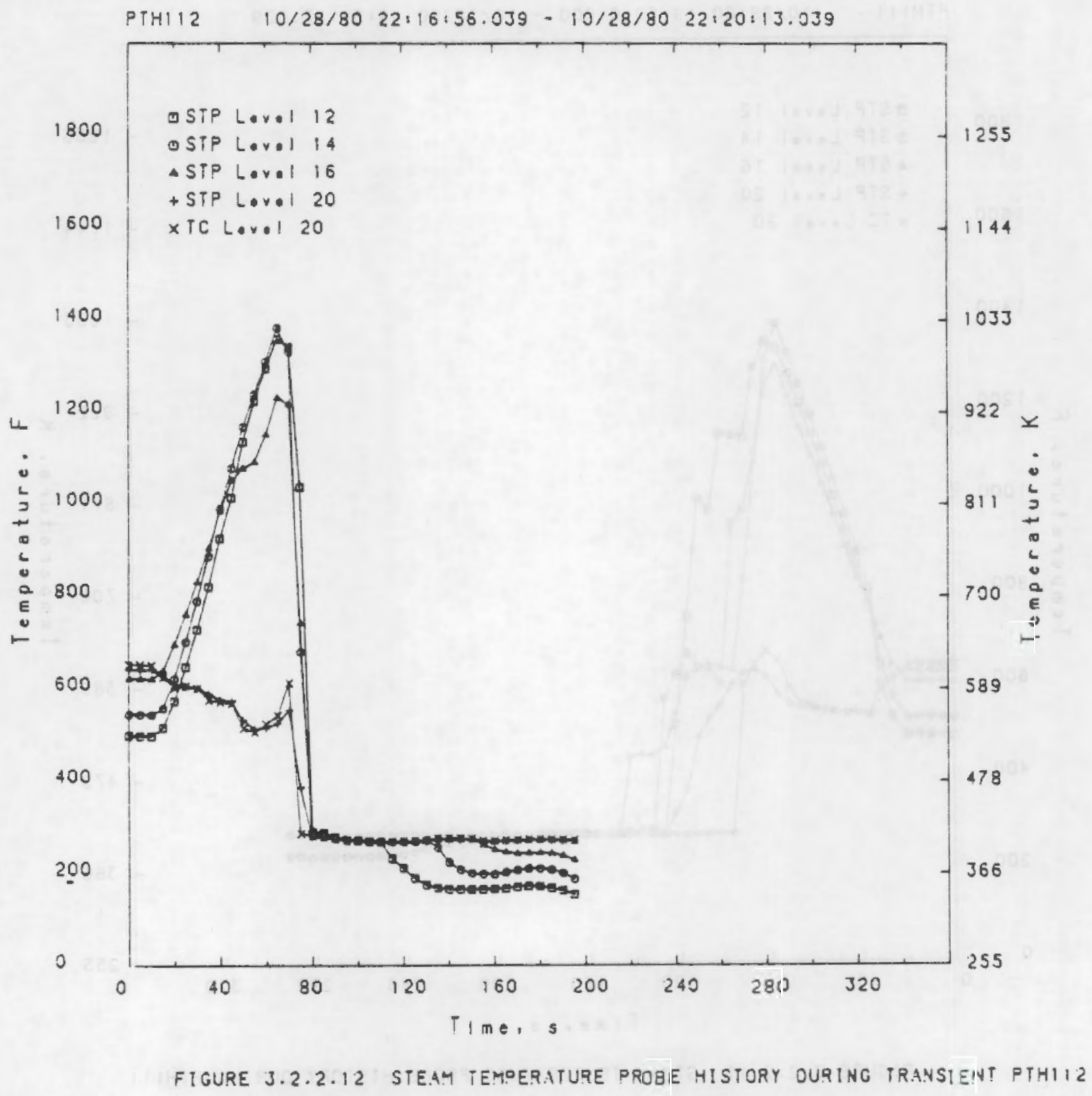

A. 188 


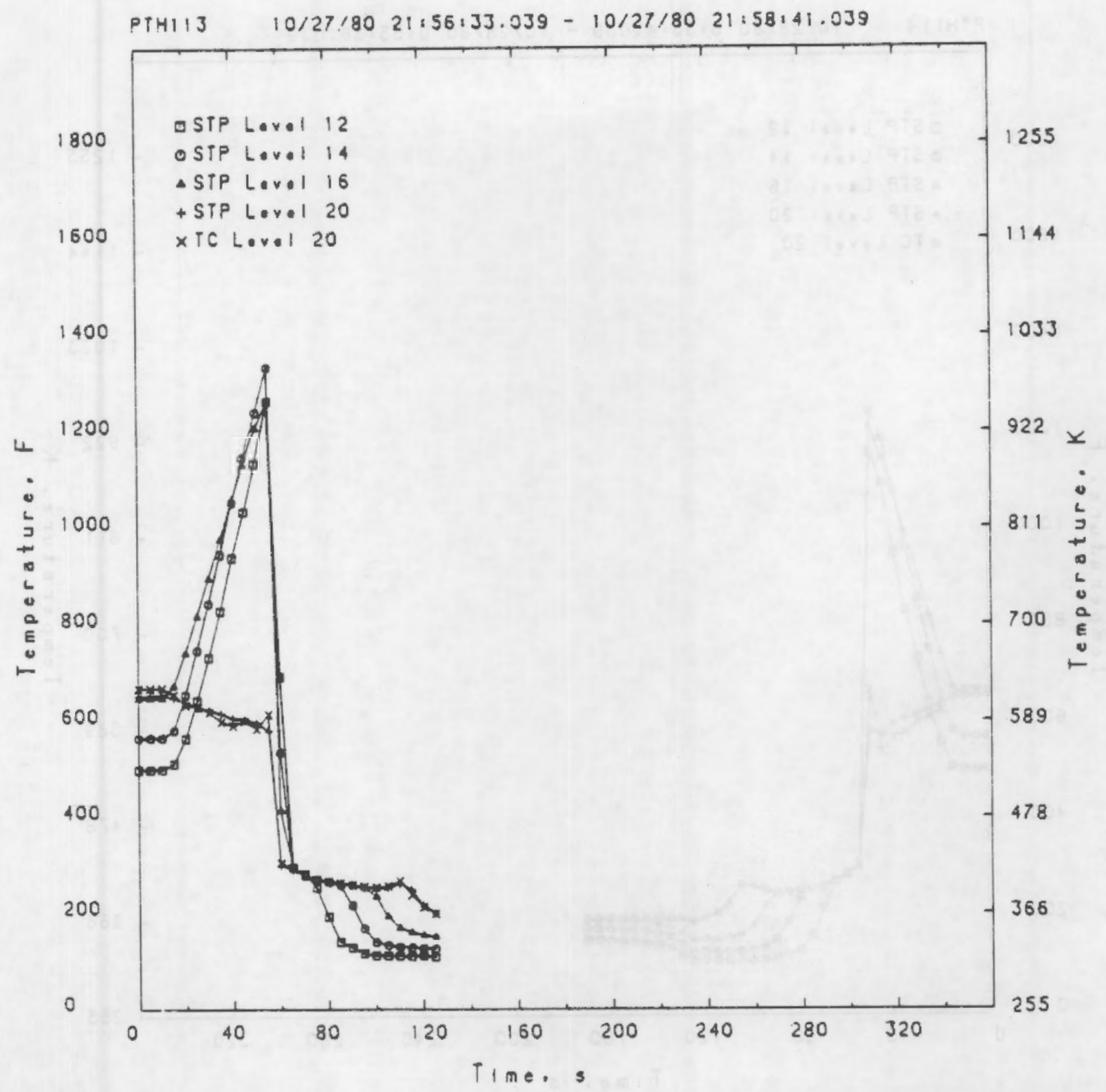

FIGURE 3.2 .2 .13 STEAM TEMPERATURE PROBE HISTORY OURING TRANSIENT PTHIIJ 


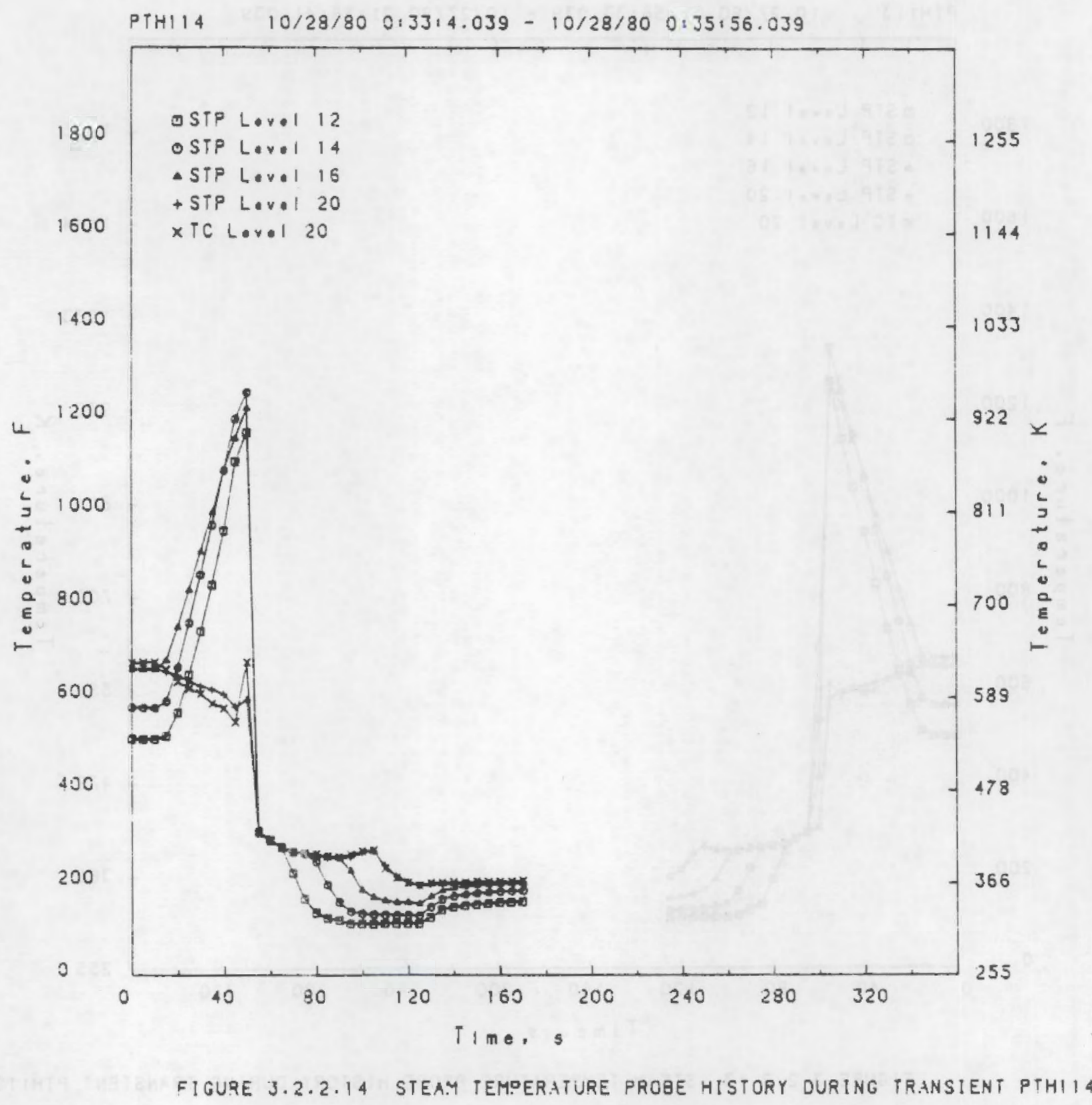

A. 190 


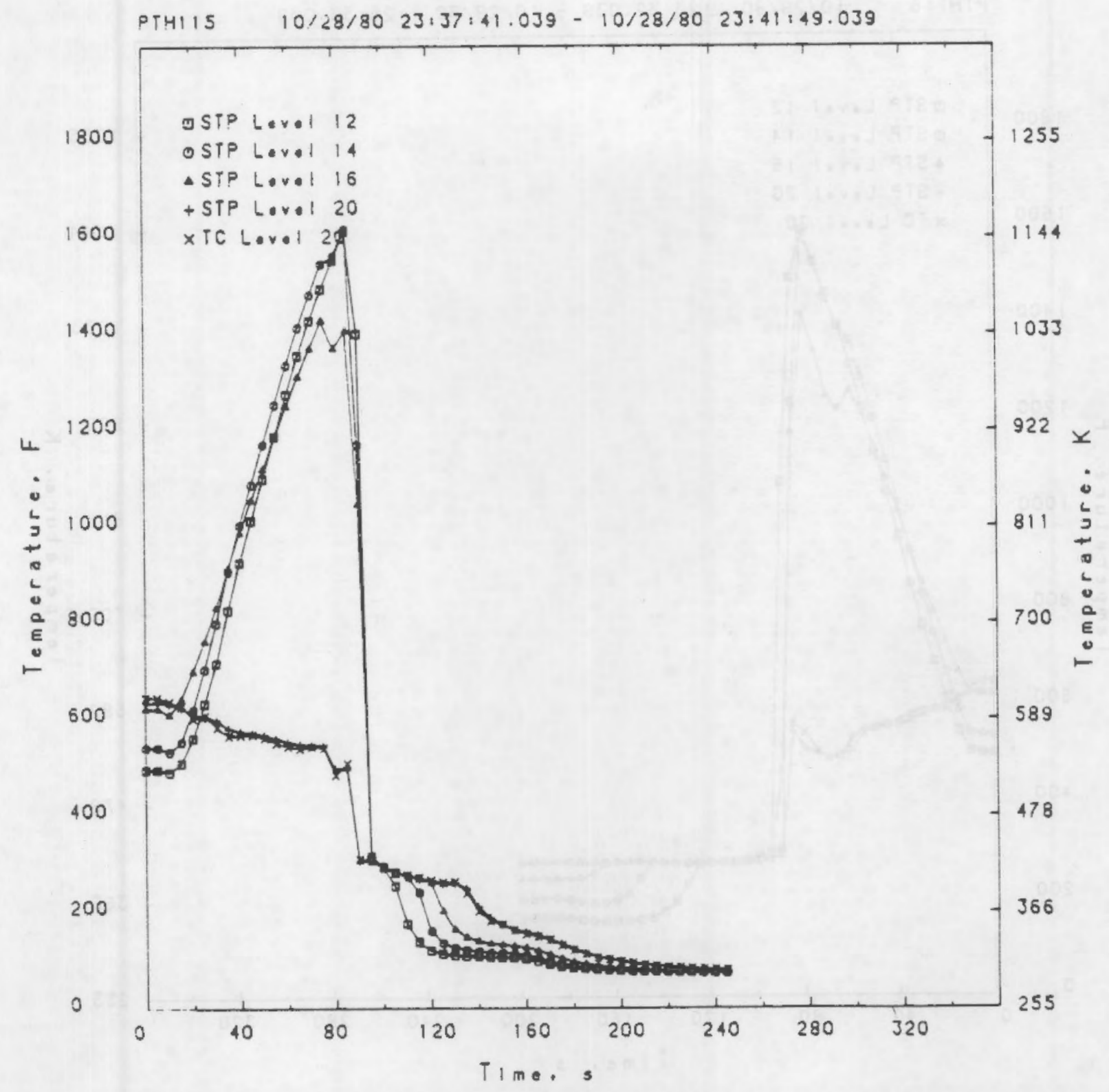

FIGURE 3.2.2.15 STEAM TEMPERATURE PROBE HISTORY OURING TRANSIENT PTHII5 


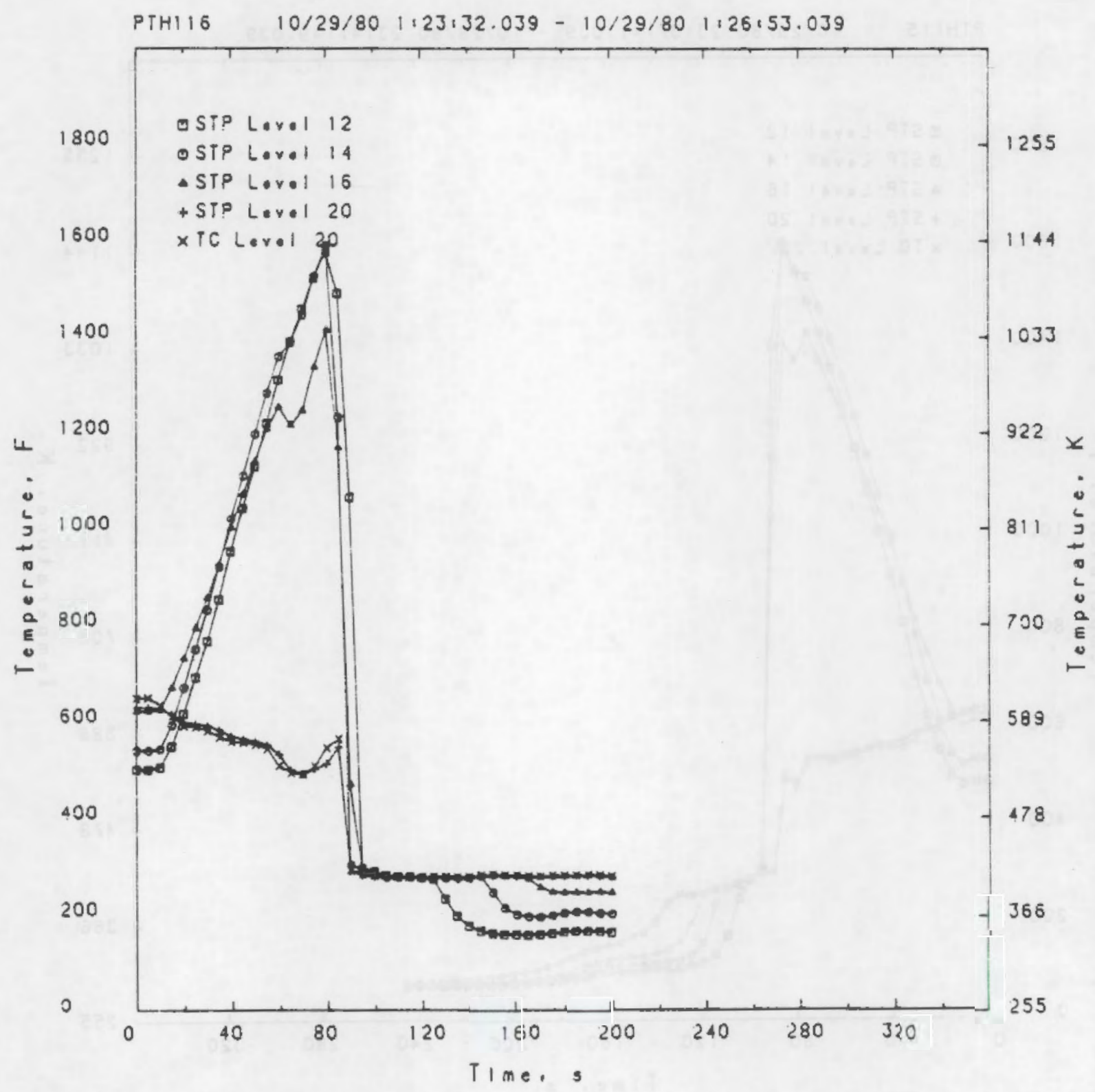

FIGUPE 3.2.2.16 STEAM TEMPERATURE PROBE HISTORY DURING PTHII6 


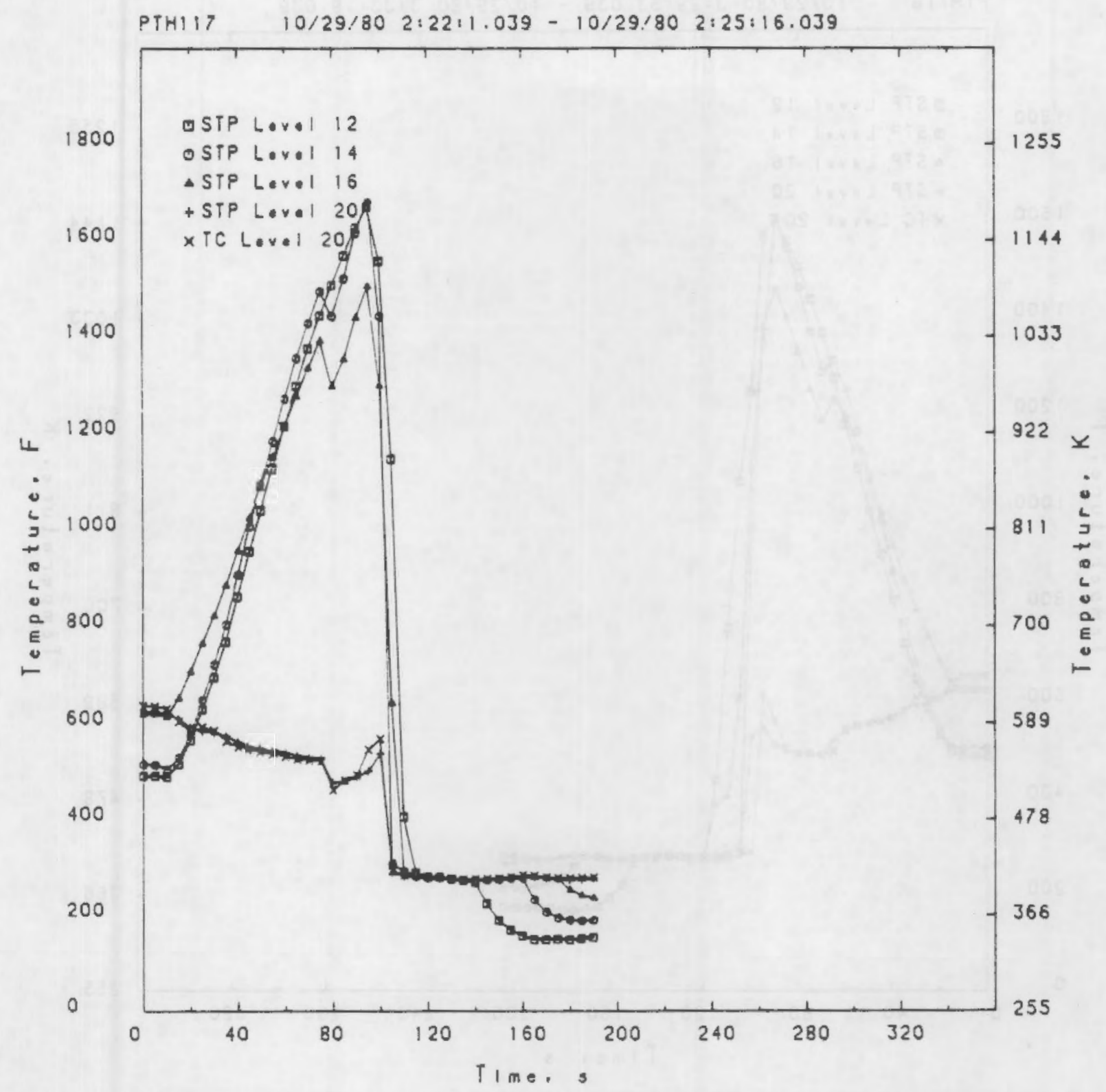

FIGURE 3.2.2.17 STEAM TEMPERATURE PROBE HISTORY OURING TR.ANSIENT PTHII7 


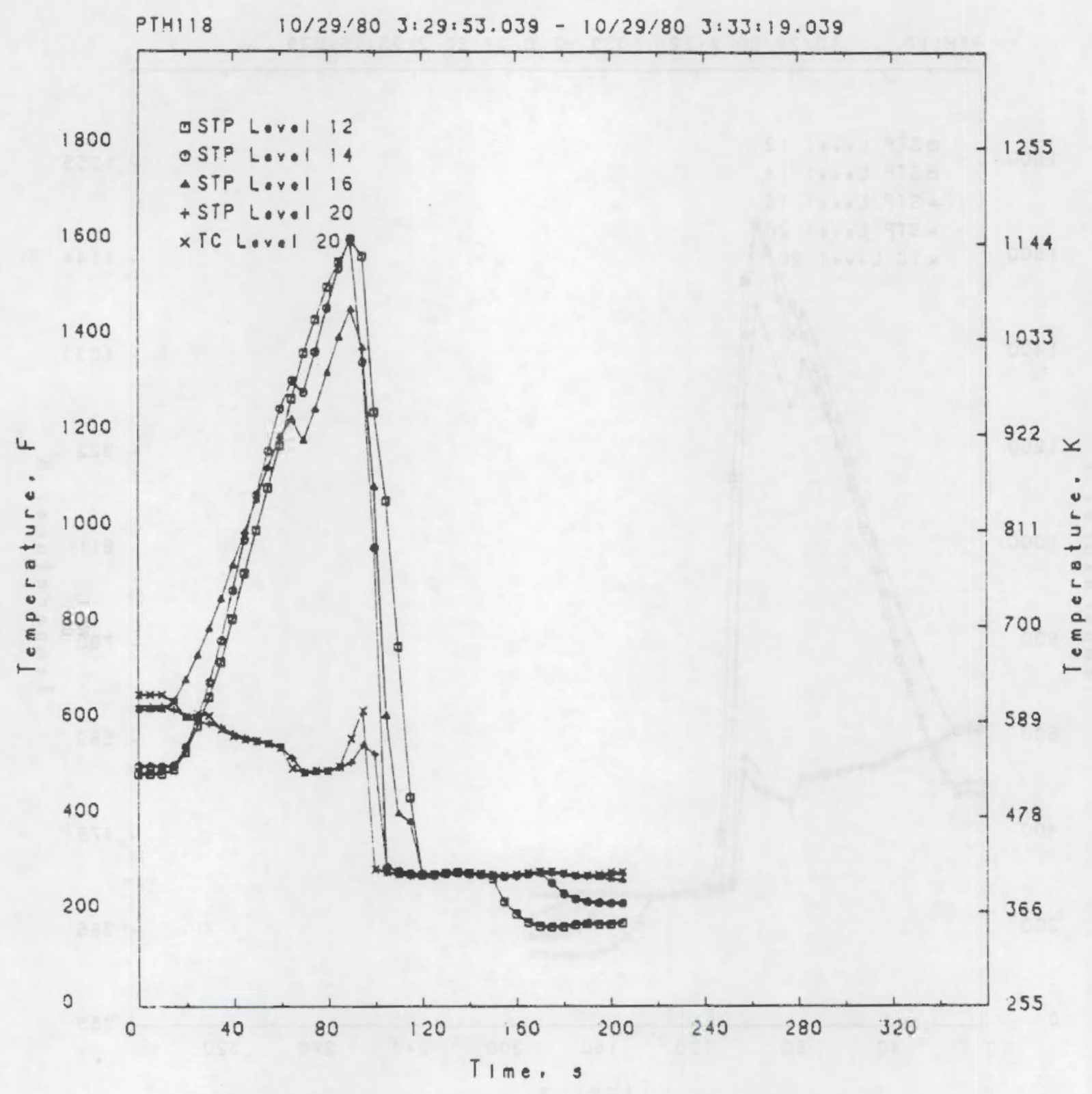

FIGURE 3.2 .2 .18 STEAM TEMOERATURE PROBE HISTORY DURING TRANSIENT PTHIIB 


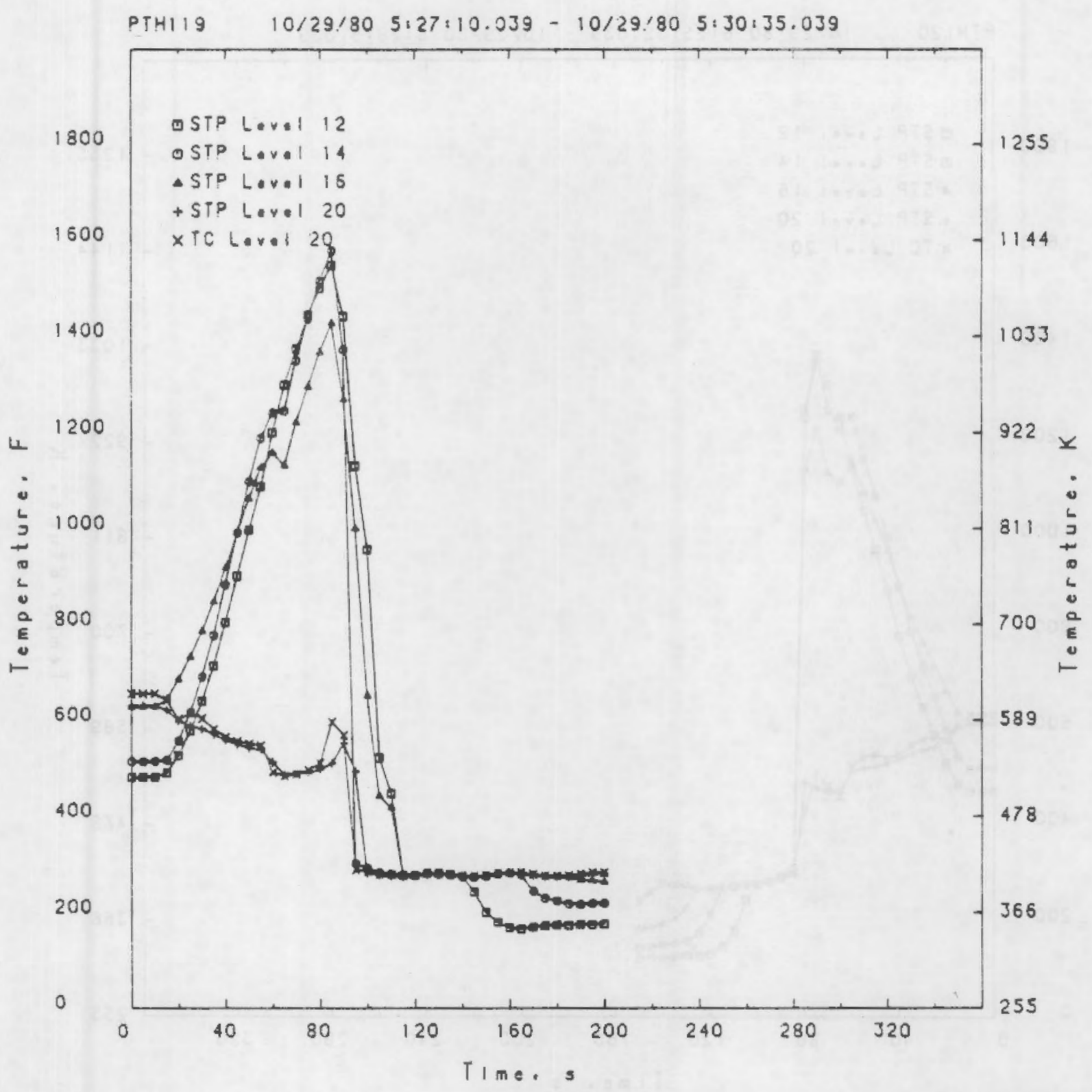

FIGURE 3.2.2.19 STEAM TEMPERATURE PROBE HISTORY DURING TRANSIENT PTHII9 


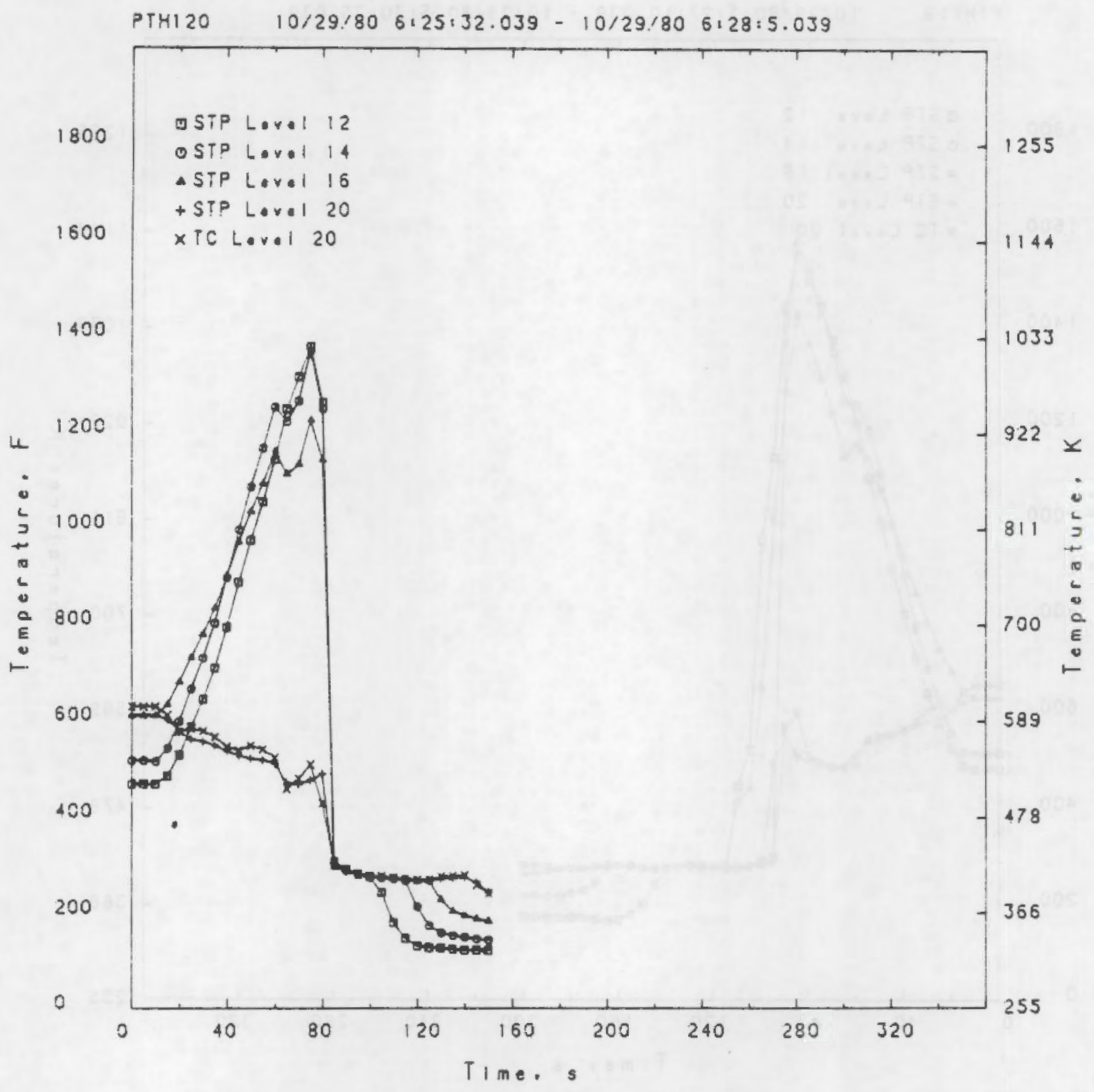

FIGURE 3.2.2.20 STEAM TEMOERATURE PROBE HISTORY DURING TRANSIENT PTHIZO 


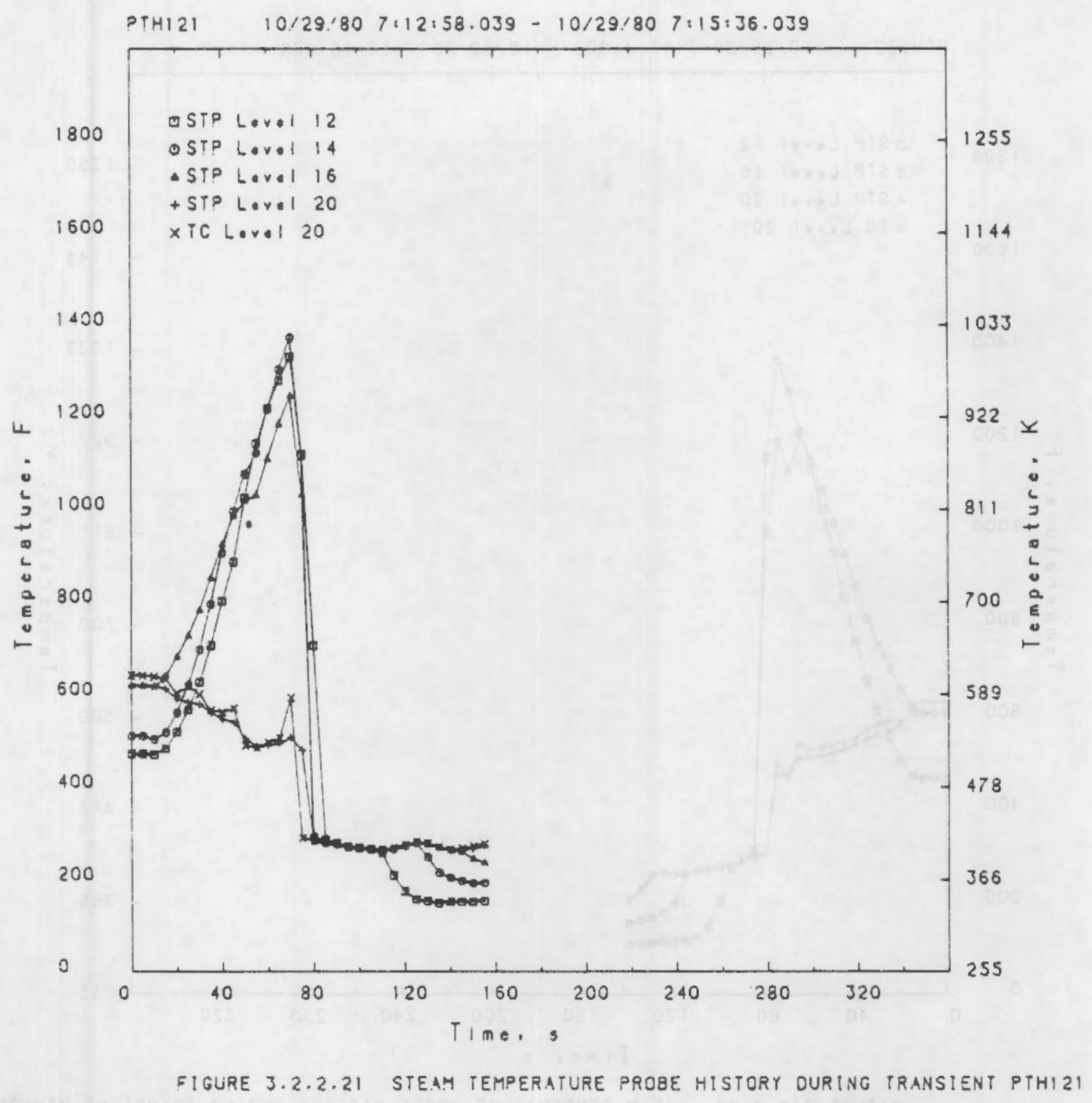

A. 197 


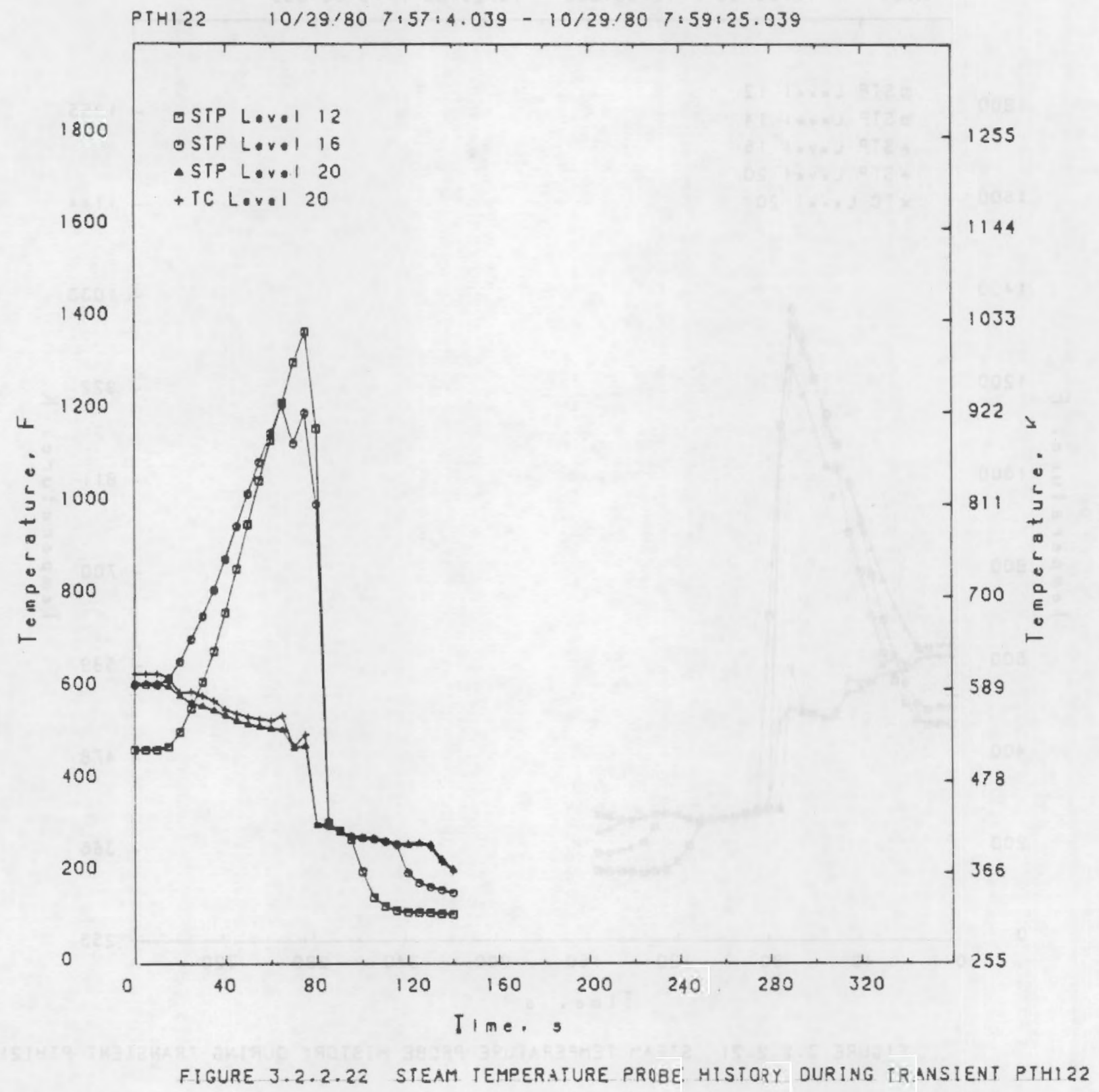

A. 198 


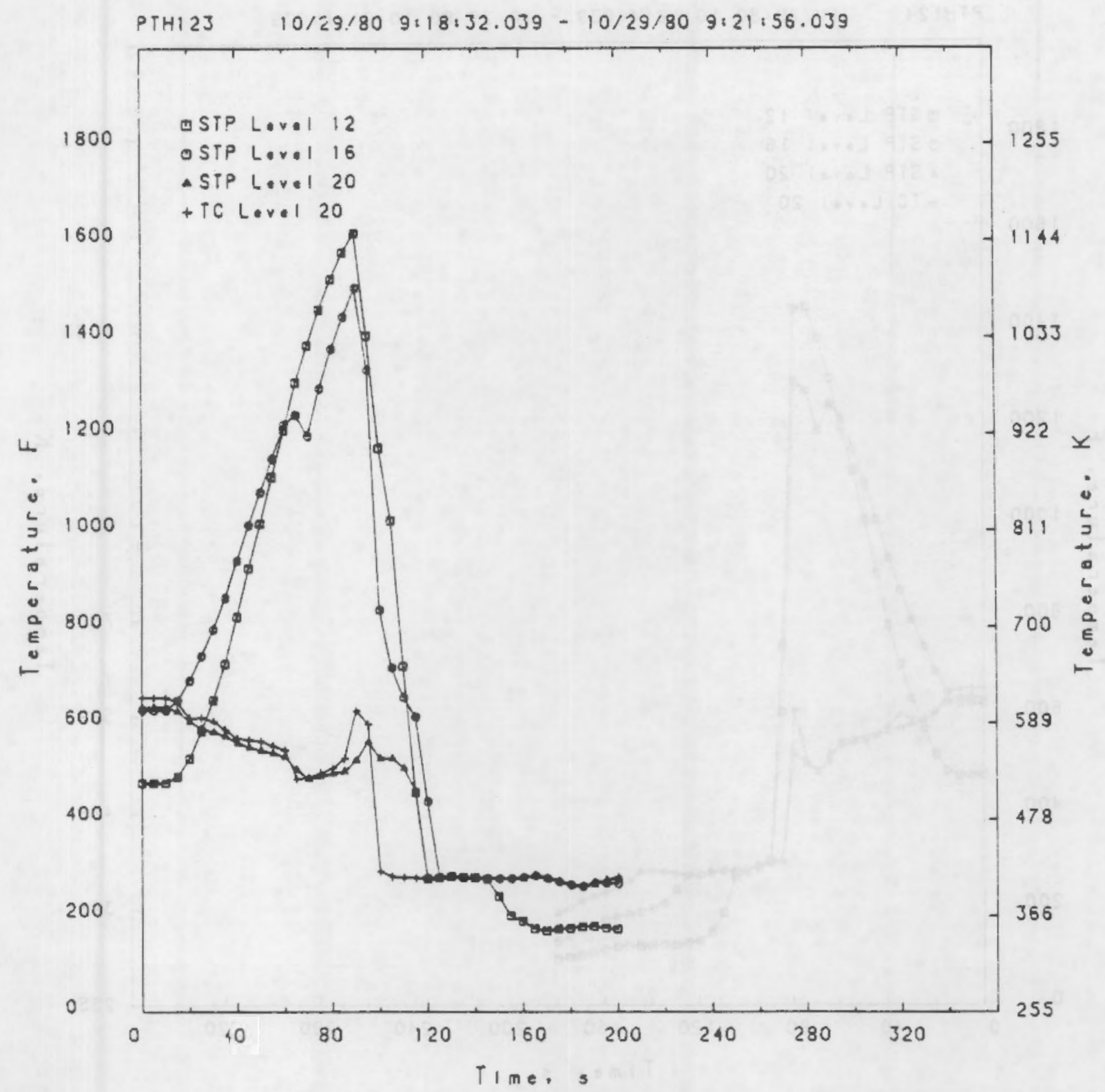

FIGURE 3.2.2.23 STEAM TEMPERATURE PROBE HISTORY DURING TRANSIENT PIHIL3 


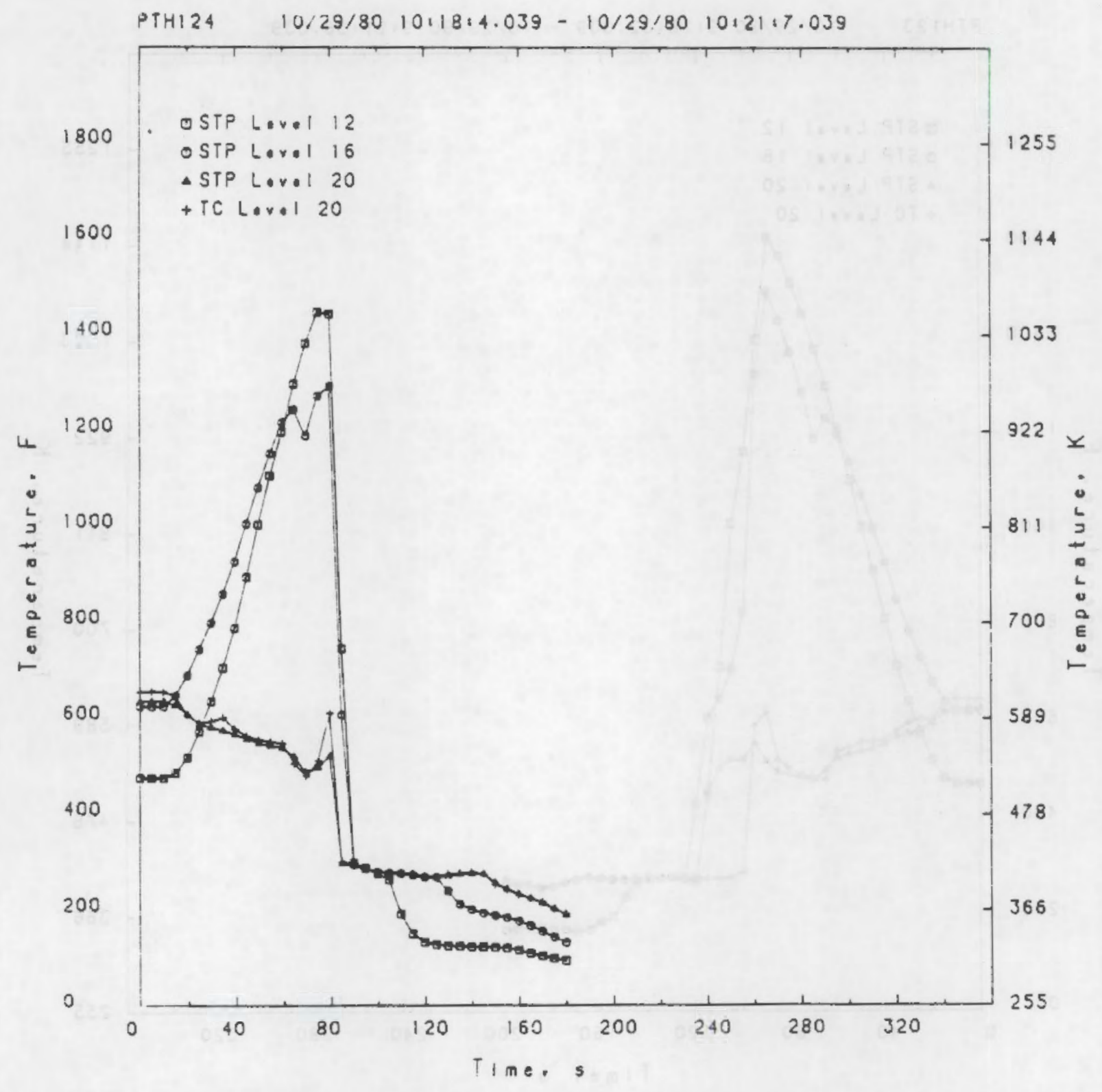

FIGURE 3.2.2.24 STEAM TEMPERATURE PROBE HISTORY OURING TRANSIENT PTHI 24 


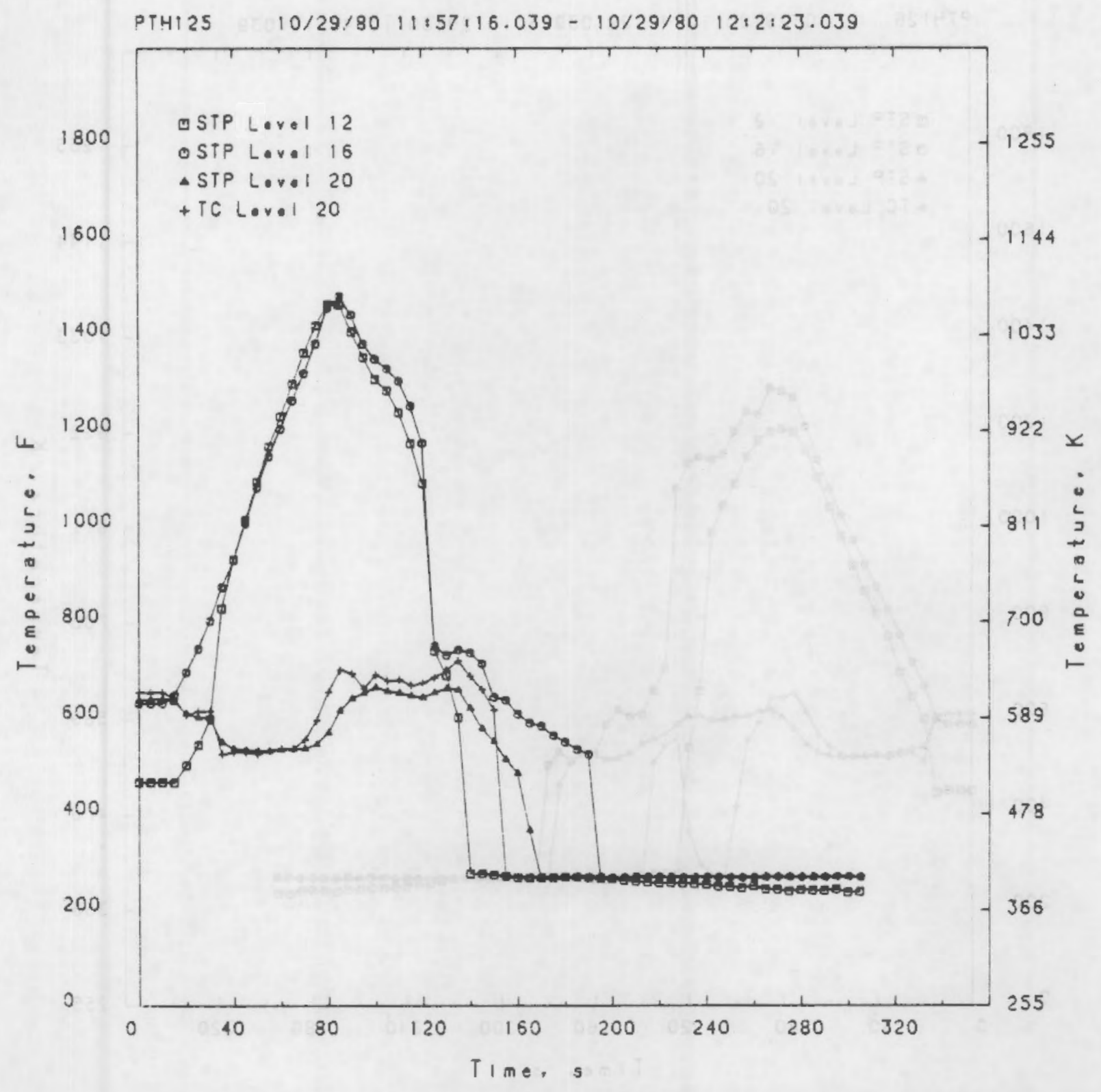

FIGURE 3.2.2.25 STEAM IEMOERATURE PROBE HISTORY OURING TRANSIENT PTHIZS 


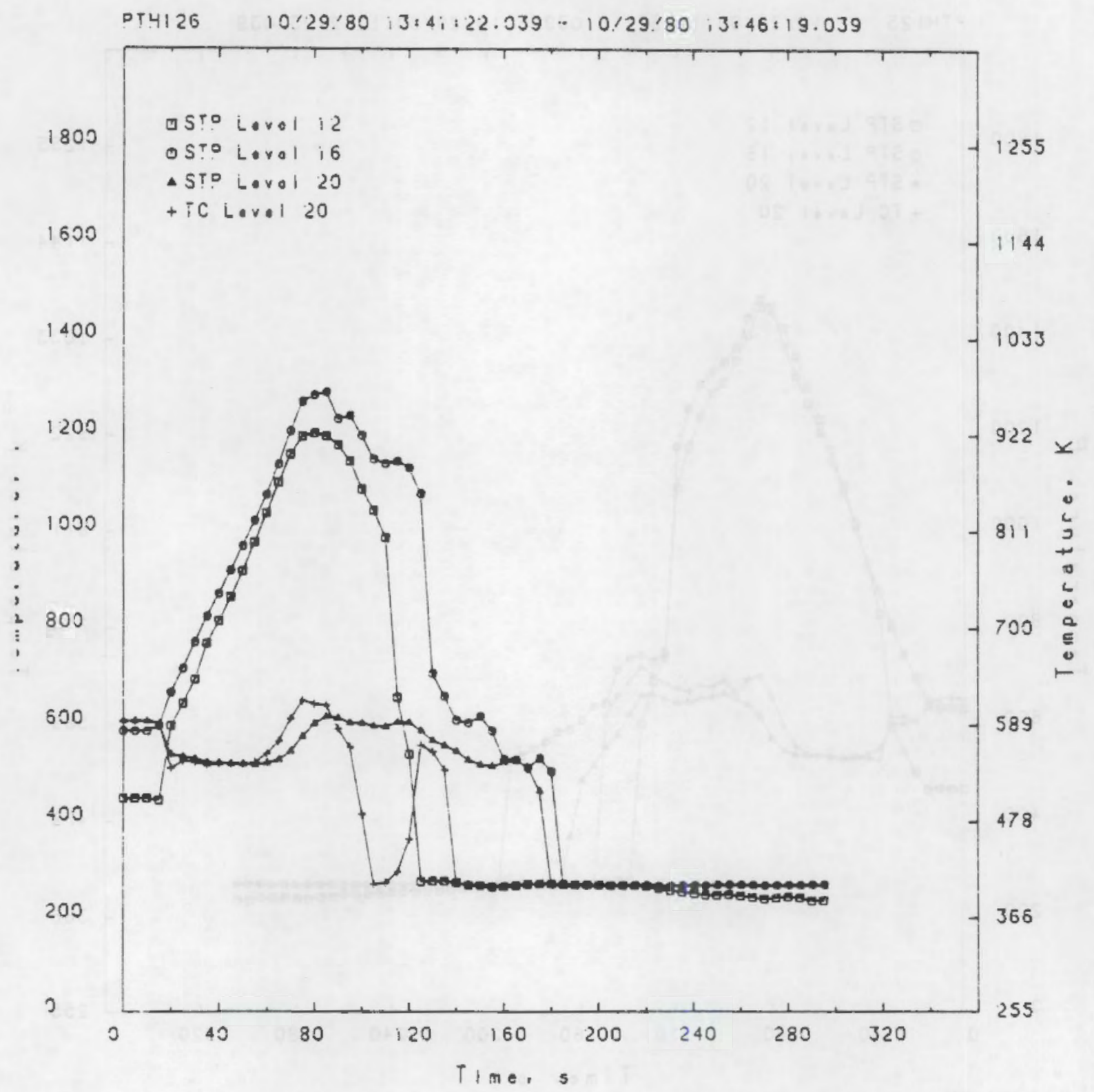

FIGURE 3.2.2.26 STEAM TEMOERATURE PROBE HISTORY OURING TRANSIENT PTHI26 


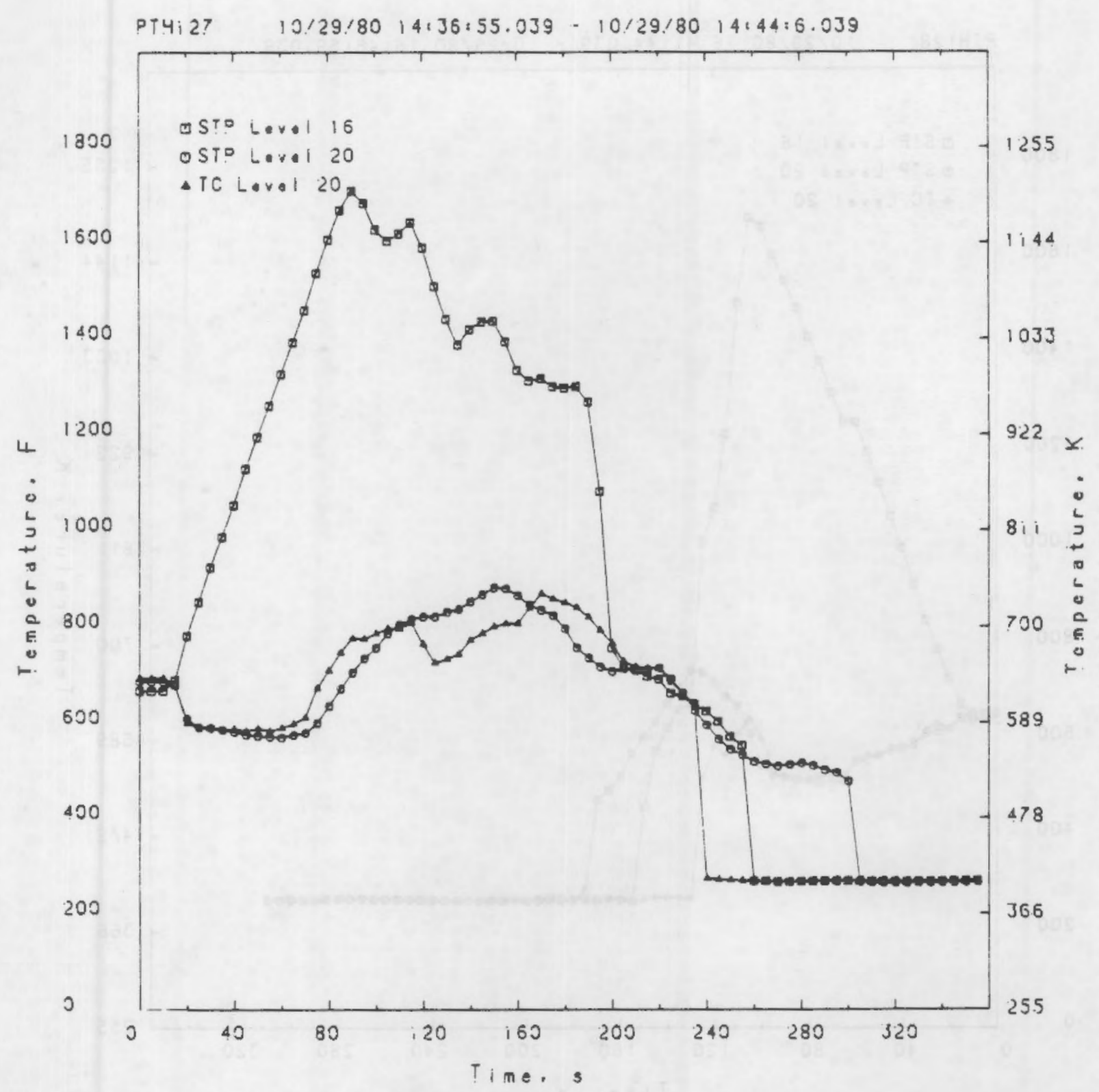

FIGURE 3.2.2.27 STEAM TEMOERATURE PQOBE HISTORY DURING TQSANSIENT PTYIZ? 


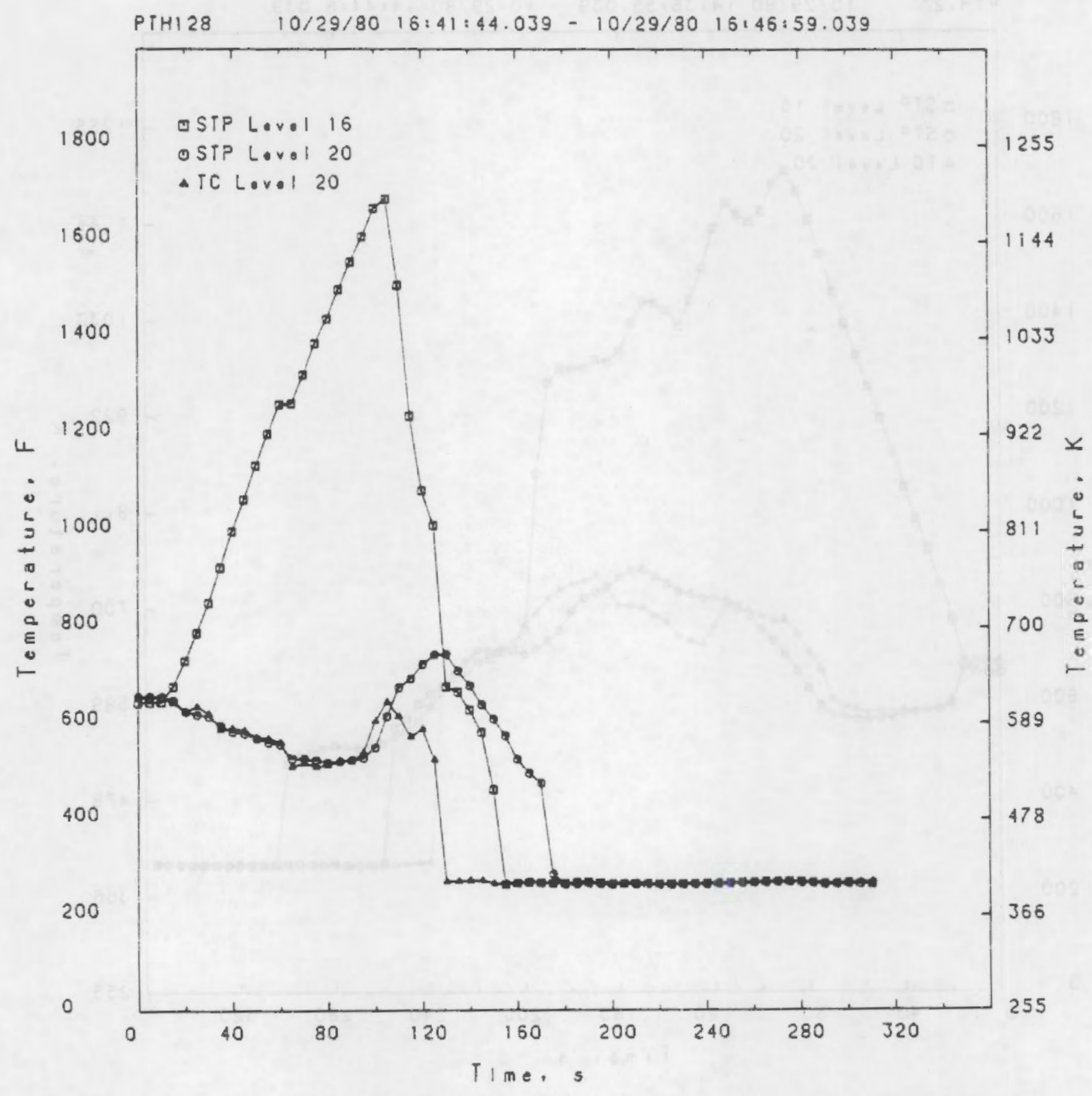

FIGURE 3.2.2.28 STEAM TEMPERATURE PROBE HISTORY DURING TRANSIENT PTH128 


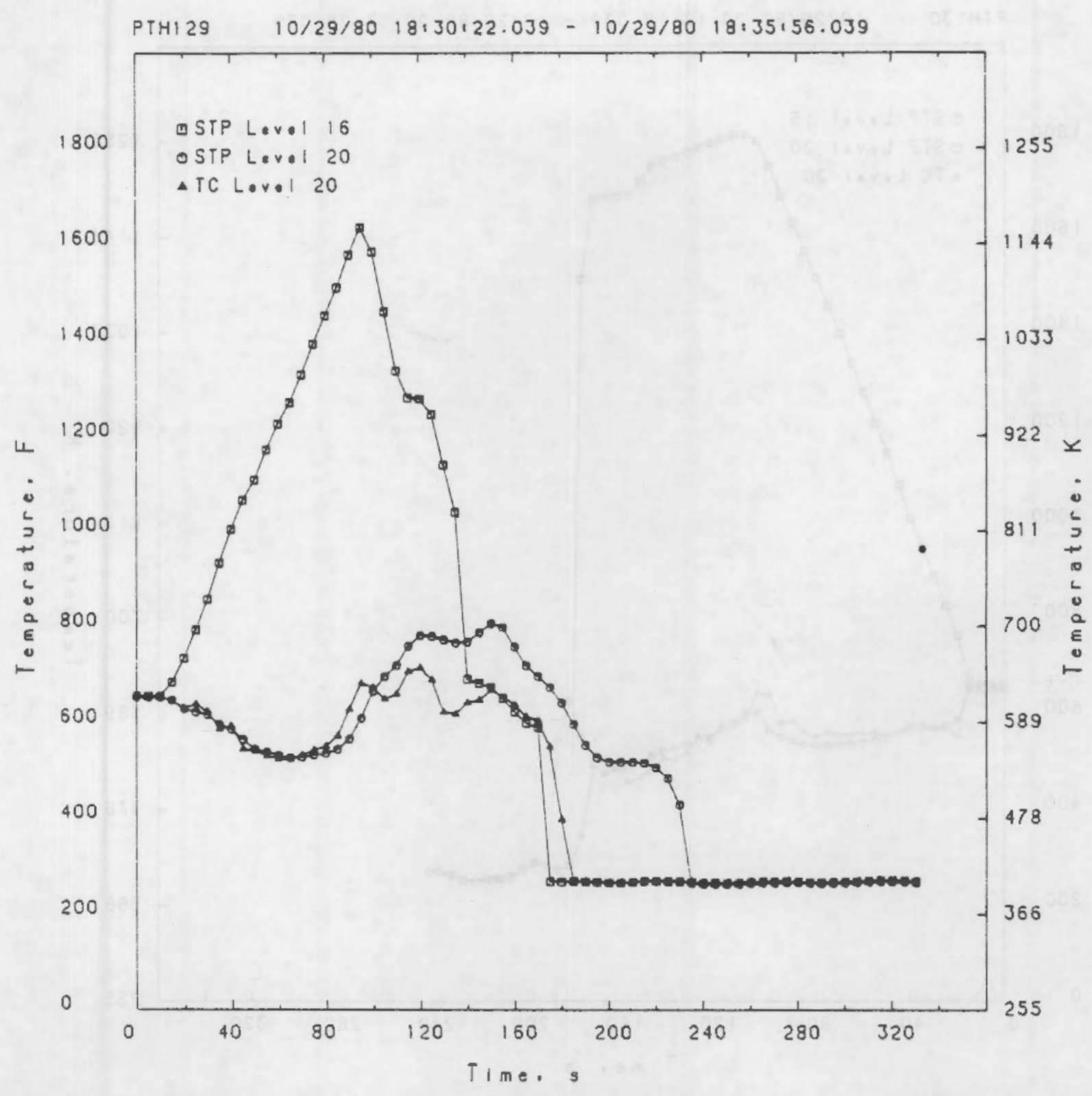

FIGURE 3.2.2.29 STEAM TEMPERATURE PROBE HISTORY DURING TRANSIENT PTHI29 


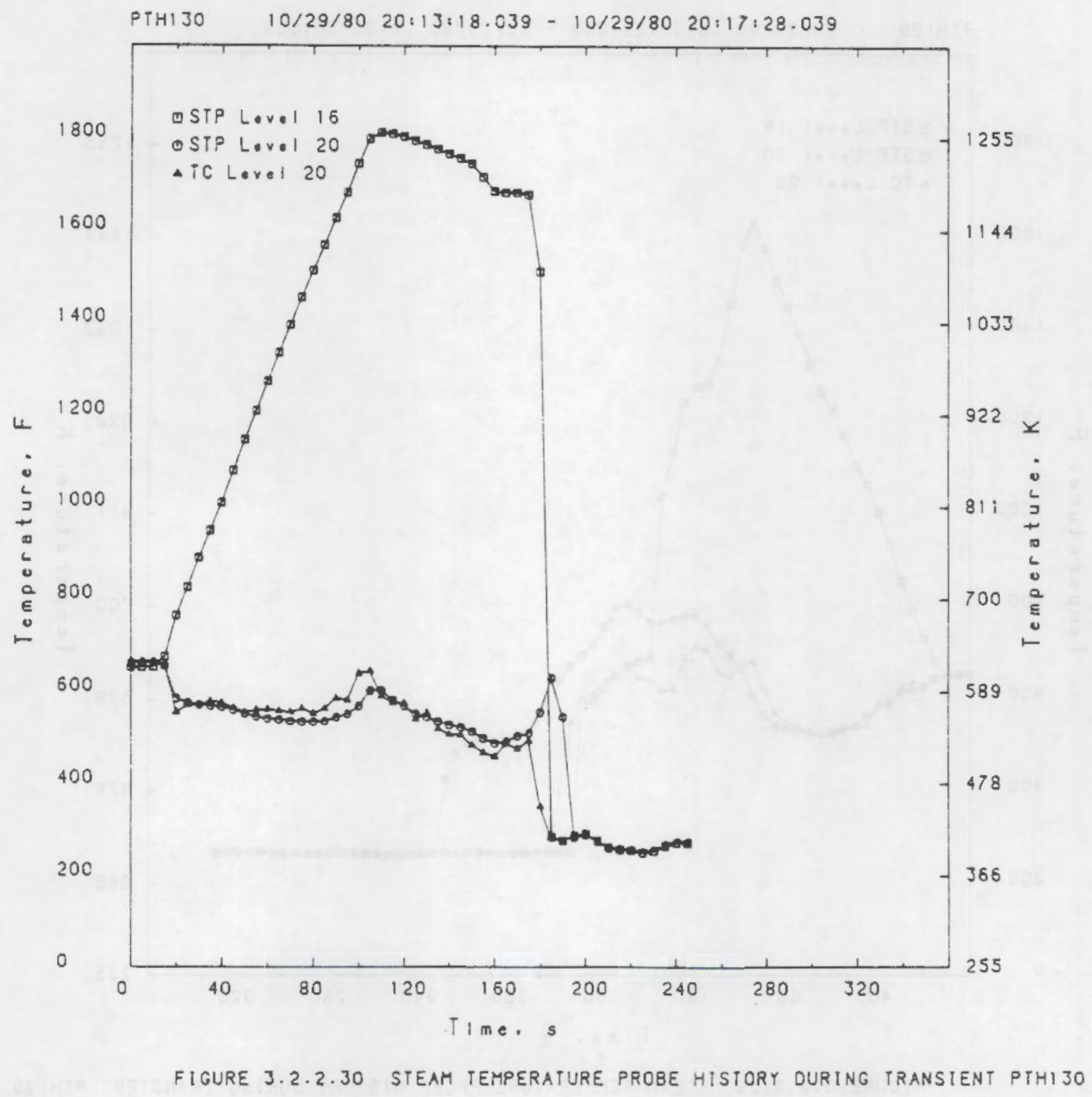




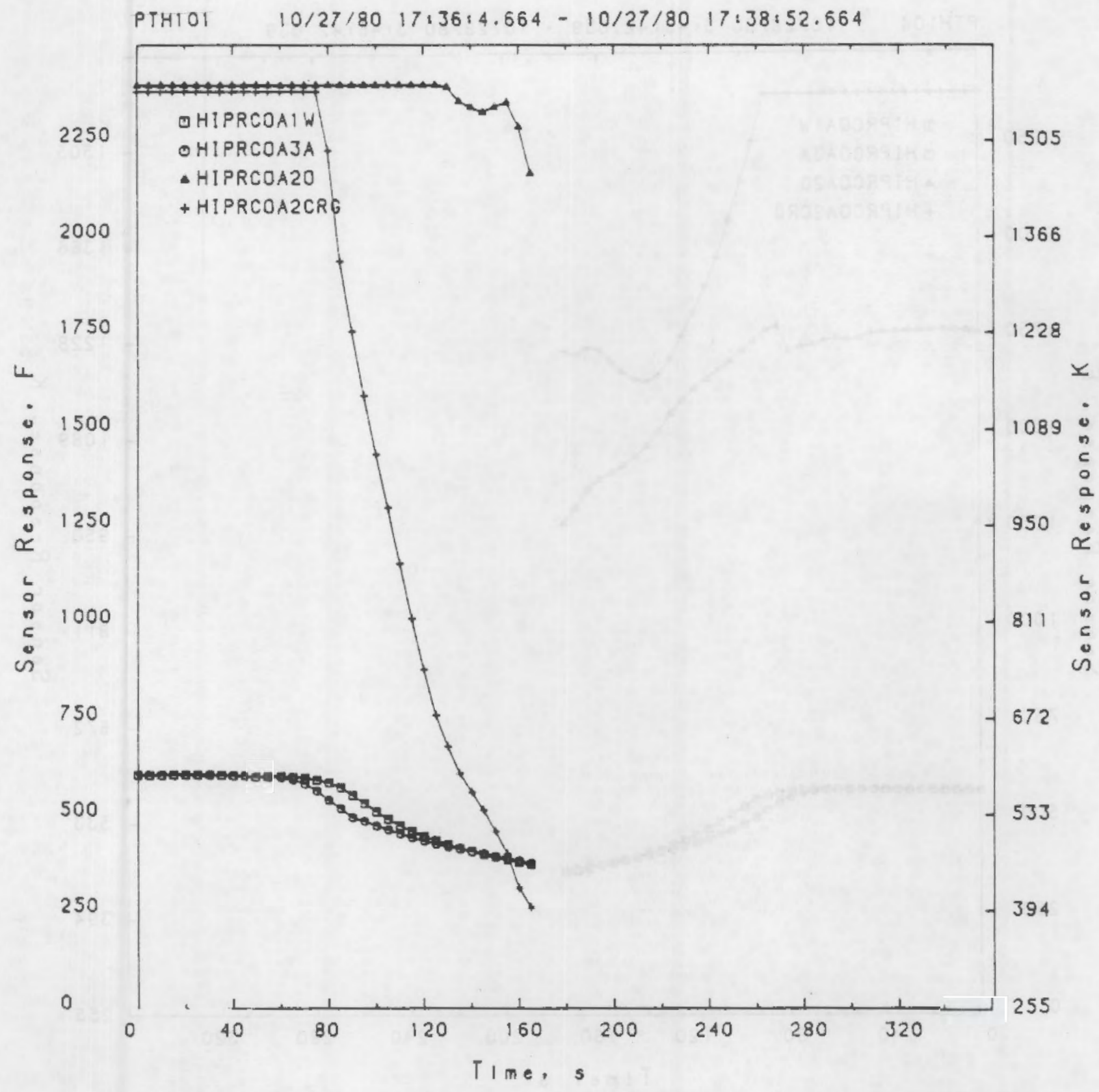

FIGURE 3.2.3.01 HIGH PRESSURE CONNECTOR TC RESPONSE HISTORY DURING TRANSIENT PTHIOI 


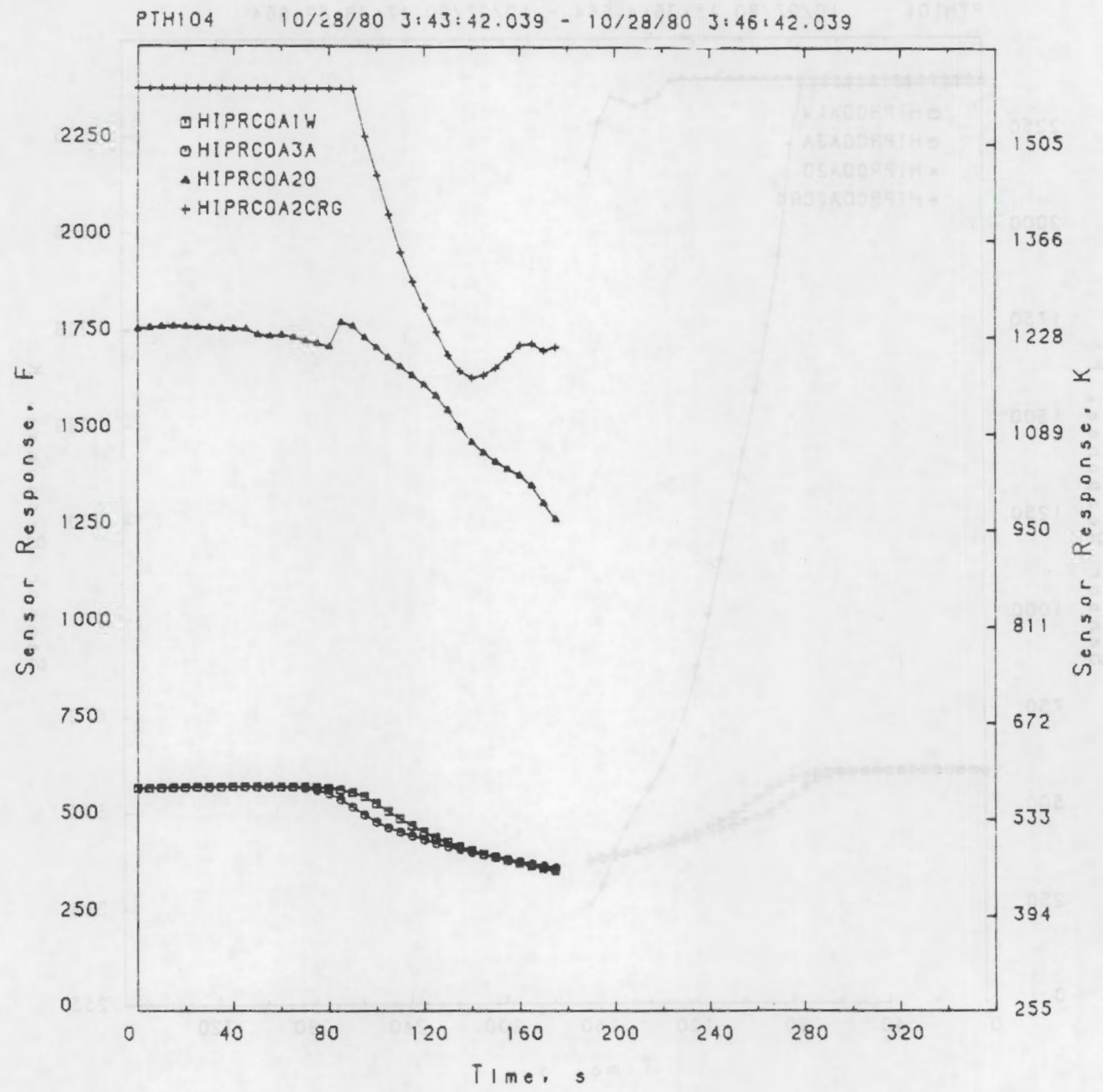

FIGURE 3.2.3.04 HIGH PRESSURE CONNECTOR TC RESPONSE HISTORY DURING TRANSIENT PTHIO4 


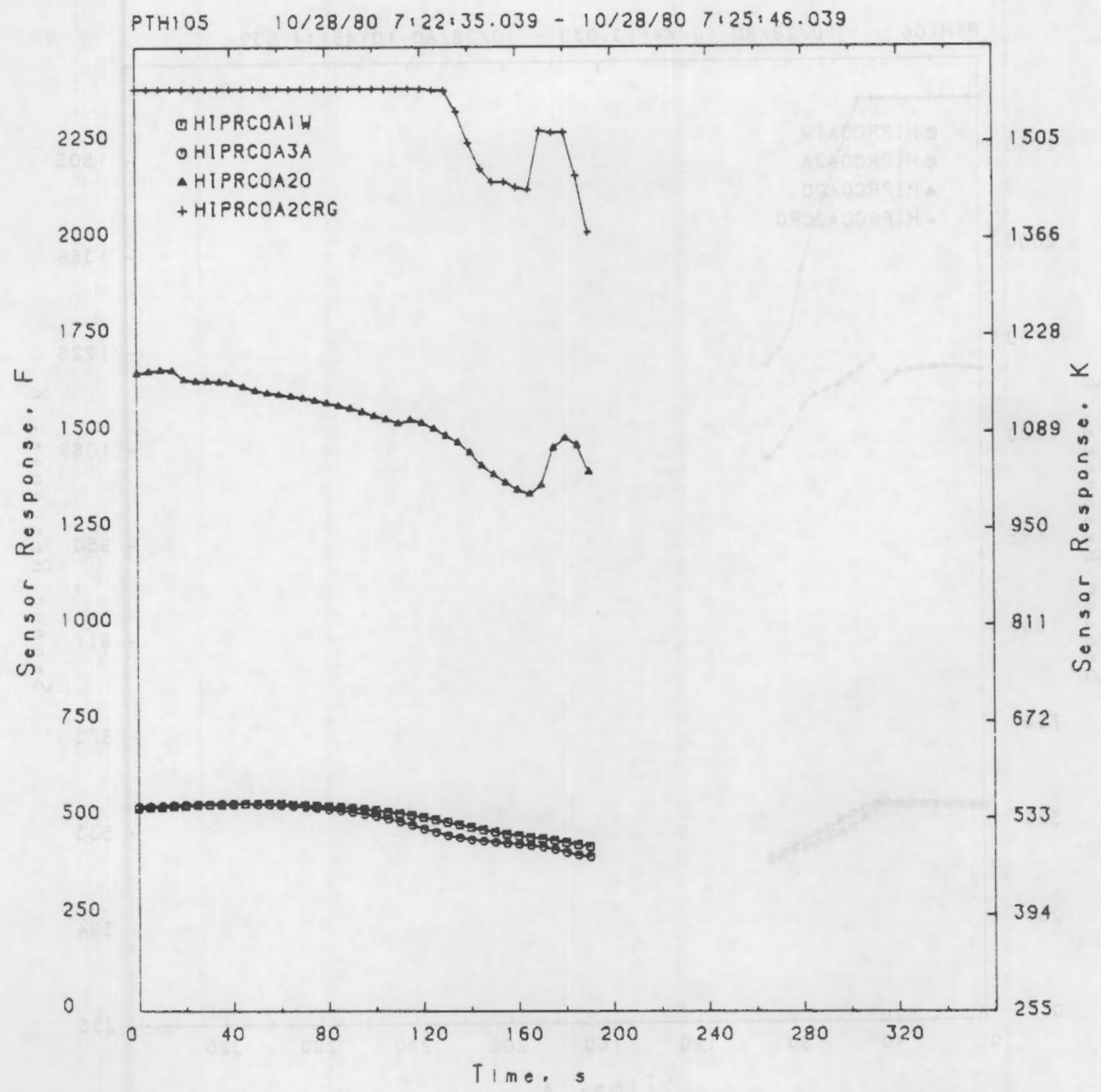

FIGURE 3.2.3.05 HIGH PRESSURE CONNECTOR TC RESPONSE HISTORY DURING TRANSIENT PTHIOS 


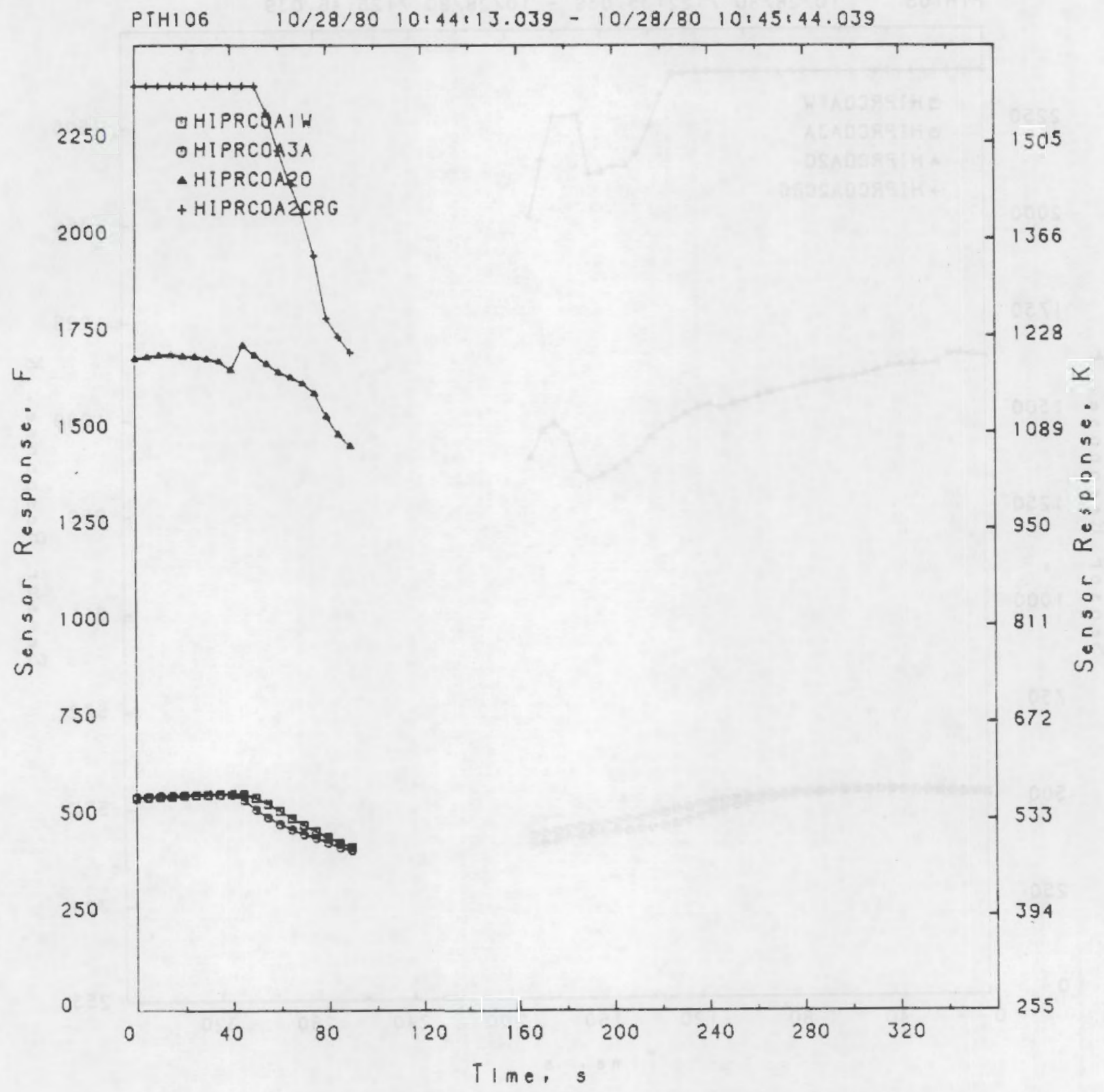

FIGURE 3.2.3.06 HIGH PRESSURE CONNECTOR TC RESPONSE HISTORY DURING TRANSIENT PTHIO6 


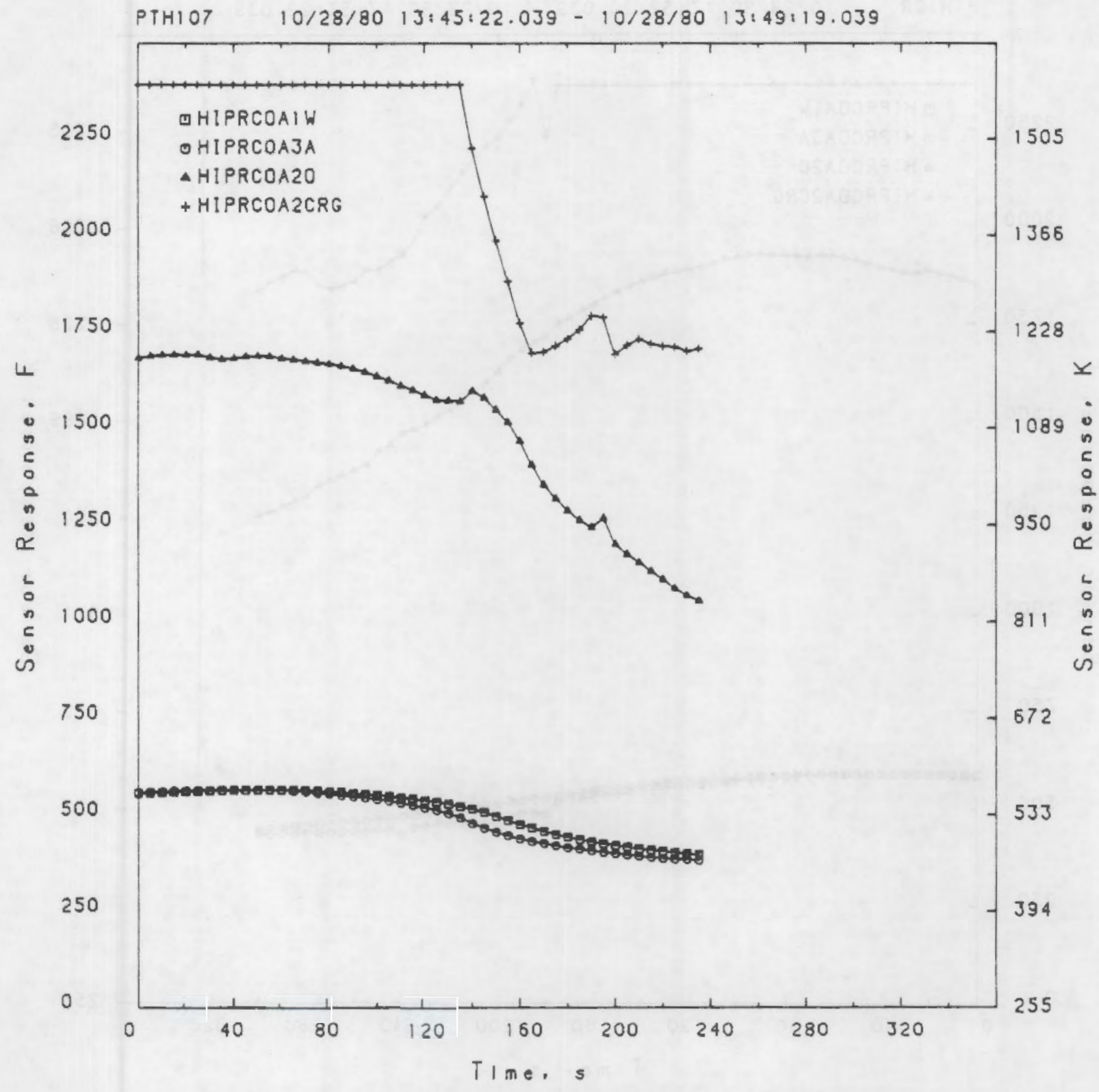

FIGURE 3.2.3.07 HIGH PRESSURE CONNECTOR TC RESPONSE HISTORY DURING TRANSIENT PTHIOT 


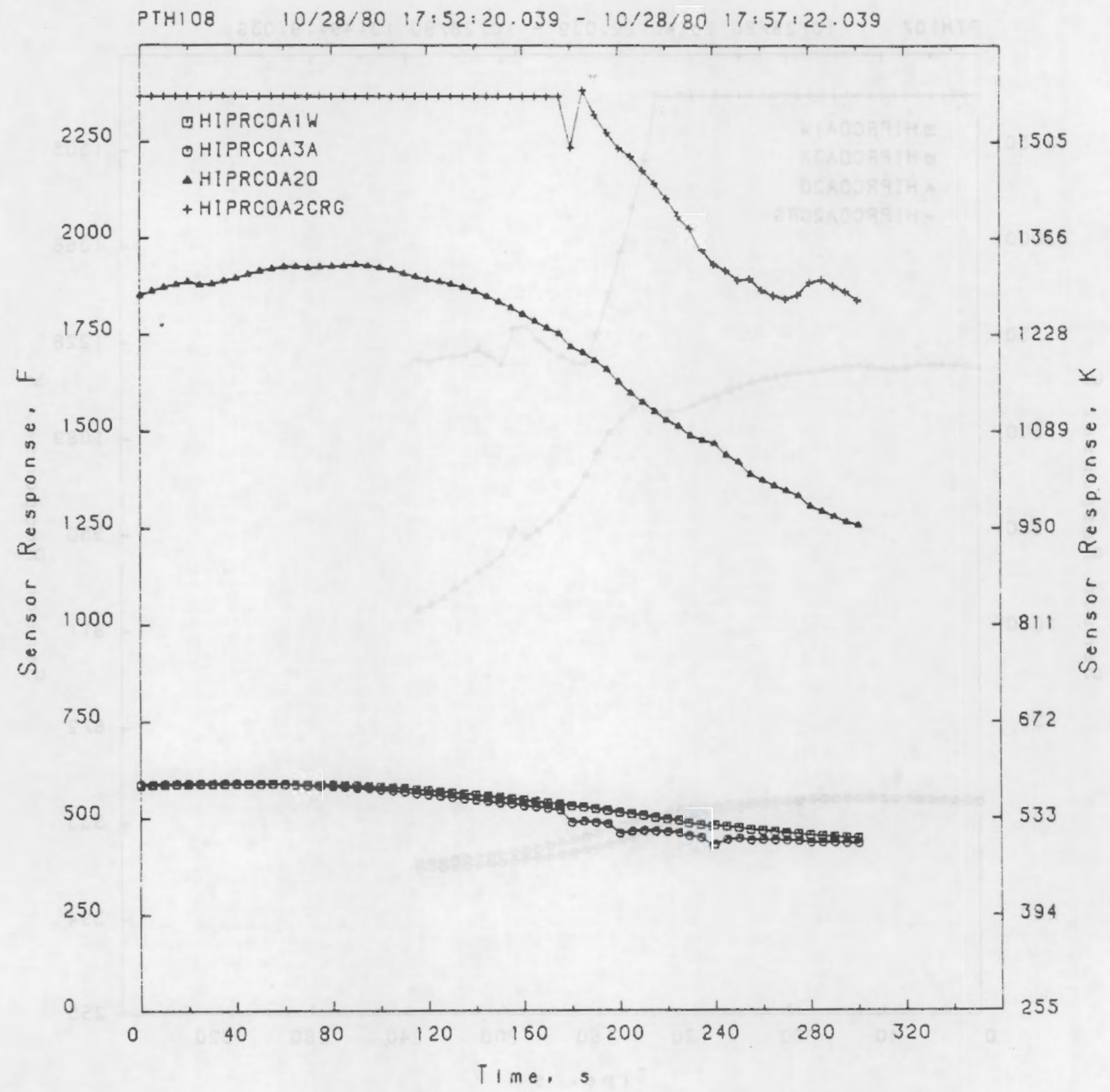

FIGURE 3.2.3.08 HIGH PRESSURE CONNECTOR TC RESPONSE HISTORY DURING TRANSIENT PTHIO8 


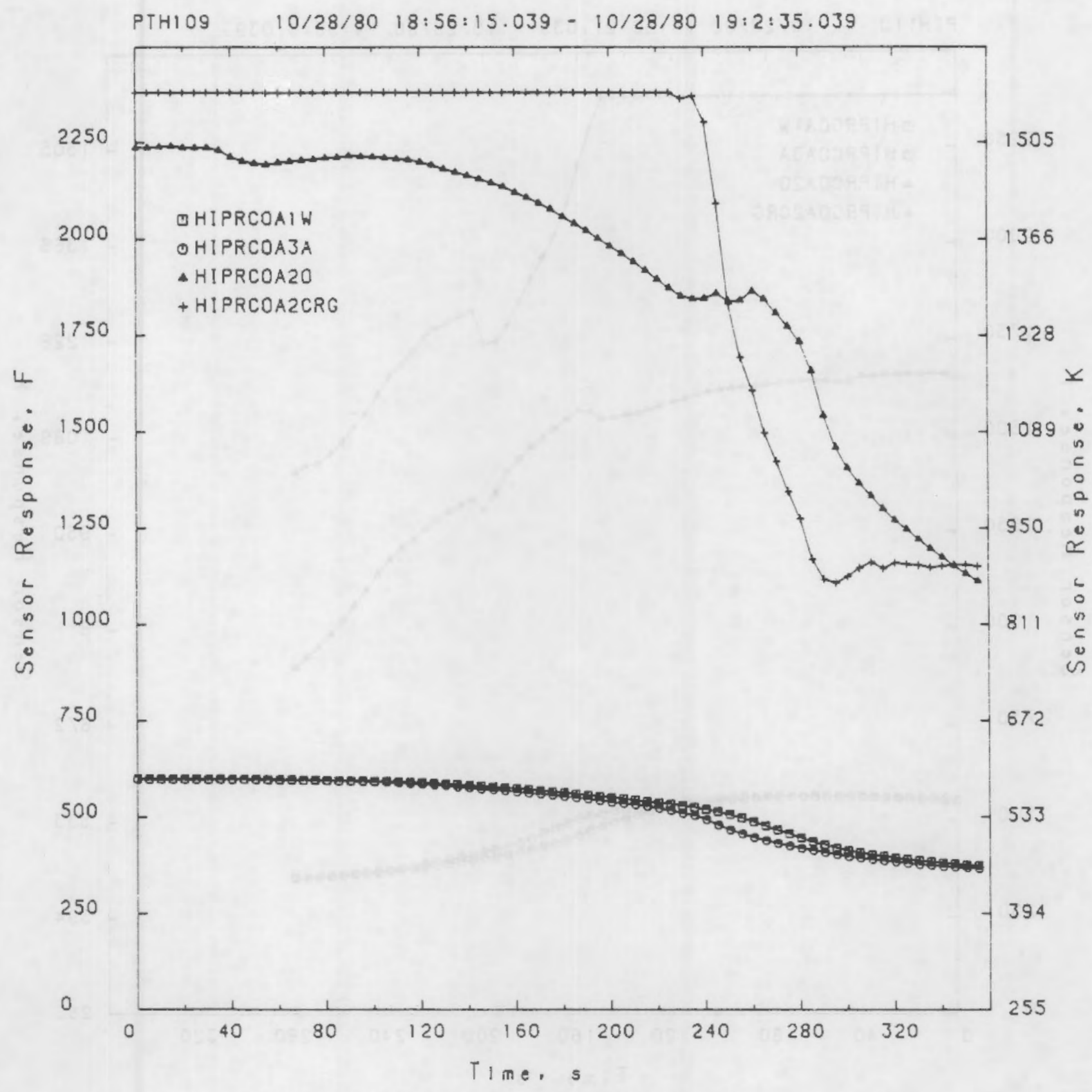

FIGURE 3.2.3.09 HIGH PRESSURE CONNECTOR TC RESPONSE HISTORY DURING TRANSIENT PIHIOG 


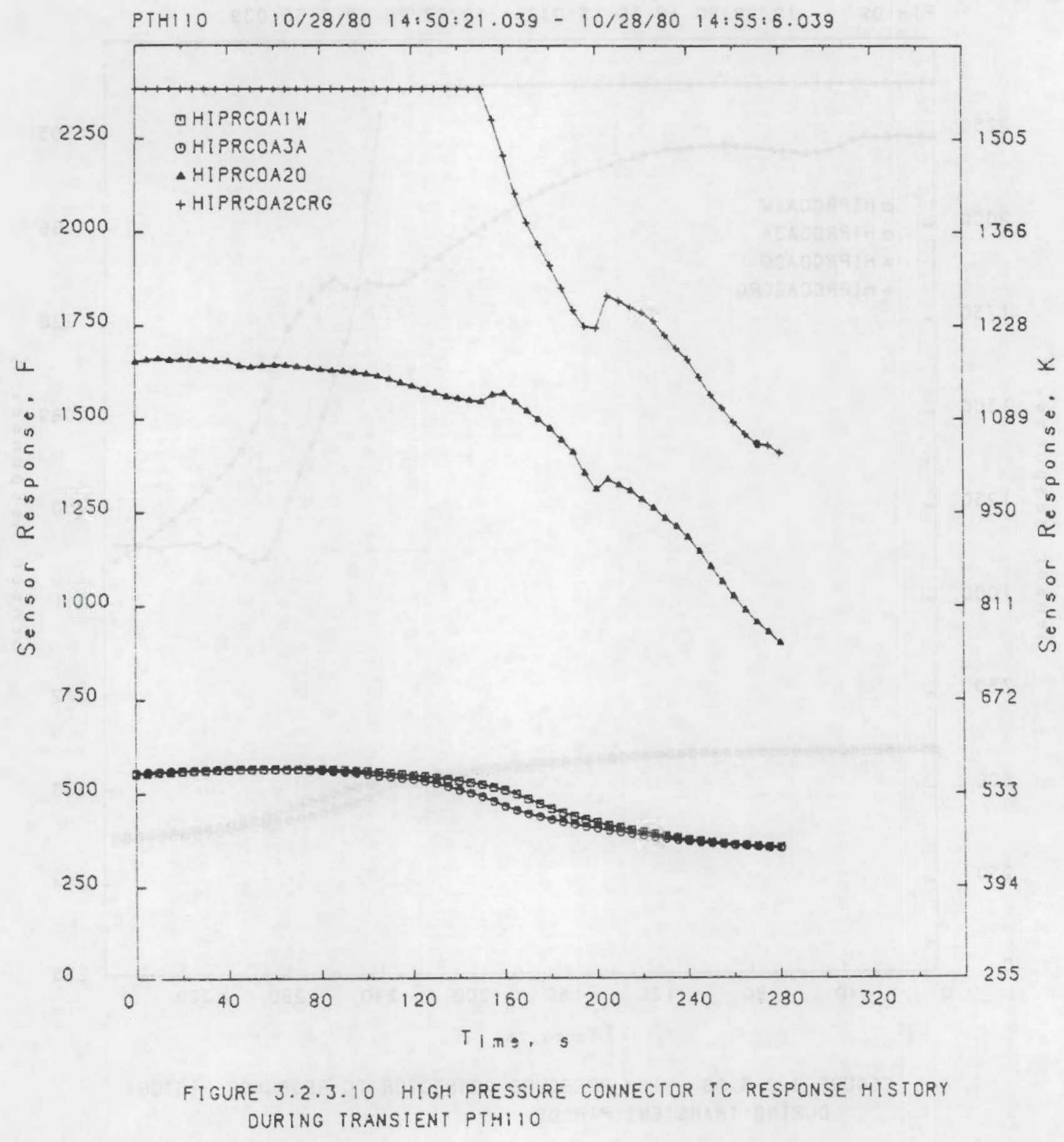




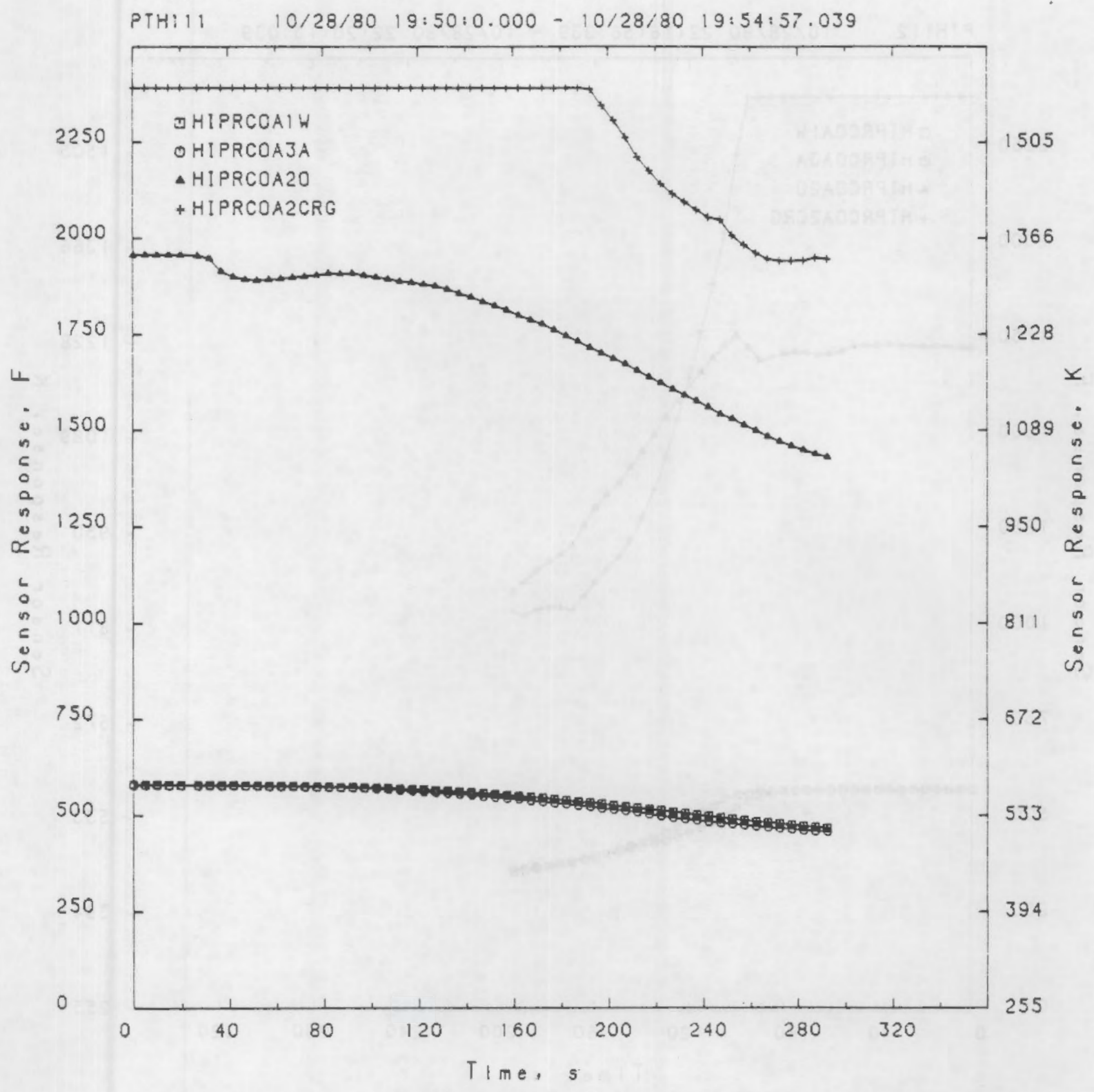

FIGURE 3.2.3.11 HIGH PRESSURE CONNECTOR TC RESPONSE HISTORY DURING TRANSIENT PTHIII 


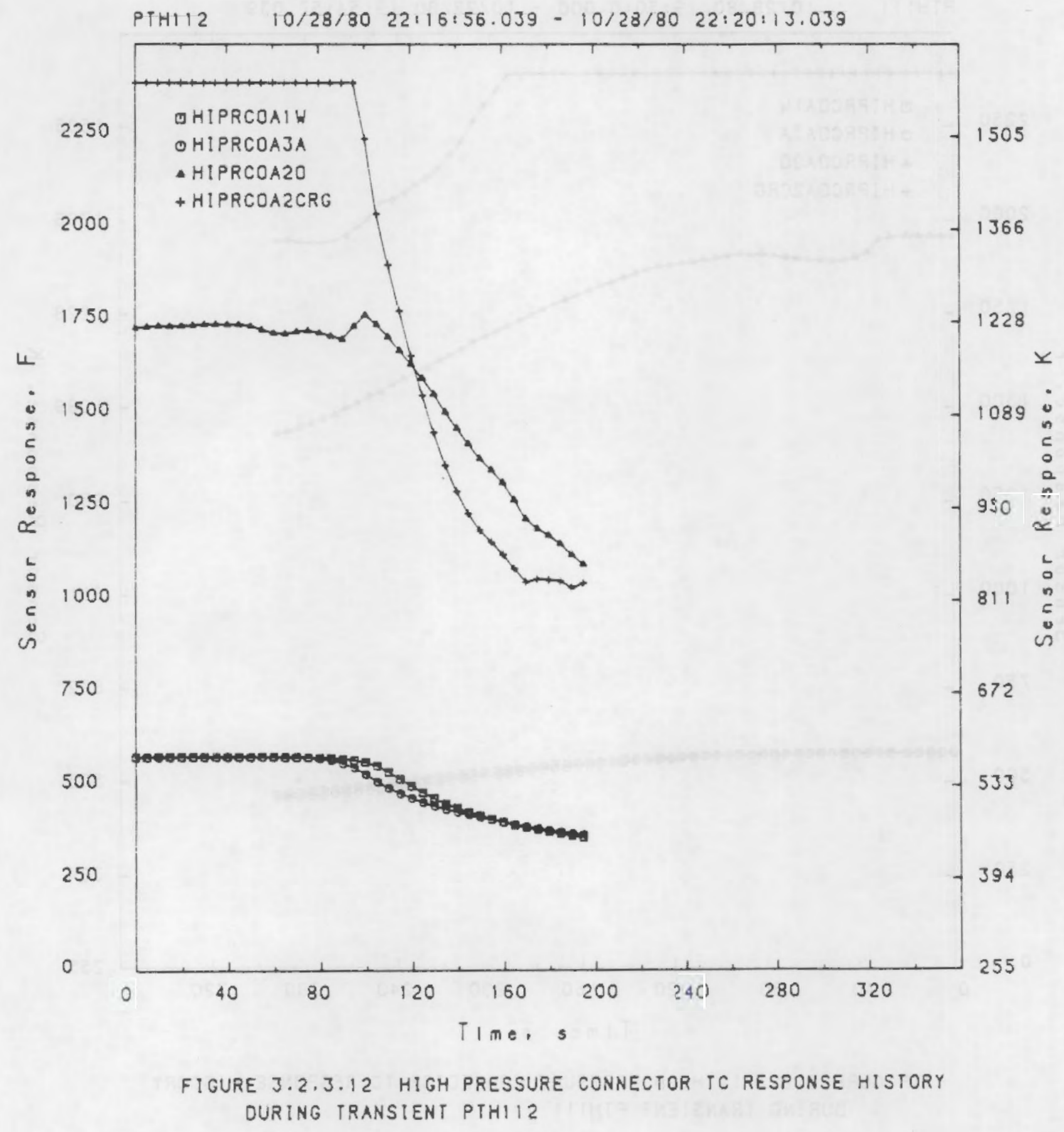




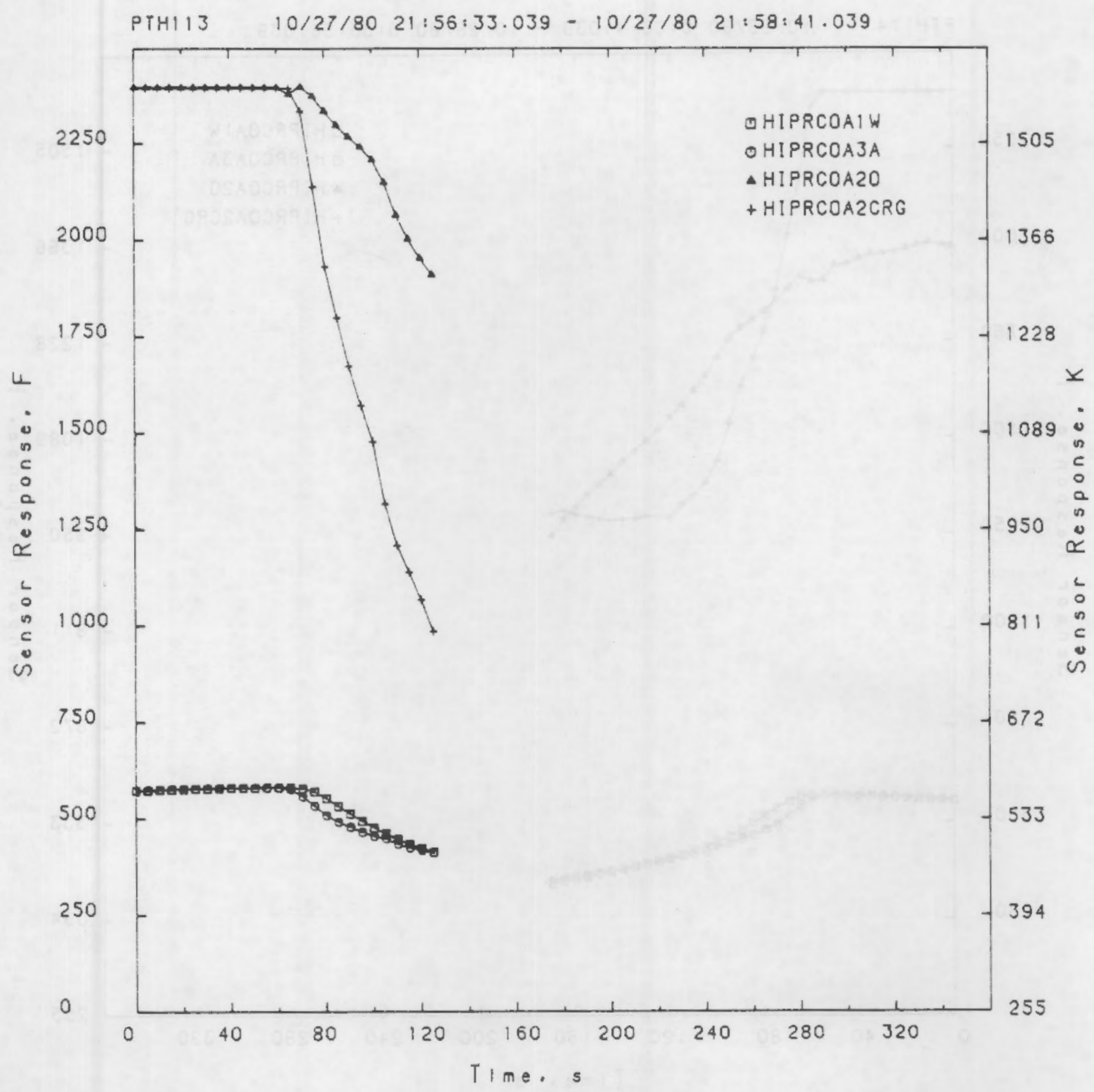

FIGURE 3.2.3.13 HIGH PRESSURE CONNECTOR TC RESPONSE HISTORY OURING TRANSIENT PIHIIJ 


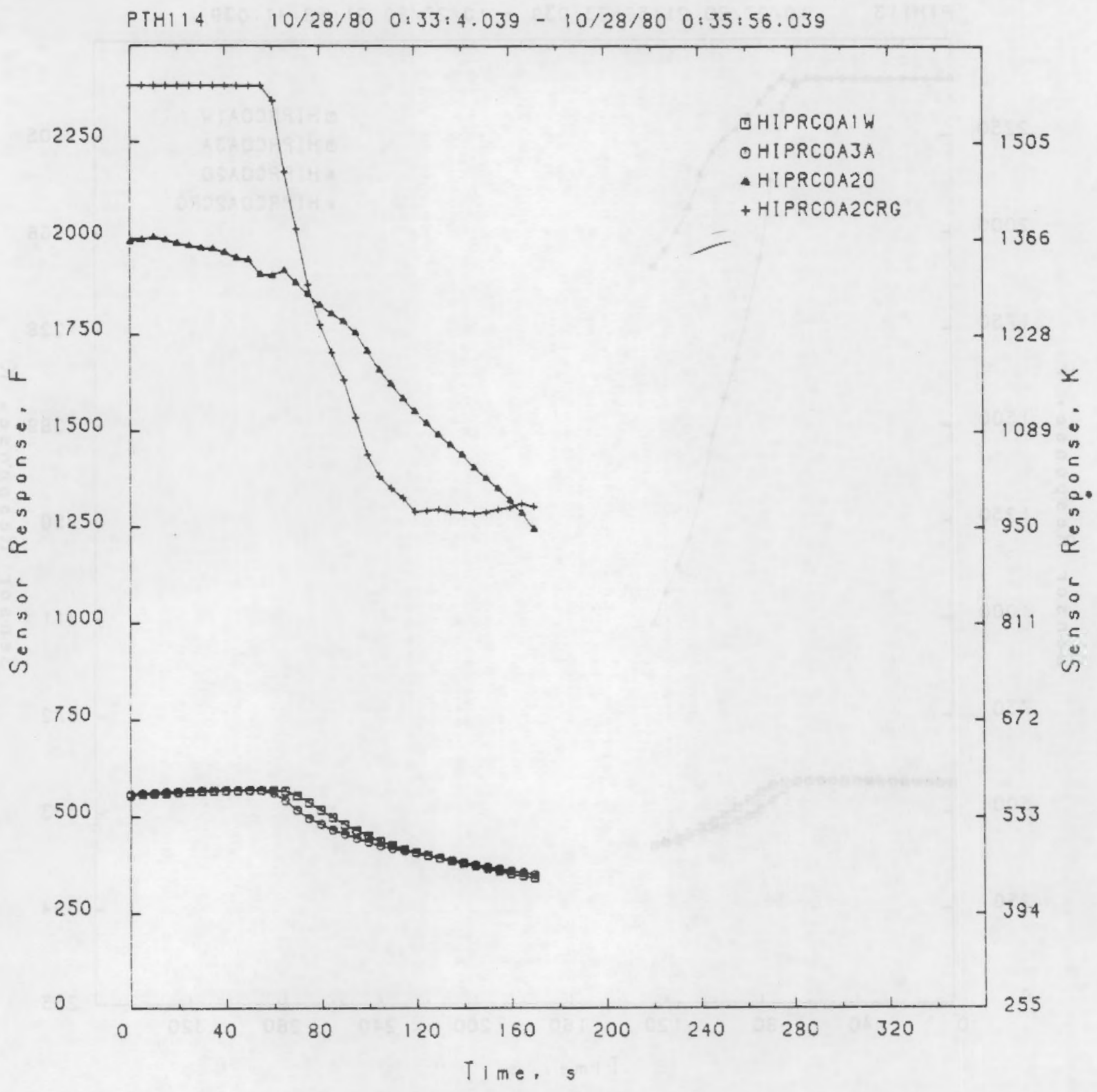

FIGURE 3.2.3.14 HIGH PRESSURE CONNECTOR TC RESPONSE HISTORY OURING TRANSIENT PTHII 4 


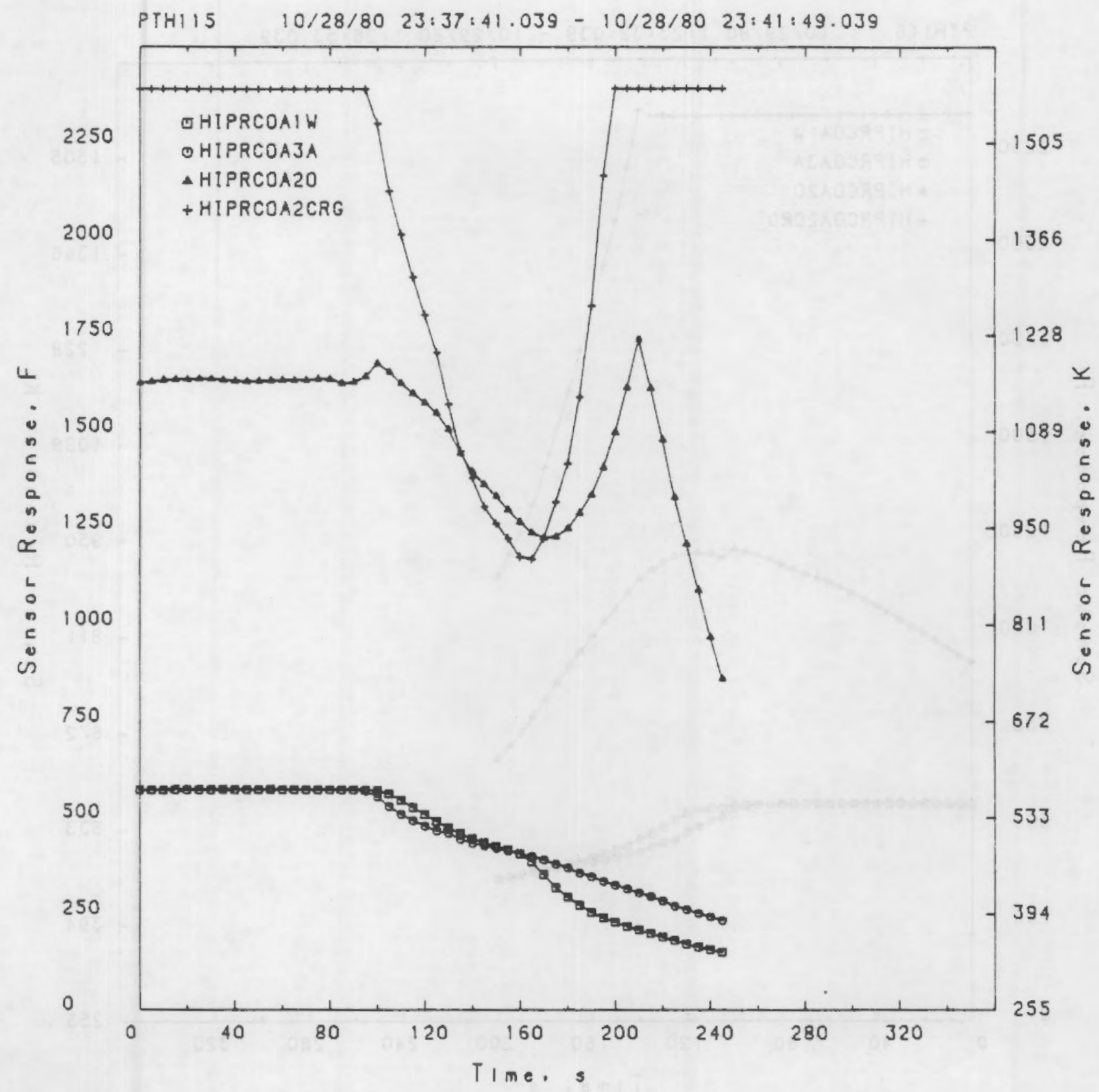

FIGURE 3.2.3.15 HIGH PRESSURE CONNECTOR TC RESPONSE HISTORY DURING TRANSIENT PTHIIS 


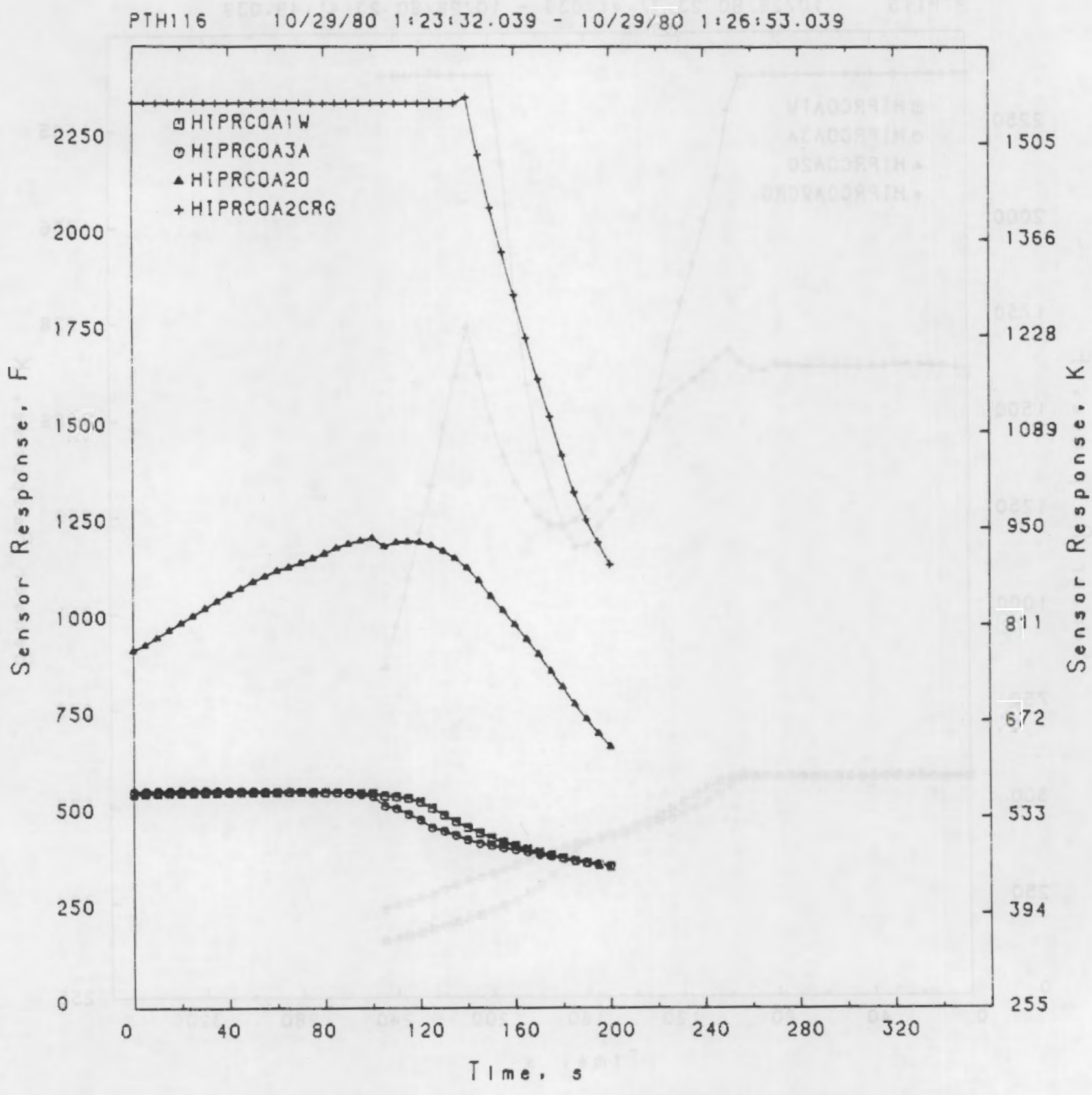

FIGURE 3.2.3.16 HIGH PRESSURE CONNECTOR TC RESPONSE HISTORY DURING TRANSIENT PTHIIG 


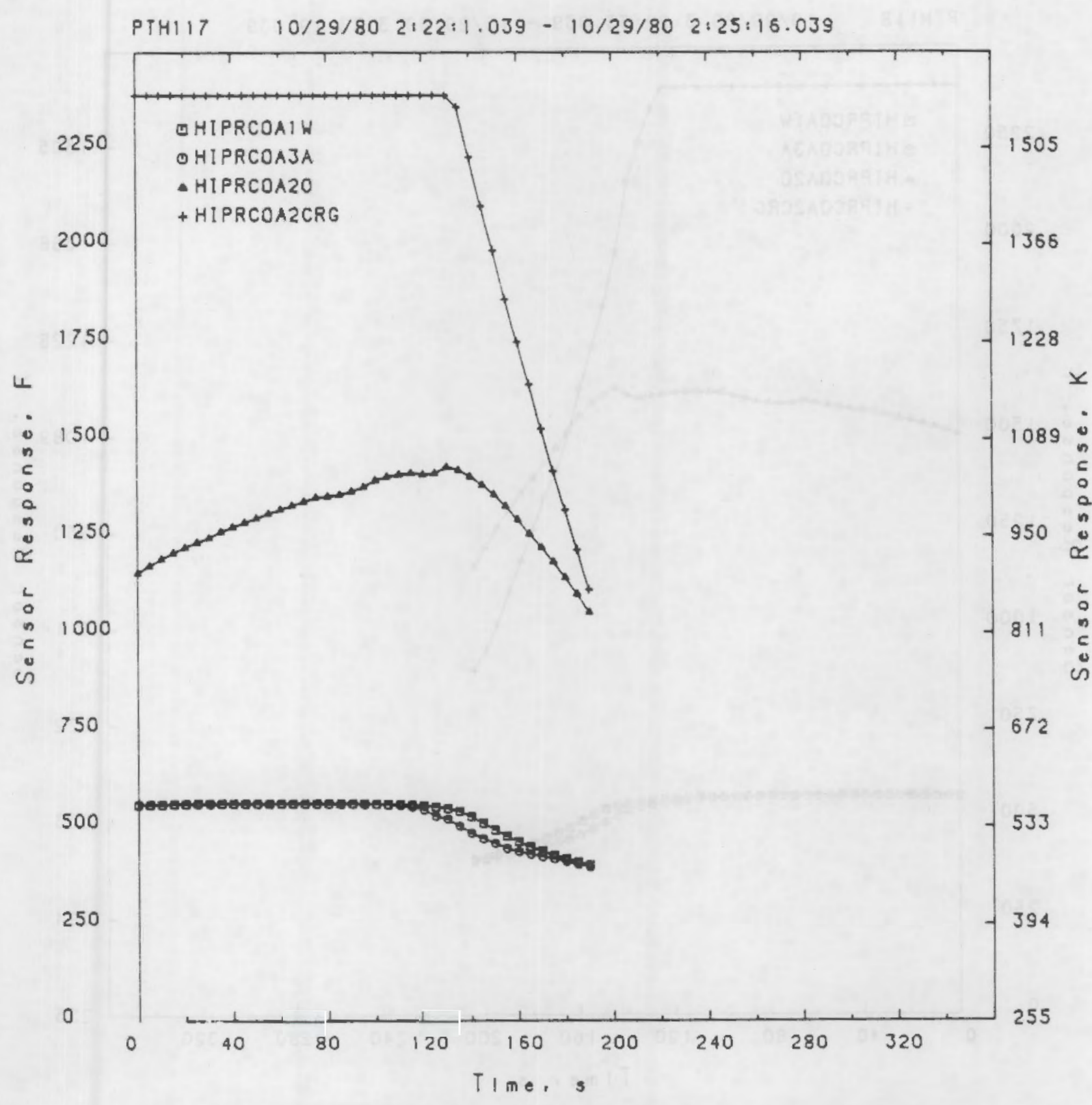

FIGURE 3.2.3.17 HIGH PRESSURE CONNECTOR TC RESPONSE HISTORY DURING TRANSIENT PTHIIT 


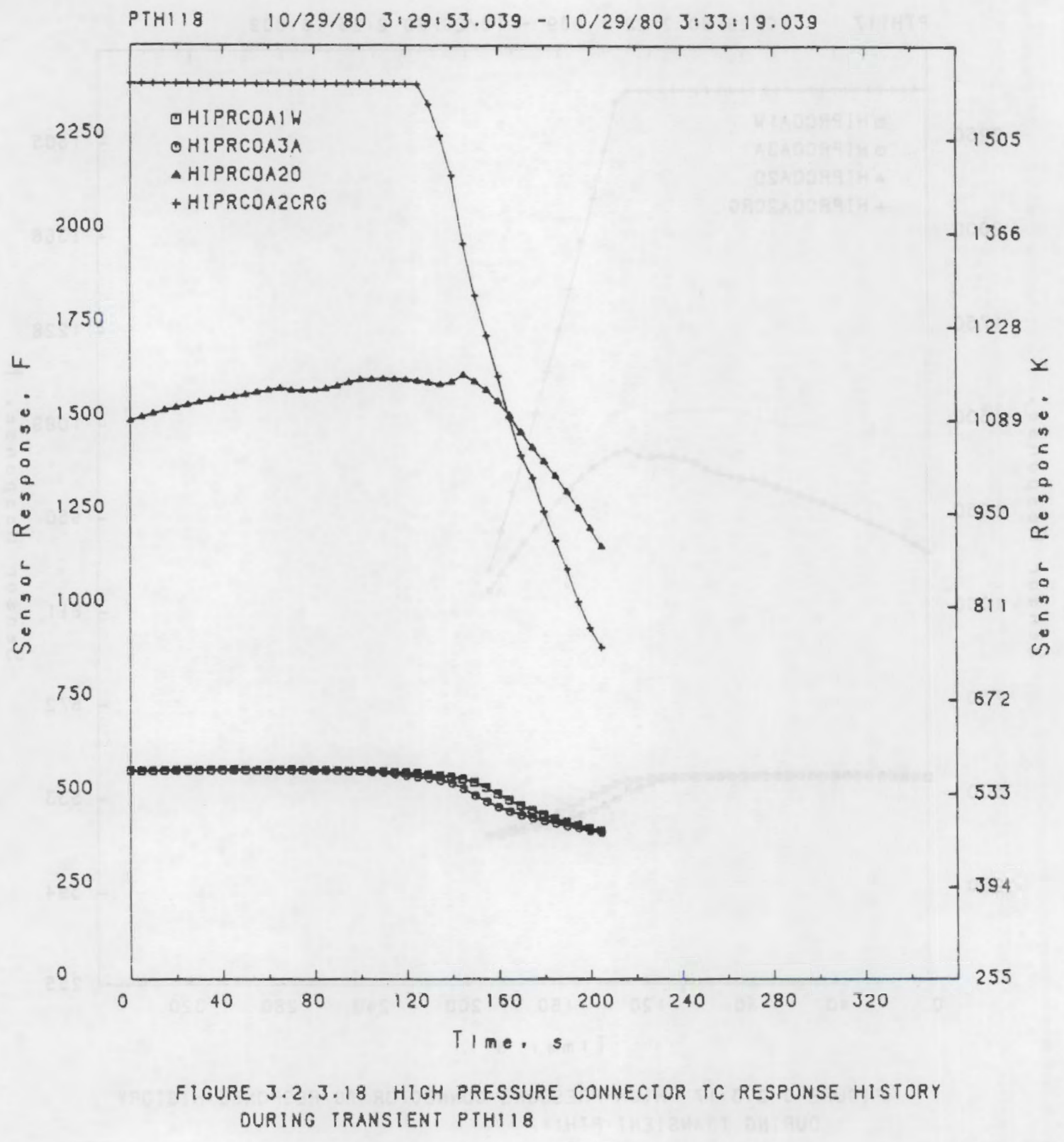




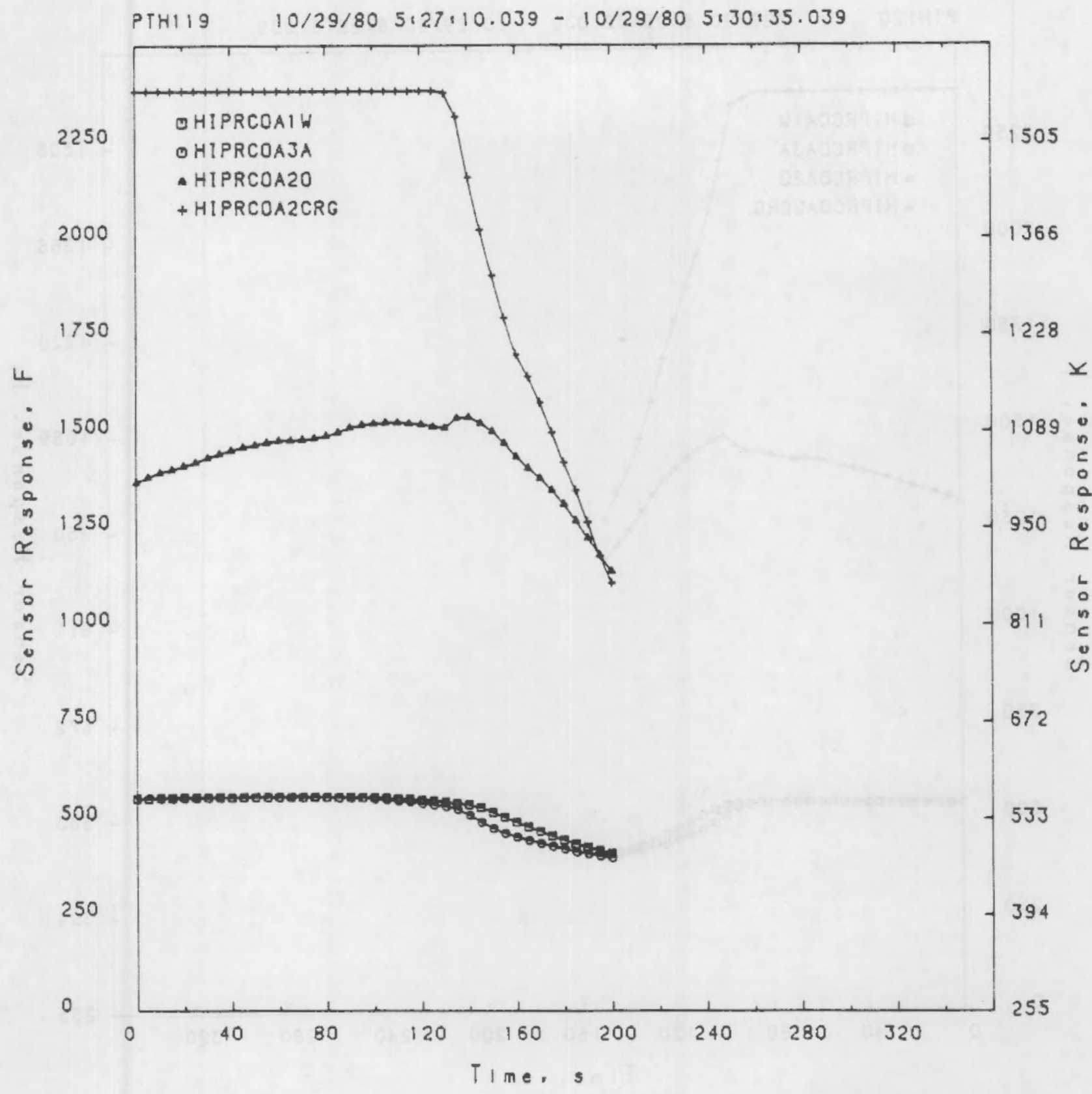

FIGURE 3.2.3.19 HIGH PRESSURE CONNECTOR TC RESPONSE HISTORY DURING TRANSIENT PTHIIG 


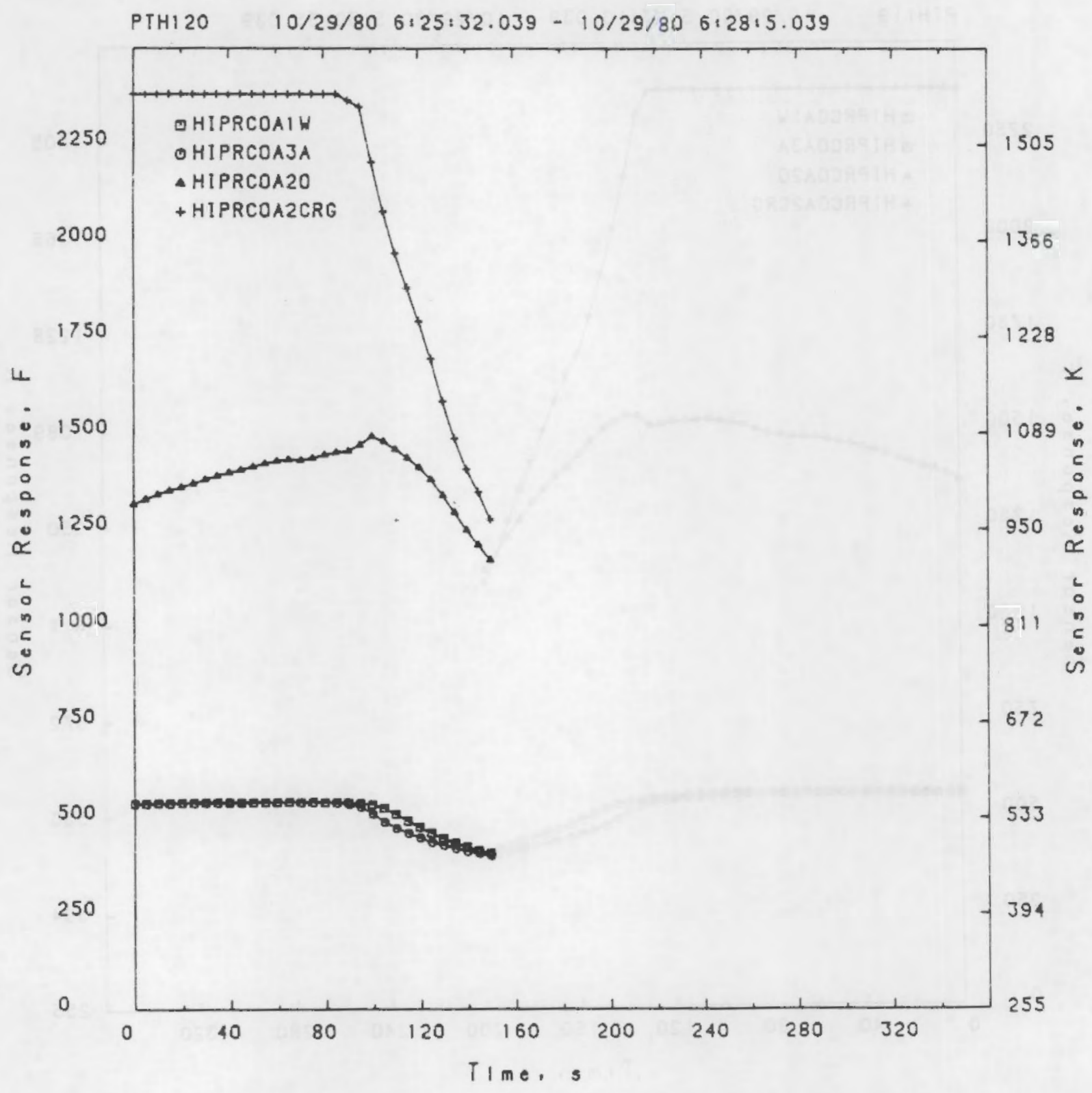

FIGURE 3.2.3.20 HIGH PRESSURE CONNECTOR TC RESPONSE HISTORY DURING TRANSIENT PIHIZO 


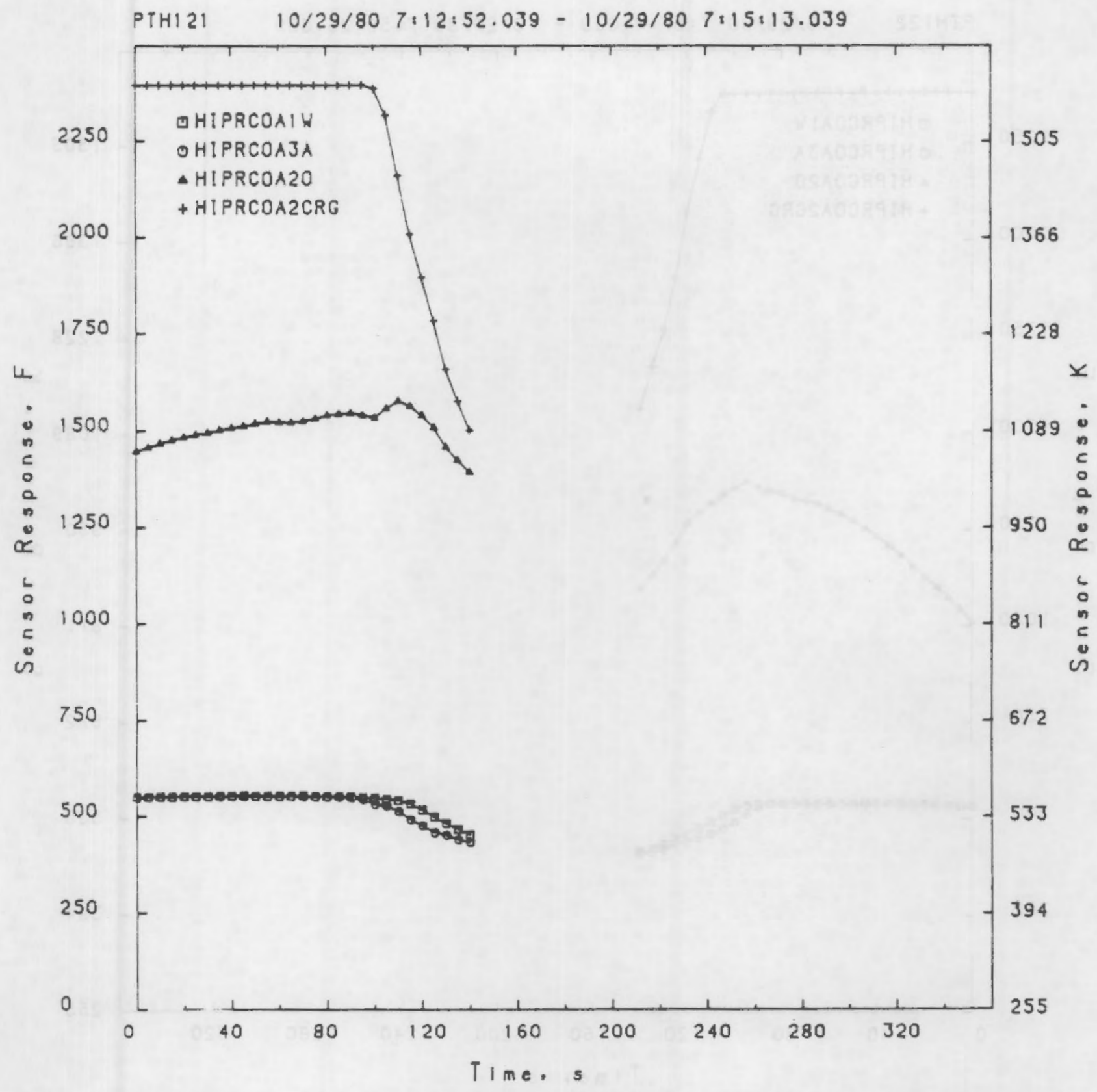

FIGURE 3.2.3.21 HIGH PRESSURE CONNECTOR TC RESPONSE HISTORY DURING TRANSIENT PIHI2I 


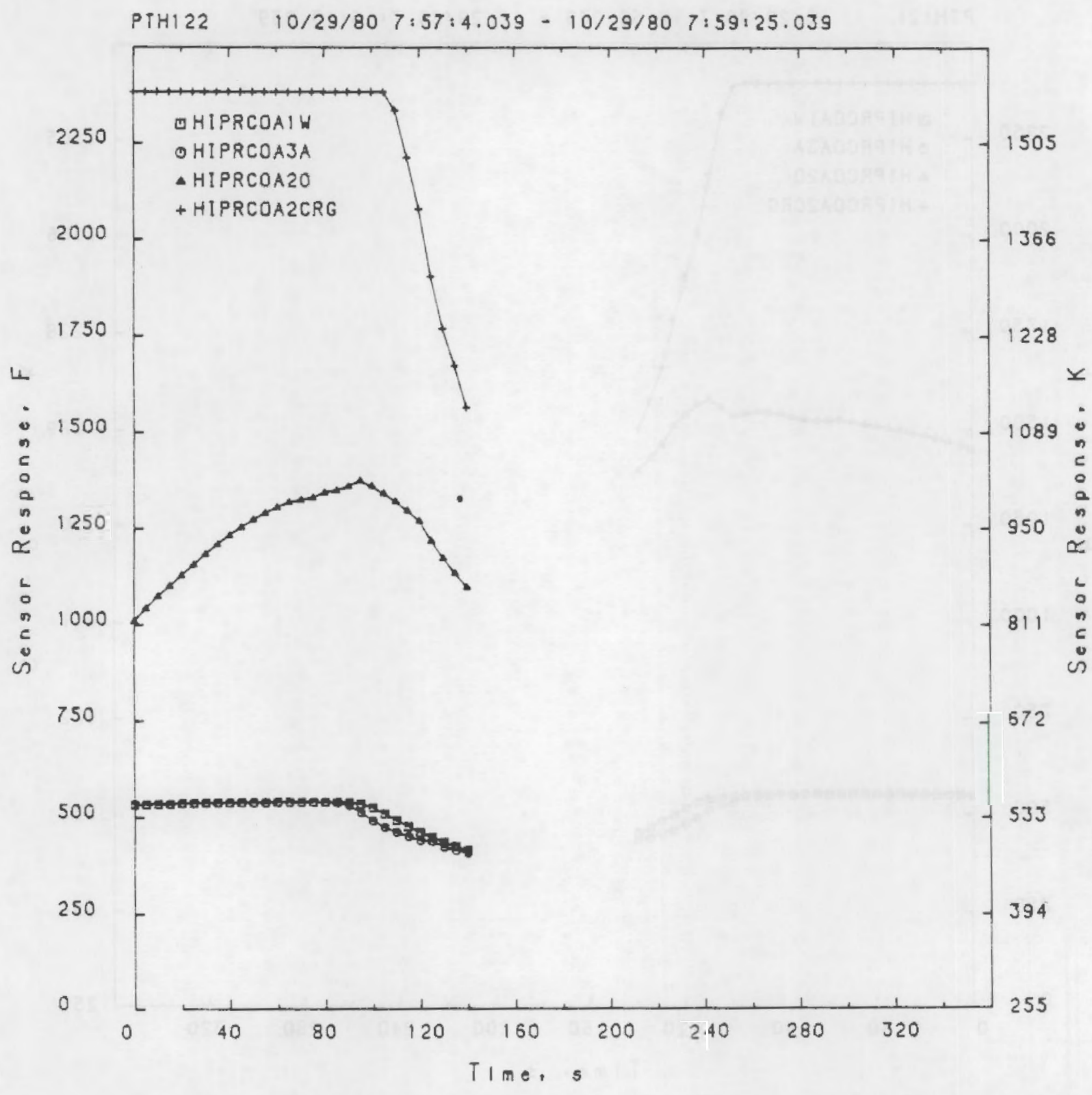

FIGURE 3.2.3.22 HIGH PRESSURE CONNECTOR TC RESPONSE HISTORY DURING TRANSIENT PTHI22 


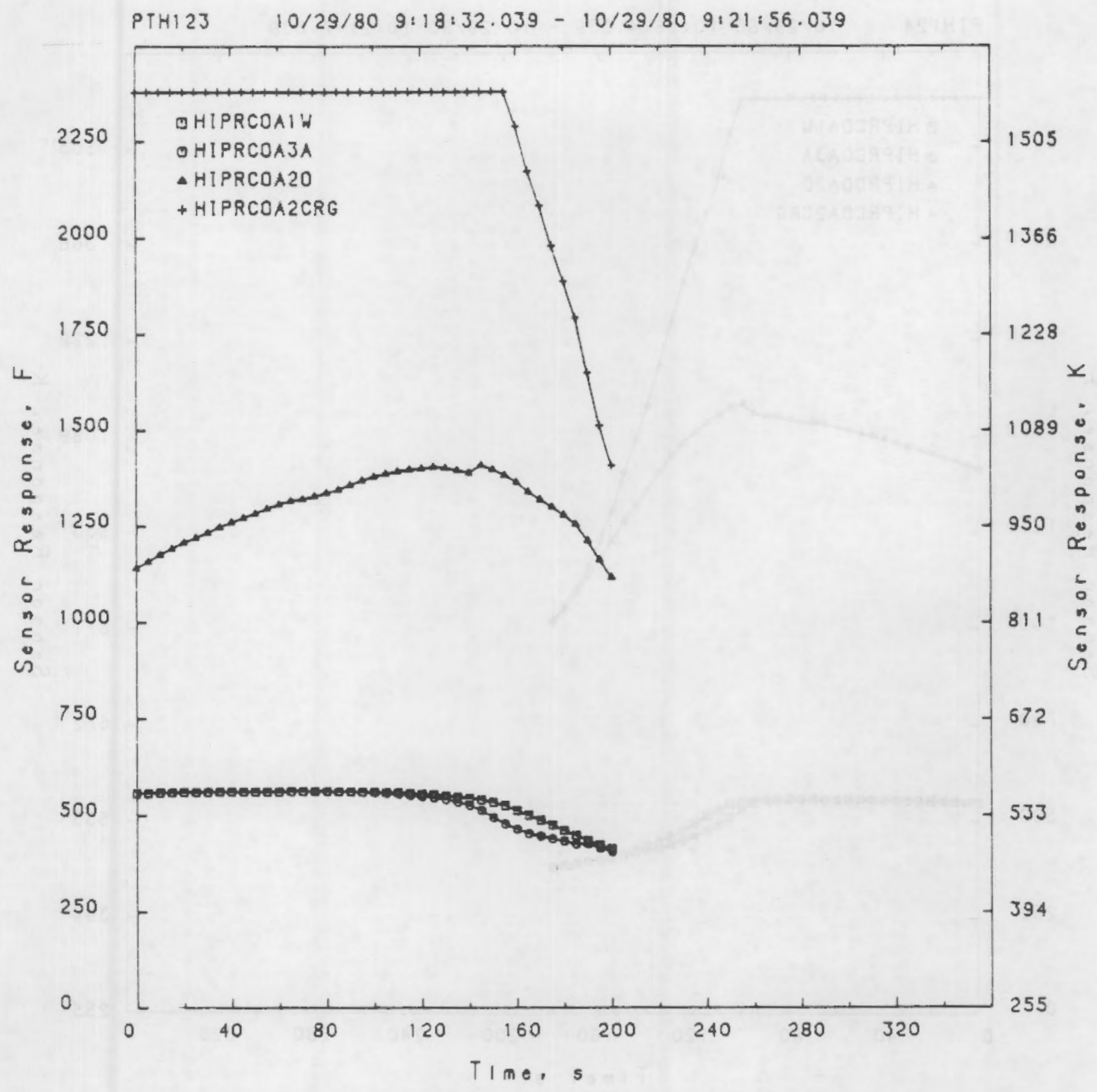

FIGURE 3.2.3.23 HIGH PRESSURE CONNECTOR TC RESPONSE HISTORY DURING TRANSIENT PTHI23 


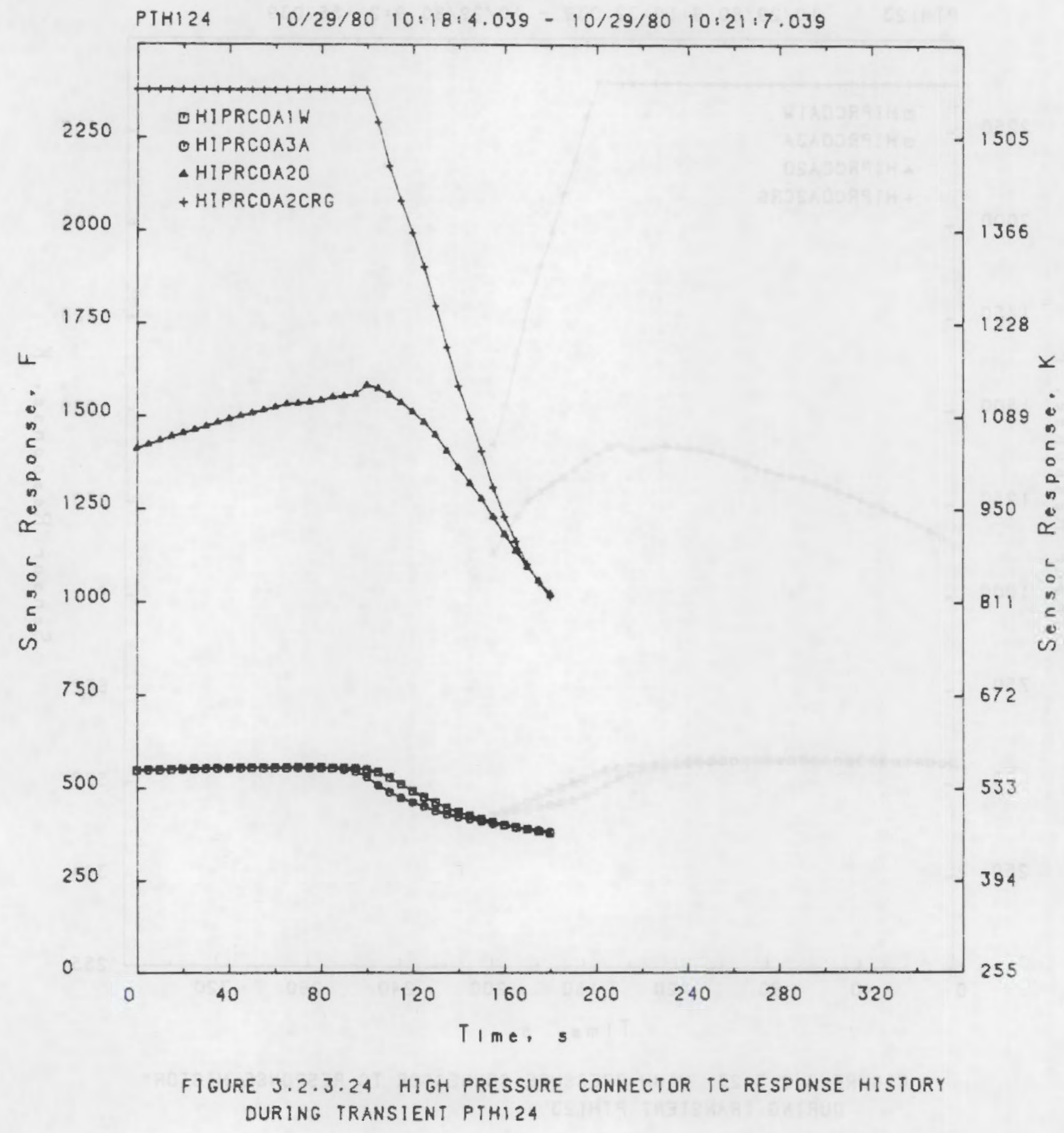




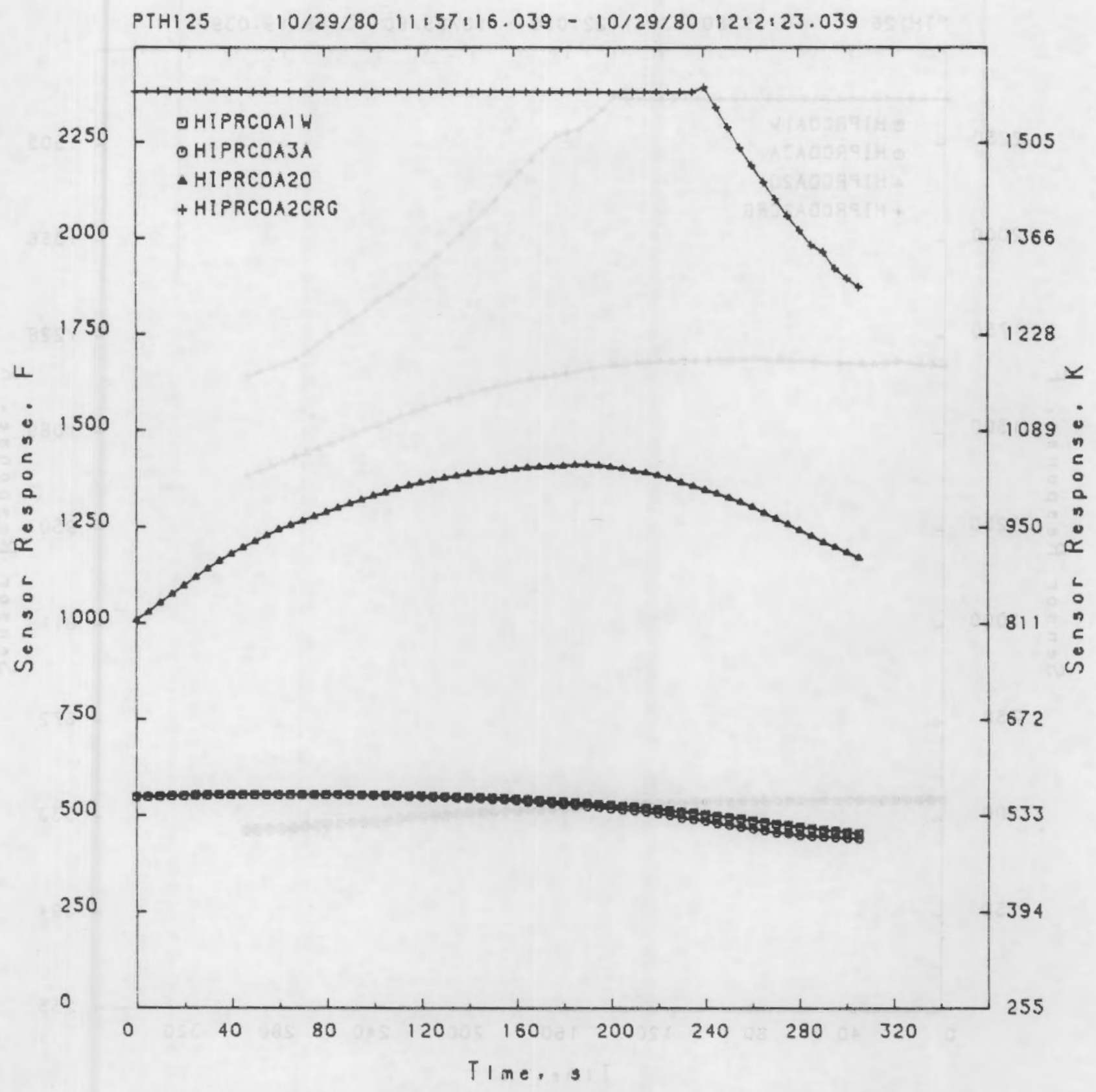

FIGURE 3.2.3.25 HIGH PRESSURE CONNECTOR TC RESPONSE HISTORY DURING TRANSIENT PTHI25 


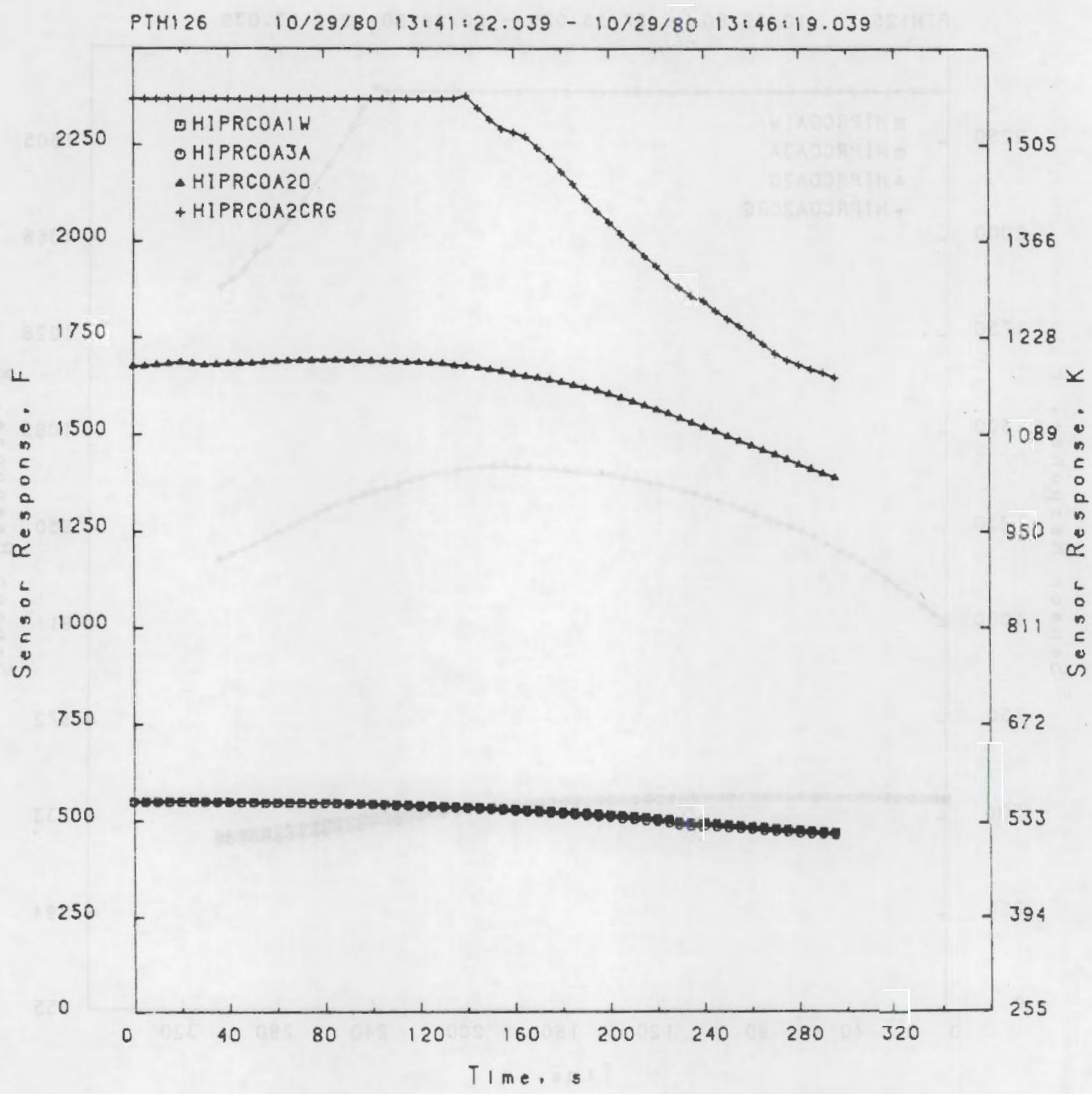

FIGURE 3.2.3.26 HIGH PRESSURE CONNECTOR TC RESPONSE HISTORY DURING TRANSIENT PTHI26 


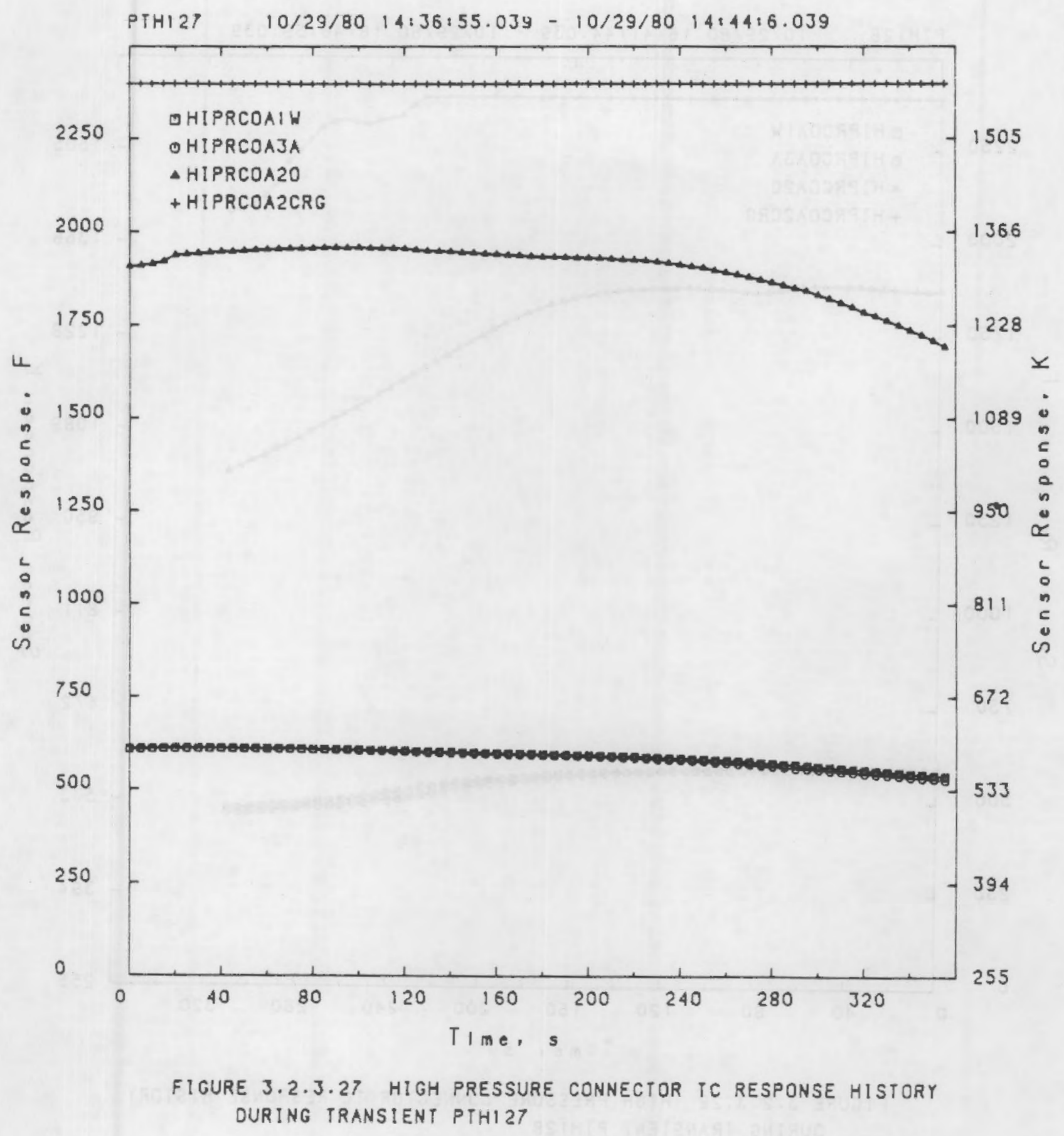




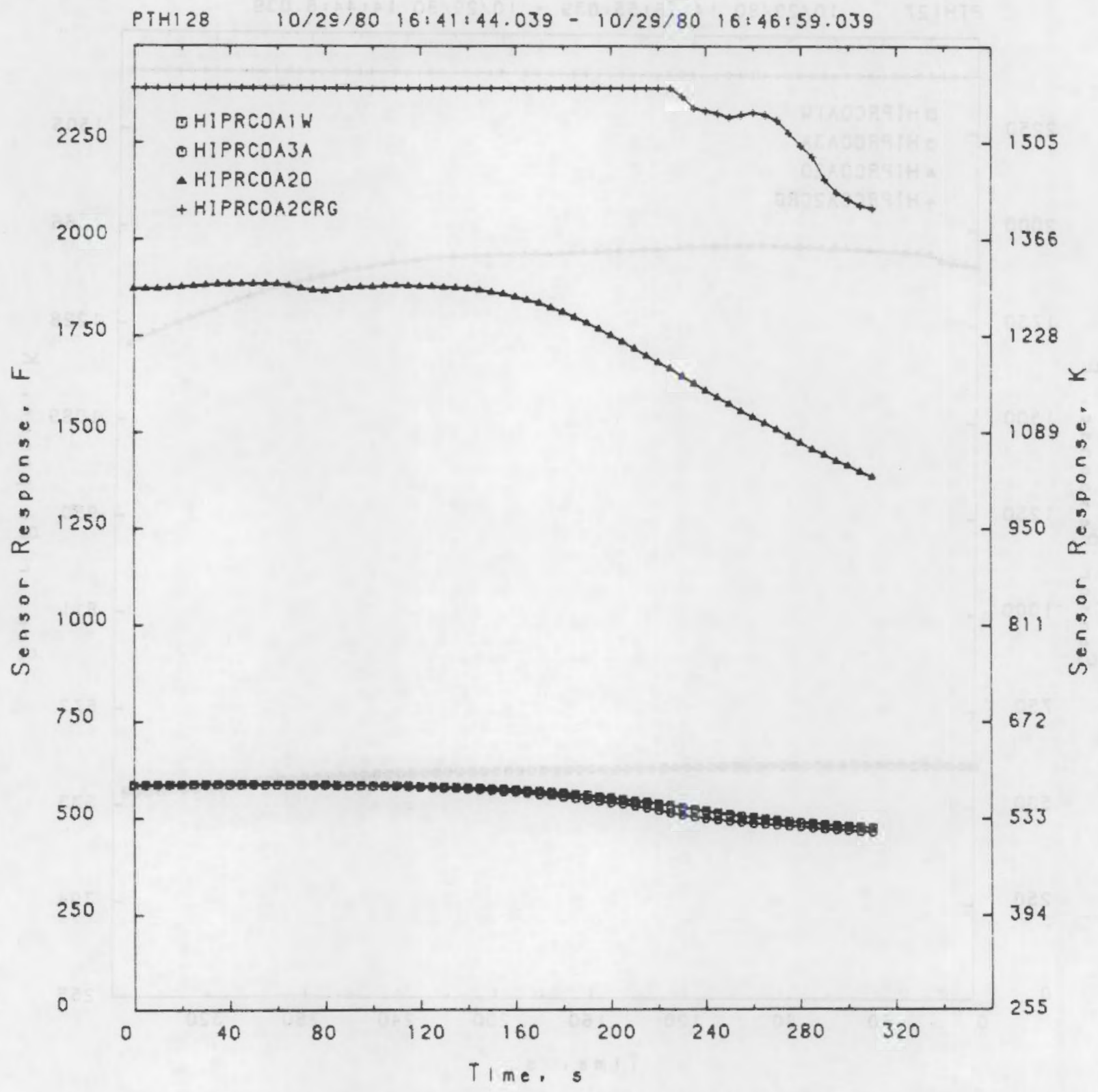

FIGURE 3.2.3.28 HIGH PRESSURE CONNECTOR TC RESPONSE HISTORY DURING TRANSIENT PTHI28 


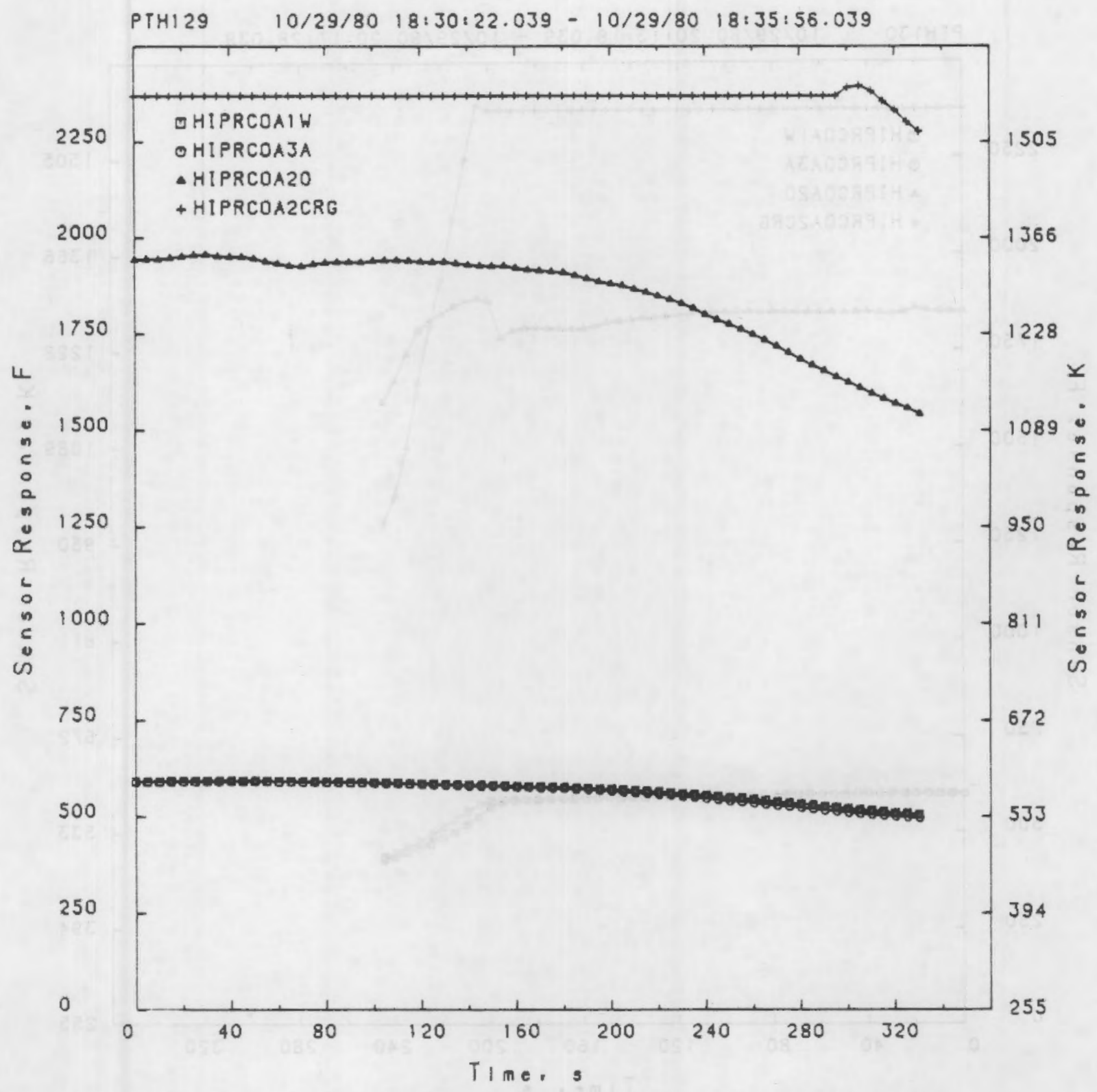

FIGURE 3.2.3.29 HIGH PRESSURE CONNECTOR TC RESPONSE HISTORY DURING TRANSIENT PTHI 29 


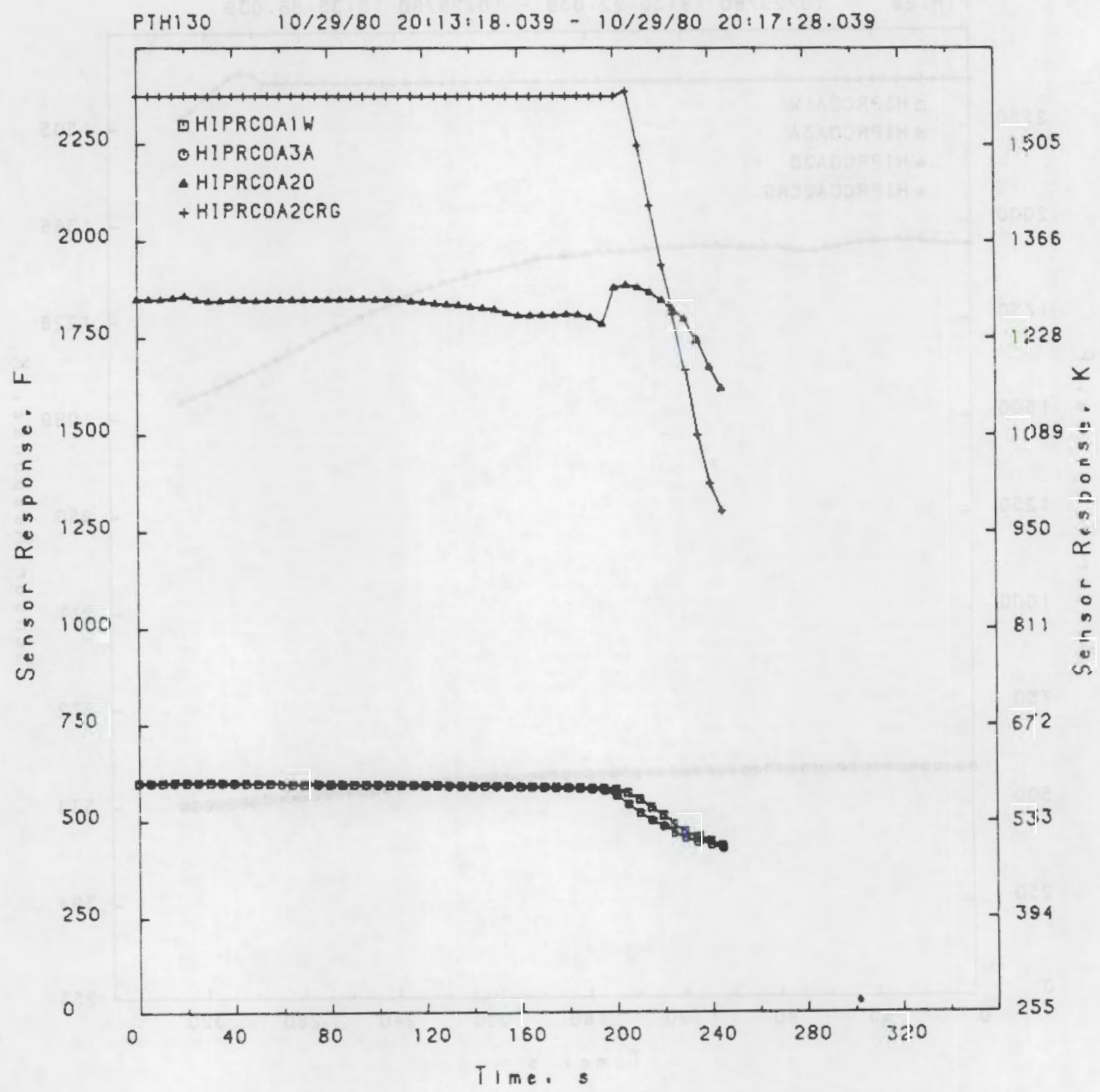

FIGURE 3.2.3.30 HIGH PRESSURE CONNECTOR TC RESPONSE HISTORY DURING TRANSIENT PTHIJO 
PART 4

SHROUD LEAK RATE CHARACTERISTICS 


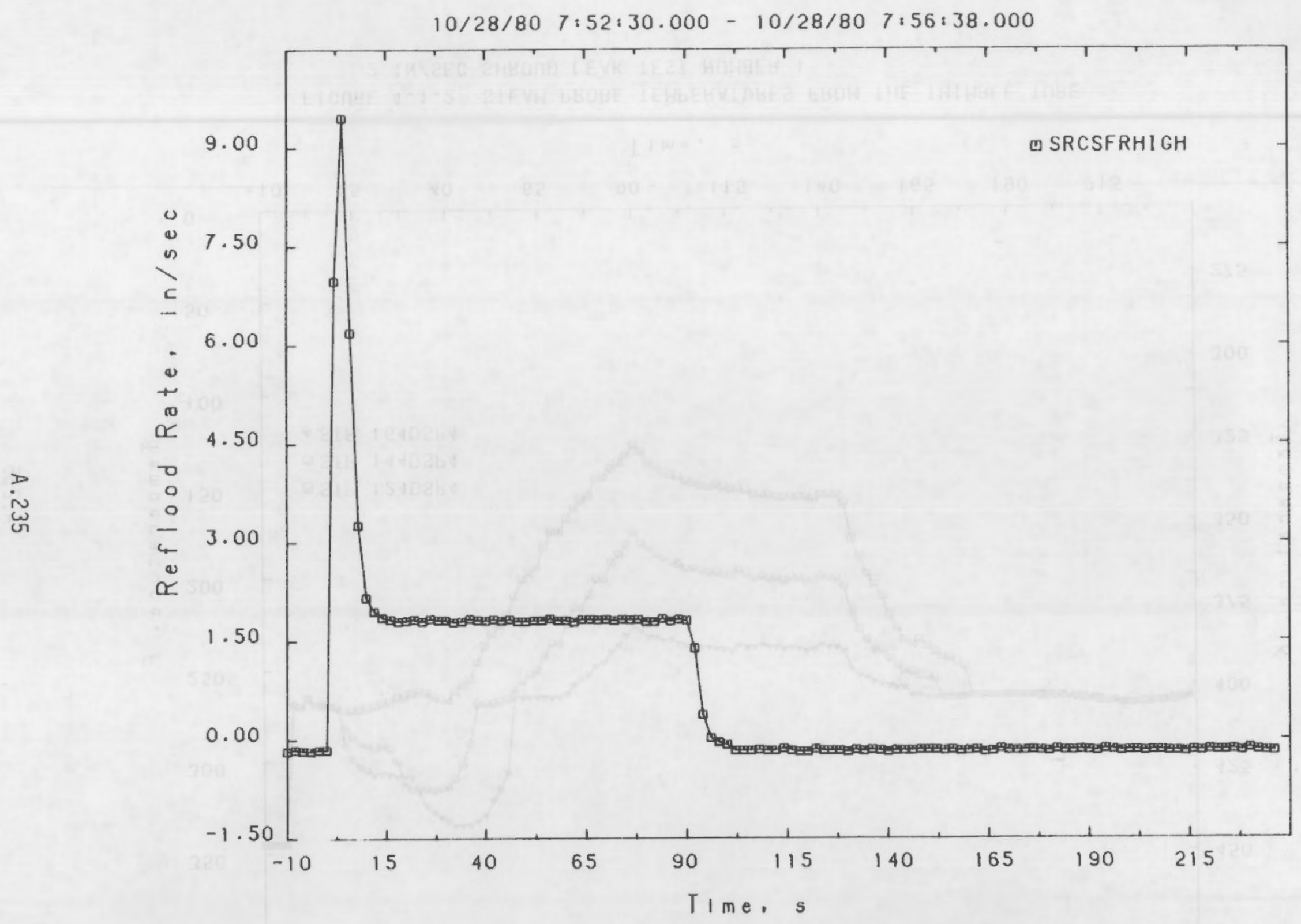

FIGURE 4.1 .1 TURBINE FLOW METER - 2 IN/SEC SHROUD LEAK TEST NUMBER I 


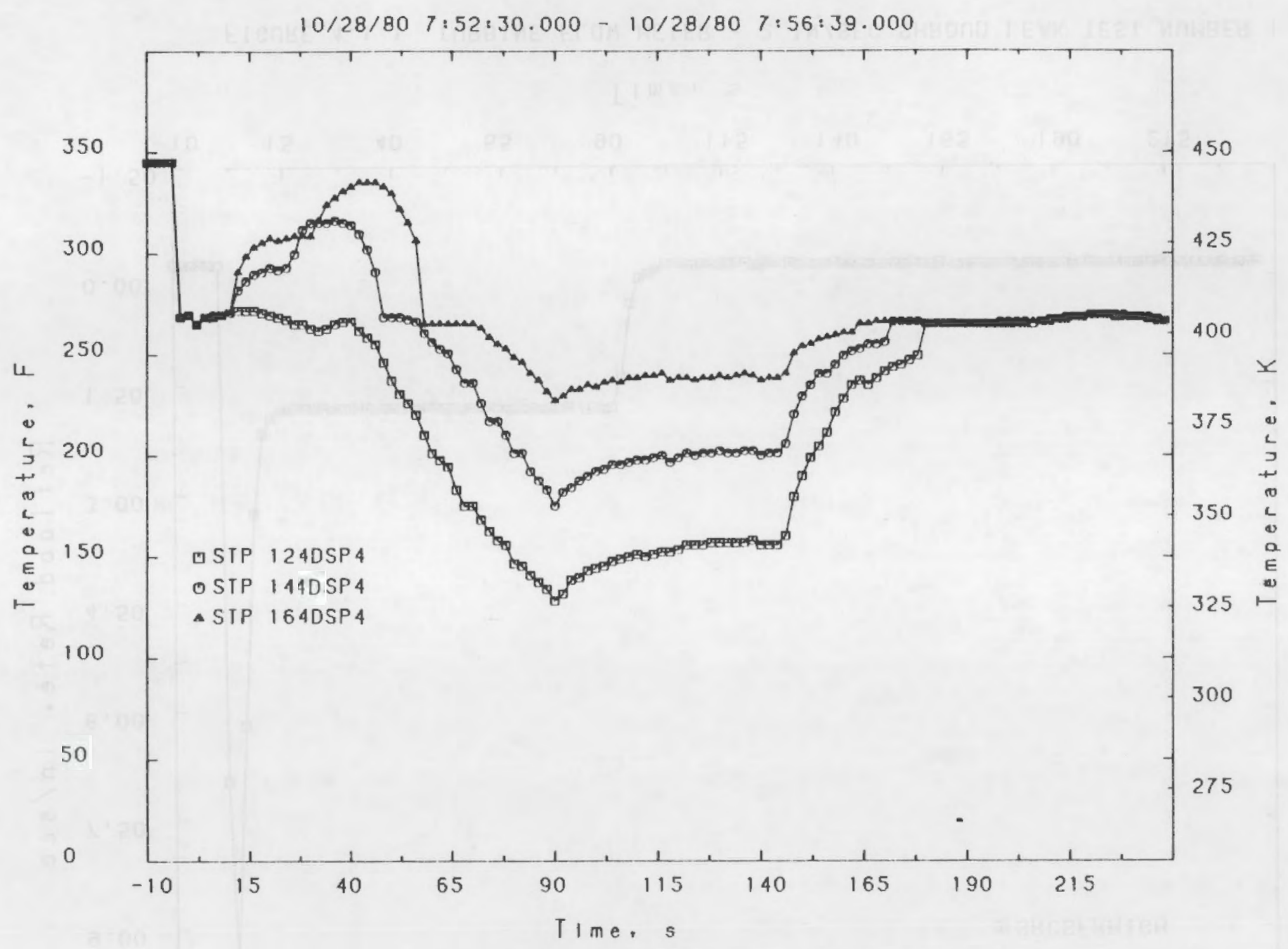

FIGURE 4.1 .2 STEAM PROBE TEMPERATURES FROM IHE THIMBLE TUBE 2 IN/SEC SHROUD LEAK TEST NUMBER 1 


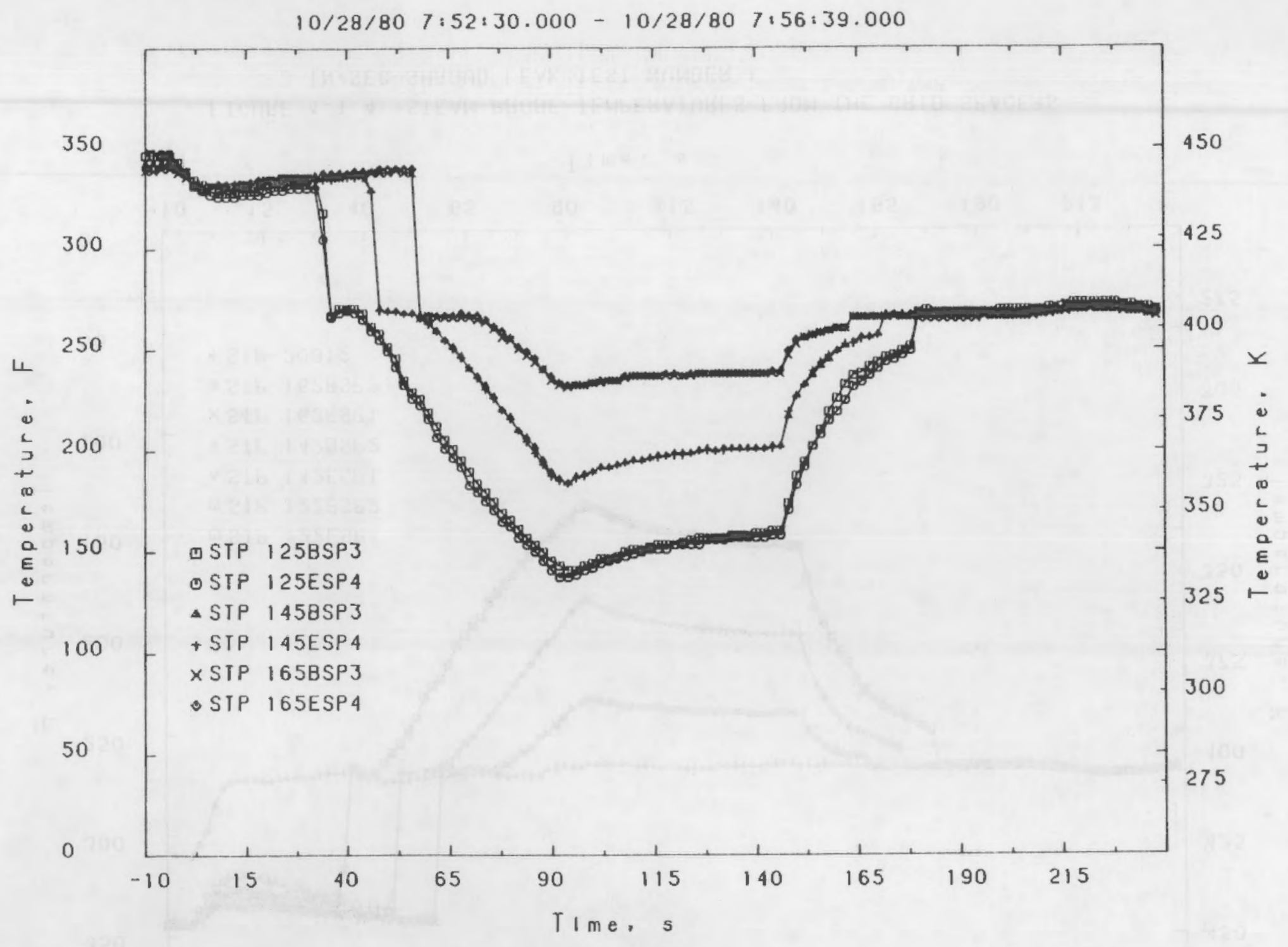

FIGURE 4.1 .3 STEAM PROBE IEMPERATURES FROM THE GRID SPACERS 2 IN/SEC SHROUD LEAK IEST NUMBER I 


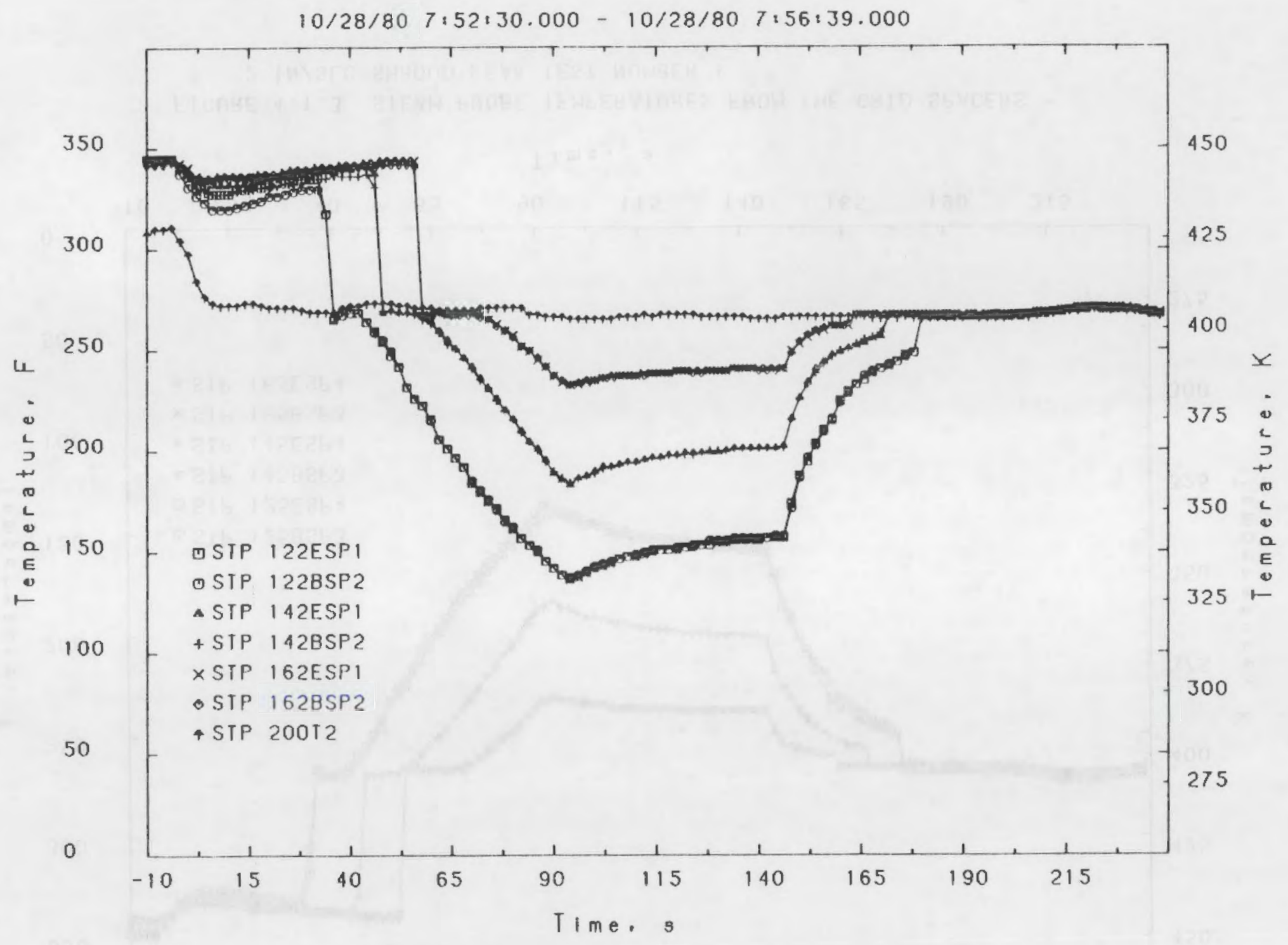

FIGURE 4.1 .4 STEAM PROBE TEMPERATURES FROM THE GRID SPACERS 2 IN/SEC SHROUD LEAK TEST NUMBER 1 


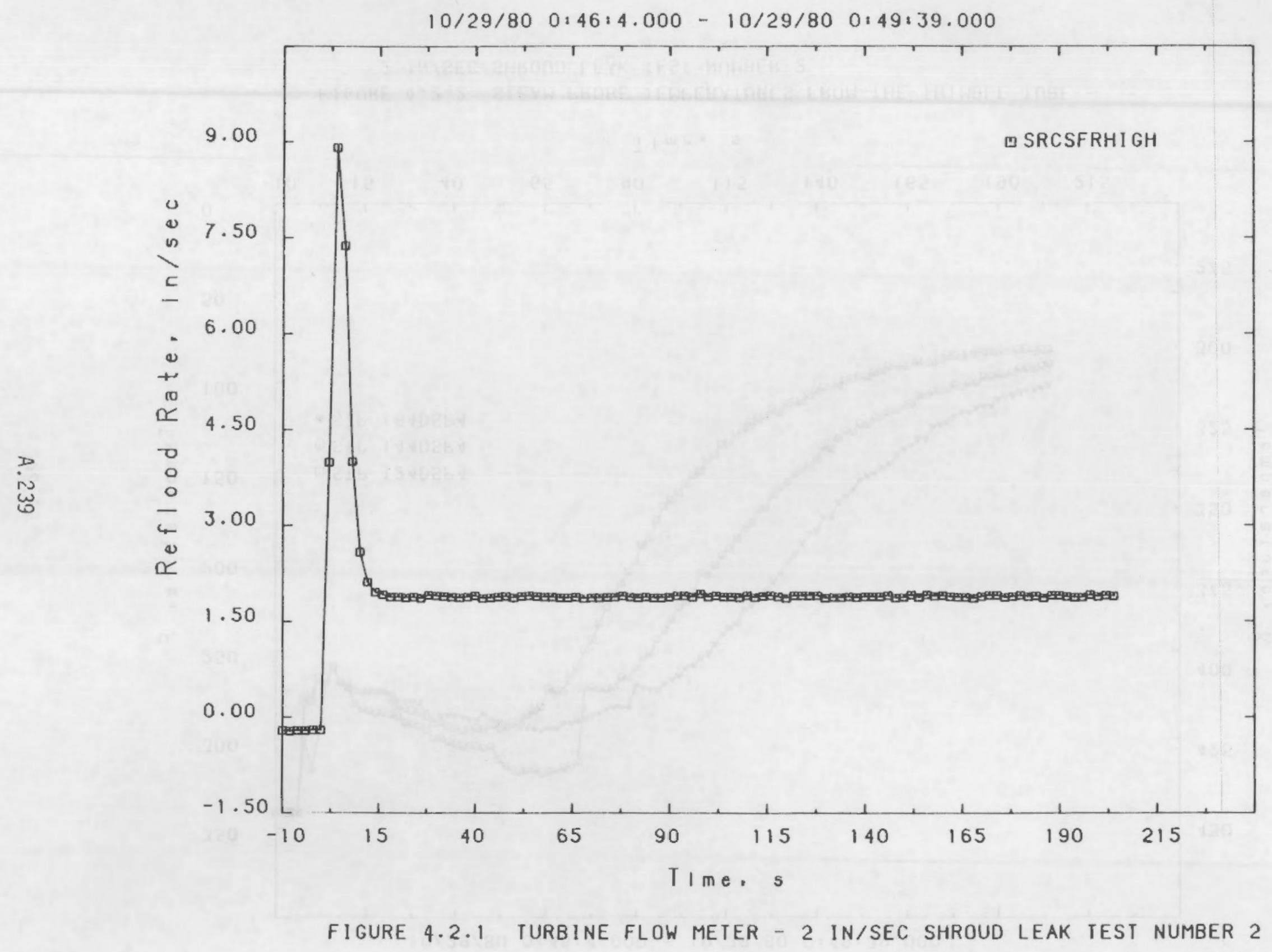




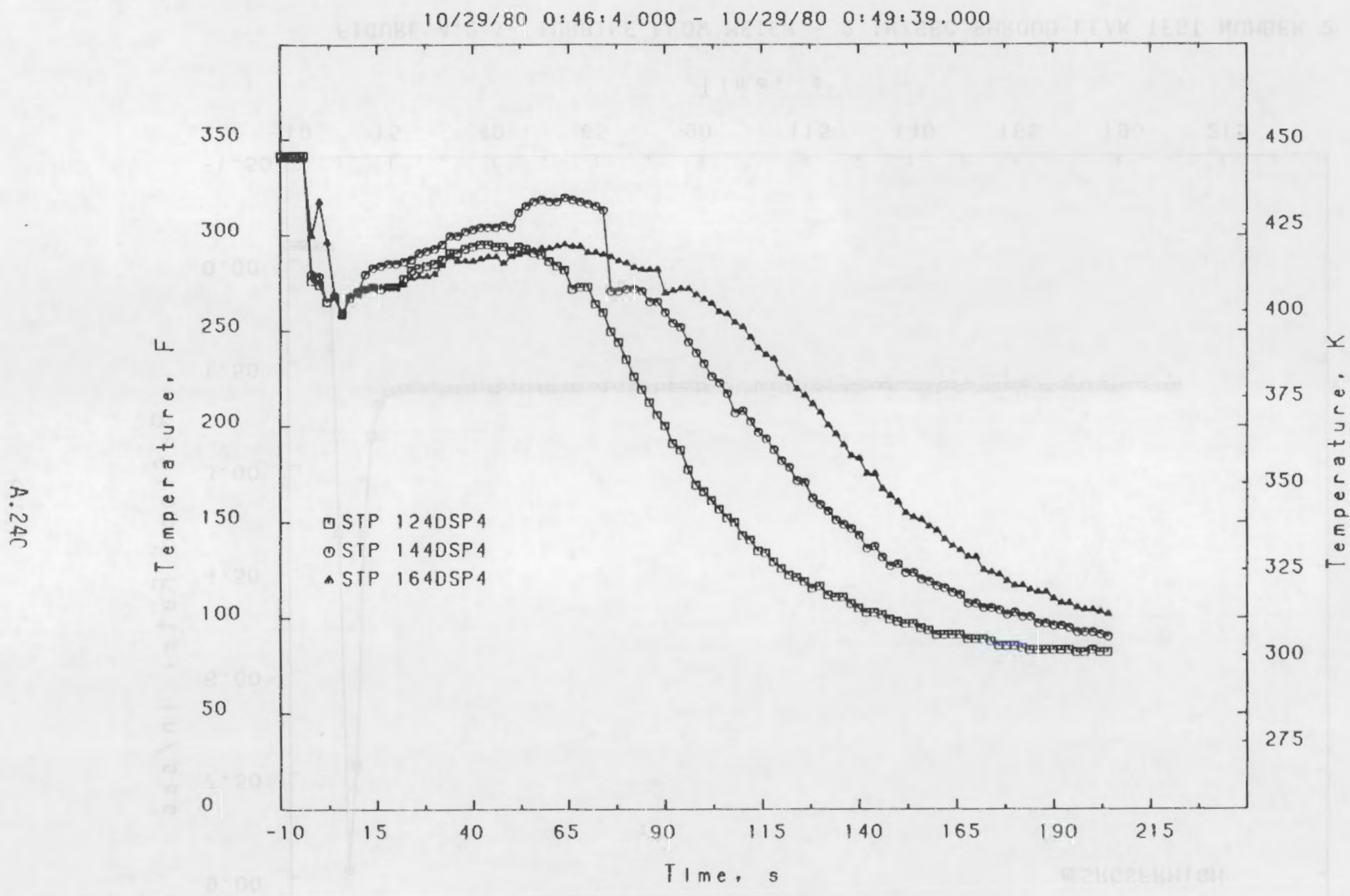

FIgURE 4.2 .2 STEAM PROBE TEMPERATURES FROM THE THIMBLE TUBE 2 IN/SEC SHROUD LEAK TEST NUMBER 2 


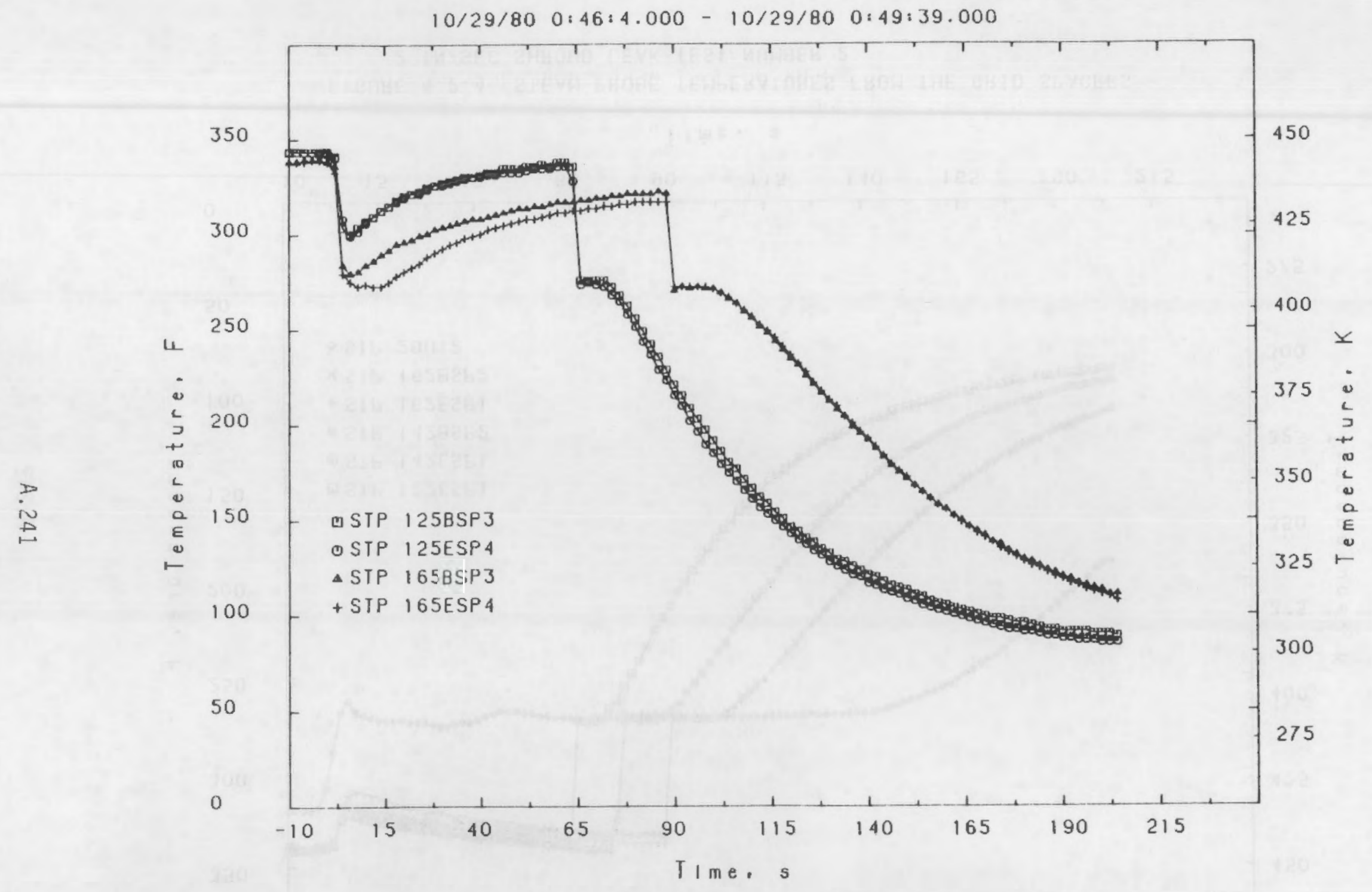

FIGURE 4.2.3 STEAM PROBE TEMPERATURES FROM THE GRID SPACERS -

2 IN/SEC SHROUD LEAK TEST NUMBER 2 


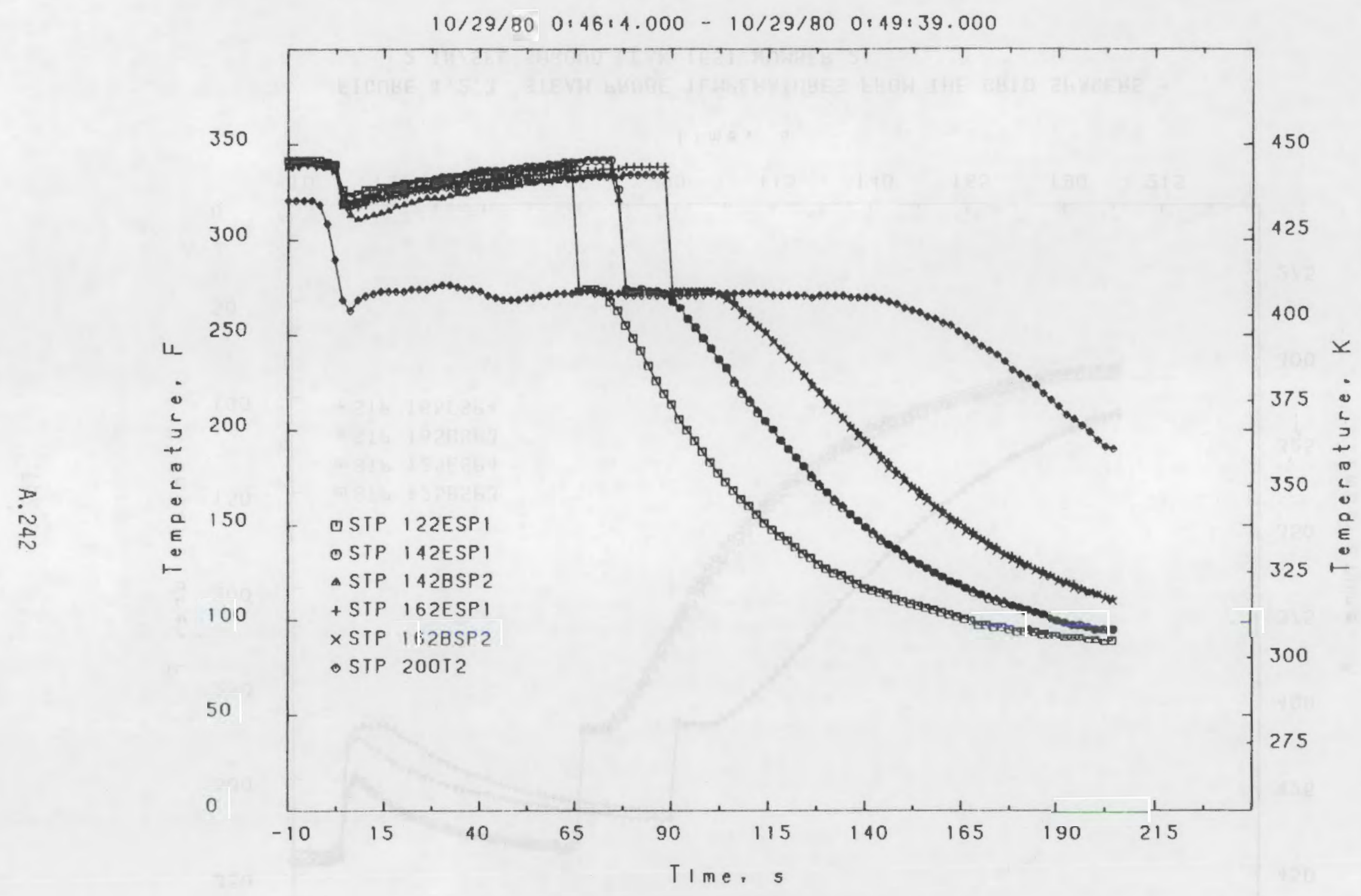

FIGURE 4.2 .4 SIEAM PROBE TEMPERATURES FROM THE GRID SPACERS 2 IN/SEC SHROUD LEAK TEST NUMBER 2 


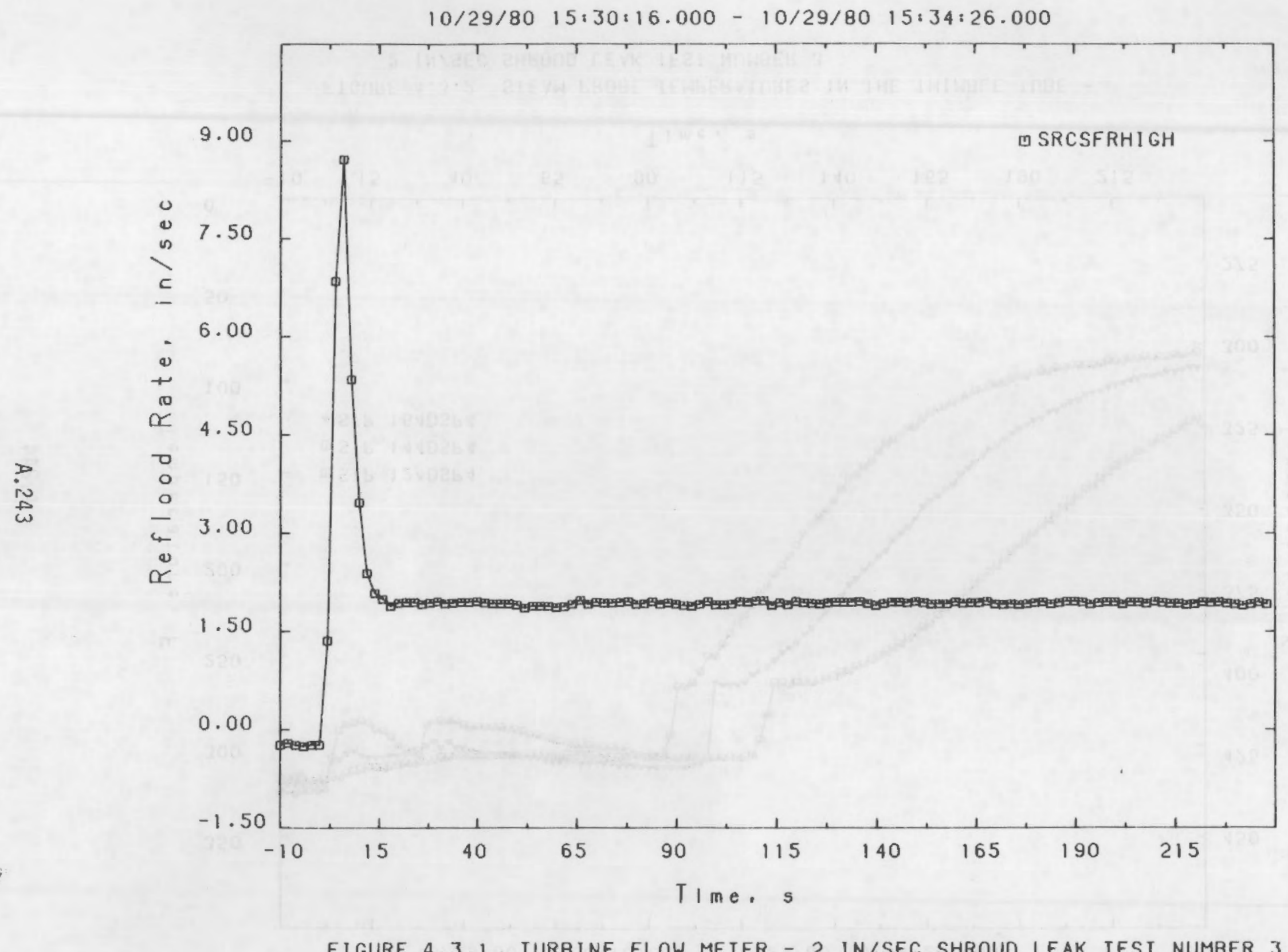

FIGURE 4.3.1 TURBINE FLOW METER - 2 IN/SEC SHROUD LEAK TEST NUMBER 3 


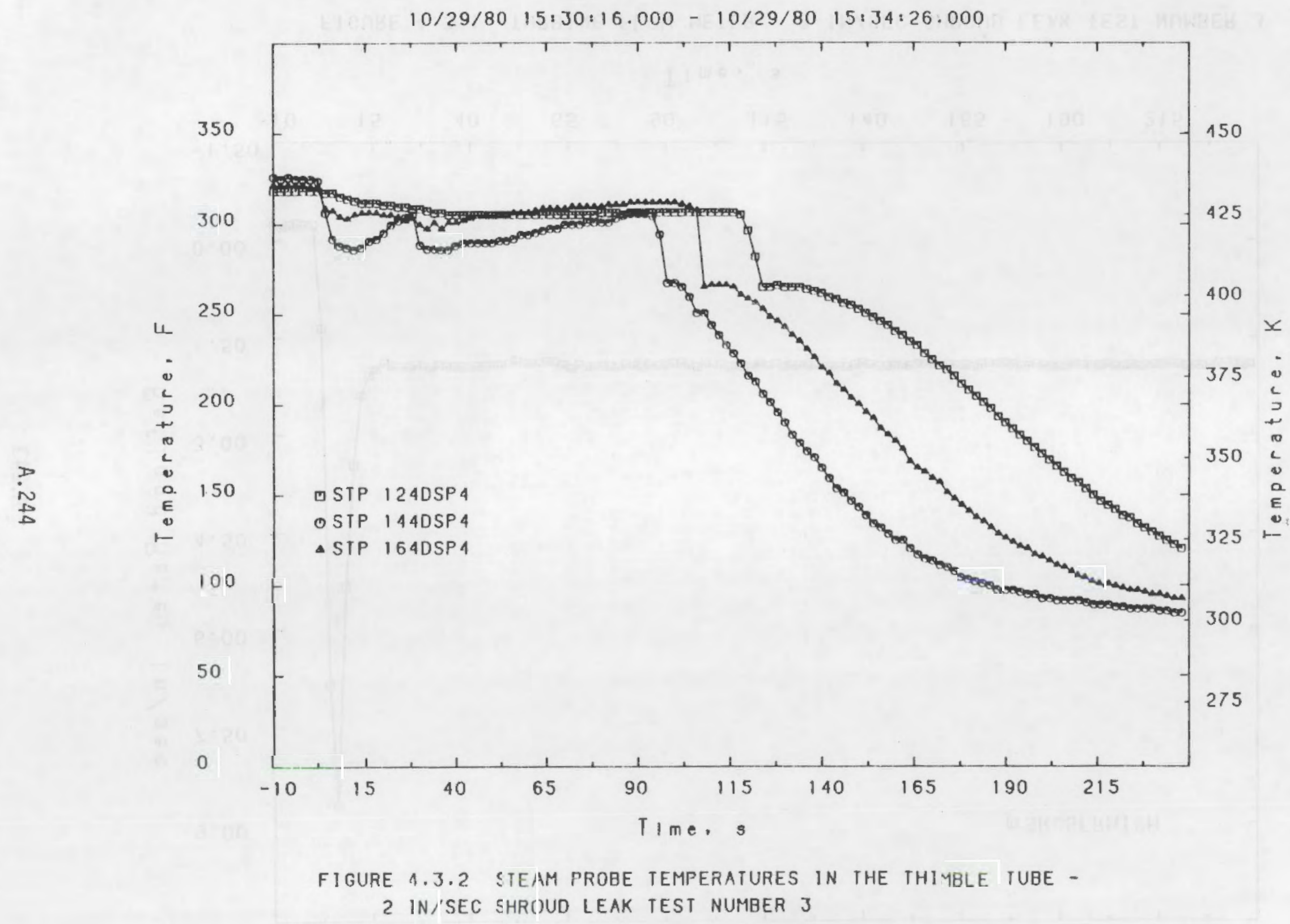




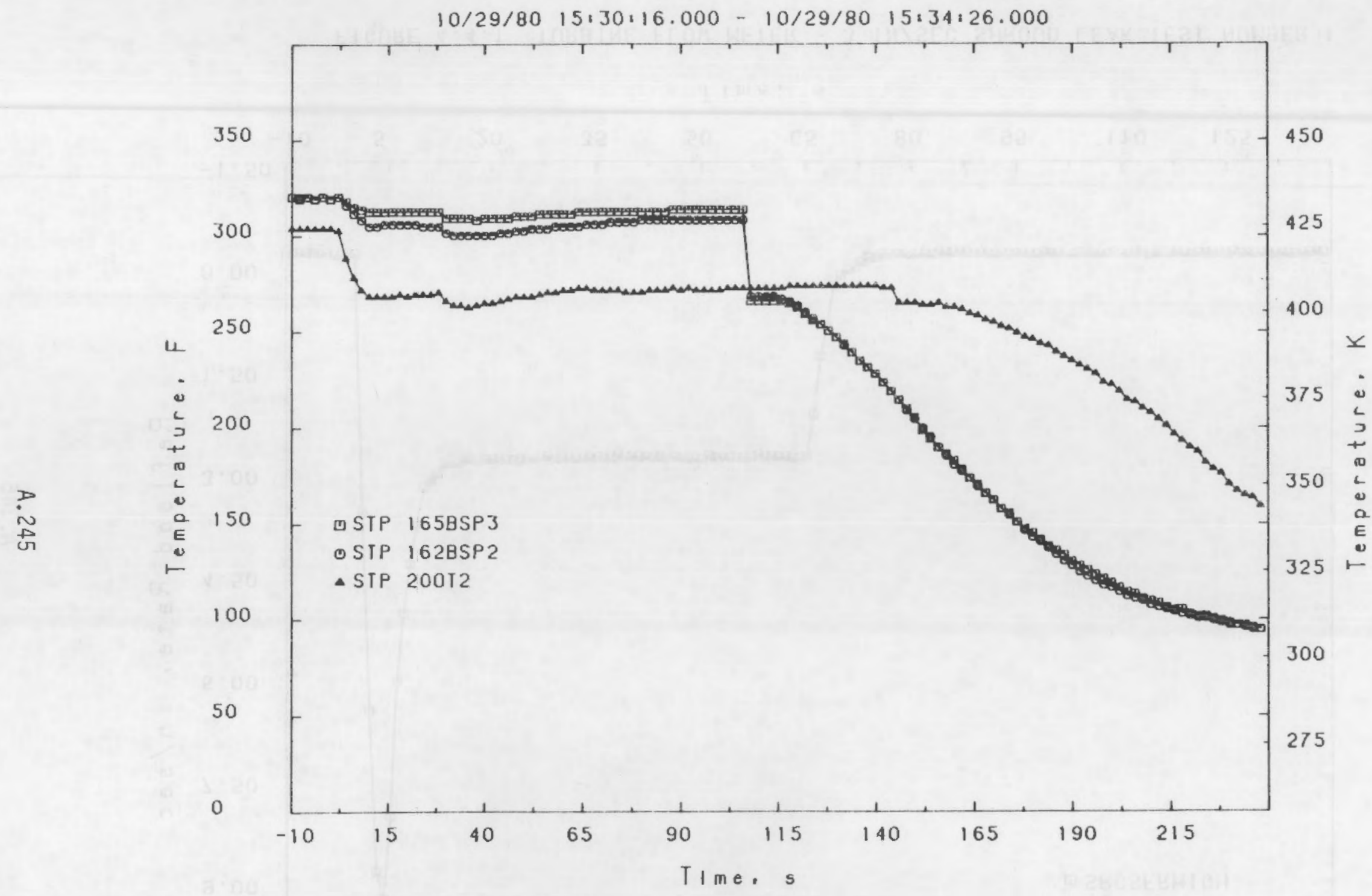

FIGURE 4.3.3 STEAM PROBE TEMPERATURES FROM THE GRID SPACERS 2 IN/SEC SHROUD LEAK TEST NUMBER 3 


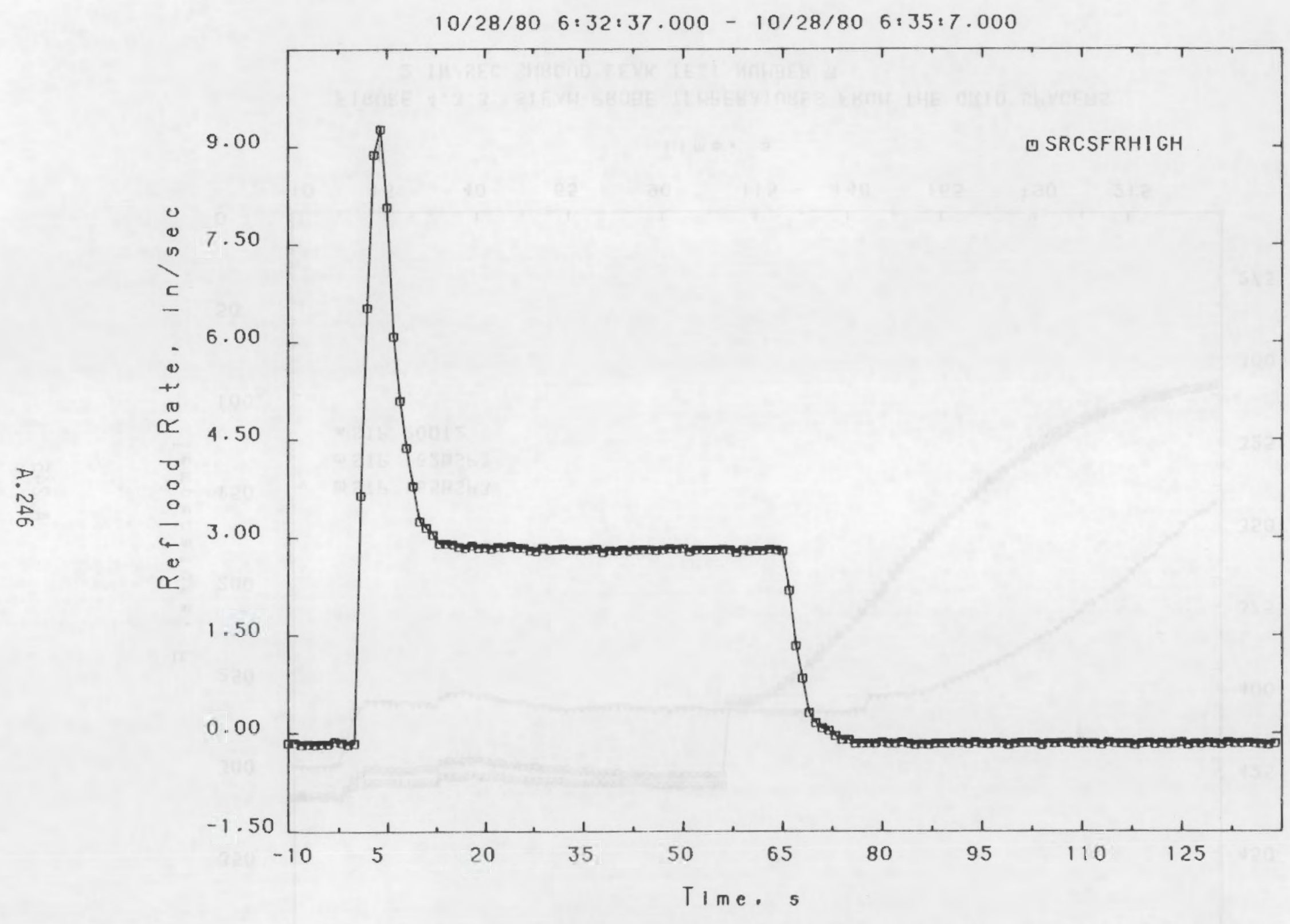

FIGURE 4.4.1 TURBINE FLOW METER - 3 IN/SEC SHROUD LEAK TEST NUMBER 1 


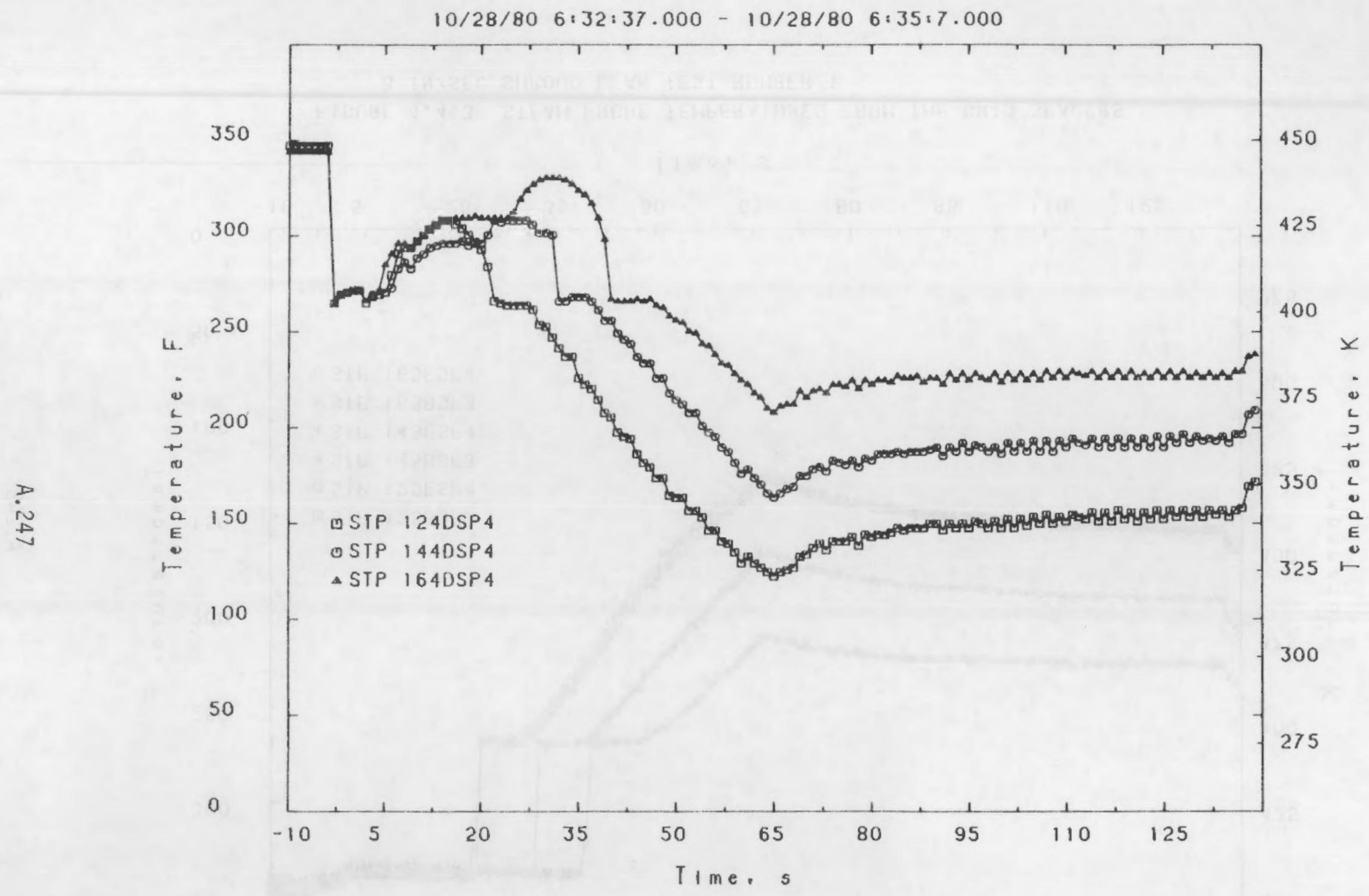

FIgURE 4.4.2 STEAM PROBE TEMPERATURES FROM THE THIMBLE TUBE 3 IN/SEC SHROUD LEAK TEST NUMBER 1 


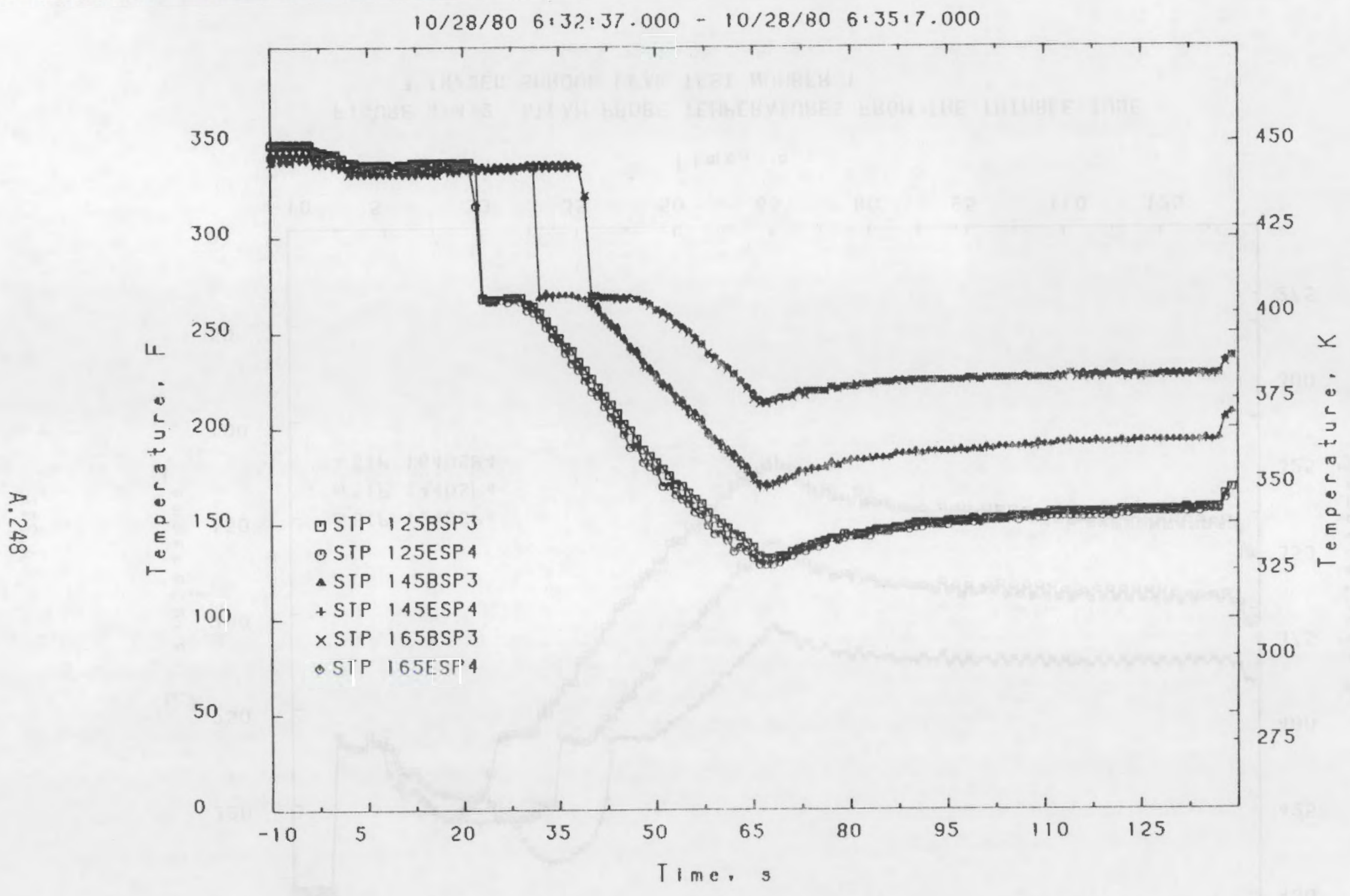

FIGURE 4.1 .3 STEAM PROBE TEMPERATURES FROM THE GRID SPACERS 3 IN/SEC SHROUD LEAK IEST NUMBER 1 


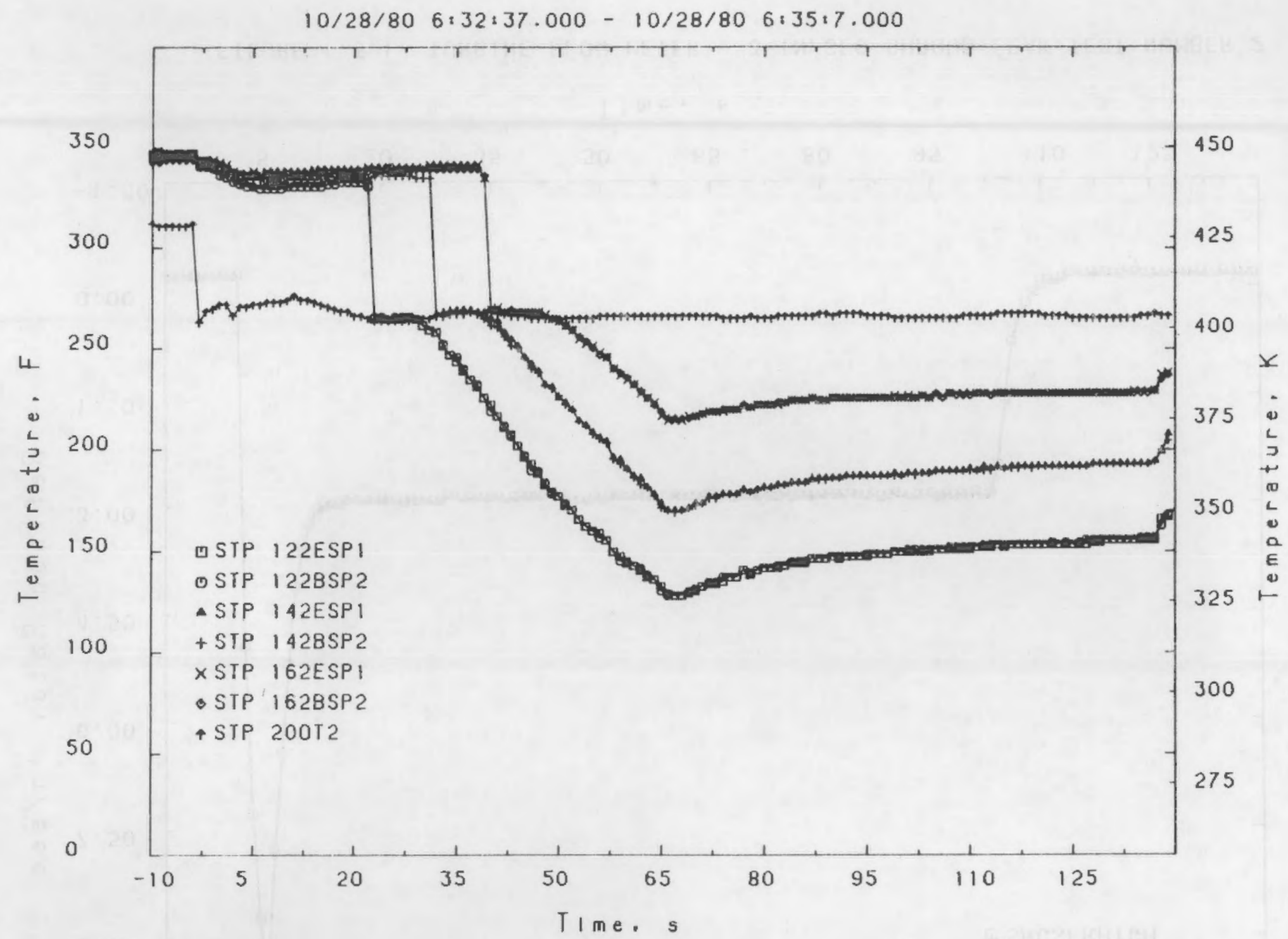

FIGURE 4.4 .4 STEAM PROBE IEMPERATURES FROM THE GRID SPACERS 3 IN/SEC SHROUD LEAK TEST NUMBER I 


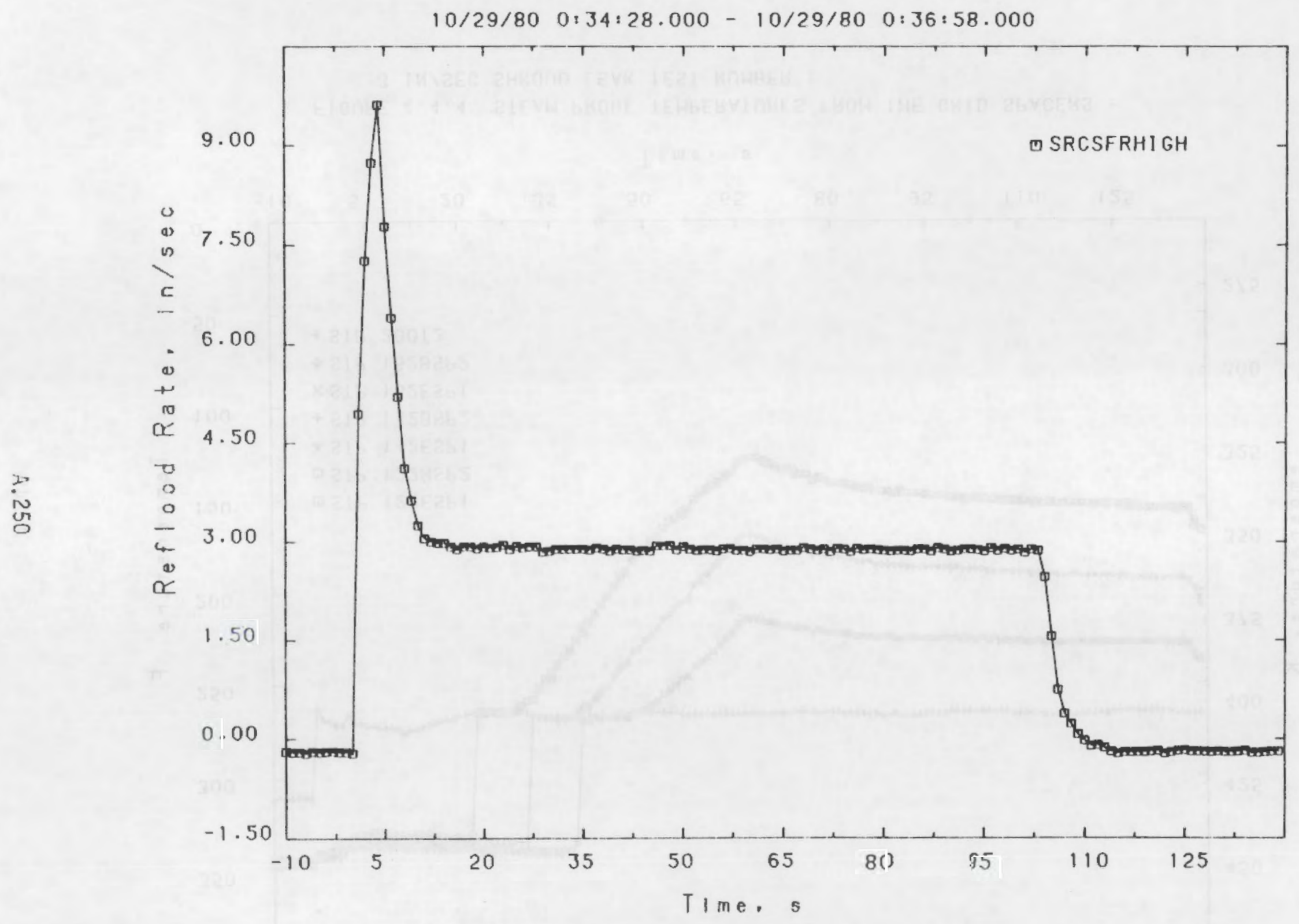

FIGURE 4.5 .1 TURBINE FL.OW METER - 3 IN/SEC SHROUD LEAK TEST NUMBER 2 


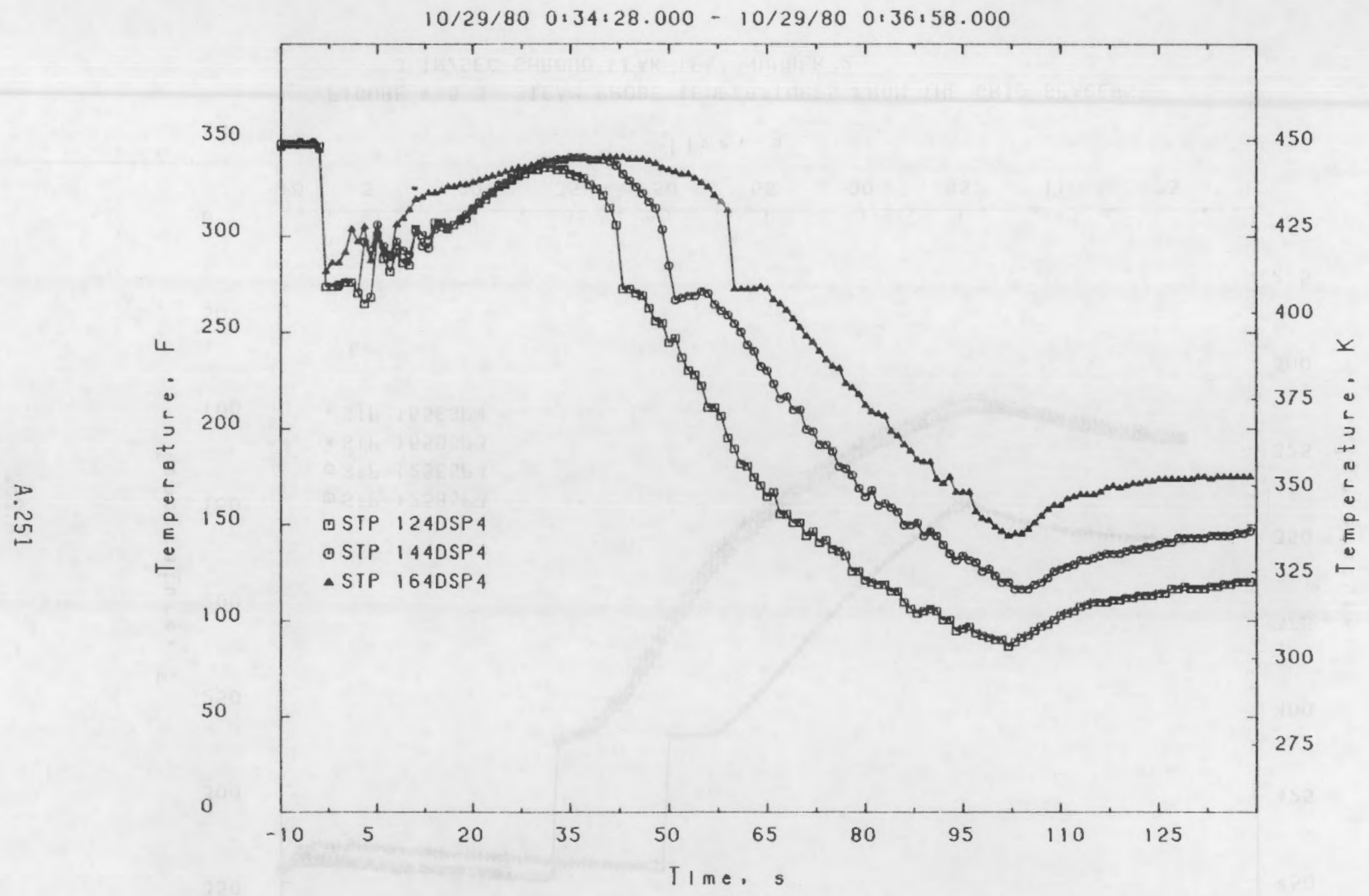

FIGURE 4.5.2 STEAM PROBE TEMPERATURES FROM THE THIMBLE TUBE -

3 IN/SEC SHROUD LEAK IEST NUMBER 2 


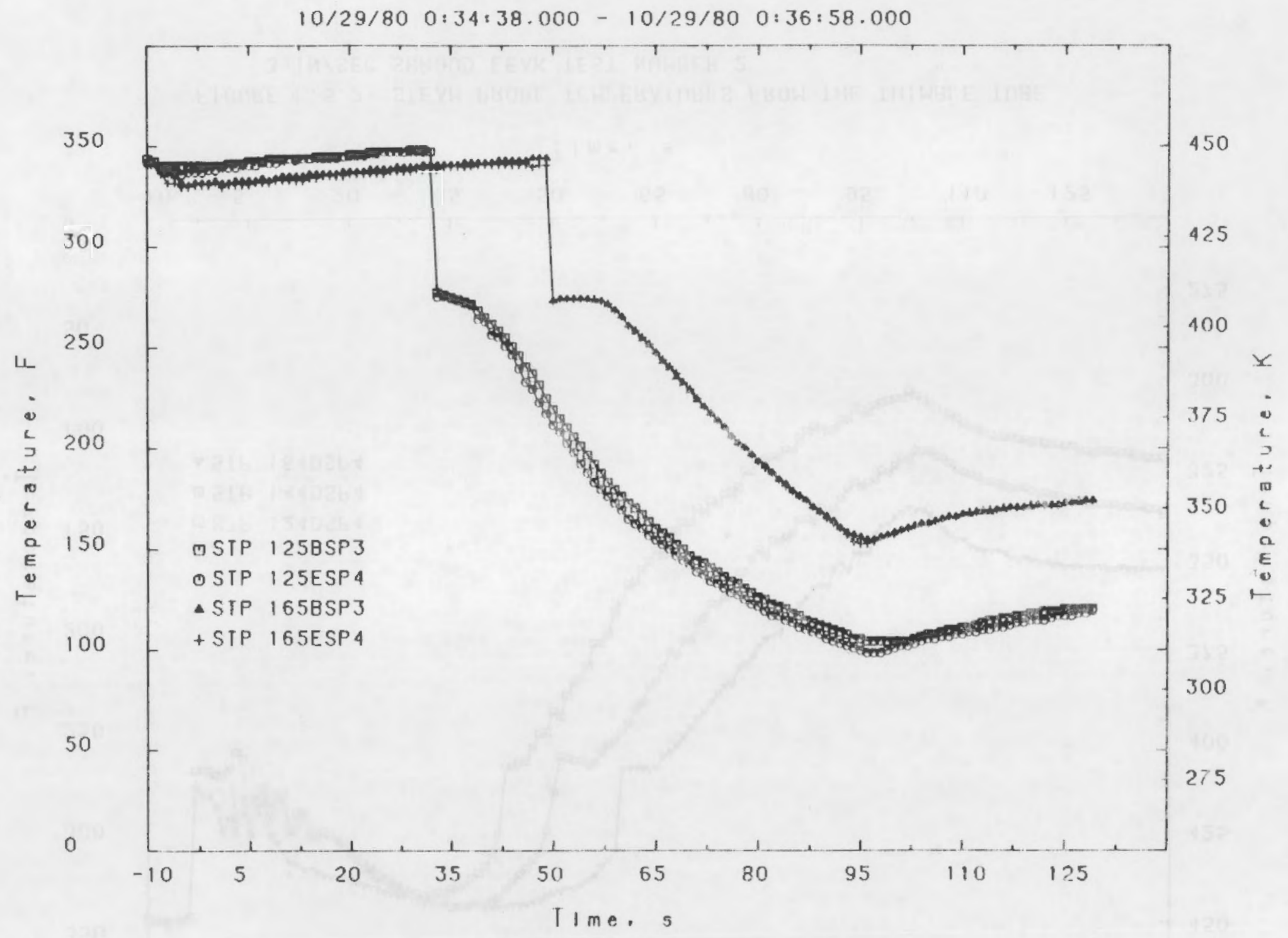

FIGURE 4.5 .3 STEAM PROBE TEMPERATURES FROM THE GRID SPACERS -

3 IN/SEC SHROUD LEAK TEST NUMBER 2 


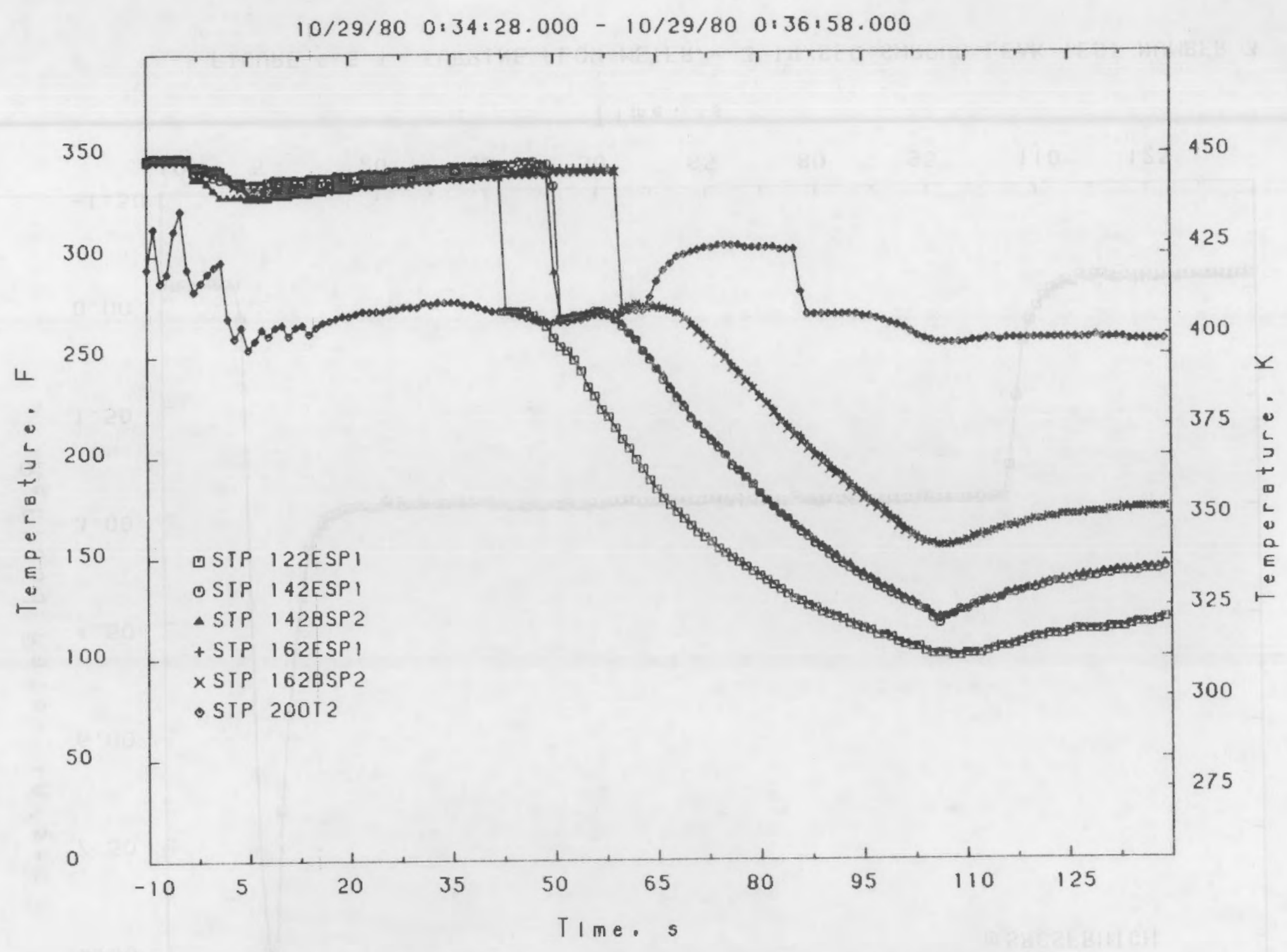

FIGURE 4 .5.4 STEAM PROBE TEMPERATURES FROM IHE GRID SPACERS -

3 IN/SEC LEAK RATE IEST NUMBER 2 


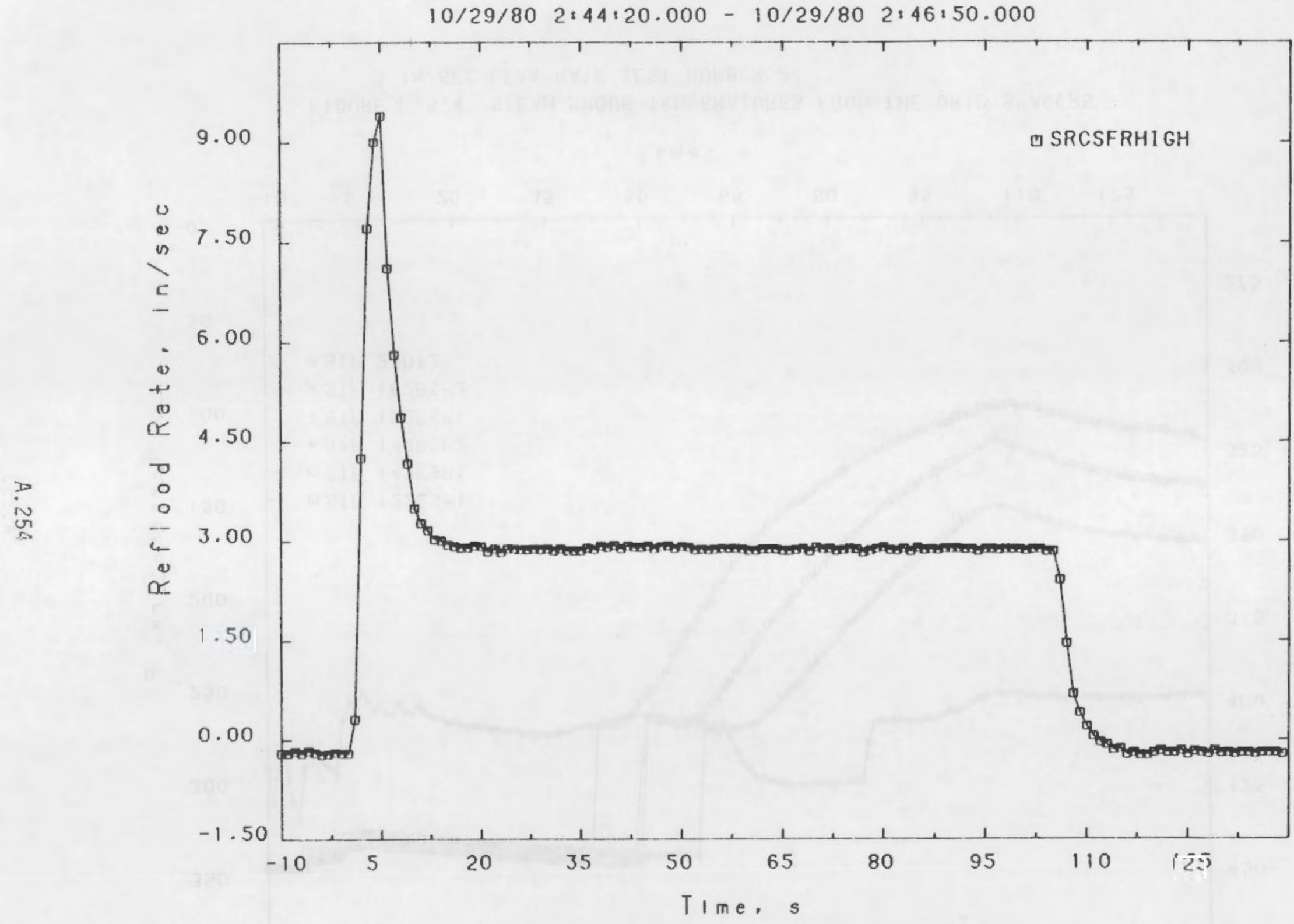

FIGURE 4.6.1 TURBINE FLOW METER - 3 IN/SEC SHROUD LEAK TEST NUMBER 3 


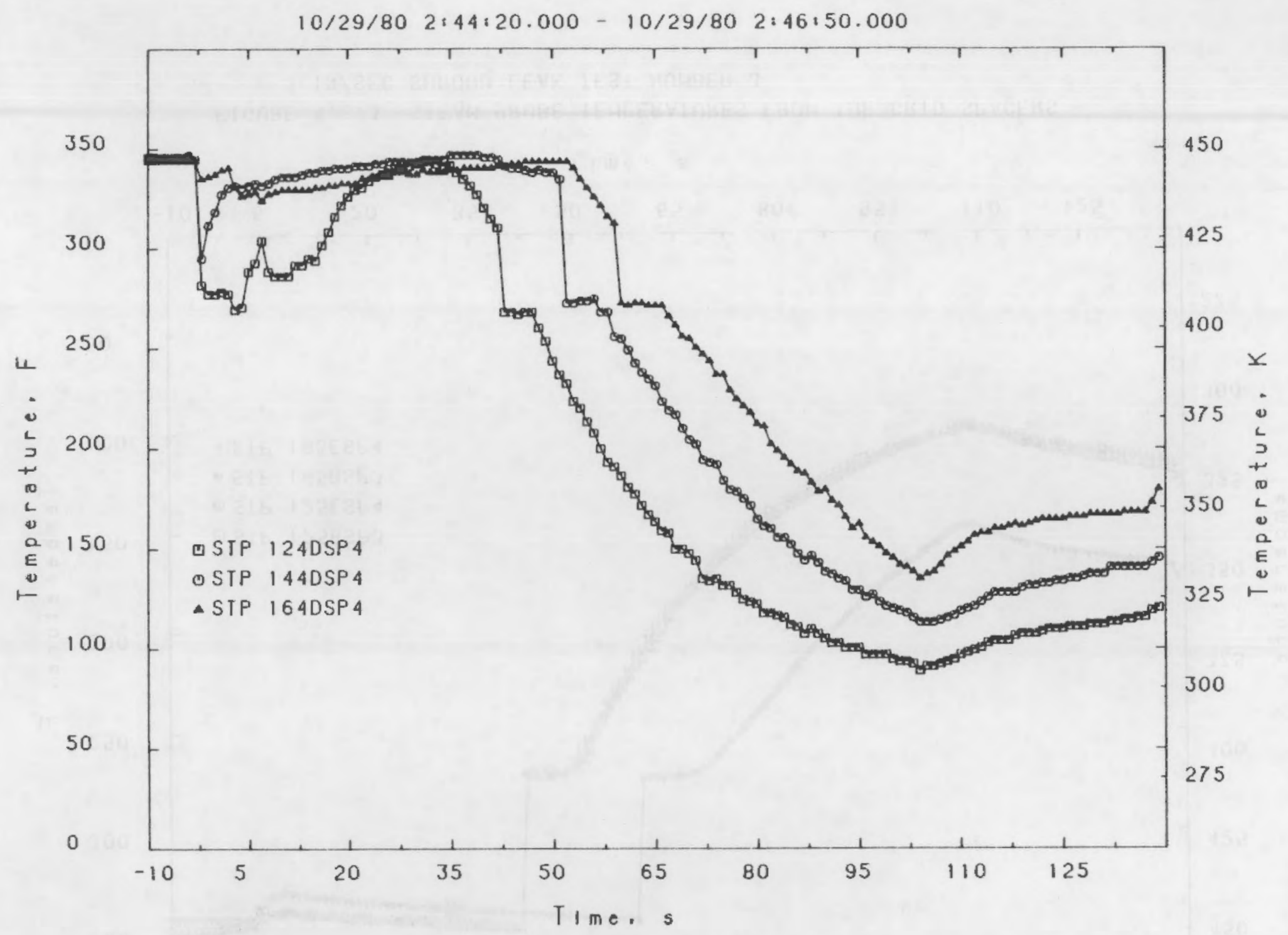

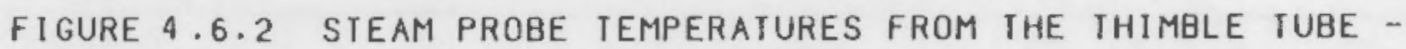

3 IN/SEC SHROUD LEAK TEST NUMBER 3 


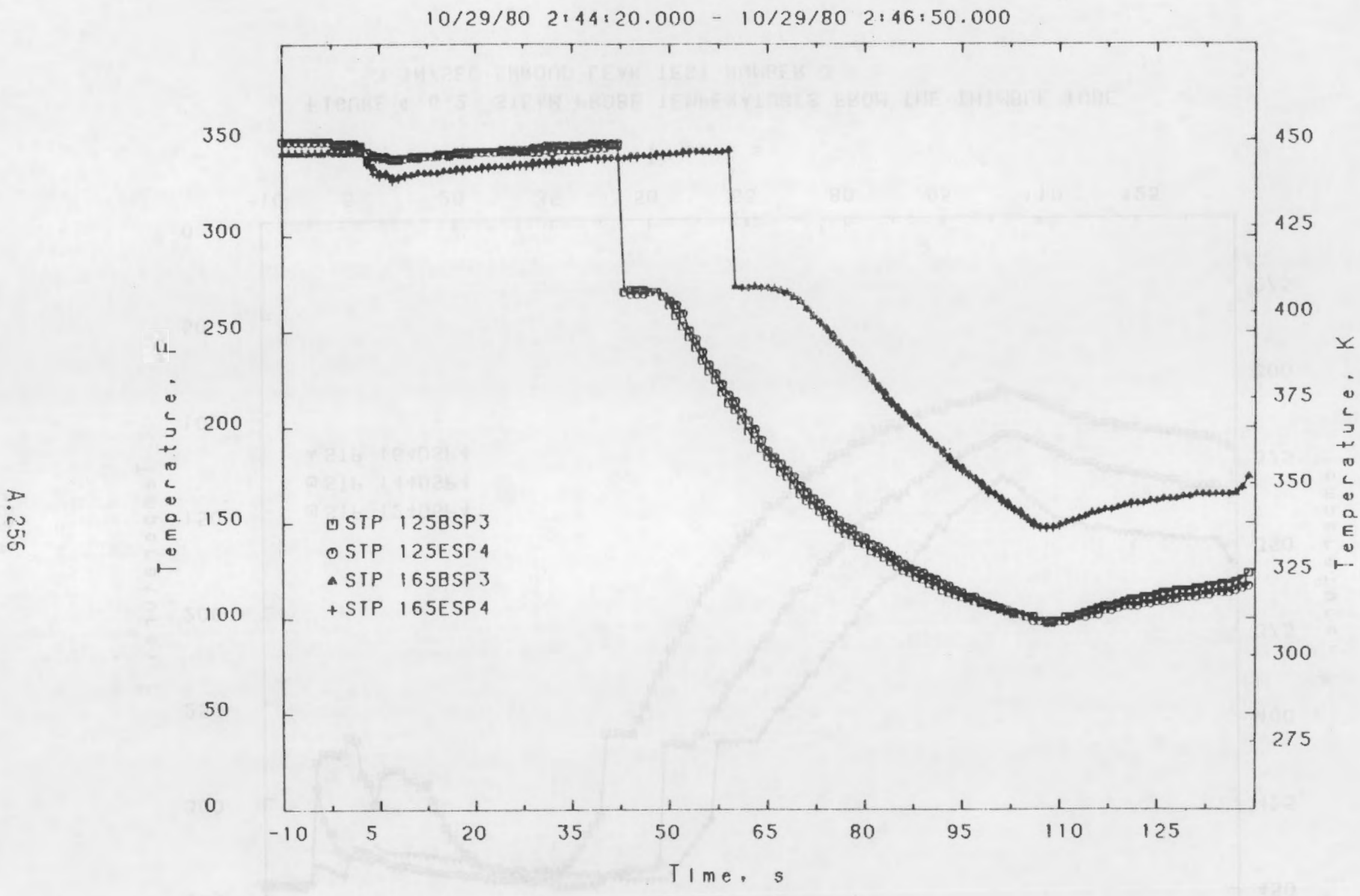

FIGURE 4.6 .3 STEAM PROBE TEMPERATURES FROM THE GRID SPACERS -

3 IN/SEC SHROUD LEAK TEST NUMBER 3 


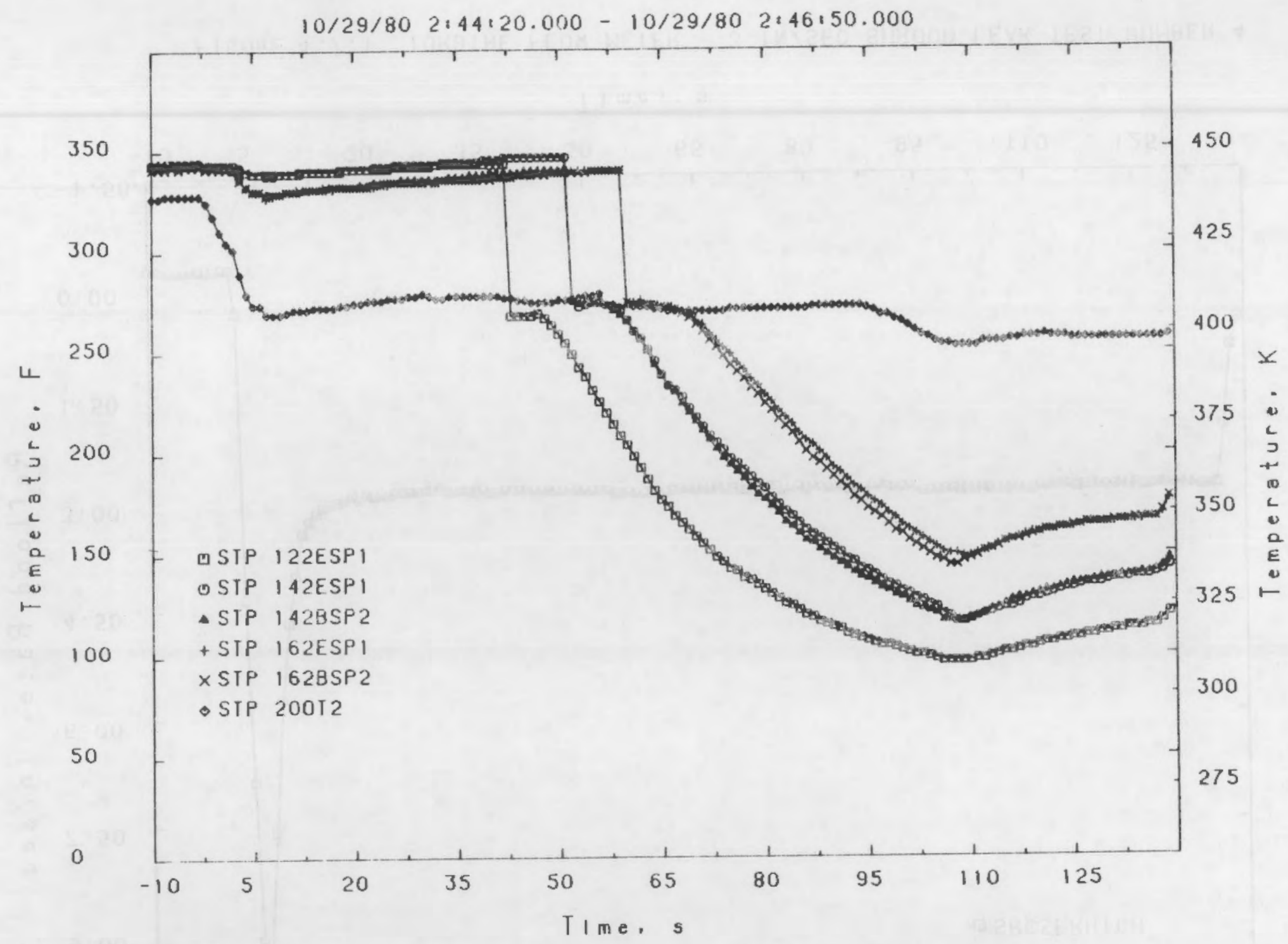

FIGURE 4.6.4 SIEAM PROBE TEMPERTURES FROM THE GRID SPACERS 3 IN/SEC SHROUD LEAK TEST NUMBER 3 


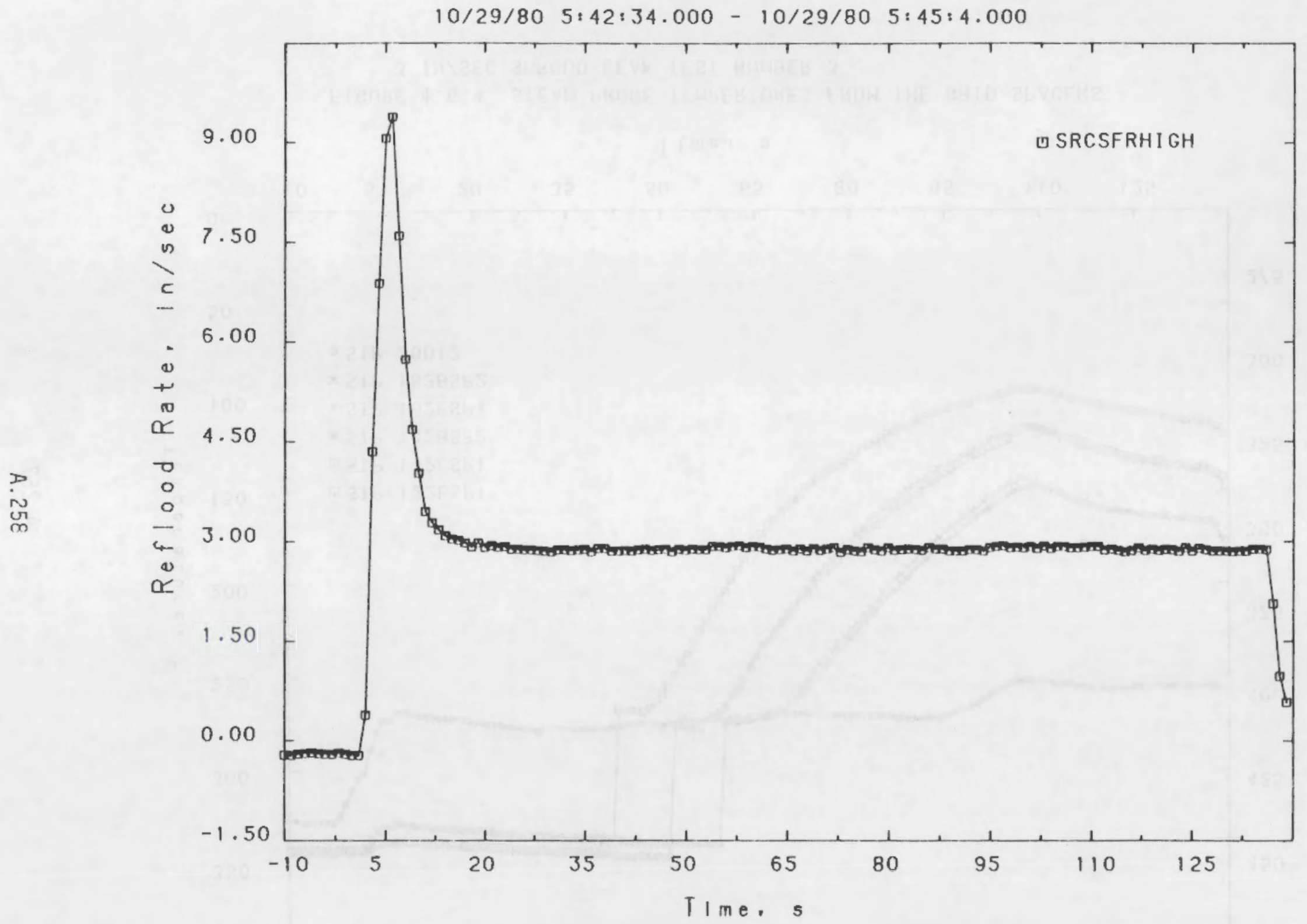

FIGURE 4.7.1 TURBINE FLOW METER - 3 IN/SEC SHROUD LEAK TEST NUMBER 4 


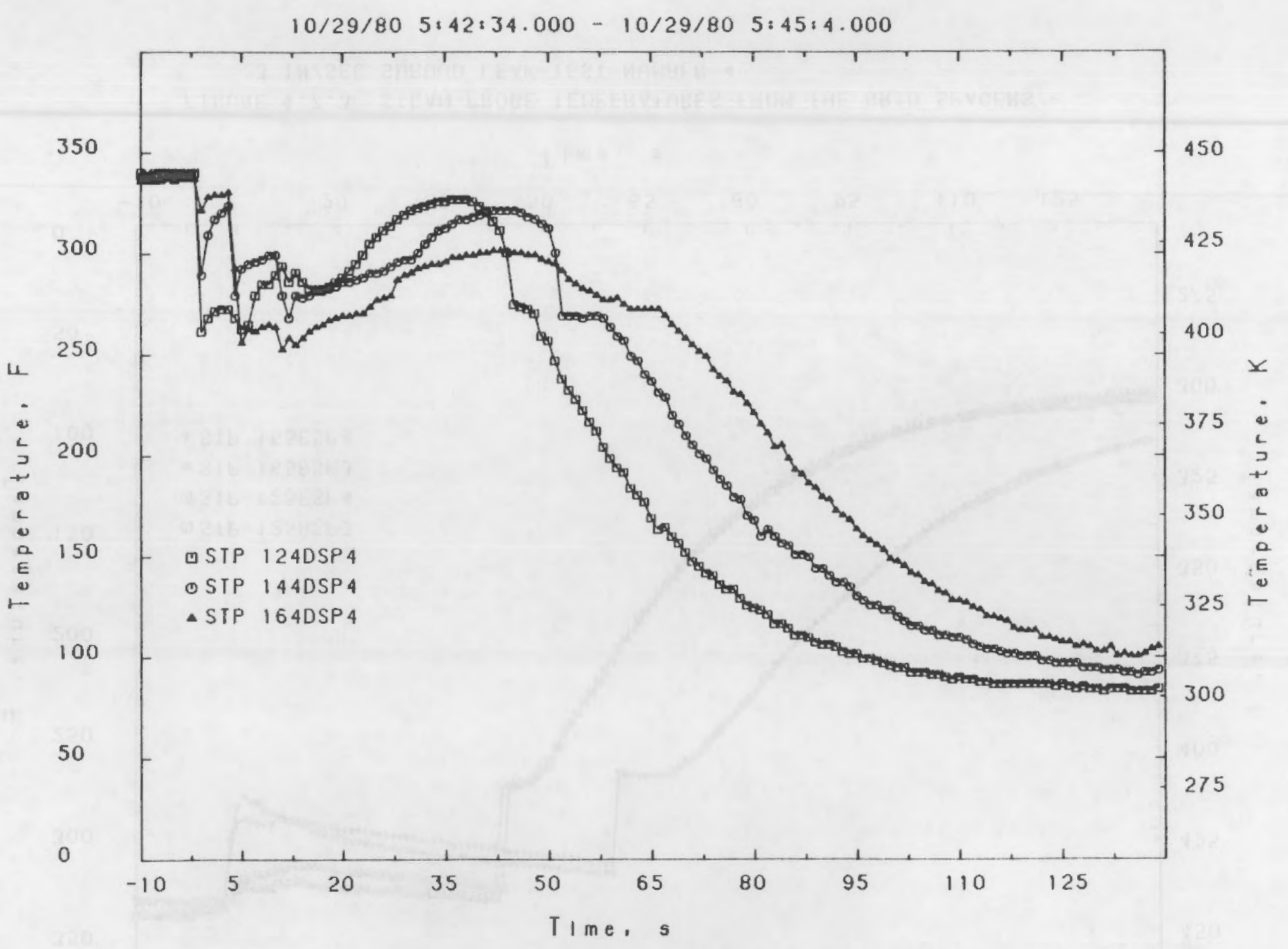

FIGURE 4.7.2 SIEAM PROBE TEMPERATURES FROM THE IHIMBLE TUBE 3 IN/SEC SHROUD LEAK TEST NUMBER 4 


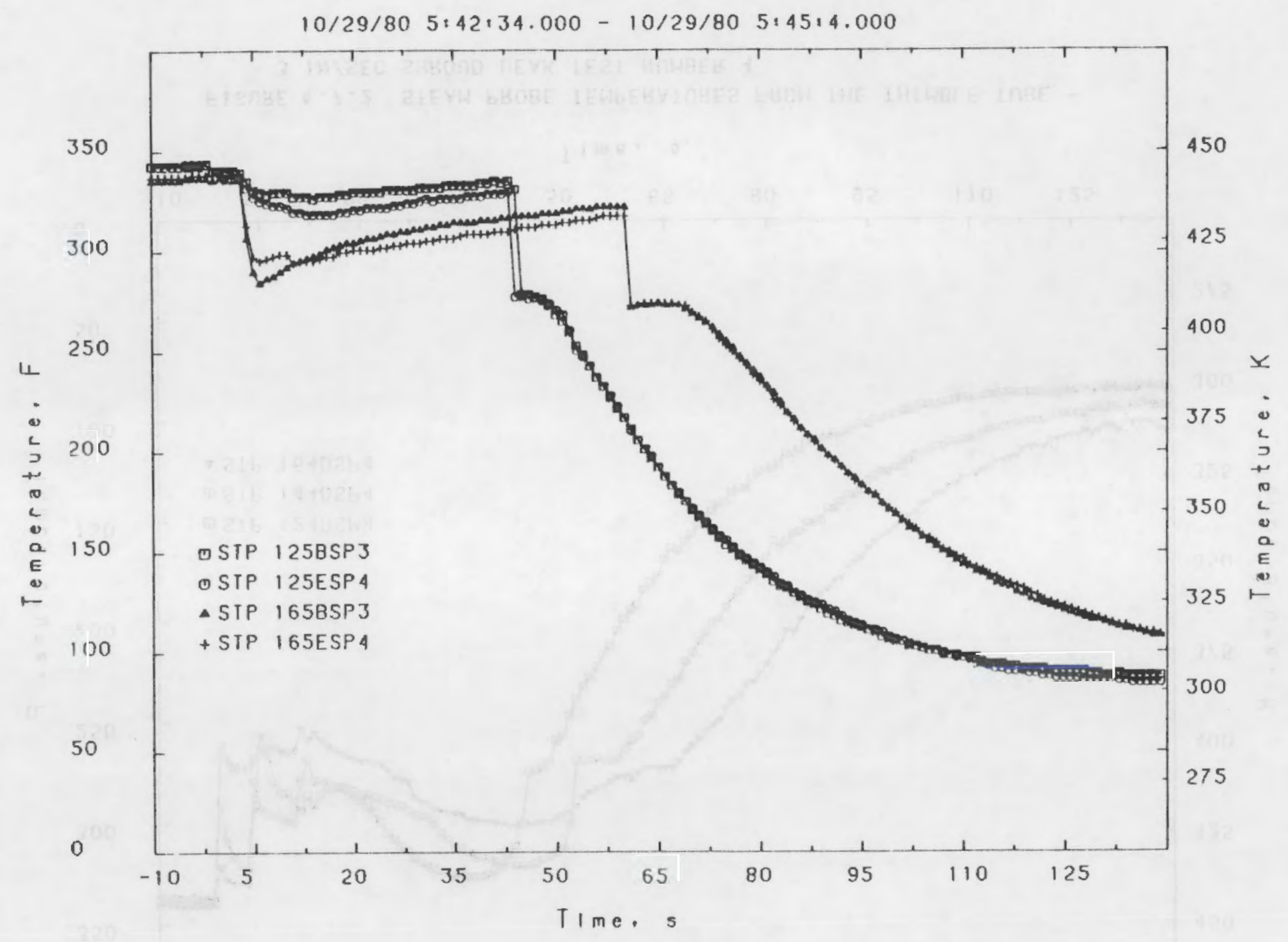

FIGURE 4.7.3 SIEAM PROBE TEMPERATURES FROM THE GRID SPACERS 3 IN/SEC SHROUD LEAK IEST NUMBER 4 


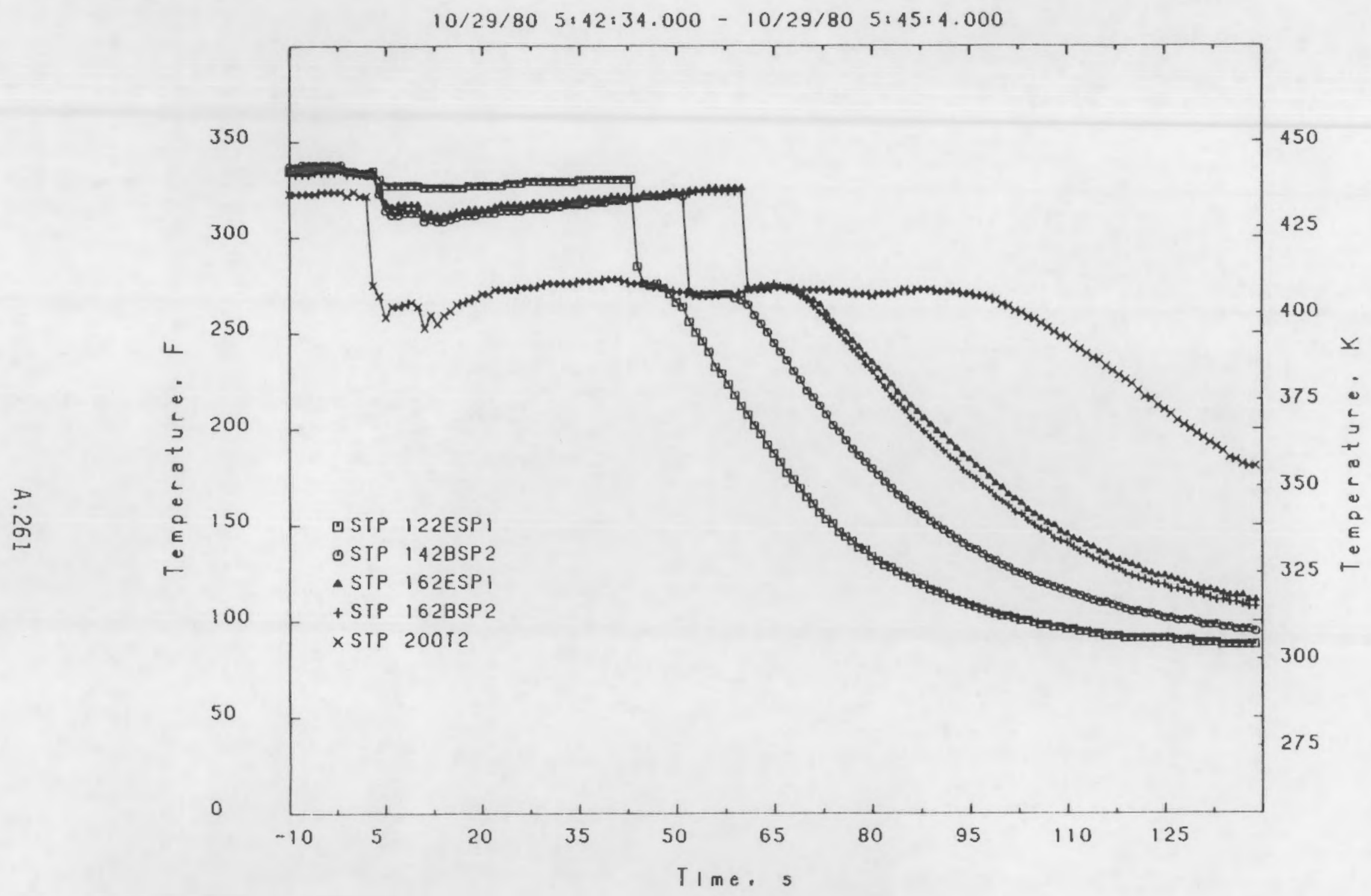

FIGURE 4.7.4 STEAM PROBE TEMPERATURES FROM THE GRID SPACERS 3 IN/SEC SHROUD LEAK TEST NUMBER 4 



\section{PART 5}

\section{FLOWMETER RATES FOR THE FLECHT}

COMPARISON TEST SERIES 


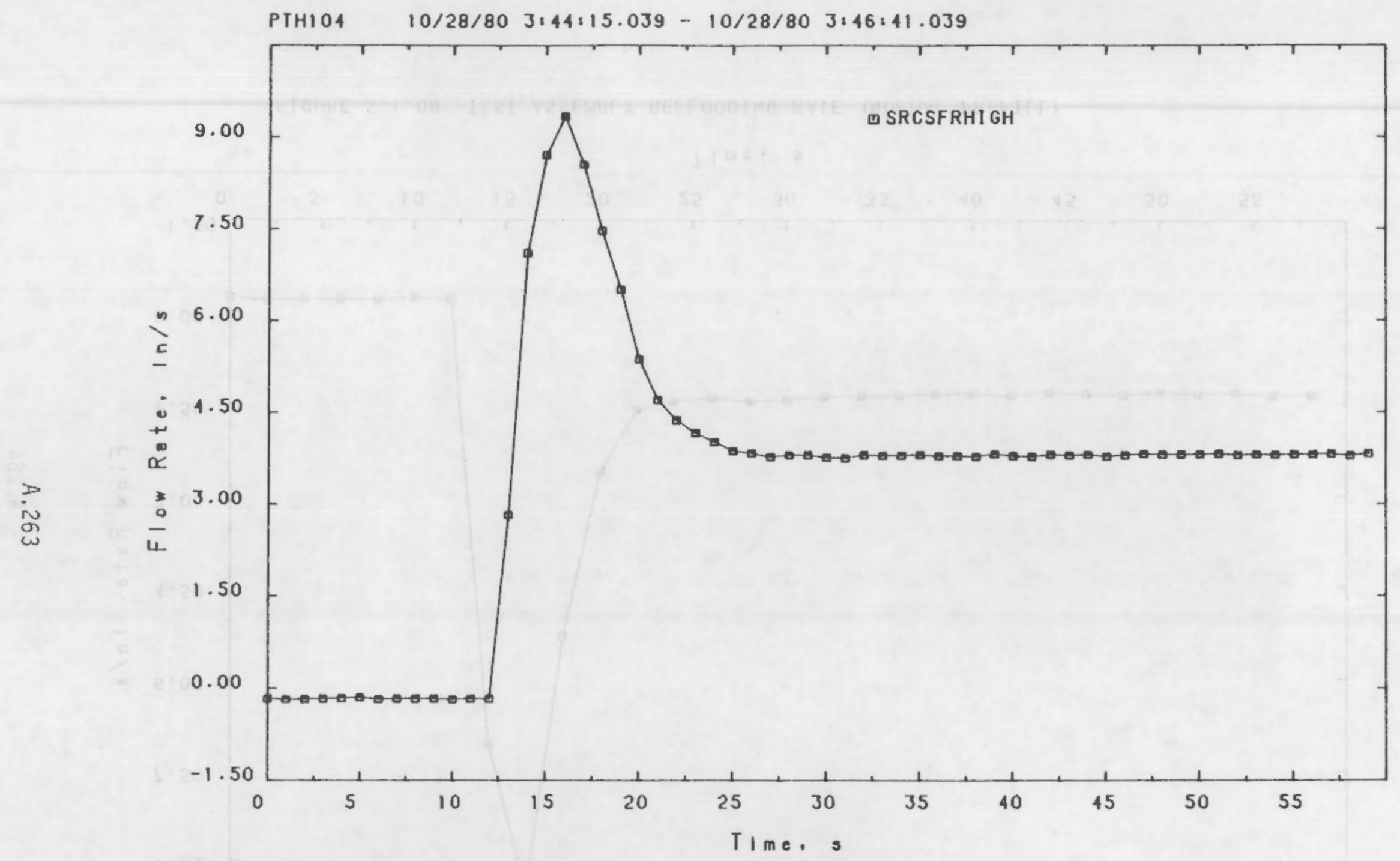

FIGURE 5.1.04 TESI ASSEMBLY REFLOODING RATE (NORMAL PREFILL) 


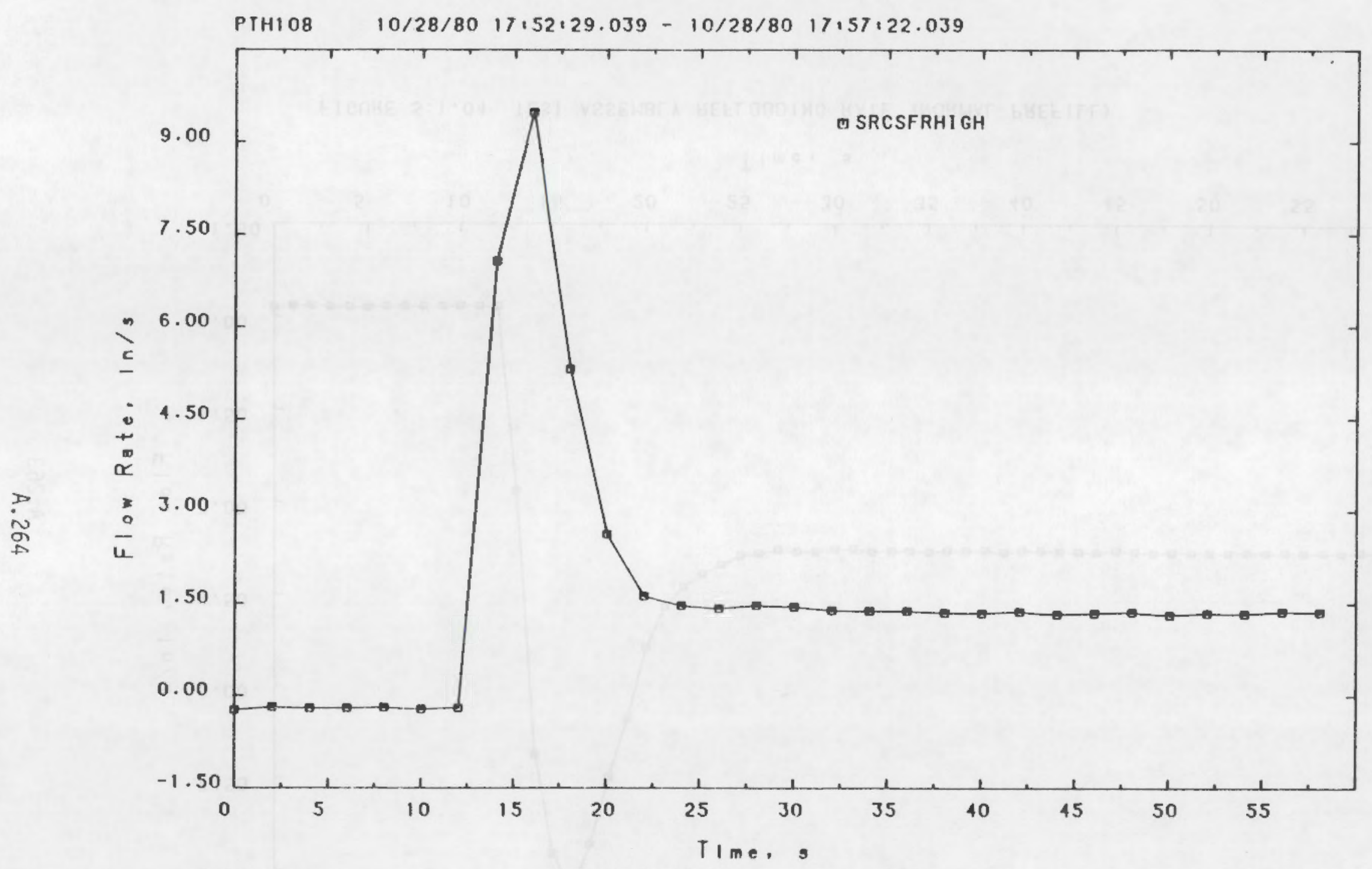

FIGURE 5.1.0B TEST ASSEMBLY REFLODDING RATE (NORMAL PREFILL) 


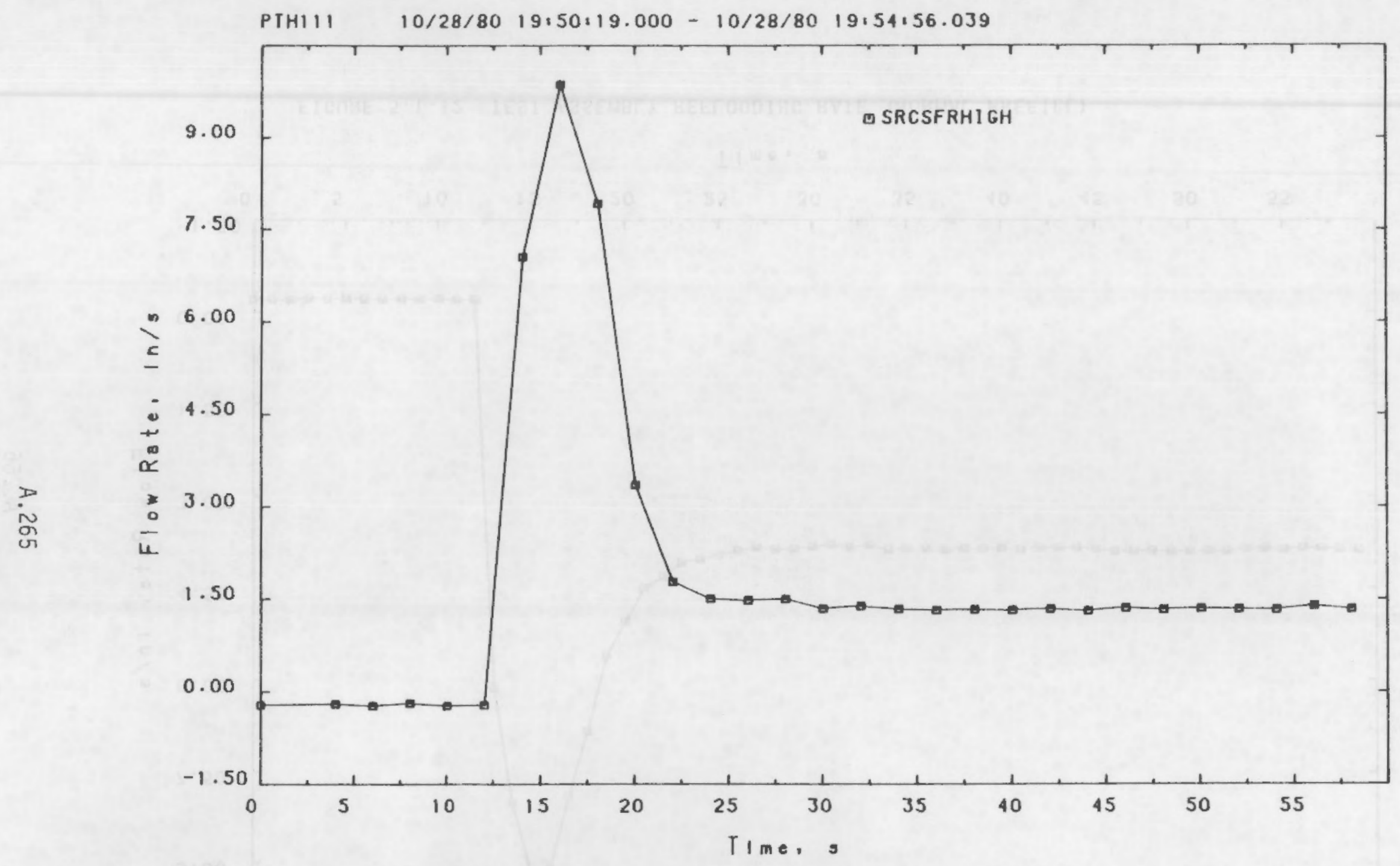

FIGURE 5.1.11 TEST ASSEMBLY REFLOODING RAIE (FAST FILLED) 


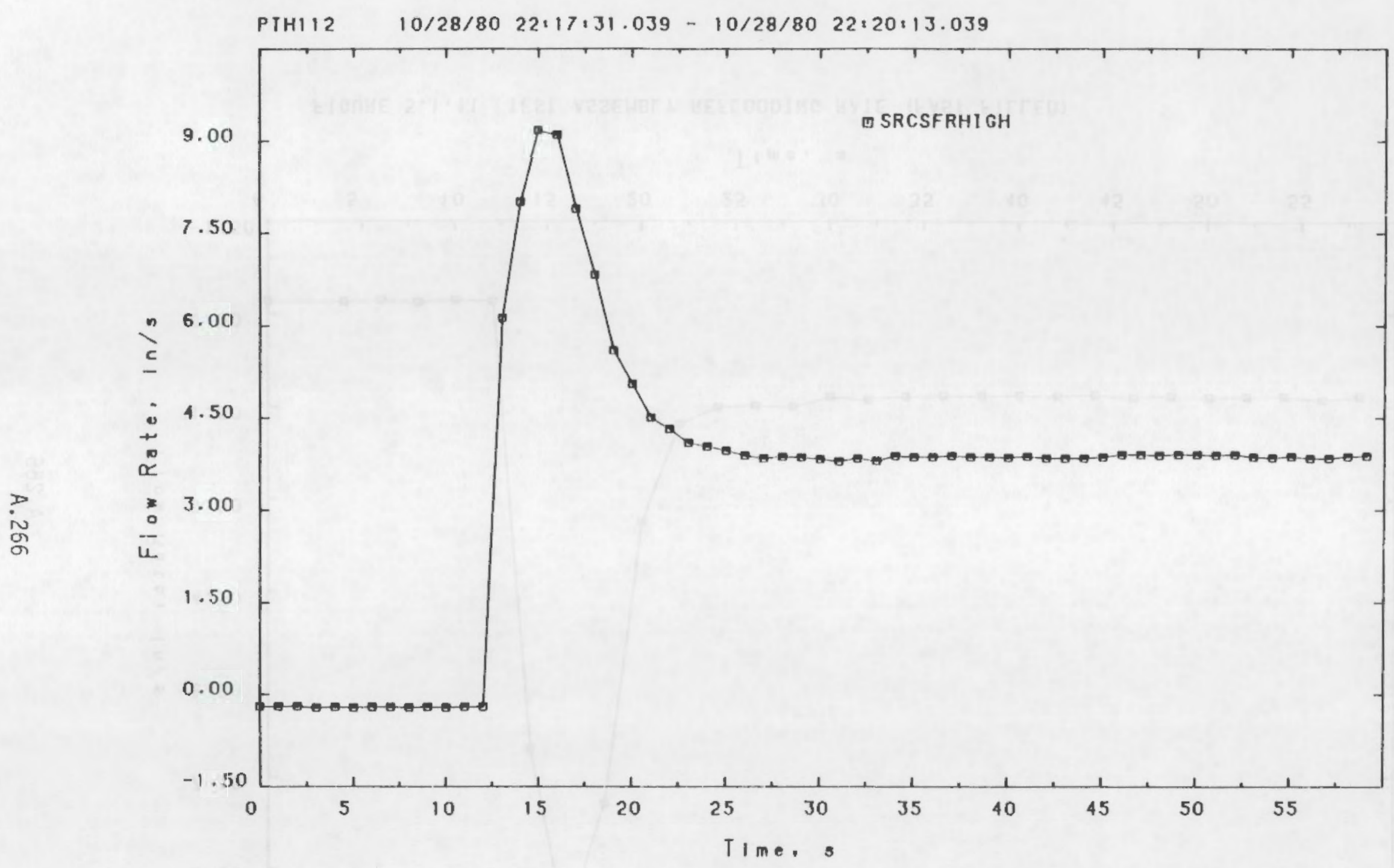

FIGURE 5.1.12 TEST ASSEMBLY REFLOODING RATE (NORMAL PREFILL) 


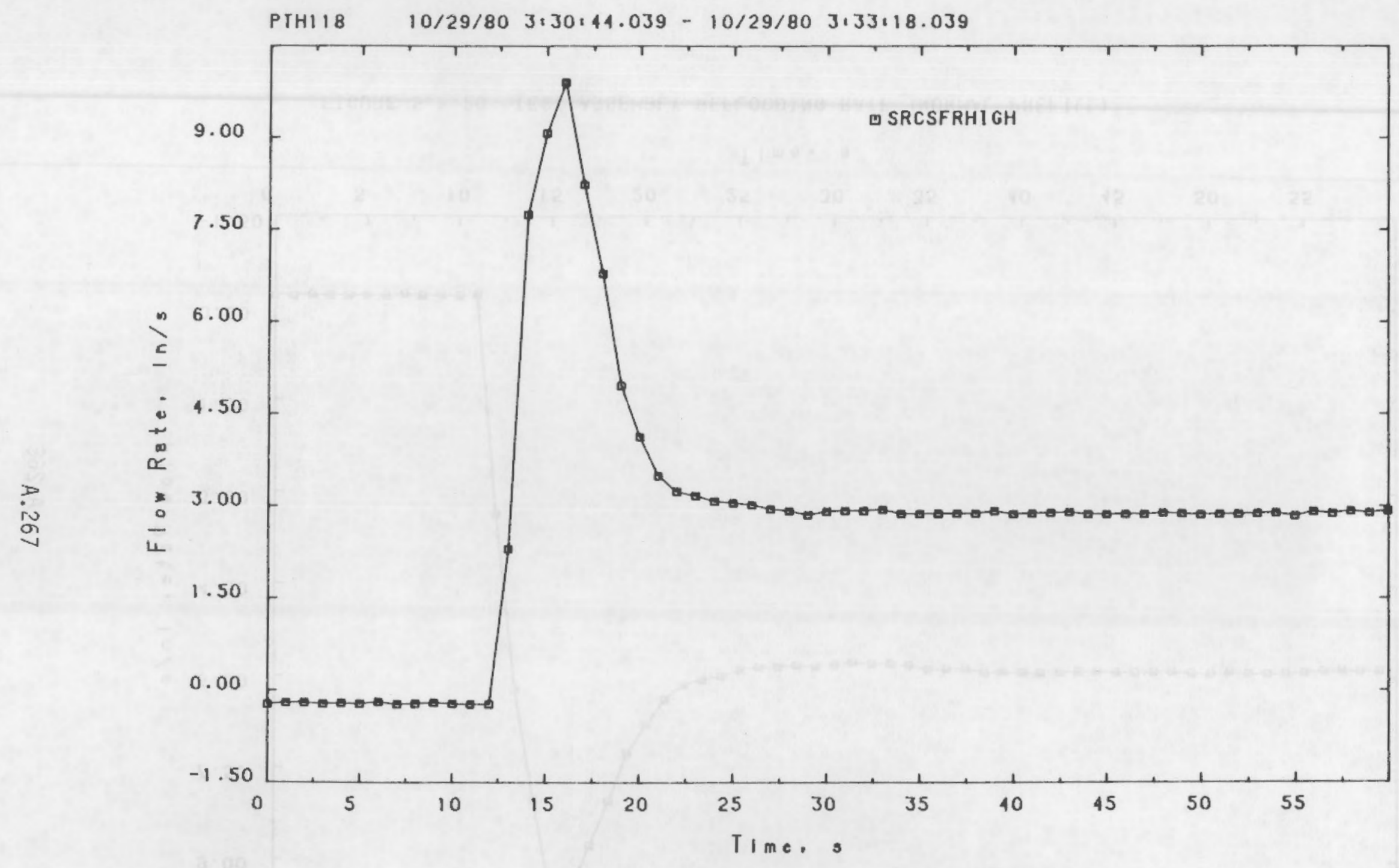

FIGURE 5.1.18 IEST ASSEMBLY REFLOODING RATE (NORMAL PREFILL) 


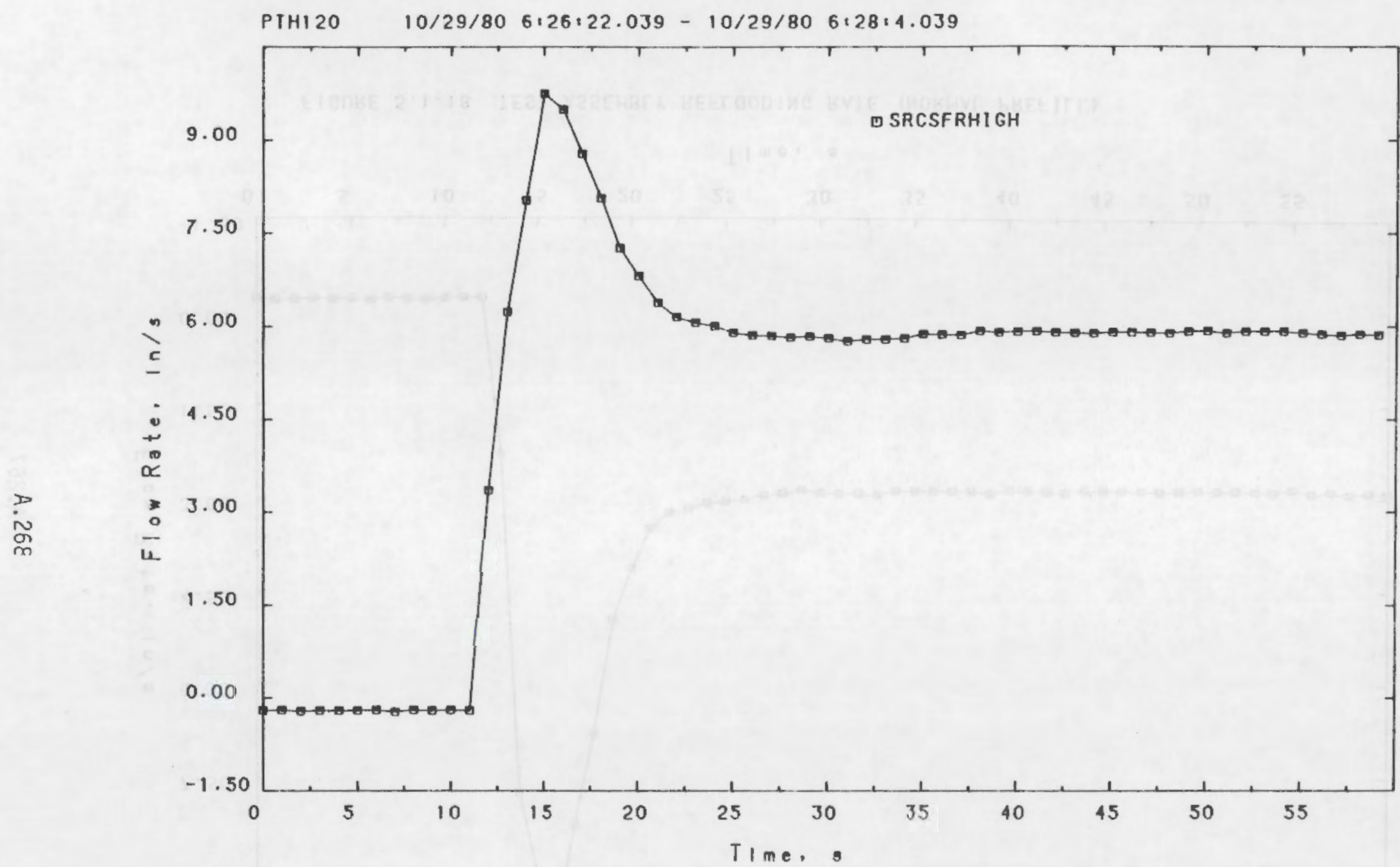

FIGURE 5.1.20 TEST ASSEMBLY REFLOODING RATE (NORMAL PREFILL) 


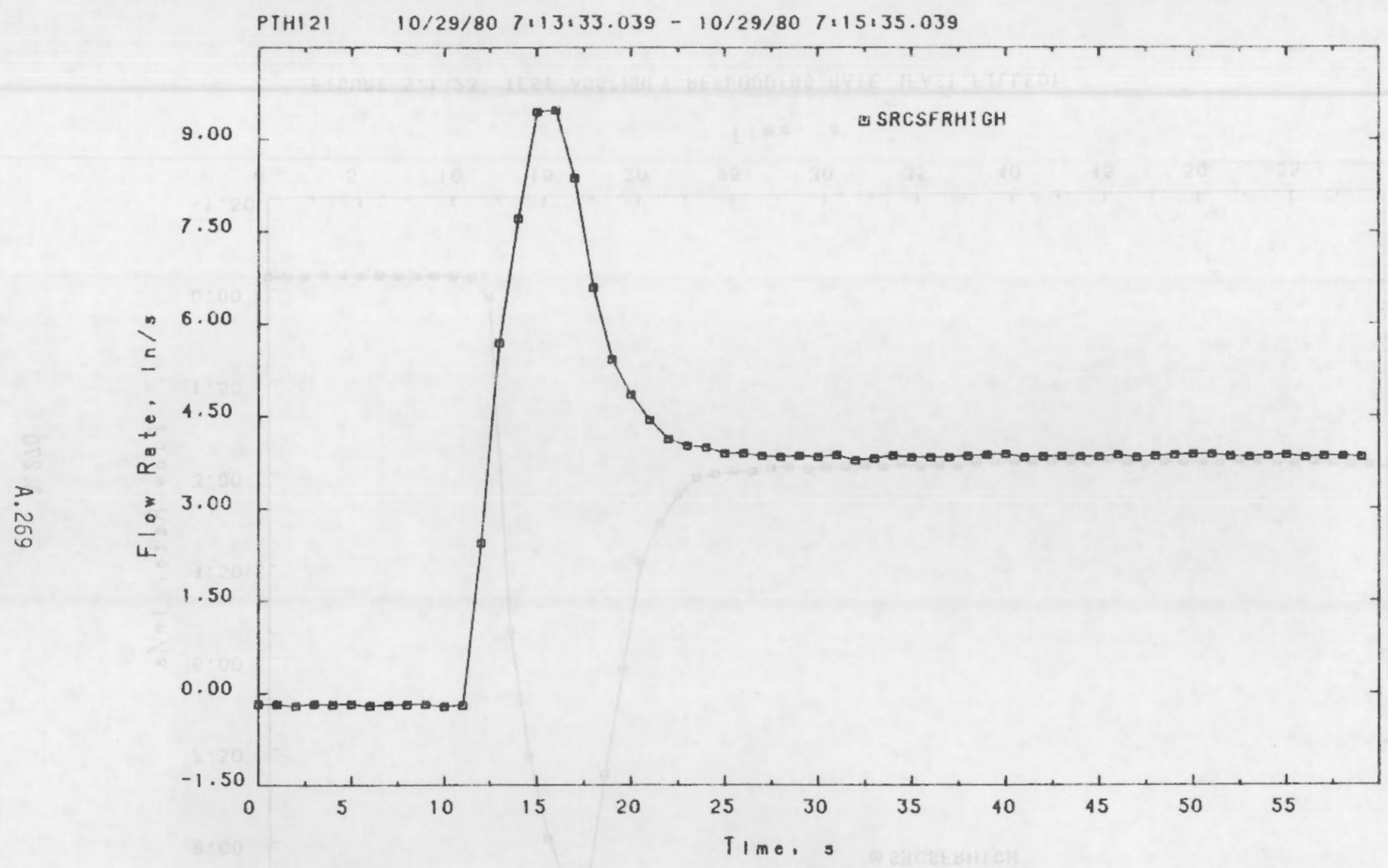

FIGURE 5.1.21 TEST ASSEMBLY REFLOODING RATE (NORMAL PREFILL) 


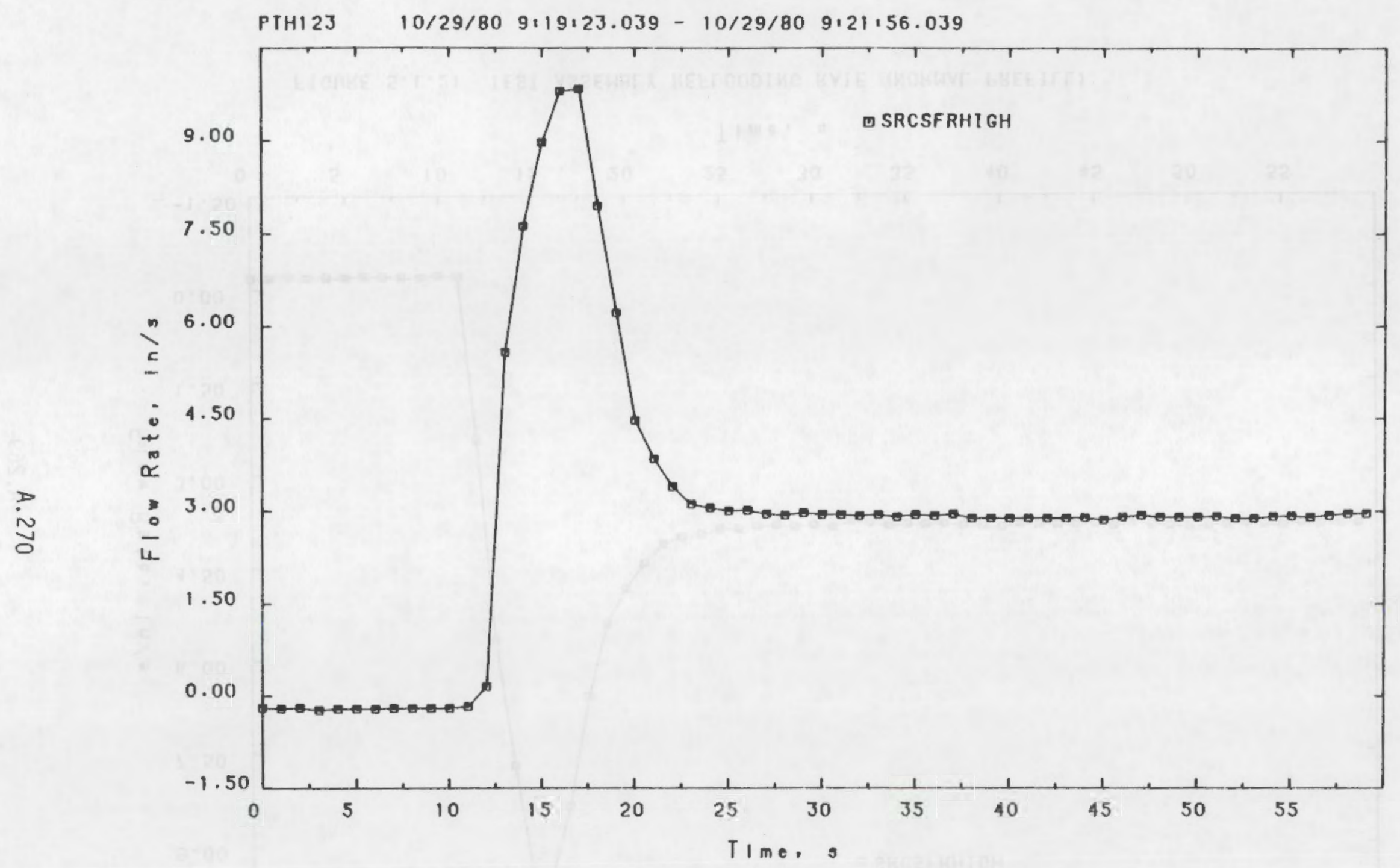

FIGURE 5.1 .23 TEST ASSEMBLY REFLOODING RATE (FAST FILLED) 


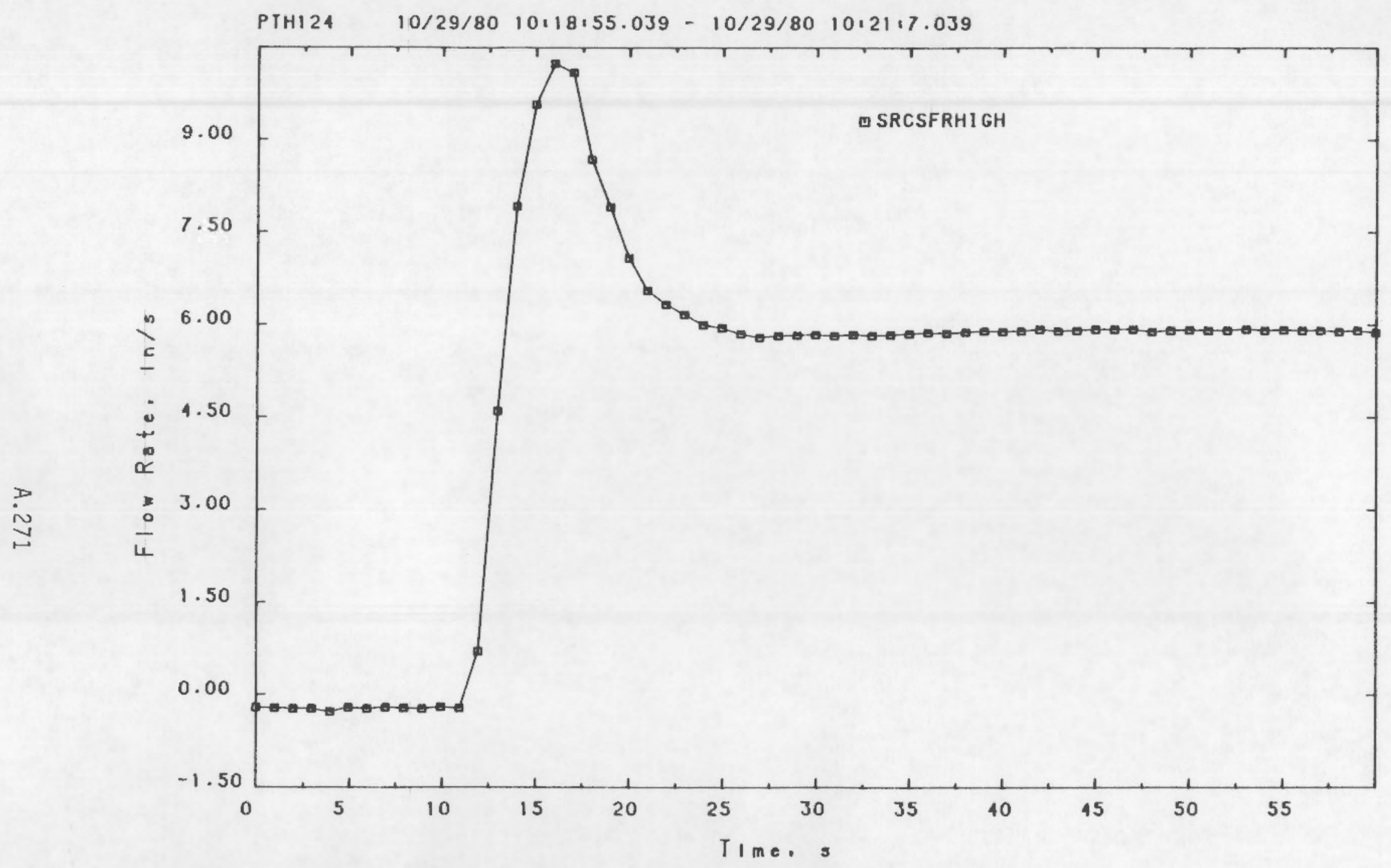

FIGURE 5.1.24 TEST ASSEMELY REFLOODING RATE (FAST FILLED) 



\section{DISTRIBUTION}

U.S. Nuclear Regulatory Commission Washington, D.C. 20555

Mail Stop
L. Shotkin
Mail Stop - 1130-SS
N. Zuber
Mail Stop - 1130-SS
R. Meyer
R. Van Houten (3)
G. Marino
G. McPherson
J. Norberg
N. Lauben
W. Hodges
L. Phillips
A. Hon
Y. Hsu
W. Johnston
D. Power
M. Pickiesimer
Mai1 Stop - P-11114
Mail Stop - 1130-SS
Mail Stop - 1130-SS
Mail Stop - 1130-SS
Mail Stop - NL-5650
Mail Stop - P-1132
Mail Stop - P-1132
Mail Stop - P-1114
Mail Stop - 1130-SS
Mail Stop - 1130-SS
Mail Stop - P-1114
Mail Stop - P-1114
L. Tong
T. Murley
Mail Stop - 1130-SS
Mail Stop - 1130-SS
Mail Stop - P-1102

Electric Power Research Institute 3412 Hillview Avenue

(6)

Palo A7to, CA 94022
W. Sun
P. Davis (ITI)
L. Thompson
R. Oehlberg
G. Thomas
R. Duffey

Westinghouse Electric Corporation P. 0. Box 355

(3)

Pittsburgh, PA 15230
L. Hochreiter
R. Rosal
D. Burman

Oak Ridge National Laboratory

P. 0. Box X

Oak Ridge, TN 37830

F. Mynatt

R. Chapman (2) 
Combustion Engineering

(2)

1000 Prospect Hill Road

P. 0. Box 500

Windsor, CT 06095

R. Duncan

S. Ritterbush

Babcock and Wilcox

P. 0. Box 1200

(2)

Lynchburg, VA 24505

C. Morgan

B. Bingham

General Electric Company

175 Curtner Avenue

San Jose, CA 95114

S. Armijo

R. Williams

L. Noble

G. Sozzi

N. Shirley

Exxon Nuclear, Inc.

2101 Horn Rapids Road

(4)

Richland, WA 99352

W. Nechodom

W. Kayser

T. Doyle

J. Morgan

(5)

U.S. Nuclear Regulatory Commission

Advisory Committee on Reactor Safeguards Washington, D.C. 20555

Mail Stop - H-1016

P. Boehnert

P. Shewmon

D. Okrent 
Kernforschungzentrum Karlsruhe

Weberstrasse 5

(4)

75 Karlsruhe 1

Federat Republic of Germany

H. Rininsland (2)

A. Fiege

F. Erbacher

JRC-ISPRA

EURATOM

CCR ESSOR Division

21020 Cento Euratom $0 i$ Ispra (Varese)

Italy

T. Doyle

R. Klersy

J. Randles

S. Finzi

Central Electricity Generating Board

Berkeley Nuclear Laboratories

Berkeley, Gloucestershire GL13 9PB

England

T. Healey (2)

M. Ishikawa, Chief (4)

Reactivity Accident Laboratory

Japan Atomic Energy Research Institute

Tokai Research Establishment

Tokai-Mura, Naka-Gun

Ibaraki-Ken

Japan

D.M. Chapin

MPR Associates, Inc.

1140 Connecticut Avenue, NW

Washington, D.C. 20036

D. Ogden

EG\&G Idaho, Inc.

P.0. Box 1625

Idaho Falls, ID 83401 
J. Davis

Nuclear Engineering Department

Potomac Electric Power Company

1900 Pennsylvania Avenue, NW

Washington, D.C. 20068

C.A. Herriot/M. Notiey (6)

Chalk River Nuclear Laboratories

Atomic Energy of Canada, Limited

Chalk River, Ontario, Canada KOJ 1JO

P. Griffith

Massachusetts Institute of Technology

Department of Nuclear Engineering

Cambridge, MA 02139

W. Kirchner

Los Alamos Scientific Laboratory

P.0. Box 1663

Los Alamos, NM 87544

J. Gittus

Springfields Nuclear Power Development Laboratory

United Kingdom Atomic Energy Authority

Springfields, SaIwick

Preston PR 4 ORR

England

Mr. Mann

Springfields Nuclear Power Development Laboratory

United Kingdom Atomic Energy Authority

Springfields, Salwick

Preston PR 4 ORR

England

C.L. Mohr (30)

Battelle, Pacific Northwest Laboratories

P. 0. Box 999

Richland, Washington 99352 


Prototypic Thermal-Hydraulic Experiment in NRU to Simulate Loss-of-Coolant Accidents

7. AUTHOR(S) C. L. Mohr, G. M. Hesson, G. E. Russchër, R. K. Marshali, L.L. King, N.J. Wildung, W.N. Rausch, W. D. Bennett

9. PERFORMING ORGANIZATION NAME AND MAILING ADDRESS (Include Zip Code)

Pacific Northwest Laboratory

Richland, Washington 99352

3. RECIPIENT'S ACCESSION NO.

12. SPONSORING ORGANIZATION NAME AND MAILING ADDRESS (Include ZiD Code)
Division of Reactor Safety Research
Dffice of Nuclear Regulatory Research
U.S. Nuclear Regulatory Commission
Washingtoin, DC 20555

\section{TYPE OF REPORT}

Preliminary Test Report

PERIOD COVEREO (Inclusive dares)

Reactor Tests of October 28-30, 1980

15. SUPPLEMENTAAY NOTES

14. (Leve biank)

\section{ABSTRACT QOO words or less)}

A series of 28 nuclear heatup and reflood tests were performed on a 32-rod bundle of unpressurized, full-length, commercial enrichment, Zircaloy clad fuel rods. These tests were performed in the NRU reactor in October 1980. Reflood rates ranged from $1.88 \mathrm{~cm} / \mathrm{sec}$ $(.074 \mathrm{in} / \mathrm{sec})$ to $28 \mathrm{~cm} / \mathrm{sec}(11 \mathrm{in} / \mathrm{sec})$, with delay times to initiate reflood of $3 \mathrm{sec}$. to $66 \mathrm{sec}$. Measured peak clad temperatures ranged from $840 \mathrm{~K}\left(1050^{\circ} \mathrm{F}\right)$ to $1370 \mathrm{~K}\left(2007^{\circ} \mathrm{G}\right)$. Preliminary observations are that actual quench times are much less than predicted while peak temperatures are in general agreement with predicted values. There is no evidence of any test rod failure.

\section{KEY WORDS AND DOCUMENT ANALYSIS}

Peak Clad Temperature, LOCA Heatup, Clad Temperature Turnaround, Rewet, Quench, Thermal-Hydraulics, Clad Temperature Profile

\section{DESCAIPTORS}

Loss of Coolant Accident (LOCA), Experimental Data, Reactor Test Data, Rewet, Quench, Cladding Temperature Profiles 


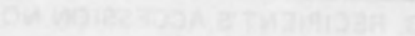

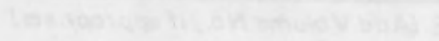

